Zootaxa 5095 (1): 001-141

https://www.mapress.com/zt/

Copyright (C) 2022 See end page footer

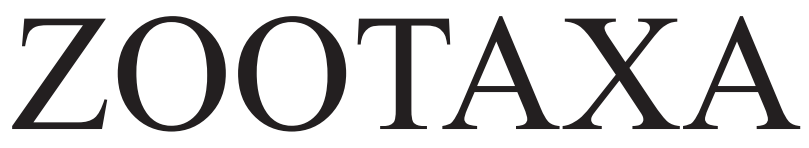

5095

\title{
Revision of the Nearctic Microphorinae (Diptera: Dolichopodidae sensu lato)
}

\section{SCOTT E. BROOKS ${ }^{1,2} \&$ JEFFREY M. CUMMING ${ }^{1,3}$}

${ }^{1}$ Diptera Unit, Canadian National Collection of Insects, Agriculture and Agri-Food Canada, K.W. Neatby Building, 960 Carling Avenue, Ottawa, Ontario, K1A 0C6, CANADA

2 झ"scott.brooks@agr.gc.ca; @ https://orcid.org/0000-0001-7915-1941

3 巨"jeff.cumming@agr.gc.ca; $\odot$ https://orcid.org/0000-0002-3619-3700

\section{E3}

Magnolia Press

Auckland, New Zealand 
SCOTT E. BROOKS \& JEFFREY M. CUMMING

Revision of the Nearctic Microphorinae (Diptera: Dolichopodidae sensu lato)

(Zootaxa 5095)

141 pp.; $30 \mathrm{~cm}$.

9 Feb. 2022

ISBN 978-1-77688-450-6 (paperback)

ISBN 978-1-77688-451-3 (Online edition)

FIRST PUBLISHED IN 2022 BY

Magnolia Press

P.O. Box 41-383

Auckland 1041

New Zealand

e-mail:magnolia@mapress.com

https://www.mapress.com/zt

(C) 2022 Magnolia Press

All rights reserved.

No part of this publication may be reproduced, stored, transmitted or disseminated, in any form, or by any means, without prior written permission from the publisher, to whom all requests to reproduce copyright material should be directed in writing.

This authorization does not extend to any other kind of copying, by any means, in any form, and for any purpose other than private research use.

ISSN 1175-5326 (Print edition)

ISSN 1175-5334 (Online edition) 


\section{Table of Contents}

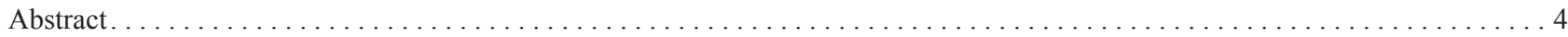

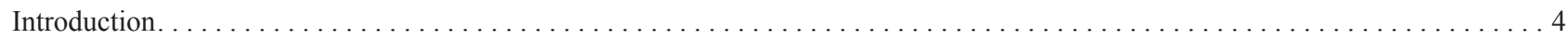

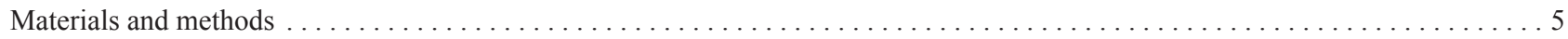

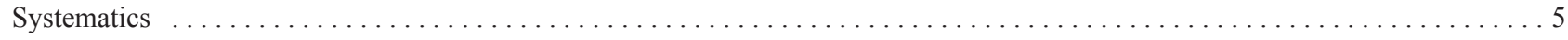

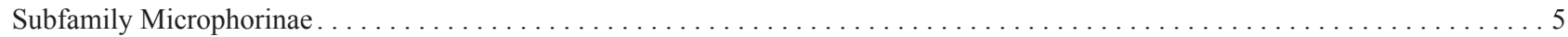

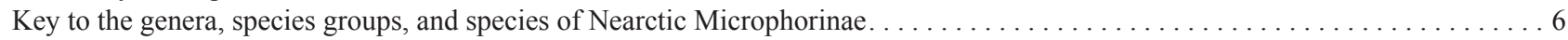

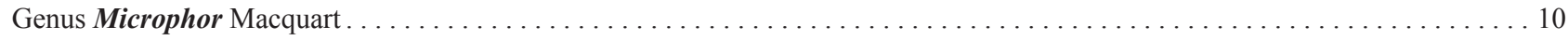

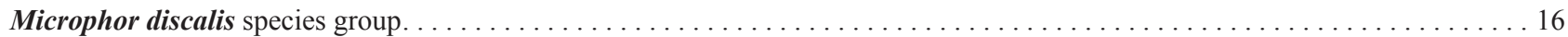

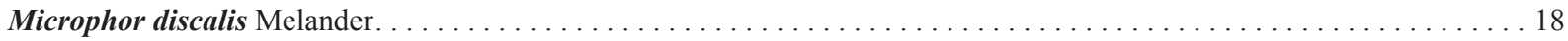

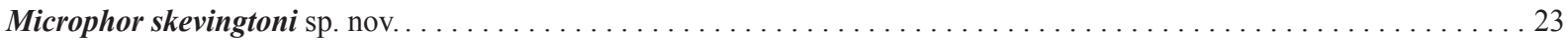

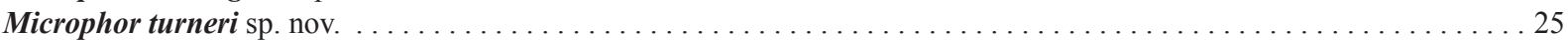

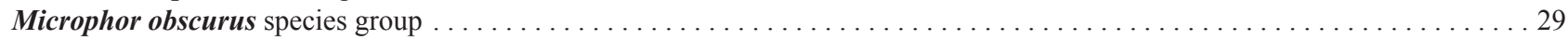

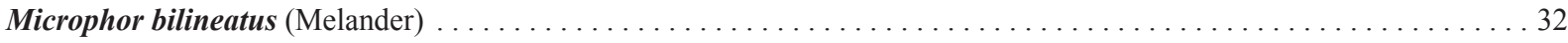

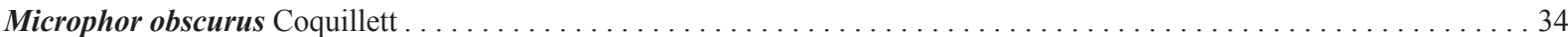

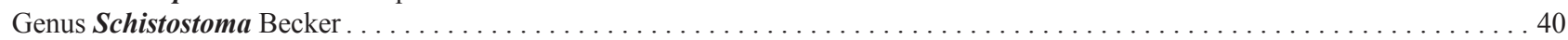

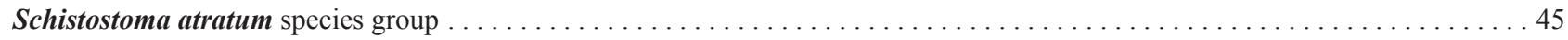

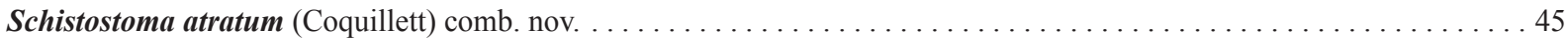

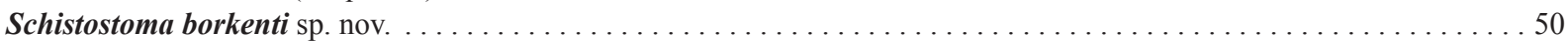

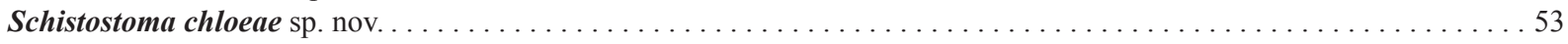

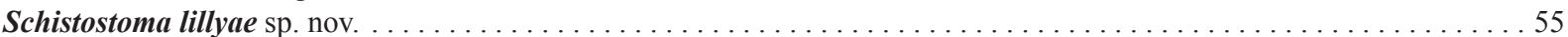

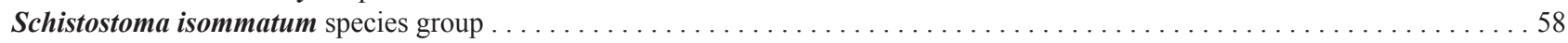

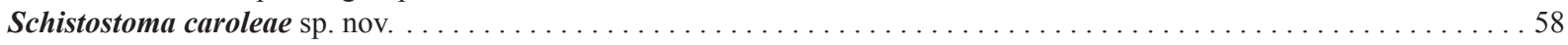

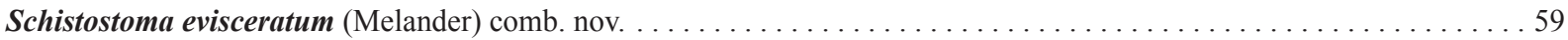

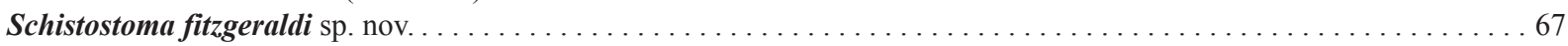

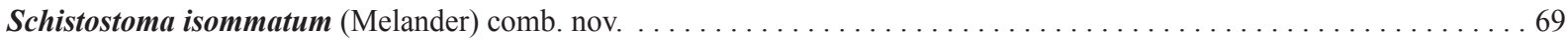

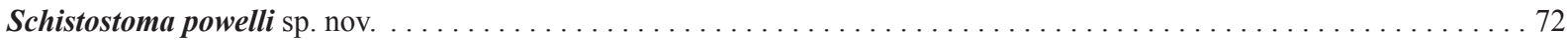

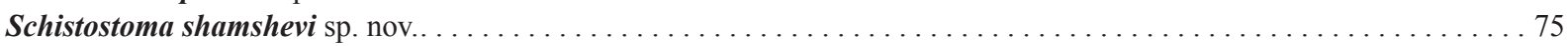

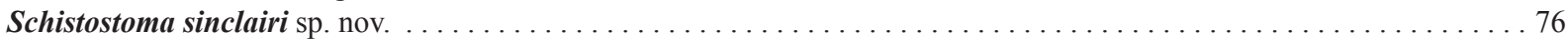

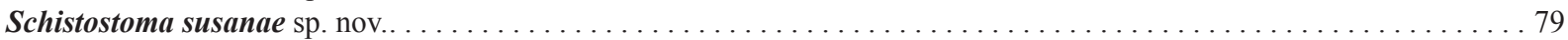

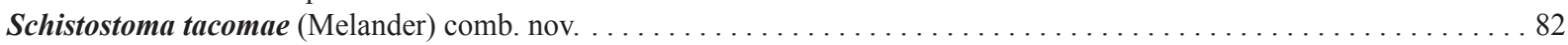

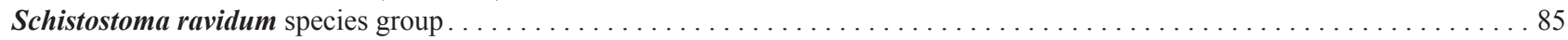

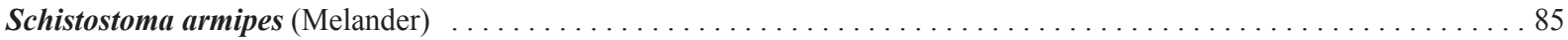

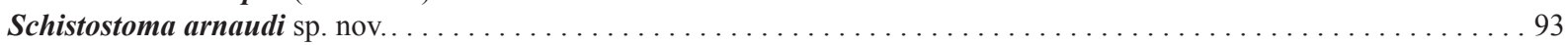

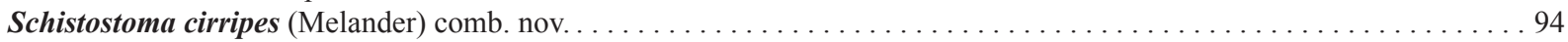

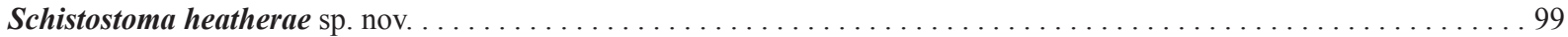

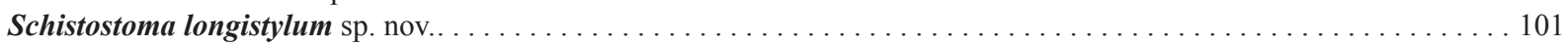

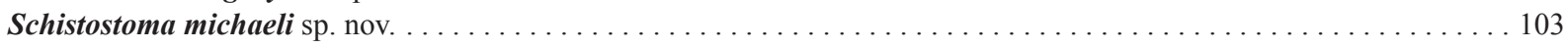

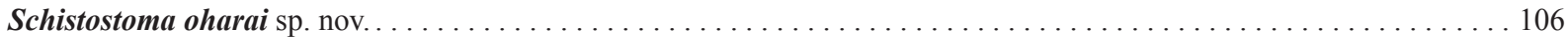

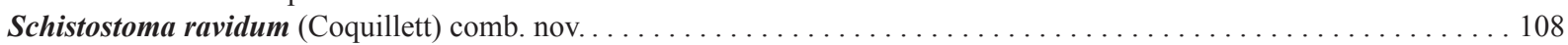

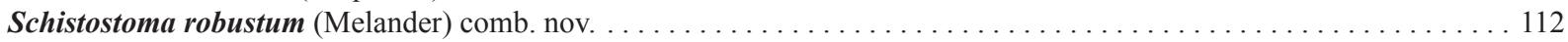

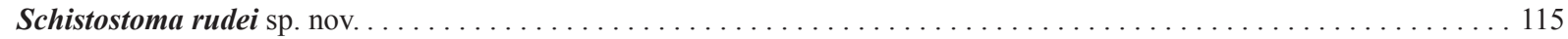

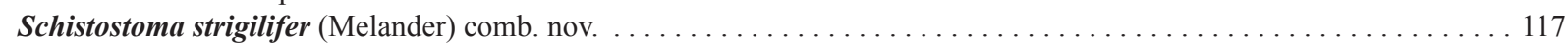

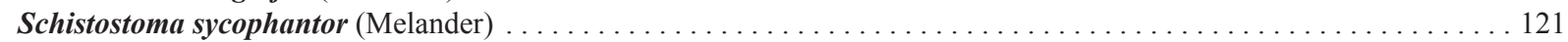

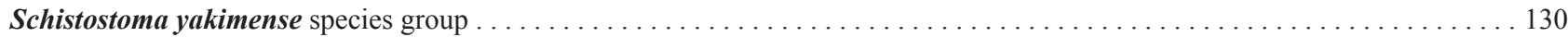

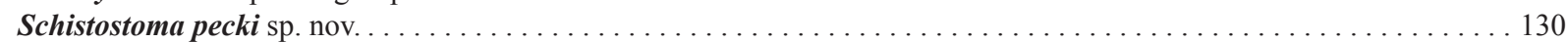

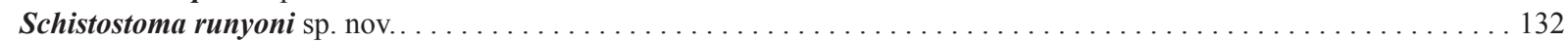

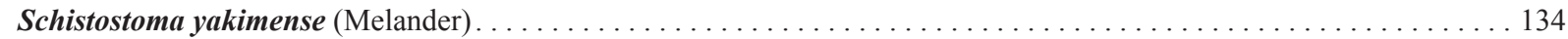

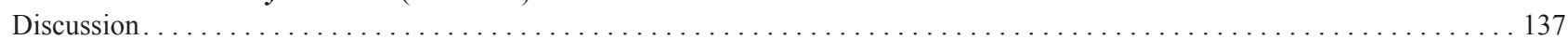

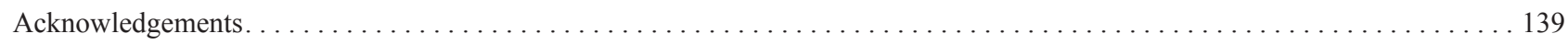

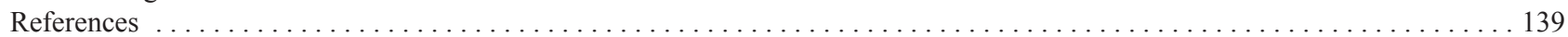




\begin{abstract}
The Nearctic species of the dolichopodid subfamily Microphorinae are revised. Two genera and 33 species are recognized including five species of Microphor Macquart and 28 species of Schistostoma Becker. Both genera are redefined, redescribed and diagnosed, a key to the genera and species in the Nearctic Region is provided, the known geographical distribution of each species is mapped and ecological information is summarized. In addition to the three previously known species of Nearctic Schistostoma, i.e., S. armipes (Melander), S. sycophantor (Melander) and S. yakimense (Melander), the Nearctic fauna includes eight species newly transferred from Microphor as well as 17 new species. These species of Schistostoma are classified into four species groups as follows: the $S$. atratum species group including $S$. atratum (Coquillett, 1900) comb. nov., S. borkenti sp. nov., S. chloeae sp. nov. and S. lillyae sp. nov.; the S. isommatum species group including $S$. caroleae sp. nov., S. evisceratum (Melander, 1940b) comb. nov., S. fitzgeraldi sp. nov., S. isommatum (Melander, 1928) comb. nov., S. powelli sp. nov., S. shamshevi sp. nov., S. sinclairi sp. nov., S. susanae sp. nov. and S. tacomae (Melander, 1940b) comb. nov.; the S. ravidum species group including S. armipes (Melander, 1928), S. arnaudi sp. nov., S. cirripes (Melander, 1940b) comb. nov., S. heatherae sp. nov., S. longistylum sp. nov., S. michaeli sp. nov., S. oharai sp. nov., S. ravidum (Coquillett, 1895) comb. nov., S. robustum (Melander, 1928) comb. nov., S. rudei sp. nov., S. strigilifer (Melander, 1940b) comb. nov. and S. sycophantor (Melander, 1902); and the S. yakimense species group including $S$. pecki sp. nov., S. runyoni sp. nov. and S. yakimense (Melander, 1928). Schistostoma ravum (Melander, 1940b) comb. nov. is also transferred from Microphor and is newly synonymized with S. evisceratum (Melander, 1940b), syn. nov. The Nearctic members of Microphor now comprise only three of the previously known species, plus two new species. These five species are classified into two species groups as follows: the $M$. discalis species group including $M$. discalis Melander, 1940b, M. skevingtoni sp. nov. and M. turneri sp. nov.; and the M. obscurus species group including M. bilineatus (Melander, 1902) and M. obscurus Coquillett, 1903. Lectotype designations are made for Holoclera bilineata Melander, Microphorus armipes Melander, Microphorus ravidus Coquillett, Microphorus strigilifer Melander and Holoclera sycophantor Melander.
\end{abstract}

Key words: Empidoidea, Microphor, Schistostoma, new species, new combinations, new synonymy, morphology, ecology, kleptoparasitism, flower visits, pollen feeding, larva

\title{
Introduction
}

The subfamily Microphorinae is a small group of empidoid flies classified within the Dolichopodidae sensu lato, along with the subfamily Parathalassiinae and the Dolichopodidae sensu stricto (Sinclair \& Cumming 2006). Adults are small (1.5-3.3 mm) non-metallic, light grey to black flies (Figs 1-8, 17, 18, 35, 59, 60, 79, 80, 105, 106, 116, $117,157,183,192,211,222,239,242)$, distinguished by a two-articled antennal arista-like stylus (Figs 36, 37, 160), holoptic male eyes (Figs 20, 62, 119, 161, 224), wing with strongly developed anal lobe, costal vein circumambient, crossvein bm-m complete and cell dm (usually present) emitting three branches (Figs 23-30, 85-90, 169-178) (Brooks et al. 2019). Microphorine flies are known from a wide range of habitats including alpine meadows, deserts, sandy sea coasts, lake margins, and various types of riparian zones from large open rivers to small forest streams (Figs 9-16). Adults are mostly predaceous (Figs 3, 4), but some species are seen on flowers (Figs 1, 2) feeding on pollen (Fig. 7) or nectar (Chvála 1986), or are found sitting on sunlit leaves (Figs 5, 6, 8). Immature stages are virtually unknown, but the larvae are presumed to be predaceous and living in soil or leaf litter.

Both modern and extinct taxa of Microphorinae are known. Extant taxa (prior to this study) include Microphor Macquart with 23 described species (12 Nearctic, nine Palaearctic, one Australasian, one Oriental) and Schistostoma Becker with 25 described species (17 Palaearctic, one Oriental, four Afrotropical, three Nearctic), although most described Nearctic Microphor species require formal transfer to Schistostoma (Brooks et al. 2019). The revisionary studies of Melander (1928, 1940a,b) laid the groundwork for our understanding of the Nearctic Microphorinae and in the 80 plus years since these publications, many more specimens have been collected across the Nearctic Region by dipterists (and other entomologists) and deposited in institutional collections. We have been actively collecting, accumulating and studying Nearctic specimens of the subfamily, which has led to the discovery of several undescribed species. The purpose of this paper is to describe these new species and revise the Nearctic fauna of Microphorinae. A key to the genera and species is provided, with the geographical distribution of each species mapped and known ecological information summarized. 


\section{Materials and methods}

This study is based on the examination of over 4600 specimens, which are deposited in the following institutions: American Museum of Natural History, New York, USA (AMNH); Academy of Natural Sciences of Philadelphia, Philadelphia, USA (ANSP); California Academy of Sciences, San Francisco, USA (CAS); Canadian National Collection of Insects, Ottawa, Canada (CNC); California State Collection of Arthropods, Sacramento, USA(CSCA); Cornell University Insect Collection, Ithaca, USA (CUIC); Essig Museum of Entomology, University of California, Berkeley, USA (EMEC); Los Angeles County Natural History Museum, Los Angeles, USA (LACM); Lyman Entomological Museum, McGill University, Ste-Anne-de-Bellevue, Canada (LEMQ); Montana Entomological Collection, Montana State University, Bozeman, USA (MTEC); Royal British Columbia Museum, Victoria, Canada (RBCM); Royal Ontario Museum, Toronto, Canada (ROM); Spencer Entomological Museum, University of British Columbia, Vancouver, Canada (UBCZ); Bohart Museum of Entomology, University of California, Davis, USA (UCDC); Entomology Research Museum, University of California, Riverside, USA (UCRC); University of Guelph Insect Collection, Guelph, Canada (UGIC); United States National Museum of Natural History, Washington D.C., USA(USNM); W.F. Barr Entomological Collection, University of Idaho, Moscow, USA(WFBM); William J. Turner Collection, Pullman, USA (WJTC); M.T. James Museum, Washington State University, Pullman, USA (WSU).

Label data for primary types are cited verbatim. Labels are listed from the top label down with data from each label in quotation marks and separated by a semicolon. Lines of text on labels are delimited by a slash (/) and annotations are placed in square brackets, i.e., [ ]. The distribution maps were created with SimpleMappr (Shorthouse 2010).

Terms used for adult structures follow Cumming \& Wood (2017). Homologies of the male terminalia follow Brooks \& Cumming $(2017,2018)$ and Brooks \& Ulrich (2012).

Male and female terminalia dissections were macerated in $85 \%$ lactic acid heated in a microwave oven for multiple 20-60 second intervals, until muscle tissue was dissolved, and subsequently examined and illustrated in glycerin on a depression slide. Unique $\mathrm{CNC}$ database numbers and labels were added to all illustrated specimens (unless already present) to allow association with their corresponding terminalia figures. These unique identifier database numbers are listed in the figure captions and cross-referenced in the lists of material examined. In several cases, these $\mathrm{CNC}$ database labels were added to specimens from other institutions.

Figures of male genitalia in lateral view are oriented with the anatomically dorsal and ventral parts directed towards the top and bottom of the page, respectively. This means that the left and right side of the figures refer to each side prior to the rotation and twisting caused by lateroflexion (see Sinclair \& Cumming 2006, p. 48).

\section{Systematics}

\section{Subfamily Microphorinae}

Small (1.5-3.3 mm) light grey to black non-metallic flies (Figs 1-8, 17, 18, 35, 59, 60, 79, 80, 105, 106, 116, 117, 157, 183, 192, 211, 222, 239, 242), distinguished from Parathalassiinae and Dolichopodidae sensu stricto by a combination of a two-articled antennal arista-like stylus (Figs 36, 37, 160), holoptic male eyes (Figs 20, 62, 119, $161,224)$, mouthparts with more than six unmodified pseudotracheae, wing with strongly developed anal lobe, costal vein circumambient, crossvein bm-m complete and cell $\mathrm{dm}$ (which is usually present) emitting three branches (Figs 23-30, 85-90, 169-178) (Sinclair \& Cumming 2006; Brooks et al. 2019). These features are probably all plesiomorphic when compared to the remaining Dolichopodidae including Parathalassiinae (Sinclair \& Cumming 2006), so the monophyly of the subfamily still requires validation.

Two extant genera, Microphor and Schistostoma, are currently recognized within the Microphorinae, in addition to four fossil genera (Brooks et al. 2019). Microphor is known from all biogeographic realms except the Afrotropical Region and Schistostoma is known from the Holarctic, Afrotropical and Oriental regions (Chvála 1991; Brooks et al. 2019; Shamshev 2020). However, the single Australasian record, Microphor hiemalis White, 1916 from Tasmania, does not appear to be congeneric with Microphor and may not even belong in the subfamily. Shamshev \& Sinclair (2006) evaluated the generic status of Schistostoma in relation to Microphor and provided key characters to distinguish both genera. Subsequently Brooks et al. (2019) indicated that two of their diagnostic characters (i.e., 
1-2 pairs of scutellar setae and female terminalia with acanthophorous spines) were more variable in Schistostoma than had previously been reported, and broadened the concept of that genus. Shamshev \& Sinclair (2006) also listed straight rather than upturned female cerci as a feature of Microphor, but some species of Schistostoma are now also known to possess straight female cerci (albeit shorter than Microphor). Brooks et al. (2019) also indicated that many of the described Nearctic species of Microphor require formal transfer to Schistostoma and this is accomplished below.

\section{Key to the genera, species groups, and species of Nearctic Microphorinae}

This key treats the 33 species of Nearctic Microphorinae now known, including the two species groups and five species of Microphor, and the four species groups and 28 species of Schistostoma. This key can be used to make generic and species group identifications for either sex; however, most species identifications rely on male characters (females are not known for $S$. caroleae sp. nov., S. lillyae sp. nov., S. pecki sp. nov., S. shamshevi sp. nov. and $S$. sinclairi sp. nov.).

Although distinct, the two main diagnostic features separating Microphor and Schistostoma (i.e., absence or presence of the medial hypandrial prolongation, and number of exposed female abdominal segments) are not convenient, user-friendly characters to put at the beginning of a key. With this in mind, we have designed the key below to prioritize more easily-observable characters where possible, and as a result, each genus keys out more than once.

1 Setae of body and legs bright white (Figs 239-245); body and legs silvery-grey; thorax with 1 scutellar seta per side; hypopygium with dorsal lobe of surstylus elongate and straight, projecting alongside similarly elongated dorsal postgonite lobe (Figs 240 , 241, 244-249); female abdomen with last exposed segment (before retracted terminalia) dark and sharply contrasting with silvery-grey anterior segments (Fig. 242); female terminalia (Fig. 101) with acanthophorite spines, cercus with curved claw-

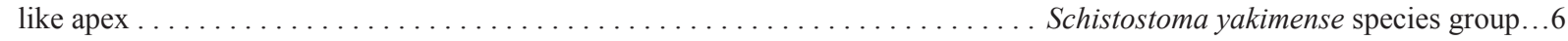
Setae of body and legs entirely black, or at least thoracic setae black, occasionally with some pale setae on head (gena and postgena), legs and abdomen; body and legs usually blackish, dull grey, brownish or blueish-grey (abdomen and legs occasionally yellowish) (Figs 17, 18, 35, 59, 60, 79, 80, 105, 106, 116, 117, 157, 183, 192, 211, 222); thorax with 2-4 scutellar setae per side; hypopygium with surstylus and postgonite not as above; female abdomen with last exposed segment (before retracted terminalia) concolorous with anterior segments (Figs 34, 68, 84, 125, 165); female terminalia with acanthophorite spines (Figs 99, 100) or setae (Figs 52, 53, 55-57, 95-98), cercus variable, with or without curved claw-like apex. . . . . . 2

2 Wing with long cell $\mathrm{dm}$, distal section of vein $\mathrm{M}_{1}$ (beyond base of $\mathrm{M}_{2}$ ) shorter than preceding section (between $\mathrm{r}-\mathrm{m}$ and base of $\mathrm{M}_{2}$ ) (Figs 23-28); hypopygium (Figs 31-33, 38-50) with left middle lobe of surstylus elongate and C-shaped; left ventral lobe of surstylus elongate (as long as middle lobe); medial hypandrial prolongation absent . Microphor discalis species group...8 Wing with shorter cell $\mathrm{dm}$, distal section of vein $\mathrm{M}_{1}$ (beyond base of $\mathrm{M}_{2}$ ) longer than preceding section (between $\mathrm{r}-\mathrm{m}$ and base of $\mathrm{M}_{2}$ ) (Figs 29, 30, 85-90, 169-176); hypopygium not as above; medial hypandrial prolongation absent or present ..... 3 Antennae with stylus distinctly shorter than postpedicel (Figs 62, 63); thorax with mesonotal setae short and dense on anterior 2/3 (Fig. 61), acrostichals quadriserial, anterior dorsocentrals similar in size to acrostichals, biserial or as a field of setae on each side; scutellum with 3 scutellar setae per side; hypopygium (Figs 67, 69-74) with right ventral postgonite lobe large and hook-shaped; medial hypandrial prolongation absent; female abdomen with 5 exposed segments, i.e., with narrow telescoping terminalia completely retractable into segment 5 (Figs 60, 68), female terminalia with cerci long and straight (Figs 56, 57). . .

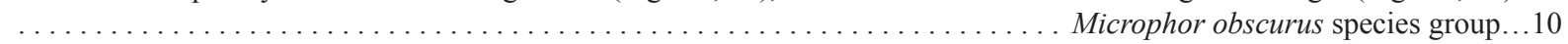
Antenna with stylus longer than, or at least subequal to postpedicel (Figs 81, 82, 107, 118-121, 160-163, 184, 193, 212, 223, 224); thorax with mesonotal setae widely spaced and conspicuous, acrostichals biserial, dorsocentrals arranged in a single row per side (rarely irregularly biserial in some males); scutellum usually with 2 setae per side, but occasionally with 3-4 (e.g., in some specimens of the $S$. atratum species group); hypopygium not as above, with right ventral postgonite lobe not large and hook-shaped, medial hypandrial prolongation present; female abdomen with 6 or 7 exposed abdominal segments, i.e., with broad telescoping terminalia retractable into segments 6 or 7 (Figs 84, 125, 165), sometimes partially retractable into segment 5 , female terminalia with cerci relatively short, curved and claw-like or straight (Figs 95-100) . . . . . . . . . . .

4 Male midleg modified (Figs 158, 159, 164, 167, 185, 200-203, 215, 216, 226), trochanter with spine-like setal pair on distal edge of medial surface (Figs 158, 159), femur usually with 2-6 long, sometimes modified posteroventral setae, tibia usually with swelling just beyond middle; female terminalia with acanthophorite spines on syntergite $9+10$ (Figs 99, 100) ......

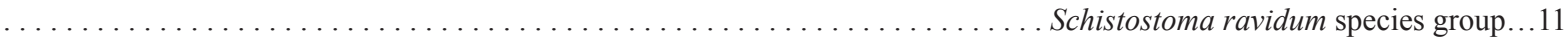
Male midleg not modified as above, trochanter without spine-like setal pair on medial surface; female terminalia with

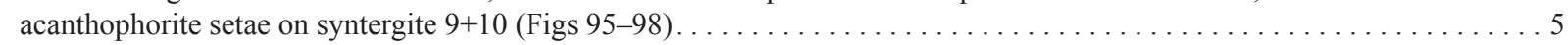

5 Male eye with demarcation line near middle between larger dorsal and smaller ventral ommatidia (Figs 81, 107); female head with gena and parafacial narrow along lower eye margin (Fig. 82); male fore tibia without series of erect posterodorsal setae; hind tibia of male and female not enlarged apically (Figs 79, 80, 105, 106); wing of male and female (Figs 85-88) with cells $r_{2+3}$ and $r_{4+5}$ evenly subtriangular; male pregenitalic abdominal sternites unmodified (Figs 83, 108); hypopygium (Figs 83, 91-94, 
108-113) small and free; hypandrium with several setae (3-8) per side; medial hypandrial prolongation with apical pair of parallel setae; epandrium without specialized setae adjacent to cercus; female cercus subtriangular and pointed apically (Figs

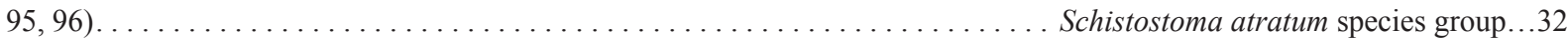
Male eye without distinct demarcation line between dorsal and ventral ommatidia (Figs 118, 119); female head with gena and parafacial distinctly projected along lower eye margin (Figs 120,121); male fore tibia with prominent series of 3-5 erect posterodorsal setae on basal half; hind tibia of both sexes enlarged apically (Figs 116, 117); wing of male and female (Figs $89,90)$ with cell $r_{2+3}$ compressed in middle and flared apically, cell $r_{4+5}$ compressed in basal part; male pregenitalic abdominal sternites modified and usually adorned with specialized setae (Figs 122-124, 126-131); hypopygium (Figs 123, 124, 126-128, 131-152) large with posterior end partially enclosed by modified pregenitalic sternites; hypandrium with single large seta per side; medial hypandrial prolongation with apical pair of setae divergent; epandrium with row or cluster of specialized setae adjacent to cercus; female cercus broad, short and rounded apically (Figs 97, 98).

Schistostoma isommatum species group . 36

Hypopygium with dorsal postgonite lobe broad with apex bluntly bifid, with short hook-like process on each side (Figs 240, 241); right ventral postgonite lobe projecting ventrally with bulbous apex (Fig. 240); male abdominal sternite 6 modified, dark and heavily sclerotized with fine longitudinal ridges (Figs 240,241$) \ldots \ldots \ldots \ldots \ldots \ldots \ldots \ldots \ldots \ldots$. . pecki sp. nov. Hypopygium with dorsal postgonite lobe slender (Figs 244-247); right ventral postgonite lobe projecting posteriorly, apex rounded (Fig. 251) or truncate with pointed apicodorsal spur (Fig. 247); male abdominal sternite 6 without ridges. . . . . 7 Hypopygium with left ventral lobe of surstylus ventrally curved with apex broadly rounded (Fig. 249); left ventral postgonite lobe bearing several spine-like apical projections (Fig. 250); right ventral postgonite lobe with rounded apex (Fig. 251) ... . .

S. runyoni sp. nov. Hypopygium with left ventral lobe of surstylus broad basally with apex narrowed (Figs 246, 248); left ventral postgonite lobe with narrow pointed tip, not bearing spine like projections (Fig. 246); right ventral postgonite lobe truncate with apicodorsal

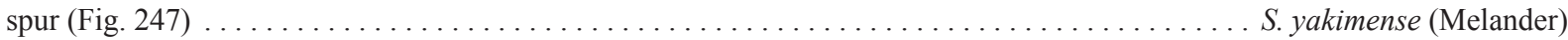
Antennal postpedicel (Fig. 36) at most $2 \mathrm{X}$ as long as wide, with apical 2/3 narrow; antennal stylus longer than postpedicel; male body colour grey with halter pale (Fig. 35); hypopygium (Fig. 38) with apex of right ventral postgonite lobe prolonged and narrowly tapered (Fig. 49); phallus undulate in distal portion, with tip narrowed (Fig. 50); with hypoproct lobes short (as

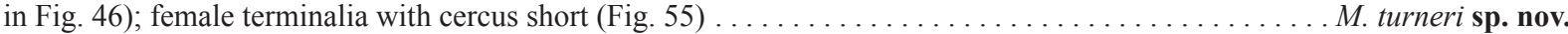
Antennal postpedicel (Figs 20,21,37) over 2X longer than wide with apical 3/4 usually narrow and digitiform; antennal stylus shorter to slightly longer than postpedicel; male body colour blackish-brown with halteres blackish (Fig. 17) to grey with halteres pale (similar to female in Fig. 18); hypopygium (Figs 40-48) with apex of right ventral postgonite lobe widely tapered; phallus straight or undulate in distal portion, tip narrowed or not; with hypoproct lobes long or short; female terminalia with

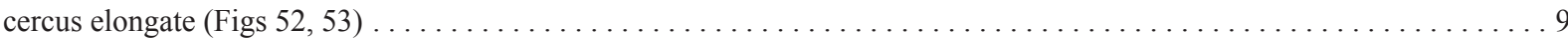
Male body blackish-brown to grey; male legs entirely dark brown, or with tibiae and basal tarsomeres pale; hypopygium (Figs 31-33, 40-43) with hypoproct lobes longer than dorsal lobe of surstylus, distinctly protruding from hypopygium as a pair of pale, narrow, pointed projections arising below cerci; dorsal lobe of surstylus with apical projection long and slender; right postgonite lobe with the dorsal edge right-angled; phallus with apex straight $\ldots \ldots \ldots \ldots \ldots \ldots \ldots$. discalis Melander Male body blackish-brown to greyish-brown; male legs entirely dark brown; hypopygium (Figs 39, 44-48) with hypoproct lobes shorter than dorsal lobe of surstylus, stubby and mostly concealed within hypopygium; dorsal lobe of surstylus with apical projection short; right postgonite lobe with the dorsal edge rounded; phallus with apex tapered. M. skevingtoni sp. nov. Notum of thorax dark brown with shiny or greyish vitta between acrostichals and dorsocentrals; halter pale; hypopygium with

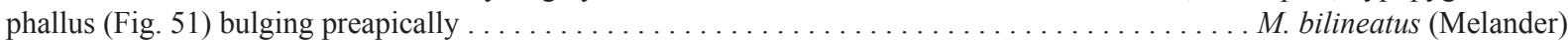
Notum of thorax usually opaque black (Figs 59-62) with vitta between acrostichals and dorsocentrals faint or absent; halter usually dark brown, rarely pale; hypopygium (Figs 67, 69-74) with phallus of uniform thickness, lacking preapical bulge ...

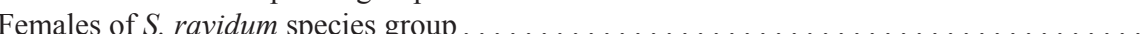

12 Wing (Fig. 171) with crossvein dm-m strongly bent at base and running parallel with $\mathrm{M}_{1}$ distally, distal portion of cell $\mathrm{dm}$ narrow and straight; vein $\mathrm{M}_{4}$ strongly curved posteriorly to wing margin; posterior wing margin expanded on either side of vein $\mathrm{M}_{4}$; fore femur (Fig. 184) with up-curled fringe of fine setae along posterior side; abdominal sternite 5 with dense patch of long setae on each side (Fig. 186); hypopygium (Figs 186-191) with long spine-like seta projecting from dorsal lobe of surstylus .

S. cirripes (Melander) comb. nov. Wing (Figs 169, 173-176) with crossvein dm-m broadly curved and convergent with $\mathrm{M}_{1}$ distally, distal portion of cell $\mathrm{dm}$ tapered; vein $\mathrm{M}_{4}$ weakly curved posteriorly to wing margin or straight; posterior wing margin evenly rounded; fore femur without up-curled fringe of fine setae along posterior side; sternite 5 with chaetotaxy variable, not as above (Figs 166, 168, 194, 204, 205, 214, 227); hypopygium (Figs 179-182, 195-198, 206-210, 217-220, 229-232) lacking long spine-like seta

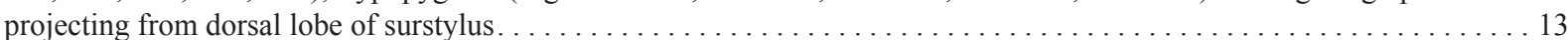
Hypopygium (Figs 211, 214, 217-220) with base of hypandrium enlarged, bulbous and strongly produced, medial hypandrial prolongation broad with distal pair of setae close-set and projecting laterally from right margin (Figs 218, 220, 221); hindleg (Fig. 213) with tarsomere 1 moderately to strongly notched near base on posterior surface, subequal to combined length of tarsomeres 2-3; apex of hind tibia with patch of fine erect setae on posterior surface (Fig. 213) . . . . . . . . . . 14 Hypopygium (Figs 166, 168, 179-182, 194-198, 204-207, 227, 229-232) with base of hypandrium shallowly dome-shaped and not strongly produced, medial hypandrial prolongation narrow with distal pair of setae not close-set and projecting laterally from right margin; hindleg with tarsomere 1 lacking basal notch, longer than combined length of tarsomeres 2-3; apex of hind

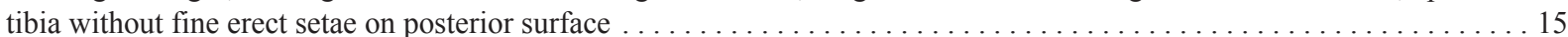


Wing with cell dm small and short (Fig. 173), distal section of vein $\mathrm{M}_{1}$ (beyond base of $\mathrm{M}_{2}$ ) $3 \mathrm{X}$ longer than preceding section (between $\mathrm{r}-\mathrm{m}$ and base of $\mathrm{M}_{2}$ ); midleg (Fig. 216) with tibia deformed and bowed; hypopygium (Figs 217, 218) with cercus elongate; base of hypandrium less strongly produced $\ldots \ldots \ldots \ldots \ldots \ldots \ldots \ldots \ldots \ldots \ldots \ldots \ldots \ldots \ldots \ldots$ michaeli sp. nov. Wing with cell $\mathrm{dm}$ larger (Fig. 175), distal section of vein $\mathrm{M}_{1}$ (beyond base of $\mathrm{M}_{2}$ ) about $1.5 \mathrm{X}$ longer than preceding section (between r-m and base of $\mathrm{M}_{2}$ ); midleg (Fig. 215) with tibia straight; hypopygium (Figs 214, 219-220) with cercus relatively short; base of hypandrium more strongly produced . . . . . . . . . . . . . . . . . S. strigilifer (Melander) comb. nov. Mid femur (Figs 200, 202, 203) with distinctively modified series of 3 thick, curved, spine-like posteroventral setae; mid tibia (Figs $201,202,203$ ) with callus at $2 / 3$ densely covered with straight or hooked setae $\ldots \ldots \ldots \ldots \ldots \ldots \ldots \ldots \ldots$ Mid femur with series of 2-6 strong, posteroventral setae (Figs 164, 167, 226), sometimes modified spine-like setae present, but arrangement and number not as above; mid tibia lacking distinct callus at $2 / 3$, or if weakly developed, then sparsely setose ..

Abdominal sternite 5 with pair of short, stout fang-like setae on each side (Fig. 204); hypopygium with left surstylus narrowed

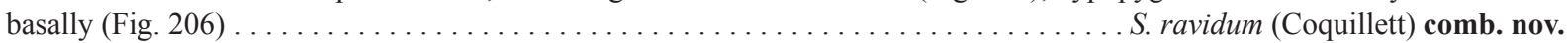
Abdominal sternite 5 (and often sternite 4) with 1-3 strong spine-like setae on each side (Fig. 205); hypopygium with left

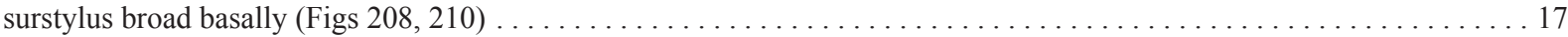

17 Mid tibial callus with hooked setae (Fig. 203); mid tarsomere 1 strongly bent at base (Fig. 203); hypopygium with left surstylus straight and evenly broad, apex truncate with pointed apicoventral process (Fig. 210) . . . . . . . . . . S. rudei sp. nov. Mid tibial callus with straight hair-like setae (Fig. 202); mid tarsomere 1 weakly bent at base (Fig. 202); hypopygium with left surstylus tapered to pointed apex (Fig. 208) ............................... arnaudi sp. nov.

18 Fore tibia with series of fine erect setae along posterior surface, setae 1.5-3X width of tibia in anterior view (Figs 222, 225); antennal stylus length variable, about 1.2-2X length of postpedicel (Figs 223, 224); hypopygium (Figs 197, 198, 229-232) with apex of phallus distinctly flared; dorsal lobe of left and right surstyli elongated $\ldots \ldots \ldots \ldots \ldots \ldots \ldots \ldots \ldots$ Fore tibia lacking series of fine erect setae along posterior surface; antennal stylus about 2.3-3.5X length of postpedicel (Figs 161, 193); hypopygium (Figs 166, 168, 179-182, 194-196) with apex of phallus at most slightly expanded; dorsal lobe of right

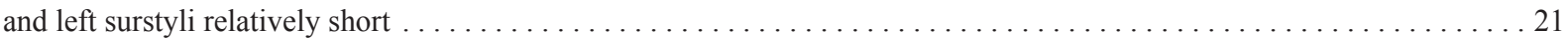

19 Body light-coloured, mainly grey, basal abdominal tergites brownish; legs pale brown with joints yellowish; coxae and abdomen with pale setae; hypopygium (Figs 197, 198) with dorsal lobe of right and left surstylus symmetrical and curved; outer right

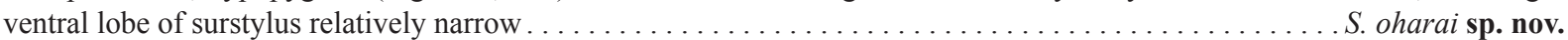
Body dark-coloured, blackish (Fig. 222); legs entirely blackish-brown; coxae and abdomen with black setae; hypopygium (Figs 229-232) with dorsal lobe of right and left surstylus asymmetrical and straight; outer right ventral lobe of surstylus broad ...

20 Male abdominal sternite 5 with subequal pair of short, stout spine-like setae on each side of posterior margin; hypopygium (Figs 231,232) with dorsal lobe of right and left surstyli not expanded apically; left ventral lobe of surstylus narrowly tapered to apex; right dorsal lobe of surstylus with hump-like dorsal projection beside cercus (cercus mostly hidden in lateral view);

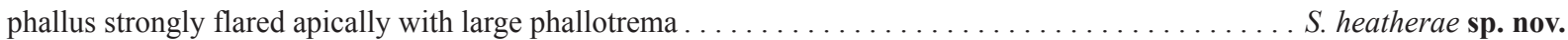
Male abdominal sternite 5 with short inner seta, longer thicker outer seta and long posterolateral seta on each side of posterior margin; hypopygium (Figs 227, 229, 230) with dorsal lobe of right and left surstyli expanded apically; left ventral lobe of surstylus widely tapered to apex; right dorsal lobe of surstylus lacking hump-like dorsal projection beside cercus (cercus exposed in lateral view); phallus flared apically with moderately-sized phallotrema . . S. sycophantor (Melander) comb. nov.

21 Antennal stylus elongate, about 3.5X longer than postpedicel (Fig. 193); fore femur with series of short pale ventral setae, setae shorter than width of femur; postgena, coxae (Fig. 193) and base of abdomen with pale setae; hypopygium (Figs 194-196) with

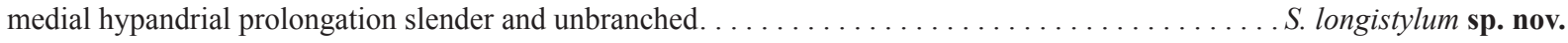
Antennal stylus shorter, about 2.3-2.5X longer than postpedicel (Fig. 161); fore femur with series of long black posteroventral setae, setae about $2 \mathrm{X}$ width of femur; postgena, coxae and base of abdomen with dark setae; hypopygium (Figs 166, 168,

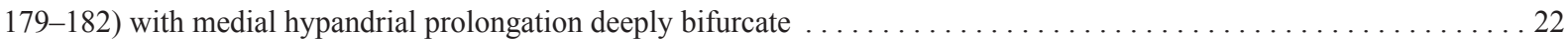

22 Body and legs brownish (Figs 167, 168); mid femur (Fig. 167) with series of 4-6 long ventral setae; apex of mid tibia (Fig. 167) not compressed, posterior surface glabrous; abdominal sternites 4-5 with close-set pair of spine-like setae on each side (Fig. 168); hypopygium (Figs 168, 181, 182) relatively elongate; medial hypandrial prolongation straight with upturned apex....

S. robustum (Melander) comb. nov. Body and legs blackish (Figs 157-159, 164, 166); mid femur (Fig. 164) with long ventral seta near middle and shorter blunttipped posteroventral seta beyond middle; apex of mid tibia (Fig. 164) strongly compressed with white concavity on posterior surface; abdominal sternite 5 with more widely-spaced pair of spine-like setae on each side; hypopygium (Figs 166, 179, 180) relatively short; medial hypandrial prolongation undulate. . . . . . . . . . . . . . . . S. armipes (Melander) comb. nov. Wing (Fig. 172) with crossvein dm-m strongly bent at base and running parallel with $\mathrm{M}_{1}$ distally, distal portion of cell $\mathrm{dm}$

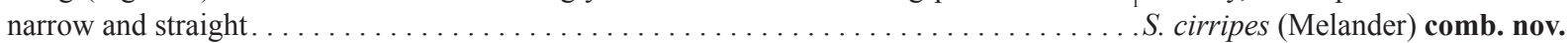
Wing (Fig. 170) with crossvein dm-m broadly curved and convergent with $\mathrm{M}_{1}$ distally, distal portion of cell dm tapered . . . 24 Antennal stylus long (Fig. 163), about 2X length of postpedicel or longer (as in Fig. 193); head with gena and parafacial

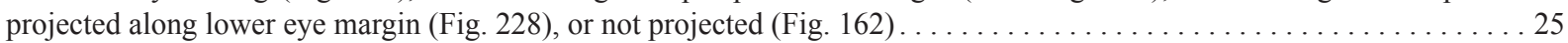
Antennal stylus (Fig. 212) usually distinctly shorter than 2X postpedicel length; head with gena and parafacial distinctly

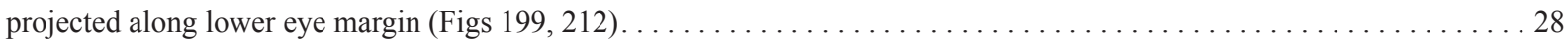
Antennal stylus about 3X length of postpedicel (as in Fig. 193); coxae and femora pale, coxae with pale setae; terminalia with cercus subtriangular and straight, not curved and claw-like $\ldots \ldots \ldots \ldots \ldots \ldots \ldots \ldots \ldots$ longistylum sp. nov. Antennal stylus less than $3 X$ length of postpedicel (as in Figs 223, 224); coxae and femora dark, blackish or brownish, with dark

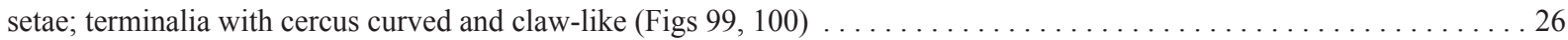



Body blackish; halteres dark, brownish . . . . . . . . . . . . . . . . . . . . . . . . . . . S. armipes (Melander) comb. nov. Body brownish; halteres pale, whitish . . . . . . . . . . . . . . . . . . . . . S. robustum (Melander) comb. nov. Wing with cell $\mathrm{dm}$ small (as in Fig. 173), distal section of vein $\mathrm{M}_{1}$ (beyond base of $\mathrm{M}_{2}$ ) $3 \mathrm{X}$ longer than preceding section

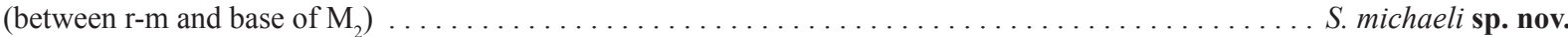
Wing with cell $\mathrm{dm}$ larger (as in Figs 174, 175), distal section of vein $\mathrm{M}_{1}$ (beyond base of $\mathrm{M}_{2}$ ) 1.5-2.0X longer than preceding

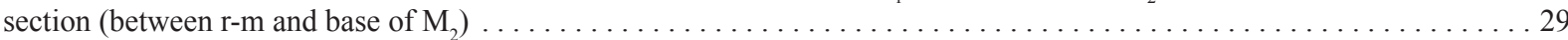
Apex of hind tibia with patch of fine erect setulae on posterior surface (similar to Fig. 213); base of hind femur with dorsal setae pale and erect; coxae with pale setae; fore and mid coxae yellow apically........... S. strigilifer (Melander) comb. nov. Apex of hind tibia without patch of fine erect setae on posterior surface; base of hind femur with dorsal setae dark and reclinate;

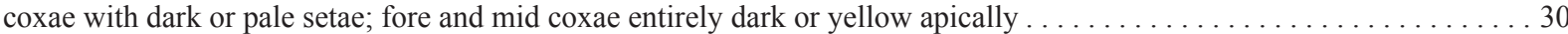
Body blackish. . . . . . . . . . . . . . . . S. arnaudi sp. nov., or S. ravidum (Coquillett) comb. nov., or $S$. rudei sp. nov.

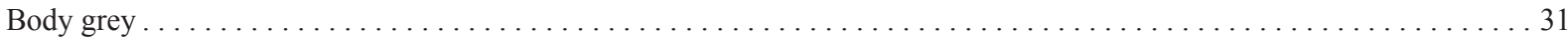
Body dark grey S. heatherae sp. nov. Body light grey. S. oharai sp. nov. Legs, wing veins and halteres pale yellow; head, thorax and male abdomen goldish-grey; female abdomen mostly pale yellow

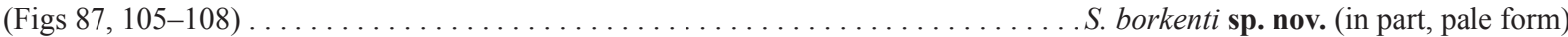
Legs and wing veins brown to blackish-brown, halteres pale yellow to blackish; head, thorax and abdomen of both sexes

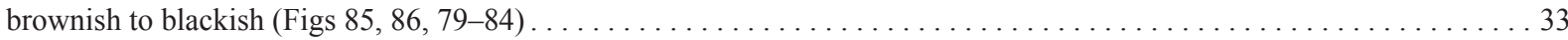

33 Medial hypandrial prolongation (Fig. 112) with extremely elongate pair of apical setae; phallus narrow; left surstylus with basal

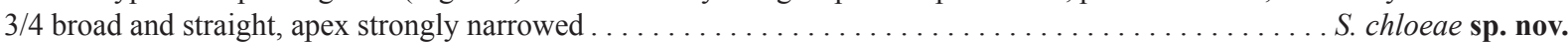
Medial hypandrial prolongation (Figs 91-94, 109-111, 113) with shorter pair of apical setae, or with 1 short seta and 1 long seta; phallus relatively broad; left surstylus not as above, with apical 3/4 narrow (Fig. 91), or with apex gradually tapered (Figs

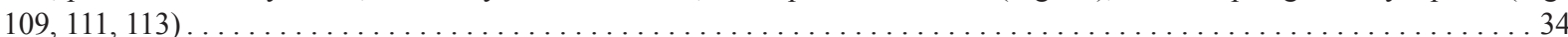
Phallus short and broad (Figs 108-111); medial hypandrial prolongation with apical setae short . . . . . . . . . . . . .

S. borkenti sp. nov. (in part, dark form) Phallus narrow and longer (Figs 83,91-94, 113); medial prolongation with apical setae long $\ldots \ldots \ldots \ldots \ldots \ldots$ Left surstylus strongly tapered beyond base with apical 3/4 narrowly pointed (Fig. 91); medial hypandrial prolongation with

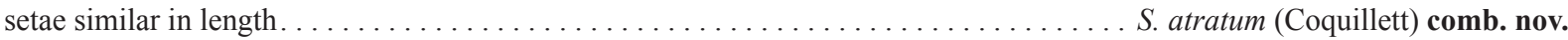
Left surstylus broad along most of length with pointed tip (Fig. 113); medial hypandrial prolongation with upper seta longer

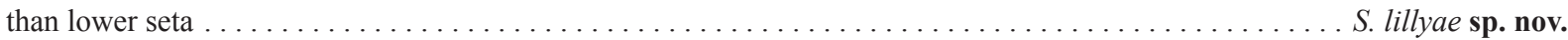
Male abdominal sternites 3-5 modified (Figs 122-124) and adorned with large thick blunt-tipped or spatulate setae; sternite 3 with thick blunt-tipped seta on each side of posteromedial emargination; sternite 4 with large medial membranous cavity enclosed by projecting lateral margin of sternite adorned with ventral setal fringe and large spatulate seta; posterior margin of sternite 5 with 3 large, highly modified setae per side (outer 2 setae spatulate); hypopygium (Figs 122-124, 132-139) with dense brush-like row of fine pale epandrial setae adjacent to base of cercus . . . . . . S. evisceratum (Melander) comb. nov. Male abdominal sternites 3-4 unmodified; posterior edge of sternite 5 (Figs 126-131) weakly emarginate to deeply cleft, with marginal setae various in form; hypopygium (Figs 140-152) with prominent row of dark epandrial setae adjacent to base of cercus, setae often apically branched

Male abdominal sternite 5 with row of prominent modified setae on posterior margin, setae pointed, blunt-tipped or spatulate (Figs 126, 128-131); hypopygium with medial hypandrial prolongation long and straight (Figs 126, 128, 131, 140-143, 147, 148 ) or short, broad and weakly curved (Figs 144-146); dorsal postgonite lobe slender (Figs 129, 131, 142-148) or broadly

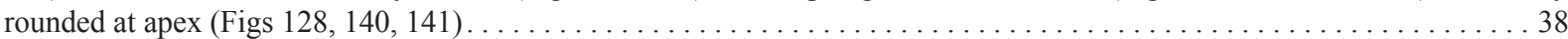
Male abdominal sternite 5 with short setae along posterior margin (Fig. 127); hypopygium (Figs 127, 149-152) with medial hypandrial prolongation long and strongly curved; dorsal postgonite lobe broad, with dorsal fringe of spicules near base . . 42 Male abdominal sternite 5 with large spatulate setae on posterior margin, outer 2 setae about $2 \mathrm{X}$ longer than inner setae (Fig.

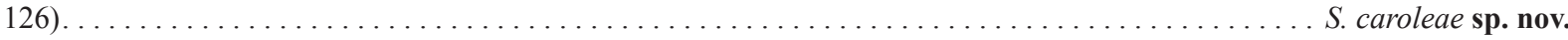
Male abdominal sternite 5 with sharply pointed or blunt-tipped setae on posterior margin (Figs 128-131) . . . . . . . . 39 Male abdominal sternite 5 (Fig. 130) deeply and narrowly cleft, with 3 blunt-tipped setae on each side of cleft; hypopygium (Figs 147, 148) with dense cluster of thick, antler-like epandrial setae borne on pronounced knob-like tubercle adjacent to base of cercus; dorsal lobe of surstylus with bare subcircular dorsal projection near base; lower middle lobe of surstylus very broad; left ventral lobe of surstylus with rounded apex (Fig. 147) . . . . . . . . . . . . . . . . . . . . S. shamshevi sp. nov. Male abdominal sternite 5 (Figs 128, 129, 131) not as above, with 5 sharply pointed posteromarginal spine-like setae per side; hypopygium (Figs 140-145) with row of unbranched or weakly branched epandrial setae adjacent to base of cercus, setae not borne on knob-like tubercle; dorsal lobe of surstylus at most with hump-like projection near base; lower middle lobe of surstylus narrow and thumb-like or subtriangular; left ventral lobe of surstylus with pointed apex (Figs 140, 142, 144) . . . 40 Male abdominal sternite 5 with wavy spine-like posteromedial setae (Fig. 129); hypopygium with medial hypandrial prolongation short, broad and weakly curved, with large horn-like apical setae (Figs 144-146) . . . . . . . . . . S. powelli sp. nov. Male abdominal sternite 5 with spine-like setae weakly curved apically, not wavy (Figs 128, 131); hypopygium with medial hypandrial prolongation long, slender and straight, with relatively short apical setae (Figs $140-143) \ldots \ldots \ldots \ldots \ldots$

41 Hypopygium (Figs 128, 140, 141) with dorsal postgonite lobe broadly rounded apically; dorsal lobe of surstylus hump-like with several strong dorsal setae; lower middle lobe of surstylus subtriangular; left ventral lobe of surstylus with 2 large preapical teeth ventrally; male abdominal sternite 5 deeply cleft posteromedially with digitiform medial protrusion $\ldots . . . \ldots \ldots \ldots$ 
.S. isommatum (Melander) comb. nov. Hypopygium (Figs 131, 142, 143) with dorsal postgonite lobe hooked apically; dorsal lobe of surstylus with pair of branched setae laterally; lower middle lobe of surstylus thumb-like; left ventral lobe of surstylus serrate ventrally, with numerous small preapical teeth; male abdominal sternite 5 weakly emarginate, with dense patch of short microtrichia medially, without

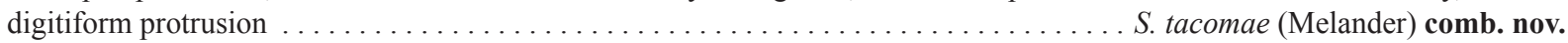
Dorsal lobe of surstylus (Figs 149, 150) with dorsal margin concave, apex notched . . . . . . . . . ...S. sinclairi sp. nov. Dorsal lobe of surstylus (Figs 151, 152) with dorsal margin convex, apex without notch $\ldots \ldots \ldots \ldots \ldots \ldots \ldots \ldots$ Dorsal lobe of surstylus (Figs 151,152) without crest-like lateral process; epandrial setae adjacent to cercus relatively fine and

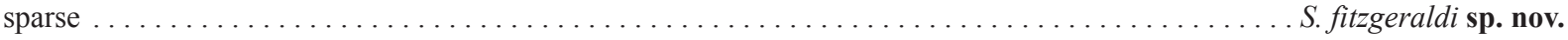
Dorsal lobe of surstylus with crest-like lateral process; epandrial setae adjacent to cercus thicker and more dense .........

S. susanae sp. nov.

\section{Genus Microphor Macquart}

(Figs 1-4, 9, 17-78)

Microphor Macquart, 1827: 139. Type species: Microphor velutinus Macquart, 1827 (= Microphor holosericeus (Meigen, 1804)), by subsequent designation (Rondani 1856).

Microphorus Macquart, 1834: 345. Unjustified emendation.

Microphora Zetterstedt, 1842: 253. Unjustified emendation or error, not Microphora Kröber, 1912: 245 (= Therevidae).

Diagnosis. Microphor is distinguished from other known microphorine genera by the following combination of features: eyes bare (Figs 19-22, 61-64); wing with cell dm present and emitting 3 branches, anal lobe welldeveloped and right-angled (Figs 23-30); hypopygium with medial hypandrial prolongation absent (Figs 43, 48, 49, 73, 74), phallic process present (Figs 42, 47, 50, 51, 72), right ventral postgonite lobe hook-shaped (Figs 43, 48, 49, 73, 74), hypandrium with 3-6 long setae per side (Figs 40, 44, 69); female abdomen with 5 exposed segments, i.e., with narrow telescoping terminalia completely retractable into segment 5 (Figs 18, 34, 60, 68); female terminalia with syntergite $9+10$ undivided with 3 acanthophorite setae per side, cerci long and straight (Figs 52, 53, 55-57).

Redescription. Male: Body length 1.8-3.3 mm, wing length 1.9-3.5 mm. Head (Figs 19, 20, 36, 37, 61, 62): Holoptic with compound eyes contiguous for most of length of frons, remainder of head capsule black to grey, with black setae. Eyes bare, without ommatrichia; dorsal ommatidia larger than ventral ommatidia, separated by line of demarcation. Frons bare, small (mostly obliterated by eyes), subtriangular, just above antennae. Ocellar tubercle with 2-3 pairs of proclinate setae. Occiput mostly clothed with black setae, sparser in upper part, except for postoculars. Gena and parafacial narrow along lower eye margin. Face plus clypeus, when visible, dark grey pruinose. Antenna dark brown to black with pedicel ringed with circlet of black subapical setae; postpedicel conical, moderately long to lengthened, pubescent with microtrichia; stylus of variable length. Palpus elongate ovate, bearing scattered black setae. Proboscis more than half as long as head height, directed forward. Thorax (Figs 17, 19, 20, 35, 59, 61, 62): Black to grey, with black setae. Mesoscutum strongly arched; prescutellar depression present. Proepisternum with 2-5 setae. Postpronotal lobe with 1 long seta and 2-4 shorter anterior setae. Acrostichal setae primarily quadriserial (sometimes biserial posteriorly); setae arranged on each side with: dorsocentrals either uniserial, biserial or as a field of setae, posteriormost dorsocentrals strong and widely separated; 2-3 intra-alar setae; 2-3 supra-alar setae; 2 strong notopleural setae with 2-5 shorter setae of variable number and strength; 1 strong postalar seta. Scutellum with posterior margin rounded, with 3-4 pairs of setae, middle pair(s) strong, outer and inner pair weaker. Mesopleuron bare. Halter dark to pale. Legs (Figs 17, 35, 59): Variable in colour from dark brown to pale brown, sometimes pale at knees or with tibiae and basal tarsomeres pale brown to yellow, with black setae. Tarsal claws, pulvilli and empodium normally developed on all legs. Foreleg: Coxa with long to moderately long setae on anterior surface. Trochanter with a few longer and shorter setae. Femur subequal in length to tibia, with series of longer posteroventral setae, otherwise variously setose. Tibia slender, with short setae, anterior surface with dense pale setulae, apex with anterior comb-like row of close-set setulae. Tarsus subequal to slightly longer than tibia, with short setae, tarsomere 1 subequal to slightly longer than combined length of tarsomeres $2-4$, with prominent or indistinct basiventral seta, tarsomeres 2-4 decreasing in length apically, tarsomere 5 subequal in length to tarsomere 2 or 3. Midleg: Coxa with several setae on anterior surface, sometimes with 1 or more weaker setae on posterior surface. Trochanter with a few longer and shorter setae. Femur subequal in length to tibia, with series of longer posteroventral setae (at least on apical half), otherwise with shorter setae. Tibia slender, usually with several longer dorsal setae, otherwise with short setae. Tarsus subequal to or longer than tibia, with short setae, tarsomere 1 
subequal to combined length of tarsomeres $2-4$, with prominent or indistinct basiventral seta, tarsomeres $2-4$ decreasing in length apically, tarsomere 5 subequal in length to tarsomere 2 or 3 . Hindleg: Coxa with 1-4 relatively long setae on outer surface and some weaker setae on anterior and posterior surface. Trochanter with a few longer and shorter setae. Femur subequal in length to tibia, with series of longer dorsal setae, usually with series of longer anteroventral setae (at least apically), anterior surface otherwise with shorter setae, posterior surface with short fine setae. Tibia slender (M. discalis species group) or enlarged apically ( $M$. obscurus species group), with several longer dorsal setae, otherwise with short setae, apex with posterior comb-like row of close-set setulae. Tarsus subequal to slightly longer than tibia, with short setae, tarsomere 1 unmodified and subequal to combined length of tarsomeres 2-3 (M. discalis species group), or broad and subequal to combined length of tarsomeres 2-4 (M. obscurus species group), tarsomeres 1 and 2 with apical comb-like row of close-set setulae posteroventrally, tarsomeres 2-4 decreasing in length apically, tarsomere 5 subequal in length to tarsomere 2 or 3. Wing (Figs 23, 25, 27, 29): Hyaline or with slight grey-brown tinge, with dark brown veins, veins sometimes pale near wing base, about 2.2-2.3X longer than wide. Pterostigma present, membrane entirely covered with minute microtrichia. Anal lobe strongly developed, right-angled, with proximal margin convex, alula absent. Costa circumambient. Extreme anterior base of costa with several strong setae, distal seta usually longer. Anterior costal section $\mathrm{h}-\mathrm{R}_{2+3}$ bearing short spine-like setae (becoming shorter distally), posterior part of costa beyond $\mathrm{R}_{2+3}$ with fine setae, setae becoming longer and curved from middle of anal lobe up to wing base. Longitudinal veins (except $\mathrm{CuA}+\mathrm{CuP}$ ) complete, reaching wing margin. Sc faint apically. $R_{1}$ straight basally with weak posterior curve in distal part, reaching costa beyond middle of wing, near base of $\mathrm{M}_{2}$ (M. discalis species group, Figs 23, 25, 27), or well beyond base of $\mathrm{M}_{2}$ (M. obscurus species group, Fig. 29). Base of Rs originating opposite humeral crossvein. $R_{2+3}$ and $R_{4+5}$ parallel in middle part and diverging near apex with cell $\mathrm{r}_{2+3}$ compressed in middle part and slightly flared at apex (M. discalis species group), or $\mathrm{R}_{2+3}$ and $\mathrm{R}_{4+5}$ more evenly diverging or subparallel to apex with cell $\mathrm{r}_{2+3}$ not distinctly compressed in middle (M. obscurus species group). $R_{4+5}$ with posterior curve to apex or straight, subparallel to $M_{1}$ beyond cell $\mathrm{dm}$. $\mathrm{M}_{1}$ and $\mathrm{M}_{2}$ diverging beyond cell $\mathrm{dm} . \mathrm{M}_{2}$ and $\mathrm{M}_{4}$ subparallel beyond cell $\mathrm{dm}$. Costal section $\mathrm{M}_{1}-\mathrm{M}_{2}$ slightly longer ( $M$. discalis species group, Figs $23,25,27)$ to distinctly longer (M. obscurus species group, Fig. 29) than $\mathrm{M}_{2}-\mathrm{M}_{4}$. Short r-m crossvein present in basal portion of wing, distal to base of $\mathrm{R}_{4+5}$. Crossvein bm-m complete. Cell dm present, closed by base of $\mathrm{M}_{2}$ and crossvein $\mathrm{dm}-\mathrm{m}$. Cell $\mathrm{dm}$ large and long (extended beyond middle of wing) with distal section of vein $\mathrm{M}_{1}$ (beyond base of $\mathrm{M}_{2}$ ) shorter than preceding section (between $\mathrm{r}-\mathrm{m}$ and base of $\mathrm{M}_{2}$ ) (M. discalis species group, Figs 23, 25, 27), or cell $\mathrm{dm}$ shorter, moderately-sized (extended to around middle of wing) with distal section of vein $\mathrm{M}_{1}$ (beyond base of $\mathrm{M}_{2}$ ) longer than preceding section (between $\mathrm{r}-\mathrm{m}$ and base of $\mathrm{M}_{2}$ ) (M. obscurus species group, Fig. 29). Cells $\mathrm{br}, \mathrm{bm}$ and cua in basal fourth of wing. Cells bm and cua broader than br. Cell cua closed, rounded apically with $\mathrm{CuA}$ curved. Vein $\mathrm{CuA}+\mathrm{CuP}$ not substantially developed, present as fold or trace, if visible. Calypter with fine setae. Abdomen (Figs 31, 65, 66): Blackish-brown to dark grey or brownish-grey, with black setae. Subconical to tubular with pregenitalic segments narrowed. Abdominal muscle plaques present on lateral margins of tergites 2-6; tergite and sternite 2 with transverse band of muscle plaques. Segment 1 short, sternite indistinct. Segment 2 slightly longer than segments 3-5. Segment 6 narrowed, often concave on right side where hypopygium sits when at rest. Segment 7 narrow and tubular, projecting anteroventrally to posteroventrally. Tergites $1-5$ clothed with long setae, dorsomedial setae somewhat shorter. Tergite 6 sparsely setose. Sternites $2-5$ with intermixed long and short setae. Sternite 6 with few weak setae. Segment 7 bare, or with pair of weak setae on sternite, occasionally with small seta(e) on tergite. Sternite 8 convex, subrectangular with long setae. Tergite 8 small, subrectangular with 2 setae at posterior margin, otherwise bare. Hypopygium (Figs 32, 33, 38, 39, 40-51, 67, 69-74): Lateroflexed to right; inverted with posterior end directed anterodorsally; small, about 1/3-1/5 length of abdomen; asymmetrical; hypopygial foramen not formed. Epandrium with left and right lamellae undivided, narrowly connected behind cerci, asymmetrical, with bilobed or trilobed surstylus projecting dorsally or distally. Hypandrium with basal part convex bearing 3-6 long setae on each side; apical part with asymmetrical left and right hypandrial lobes, right lobe longer. Medial hypandrial prolongation absent. Postgonite flanking phallus on both sides, continuous medially at base of postgonite apodeme and cradling phallus; left and right dorsal postgonite lobes symmetrical, bifid; ventral postgonite asymmetrical, left lobe short or absent, right lobe large, hook-shaped; postgonite apodeme V-shaped in ventral view with robust rod-like left and right branch projecting anteriorly. Phallus tubular, shape and length variable, phallic process present. Ejaculatory apodeme small, keel-like. Hypoproct projected as pair of lobes below cerci (M. discalis species group), or not substantially developed (M. obscurus species group). Cerci symmetrical, each cercus short with several long setae dorsally and apically. 

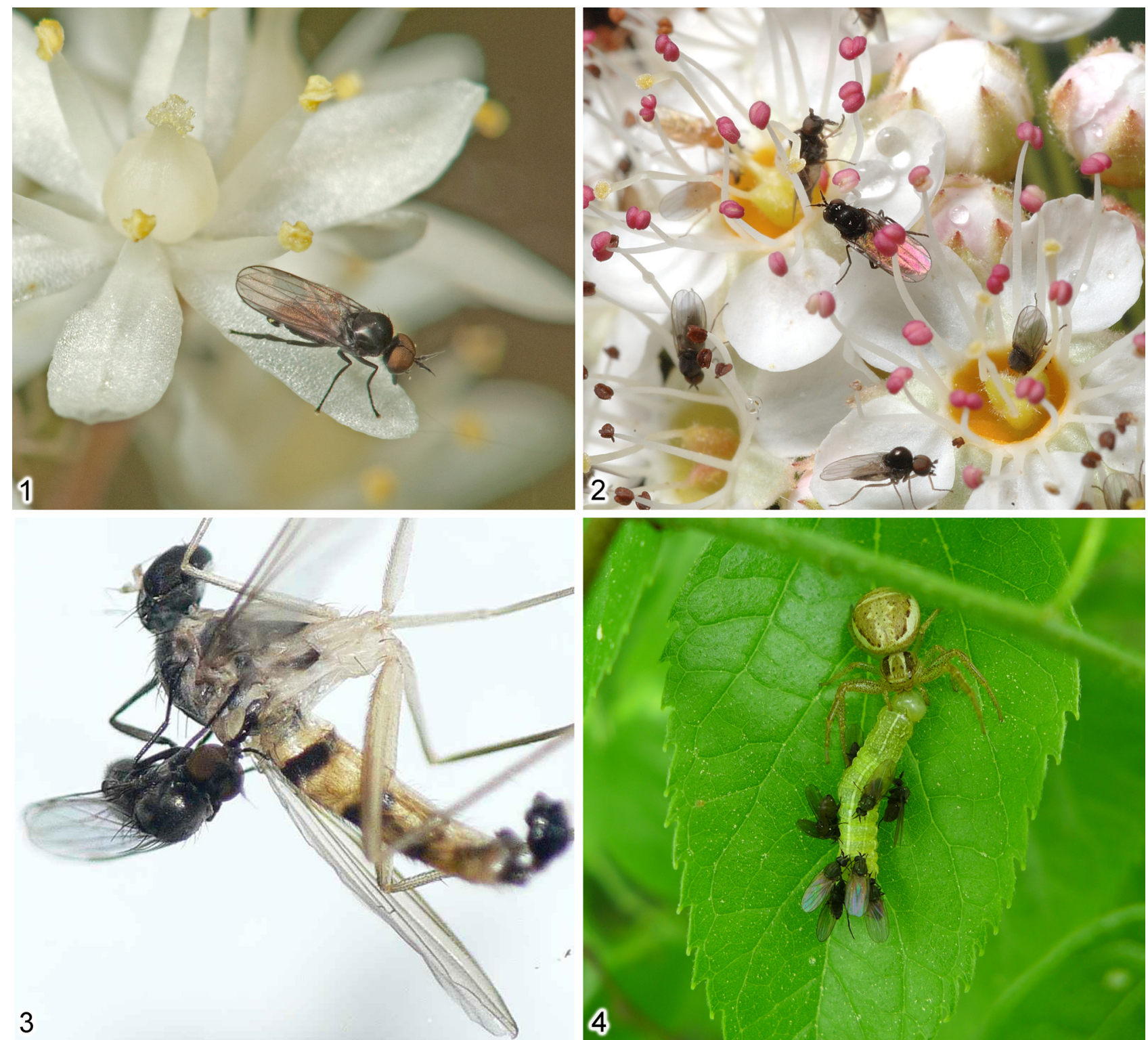

FIGURES 1-4. Photographs of live specimens of Microphor in situ. 1. Male of M. obscurus Coquillett resting on petal of Maianthemum racemosum (L.) Link (false solomon's seal) at Dorcas Bay, Ontario. 2. Female of M. obscurus (center), surrounded by several individuals of Anthalia sp. (Hybotidae), on Physocarpus sp. (ninebark) at Warner Bay, Ontario. 3. Female of Microphor sp. feeding on a male Neurigona sp. (Dolichopodidae) trapped in a spider's web at Borgholzhausen, Germany. 4. Females of Microphor (probably M. holosericeus) feeding on a caterpillar (Noctuidae, Noctuinae) caught by a crab spider (Thomisidae, Xysticus sp.) at Göttingen, Germany. Photographs by Steve Marshall (Figs 1, 2), Juergen Peters (Fig. 3) and Gerrit Öhm (Fig. 4).

Female: Body length: 1.6-2.8 mm, wing length 1.9-3.5 mm. Similar to male except as follows: Head (Figs 21, 22, 63, 64): Dichoptic; eyes smaller; dorsal and ventral ommatidia similar in size, line of demarcation incomplete or absent. Frons subrectangular (broader than high) to subquadrate, distance between antennae and ocellar tubercle shorter. Thorax (Figs 18, 21, 22, 60, 63, 64): Mesoscutum with slightly less pronounced arch. Legs (Figs 18, 60): With shorter setae. Hindleg: With tibia slender, not enlarged apically; tarsomere 1 not enlarged. Wing (Figs 24, 26, 28, 30): Slightly narrower (2.3-2.5X longer than wide). Anal lobe smaller. Abdomen (Figs 18, 34, 60, 68): Subconical, tapered posteriorly, with 5 exposed segments, i.e., with narrow telescoping terminalia completely retractable into segment 5 . Tergites and sternites $2-5$ setose, setae shorter and relatively sparse, segment 5 concolorous with anterior abdominal segments. Terminalia (Figs 52-58): Segments 6, 7 and 8 mainly bare. Segment 6 and 7 with longitudinal 
sclerotized band laterally between tergites and sternites. Tergites 6 and 7 with anterior end deeply emarginate and darkened, longer than wide, with retractable band-like posterior sclerite extensions on each side, with transverse row of setae at posterior margin (i.e., before retractable band-like posterior sclerite extensions), sometimes with additional small setae anteriorly; sternites 6 and 7 similar but anterior end not deeply emarginate. Tergite 8 divided (desclerotized) medially, hemitergites with darkened margins, articulated with sternite 8 anterolaterally (Fig. 53) or separate (Fig. 56); sternite 8 divided (desclerotized) medially. Sternite 9 inconspicuous, apparently membranous. Spermatheca (Figs 54, 58) developed as darkened spherical to teardrop-shaped terminal expansion of spermathecal duct. Syntergite $9+10$ undivided, partially desclerotized medially, with 3 acanthophorite setae per side. Sternite 10 subtriangular, with 2-3 setae per side and setulae apically. Cercus long and narrow, with long setae apically and ventrally.

Immatures: Very little is known of the larvae (see below) and nothing is known of the eggs or pupae.
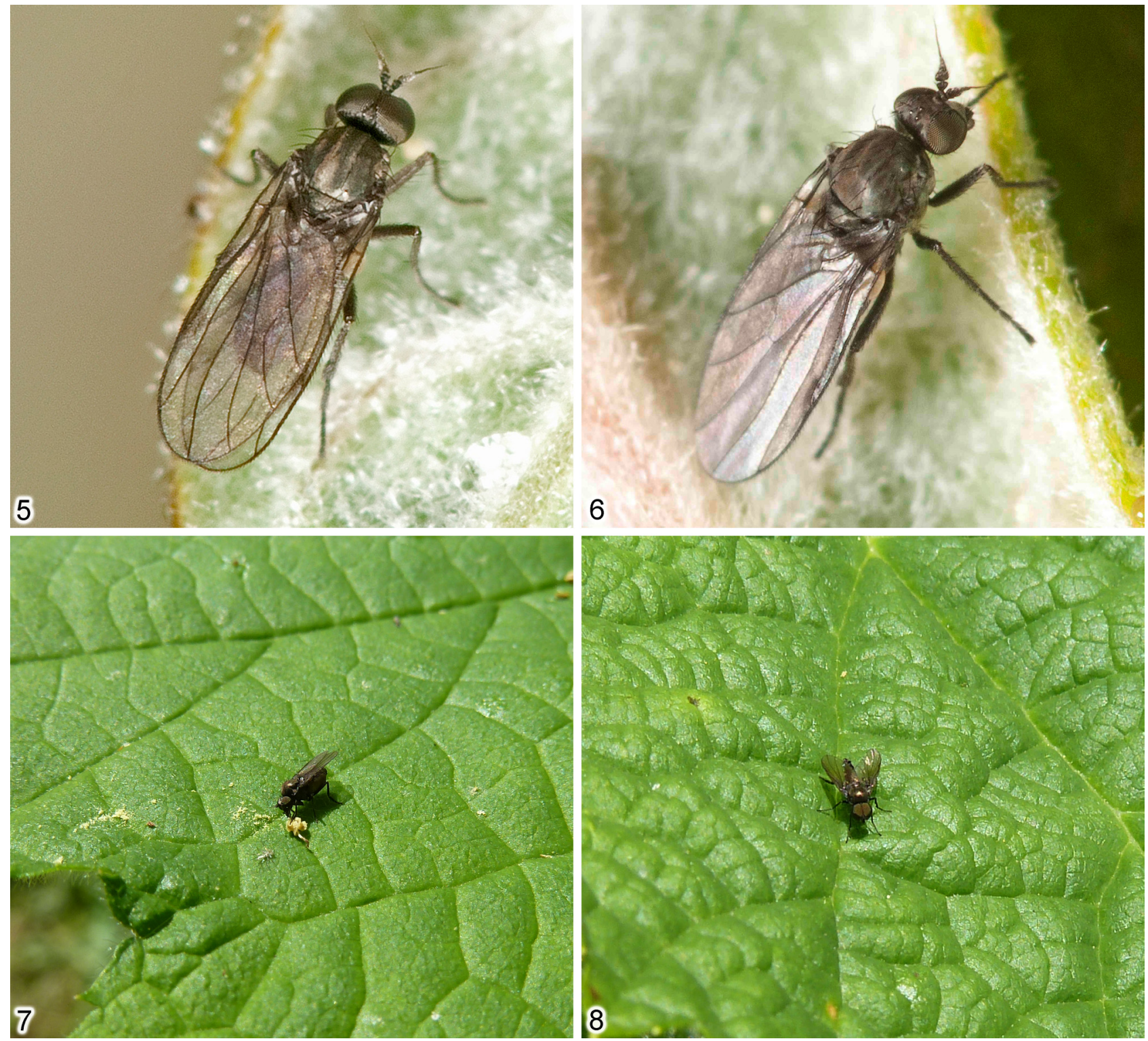

FIGURES 5-8. Photographs of live specimens of Schistostoma in situ. 5. Male of S. evisceratum (Melander) comb. nov., resting on leaf along the Hoh River, Washington. 6. Female of S. evisceratum (Melander) comb. nov., resting on leaf along the Hoh River, Washington. 7. Female of S. armipes (Melander), eating pollen from dehisced anther of Rubus parviflorus Nuttall (thimbleberry) at Mary's Peak Campground, Oregon. 8. Male of S. armipes (Melander), resting on leaf of Rubus parviflorus Nuttall (thimbleberry) at Mary's Peak Campground, Oregon. Figures 5 and 6 photographed by Steve Marshall. 

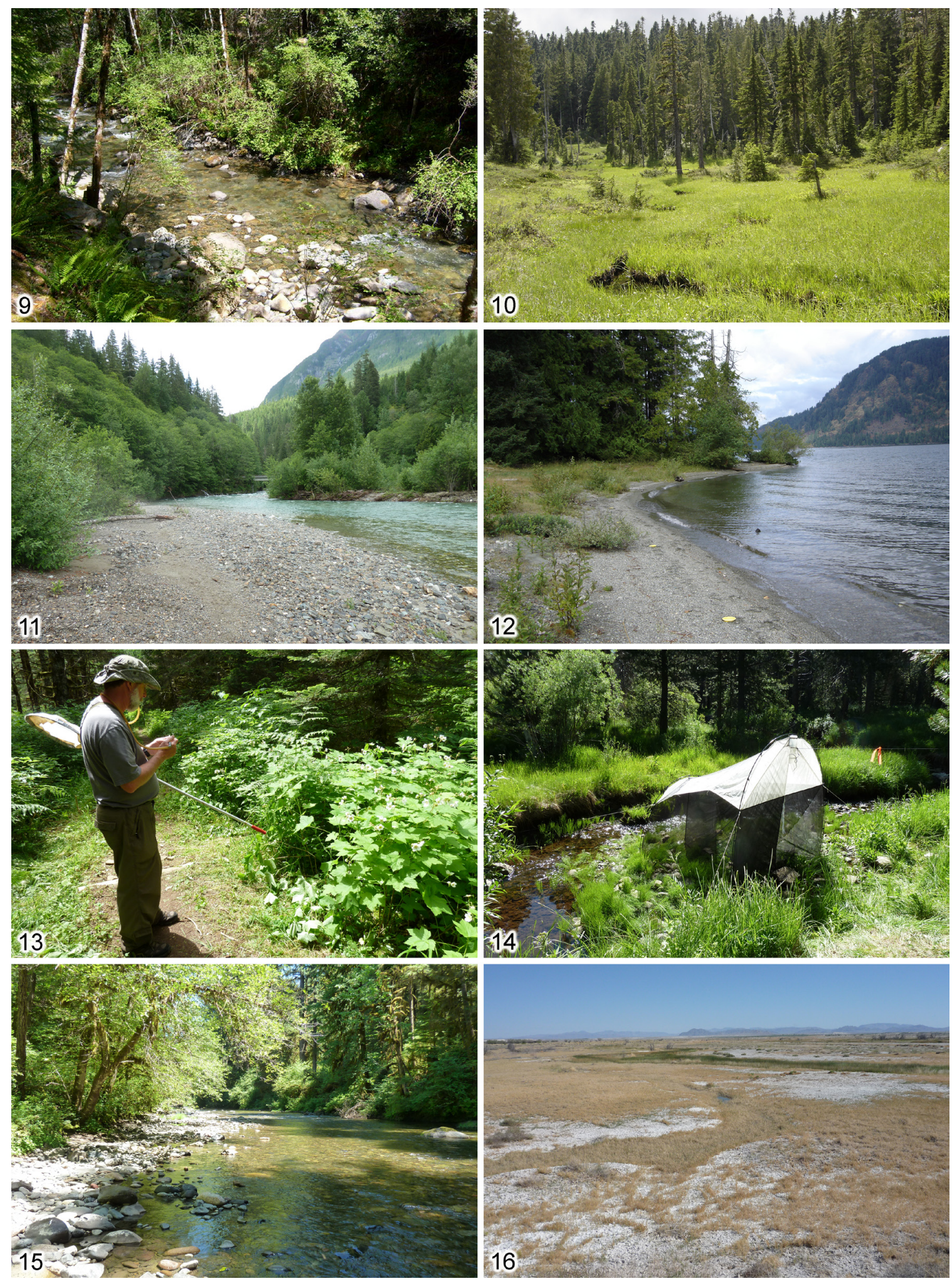

FIGURES 9-16. Collection localities and habitats of Nearctic Microphor and Schistostoma. 9. West Fork of Patrick Creek, California, collection locality of M. discalis Melander. 10. Trail to Battleship Lake, British Columbia, collection locality of S. atratum (Melander) comb. nov. 11. Cascade River, Washington, collection locality of $S$. caroleae sp. nov., S. evisceratum (Melander) comb. nov. and $S$. susanae sp. nov. 12. Cowichan Lake, British Columbia, collection locality of $S$. evisceratum (Melander) comb. nov. 13. Second author at Mary's Peak Campground, Oregon, collection locality of S. armipes (Melander). 14. Sagehen Creek Field Station, California, collection locality of S. armipes (Melander), S. borkenti sp. nov. and S. sycophantor (Melander). 15. Trout Creek Campground, Oregon, collection locality of S. armipes (Melander) and S. cirripes (Melander) comb nov. 16. Ash Meadows National Wildlife Refuge, Nevada, collection locality of S. runyoni sp. nov. 
TABLE 1. List of flowers visited by Microphor and Schistostoma species.

\begin{tabular}{|c|c|c|c|c|}
\hline Plant Taxon & Plant family & Common name & $\begin{array}{l}\text { Microphorinae } \\
\text { species }\end{array}$ & Source \\
\hline Achillea milefolium $\mathrm{L}$. & Asteraceae & Yarrow & S. strigilifer & Label data \\
\hline Arctostaphylos sp. & Ericaceae & Manzanita & $\begin{array}{l}\text { S. evisceratum; } \\
\text { S. rudei }\end{array}$ & Label data \\
\hline Artemesia californica Lessing & Asteraceae & California sagebrush & M. discalis & Label data \\
\hline Aruncus sp. & Rosaceae & Bride's feathers & M. obscurus & Label data \\
\hline Ceanothus cordulatus Kellogg & Rhamnaceae & Whitethorn ceanothus & S. sycophantor & Label data \\
\hline Ceanothus cuneatus (Hooker) Nuttall & Rhamnaceae & Buckbrush & S. sycophantor & Label data \\
\hline Ceanothus integerrimus Hooker \& Arnott & Rhamnaceae & Deer brush & $\begin{array}{l}\text { M. skevingtoni; } \\
\text { S. armipes; } \\
\text { S. sycophantor }\end{array}$ & Label data \\
\hline Ceanothus sp. & Rhamnaceae & White ceanothus & $\begin{array}{l}\text { S. ravidum; } \\
\text { S. rudei; } \\
\text { S. strigilifer }\end{array}$ & Label data \\
\hline Coreopsis bigelovii (A. Gray) Voss & Asteraceae & Bigelow's tickseed & S. rudei & Label data \\
\hline Crataegus sp. & Rosaceae & Hawthorn & S. robustum & Label data \\
\hline Eriogonum nudum Douglas ex Bentham & Polygonaceae & Naked buckwheat & S. sycophantor & Label data \\
\hline Euphorbia sp. & Euphorbiaceae & Spurge & M. obscurus & Label data \\
\hline Gilla capitata Sims & Polemoniaceae & Bluehead gilia & S. strigilifer & Label data \\
\hline Horkelia fusca Lindley & Rosaceae & Dusky horkelia & S. sycophantor & Label data \\
\hline $\begin{array}{l}\text { Lomatium dasycarpum (Torrey \& A. } \\
\text { Gray) J.M. Coulter \& Rose }\end{array}$ & Apiaceae & $\begin{array}{l}\text { Woolly fruit desert } \\
\text { parsley }\end{array}$ & S. ravidum & Label data \\
\hline Lomatium sp. & Apiaceae & Desert parsley & S. rudei & Label data \\
\hline Lonicera sp. & Caprifoliaceae & Honeysuckle & S. heatherae & Label data \\
\hline Maianthemum racemosum (L.) Link & Asparagaceae & False solomon's seal & M. obscurus & $\begin{array}{l}\text { Marshall } \\
\text { (2012, p. } \\
\text { 281). Fig. } 1\end{array}$ \\
\hline Nemophila menziesii Hooker \& Arnott & Boraginaceae & Baby blue eyes & S. ravidum & Label data \\
\hline Nemophila sp. & Boraginaceae & Baby blue eyes & S. strigilifer & Label data \\
\hline Nitraria sp. & Nitrariaceae & & S. thalhammeri & $\begin{array}{l}\text { Chvála } \\
(1987)\end{array}$ \\
\hline Phacelia davidsonii A. Gray & Boraginaceae & Davidson's phacelia & S. strigilifer & Label data \\
\hline Physocarpus capitatus (Pursh) Kuntze & Rosaceae & Ninebark & S. sycophantor & Label data \\
\hline Physocarpus sp. & Rosaceae & Ninebark & M. obscurus & Fig. 2 \\
\hline $\begin{array}{l}\text { Plagiobothrys nothofulvus (A. Gray) A. } \\
\text { Gray }\end{array}$ & Boraginaceae & Rusty popcorn flower & $\begin{array}{l}\text { M. obscurus; } \\
\text { S. rudei; } \\
\text { S. strigilifer }\end{array}$ & Label data \\
\hline Prunus subcordata Bentham & Rosaceae & Pacific plum & S. rudei & Label data \\
\hline Ranunculus sp. & Ranunculaceae & Buttercup & M. obscurus & Label data \\
\hline Rubus parviflorus Nuttall & Rosaceae & Thimbleberry & S. armipes & Fig. 7 \\
\hline Salix sp. & Salicaceae & Willow & $\begin{array}{l}\text { S. powelli; } \\
\text { S. rudei }\end{array}$ & Label data \\
\hline Symphoricarpos sp. & Caprifoliaceae & Snowberry & S. heatherae & Label data \\
\hline Ziza sp. & Apiaceae & Meadow parsnip & M. obscurus & Label data \\
\hline
\end{tabular}


Included species, distribution and ecology. The genus now comprises at least 16 known species with nine described species from the Palaearctic Region and several undescribed species from the sub-Mediterranean region of Europe and Turkey (Chvála 1986; Shamshev 1992, 1995; Shamshev \& Sinclair 2006, I.V. Shamshev pers. comm. 2021), one described species from the Oriental Region (Saigusa \& Yang 2003), one undescribed species from the Neotropical Region (Chvala 1991), and five described species from the Nearctic Region (including two new species described herein). Adults are found in various habitats (e.g., Fig. 9) such as forest margins, meadows, and gardens (Chvála 1983, 1986). The Nearctic species are classified into two distinct species groups.

Adult Microphor species are mostly predaceous, but are often found on flowers (Chvála 1983). Males have been seen hovering in small swarms that are not associated with mating activity (Chvála 1986). Females have also been noticed hovering near window panes, apparently looking for insect prey (Collin 1961). Females of at least four species, namely M. anomalus (Meigen), M. crassipes Macquart, M. holosericeus (Meigen) and M. obscurus Coquillett, have been observed feeding on insects trapped in spider webs (Nentwig 1985), a specialized hunting technique (i.e., kleptoparasitism) that may characterize the genus (Fig. 3). In Germany several female Microphor (probably M. holosericeus) were recently observed (Fig. 4) feeding on a caterpillar prey item (Noctuidae, Noctuinae) while it was being consumed by a crab spider (Thomisidae, Xysticus sp.), suggesting a greater association between certain female Microphor and hunting spiders as reported here for the first time. In addition, several species of Microphor have been observed visiting flowers (Table 1) probably for nectar (Figs 1-2), but it is not known if any of these species ingest pollen. Pollen grains have not been found in the gut of dissected specimens of Microphor, unlike Schistostoma (see below).

Beling (1882, p. 212) described a single larva of the European species, M. anomalus, which was collected May 2-13 under leaves in a beech (Fagus L.) plantation and was reared as an adult male on May 29. The larva was described without figures as small $(7 \mathrm{~mm}$ long), cylindrical $(0.9 \mathrm{~mm}$ thick) and yellowish with an anteriorly tapered generalized empidoid head. The body was made up of 12 segments, including the head, with segments 5-11 each bearing shallow creeping welts ventrally. Segment 12 was one fourth shorter than segment 11 and terminated in 2 widely spaced pale yellowish-brown posterior spiracles situated above a dorsally curved membranous toothlike abdominal apex. This is the only known report (also summarized by Lundbeck 1910) of an immature stage, including larval habitat, in the Microphorinae.

\section{Microphor discalis species group}

(Figs 9, 17-28, 31-50, 52-55, 75-77)

Diagnosis. Setae of body and legs black, body blackish-brown to grey, legs dark brown to partially pale (Figs 17, 18); male compound eye with demarcation line between larger dorsal and smaller ventral ommatidia (Figs 19, 20); female head with gena and parafacial narrow along lower eye margin (Fig. 21); antenna with stylus slightly shorter to longer than postpedicel (Figs 20, 21, 36, 37); thorax with mesonotal setae widely spaced and conspicuous; acrostichals primarily quadriserial (sometimes biserial posteriorly), dorsocentrals arranged in a single row per side (rarely irregularly biserial); scutellum with 3-4 setae per side; male midleg unmodified, trochanter without medial spine-like setal pair; wing with cell $\mathrm{dm}$ large and long (Figs 23-28), cell $\mathrm{m}_{1}$ relatively short with broad base; male pregenitalic abdominal sternites unmodified (Fig. 31); hypopygium (Figs 31-33, 38-50) small and free, epandrium without specialized setae adjacent to cercus, dorsal lobe of surstylus and dorsal postgonite lobe slightly projected and subequal in length, left middle lobe of surstylus elongate and C-shaped, left ventral lobe of surstylus elongate (as long as middle lobe), right hypandrial lobe long and broad and up-curved with rounded tip, hypandrium with 3-6 setae per side, medial hypandrial prolongation absent, right ventral postgonite lobe large and hook-shaped; female terminalia (Fig. 34) completely retractable into segment 5 (i.e., with 5 exposed abdominal segments), segment 5 concolorous with anterior abdominal segments, syntergite $9+10$ with acanthophorite setae, cercus long and narrow with long setae apically and ventrally (Figs 52, 53, 55).

Remarks. This species group includes M. discalis Melander, M. skevingtoni sp. nov. and M. turneri sp. nov. 

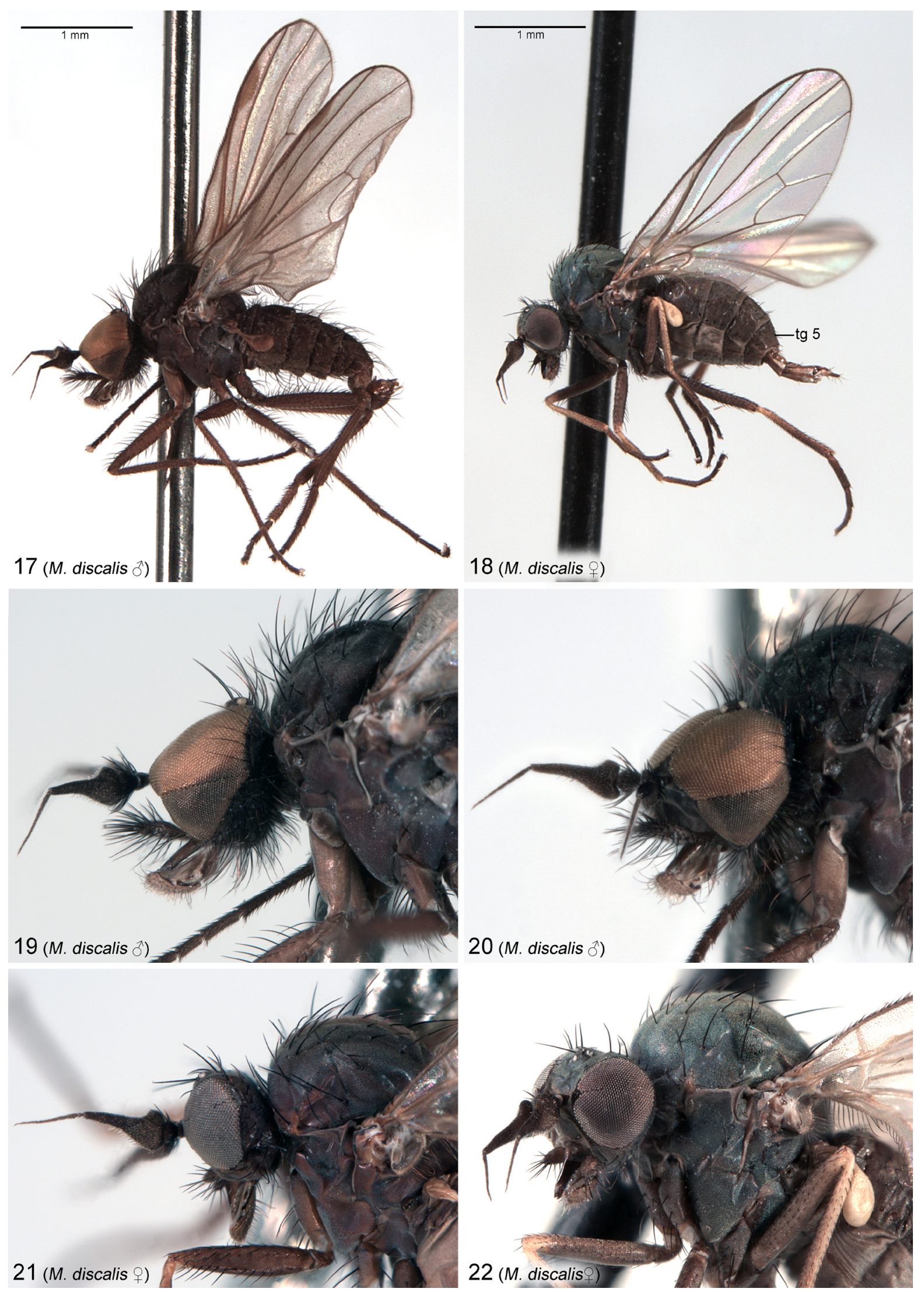

FIGURES 17-22. Habitus and head of Microphor discalis Melander. 17. Male habitus. 18. Female habitus. 19. Male head and anterior portion of thorax, lateral view. 20. Male head and anterior portion of thorax, oblique view. 21. Female head and thorax, lateral view. 22. Female head and thorax, oblique view. Specimens from: Lily Pond, California (Figs 17, 19, 20, 21); BYA Harmony Pines Youth Camp, California (Figs 18, 22). Abbreviation: tg-tergite. 


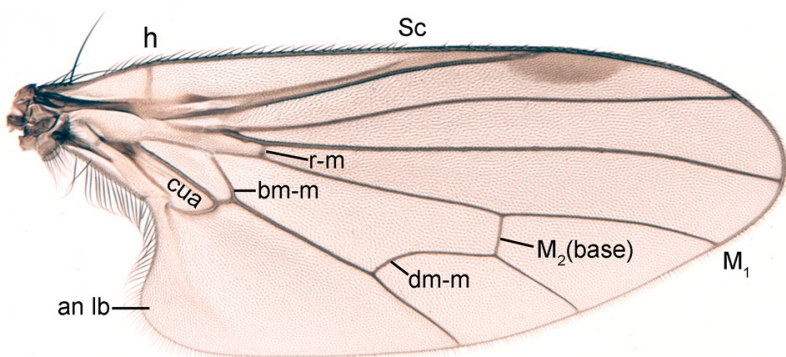

23 (M. discalis ${ }^{\Uparrow}$ )

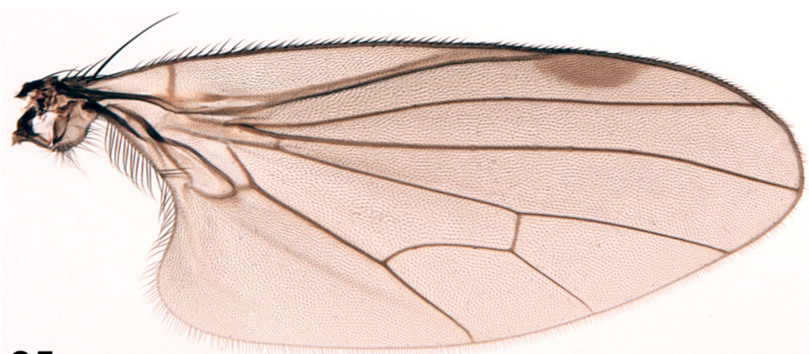

25 (M. skevingtoni $\left.{ }^{\lambda}\right)$

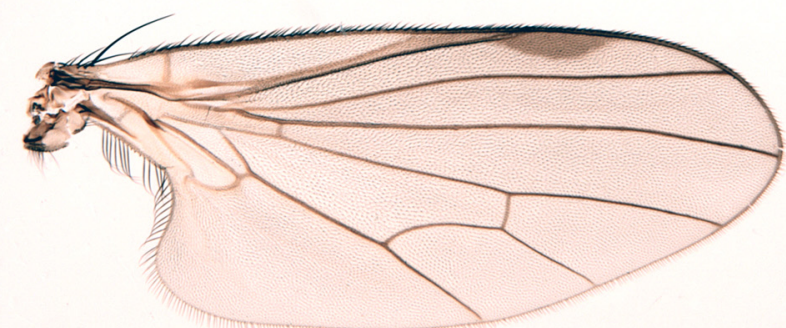

27 (M. turneri $\precsim$ )

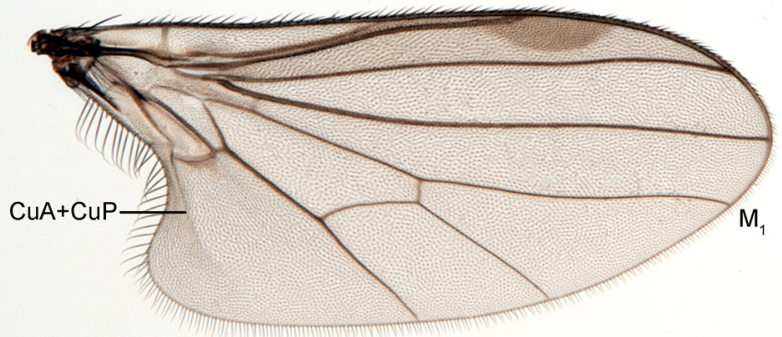

29 (M. obscurus $\stackrel{\text { त) }}{\circ}$
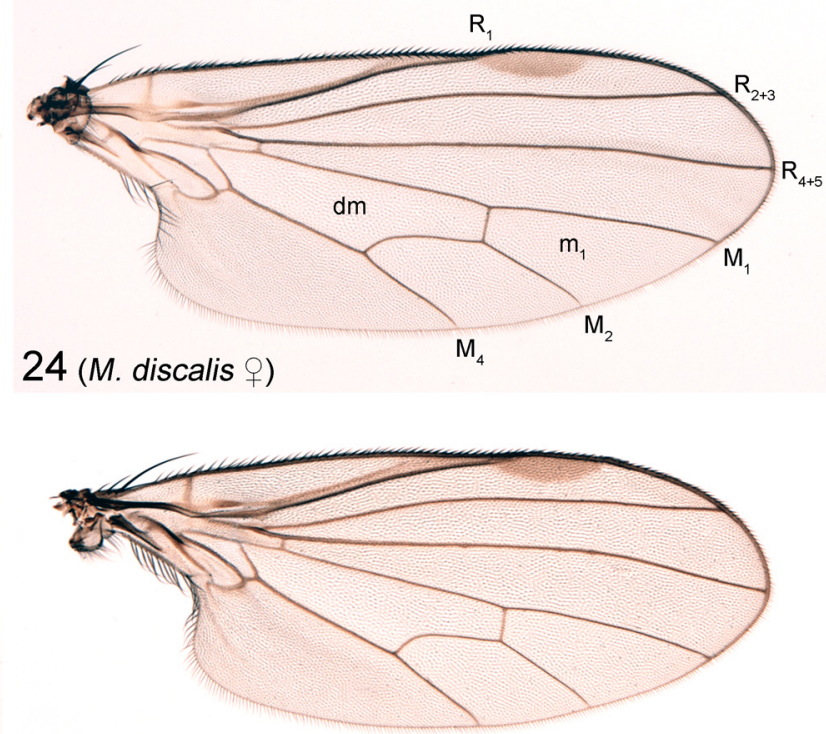

26 (M. skevingtoni ㅇ)

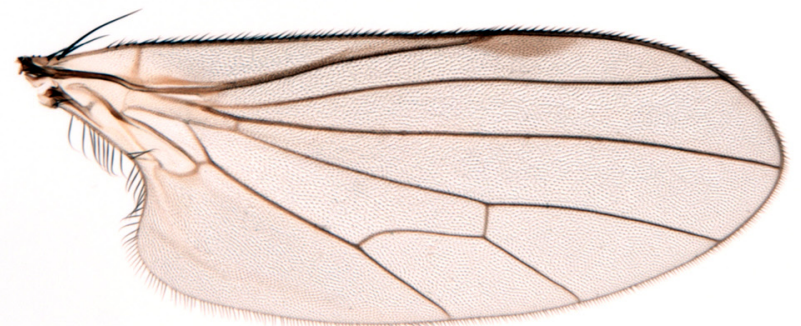

28 (M. turneri + )

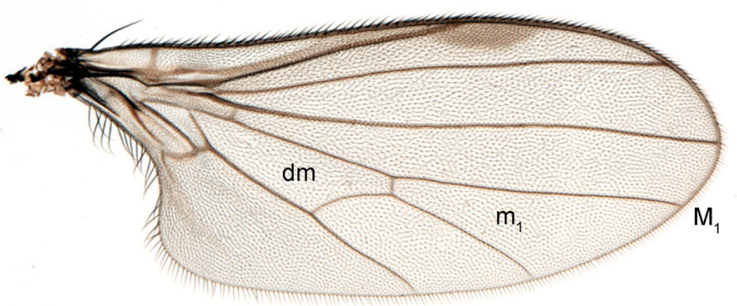

30 (M. obscurus + )

FIGURES 23-30. Wings of Nearctic Microphor. 23. $M$. discalis Melander, male. 24. $M$. discalis Melander, female. 25. $M$. skevingtoni sp. nov., male . 26. M. skevingtoni sp. nov., female. 27. M. turneri sp. nov., male. 28. M. turneri sp. nov., female. 29. M. obscurus Coquillett, male. 30. M. obscurus Coquillett, female. Specimens from: King City, California (Figs 23, 24); Lafayette, California (Figs 25, 26); Kramer Strip, Washington (Figs 27, 28); Glade Gap, North Carolina (Fig. 29); Great Smoky Mountains NP, North Carolina (Fig. 30). Abbreviations: an lb — anal lobe; bm-m—basal medial crossvein; cua — anterior cubital (=anal) cell; $\mathrm{CuA}+\mathrm{CuP}$ - anterior branch of cubital vein + posterior branch of cubital vein; dm-discal medial cell; dm-mdiscal medial crossvein; $h$ - humeral crossvein; $\mathrm{m}_{1}$ - first medial cell; $\mathrm{M}_{1}, \mathrm{M}_{2}, \mathrm{M}_{4}$-medial veins; $\mathrm{R}_{1}, \mathrm{R}_{2+3}, \mathrm{R}_{4+5}$-radial veins; r-m-radial-medial crossvein; Sc — subcostal vein.

\section{Microphor discalis Melander}

(Figs 9, 17-24, 31-34, 40-43, 54, 75)

Microphorus discalis Melander, 1940b: 64.

Type material. HOLOTYPE, ô collected from Muir Woods [ca $37^{\circ} 53^{\prime} \mathrm{N} 122^{\circ} 34^{\prime} \mathrm{W}$ ], Marin County, California, USA, 7.viii.1915. See "Remarks". ALLOTYPE: USA: California: Humboldt County: Dyerville [ca $40^{\circ} 21^{\prime} \mathrm{N}$ 


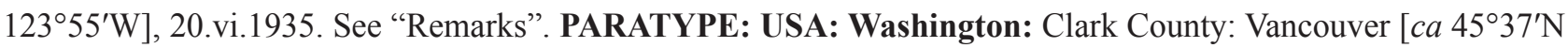
$\left.122^{\circ} 40^{\prime} \mathrm{W}\right]$, 7.vii.1917. See "Remarks".

Material examined. MEXICO: Baja California: Sierra S Pedro Mártir [ca $30^{\circ} 44^{\prime} \mathrm{N} 115^{\circ} 13^{\prime} \mathrm{W}$ ], trail from La

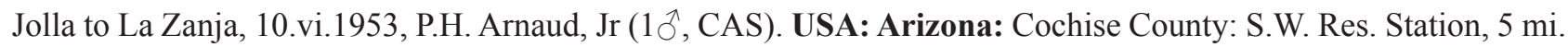
W Portal [ca 31 ${ }^{\circ} 53^{\prime} \mathrm{N} 109^{\circ} 12^{\prime} \mathrm{W}$ ], 1.vi.1965, Malaise, V. Roth (1 ${ }^{\jmath}$, UCRC); Coconino County: Oak Creek Canyon,

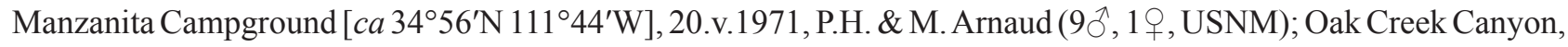

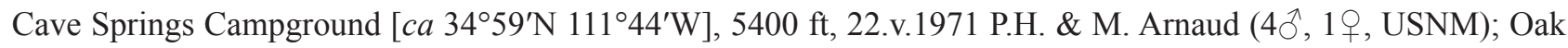

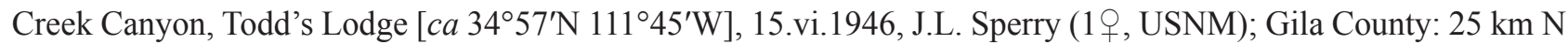

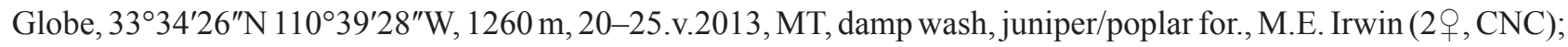
Pima County: Santa Rita Mtns, Coronado NF, Madera Canyon, Bog Springs Rd, 31 ${ }^{\circ} 43^{\prime} \mathrm{N} 110^{\circ} 52^{\prime} \mathrm{W}$, MT in wet wash, 1650 m, 25-27.iii.2001, M.E. Irwin (1へ̂, CNC); Santa Cruz County: Santa Rita Mts, Coronado NF, Madera Canyon, Bog Spring [ca 31 $43^{\prime} \mathrm{N} 110^{\circ} 52^{\prime} \mathrm{W}$ ], $6000 \mathrm{ft}$, 3.vi.1991, B.J. Sinclair (1ㅇ, CNC). California: Contra Costa County: Briones Reg. Park [ $\mathrm{ca} 37^{\circ} 57^{\prime} \mathrm{N} 122^{\circ} 08^{\prime} \mathrm{W}$ ], along Cascade Creek at Bear Creek Rd entrance, 14.iii.1978, D. Wilder (1ð̂, CAS); same data except, Toyon Canyon, 25.v.1979, D.D. Wilder (3ㅇ, CAS); same data except, 26.v.1979 (4ㅇ, CAS); Lafayette [ $\mathrm{ca} 37^{\circ} 53^{\prime} \mathrm{N} 122^{\circ} 07^{\prime} \mathrm{W}$ ], 6.iv.1968, D.D. Munroe $\left(2{ }^{\top}, 1\right.$,, CNC); same data except, 18.iv.1968 $\left(8{ }^{\wedge}, 10\right.$ ㅇ, CNC); 2 mi. SE Lafayette [ca $37^{\circ} 53^{\prime} \mathrm{N} 122^{\circ} 07^{\prime} \mathrm{W}$ ], $756 \mathrm{ft}, 10 . i v .1968$, dry ice Malaise trap, W.J. Turner

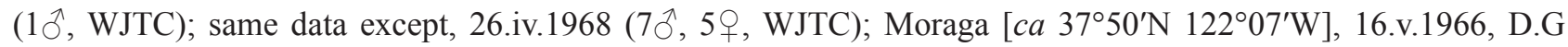
Denning (1 $\jmath^{\jmath}$, UCDC); Del Norte County: West Fork of Patrick Creek, $41^{\circ} 55^{\prime} 03^{\prime \prime} \mathrm{N} 123^{\circ} 51^{\prime} 28^{\prime \prime} \mathrm{W}, 24-31 . v .2009$, Malaise, J.M. Cumming \& S.E. Brooks (4 $0^{\dagger}$, CNC); Humboldt County: [ca $40^{\circ} 43^{\prime} \mathrm{N} 124^{\circ} 03^{\prime} \mathrm{W}$ ] F.W. Nunenmacher

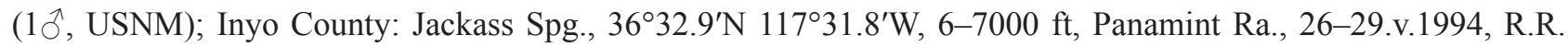
Snelling (3 $\left.3^{\wedge}, \mathrm{LACM}\right)$; Los Angeles County: BYA Harmony Pines Youth Camp, $34^{\circ} 23^{\prime} 21^{\prime \prime} \mathrm{N} 117^{\circ} 42^{\prime} 53^{\prime \prime} \mathrm{W}$, 616.vi.2017, veg. along flowing creek, MT, J.H. Skevington $\left(3{ }^{\top}, 6 \circ\right.$, CNC); Santa Catalina Is., Middle Canyon [ca

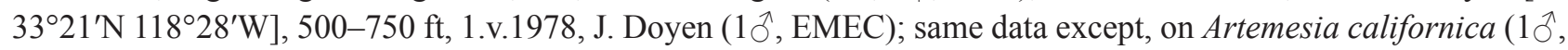

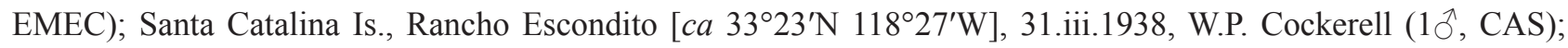

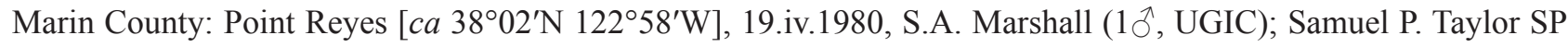
along Lagunitas Creek [ca $38^{\circ} 01^{\prime} \mathrm{N} 122^{\circ} 43^{\prime} \mathrm{W}$ ], 20.v.1977, D.D. Wilder (1 $0^{\wedge}$, CAS); along Lagunitas Creek below Alpine Dam [ $c a 37^{\circ} 56^{\prime} \mathrm{N} 122^{\circ} 38^{\prime} \mathrm{W}$ ], 28.v.1979, D.D. Wilder (1 ${ }^{`}, 1$,, CAS); Lily Pond, Alpine Lake [ca $37^{\circ} 55^{\prime} \mathrm{N}$

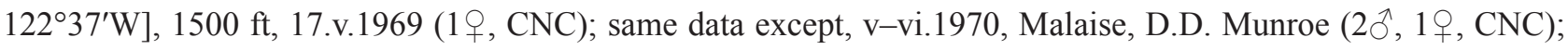

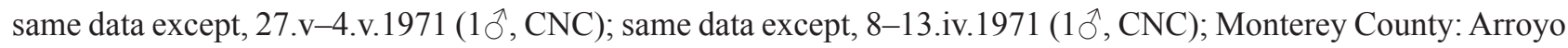
Seco [ $c a 36^{\circ} 14^{\prime} \mathrm{N} 121^{\circ} 28^{\prime} \mathrm{W}$ ], The Lakes, $880 \mathrm{ft}$, 12.iv.1997, Arnaud flight trap, P.H. \& M.M. Arnaud Collection No. 01737-A/01738/02194 (1§, USNM); same data except, 13.iv.1997, Collection No. 01738 (1 9 , USNM); King City, San Lorenzo Rec. Area, 36¹1'53.4"N 1218'59.4"W, 60 m, 4-7.iv.2011, MT in Salinas R. Dunes, M.E. Irwin $\left(15{ }^{\wedge}, 3\right.$,, $\left.\mathrm{CNC}\right)$; same data except, CNC958495 (1ㅇ, CNC); Riverside County: Agua Caliente Ind. Res., Palm

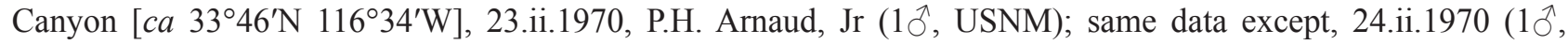
USNM); same data except, 25.ii.1970 (1 ${ }^{\wedge}, 4$, , USNM); same data except, 27.ii.1970 (3ㅇ, USNM); Indio [ca

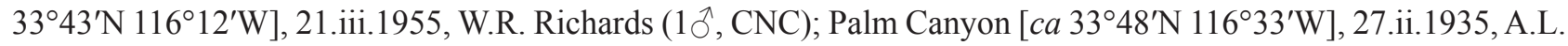
Melander (1 1 , USNM); same data except, Palm Springs, 23.ii.1955, W.R.M. Mason (10ิ, CNC); Riverside [ca $33^{\circ} 58^{\prime} \mathrm{N} 117^{\circ} 22^{\prime} \mathrm{W}$ ], 10.ii.1935, A.L. Melander (1ㅇ, USNM); same data except, 19.iii.1944, A.L. Melander (1우, USNM); same data except, 2.iv.1944, A.L. Melander (19, USNM); same data except, 10.iii.1946, A.L. Melander

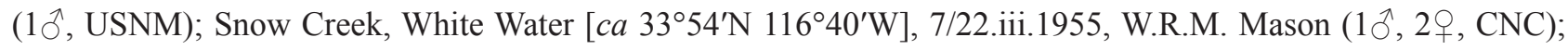

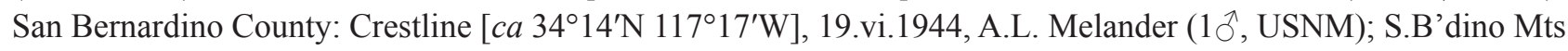

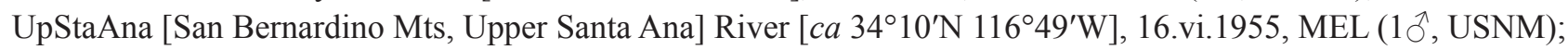

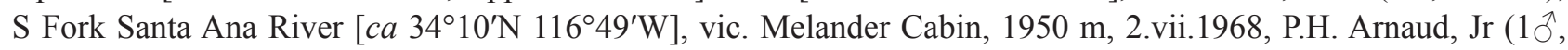
USNM; 1ㅇ, CAS); San Diego County: El Capitan Reservoir [ca 32 $52^{\prime} \mathrm{N} 116^{\circ} 47^{\prime} \mathrm{W}$ ], 31.iii.1962, P.A. Rude (2 ${ }^{\prime}$,

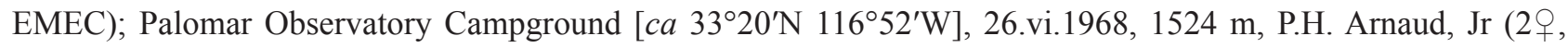
USNM); San Luis Obispo County: Dune Lakes, 3 mi. S Oceano [ca $35^{\circ} 04^{\prime} \mathrm{N} 120^{\circ} 36^{\prime} \mathrm{W}$ ], 20.iii.1974, Doyden \& Powell (3 ${ }^{\wedge}, 5$,, EMEC); San Mateo County: Alpine Rd along Corte Madera Creek [ca $37^{\circ} 21^{\prime} \mathrm{N} 122^{\circ} 13^{\prime} \mathrm{W}$ ], 230

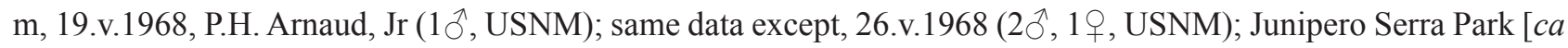
$37^{\circ} 36^{\prime} \mathrm{N} 122^{\circ} 25^{\prime} \mathrm{W}$ ], iii-iv.1964, P.H. Arnaud, Jr (6 ${ }^{`}$, USNM); Purisima Creek Canyon [ $c a 37^{\circ} 26^{\prime} \mathrm{N} 122^{\circ} 22^{\prime} \mathrm{W}$ ],

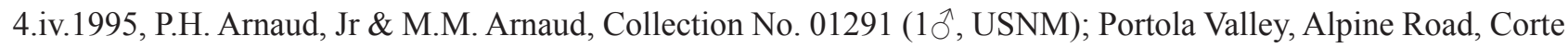
de Madera Creek [ $\mathrm{ca} 37^{\circ} 23^{\prime} \mathrm{N} 122^{\circ} 17^{\prime} \mathrm{W}$ ], $230 \mathrm{~m}, 12 . v i .1983$, P.H. Arnaud, Jr (1ㅇ, USNM); same data except, 29.iii.1984, creek bed, sun, cool, windy, 1000-1600 hrs, P.H. Arnaud, Jr (3 ${ }^{\wedge}$, USNM), same data except, 30.iv.1984, 
flight trap, creek bed, 1300-1730 hrs, P.H. Arnaud, Jr (2甲, USNM); Santa Barbara County: Santa Cruz Is. [ca $34^{\circ} 00^{\prime} \mathrm{N} 119^{\circ} 47^{\prime} \mathrm{W}$ ], Upper Central Valley, $1000 \mathrm{ft}$, 15.iii.1969, P.A. Opler (1ð̄, EMEC); same data except, Canada de la Cuesta, 15.iii.1969, J. Powell (1ð̋, EMEC); same data except, Prisoner's Harbor, 14.iii.1969, J. Powell (1오, EMEC); Sonoma County: Annadel SP, 0.9 km from park lot Richardson Trail, $38^{\circ} 26.11^{\prime} \mathrm{N} 122^{\circ} 36.67^{\prime} \mathrm{W}, 220 \mathrm{~m}, 6 \mathrm{~m}$ MT, 18.iii-2.v.2008, P. Kerr, CSCA08L283 (8ð̄, CSCA); same data except, CNC1155682 (1ठ̄, CSCA); Stanislaus County: Del Puerto Canyon, Frank Raines Park [ca $\left.37^{\circ} 25^{\prime} \mathrm{N} 121^{\circ} 22^{\prime} \mathrm{W}\right], 21 . i i \mathrm{i} .1970$, P.H. Arnaud, Jr (3 $\bigcirc^{\wedge}, 1{ }^{\circ}$, USNM); same data except, 22.iii.1970 (1つ̋, 4ㅇ, USNM).

Diagnosis. As indicated in the key (couplets 8 and 9), this species can be distinguished from other members of the $M$. discalis species group by its elongate postpedicel (Figs 20,21) and several male genitalic features, of which, the long narrow hypoproct lobes are the most diagnostic (Figs 31-33). This species is very close to M. skevingtoni sp. nov. and females are virtually identical (see "Remarks").

Redescription. Male (Figs 17, 19, 20, 23, 31-33, 40-43): Body length 2.1-3.3 mm, wing length 2.8-3.2 mm. Head (Figs 19, 20): Ocellar tubercle with 3 pairs of black proclinate setae, anterior and posterior pair subequal in length, middle pair shorter, posterior pair inserted at posterior margin. Occiput greyish pruinose, mostly clothed with black setae, almost bare in upper part, except for postoculars. Gena and parafacial narrow along lower eye margin. Antenna (Fig. 20) dark brown to black; postpedicel over 2X longer than wide with apical 3/4 usually narrow and digitiform; stylus usually slightly shorter than postpedicel. Palpus brownish-black, elongate ovate, approximately length of labrum, pubescent with microtrichia and bearing scattered black setulae. Proboscis brownish-black, slightly more than half as long as head height, directed forward. Thorax (Figs 17, 19, 20): Mesonotum blackishbrown to grey with faint vitta between acrostichals and dorsocentrals. Mesonotal setae black, relatively long with acrostichals primarily quadriserial and dorsocentrals mostly arranged in single row per side. Scutellum with with 3-4 pairs of setae, middle pair(s) strong, outer and inner pair weaker. Mesopleuron blackish-brown to grey. Halter darkish-brown to pale. Legs (Fig. 17): Entirely dark brown to brown and sometimes pale at knees, or with tibiae and basal tarsomeres pale brown to yellow, with black setae. Foreleg: Coxa with several setae on anterior surface. Femur subequal in length to tibia, posterior surface with series of long posterodorsal and posteroventral setae (longer than femur width) and shorter setae along middle, anterior surface with short setae and series of slightly longer anteroventral setae in basal third. Tibia slender, with short setae. Tarsus slightly longer than tibia, with short setae, tarsomere 1 slightly longer than combined length of tarsomeres $2-4$, with prominent basiventral seta (usually longer than tarsomere width), tarsomeres 2-4 decreasing in length apically, tarsomere 5 subequal in length to tarsomere 3. Midleg: Coxa with several setae on anterior surface and a few somewhat weaker setae on posterior surface. Femur subequal in length to tibia, with series of longer posteroventral setae (subequal to slightly longer than femur width, longest near middle) and relatively short setae on posterior and anterior surfaces. Tibia slender, with several longer dorsal setae (slightly longer than tibia width), otherwise with short setae. Tarsus 1.2-1.3X longer than tibia, with short setae, tarsomere 1 subequal to combined length of tarsomeres 2-4, with strong basiventral seta (usually slightly longer than tarsomere width), tarsomeres 2-4 decreasing in length apically, tarsomere 5 slightly shorter than tarsomere 3. Hindleg: Coxa usually with 3-4 setae on outer surface, and a few weaker setae on anterior and posterior surface. Femur subequal in length to tibia, with series of longer dorsal setae (subequal to femur width), apical half with series of longer anteroventral setae (subequal to femur width), anterior surface otherwise with shorter setae, posterior surface with short fine setae. Tibia slender, with short setae, dorsal setae at most slightly longer than tibia width. Tarsus subequal in length to tibia, with short setae, tarsomere 1 subequal to combined length of tarsomeres 2-3, tarsomeres 2-4 decreasing in length apically, tarsomere 5 subequal in length to tarsomere 3. Wing (Fig. 23): Hyaline or with slight grey-brown tinge, veins dark brown, pale at base near humeral crossvein. $\mathrm{R}_{1}$ reaching costa just beyond base of $M_{2}$. Costal section $M_{1}-M_{2}$ slightly longer than $M_{2}-M_{4}$. Cell dm large and long, extended beyond middle of wing, distal section of vein $\mathrm{M}_{1}$ (beyond base of $\mathrm{M}_{2}$ ) shorter than preceding section (between $\mathrm{r}-\mathrm{m}$ and base of $\mathrm{M}_{2}$ ). Cell $\mathrm{m}_{1}$ relatively short with broad base. Abdomen (Fig. 31): Blackish-brown to dark grey or brownish-grey, with black setae on tergites and sternites. Tergites 1-5 with long setae, lateral tergal setae very long (some at least as long as width of abdomen in dorsal view). Tergite 6 sparsely setose. Sternites $2-5$ with long setae, sternites 4 and 5 medially with short setae. Sternite 6 with a few minute short setae. Segment 7 bare, or with occasional seta(e). Sternite 8, subrectangular, setose. Hypopygium (Figs 31-33, 40-43): Small, about 1/3-1/4 length of abdomen. Left epandrial lamella (Figs 40, 41) subrectangular basally, longer than high, with surstylar lobes projecting dorsally and distally, with setae along dorsal margin. Left dorsal lobe of surstylus broad at base with narrow apical projection bearing short setae on rounded tip, apical projection slender and elongate. Left middle lobe of surstylus elongate, 
as long as ventral lobe of surstylus, C-shaped and curved ventrally, with apex gradually tapered. Left ventral lobe of surstylus elongate and weakly curved ventrally, apical half narrow and digitiform with short thick spine-like seta at tip and long preapical medial seta. Right epandrial lamella subrectangular, longer than high, with surstylar lobes projecting dorsally and distally, with setae along dorsal margin. Right dorsal lobe of surstylus similar to left side. Right middle lobe of surstylus short and broad, apex rounded. Right ventral lobe of surstylus short with long spine-like setae at tip and long preapical ventral seta (similar to Fig. 45). Hypandrium (Figs 40, 43) with series of 3 long ventral setae on each side of basal part. Medial hypandrial prolongation absent. Left hypandrial lobe short and broad with squared-off apex. Right hypandrial lobe long and broad, up-curved with rounded tip. Left dorsal postgonite lobe broad basally with pair of slender digitiform projections. Left ventral postgonite lobe narrow and pointed, shorter than right postgonite lobe. Right dorsal postgonite lobe similar to left side. Right ventral postgonite lobe with dorsal edge right-angled, apex widely tapered. Postgonite apodeme V-shaped in ventral view. Phallus weakly undulate beyond phallic process, tip not narrowed. Phallic process beak-like. Ejaculatory apodeme short. Left and right hypoproct lobes longer than dorsal lobe of surstyli, distinctly protruding from hypopygium as pair of pale, narrow, pointed projections arising below cerci. Left and right cercus short, slightly tapered apically with several long setae dorsally and apically.
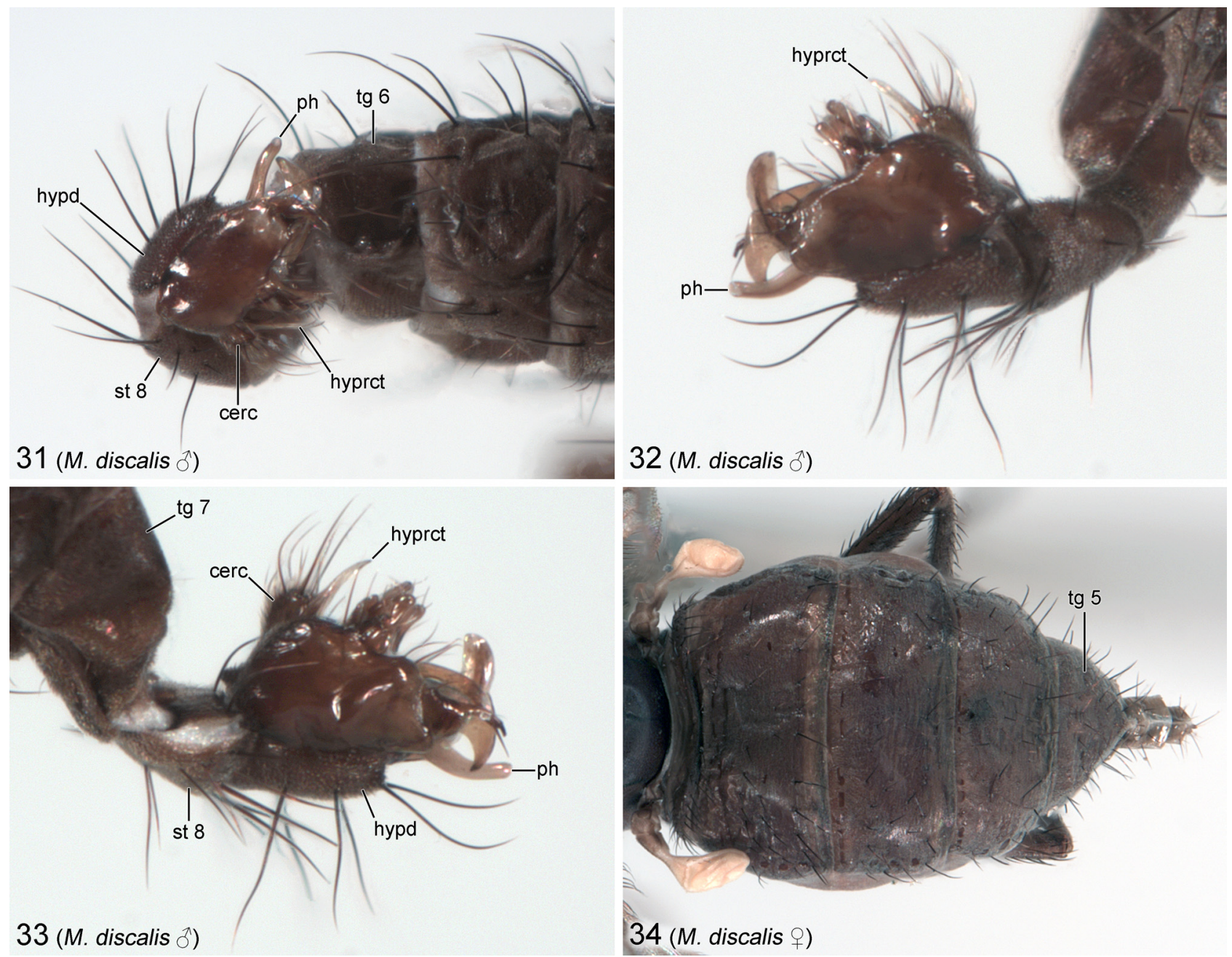

34 (M. discalis +)

FIGURES 31-34. Abdomen and terminalia of Microphor discalis Melander. 31. Male abdomen and terminalia, right lateral view. 32. Male terminalia showing right lateral surface of hypopygium. 33. Male terminalia showing left lateral surface of hypopygium. 34. Female abdomen, dorsal view. Specimens from: Patrick Creek, California (Fig. 31); King City, California (Figs 32, 33); Lily Pond, California (Fig. 34). Abbreviations: cerc — cercus; hypd—hypandrium; hyprct—hypoproct; ph—phallus; st—sternite; tg-tergite.

Female (Figs 18, 21, 22, 24, 34, 54): Body length 1.9-2.7 mm, wing length 2.5-3.5 mm. Similar to male except as follows: Thorax (Figs 18, 21, 22). Legs (Fig. 18): With shorter setae. Wing (Fig. 24): Slightly narrower. Anal lobe smaller. Abdomen (Figs 18, 34): Brownish-grey, tergites and sternites with short setae. Terminalia (similar 
to Figs 52, 53): Tergite 8 articulated with sternite 8 anterolaterally. Spermatheca teardrop-shaped (Fig. 54). Cercus about $2 \mathrm{X}$ width of syntergite $9+10$.

Distribution and seasonal occurrence. Microphor discalis is known from southern Washington, south to Baja California, Mexico, including numerous localities in California (e.g., Fig. 9) and Arizona (Fig. 75). Adults have been collected from mid-February to early August.

Remarks. The male holotype of M. discalis was originally reported by Melander (1940b) to be in his personal collection, along with the allotype and a single female paratype. These types could not be located in any of the known depositories of Melander's collection including the USNM, the AMNH, the Academy of Natural Sciences (ANSP), Philadelphia, the Museum of Comparative Zoology (MCZ), Harvard, the Senckenberg German Entomological Institute (SDEI), Müncheberg, and the Oxford University Museum of Natural History (OUMNH), Oxford, and appear to be lost.

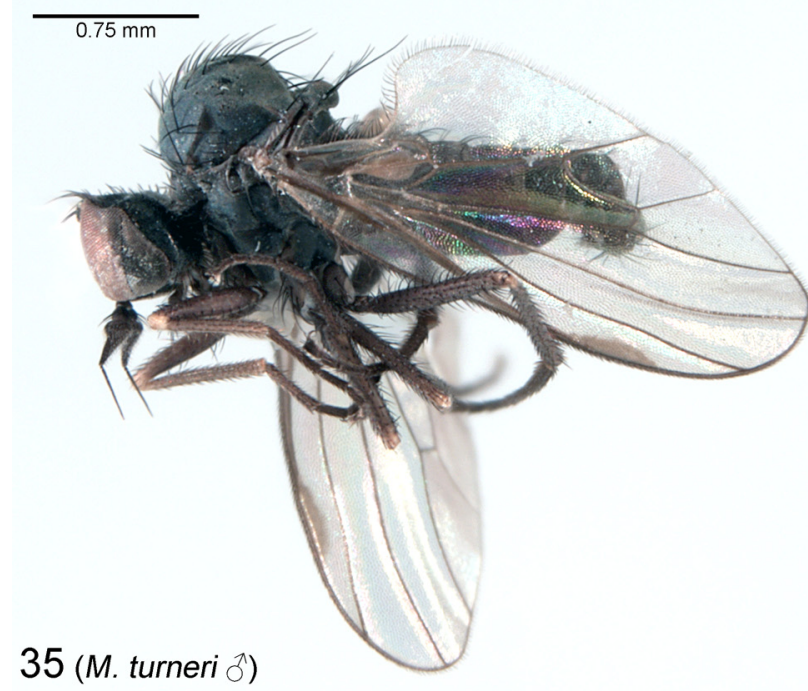

36 (M. turneri ð’)
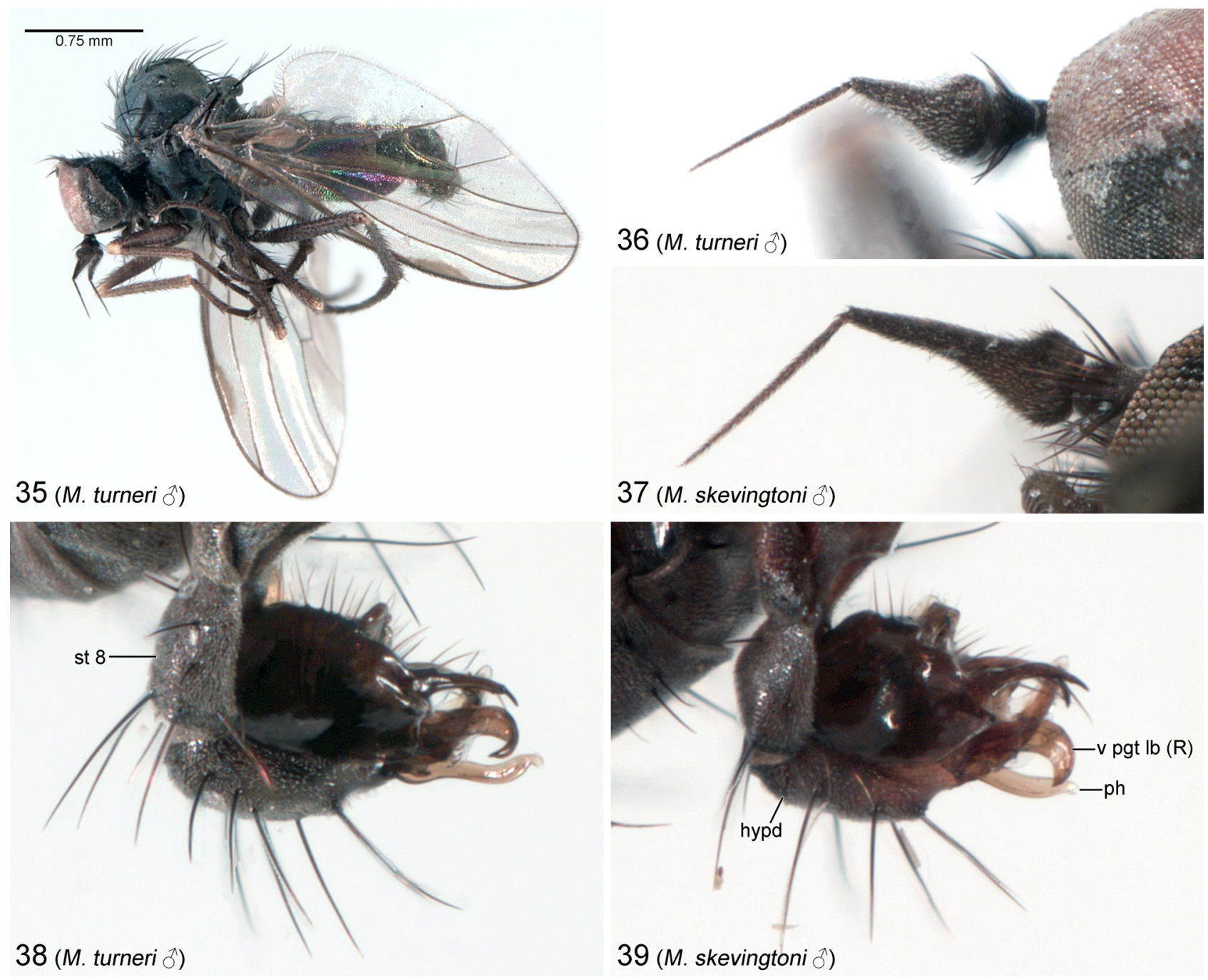

FIGURES 35-39. Males of Microphor turneri sp. nov. and M. skevingtoni sp. nov. 35. Habitus of M. turneri sp. nov. 36. Antenna of $M$. turneri sp. nov., lateral view. 37. Antenna of $M$. skevingtoni sp. nov., lateral view. 38. Terminalia of $M$. turneri sp. nov., showing left lateral surface of hypopygium. 39. Terminalia of M. skevingtoni sp. nov., showing left lateral surface of hypopygium. Specimens from: Spring Creek Campground, Colorado (Figs 35, 36); Junipero Serra Park, California (Fig. 37); Kramer Strip, Washington (Fig. 38); Kern River Campground, California (Fig. 39). Abbreviations: hypd—hypandrium; ph—phallus; (R) —right; st—sternite; v pgt lb—ventral postgonite lobe.

In the early stages of this study we distinguished two closely-related, sympatric morphospecies on the basis of male genitalic characters, which both ran to M. discalis in Melander's (1940a) key. Without the male holotype to examine, Melander's (1940b) short description of M. discalis and drawing of the antenna (Melander 1940a, fig. 11) became the only means available to establish the identity of that species. After careful study of the specimens 
on hand (especially those from sites near the Muir Woods type locality), we noticed that the morphospecies with long hypoproct lobes (Figs 31-33, 40, 41) also has an antennal stylus that is slightly shorter than the postpedicel (Fig. 20), which matched-up well with Melander's description and figure. That morphospecies is here recognized as $M$. discalis. In contrast, the morphospecies with short hypoproct lobes (Figs 39, 44-46) has a slightly longer antennal stylus that is subequal in length to the postpedicel (Fig. 37) or somewhat longer, and is described below as M. skevingtoni sp. nov.

Flower visitation records for this species are listed in Table 1.

\section{Microphor skevingtoni sp. nov.}

(Figs 25, 26, 37, 39, 44-48, 52, 53, 76)

urn:lsid:zoobank.org:act: C957595C-629B-43C0-9840-C0C52A3F88A9

Type material. HOLOTYPE, ô collected from Sutter Buttes, summit of 'Old Man Hill', Sutter County, California, USA, 18.iv.2003, by J. \& A. Skevington, labelled: "USA: CA: SutterCo., Sutter/ Buttes, Summit Of 'Old/ Man

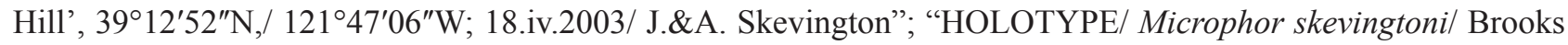
\& Cumming [red label]" (CNC). PARATYPES: USA: California: Same data as holotype (9 $\left.{ }^{\wedge}, \mathrm{CNC}\right)$; Sonoma County: Mark West Springs Rd, Pepperwood Ranch Natural Reserve [ca 38 $32^{\prime}$ N 122 ${ }^{\circ} 43^{\prime}$ W], 8.v.1993, Arnaud Flight Trap over tiny creek under shaded trees, Collection 00924-B, P.H. Arnaud, Jr (10ิ, 4ㅇ, USNM); same data except, Arnaud Flight Trap adjacent Quercus durata Jeps., Collection 00924-A (19, USNM).

Other material examined. USA: California: Alameda County: Sunol Valley Regional Park [ $\mathrm{ca} 37^{\circ} 30^{\prime} \mathrm{N}$ $\left.121^{\circ} 49^{\prime} \mathrm{W}\right]$, 31.v.1968, P.H. Arnaud, Jr (19, USNM); same data except, 1.vi.1968 (1웅 USNM); Sunol Regional

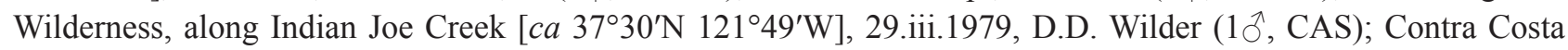
County: Briones Reg. Park [ $c a 37^{\circ} 57^{\prime} \mathrm{N} 122^{\circ} 08^{\prime} \mathrm{W}$ ], Toyon Canyon, 25.v.1979, D.D. Wilder (4ㅇ, CAS); same data

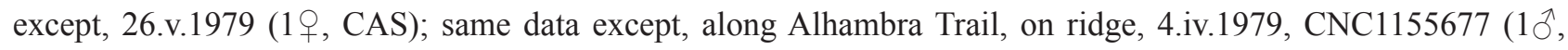
CAS); Lafayette [ $\mathrm{ca} 37^{\circ} 53^{\prime} \mathrm{N} 122^{\circ} 07^{\prime} \mathrm{W}$ ], 6.iv.1968, D.D. Munroe (1ㅇ, CNC); same data except, 18.iv.1968 (15 $\partial^{\prime}$,

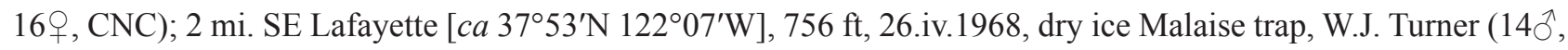
10ㅇ, WJTC); same data except, 5.v.1969 (10, WJTC); same data except, 17.v.1969 (5우, WJTC); same data except,

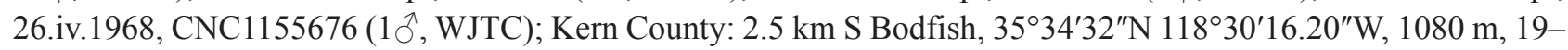

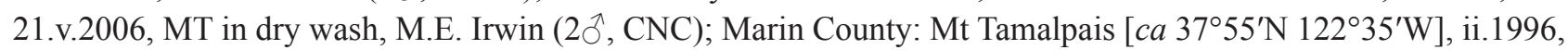

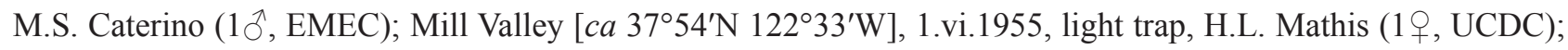
same data except, 110 m, 13-14.v.1965, P.H. Arnaud, Jr (19, CAS); same data except, 360 ft, 27.iv.1965, flight trap

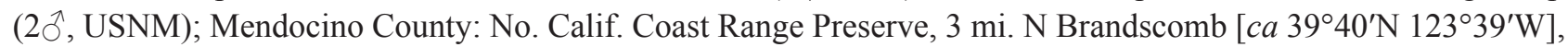

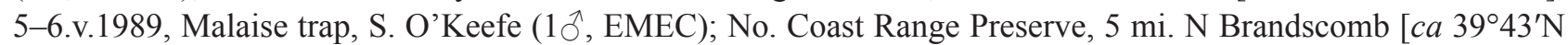

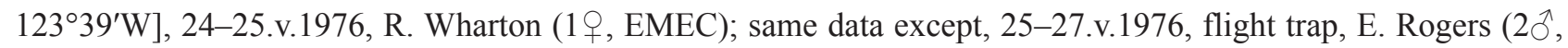

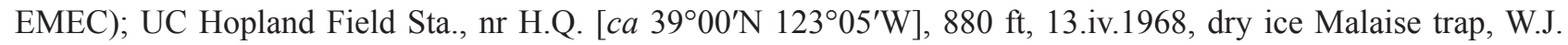

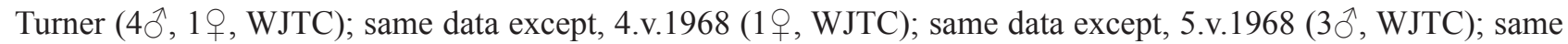

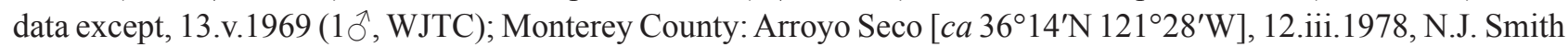

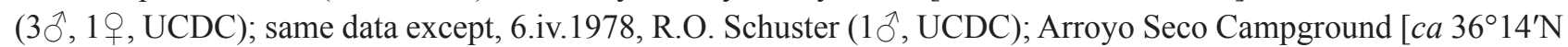
$121^{\circ} 28^{\prime} \mathrm{W}$ ], Malaise trap 7A-7P. 24.iv.1976, M. Wasbauer (1 ${ }^{\top}$, CSCA); Arroyo Seco Campground [ca $36^{\circ} 14^{\prime} \mathrm{N}$ $121^{\circ} 28^{\prime} \mathrm{W}$ ], Abbott Lakes, $18-19$. iv.1970, P.H. Arnaud, Jr (6 $0^{`}, 6$ ㅇ, USNM); Arroyo Seco [ca $36^{\circ} 14^{\prime} \mathrm{N} 121^{\circ} 28^{\prime} \mathrm{W}$ ],

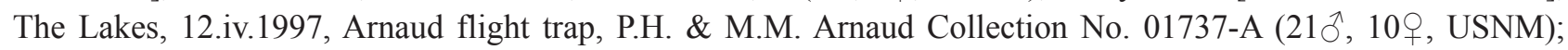
same data except, 13.iv.1997, Collection No. 01738 (4), USNM); same data except, 24.iv.1997, $880 \mathrm{ft}$, Collection

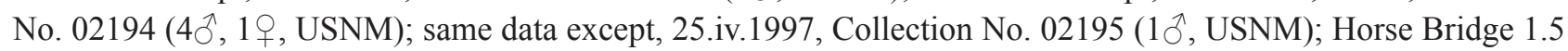
air mi. SW Arroyo Seco Grd Sta. [ca 36 $14^{\prime} \mathrm{N} 121^{\circ} 28^{\prime} \mathrm{W}$ ], $1300 \mathrm{ft}, 6 . \mathrm{v} .1975$, R. Wharton (1 ${ }^{\AA}$, EMEC); same data

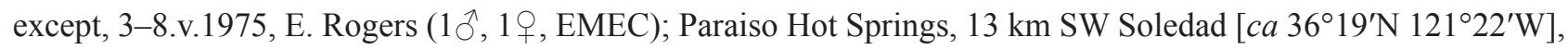
400m, 20-21.iv.1974, P.H. Arnaud, Jr (3ㅇ, USNM); same data except, 25.v.1974 (5ㅇ, USNM); same data except,

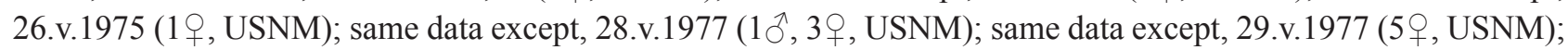
San Benito County: S of Hollister, Limekiln Canyon [ca $36^{\circ} 00^{\prime} \mathrm{N} 121^{\circ} 30^{\prime} \mathrm{W}$ ], 3.iv.1979, D.D. Wilder (2 ${ }^{\prime}$, CAS); San

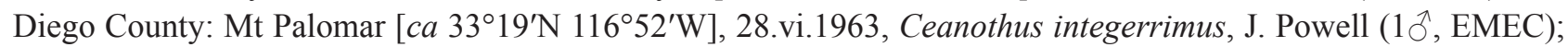

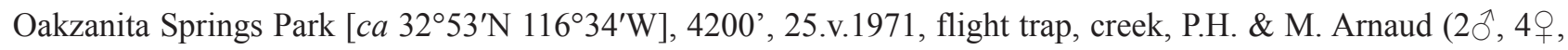
CAS); same data except, CNC1155685 (1 9 , CAS); San Francisco County: San Francisco, Lake Merced [37² $43^{\prime} \mathrm{N}$ 
$122^{\circ} 30^{\prime} \mathrm{W}$ ], 1964, P.H. Arnaud, Jr (7ô, USNM); same data except, 4.v.1967 (20ิ, USNM); same data except,

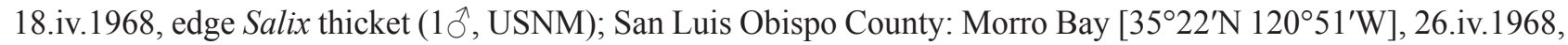

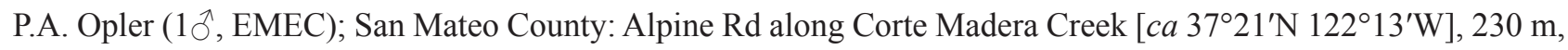
26.v.1968, P.H. Arnaud, Jr (1 $0^{\top}, 1$ \% , USNM); Junipero Serra Park [ca $37^{\circ} 36^{\prime} \mathrm{N} 122^{\circ} 25^{\prime} \mathrm{W}$ ], iii-iv.1964, P.H. Arnaud,

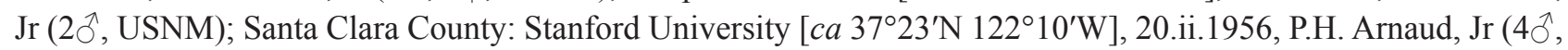
USNM); same data except, 19.iii.1956 (10ิ, USNM); same data except, 23.iii.1956 (10, USNM); same data except,

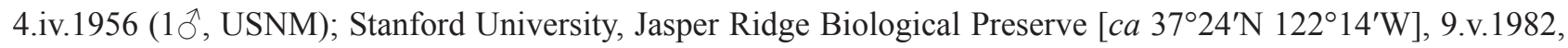

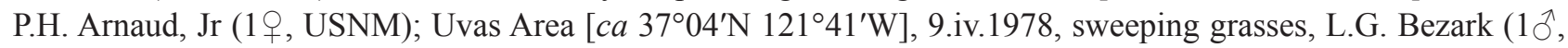
CNC); Solano County: Green Valley [ca $38^{\circ} 15^{\prime} \mathrm{N} 122^{\circ} 09^{\prime} \mathrm{W}$ ], 24.iii.1954, E.I. Schlinger (1 $0^{\wedge}$, UCDC); Stebbins Cold Canyon Reserve, $38^{\circ} 31^{\prime} \mathrm{N} 122^{\circ} 06^{\prime} \mathrm{W}, 100$ m, 20.v.2003, S.D. Gaimari (03-24) (1웅, CSCA); Stebbins Cold Canyon Reserve, $38^{\circ} 30^{\prime} \mathrm{N} 122^{\circ} 06^{\prime} \mathrm{W}, 120$ m, 17.iv.2005, K.A. Williams \#007 (1 $\hat{\jmath}$, CNC); Stanislaus County: Del Puerto Canyon, Frank Raines Park [ca $37^{\circ} 25^{\prime} \mathrm{N} 121^{\circ} 22^{\prime} \mathrm{W}$ ], 335 m, 16.v.1970, P.H. Arnaud, Jr (1 $\widehat{\delta}^{\lambda}$, CAS); Tulare

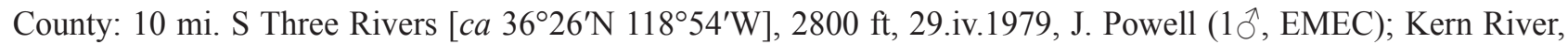

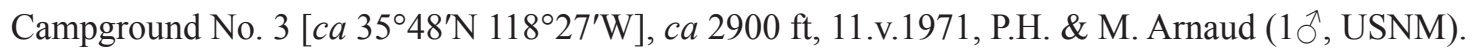

Diagnosis. As indicated in the key (couplets 8 and 9), this species can be distinguished from other members of the M. discalis species group by its elongate postpedicel (Fig. 37) and several male genitalic features, including short concealed hypoproct lobes (Figs 39, 44, 45), which differentiates it from the closely related M. discalis. The females of $M$. skevingtoni sp. nov. and $M$. discalis are virtually identical.

Description. Male (Figs 25, 37, 39, 44-48): Body length 1.9-2.9 mm, wing length 2.6-3.1 mm. Head: Ocellar tubercle with 3 pairs of black proclinate setae, anterior and posterior pair subequal in length, middle pair shorter, posterior pair inserted at posterior margin. Occiput greyish pruinose, mostly clothed with black setae, almost bare in upper part, except for postoculars. Gena and parafacial narrow along lower eye margin. Antenna (Fig. 37) black; postpedicel over $2 \mathrm{X}$ longer than wide with apical $3 / 4$ usually narrow and digitiform; stylus subequal to slightly longer than postpedicel. Palpus black, elongate ovate, approximately length of labrum, pubescent with microtrichia and bearing scattered black setulae. Proboscis brownish-black, slightly more than half as long as head height, directed forward. Thorax: Mesonotum blackish-brown to greyish-brown with vitta between acrostichals and dorsocentrals faint or absent. Mesonotal setae black, relatively long with acrostichals primarily quadriserial and dorsocentrals mostly arranged in single row per side. Scutellum with 3-4 pairs of setae, middle pair(s) strong, outer and inner pair weaker. Mesopleuron blackish-brown to greyish-brown. Halter darkish-brown. Legs: Entirely dark brown to brown, sometimes pale on knees of fore and midleg, with black setae. Foreleg: Coxa with several setae on anterior surface. Femur subequal in length to tibia, posterior surface with series of long posterodorsal and posteroventral setae (longer than femur width) and shorter setae along middle, anterior surface with short setae and series of slightly longer anteroventral setae in basal third. Tibia slender, with short setae. Tarsus slightly longer than tibia, with short setae, tarsomere 1 slightly longer than combined length of tarsomeres $2-4$, with prominent basiventral seta (about 2X longer than tarsomere width), tarsomeres 2-4 decreasing in length apically, tarsomere 5 subequal in length to tarsomere 3. Midleg: Coxa with several setae on anterior surface and usually 1 somewhat weaker seta on posterior surface. Femur subequal in length to tibia, with series of longer posteroventral setae (subequal to longer than femur width, longest near middle) and relatively short setae on posterior and anterior surfaces. Tibia slender, with several longer dorsal setae (slightly longer than tibia width), otherwise with short setae. Tarsus 1.2-1.3X longer than tibia, with short setae, tarsomere 1 subequal to combined length of tarsomeres 2-4, with strong basiventral seta (about 2X longer than tarsomere width), tarsomeres 2-4 decreasing in length apically, tarsomere 5 slightly shorter than tarsomere 3. Hindleg: Coxa usually with 3 setae on outer surface, and a few somewhat weaker setae on anterior and posterior surface. Femur subequal in length to tibia, with series of longer dorsal and anteroventral setae (subequal to femur width), anterior surface otherwise with short setae, posterior surface with short fine setae. Tibia slender, with short setae, dorsal setae at most slightly longer than tibia width. Tarsus subequal to slightly longer than tibia, with short setae, tarsomere 1 subequal to combined length of tarsomeres 2-3, tarsomeres 2-4 decreasing in length apically, tarsomere 5 slightly shorter than tarsomere 3. Wing (Fig. 25): With slight grey-brown tinge, veins dark brown, pale at base near humeral crossvein. $R_{1}$ reaching costa just beyond base of $M_{2}$. Costal section $M_{1}-M_{2}$ slightly longer than $\mathrm{M}_{2}-\mathrm{M}_{4}$. Cell dm large and long, extended beyond middle of wing, distal section of vein $\mathrm{M}_{1}$ (beyond base of $\mathrm{M}_{2}$ ) shorter than preceding section (between $\mathrm{r}-\mathrm{m}$ and base of $\mathrm{M}_{2}$ ). Cell $\mathrm{m}_{1}$ relatively short with broad base. Abdomen: Black, with black setae on tergites and sternites. Tergites 1-5 with long setae, lateral tergal setae very long (some at least as long as width of abdomen in dorsal view). Tergite 6 sparsely setose. Sternites $2-5$ with long 
setae, sternites 4 and 5 medially with short setae. Sternite 6 with a few minute short setae. Segment 7 bare. Sternite 8, subrectangular, setose. Hypopygium (Figs 39, 44-48): Small, about 1/3-1/4 length of abdomen. Left epandrial lamella (Figs 44, 46) subrectangular basally, longer than high, with surstylar lobes projecting dorsally and distally, with setae along dorsal margin. Left dorsal lobe of surstylus broad at base with narrow apical projection bearing short setae on rounded tip, apical projection short and relatively broad. Left middle lobe of surstylus elongate, as long as ventral lobe of surstylus, C-shaped and curved ventrally, with apex narrowly pointed. Left ventral lobe of surstylus elongate and weakly curved ventrally, narrow and digitiform with short thick spine-like seta at tip and long preapical medioventral seta. Right epandrial lamella (Fig. 45) subrectangular, longer than high, with surstylar lobes projecting dorsally and distally, with setae along dorsal margin. Right dorsal lobe of surstylus similar to left side. Right middle lobe of surstylus short and broad, apex rounded. Right ventral lobe of surstylus short with long spinelike setae at tip and long preapical ventral seta. Hypandrium (Figs 44, 45, 48) with series of 3-4 long ventral setae on each side of basal part. Medial hypandrial prolongation absent. Left hypandrial lobe short with rounded apex. Right hypandrial lobe long and broad, up-curved with rounded tip. Left dorsal postgonite lobe broad basally with pair of short stout projections. Left ventral postgonite lobe narrow and pointed, shorter than right postgonite lobe. Right dorsal postgonite lobe similar to left side. Right ventral postgonite lobe with dorsal edge rounded, apex widely tapered. Postgonite apodeme V-shaped in ventral view. Phallus L-shaped beyond phallic process, straight in distal portion, tip narrowed. Phallic process broad and flat with rounded dorsal margin. Ejaculatory apodeme with rounded margin. Left and right hypoproct lobes shorter than dorsal lobe of surstyli, stubby and mostly concealed within hypopygium. Left and right cercus short with rounded margin, with several long setae dorsally and apically.

Female (Figs 26, 52, 53): Body length 1.8-2.8 mm, wing length 2.5-3.1 mm. Similar to male except as follows: Thorax (similar to females in Figs 18, 21, 22): Halter often pale. Legs: Entirely dark brown to pale brown, or sometimes with tibiae and basal tarsomeres paler, with shorter setae. Wing (Fig. 26): Slightly narrower. Anal lobe smaller. Abdomen: Tergites and sternites with short setae. Terminalia (Figs 52, 53): Tergite 8 articulated with sternite 8 anterolaterally. Spermatheca teardrop-shaped (similar to Fig. 54). Cercus about $2 X$ width of syntergite $9+10$.

Distribution and seasonal occurrence. Microphor skevingtoni sp. nov. is known from numerous localities in California, from Mendocino and Sutter Counties in the north to San Diego County in the south (Fig. 76). Adults have been collected from late February to late June.

Etymology. This species is named in honour of our colleague and dipterist, Dr. Jeffrey H. Skevington, who with his wife Angela, collected part of the type series, including the holotype, from the type locality in Sutter County, California.

Remarks. See "Remarks" section of M. discalis above for comments on the recognition of M. discalis in the absence of the holotype and the establishment of $M$. skevingtoni sp. nov. as a new species.

Flower visitation records for this species are listed in Table 1.

\section{Microphor turneri sp. nov.}

(Figs 27, 28, 35, 36, 38, 49, 50, 55, 77)

urn:lsid:zoobank.org:act: E36B298C-5345-4FC8-877F-42D60FB8D29B

Type material. HOLOTYPE, ${ }^{\top}$ collected from Kramer Strip nr Colton $\left[c a 46^{\circ} 34^{\prime} \mathrm{N} 117^{\circ} 07^{\prime} \mathrm{W}\right]$, Whitman County, Washington, USA, 12.vi.1982, by W.J. Turner, labelled: "WASHINGTON: Kramer/ Strip (WSU WL Area)/ nr Colton, Whitman/ Co., 12 June 1982/ W.J. Turner"; "HOLOTYPE/ Microphor turneri/ Brooks \& Cumming [red label]" (WJTC). PARATYPES: USA: Washington: Same data as holotype $(37 \hat{\jmath}, 11 \rho$, WJTC); same data as holotype $(3 \hat{\partial}, 3$,, $\mathrm{CNC})$; same data as holotype except, CNC1155683 (1 $\hat{\jmath}, \mathrm{CNC})$; same data as holotype except, $\mathrm{CNC} 1155688$ (1ㅇ, CNC).

Other material examined. CANADA: British Columbia: Vaseaux Lake, Oliver [ca $49^{\circ} 17^{\prime} \mathrm{N} 119^{\circ} 32^{\prime} \mathrm{W}$ ], 16.v.1959, R.E. Leech $(1 \hat{\jmath}, 1$ q , CNC). USA: Colorado: Gunnison County: Spring Creek Campground, 5 mi.

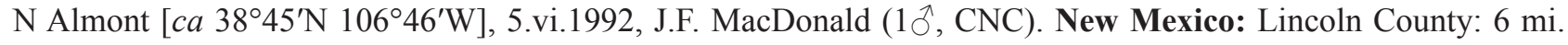

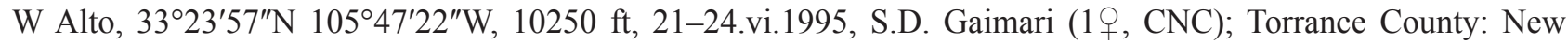

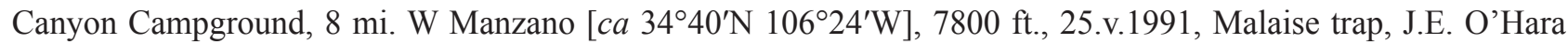
(1 9 , CNC). Washington: Whitman County: Yakawawa Canyon, 7 mi. NW Colton [ca $\left.46^{\circ} 36^{\prime} \mathrm{N} 117^{\circ} 15^{\prime} \mathrm{W}\right], 2500$ ft, 11-12.vi.1977, Malaise, W.J. Turner (1ठึ, WJTC). 
Diagnosis. As indicated in couplet 8 of the key, this species can be distinguished from other members of the M. discalis species group by its relatively short postpedicel (at most $2 \mathrm{X}$ longer than wide (Fig. 36) and grey body colour of males (Fig. 35).

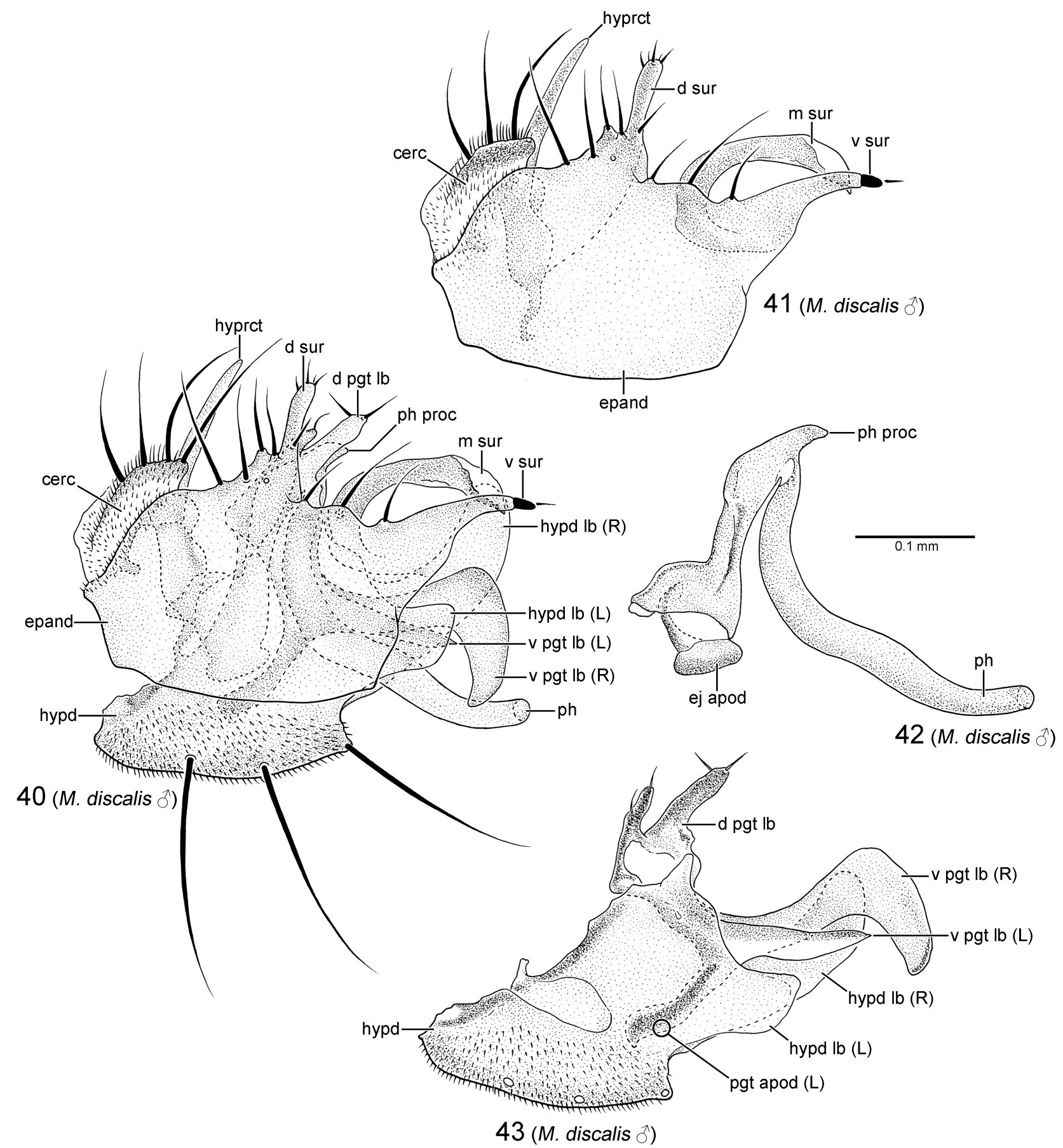

FIGURES 40-43. Hypopygium of Microphor discalis Melander, left lateral view 40. Hypopygium. 41. Epandrium and cercus. 42. Phallus. 43. Hypandrium and postgonite. Figures 40-43 based on specimen CNC1155682 (Annadel SP, California). Abbreviations: cerc — cercus; d pgt lb — dorsal postgonite lobe; d sur — dorsal lobe of surstylus; ej apod—ejaculatory apodeme; epand — epandrium; hypd —-hypandrium; hypd lb — hypandrial lobe; hyprct—hypoproct; (L)—left; m sur — middle lobe of surstylus; ph—phallus; ph proc—phallic process; pgt apod—postgonite apod; (R)—right; v pgt lb—ventral postgonite lobe; $\mathrm{v}$ sur-ventral lobe of surstylus. 

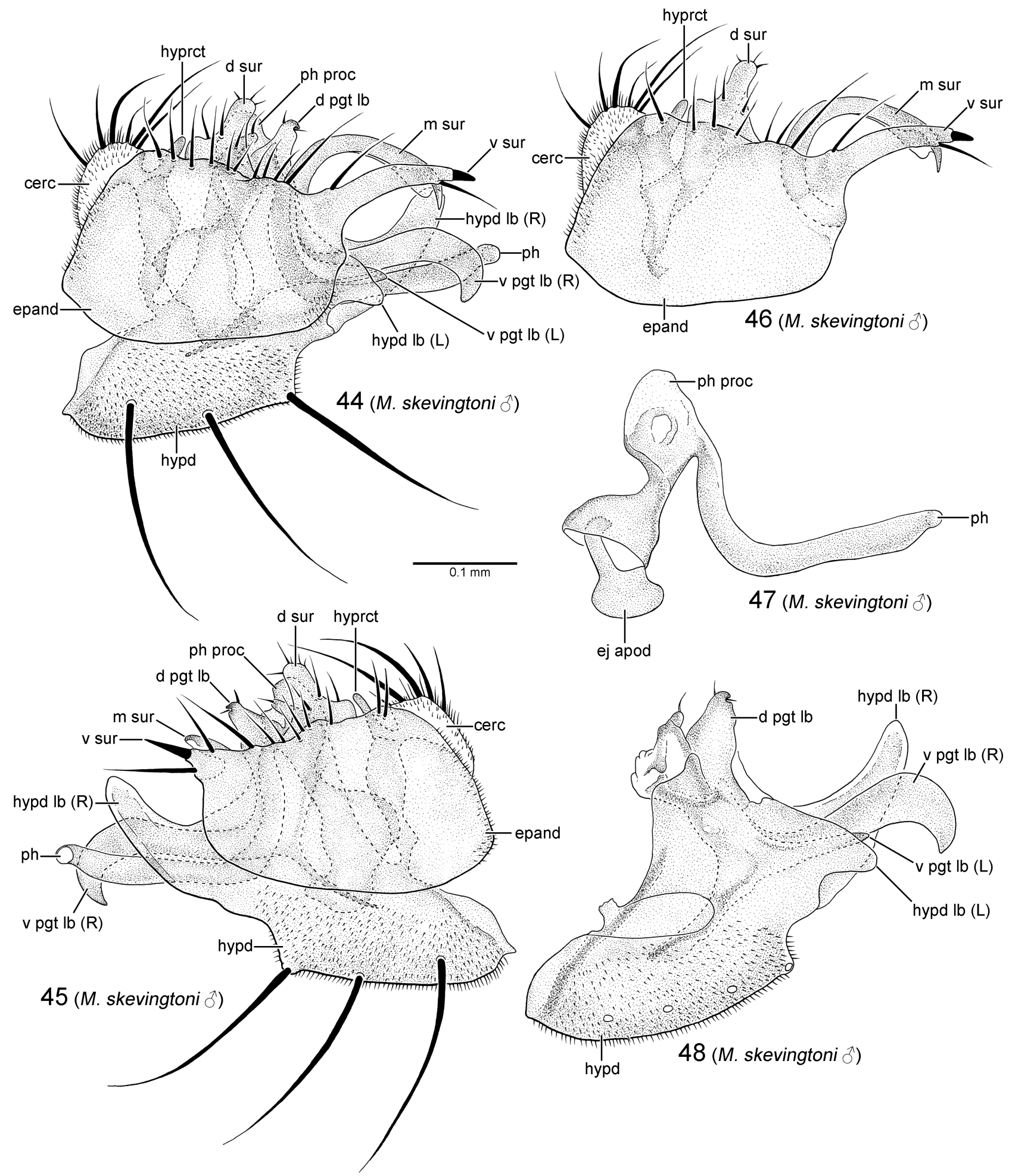

FIGURES 44-48. Hypopygium of Microphor skevingtoni sp. nov. 44. Hypopygium, left lateral view. 45. Hypopygium, right lateral view. 46. Epandrium and cercus, left lateral view. 47. Phallus, left lateral view. 48. Hypandrium and postgonite, left lateral view. Figures 44-46 based on specimen CNC1155677 (Toyon Canyon, California). Figures 47 and 48 based on specimen CNC1155676 (2 mi. SE Lafayette, California). Abbreviations: cerc—cercus; d pgt lb—dorsal postgonite lobe; d sur—dorsal lobe of surstylus; ej apod — ejaculatory apodeme; epand — epandrium; hypd — hypandrium; hypd lb — hypandrial lobe; hyprct— hypoproct; (L)—left; m sur-middle lobe of surstylus; ph—phallus; ph proc — phallic process; (R) — right; v pgt lb—ventral postgonite lobe; $v$ sur - ventral lobe of surstylus. 

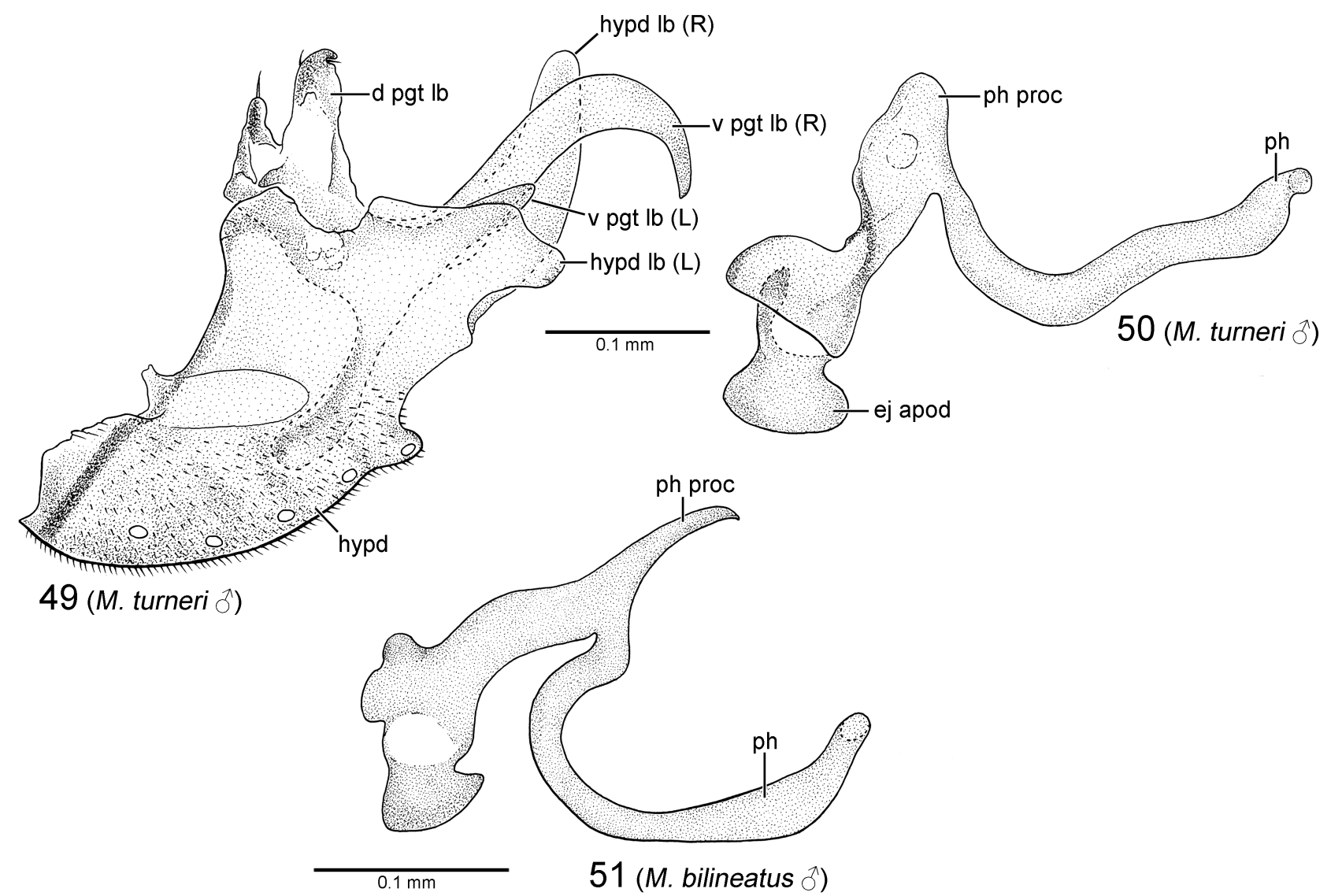

FIGURES 49-51. Hypandrium, postgonite and phallus of Nearctic of Microphor, left lateral view. 49. Hypandrium and postgonite of M. turneri sp. nov. 50. Phallus of M. turneri sp. nov. 51. Phallus of M. bilineatus (Melander). Figures 49 and 50 based on specimen CNC1155683 (Kramer Strip, Washington). Figure 51 based on paralectotype CNC1155686 (Opelousas, Louisiana). Abbreviations: d pgt lb—dorsal postgonite lobe; ej apod—ejaculatory apodeme; hypd—hypandrium; hypd lb— hypandrial lobe; (L)—left; ph—phallus; ph proc_phallic process; (R)—right; v pgt lb—ventral postgonite lobe.

Description. Male (Figs 27, 36, 38, 49, 50): Body length 2.1-2.7 mm, wing length 2.4-2.8 mm. Head: Ocellar tubercle with 3 pairs of black proclinate setae, anterior and posterior pair subequal in length, middle pair shorter, posterior pair inserted at posterior margin. Occiput greyish pruinose, mostly clothed with black setae, almost bare in upper part, except for postoculars. Gena and parafacial narrow along lower eye margin. Antenna (Fig. 36) dark brown; postpedicel at most $2 \mathrm{X}$ longer than wide with apical 3/4 narrow; stylus longer than postpedicel. Palpus dark brown, elongate ovate, approximately length of labrum, pubescent with microtrichia and bearing scattered black setulae. Proboscis dark brown, slightly more than half as long as head height, directed forward. Thorax (Fig. 35): Mesonotum grey with vitta between acrostichals and dorsocentrals faint or absent. Mesonotal setae black, relatively long with acrostichals primarily quadriserial and dorsocentrals mostly arranged in single row per side. Scutellum with 3-4 pairs of setae, middle pair(s) strong, outer and inner pair weaker. Mesopleuron grey. Halter pale. Legs (Fig. 35): Dark brown to brown, pale on knees, with black setae. Foreleg: Coxa with several setae on anterior surface. Femur subequal in length to tibia, posterior surface with series of long posterodorsal and posteroventral setae (longer than femur width) and shorter setae along middle, anterior surface with short setae and series of slightly longer anteroventral setae in basal third. Tibia slender, with short setae. Tarsus slightly longer than tibia, with short setae, tarsomere 1 subequal to combined length of tarsomeres 2-4, with prominent basiventral seta (slightly longer than tarsomere width), tarsomeres 2-4 decreasing in length apically, tarsomere 5 subequal in length to tarsomere 3 . Midleg: Coxa with several setae on anterior surface and usually 1 somewhat weaker seta on posterior surface. Femur subequal in length to tibia, with series of longer posteroventral setae (subequal to femur width) and relatively short setae on posterior and anterior surfaces. Tibia slender, with several longer dorsal setae (slightly longer than tibia width), otherwise with short setae. Tarsus about $1.3 \mathrm{X}$ longer than tibia, with short setae, tarsomere 1 subequal to combined length of tarsomeres 2-4, with strong basiventral seta (about $2 \mathrm{X}$ longer than tarsomere width), tarsomeres 
2-4 decreasing in length apically, tarsomere 5 slightly shorter than tarsomere 3. Hindleg: Coxa usually with 3 setae on outer surface, and a few weaker setae on anterior and posterior surfaces. Femur subequal in length to tibia, with series of longer dorsal and anteroventral setae (subequal to femur width), anterior surface otherwise with shorter setae, posterior surface with short fine setae. Tibia slender, with short setae, dorsal setae at most slightly longer than tibia width. Tarsus slightly longer than tibia, with short setae, tarsomere 1 subequal to combined length of tarsomeres 2-3, tarsomeres 2-4 decreasing in length apically, tarsomere 5 slightly shorter than tarsomere 3 . Wing (Fig. 27): Hyaline, veins dark brown, pale at base near humeral crossvein. $R_{1}$ reaching costa just beyond base of $M_{2}$. Costal section $M_{1}-M_{2}$ slightly longer than $M_{2}-M_{4}$. Cell dm large and long, extended beyond middle of wing, distal section of vein $M_{1}$ (beyond base of $M_{2}$ ) shorter than preceding section (between r-m and base of $M_{2}$ ). Cell $m_{1}$ relatively short with broad base. Abdomen: Dark grey to brownish-grey, with black setae on tergites and sternites. Tergites 1-5 with long setae, lateral tergal setae very long (some at least as long as width of abdomen in dorsal view). Tergite 6 sparsely setose. Sternites $2-5$ with long setae, sternites 4 and 5 medially with short setae. Sternite 6 with a few minute short setae. Segment 7 bare. Sternite 8, subrectangular, setose. Hypopygium (Figs 38, 49, 50): small, about 1/3-1/4 length of abdomen. Left epandrial lamella (similar to Figs 44, 46) subrectangular, longer than high, with surstylar lobes projecting dorsally and distally, with setae along dorsal margin. Left dorsal lobe of surstylus broad at base with narrow apical projection bearing short setae on rounded tip, apical projection short and relatively broad. Left middle lobe of surstylus elongate, as long as ventral lobe of surstylus, C-shaped and curved ventrally, with apex narrowly pointed. Left ventral lobe of surstylus elongate and weakly curved ventrally, narrow and digitiform with short thick spine-like seta at tip and long preapical medioventral seta. Right epandrial lamella (similar to Fig. 45) subrectangular, longer than high, with surstylar lobes projecting dorsally and distally, with setae along dorsal margin. Right dorsal lobe of surstylus similar to left side. Right middle lobe of surstylus short and broad, apex rounded. Right ventral lobe of surstylus short with long spine-like setae at tip and long preapical ventral seta (similar to Fig. 45). Hypandrium (Fig. 49) with series of 5-6 long ventral setae on each side of basal part. Medial hypandrial prolongation absent. Left hypandrial lobe short with rounded apex. Right hypandrial lobe long and broad, up-curved with rounded tip. Left dorsal postgonite lobe broad basally with pair of short stout projections. Left ventral postgonite lobe narrow and pointed, shorter than right postgonite lobe. Right dorsal postgonite lobe similar to left side. Right ventral postgonite lobe with apex prolonged and narrowly tapered. Postgonite apodeme V-shaped in ventral view. Phallus L-shaped beyond phallic process, undulate in distal portion, tip narrowed. Phallic process broad and flat with rounded dorsal margin. Ejaculatory apodeme with rounded margin. Left and right hypoproct lobes shorter than dorsal lobe of surstyli, stubby and mostly concealed within hypopygium (as in Fig. 49). Left and right cercus short with rounded margin, with several long setae dorsally and apically.

Female (Figs 28, 55): Body length 1.6-2.2 mm, wing length 2.5-2.8 mm. Similar to male except as follows: Legs: With shorter setae. Wing (Fig. 28): Slightly narrower. Anal lobe smaller. Abdomen: Tergites and sternites with short setae. Terminalia (Fig. 55): Tergite 6 with a few small setae anterior to transverse row of setae. Tergite 8 articulated with sternite 8 anterolaterally. Spermatheca teardrop-shaped (similar to Fig. 54). Cercus about 1.5X width of syntergite $9+10$.

Distribution and seasonal occurrence. Microphor turneri sp. nov. is known from southern British Columbia and eastern Washington, south through Colorado to Torrance and Lincoln Counties in New Mexico (Fig. 77). Adults have been collected from mid-May to late June.

Etymology. This species is named in honour of fellow dipterist, Dr. William J. Turner, who collected the large type series from Whitman County, Washington.

\section{Microphor obscurus species group}

(Figs 1, 2, 29, 30, 51, 56-74, 77, 78)

Diagnosis. Setae of body and legs black, body and legs dark brown to black (Figs 1, 59, 60); male compound eye with demarcation between larger dorsal and smaller ventral ommatidia (Figs 61, 62); female head with gena and parafacial narrow along lower eye margin (Figs 63, 64); antenna with stylus distinctly shorter than postpedicel (Figs 62, 63); thorax with mesonotal setae short and dense on anterior 2/3 (Fig. 61), acrostichals quadriserial, anterior dorsocentrals similar in size to acrostichals, biserial or as a field of setae on each side; scutellum with 3 setae per side; male midleg unmodified, trochanter without medial spine-like setal pair; wing with cell dm moderately-sized (Figs 29, 30), 

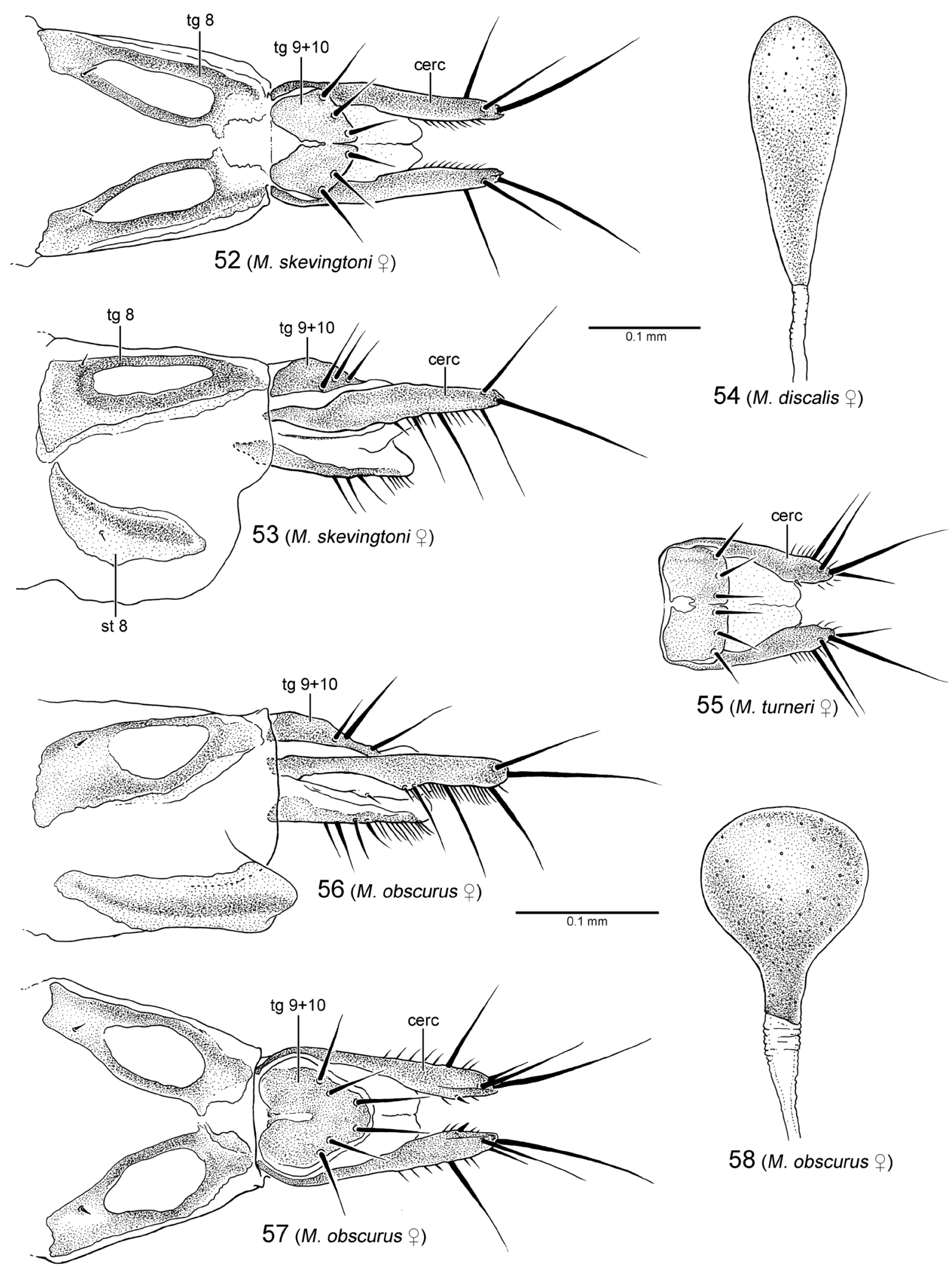

58 (M. obscurus + )

FIGURES 52-58. Female terminalia of Nearctic Microphor. 52. M. skevingtoni sp. nov., dorsal view. 53. M. skevingtoni $\mathbf{s p .}$ nov., left lateral view. 54. Spermatheca of $M$. discalis Melander, lateral view. 55. Syntergite 9+10 and cerci of $M$. turneri sp. nov., dorsal view. 56. $M$. obscurus Coquillett, left lateral view. 57. M. obscurus Coquillett, dorsal view. 58. Spermatheca of $M$. obscurus Coquillett, lateral view. Figures 52 and 53 based on specimen CNC1155685 (Oakzanita Springs Park, California). Figure 54 based on specimen CNC958495 (Salinas R. Dunes, California). Figure 55 based on specimen CNC1155688 (Kramer Strip, Washington). Figures 56-58 based on specimen CNC1155689. Abbreviations: cerc — cercus; st—sternite; tg—tergite. 

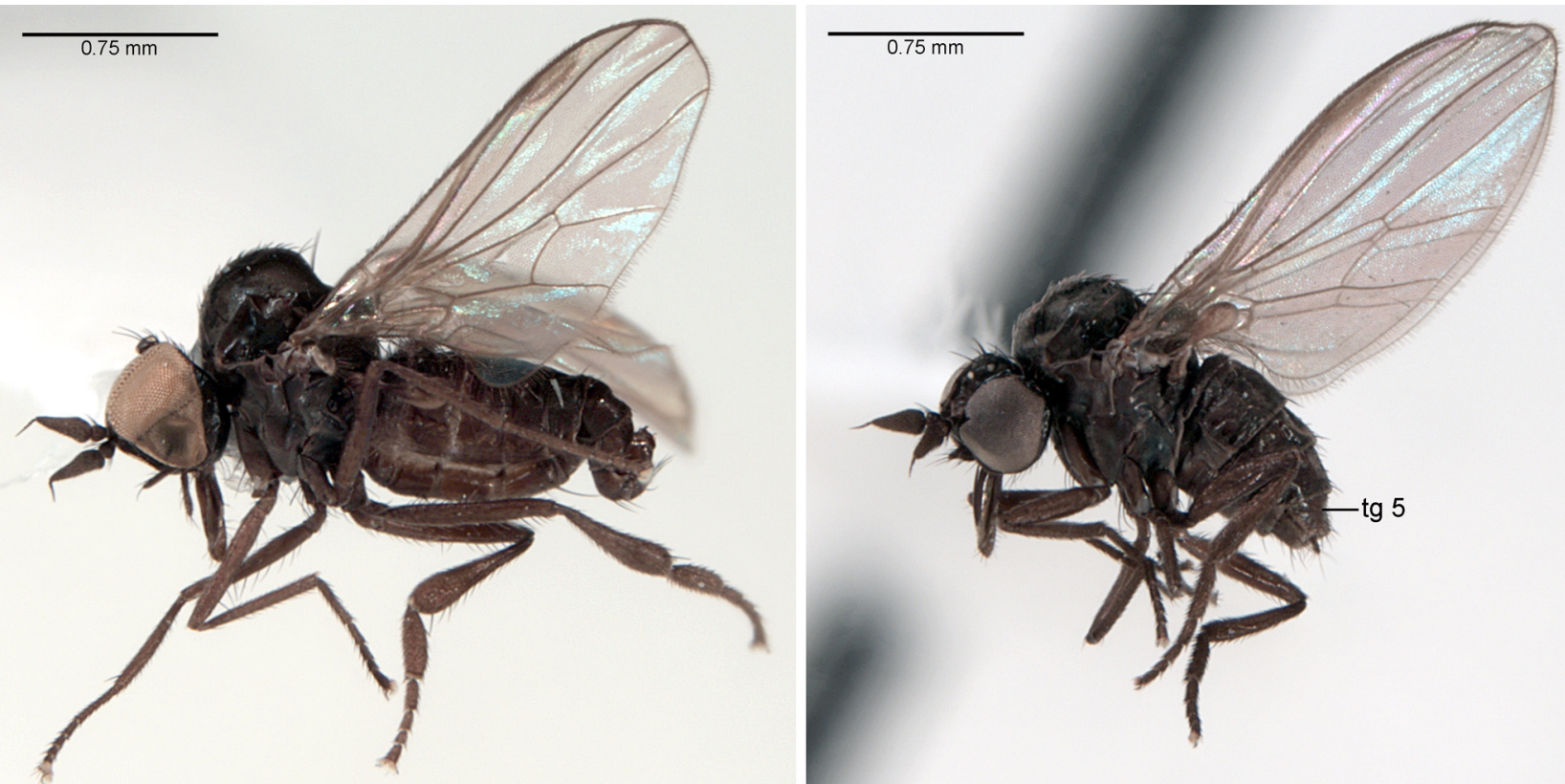

59 (M. obscurus $\left.{ }^{\lambda}\right)$

60 (M. obscurus + )

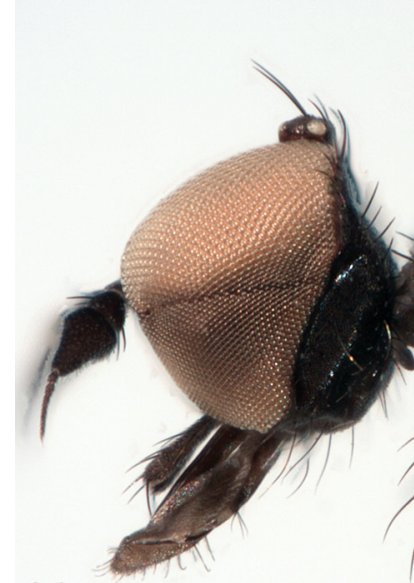

61 (M. obscurus $\left.{ }^{\Uparrow}\right)$
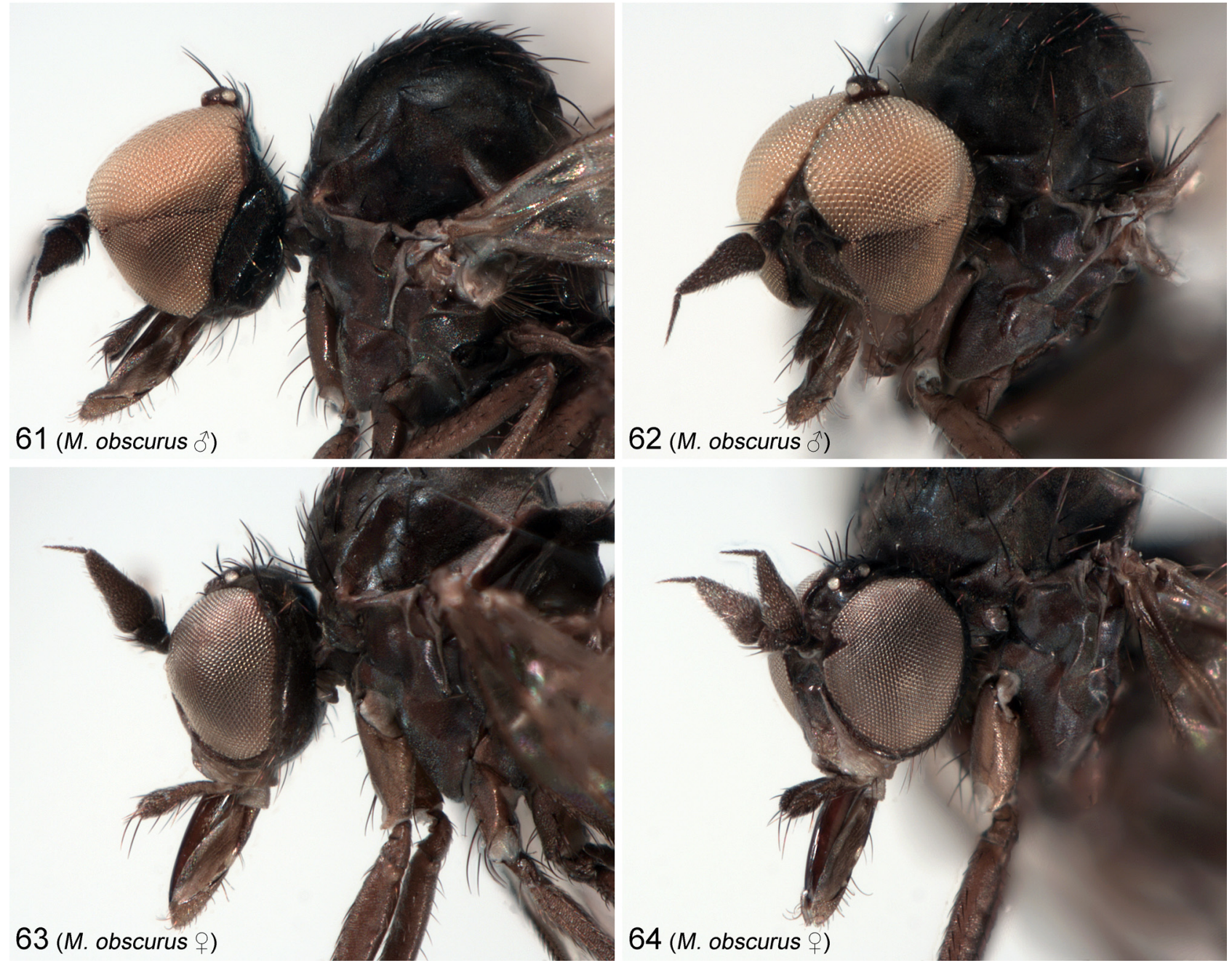

FIGURES 59-64. Habitus, head and thorax of Microphor obscurus Coquillett. 59. Male habitus. 60. Female habitus. 61. Male head and thorax, lateral view. 62. Male head and thorax, oblique view. 63. Female head and thorax, lateral view. 64. Female head and thorax, oblique view. Specimens from: Rondeau Provincial Park, Ontario (Figs 59-62); Carter Bay, Ontario (Figs 63, 64). Abbreviation: $\operatorname{tg}$ - tergite. 
cell $\mathrm{m}_{1}$ long with narrow base; male pregenitalic abdominal sternites unmodified (Figs 65-67); hypopygium (Figs 67, 69-74) small and free, epandrium without specialized setae adjacent to cercus, dorsal lobe of surstylus projected and longer than short dorsal postgonite lobe, left middle lobe of surstylus not developed, hypandrium with 3 setae per side, medial hypandrial prolongation absent, right hypandrial lobe broad basally with narrow digitiform dorsally projected apex, left ventral postgonite lobe not developed, right ventral postgonite lobe large, hook-shaped, phallus C-shaped beyond narrow beak-like phallic process; female terminalia (Fig. 68) completely retractable into segment 5 (i.e., with 5 exposed abdominal segments), segment 5 concolorous with anterior abdominal segments, syntergite $9+10$ with acanthophorite setae, cercus long and narrow with long setae apically and ventrally (Figs 56, 57).

Remarks. This species group includes M. bilineatus (Melander) and M. obscurus Coquillett.
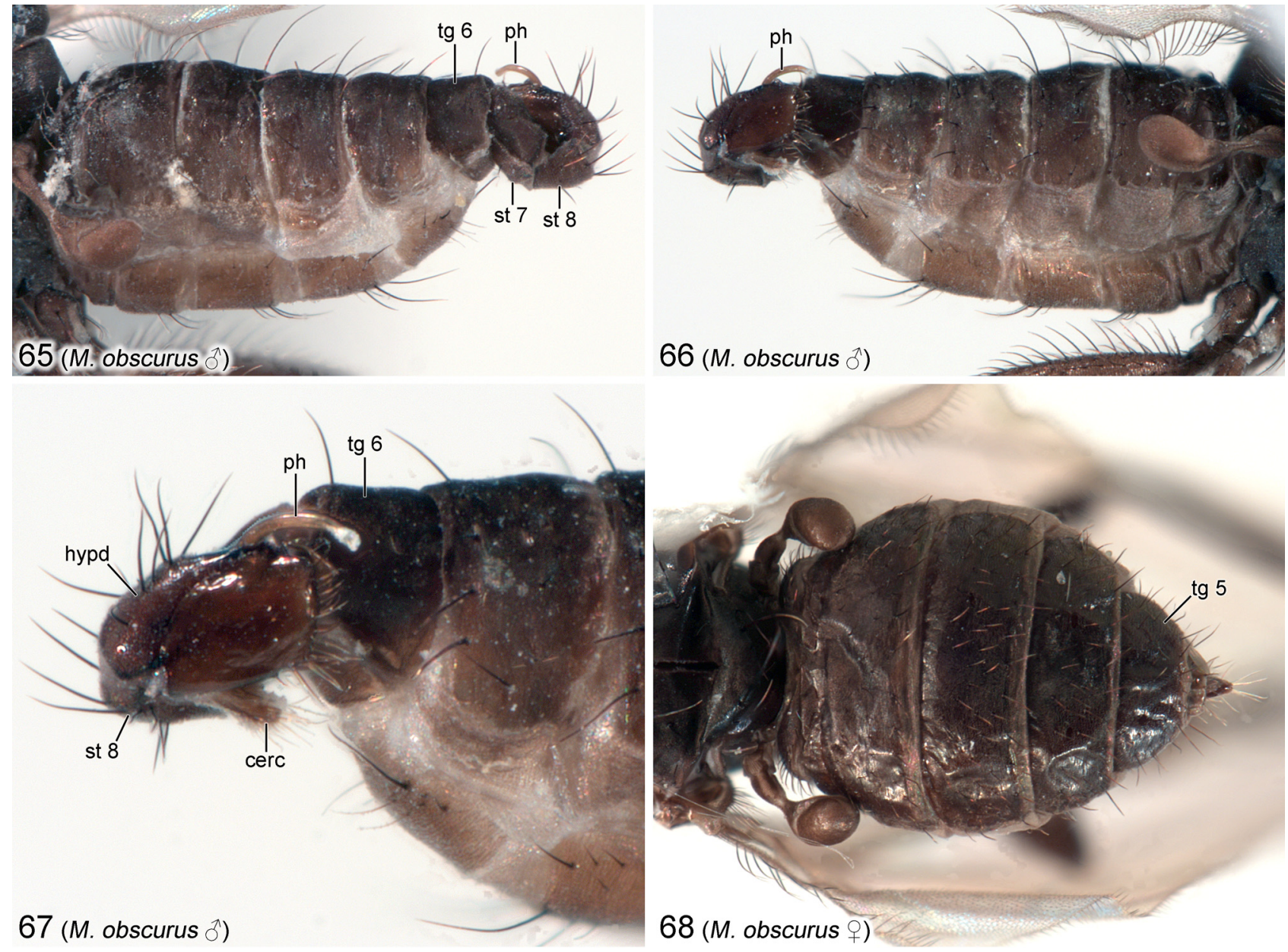

FIGURES 65-68. Abdomen and terminalia of Microphor obscurus Coquillett. 65. Male abdomen, left lateral view. 66. Male abdomen, right lateral view. 67. Male abdomen and terminalia, right lateral view. 68. Female abdomen, dorsal view. Specimens from: Dorcus Bay, Ontario (Figs 65-67); Carter Bay, Ontario (Fig. 68). Abbreviations: cerc — cercus; hypd—hypandrium; ph— phallus; st—sternite; $\operatorname{tg}$ - tergite.

\section{Microphor bilineatus (Melander)}

(Figs 51, 77)

Holoclera bilineata Melander, 1902: 334.

Microphorus bilineatus (Melander): Coquillett (1903: 263).

Type material examined. LECTOTYPE (here designated to fix the identity of the species), of collected from Opelousas [ $\mathrm{ca} 30^{\circ} 32^{\prime} \mathrm{N} 92^{\circ} 05^{\prime} \mathrm{W}$ ], St. Landry Parish, Louisiana, USA, iii.1897, labelled: “Opelousas,/ March, '97. La"; "H. bilineata/ TYPE Mel."; "COTYPE/ Holoclera/ bilineata/ Mel. [red label]"; "ALMelander/ Collection/ 1961"; "Microphorus/ bilineatus/ Mel."; "LECTOTYPE/ Holoclera/ bilineata Melander/ des. Brooks \& Cumming 


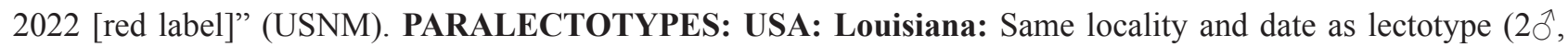
USNM; 4⿳⺈, AMNH); same locality and date as lectotype except, CNC1155686 (10, USNM). Two of the seven examined paralectotypes lack collection data labels, but each bears a red type label indicating inclusion in the type series.

Other material examined. USA: Alabama: Conecuh County: $10 \mathrm{~km}$ E Evergreen [ca $31^{\circ} 26^{\prime} \mathrm{N} 86^{\circ} 57^{\prime} \mathrm{W}$ ], 23.iv.1989, J.M. Cumming (1 9 , CNC); same data except, ex: along woodland sandbottom stream (3, CNC). Florida: Liberty County: Torreya SP, nr Rock Bluff [ca 30 $\left.34^{\circ} \mathrm{N} 84^{\circ} 57^{\prime} \mathrm{W}\right]$, 21.iv.1989, J.M. Cumming (2q, CNC). Maryland: [ca $39^{\circ} 17^{\prime} \mathrm{N} 76^{\circ} 36^{\prime} \mathrm{W}$ ] March. Hall, 28.v.1899, 8592, ovipositing on leaves of willow (2q, USNM). North Carolina: Watauga County: Valle Crucis [ $c a 36^{\circ} 11^{\prime} \mathrm{N} 81^{\circ} 45^{\prime} \mathrm{W}$ ], Camp Broadstone 6 mi. W Boone, 25.vi.1999, Malaise, J.M. Cumming (10๊, 1ㅇ, CNC). Texas: Brazos County: College Station, Lick Creek Pk [ca $30^{\circ} 34^{\prime} \mathrm{N} 96^{\circ} 12^{\prime} \mathrm{W}$ ], post oak savanna by creek, Malaise, 26-28.iii.2000, M. Buck (1웅 UGIC).

Diagnosis. This rarely collected eastern species can usually be differentiated from $M$. obscurus (the only other member of the M. obscurus species group) by the coloration of the thorax and halteres as indicated in couplet 10 of the key; however, some variation in these features is known to occur. The preapically bulging phallus (Fig. 51), which is usually visible without dissection, is the most reliable feature to separate this species from M. obscurus.

Redescription. Male (Fig. 51): Body length 2.0-2.2 mm, wing length 2.0-2.1 mm. Head: Ocellar tubercle with 2 pairs of black proclinate setae, anterior pair longer, posterior pair inserted at posterior margin. Occiput greyish pruinose, sparsely clothed with black setae in lower part, almost bare in upper part, except for postoculars. Gena and parafacial narrow along lower eye margin. Antenna dark brown; postpedicel approximately $2 \mathrm{X}$ as long as wide with apical 1/2 narrow; stylus distinctly shorter than postpedicel. Palpus dark brown, elongate ovate, nearly length of labrum, pubescent with microtrichia and bearing scattered black setulae. Proboscis dark brown, moderately long, nearly $2 / 3$ as long as head height, directed forward. Thorax: Mesonotum dark brown with shiny or greyish vitta between acrostichals and dorsocentrals. Mesonotal setae black, relatively short and dense on anterior 2/3 with dorsocentrals biserial or as a field of setae on each side. Scutellum with 3 pairs of setae, middle pair strong, outer and inner pair weaker. Mesopleuron dark brown to brown. Halter pale. Legs: Entirely pale brown, with black setae. Foreleg: Coxa with a few setae on anterior surface. Femur subequal in length to tibia, apical 1/3 with series of longer posteroventral setae (subequal to femur width), with short setae dorsally, anterior surface with short fine setae. Tibia slender, with short setae. Tarsus subequal in length to tibia, with short setae, tarsomere 1 subequal to combined length of tarsomeres 2-4, with short or indistinct basiventral seta, tarsomeres $2-4$ decreasing in length apically, tarsomere 5 subequal in length to tarsomere 2. Midleg: Coxa with several setae on anterior surface. Femur subequal in length to tibia, apical $1 / 2$ with series of longer posteroventral setae (longer than femur width) and short setae on posterior and anterior surfaces. Tibia slender, often with 1 or 2 slightly longer dorsal setae, otherwise with short setae. Tarsus slightly longer than tibia, with short setae, tarsomere 1 subequal to combined length of tarsomeres $2-4$, with short or indistinct basiventral seta, tarsomeres 2-4 decreasing in length apically, tarsomere 5 subequal in length to tarsomere 3. Hindleg: Coxa with 1 seta on outer surface, a few weaker setae below and on anterior surface, 1 seta on posterior surface. Femur subequal in length to tibia, with series of longer dorsal setae (at most subequal to femur width), apical $1 / 2$ with series of longer anteroventral setae (subequal to femur width), anterior surface otherwise with shorter setae, posterior surface with short fine setae. Tibia enlarged apically, with series of longer dorsal setae (apical seta longest), otherwise with short setae and setulae (dense ventrally). Tarsus subequal in length to tibia, with short setae, tarsomere 1 broad, subequal to combined length of tarsomeres $2-4$, with a few short basiventral setae, tarsomeres 2-4 decreasing in length apically, tarsomere 5 subequal in length to tarsomere 3. Wing (similar to Fig. 29): With slight grey-brown tinge, veins dark brown. $R_{1}$ reaching costa well beyond base of $M_{2}$. Costal section $M_{1}-$ $\mathrm{M}_{2}$ distinctly longer than $\mathrm{M}_{2}-\mathrm{M}_{4}$. Cell dm moderately-sized, extended to around middle of wing, distal section of vein $M_{1}$ (beyond base of $M_{2}$ ) longer than preceding section (between r-m and base of $M_{2}$ ). Cell $m_{1}$ long with narrow base. Abdomen: Blackish-brown, with black setae on tergites and sternites. Tergites 1-6 with long setae, setae sparse on tergite 6 . Sternites 2-5 sparsely setose with long setae at posterior margin. Sternite 6 with pair of weak setae. Segment 7 with pair of weak setae on sternite, otherwise bare. Sternite 8 subrectangular, setose. Hypopygium: Small, about 1/5 length of abdomen. Left epandrial lamella subrectangular, longer than high, with surstylar lobes projecting distally, with setae along posterior margin. Left dorsal lobe of surstylus elongate, digitiform and slender. Left middle lobe of surstylus not developed. Left ventral lobe of surstylus digitiform with short thick seta at tip and long preapical medial seta. Right epandrial lamella subrectangular, longer than high, with surstylar lobes projecting distally, with setae along posterior margin. Right dorsal lobe of surstylus similar to left side. Right middle lobe 
of surstylus not developed. Right ventral lobe of surstylus weakly developed and short with short thick seta at tip and long preapical ventral seta. Hypandrium with series of 3 long ventral setae on each side of basal part. Medial hypandrial prolongation absent. Left hypandrial lobe broad with rounded apex. Right hypandrial lobe broad basally with narrow digitiform dorsally projected apex. Left dorsal postgonite lobe with larger conical posterior lobe bearing apical seta and smaller anterior lobe bearing apical setae. Left ventral postgonite lobe not developed. Right dorsal postgonite lobe similar to left side. Right ventral postgonite lobe large, hook-shaped. Postgonite apodeme V-shaped in ventral view. Phallus (Fig. 51) C-shaped beyond phallic process, with preapical bulge present. Phallic process narrow, beak-like. Ejaculatory apodeme short. Hypoproct lobes not substantially developed. Left and right cercus short with several long setae dorsally and apically.

Female (described for the first time): Body length 1.6-2.0 mm, wing length 1.9-2.0 mm. Similar to male except as follows: Legs: With shorter setae. Hindleg: With tibia slender, not enlarged apically; tarsomere 1 not enlarged. Wing (similar to Fig. 30): Slightly narrower. Anal lobe smaller. Abdomen: Tergites and sternites with short setae. Terminalia (similar to Figs 56-58): Tergite 8 apparently separated from sternite 8 anterolaterally. Spermatheca ovoid. Cercus about $2 \mathrm{X}$ width of syntergite $9+10$.

Distribution and seasonal occurrence. Microphor bilineatus is known from eastern USA, including Maryland, North Carolina, northern Florida, Alabama, Louisiana and eastern Texas (Fig. 77). Adults have been collected from late March to late June.

Remarks. Melander (1902) indicated nine males in the type series, but one of these specimens (now a paralectotype), was not examined by us and its location is unknown.

\section{Microphor obscurus Coquillett}

(Figs 1, 2, 29, 30, 56-74, 78)

Microphorus obscurus Coquillett, 1903: 268.

Type material examined. HOLOTYPE, $\overbrace{}^{\wedge}$ from Franconia $\left[\mathrm{ca}_{4} 4^{\circ} 13^{\prime} \mathrm{N} 71^{\circ} 44^{\prime} \mathrm{W}\right]$, Grafton County, New Hampshire, USA, labelled: "FRANCONIA, N.H."; "MrsSlosson/ Collector"; "Type/ No 6782/ U.S.N.M."; "Microphorus/ obscurus/ Coq." (USNM).

Other material examined. CANADA: Alberta: $11 \mathrm{mi}$. W Banff [ca $51^{\circ} 13^{\prime} \mathrm{N} 115^{\circ} 56^{\prime} \mathrm{W}$ ], Banff NP, 11vii.1955,

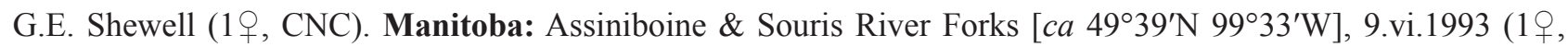

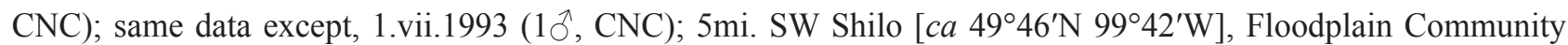
nr Tamarack Bog, 11.vii.1958, J.G. Chillcott (1へ̂, CNC); 2 mi. NE Treesbank, Assiniboine \& Souris River Forks

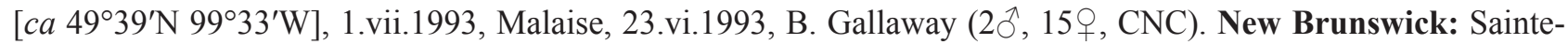

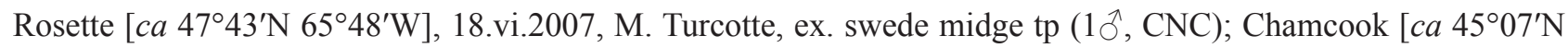
6704'W], 7.vii.1965, G.E. Shewell (19, CNC); same data except, Birch Cove, 4.vii.1965 (1q, CNC); same data except, Glebe Road, 26.vi.1965 (3ð̄, 2ᄋ, CNC). Northwest Territories: Norman Wells, along Goat Trail, Schooner Creek alluvial fan, $65.309^{\circ}-126.698^{\circ}$, sweep, 15.vi.2011, A.M. Soleki (2ð, LEMQ). Nova Scotia: Cape Breton Is., North Shore, $46^{\circ} 24.8^{\prime} \mathrm{N} 60^{\circ} 28.5^{\prime} \mathrm{W}$, sweep damp forest path $\mathrm{nr}$ beach, 21.vii.2002, J. Forrest \& T.A. Wheeler (1웅, LEMQ). Ontario: Dorcas Bay, $45^{\circ} 11^{\prime} \mathrm{N} 81^{\circ} 35^{\prime} \mathrm{W}$, 4.vi.2001, on false solomon's seal flowers, S.A. Marshall (3 ${ }^{\prime}$,

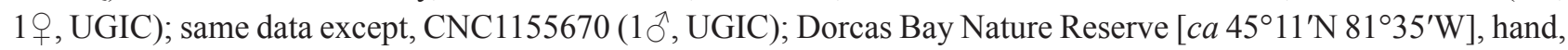
8.vi.2000, C.S. Onodera (1 $\widehat{\partial}^{\wedge}$, UGIC); Fathom Five National Marine Park, SW Bears Rump Island $\left[\mathrm{ca} 45^{\circ} 18^{\prime} \mathrm{N}\right.$

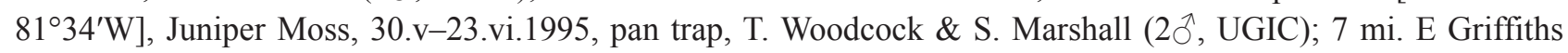

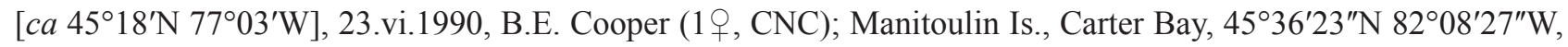
23-24.vi.2003, dunes, S.M. Paiero (2q, UGIC); same data except, 27.vi-13.vii.2003, dunes by stream, Malaise,

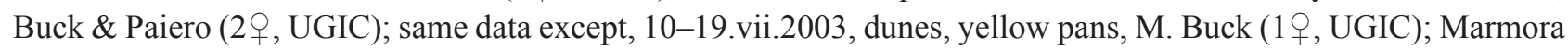

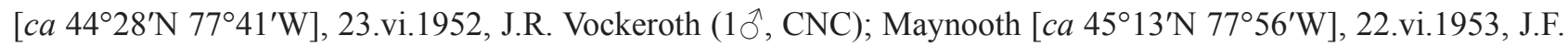
McAlpine (1ㅇ, CNC); Moosonee, 51.28034은 -80.64252, Repl. 1 wet, Malaise trap, 15-18.vi.2010, NBP field party (4ㅇ, LEMQ); Ottawa [ca 452 $\left.26^{\prime} \mathrm{N} 75^{\circ} 38^{\prime} \mathrm{W}\right]$, 17.vi.1946, G.E. Shewell (2ㅇ, CNC); same data except, 4.viii.1991,

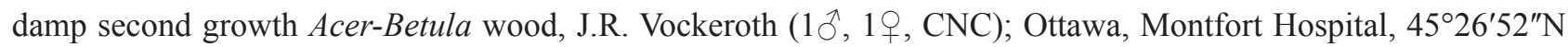

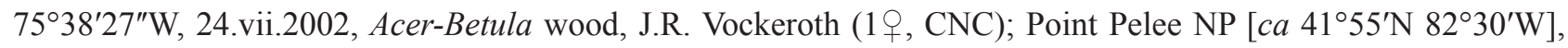
3.vi.1982, D. Morris (2ᄋ, UGIC); same data except, Visitor's Centre, Malaise \& pan traps, 10-15.v.2000, O. Lonsdale

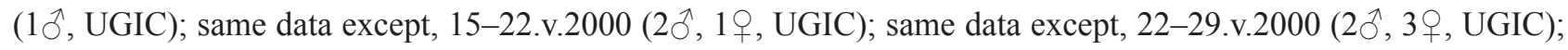



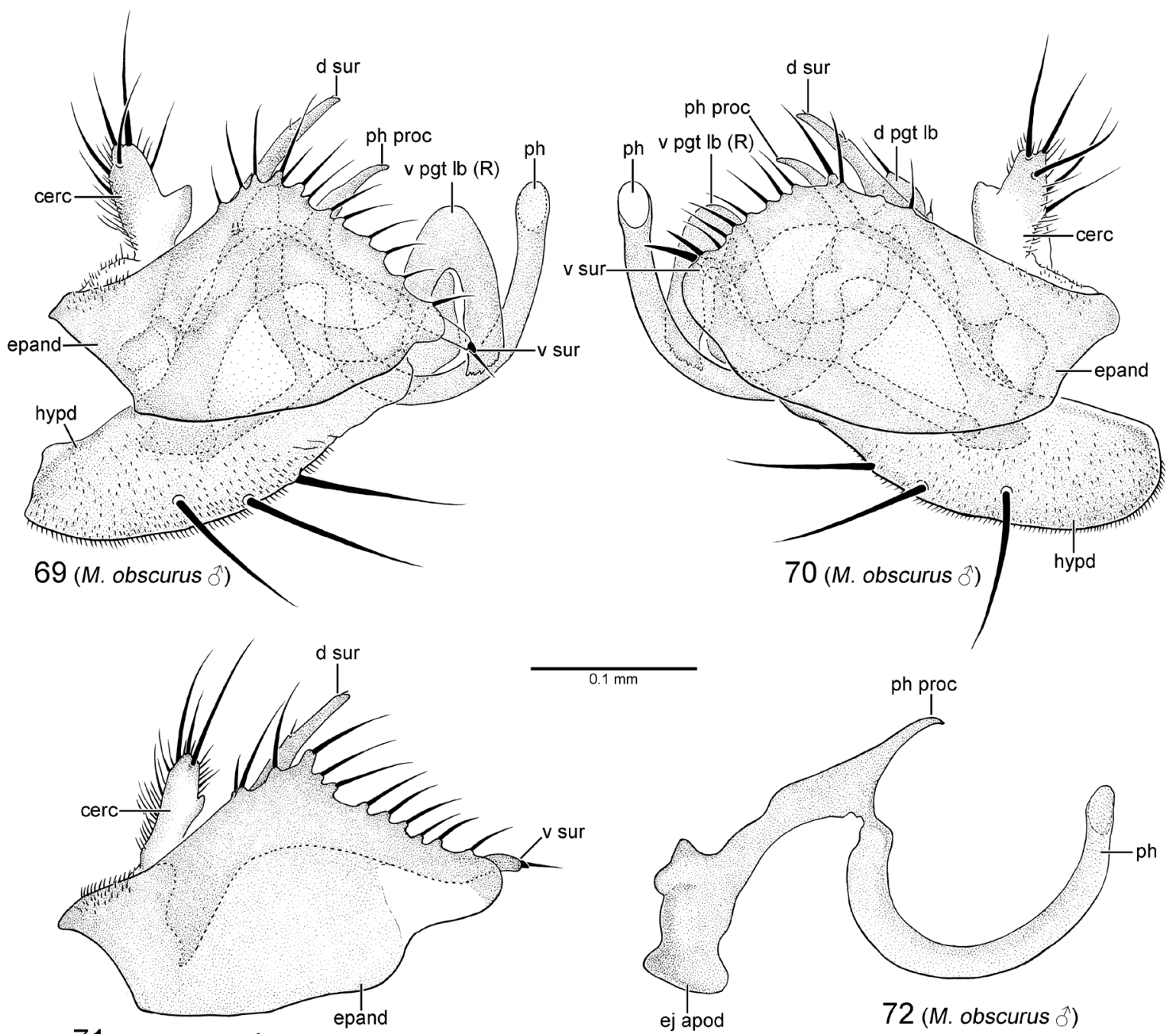

$0.1 \mathrm{~mm} \quad \mathrm{ph}$ proc

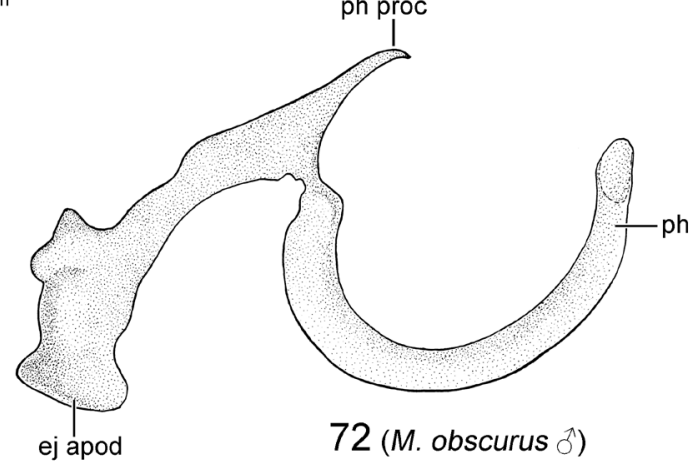

$71($ M. obscurus ô)
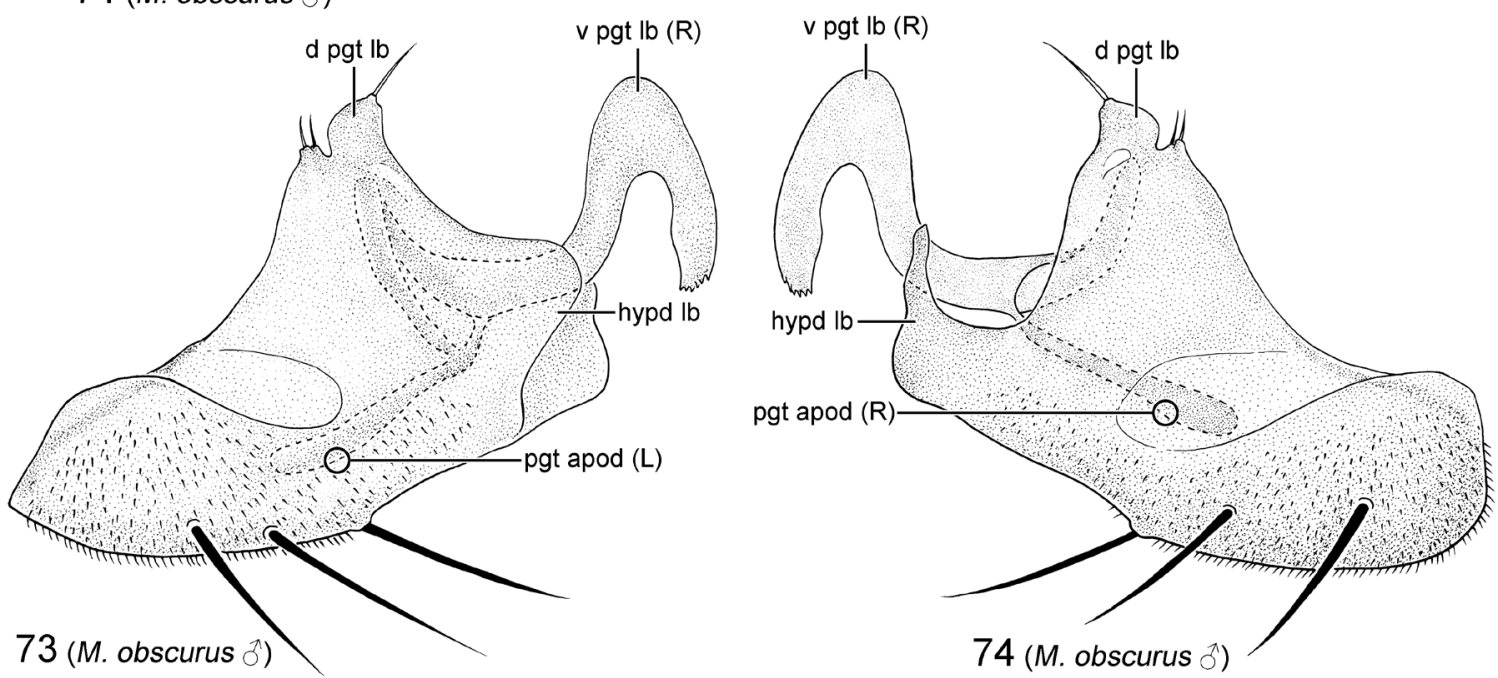

FIGURES 69-74. Hypopygium of Microphor obscurus Coquillett 69. Hypopygium, left lateral view. 70. Hypopygium, right lateral view. 71. Epandrium and cercus, left lateral view. 72. Phallus, left lateral view. 73. Hypandrium and postgonite, left lateral view. 74. Hypandrium and postgonite, right lateral view. Figures 69 and 70 based on specimen CNC1155673 (Stevensville, Michigan). Figures 71-74 based on specimen CNC1155670 (Dorcas Bay, Ontario). Abbreviations: cerc_cercus; d pgt lb_ dorsal postgonite lobe; d sur — dorsal lobe of surstylus; ej apod — ejaculatory apodeme; epand — epandrium; hypd—hypandrium; hypd lb—hypandrial lobe; (L)—left; pgt apod—postgonite apodeme; ph—phallus; ph proc — phallic process; (R) —right; v pgt $\mathrm{lb}$ — ventral postgonite lobe; v sur—ventral lobe of surstylus. 

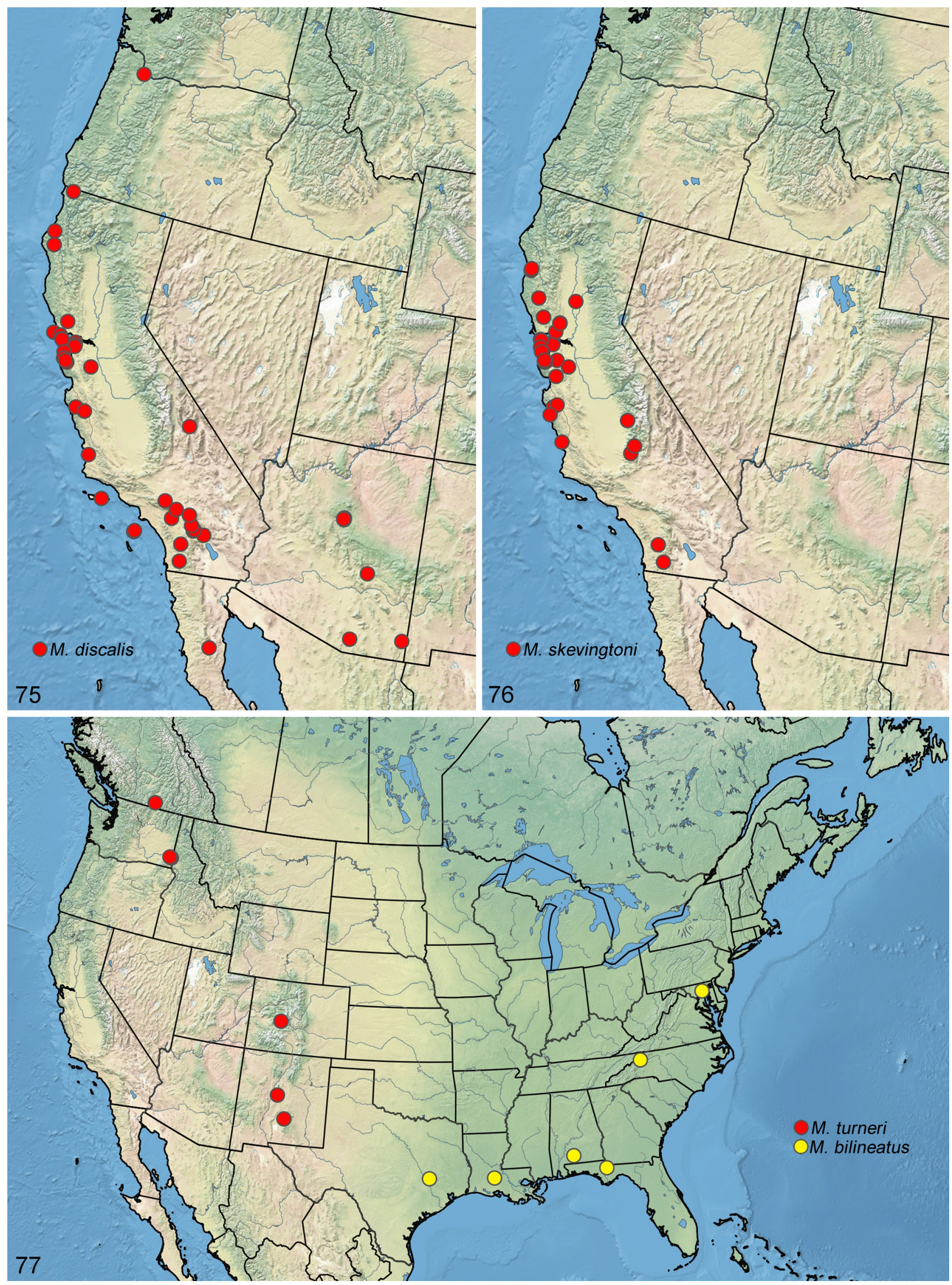

FIGURES 75-77. Known geographical distributions of Nearctic Microphor. 75. M. discalis Melander. 76. M. skevingtoni sp. nov. 77. M. turneri sp. nov. and M. bilineatus (Melander). 


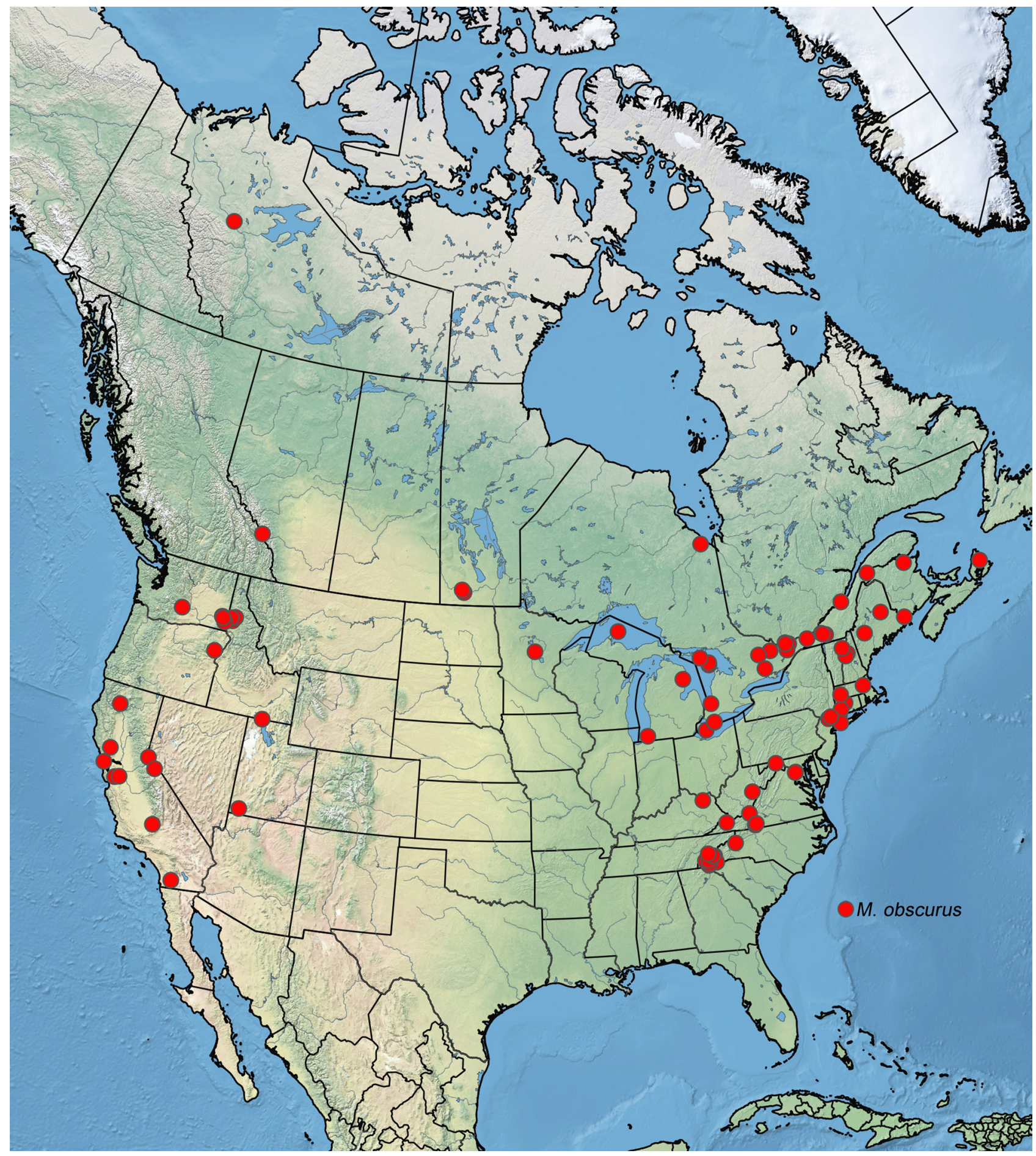

FIGURE 78. Known geographical distribution of Microphor obscurus Coquillett.

same data except, 22-30.vii.2000 (2q, UGIC); same data except, CNC1155689 (1ㅇ, UGIC); Port Franks [ca $\left.43^{\circ} 13^{\prime} \mathrm{N} 81^{\circ} 53^{\prime} \mathrm{W}\right]$, Watson property nr L-lake, 15-17.vi.1996, Malasie, J. Skevington (1 9 , UGIC); same data except, 17-20.vi.1996 (1ㅇ, UGIC); same data except, 20-26.vi.1996 (1우, UGIC); 10 km S Richmond [ca 4509'N $\left.75^{\circ} 51^{\prime} \mathrm{W}\right]$, 29.v.1987, fen, J.M. Cumming (19, CNC); Rondeau PP, $42^{\circ} 15^{\prime} \mathrm{N} 81^{\circ} 52^{\prime} \mathrm{W}$, 10.vi.2003, roadside, on Euphorbia, S.A. Marshall $\left(10{ }^{\lambda}, 18 \hat{\jmath}^{\lambda}\right.$, UGIC); same data except, South Point nr east parking lot, $42^{\circ} 15^{\prime} 42^{\prime \prime} \mathrm{N}$

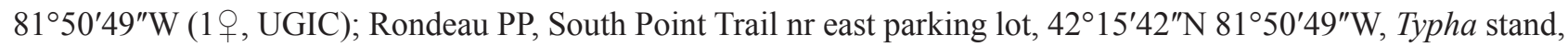
mal., 29.v-10.vi.2003, S.A. Marshall (9ð, 5, UGIC); same data except, 10-17.vi.2003, Marshall et al. (2仓, 4ㅇ, UGIC); same data except, savanna mal., 29.v-10.vi.2003, S.A. Marshall (2 $\jmath^{2}, 2+$, UGIC); same data except, 17.vi-

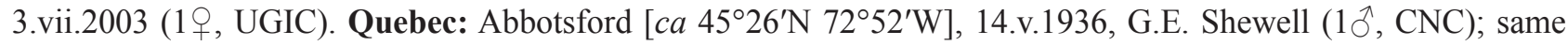




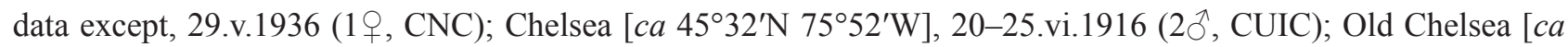
$\left.45^{\circ} 29^{\prime} \mathrm{N} 75^{\circ} 51^{\prime} \mathrm{W}\right]$, 25.vi.1959, J.G. Chillcott (1 9 , CNC); same data except, 18.vi.1963, J.R. Vockeroth (1 9 , CNC); same data except, 9.vii.1959 (1 9, CNC); same data except, King Mtn, 26.v.1963, J.G. Chillcott (3 9 , CNC); Lac du

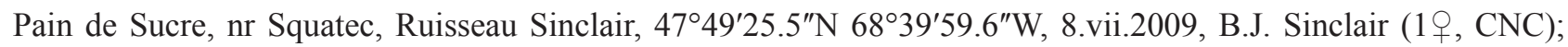

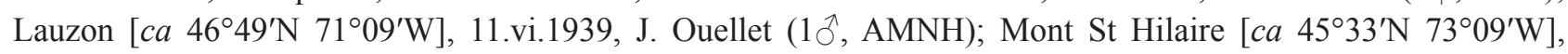
4.vi.1963, J.G. Chillcott (1+, CNC); same data except, Pain de Sucre Trail, 27.vi.2001, sweep trail edge, S.E. Brooks (10̂, LEMQ); same data except, 27.vi.2001, brook bank, M. Pollet (1, LEMQ); Rigaud, Parc LéryMacdonald, $45^{\circ} 28^{\prime} 9^{\prime \prime} \mathrm{N} 74^{\circ} 15^{\prime} 19^{\prime \prime} \mathrm{W}, 30 . v .2007$, J.M. Cumming (19, CNC); Rougemont RMAL 1.6, flight intercept trap, $45^{\circ} 29.614^{\prime} \mathrm{N} 73^{\circ} 03.854^{\prime} \mathrm{W}, 9-16 . v i .2008$, V. Levesque (1 $0^{\wedge}$, LEMQ). USA: California: Alpine County: W Fork Carson River, Snowshoe Springs Campground [ $c a 38^{\circ} 46^{\prime}$ N 119 $53^{\prime} \mathrm{W}$ ], 6600 ft, 19.vi.1971, P.H. \& M. Arnaud

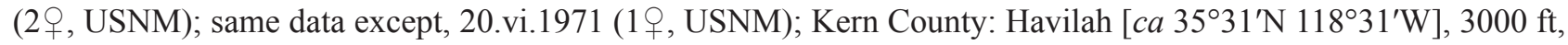

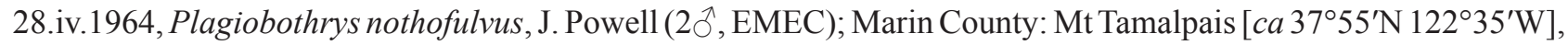
vic. of Rock Springs, 13.v.1978, ca 610 m, at flower of Ranunculus sp., P.H. Arnaud, Jr (2へ, 3 + , USNM); Mono

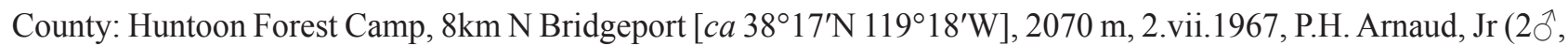
USNM); same data except, Swauger Creek, 2010 m (1へ̂, USNM); Napa County: Butts Canyon, 13 km NW Pope Valley [ca $38^{\circ} 42^{\prime} \mathrm{N} 122^{\circ} 27^{\prime} \mathrm{W}$ ], 21.iv.1979, T.W. Davies (1ㅇ, CAS); San Diego County: Lake Cuyamaca [ca

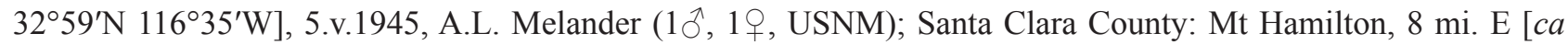
$\left.37^{\circ} 20^{\prime} \mathrm{N} 121^{\circ} 38^{\prime} \mathrm{W}\right], 16 . i v .1955$, D.J. Burdick (19, EMEC); Stanislaus County: Del Puerto Canyon, Frank Raines Park [ca $37^{\circ} 25^{\prime} \mathrm{N} 12^{\circ} 22^{\prime} \mathrm{W}$ ], 335 m, 5.iv.1970, P.H. Arnaud, Jr (1ㅇ, CAS); Trinity County: Trinity Center [ca $\left.40^{\circ} 59^{\prime} \mathrm{N} 122^{\circ} 42^{\prime} \mathrm{W}\right], 2 . v i .1951$, A.T. McClay (19, UCDC). Connecticut: Fairfield County: New Canaan [ca $41^{\circ} 08^{\prime} \mathrm{N} 73^{\circ} 29^{\prime} \mathrm{W}$ ], 27.v.1962, M. Statham (2 ${ }^{\circ}$, AMNH); Fairfield County: Redding [ca $41^{\circ} 18^{\prime} \mathrm{N} 73^{\circ} 23^{\prime} \mathrm{W}$ ],

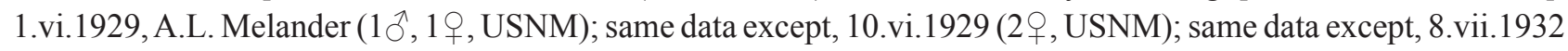

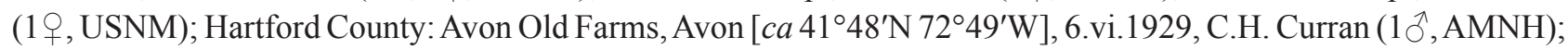

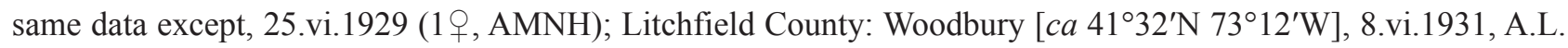
Melander (1, USNM). Idaho: Latah County: Kendrick [ca 46 $36^{\prime} \mathrm{N} 116^{\circ} 38^{\prime} \mathrm{W}$ ], 7.vi.1917 (1ㅇ, USNM); Latah County: 3 mi. S Helmer [ $c a 46^{\circ} 48^{\prime} \mathrm{N} 116^{\circ} 28^{\prime} \mathrm{W}$ ], on Potlatch Rd, nr Ltl. Boulder Cmpgr., 2600-2800 ft, 29.v.1991,

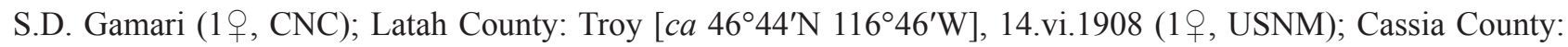

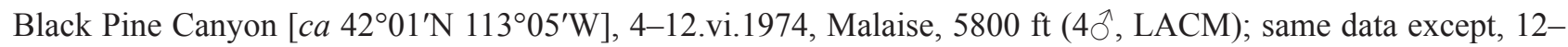

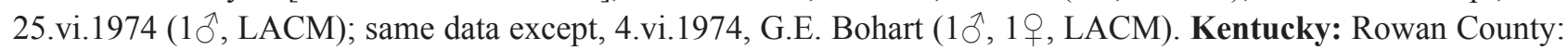

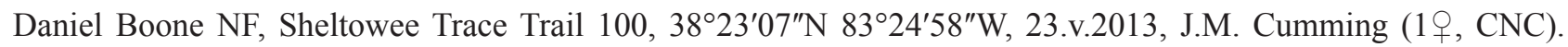
Maine: Franklin County: Kingfield [ $c a 44^{\circ} 57^{\prime} \mathrm{N} 70^{\circ} 09^{\prime} \mathrm{W}$ ], attracted to and or feeding on prey in spider's web, 20.vi.1966, S.M. Smith \& L. Forester (5, CNC); Penobscot County: Grindstone Falls Rest Area, $45^{\circ} 43.8^{\prime} \mathrm{N}$ $68^{\circ} 35.4^{\prime} \mathrm{W}$, sweep vegetation along Penobscot River, 16.vii.2002, J. Forrest \& T.A. Wheeler (19, LEMQ).

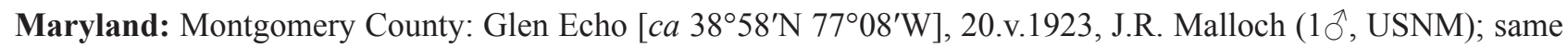

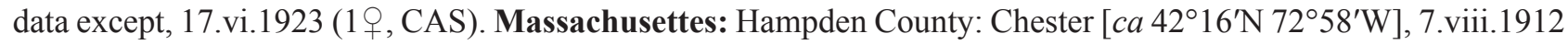
( 1 ㅇ, USNM); Middlesex County: Lincoln [ca $\left.42^{\circ} 25^{\prime} \mathrm{N} 71^{\circ} 18^{\prime} \mathrm{W}\right]$, 9.vi.1982, Malaise, E.T. Armstrong (1 ${ }^{\circ}$, USNM);

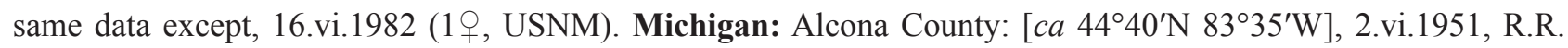

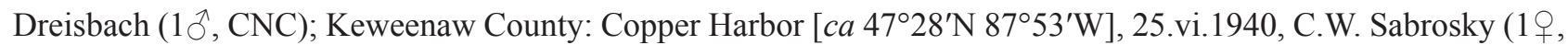
USNM); Berrien County: Stevensville [ca $\left.42^{\circ} 00^{\prime} \mathrm{N} 86^{\circ} 31^{\prime} \mathrm{W}\right]$, 29.v.1938, G. Steyskal (1 $\jmath^{\wedge}, 1$, , USNM); same data

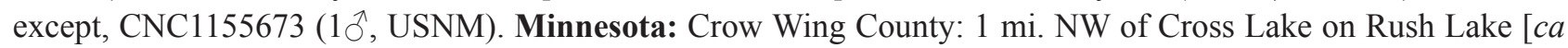

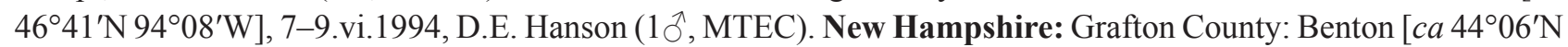
$71^{\circ} 54^{\prime} \mathrm{W}$ ], 6.vii.1931, A.L. Melander (1ㅇ, USNM). New York: Orange County: Tuxedo [ca $41^{\circ} 14^{\prime} \mathrm{N} 74^{\circ} 11^{\prime} \mathrm{W}$ ],

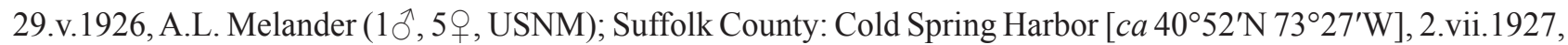
A.L. Melander (1, USNM); Rockland County: Bear Mountain [ $\left.c a 41^{\circ} 18^{\prime} \mathrm{N} 74^{\circ} 00^{\prime} \mathrm{W}\right]$, 3.vii.1929, A.L. Melander

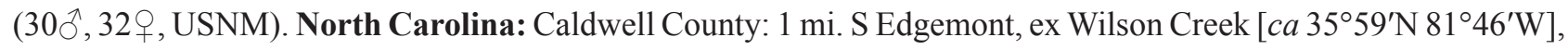

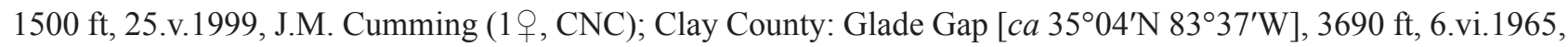
J.G. Chillcott (4⿳⺈, CNC); Graham County: Robbinsville [ca $35^{\circ} 19^{\prime} \mathrm{N} 83^{\circ} 48^{\prime} \mathrm{W}$ ], 9.vi.1976, G.E. Bohart (2q,

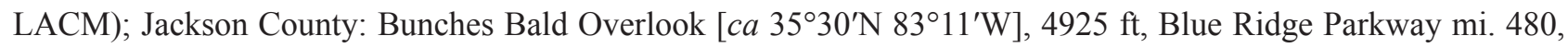
8.vi.1965, ex blossoms Zizia sp., J.G. Chillcott (2ㅇ, CNC); Glenville, 2 mi. N [ca 35 $\left.{ }^{\circ} 10^{\prime} \mathrm{N} 83^{\circ} 07^{\prime} \mathrm{W}\right]$, 4.vi.1965, on

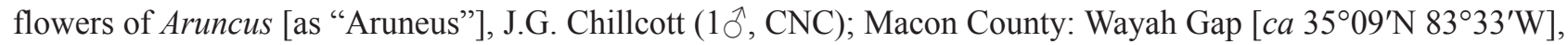
$3100 \mathrm{ft}$, 5.vi.1965, on flowers of Aruncus [as "Aruneus"], J.G. Chillcott (1, CNC); same data except, 6.vi.1965

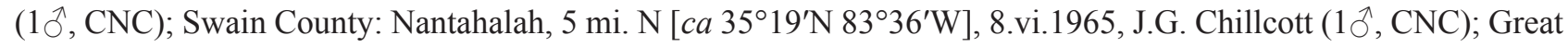




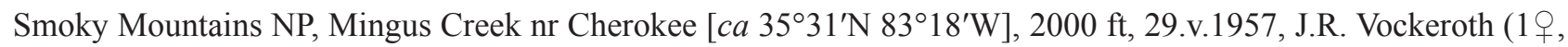

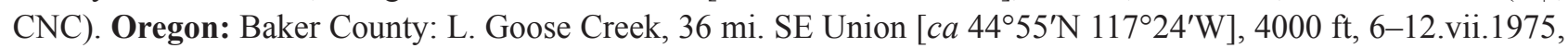
Malaise baited with $\mathrm{CO}_{2}$, E.J. Davis (19, WSU); same data except, Wallowa-Whitman NF, 24-25.1976, W.J., Turner (19, WJTC). Tennessee: Sevier County: Great Smoky Mountains NP, Elkmont [ $c a 35^{\circ} 39^{\prime} \mathrm{N} 83^{\circ} 34^{\prime} \mathrm{W}$ ],

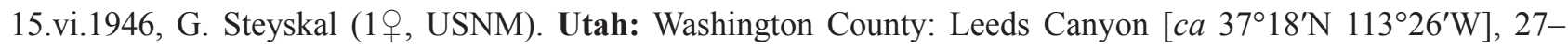

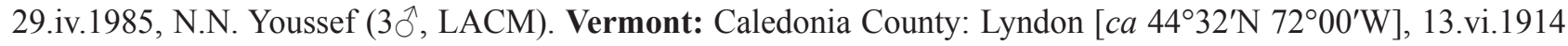

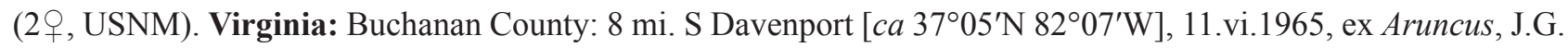

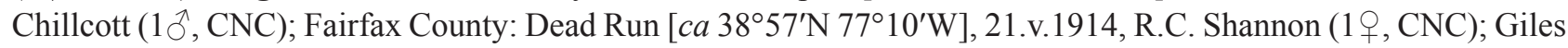

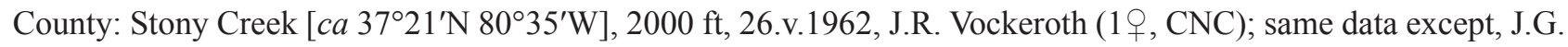

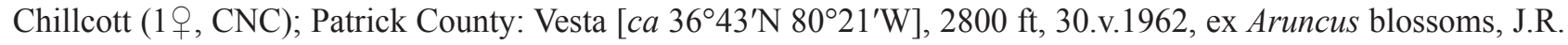
Vockeroth (1, CNC); Woolwine [ca 36 $47^{\prime} \mathrm{N} 80^{\circ} 16^{\prime} \mathrm{W}$ ], $2500 \mathrm{ft}$, 2.vi.1962, ex Aruncus blossoms, J.G. Chillcott

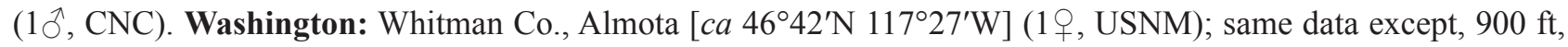
17-18.iv.1981, sweeping Salix flowers, W.J. Turner (1 ${ }^{\top}$, 1 9 , WJTC); Steptoe Canyon [ca $\left.46^{\circ} 27^{\prime} \mathrm{N} 117^{\circ} 11^{\prime} \mathrm{W}\right]$, ca. 10 mi. SW Colton, $900 \mathrm{ft}$, 8.v.1986, sweeping shrubs, W. Turner (1ㅇ, WJTC); Waiwawai [ca 46 $38^{\circ} \mathrm{N} 117^{\circ} 22^{\prime} \mathrm{W}$ ], 20.v.1911 (1 ${ }^{\circ}$, USNM); Yakima Co., No. Yakima [ $c a 4^{\circ} 37^{\prime}$ N 120²9’W], 22.v.1917, A.L. Melander (1 ${ }^{\circ}$, USNM).

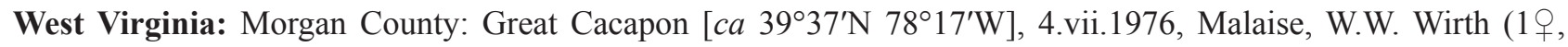

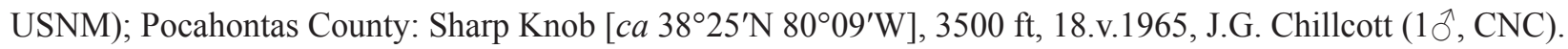

Diagnosis. This widespread species can usually be differentiated from M. bilineatus (the only other member of the M. obscurus species group) by the coloration of the thorax and halteres as indicated in couplet 10 of the key; however, some variation in these features is known to occur. The uniformly tubular phallus (Figs 65-67), which is usually visible without dissection, is the most reliable feature to separate this species from M. bilineatus.

Redescription. Male (Figs 29, 59, 61, 62, 65-67, 69-74): Body length 1.8-2.3 mm, wing length 1.9-2.2 $\mathrm{mm}$. Head (Figs 61, 62): Ocellar tubercle with 2 pairs of black proclinate setae, anterior pair longer, posterior pair inserted at posterior margin. Occiput greyish pruinose, sparsely clothed with black setae in lower part, almost bare in upper part, except for postoculars. Gena and parafacial narrow along lower eye margin. Antenna (Fig. 62) dark brown to black; postpedicel approximately $2 \mathrm{X}$ as long as wide with apical $1 / 2$ narrow; stylus distinctly shorter than postpedicel. Palpus brownish-black, elongate ovate, nearly length of labrum, pubescent with microtrichia and bearing scattered black setulae. Proboscis brownish-black, moderately long, nearly $2 / 3$ as long as head height, directed forward. Thorax (Fig. 61): Mesonotum opaque black with vitta between acrostichals and dorsocentrals faint or absent. Mesonotal setae black, relatively short and dense on anterior $2 / 3$ with dorsocentrals biserial or as a field of setae on each side. Scutellum with 3 pairs of setae, middle pair strong, outer and inner pair weaker. Mesopleuron black to dark brown. Halter darkish-brown, rarely pale. Legs (Fig. 59): Entirely dark brown, with black setae. Foreleg: Coxa with a few setae on anterior surface. Femur subequal in length to tibia, with series of long posteroventral setae (at most slightly longer than femur width), with short setae dorsally, anterior surface with short fine setae. Tibia slender, with short setae. Tarsus subequal in length to tibia, with short setae, tarsomere 1 subequal to combined length of tarsomeres $2-4$, with prominent basiventral seta ( $2 \mathrm{X}$ longer than tarsomere width), tarsomeres 2-4 decreasing in length apically, tarsomere 5 subequal in length to tarsomere 2. Midleg: Coxa with several setae on anterior surface. Femur subequal in length to tibia, with series of longer posteroventral setae (slightly longer than femur width) and short setae on posterior and anterior surface. Tibia slender, with 2-3 longer dorsal setae (slightly longer than tibia width), otherwise with short setae. Tarsus subequal in length to tibia, with short setae, tarsomere 1 subequal to combined length of tarsomeres 2-4, with short basiventral seta, tarsomeres 2-4 decreasing in length apically, tarsomere 5 subequal in length to tarsomere 2. Hindleg: Coxa with 1 seta on outer surface, a few weaker setae below and on anterior surface, 1 seta on posterior surface. Femur subequal in length to tibia, with series of longer dorsal setae (shorter than femur width), anterior surface otherwise with shorter setae, posterior surface with short fine setae. Tibia enlarged apically, with series of longer dorsal setae (apical seta longest), otherwise with short setae and setulae (dense ventrally). Tarsus subequal in length to tibia, with short setae, tarsomere 1 broad, subequal to combined length of tarsomeres $2-4$, with a few short basiventral setae, tarsomeres $2-4$ decreasing in length apically, tarsomere 5 subequal in length to tarsomere 2. Wing (Fig. 29): With slight grey-brown tinge, veins dark brown. $R_{1}$ reaching costa well beyond base of $M_{2}$. Costal section $M_{1}-M_{2}$ distinctly longer than $M_{2}-M_{4}$. Cell dm moderately-sized, extended to around middle of wing, distal section of vein $\mathrm{M}_{1}$ (beyond base of $\mathrm{M}_{2}$ ) longer than preceding section (between $\mathrm{r}-\mathrm{m}$ and base of $\mathrm{M}_{2}$ ). Cell $\mathrm{m}_{1}$ long with narrow base. Abdomen (Figs 65, 66): Blackishbrown, with black setae on tergites and sternites. Tergites 1-6 with long setae, setae sparse on tergite 6 . Sternites 
2-5 sparsely setose with long setae at posterior margin. Sternite 6 with pair of weak setae. Segment 7 with pair of weak setae on sternite, otherwise bare. Sternite 8 subrectangular, setose. Hypopygium (Figs 67, 69-74): small, about 1/5 length of abdomen. Left epandrial lamella (Figs 69, 71) subrectangular, longer than high, with surstylar lobes projecting distally, with setae along posterior margin. Left dorsal lobe of surstylus elongate, digitiform and slender. Left middle lobe of surstylus not developed. Left ventral lobe of surstylus digitiform with short thick seta at tip and long preapical medial seta. Right epandrial lamella (Figs 68, 70) subrectangular, longer than high, with surstylar lobes projecting distally, with setae along posterior margin. Right dorsal lobe of surstylus similar to left side. Right middle lobe of surstylus not developed. Right ventral lobe of surstylus weakly developed and short with short thick inner seta and long outer seta. Hypandrium (Figs 69, 70, 73, 74) with series of 3 long ventral setae on each side of basal part. Medial hypandrial prolongation absent. Left hypandrial lobe broad with rounded apex. Right hypandrial lobe broad basally with narrow digitiform dorsally projected apex. Left dorsal postgonite lobe with larger conical posterior lobe bearing apical seta and smaller anterior lobe bearing apical setae. Left ventral postgonite lobe not developed. Right dorsal postgonite lobe similar to left side. Right ventral postgonite lobe large, hook-shaped. Postgonite apodeme V-shaped in ventral view. Phallus (Fig. 72) C-shaped beyond narrow phallic process, lacking preapical bulge. Phallic process narrow, beak-like. Ejaculatory apodeme short. Hypoproct lobes not substantially developed. Left and right cercus short with several long setae dorsally and apically.

Female (Figs 30, 56-58, 60, 63, 64, 68): Body length 1.6-2.0 mm, wing length 1.9-2.2 mm. Similar to male except as follows: Legs (Fig. 60): With shorter setae. Hindleg: With tibia slender, not enlarged apically; tarsomere 1 not enlarged. Wing (Fig. 30): Slightly narrower. Anal lobe smaller. Abdomen (Figs 60, 68): Tergites and sternites with short setae. Terminalia (Figs 56-58): Tergite 8 separated from sternite 8 anterolaterally. Spermatheca spherical (Fig. 58). Cercus about $2 \mathrm{X}$ width of syntergite $9+10$.

Distribution and seasonal occurrence. Microphor obscurus is a widespread transcontinental species, known across Canada, including the Northwest Territories in the north to southern California, southern Utah, Tennessee and North Carolina in the south (Fig. 78). Adults have been collected from early April to early August.

Remarks. Females of M. obscurus have been observed feeding on insects trapped in spider webs (Downes \& Smith 1969). Flower visitation records for this species (Figs 1-2) are listed in Table 1.

\section{Genus Schistostoma Becker}

(Figs 5-8, 10-16, 79-253)

Schistostoma Becker, 1902: 46. Type species: Schistostoma eremita Becker, 1902, by monotypy.

Diagnosis. Schistostoma is distinguished from other known microphorine genera by the following combination of features: eyes usually bare (e.g., Figs 81, 82, 118-121, 160-163, 243); wing with cell dm present and emitting 3 branches, anal lobe well-developed and right-angled (Figs 85-90, 169-178); hypopygium with medial hypandrial prolongation present bearing pair of apical setae (e.g., Figs 109, 127, 140, 179, 195, 220, 221, 246), phallic process absent (Figs 93, 134, 190), right ventral postgonite lobe not hook-shaped (Figs 94, 138, 191, 247), hypandrium with single large seta per side (e.g., Figs 140, 141, 179, 180, 246, 247) or irregular series of 3-7 per side (e.g., Figs 91, 92); female abdomen with 6 or 7 exposed segments (e.g., Figs 125, 165), i.e., with broad telescoping terminalia retractable into segment 6 or 7 (sometimes partially into segment 5); female terminalia with syntergite 9+10 divided medially into hemitergites bearing 3-4 acanthophorite setae or spines per side, cerci relatively short, curved and claw-like or straight (Figs 95-101).

Redescription. Male: Body length 1.6-3.1 mm, wing length 1.7-3.1 mm. Head (Figs 81, 107, 118, 119, 160, $161,184,193,223,224)$ : Holoptic with compound eyes contiguous for most of length of frons, remainder of head capsule dark grey, grey, or silvery-grey with black, brown, pale or bright white setae. Eyes usually bare and without ommatrichia, sparse ommatrichia present in the Old World S. albopilosum species group (Shamshev 2020); dorsal ommatidia larger than ventral ommatidia, not always separated by line of demarcation. Frons bare, small (mostly obliterated by eyes), subtriangular, just above antennae. Ocellar tubercle with 2-3 pairs of proclinate setae, anterior pair longer, middle pair (if present) shortest, posterior pair inserted at posterior margin. Occiput mostly clothed with setae, sparse in upper part, except for postoculars. Gena and parafacial narrow to strongly projected along lower eye margin. Face plus clypeus, when visible, grey to dark grey pruinose. Antenna brown to black (rarely scape and 
pedicel yellow in some Asiatic species) with pedicel ringed with circlet of black or white subapical setae; postpedicel elongate subtriangular to elongate conical, short to moderately long, pubescent with microtrichia; stylus of variable length. Palpus elongate ovate, bearing scattered setae. Proboscis much less than half as long as head height to subequal head height, directed mainly forward. Thorax (Figs 79, 81, 105, 107, 116, 118, 119, 157, 160, 183, 192, 193, 211, 222-224, 239): Black, brown, grey, or silvery-grey, with black or bright white setae. Mesoscutum moderately to strongly arched, prescutellar depression present. Proepisternum with 1 to several clustered setae. Postpronotal lobe with 1 long seta and 1-4 shorter anterior setae. Acrostichal setae biserial; setae arranged on each side with: dorsocentrals uniserial or rarely irregularly biserial, posteriormost dorsocentrals strong and widely separated; 1-8 intra-alar setae; 2-4 supra-alar setae; $2-4$ strong notopleural setae with $0-5$ shorter setae of variable number and strength; 1 strong postalar seta. Scutellum with posterior margin rounded, with 1-4 pairs of setae. Mesopleuron bare. Halter dark to pale. Legs (Figs 79, 105, 116, 157-159, 164, 167, 183-185, 192, 200-203, 213, 215-216, 225-226, 239): Variable in colour from blackish-brown to pale brown, to mainly pale yellow, or grey, with setae usually predominantly dark (usually black, sometimes brown, with or without some pale setae), or entirely bright white. Tarsal claws, pulvilli and empodium normally developed on all legs. Foreleg: Coxa with long to moderately long setae on anterior surface. Trochanter with a few small setae and/or setulae. Femur subequal to slightly shorter than tibia, variously setose. Tibia slender, with short setae, or sometimes with series of long erect posterior or posterodorsal setae up to $3 \mathrm{X}$ longer than tibia width ( $S$. isommatum group and some species of $S$. ravidum group, Fig. 225), anterior surface usually with pale (usually dense) setulae, apex with anterior comb-like row of close-set setulae. Tarsus subequal to slightly shorter than tibia, usually with short setae, tarsomeres 1-4 decreasing in length apically, tarsomere 5 subequal in length to tarsomere 2 or 3. Midleg: Unmodified or variously modified in form and chaetotaxy (S. ravidum group, Figs 158, 159, 164, 167, 185, 200-203, 215, 216, 226). Coxa with relatively long setae on anterior surface, sometimes with 1-3 posterior setae (S. isommatus group). Trochanter with a few longer and shorter setae, sometimes with prominent spine-like setal pair on distal edge of medial surface (S. ravidum group, Figs 158, 159). Femur slightly shorter to slightly longer than tibia, variously setose, sometimes with 2-6 long, often modified posteroventral setae (S. ravidum group, Figs 164, 167, 185, 200, 202, 203, 215, 216). Tibia slender with mainly short setae, or sometimes distorted with swelling just beyond middle and specialized setae (S. ravidum group, Figs 164, 167, 185, 200-203, 215, 216, 226). Tarsus slightly shorter to distinctly longer than tibia (up to $1.5 \mathrm{X}$ longer), with short setae, tarsomere 1 sometimes modified and/or with specialized setae, tarsomeres 1-4 decreasing in length apically, tarsomere 5 usually subequal in length to tarsomere 2 or 3 . Hindleg: Coxa with $2-5$ relatively long setae on outer surface and a few setae on anterior surface, sometimes with 1 seta on posterior surface (S. atratum group). Trochanter with a few longer and shorter setae. Femur subequal to somewhat longer than tibia, variously setose, often with series of longer dorsal and anteroventral/ventral setae, anterior surface with short setae, posterior surface with short fine setae, sparse setulae, or mainly bare. Tibia slender or enlarged apically, variously setose, often with longer dorsal setae, anterior surface usually with short setae, posterior surface usually with dense setulae on apical portion, apex with posterior comb-like row of close-set setulae. Tarsus slightly shorter to slightly longer than tibia, usually with short setae, tarsomere 1 sometimes modified (enlarged and/or with long dorsal setae, or with basal notch), tarsomere 1 (and usually 2) with apical comb-like row of close-set setulae posteroventrally, tarsomeres 1-4 decreasing in length apically, tarsomere 5 subequal in length to tarsomere 2 or 3 . Wing (Figs 85, 87-89, 169, 171, 173-178): Hyaline or with grey-brown tinge, veins usually dark brown, rarely yellowish (some males of $S$. borkenti sp. nov., Fig. 87), about 2.2-2.5X longer than wide. Pterostigma usually present, sometimes weakly developed (e.g., S. michaeli sp. nov., S. strigilifer), membrane entirely covered with minute microtrichia. Anal lobe strongly developed, right-angled, with proximal margin convex to straight, alula absent. Costa circumambient. Extreme anterior base of costa with several strong setae, distal seta usually longer. Anterior costal section from humeral crossvein to $\mathrm{R}_{2+3}$ bearing short spine-like setae (becoming shorter distally), posterior part of costa beyond $\mathrm{R}_{2+3}$ with fine setae, setae becoming longer and curved from middle of anal lobe up to wing base. Posterior margin of wing usually evenly curved, sometimes modified (S. cirripes, Fig. 171, S. michaeli sp. nov., Fig. 173). Longitudinal veins (except $\mathrm{CuA}+\mathrm{CuP}$ ) complete, reaching wing margin. Sc usually strong apically, sometimes faint, wing membrane often infuscate between $S c$ and $R_{1} \cdot R_{1}$ straight or with weak posterior curve in distal part, reaching costa beyond middle of wing, beyond base of $\mathrm{M}_{2}$. Base of Rs originating opposite humeral crossvein. $\mathrm{R}_{2+3}$ and $\mathrm{R}_{4+5}$ evenly diverging to apex with cell $\mathrm{r}_{2+3}$ subtriangular (S. atratum species group, Figs $85,87,88$ ), or with $\mathrm{R}_{2+3}$ and $\mathrm{R}_{4+5}$ parallel in middle part and diverging near apex with cell $\mathrm{r}_{2+3}$ compressed in middle part and flared at apex (e.g., Fig. 89). $\mathrm{R}_{4+5}$ straight in basal portion with gradual posterior curve to apex with cell $\mathrm{r}_{4+5}$ 
subtriangular and evenly narrowed in basal part ( $S$. atratum species group, Figs $85,87,88$ ), or $\mathrm{R}_{4+5}$ sinuous usually with more pronounced posterior curve to apex with cell $\mathrm{r}_{4+5}$ slightly to distinctly compressed in basal part (e.g., Fig. 89). $\mathrm{R}_{4+5}$ and $\mathrm{M}_{1}$ subparallel beyond cell $\mathrm{dm}$ (S. atratum species group, Figs 85, 87, 88) or diverging (e.g., Fig. 89). $M_{1}$ and $M_{2}$ diverging beyond cell dm. $M_{2}$ and $M_{4}$ subparallel or diverging beyond cell dm. Costal section $M_{1}-M_{2}$ subequal or slightly longer than $\mathrm{M}_{2}-\mathrm{M}_{4}$, rarely shorter (S. cirripes, Fig. 171). Short r-m crossvein present in basal portion of wing, distal to base of $\mathrm{R}_{4+5}$. Crossvein bm-m complete, vein sometimes faint near connection point. Cell $\mathrm{dm}$ present, closed by base of $\mathrm{M}_{2}$ and crossvein $\mathrm{dm}-\mathrm{m}$. Cell $\mathrm{dm}$ moderately-sized, usually extended to around middle of wing (short in S. michaeli sp. nov., Fig. 173) with distal section of vein $\mathrm{M}_{1}$ (beyond base of $\mathrm{M}_{2}$ ) longer than preceding section (between $\mathrm{r}-\mathrm{m}$ and base of $\mathrm{M}_{2}$ ). Crossvein $\mathrm{dm}-\mathrm{m}$ usually broadly curved and convergent with $\mathrm{M}_{1}$ distally (with cell $\mathrm{dm}$ tapered distally, e.g., Fig. 169), sometimes strongly bent at base and running parallel with $\mathrm{M}_{1}$ distally (with cell dm narrow and straight distally, S. cirripes, Fig. 171). Cells br, bm and cua in basal fourth of wing. Cells bm and cua broader than br. Cell cua closed, rounded apically with $\mathrm{CuA}$ curved. Vein $\mathrm{CuA}+\mathrm{CuP}$ not substantially developed, present as a fold or trace, if visible. Calypter with fine setae. Abdomen (Figs 83, 108, 122-124, 126-131, 166, 168, 186, 194, 204, 205, 214, 227, 240, 241, 244, 245): Variable in colour from black to brown, greyish-black, greyish-brown, blueish-grey, goldish-grey, or silvery-grey, with setae usually predominantly dark (usually black, sometimes brown, with or without some pale setae), predominantly pale, or entirely bright white. Subconical to tubular with pregenitalic segments narrowed. Abdominal muscle plaques usually visible on lateral margins of tergites 2-5 and often tergite 6; tergite and sternite 2 with transverse band of muscle plaques. Segment 1 short, sternite indistinct. Segment 2 slightly longer than segments 3-5. Segment 6 usually somewhat narrowed, often concave on right side where hypopygium sits when at rest, sternite often tilted dorsally. Segment 7 narrow and tubular, projecting posteroventrally. Tergites $1-5$ and often tergite 6 (S. atratum and S. ravidum species groups) clothed with long, dense setae laterally and short, sparse setae dorsomedially (i.e., setae only along posterior tergal margins); tergite 6 alternately with only single row of setae along posterior margin (S. isommatum species group), or mainly bare (S. yakimense species group). Sternite 2 unmodified, with normal setae; sternites 3-6 unmodified, with normal setae, or modified and/or bearing specialized setae. Tergite 7 usually bare, rarely with a few tiny setae; sternite 7 bare, or with a few (usually short) setae. Sternite 8 convex, with long setae on distal part, basal part usually bare. Tergite 8 small, subrectangular, subquadrate or irregular in shape, usually with 2 posterolateral setae, or bare. Hypopygium (Figs 91-94, 109-113, 132-152, 179-182, 187-191, 195-198, 206-210, 217-221, 229-232, 246-251): Lateroflexed to right; inverted with posterior end directed anteriorly to slightly anterodorsally or slightly anteroventrally; small to large (about $1 / 4-1 / 2$ length of abdomen), with posterior end free or partially enclosed by modified pregenitalic sternites; asymmetrical; hypopygial foramen not formed. Epandrium with left and right lamellae undivided, narrowly connected behind cerci, asymmetrical, with single-lobed or multilobed surstylus projecting distally. Hypandrium with basal part convex bearing a single large seta on each side, or sometimes with an irregular series of 3-7 setae on each side (S. atratum species group, e.g., Figs 91-94); apicodorsal part usually with asymmetrical left and right hypandrial lobes; apicoventral part with unpaired medial hypandrial prolongation bearing pair of apical setae. Postgonite flanking phallus on both sides, continuous medially at base of postgonite apodeme and cradling phallus; dorsal postgonite lobe variable, with left and right lobes large symmetrical and elongate (S. isommatum species group, e.g., Figs 134, 138), with left and right lobes fused to form unpaired medial lobe (S. yakimense species group, e.g., Figs 241, 245-247), or not substantially developed (S. atratum and $S$. ravidum species groups, e.g., Figs 93, 190); ventral postgonite lobe variously developed, left and right lobes asymmetrical; postgonite apodeme projecting anteriorly, variously developed. Phallus tubular, shape, length and thickness variable, phallic process absent. Ejaculatory apodeme keel-like, variously developed. Hypoproct not substantially developed. Cerci symmetrical, each cercus usually with convex hump-like base bearing several setae and narrowed apex of varying length (short and stubby to long and digitiform) bearing several setae.

Female: Body length: 1.7-3.0 mm, wing length 1.8-3.2 mm. Similar to male except as follows: Head (Figs 82, 120, 121, 162, 163, 199, 212, 228, 243): Dichoptic; eyes smaller; dorsal and ventral ommatidia similar in size. Frons subrectangular (broader than high) to subquadrate, distance between antennae and ocellar tubercle shorter. Gena and parafacial narrow to strongly projected along lower eye margin. Legs (Figs 80, 106, 117, 242): With shorter, unspecialized setae and lacking secondary sexual characters of males. Thorax (Figs 80, 82, 106, 117, 120, 121, 162, 163, 212, 228, 242, 243): Mesoscutum with slightly less pronounced arch. Wing (Figs 86, 90, 170, 172): Pterostigma sometimes absent. Anal lobe usually smaller. Abdomen (Figs 80, 84, 106, 117, 125, 165, 242): Subconical, tapered posteriorly, with 6 or 7 exposed (or partially exposed) segments, i.e., with broad telescoping terminalia retractable 

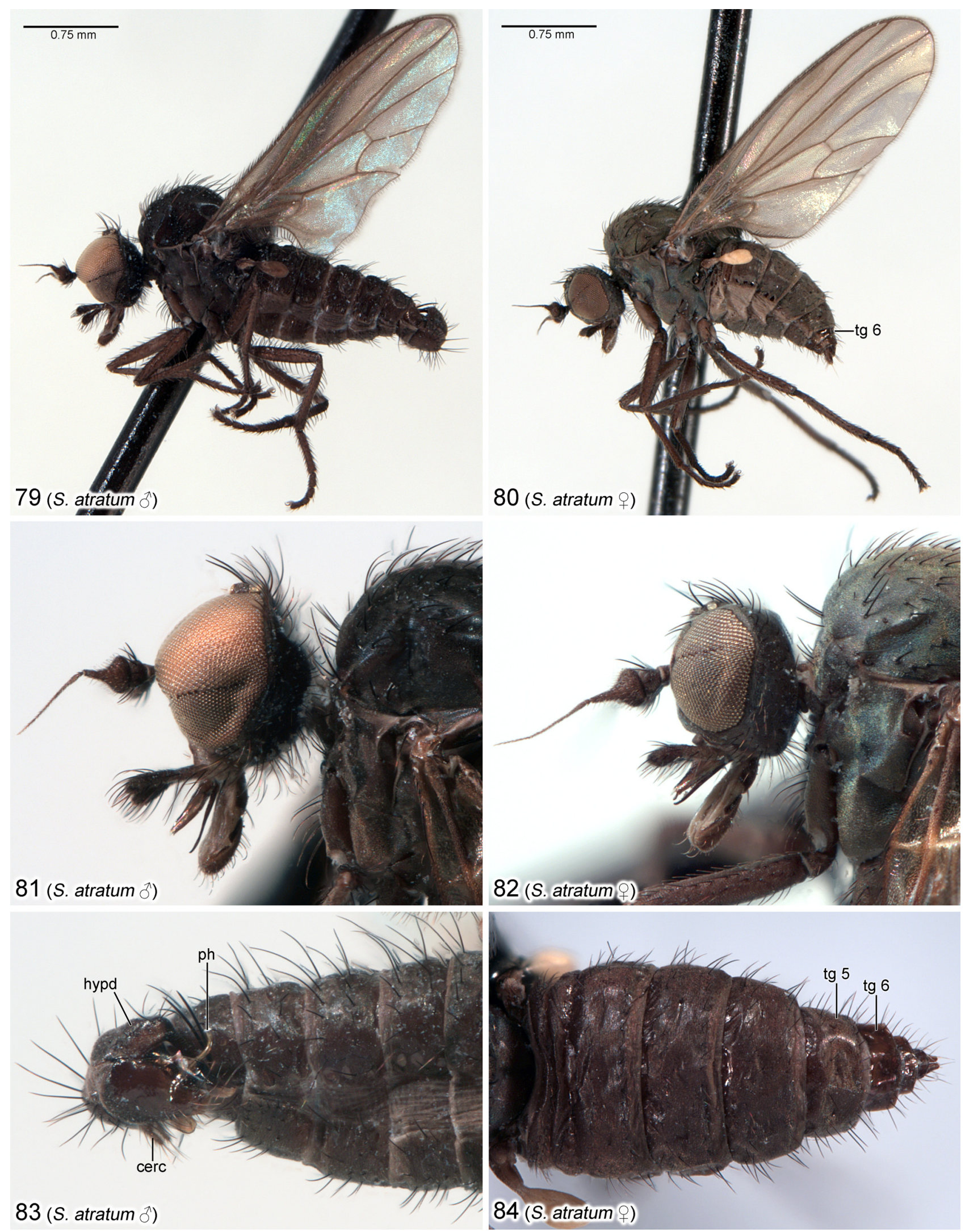

FIGURES 79-84. Habitus, head and abdomen of Schistostoma atratum (Coquillett) comb. nov. 79. Male habitus. 80. Female habitus. 81. Male head and anterior portion of thorax, lateral view. 82. Female head and anterior portion of thorax, lateral view. 83. Male abdomen and terminalia, right lateral view. 84. Female abdomen, dorsal view. Specimens from: Mt Washington area, British Columbia (Figs 79-84). Abbreviations: cerc—cercus; hypd—hypandrium; ph—phallus; tg—tergite. 
into segment 6 or 7 , or sometimes partially retractable into segment five. Tergites and sternites $2-5$ setose, setae shorter and usually more sparse. Terminalia (Figs 95-104): Segment 6 usually without longitudinal sclerotized band laterally between tergite and sternite (present in some S. atratum). Segment 7 usually with longitudinal sclerotized band laterally between tergite and sternite. Segments 6 and 7 with tergites and sternites usually subrectangular (wider than long) to subquadrate, with or without retractable band-like posterior sclerite extensions on each side, with setae at least on posterior margin (i.e., before retractable band-like posterior sclerite extensions, if present); tergite 7 sometimes with anterior end emarginate (S. ravidum species group and S. yakimense species group); sternite 7 sometimes with posterior end emarginate (S. yakimense species group). Segment 8 mainly bare. Tergite 8 with anterior end deeply emarginate, undivided or divided (desclerotized) medially, articulated with (Fig. 96), or fused to (Figs 98, 100) sternite 8 anterolaterally; sternite 8 divided (desclerotized) medially. Sternite 9 usually desclerotized and inconspicuous, sometimes sclerotized ( $S$. atratum species group and S. yakimense species group, Figs 95, 96, 101). Spermatheca (Figs 102-104) developed as a darkened spherical to ovoid terminal expansion of the spermathecal duct. Syntergite 9+10 divided medially into hemitergites bearing 3-4 acanthophorite setae (Figs 95-98, S. atratum species group and S. isommatum species group) or spines (Figs 99-101, S. ravidum species group and $S$. yakimense species group) per side. Sternite 10 variable, sclerotized to entirely membranous, with several setae and setulae. Cercus relatively short (compared to Microphor), curved and claw-like or straight.

Immatures: Nothing is known of the eggs, larvae, or pupae.
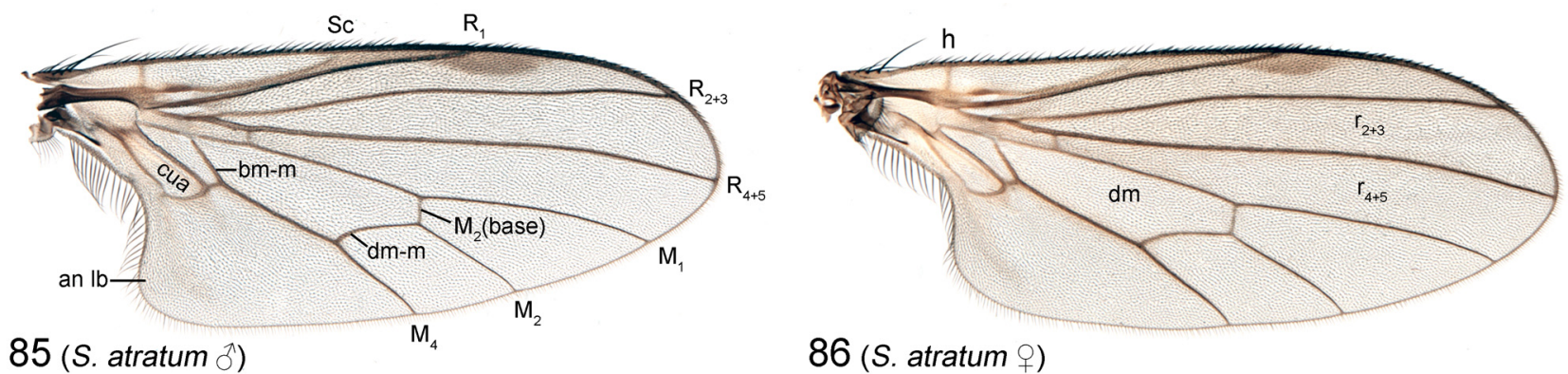

86 (S. atratum + )

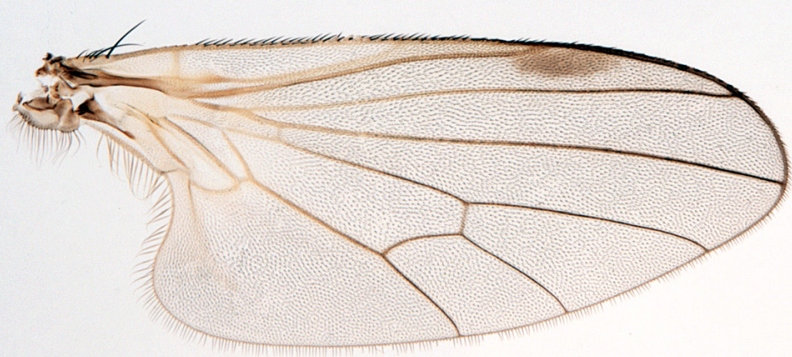

87 (S. borkenti $\left.{ }^{\top}\right)$

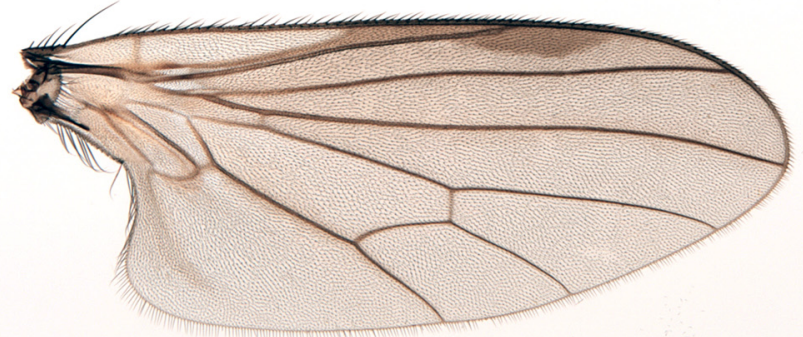

$88\left(\right.$ S. chloeae $\left.{ }^{\lambda}\right)$

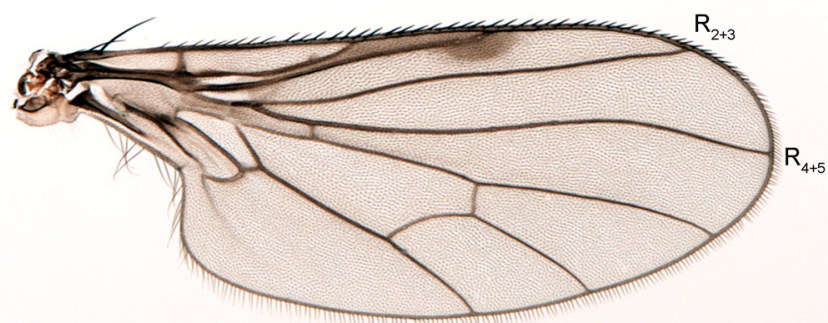

89 (S. evisceratum ふึ)

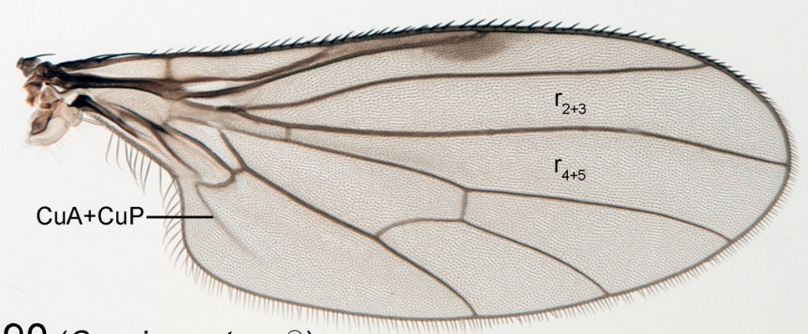

90 (S. evisceratum ○)

FIGURES 85-90. Wings of Nearctic Schistostoma. 85. S. atratum (Coquillett) comb. nov., male. 86. S. atratum (Coquillett) comb. nov., female. 87. S. borkenti sp. nov., male. 88. S. chloeae sp. nov., male. 89. S. evisceratum (Melander) comb. nov., male. 90. S. evisceratum (Melander) comb. nov., female. Specimens from: Bella Coola, British Columbia (Figs 85, 86); Sagehen Creek, California (Fig. 87); Olympic NP, Washington (Fig. 88); Cowichan Lake, British Columbia (Figs 89, 90). Abbreviations: an $\mathrm{lb}$ - anal lobe; bm-m — basal medial crossvein; cua — anterior cubital (=anal) cell; $\mathrm{CuA}+\mathrm{CuP}$ — anterior branch of cubital vein + posterior branch of cubital vein; $\mathrm{dm}$ — discal medial cell; dm-m—discal medial crossvein; $\mathrm{h}$ — humeral crossvein; $\mathrm{M}_{1}, \mathrm{M}_{2}$, $\mathrm{M}_{4}$ - medial veins; $\mathrm{R}_{1}, \mathrm{R}_{2+3}, \mathrm{R}_{4+5}$-radial veins; $\mathrm{r}_{2+3}, \mathrm{r}_{4+5}$-radial cells; $\mathrm{Sc}$ - subcostal vein. 
Included species, distribution and ecology. The genus now comprises at least 50 known species including 16 described and several undescribed species from the Palaearctic Region (Chvála 1987; Shamshev 1991, 1993, 2021; I.V. Shamshev pers. comm. 2021), one described species from the Oriental Region (Shamshev 2020), four described and one undescribed species from the Afrotropical Region (Chvála 1991; Shamshev \& Sinclair 2006; Gatt 2014; Grichanov \& Brooks 2017) and 28 described species from the Nearctic Region (including 17 new species described herein). Adults have been repeatedly reported in the Palaearctic from dry xeric habitats, including deserts, and sandy or saline coastlines (Chvála 1987); however, some undescribed Middle Asiatic species are known from mountain localities up to $4300 \mathrm{~m}$ (I.V. Shamshev pers. comm. 2021). The South African species inhabit small mountain headwater streams or well-vegetated ephemeral watercourses with reliable seasonal rainfall (Chvála 1991; Shamshev \& Sinclair 2006). Nearctic species are generally found in riparian habitats (Figs 10-15), but some species occur in drier areas (Fig. 16). The Nearctic species are classified into four distinct species groups.

Nothing has been published on the biology or immature stages of Schistostoma (Chvála 1987). Adults are thought to be predaceous, but are commonly found on flowers and leaves (Figs 5-6). Males of S. armipes (Melander) have been observed perching on sunlit leaves of thimbleberry (Rubus parviflorus Nuttall) close to females who were seen feeding on pollen. Males of $S$. armipes when at rest, held their wings at a slight angle from the body, giving off a distinctive reddish reflection (Fig. 8) compared with females who held their wings folded over their bodies. Numerous females of $S$. armipes were observed feeding on thimbleberry pollen (Fig. 7), whereas males were not seen feeding. Pollen grains have also been found in the gut of dissected specimens of S. armipes (female), S. arnaudi sp. nov. (female), S. michaeli sp. nov. (male and female), S. ravidum comb. nov. (male and female), S. robustum comb. nov. (female), S. rudei sp. nov. (female), S. strigilifer comb. nov. (female) and S. sycophantor (female). A complete list of flower visitation records for species of Schistostoma is given in Table 1, mostly derived from specimens studied in this project.

\section{Schistostoma atratum species group}

(Figs 10, 14, 79-88, 91-96, 102, 105-115)

Diagnosis. Setae of body and legs black, body blackish-brown to grey (abdomen sometimes partially or mostly yellow), legs blackish-brown to yellow (Figs 79, 80, 105, 106); male compound eye with demarcation line between larger dorsal and smaller ventral ommatidia (Figs 81, 107); female head with gena and parafacial narrow along lower eye margin (Fig. 82); antenna with stylus about 1.5X longer than postpedicel (Fig. 82); thorax with mesonotal setae widely spaced and conspicuous; acrostichals biserial, dorsocentrals arranged in a single row per side or irregularly biserial; scutellum with 2-4 setae per side; male midleg unmodified, trochanter without medial spine-like setal pair; wing (Figs 85-88) with cells $\mathrm{r}_{2+3}$ and $\mathrm{r}_{4+5}$ evenly subtriangular, cell $\mathrm{dm}$ moderately-sized; male pregenitalic abdominal sternites unmodified (Figs 83, 108); hypopygium (Figs 83, 91-94, 108-113) small and free, epandrium without specialized setae adjacent to cercus, surstylus single-lobed, left surstylus ventrally curved and beak-like, hypandrium with 3-7 setae per side, medial hypandrial prolongation curved to right with apical pair of long thick parallel setae, ventral postgonite lobes asymmetrical, right lobe longer and larger with pair of circular pores near basal (internal) part, phallus gently curved with apex projecting ventrally, hypoproct not substantially developed; female terminalia (Figs 80, 84, 106) retracted into segment 6 or sometimes partially into 5 (i.e., with 6 exposed abdominal segments), segment 6 concolorous with anterior abdominal segment, syntergite $9+10$ with acanthophorite setae, cercus subtriangular and pointed apically (Figs 95, 96).

Remarks. This species group includes $S$. atratum comb. nov., S. borkenti sp. nov., S. chloeae sp. nov. and $S$. lillyae sp. nov.

\section{Schistostoma atratum (Coquillett) comb. nov.}

(Figs 10, 79-86, 91-96, 102, 114)

Microphorus atratus Coquillett, 1900: 412.

Holoclera atrata (Coquillett, 1900): Melander, 1902: 333.

Anthalia atratus (Coquillett, 1900): Coquillett, 1903: 263. 
Type material examined. HOLOTYPE, ð̊ collected from Kodiak [ $c$ a $\left.57^{\circ} 47^{\prime} \mathrm{N} 152^{\circ} 24^{\prime} \mathrm{E}\right]$, Alaska, USA, 20.vii.1899, by T. Kincaid, labelled: “Kadiak[sic], Alaska/ July 20'99”; "Harriman Expedition'99/ T. Kincaid, Collector”; “Type/ No5218/ U.S.N.M. [red label]"; "Microphorus/atratus/Coq."; "Anthalia/ atratus/ Coq."; "published as/ Microphous/ atratus/ d.L. Knutson'68 [red label]" (USNM).

Other material examined. CANADA: British Columbia: $14 \mathrm{~km} \mathrm{SW}$ Bella Coola [ca 52 $2^{\circ} 17^{\prime} \mathrm{N} 126^{\circ} 52^{\prime} \mathrm{W}$ ], 10-11.vii.1992, CD1427, A. Borkent (7仓ิ, 5ㅇ, CNC); same data except, CNC1155609 (1へ̂, CNC); Banks Is.,

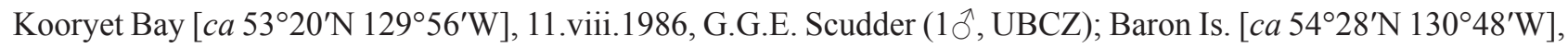
28.vii.1987, central N side grassy estuary, C.S. Guppy (2ᄋ, RBCM); Dundas Is., Brundige Inlet delta at head [ca

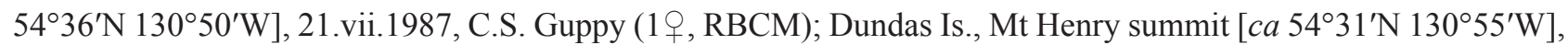
open and scrub, 1450-1520 ft, 27.vii.1987, C.S. Guppy (10̂, RBCM); Haida Gwaii (Queen Charlotte Is.), Graham Is.,

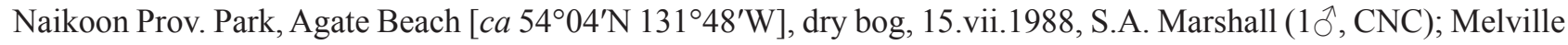
Is. [ca $50^{\circ} 08^{\prime} \mathrm{N} 124^{\circ} 43^{\prime} \mathrm{W}$ ], Knee Hill, $2 \mathrm{~km}$ E in bog \& rock outcrop, 27.vii.1987, C.S. Guppy (2q, RBCM); Mt Cheam, $49^{\circ} 10^{\prime} 28.32^{\prime \prime} \mathrm{N} 121^{\circ} 40^{\prime} 52.80^{\prime \prime} \mathrm{W}, 1500 \mathrm{~m}$, meadow below summit, 8.viii.2001, Gillespie, Goulet \& Klassen,

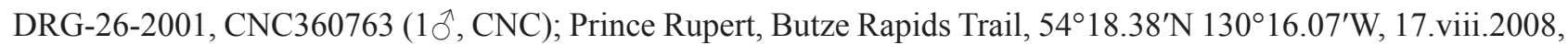

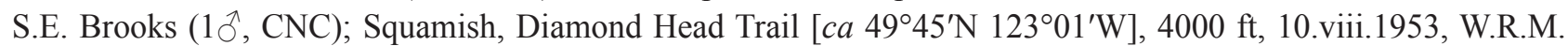
Mason (1へ̂, CNC); same data except, $3200 \mathrm{ft}$, 25.viii.1953 (1ㅇ, CNC); same data except, $4600 \mathrm{ft}$, 28.viii.1953 (4`, $3 \circ$, CNC); Vancouver Is., Brooks Peninsula, Cassiope Lake E ridge, $50^{\circ} 10^{\prime} \mathrm{N} 127^{\circ} 45^{\prime} \mathrm{W}, 2300 \mathrm{ft}$, 31.vii.1981, BCPM Brooks Pen. Project, R.A. Cannings, S.G. Cannings (1へ̄, 1 ,, RBCM); Vancouver Is., Courtenay [ca $\left.49^{\circ} 41^{\prime} \mathrm{N} 124^{\circ} 59^{\prime} \mathrm{W}\right]$, 17.vii.1991, CD1359, A. Borkent (11 $0^{\top}, 3$,, CNC); Vancouver Is., Mt Washington area, trail to Battleship Lake, $1150 \mathrm{~m}, 49^{\circ} 43.90^{\prime} \mathrm{N} 125^{\circ} 18.84^{\prime} \mathrm{W}$, 13.viii.2008, J.M. Cumming (19ð, 40 ๆ, CNC); same data except, CNC1155611 (1ठ, CNC); same data except, CNC1155708 (1ㅇ, CNC); same data except, S.E. Brooks

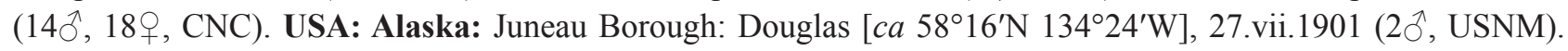

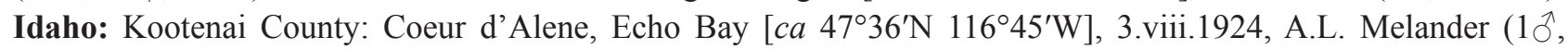
USNM). USA: Oregon: Clackamas County: Mt Hood NF, Still Creek Campground, 45 $17.703^{\prime} \mathrm{N} 121^{\circ} 44.313^{\prime} \mathrm{W}$, 1150 m, 9.vii.2013, B.J. Sinclair (1ð, 11, , CNC). Washington: Clallam County: Olympic NP, meadow below Sunrise Ridge, Mt Angeles [ $c a 4^{\circ} 58^{\prime} \mathrm{N} 123^{\circ} 29^{\prime} \mathrm{W}$ ], 1550 m, 22.vii.1978, D.D. Wilder (10, 1ㅇ, CAS); same data except, 24.vii.1978 (6今, 39, CAS); Lewis County: Mt Rainier NP, along Sunbeam Creek above Louise Lake [ca $\left.46^{\circ} 46^{\prime} \mathrm{N} 121^{\circ} 43^{\prime} \mathrm{W}\right], 1520 \mathrm{~m}$, 4.viii.1977, D.D. Wilder $\left(75 \hat{0}^{\wedge}, 109\right.$,, CAS); Pierce County: Mt Rainier NP, Alta Vista

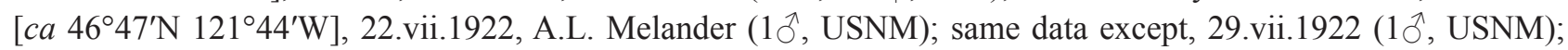

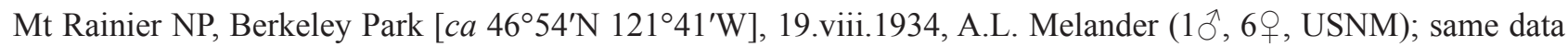
except, 23.viii.1934 (2 $\hat{O}^{\lambda}$ USNM); same data except, 27.viii.1934 (2ㅇ, USNM); Mt Rainier NP, Chinook Pass [ca $\left.46^{\circ} 52^{\prime} \mathrm{N} 121^{\circ} 31^{\prime} \mathrm{W}\right]$, 18.viii.1934, A.L. Melander (6ㅇ, USNM); Mt Rainier NP, Comet Falls Trail above Van Trump Creek [ $c a 6^{\circ} 47^{\prime} \mathrm{N} 12^{\circ} 46^{\prime} \mathrm{W}$ ], $4500 \mathrm{ft}$, 13.viii.1977, sweeping, W.J. Turner (1 $\partial^{\lambda}$, WJTC); Mt Rainier NP, Fairfax

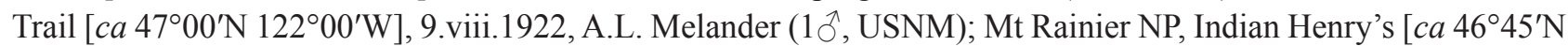
$\left.121^{\circ} 48^{\prime} \mathrm{W}\right]$, 2.viii.1922, A.L. Melander (51 ${ }^{\AA}, 19$, USNM); same data except, 8.viii.1922 (10, USNM); Mt Rainier

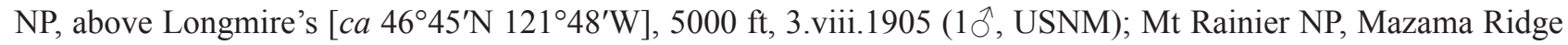
[ca $46^{\circ} 47^{\prime} \mathrm{N} 121^{\circ} 43^{\prime} \mathrm{W}$ ], 23.vii.1922, A.L. Melander (2 ${ }^{\top}$, USNM); Mt Rainier NP, Paradise Park [ca 46 ${ }^{\circ} 47^{\prime} \mathrm{N}$ $121^{\circ} 44^{\prime} \mathrm{W}$ ], viii.1917, A.L. Melander (6 $0^{\wedge}$ [including 1 paratype of M. tacomae Melander, 1940], 39 , USNM); Mt Rainier NP, Paradise Park, Edith Creek [ $c a 4^{\circ} 47^{\prime} \mathrm{N} 12^{\circ} 44^{\prime} \mathrm{W}$ ], 1650 m, 2.viii.1977, D.D. Wilder (5 $\partial^{\lambda}$, CAS); Mt Rainier NP, Paradise River nr Paradise [ $c a 4^{\circ} 47^{\prime} \mathrm{N} 11^{\circ} 44^{\prime} \mathrm{W}$ ], 20.viii.1977, swept from moist meadow seep, N.E.

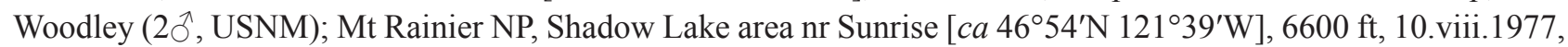
R.S. Zack (5ㅅ, 14우, WSU); Mt Rainier NP, Shadow Lake area nr Sunrise Campground [ $c a 46^{\circ} 54^{\prime} \mathrm{N} 121^{\circ} 39^{\prime} \mathrm{W}$ ], 6000-6500 ft, 21.viii.1973, Malaise trap with dry ice, W.J. Turner (19, WJTC); Mt Rainier NP, Sluiskin [ca 46 $47^{\circ} \mathrm{N}$ $121^{\circ} 43^{\prime} \mathrm{W}$ ], 28.vii.1922, A.L. Melander (5’, 1 ${ }^{\circ}$, USNM); Mt Rainier NP, Summerland [ca $46^{\circ} 53^{\prime} \mathrm{N} 121^{\circ} 36^{\prime} \mathrm{W}$ ],

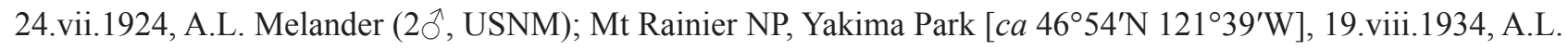
Melander (11 $\hat{\jmath}, 17$, , USNM); same data except, 14.viii.1940 (3 $\partial^{\lambda}$, USNM); Snohomish County: Big Four Mountain [ca $\left.48^{\circ} 03^{\prime} \mathrm{N} 121^{\circ} 30^{\prime} \mathrm{W}\right]$, 5.vii.1924, A.L. Melander (2^, USNM).

Diagnosis. This species can be distinguished from other members of the $S$. atratum species group by its dark body, legs and wing veins (Figs 79-86), narrowly tapered left surstylus (Fig. 91), and long subequal pair of apical setae on the medial hypandrial prolongation, as indicated in couplets 32-34 of the key.

Redescription. Male (Figs 79, 81, 83, 85, 91-94): Body length 2.4-3.1 mm, wing length 2.6-3.1 mm. Head (Fig. 81): Ocellar tubercle with 3 pairs of black proclinate setae, anterior and posterior pair subequal in length, 
middle pair shorter, posterior pair inserted at posterior margin. Occiput dark greyish pruinose, mostly clothed with black setae, sparse in upper part, except for postoculars. Gena and parafacial narrow along lower eye margin. Antenna dark brown; postpedicel elongate subtriangular with apical $1 / 2$ narrow and digitiform; stylus about $1.5 \mathrm{X}$ length of postpedicel. Palpus dark brown to black, elongate ovate, slightly longer than length of labrum, pubescent with microtrichia and bearing scattered black setulae. Proboscis dark brown, moderately long, approximately $2 / 3$ as long as head height, directed forward. Thorax (Figs 79, 81): Mesonotum greyish-brown to blackish-brown. Proepisternum with patch of setae. Mesonotal setae black, relatively long with dorsocentrals arranged in single row per side or irregularly biserial. Notopleuron with 3-4 strong setae. Scutellum with 2-3 pairs of setae, middle pair strong, outer pair usually weaker. Mesopleuron greyish-brown to blackish-brown. Halter darkish-brown to pale. Legs (Fig. 79): Entirely blackish-brown, with black setae. Foreleg: Coxa with several setae on anterior surface. Femur subequal in length to tibia, posterior surface with series of longer posterodorsal and posteroventral setae (subequal to slightly longer than femur width) and shorter setae along middle, anterior surface with short setae and series of slightly longer anteroventral setae in basal third. Tibia slender, with short setae. Tarsus subequal in length to tibia, with short setae, tarsomere 1 subequal to combined length of tarsomeres $2-4$, with ventral setae somewhat stouter, tarsomeres 2-4 decreasing in length apically, tarsomere 5 subequal in length to tarsomere 3. Midleg: Coxa with several setae on anterior surface. Femur subequal in length to tibia, with series of longer posteroventral setae (subequal to slightly longer than femur width) and shorter setae on posterior and anterior surface. Tibia slender, with short setae, dorsal setae longer (subequal to slightly longer than tibia width), with slightly longer anterodorsal/ posterodorsal pair of setae in basal part, with 1 stout preapical ventral seta. Tarsus slightly longer than tibia, with short setae, tarsomere 1 subequal to combined length of tarsomeres 2-5, tarsomeres 2-4 decreasing in length apically, tarsomere 5 subequal in length to tarsomere 3. Hindleg: Coxa with 2-3 setae on outer surface, 2-3 setae near apex of anterior surface and 1 seta on posterior surface. Femur subequal in length to tibia, with series of longer dorsal and anteroventral setae (slightly longer than femur width), anterior surface with short setae on upper half, posterior surface with short fine setae. Tibia slender, with series of longer dorsal setae (longer than tibia width), otherwise with short setae. Tarsus subequal in length to tibia, with short setae, tarsomere 1 slightly shorter than combined length of tarsomeres 2-5, tarsomeres 2-4 decreasing in length apically, tarsomere 5 subequal in length to tarsomere 2. Wing (Fig. 85): With slight grey-brown tinge, veins dark brown. Pterostigma well-developed. Anal lobe with proximal margin convex. $\mathrm{R}_{2+3}$ and $\mathrm{R}_{4+5}$ evenly diverging to apex with cell $\mathrm{r}_{2+3}$ subtriangular. $\mathrm{R}_{4+5}$ straight in basal portion with gradual posterior curve to apex with cell $\mathrm{r}_{4+5}$ subtriangular and evenly narrowed in basal part. $\mathrm{R}_{4+5}$ and $M_{1}$ subparallel beyond cell $\mathrm{dm} . \mathrm{M}_{2}$ and $\mathrm{M}_{4}$ subparallel beyond cell $\mathrm{dm}$. Costal section $\mathrm{M}_{1}-\mathrm{M}_{2}$ slightly longer than $\mathrm{M}_{2}-\mathrm{M}_{4}$. Cell dm moderately-sized, extended to around middle of wing, distal section of vein $\mathrm{M}_{1}$ (beyond base of $\mathrm{M}_{2}$ ) longer than preceding section (between $\mathrm{r}-\mathrm{m}$ and base of $\mathrm{M}_{2}$ ). Crossvein $\mathrm{dm}-\mathrm{m}$ broadly curved and convergent with $\mathrm{M}_{1}$ distally. Abdomen (Fig. 83): Black to blackish-brown, with black setae on tergites and sternites. Tergites 1-6 clothed with long, dense setae laterally, setae short and sparse dorsomedially. Sternites $2-5$ with some long and short setae medially, sternites 3-5 with long setae along lateral margins (progressively stronger posteriorly). Sternite 6 with short setae. Segment 7 with several setae on sternite, tergite bare. Sternite 8 quadrate, setose. Hypopygium (Figs 91-94): Small, about 1/4 length of abdomen. Left epandrial lamella (Fig. 91) subquadrate basally, with singlelobed surstylus projecting distally, with patch of setae at base of surstylus and marginal seta below surstylus. Left surstylus, beak-like, curved and projecting ventrally, strongly tapered beyond base with apical 3/4 narrowly pointed, with setae basally. Right epandrial lamella (Fig. 92) subrectangular basally, longer than high, with single-lobed surstylus projecting distally, with setae on dorsal margin and on surstylus. Right surstylus broad and setose, with blunt apex. Hypandrium (Figs 93, 94) with irregular series of 4-7 setae on each side of basal part (setae longer on right side). Medial hypandrial prolongation digitiform, curved to right side; apex bearing pair of long thick setae of similar length, about as long as prolongation. Left hypandrial lobe broad, posterior margin straight. Right hypandrial lobe broad, posterior margin straight, with acute ventral projection. Postgonite with dorsal postgonite lobes not substantially developed. Left ventral postgonite lobe broad and short with subtriangular apex protruding just beyond posterior margin of hypandrial lobe, with pair of circular pores near mid-basal part. Right ventral postgonite lobe large, broad tongue-shaped, with fang-like process ventrobasally, with pair of circular pores near mid-basal part. Postgonite apodeme narrowly V-shaped in ventral view with robust rod-like left and right branch. Phallus (Figs 93, 94) with apical portion long and narrow. Ejaculatory apodeme small, with short posterior extension. Left and right cercus with hump-like base bearing several setae and narrow short digitiform apex bearing several setae.

Female (Figs 80, 82, 84, 86, 95, 96, 102): Body length 2.2-2.8 mm, wing length 2.6-2.8 mm. Similar to male 
except as follows: Thorax (Figs 80, 82). Legs (Fig. 80): With shorter setae. Wing (Fig. 86): Anal lobe smaller. Abdomen (Figs 80, 84): Dark brown, tergites and sternites with short setae. With 6 exposed abdominal segments, segment 6 concolorous with anterior abdominal segments, often shiny, usually mostly exposed but sometimes partially retracted into segment 5, segment 7 also often partially exposed. Terminalia (Figs 95, 96, 102): Segment 6 with tergite and sternite subrectangular (wider than long), with setae along posterior and lateral margins, with narrow band-like posterior sclerite extension on each side. Segment 7 with tergite and sternite subrectangular (slightly wider than long), with setae along posterior margin and narrow band-like posterior sclerite extension on each side. Tergite 8 narrowly divided (desclerotized) medially, narrowly articulated with sternite 8 anterolaterally. Sternite 9 sclerotized, slightly longer than wide, widening posteriorly, concave below. Spermatheca (Fig. 102) ovoid. Syntergite 9+10 with hemitergites subquadrate, each with 3 acanthophorite setae. Sternite 10 subtriangular, undivided, with several setae, apically setulose. Cercus conical-subtriangular, pointed apically, with long setae apically, ventrally and lateroventrally.

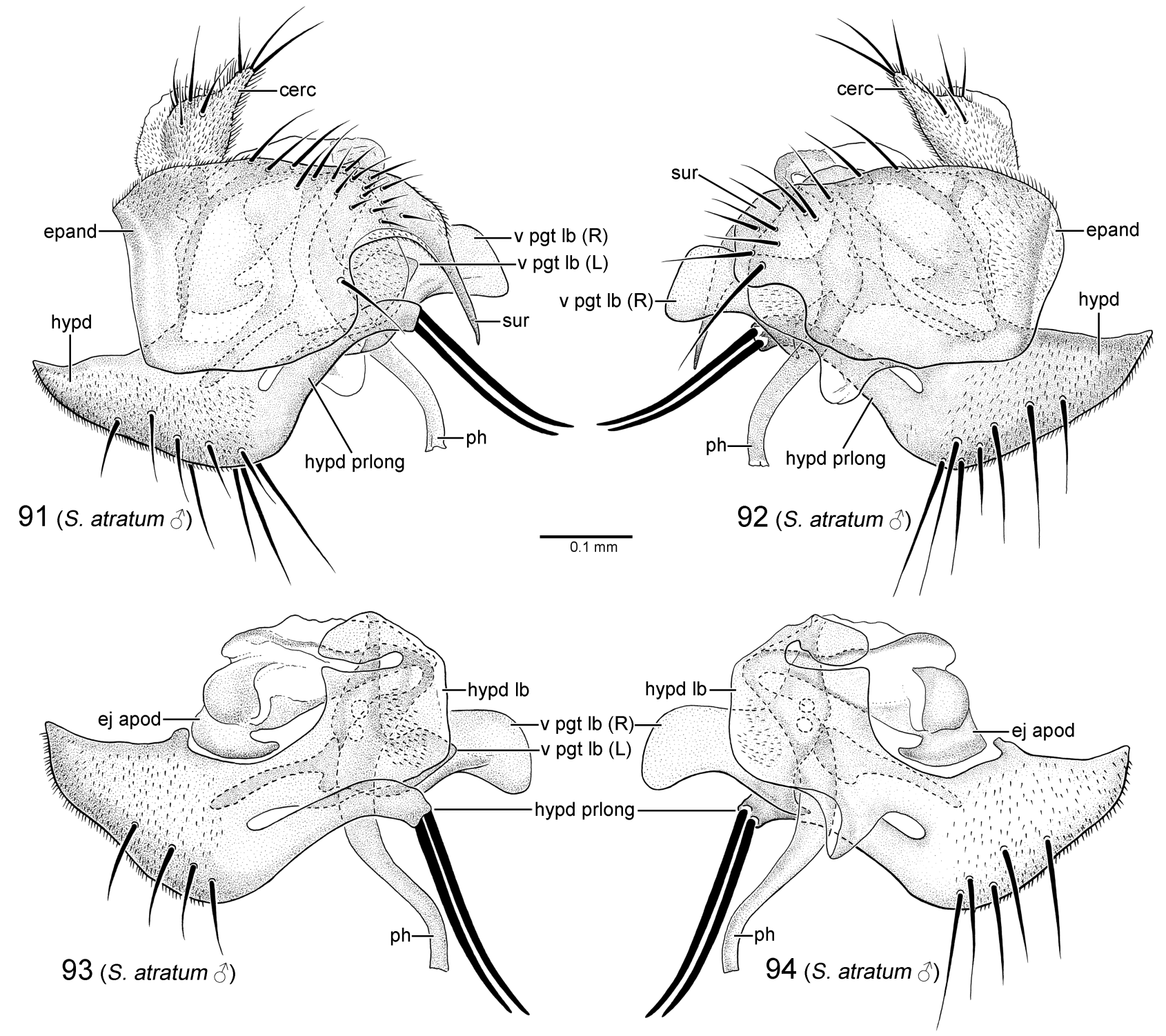

FIGURES 91-94. Hypopygium of Schistostoma atratum (Coquillett) comb. nov. 91. Hypopygium, left lateral view. 92. Hypopygium, right lateral view. 93. Hypandrium, postgonite and phallus, left lateral view. 94. Hypandrium, postgonite and phallus, right lateral view. Figures 91 and 92 based on specimen CNC1155611 (Mt Washington, British Columbia). Figures 93 and 94 based on specimen CNC1155609 (14 km SW Bella Coola, British Columbia). Abbreviations: cerc — cercus; ej apod - ejaculatory apodeme; epand - epandrium; hypd - hypandrium; hypd lb-hypandrial lobe; hypd prlong — hypandrial prolongation; (L)—left; ph—phallus; (R)—right; sur—surstylus; v pgt lb—ventral postgonite lobe. 

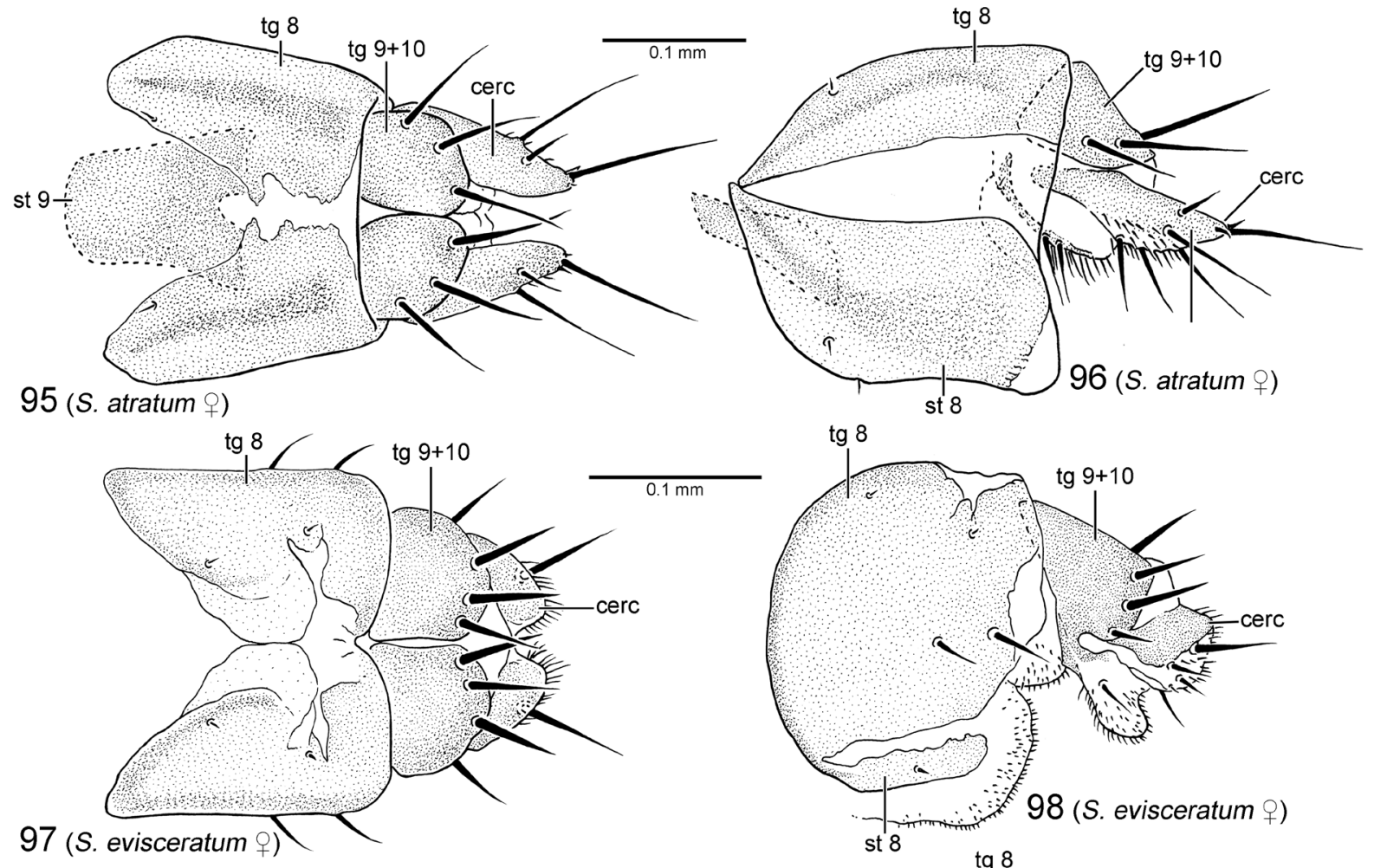
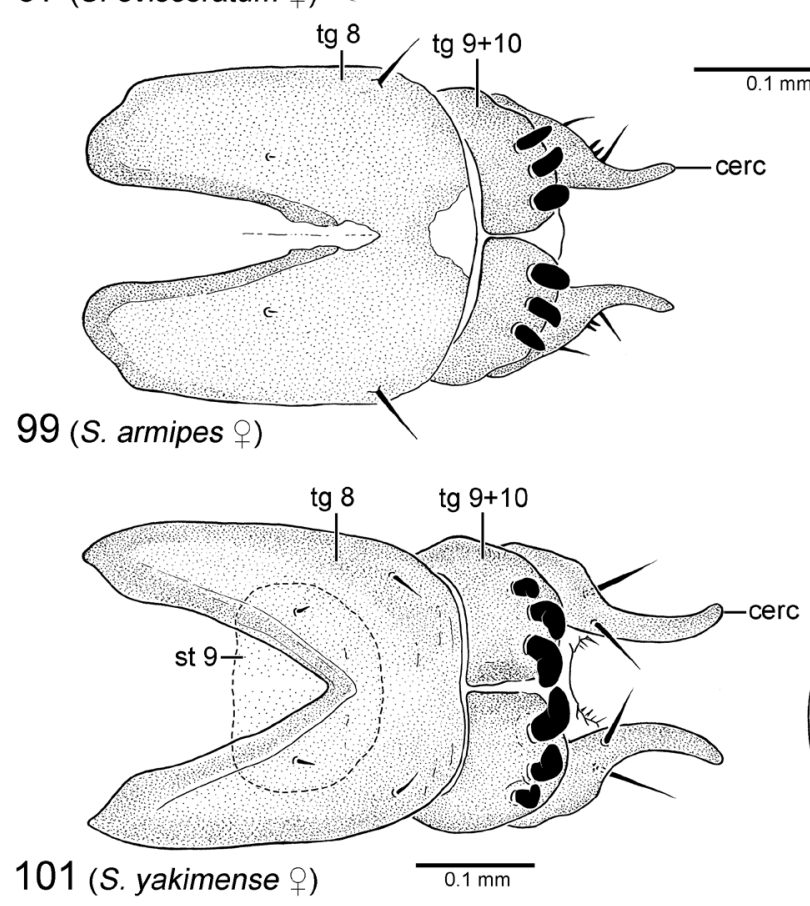

102 (S. atratum + )

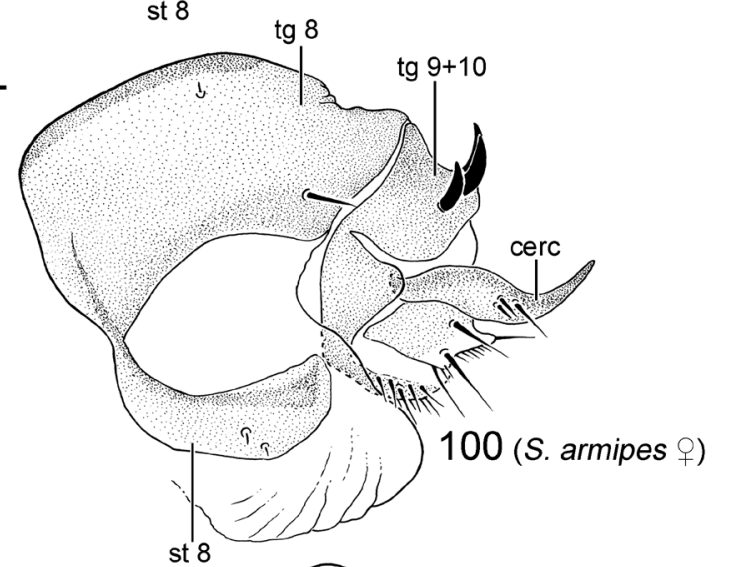

100 (S. armipes )
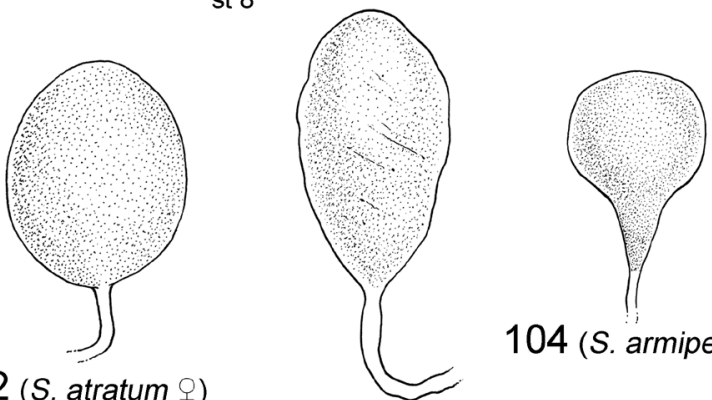

104 (S. armipes +)

FIGURES 95-104. Female terminalia of Nearctic Schistostoma. 95. S. atratum (Coquillett) comb. nov., dorsal view. 96. S. atratum (Coquillett) comb. nov., left lateral view. 97. S. evisceratum (Melander) comb. nov., dorsal view. 98. S. evisceratum (Melander) comb. nov., left lateral view. 99. S. armipes (Melander), dorsal view. 100. S. armipes (Melander), left lateral view. 101. S. yakimense (Melander), dorsal view. 102. S. atratum (Coquillett) comb. nov., spermatheca, lateral view. 103. S. evisceratum (Melander) comb. nov., spermatheca, lateral view. 104. S. armipes (Melander), spermatheca, lateral view. Figures 95, 96 and 102 based on specimen CNC1155708 (Mt Washington, British Columbia). Figures 97, 98 and 103 based on specimen CNC1099665 (La Wis Wis Campground, Washington). Figures 99, 100 and 104 based on specimen CNC1155666 (Nahalem R., Oregon). Figure 101 based on specimen CNC1155707 (Onefour, Alberta). Abbreviations: cerc—cercus; st—sternite; tg— tergite. 
Distribution and seasonal occurrence. Schistostoma atratum is a northwestern North America species known from several localities in southern Alaska, British Columbia (e.g., Fig. 10), Washington, Idaho and northern Oregon (Fig. 114). Melander (1940b) listed a record from Maine (Procter 1938, p. 321) that appears to based on a misidentification. Adults have been collected from early July to late August.

\section{Schistostoma borkenti sp. nov.}

(Figs 14, 87, 105-111, 115)

urn:Isid:zoobank.org:act: D450FBF3-3550-4F5F-AA6F-D85CF868FD9D

Type material. HOLOTYPE, ô collected from Huntington Lake Rancheria [ca $37^{\circ} 14^{\prime} \mathrm{N} 119^{\circ} 09^{\prime} \mathrm{W}$ ], Fresno County, California, USA, 10.viii.1984, by J. MacDonald, labelled: "CA. Huntington L./ Rancheria C. 2600m/ Fresno Co. 10-VIII/ J. MacDonald 1984"; "84-0063a"; "Microphorus/ new sp./ Det. J.F. MacDonald"; "HOLOTYPE/ Schistostoma borkenti/ Brooks \& Cumming [red label]" (CNC). PARATYPES: USA: California: Same data as holotype (19, CNC); same data as holotype except, 23.vii.1984, 84-0039a (19, CNC); same data as holotype except, 31.viii.1984, 84-0050a (10ิ, CNC).

Other material examined. USA: California: Madera County: meadow nr locked gate, road to Mark

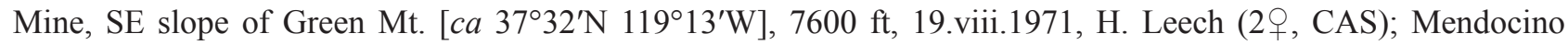
County: Inglenook Fen, 4 mi. N Ft. Bragg [ca 39 $30^{\circ} \mathrm{N} 123^{\circ} 46^{\prime} \mathrm{W}$ ], 2.vii.1975, M.E. Buegler \& E.I. Schlinger $\left(2{ }^{\jmath}, 2\right.$,, EMEC); same data except, CNC1155610 (10ิ, EMEC); Nevada County: Sagehen Creek [ca 39 $25^{\prime} 55^{\prime \prime} \mathrm{N}$

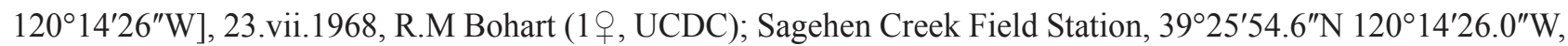
13-19.vii.2012, Malaise, J.M. Cumming \& S.E. Brooks (1ð̄, 1ㅇ, CNC); same data except, 19.vii-10.viii.2012, Malaise, C.J. Borkent, J.M. Cumming \& S.E. Brooks ( $3 \overbrace{}^{\lambda}, 7$,, CNC); Sagehen Creek Field Station, Big Culvert along Sagehen Creek, 39 $26^{\prime} 04.4^{\prime \prime} \mathrm{N} 120^{\circ} 16^{\prime} 52.2^{\prime \prime} \mathrm{W}, 11-17 . v i i .2012$, Malaise, J.M. Cumming, S.E. Brooks, C.

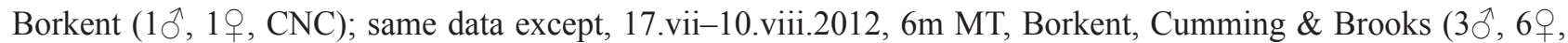
CNC); same data except, 10.viii-10.ix.2012, 6m MT, Borkent, Cumming \& Brooks (1 9 , CNC); Siskiyou County: Poker Flat, 21 mi. NW Happy Camp [ca 41 ${ }^{\circ} 55^{\prime} \mathrm{N} 123^{\circ} 32^{\prime} \mathrm{W}$ ], 5040 ft, 13.viii.1966, H.B. Leech (2ᄋ, CAS); same

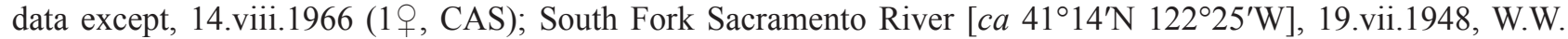
Wirth (2 ${ }^{\wedge}$, USNM); Trinity County: Shasta NF, Horse Heaven Meadows [ca $\left.41^{\circ} 09^{\prime} \mathrm{N} 122^{\circ} 27^{\prime} \mathrm{W}\right]$, 18.vii.1980, D.D. Wilder (1 9, CAS); same data except, CNC1155651 (1 ${ }^{\lambda}$, CAS). Montana: Missoula County: 1.5 mi. SW Lolo Hot Springs, Lee Creek [ $c a 6^{\circ} 43^{\prime} \mathrm{N} 114^{\circ} 32^{\prime} \mathrm{W}$ ], $4200 \mathrm{ft}$, 22.vii.1978, sweeping vegetation nr creek, N.L. Herman (1웅, AMNH).

Diagnosis. The pale form of this species is easily recognized by its yellow legs, wing veins, halteres and mostly yellow female abdomen (Figs 105, 106), whereas, the dark form is distinguished from other members of the $S$. atratum species group by the gradually tapered left surstylus, short phallus, and short apical setae on the medial hypandrial prolongation (Fig. 111), as indicated in couplets 32-34 of the key.

Description. Male (Figs 87, 105, 107-111): Body length 2.3-2.7 mm, wing length 2.7-3.0 mm. Head (Fig. 107): Ocellar tubercle with 3 pairs of black proclinate setae, anterior and posterior pair subequal in length, middle pair short or absent, posterior pair inserted at posterior margin. Occiput goldish-grey to grey pruinose, mostly clothed with black setae, almost bare in upper part, except for postoculars. Gena and parafacial narrow along lower eye margin. Antenna dark brown; postpedicel elongate subtriangular with apical 1/2 narrow and digitiform; stylus about 1.5X length of postpedicel. Palpus brown to dark brown, elongate ovate, slightly longer than length of labrum, pubescent with microtrichia and bearing scattered black setulae. Proboscis greyish-brown to dark brown, moderately long, approximately 2/3 as long as head height, directed forward. Thorax (Figs 105, 107): Mesonotum goldish-grey (pale form) to greyish-brown (dark form). Proepisternum with 1-2 setae. Mesonotal setae black, of moderate length with dorsocentrals arranged in single row per side. Notopleuron with 2 strong setae. Scutellum with 2 pairs of setae, inner pair stronger. Mesopleuron goldish-grey (pale form) to greyish-brown (dark form). Halter brown (dark form) to pale yellow (pale form). Legs (Fig. 105): Mainly pale yellow to entirely brown, with black setae. Tarsi of yellowlegged form usually infuscate from tip of tarsomere 1 to apex. Foreleg: Coxa with several setae on anterior surface. Femur subequal in length to tibia, sometimes infuscate ventrally (in pale form), posterior surface with series of longer posterodorsal and posteroventral setae (subequal to slightly longer than femur width) and shorter setae along middle, anterior surface with short setae and series of slightly longer anteroventral setae in basal third. Tibia slender, with short setae. Tarsus subequal in length to tibia, with short setae, tarsomere 1 subequal to combined length of 
tarsomeres 2-4, tarsomeres 2-4 decreasing in length apically, tarsomere 5 subequal in length to tarsomere 3. Midleg: Coxa with several setae on anterior surface. Femur subequal in length to tibia, sometimes infuscate ventrally (in pale form), with series of slightly longer posteroventral setae (shorter than femur width) and shorter setae on posterior and anterior surface. Tibia slender, with short setae (posterodorsal setae sometimes longer), with slightly longer anterodorsal/posterodorsal pair of setae in basal part, with 1 stout preapical ventral seta, otherwise with short setae. Tarsus slightly longer than tibia, with short setae, tarsomere 1 slightly shorter than combined length of tarsomeres 2-5, tarsomeres 2-4 decreasing in length apically, tarsomere 5 subequal in length to tarsomere 3. Hindleg: Coxa with 2 setae on outer surface, 2 setae on anterior surface and 1 seta on posterior surface. Femur subequal in length to tibia, with series of longer dorsal setae (slightly longer than femur width) and series of shorter anteroventral setae, anterior surface with short setae on upper half, posterior surface with sparse setulae. Tibia slender, with series of longer dorsal setae (subequal to tibia width), otherwise with short setae, ventral setae denser especially on apical half. Tarsus subequal in length to tibia, with short setae, tarsomere 1 as long as combined length of tarsomeres 2-5, tarsomeres 2-4 decreasing in length apically, tarsomere 5 subequal in length to tarsomere 3. Wing (Fig. 87): Hyaline or with slight grey-brown tinge, veins pale yellow to dark brown. Pterostigma well-developed. Anal lobe with proximal margin convex. $\mathrm{R}_{2+3}$ and $\mathrm{R}_{4+5}$ evenly diverging to apex with cell $\mathrm{r}_{2+3}$ subtriangular. $\mathrm{R}_{4+5}$ straight in basal portion with gradual posterior curve to apex with cell $\mathrm{r}_{4+5}$ subtriangular and evenly narrowed in basal part. $\mathrm{R}_{4+5}$ and $\mathrm{M}_{1}$ subparallel beyond cell $\mathrm{dm} . \mathrm{M}_{2}$ and $\mathrm{M}_{4}$ subparallel beyond cell $\mathrm{dm}$. Costal section $\mathrm{M}_{1}-\mathrm{M}_{2}$ slightly longer than $\mathrm{M}_{2}-\mathrm{M}_{4}$. Cell dm moderately-sized, extended to around middle of wing, distal section of vein $\mathrm{M}_{1}$ (beyond base of $\mathrm{M}_{2}$ ) longer than preceding section (between $\mathrm{r}-\mathrm{m}$ and base of $\mathrm{M}_{2}$ ). Crossvein $\mathrm{dm}-\mathrm{m}$ broadly curved and convergent with $\mathrm{M}_{1}$ distally. Abdomen (Fig. 108): Goldish-grey (pale form), or brownish to blackish (dark form), with black setae on tergites and sternites. Tergites 1-6 clothed with long, dense setae laterally, setae short and sparse dorsomedially. Sternites 2-6 with short setae, sternites 4 and 5 with lateral setae longer. Segment 7 with several setae on sternite, tergite bare. Sternite 8 quadrate, setose. Hypopygium (Figs 109-111): Small, about 1/4 length of abdomen. Left epandrial lamella (Figs 109,111) subquadrate basally, with single-lobed surstylus projecting distally, with patch of setae at base of surstylus and marginal seta below surstylus. Left surstylus, beak-like, curved and projecting ventrally, gradually tapered beyond base to acute point. Right epandrial lamella (Fig. 110) subrectangular basally, longer than high, with single-lobed surstylus projecting distally, with setae on dorsal margin and on surstylus. Right surstylus broad, short and setose, with blunt apex. Hypandrium with irregular series of 4-7 setae on each side of basal part (setae longer on right side). Medial hypandrial prolongation digitiform, curved to right side; apex bearing pair of long thick setae of similar length, about as long as prolongation. Left hypandrial lobe broad, posterior margin straight. Right hypandrial lobe broad, posterior margin broadly rounded. Postgonite with dorsal postgonite lobes not substantially developed. Left ventral postgonite lobe large and subquadrate, with pair of circular pores near mid-basal part. Right ventral postgonite lobe large, broadly subrectangular, with fang-like process ventrobasally, with pair of circular pores near mid-basal part. Postgonite apodeme V-shaped in ventral view with robust rod-like left and right branch. Phallus with apical portion short and broad. Ejaculatory apodeme small, with short posterior extension. Left and right cercus with hump-like base bearing several setae and narrow short digitiform apex bearing several setae.

Female (Fig. 106): Body length 2.0-2.8 mm, wing length 2.5-3.0 mm. Similar to male except as follows: Thorax (Fig. 106). Legs (Fig. 106): With shorter setae, sometimes more extensively infuscate in yellow-legged form. Wing: Anal lobe smaller. Abdomen (Fig. 106): Mainly pale yellow to extensively infuscate (pale form), or dark brown (dark form), tergites and sternites with short setae. Six exposed abdominal segments, segment 6 concolorous with anterior abdominal segments, segment 7 also often partially exposed. Terminalia (similar to Figs 95, 96, 102): Segment 6 with tergite and sternite subrectangular (wider than long), setose on posterior half. Segment 7 with tergite and sternite subrectangular (slightly wider than long), with setae along posterior margin and narrow band-like posterior sclerite extension on each side. Tergite 8 narrowly divided (desclerotized) medially, narrowly articulated with sternite 8 anterolaterally. Sternite 9 sclerotized, with anterior crescent-shaped band and posterior subrectangular plate. Spermatheca ovoid. Syntergite $9+10$ with hemitergites subquadrate, each with 3-4 acanthophorite setae. Sternite 10 subtriangular, undivided, with several setae, apically setulose. Cercus conicalsubtriangular, pointed apically, with long setae apically, ventrally and lateroventrally.

Distribution and seasonal occurrence. Schistostoma borkenti sp. nov. is known from western USA, including Montana and California (Fig. 115). Adults have been collected from early July to late August, generally in riparian habitats (Fig. 14). 

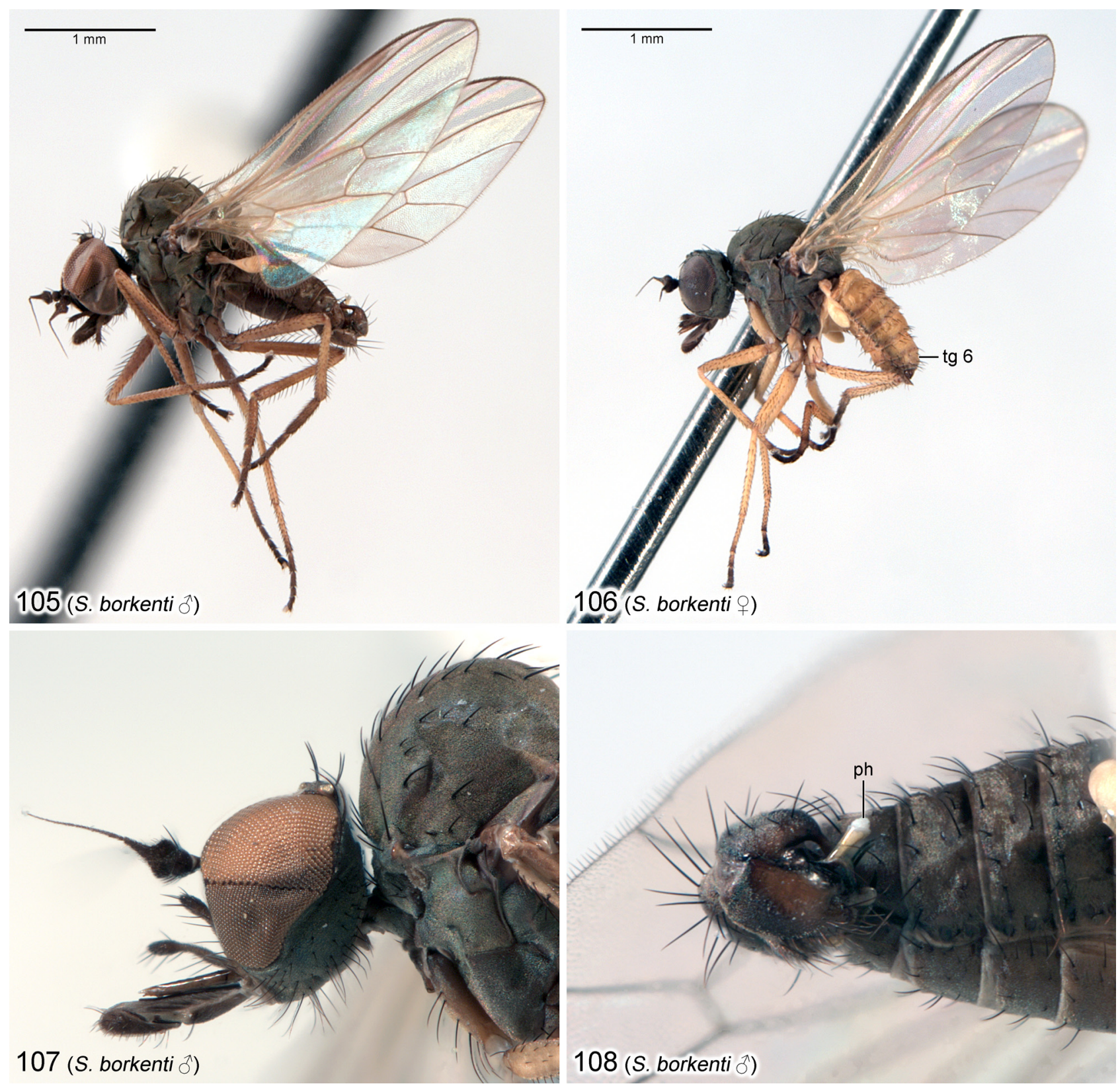

FIGURES 105-108. Habitus, head and abdomen of pale form of Schistostoma borkenti sp. nov. 105. Male habitus. 106. Female habitus. 107. Male head and anterior portion of thorax, lateral view. 108. Male abdomen and terminalia, right lateral view. Specimens from: Huntington Lake, California (Figs 105,107, 108); Sagehen Creek, California (Fig. 106). Abbreviations: ph-phallus; tg-tergite.

Etymology. This species is named in honour of fellow dipterist, Dr. Christopher J. Borkent, who helped collect a large number of specimens of this species from Nevada County, California.

Remarks. The dark form of S. borkenti sp. nov. is known only from two localities in California (Inglenook Fen and South Fork Sacramento River) and has not been collected together with the pale form. The pale form of this species was collected together with S. armipes and S. sycophantor along Sagehen Creek (Fig. 14) in California by the authors in July, 2012. 


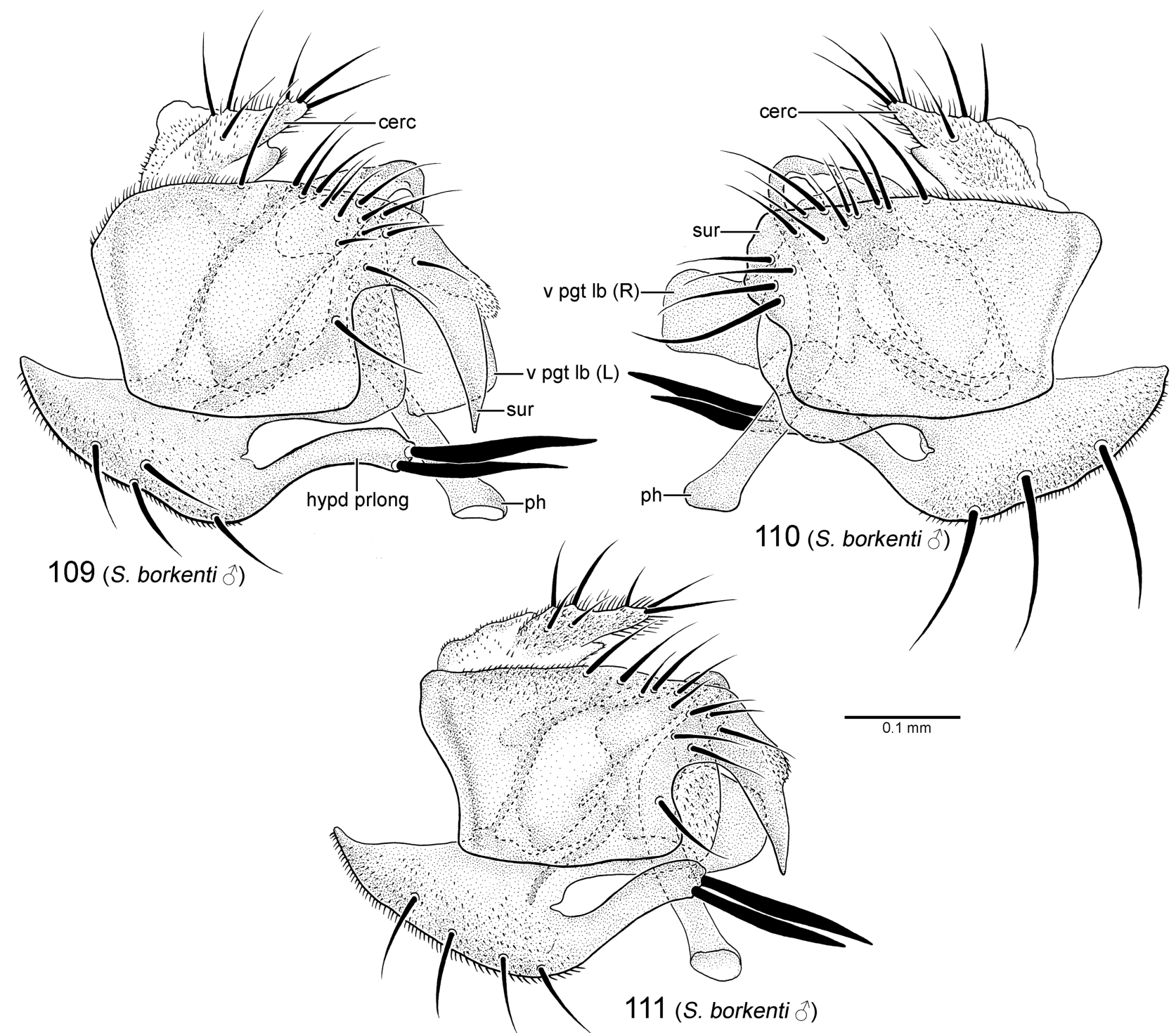

FIGURES 109-111. Hypopygium of Schistostoma borkenti sp. nov. 109. Hypopygium of pale form, left lateral view. 110. Hypopygium of pale form, right lateral view. 111. Hypopygium of dark form, left lateral view. Figures 109 and 110 based on specimen CNC1155651 (Horse Heaven Meadows, California). Figure 111 based on specimen CNC1155610 (Inglenook Fen, California). Abbreviations: cerc — cercus; hypd prlong—hypandrial prolongation; (L)—left; ph—phallus; (R)—right; sur— surstylus; v pgt lb_-ventral postgonite lobe.

\section{Schistostoma chloeae sp. nov.}

(Figs 88, 112, 115)

urn:lsid:zoobank.org:act:B8356BAC-6C2C-4282-AAC6-71C4EBA53B95

Type material. HOLOTYPE, ô collected from Olympic National Park, [ca $47^{\circ} 42^{\prime} \mathrm{N} 124^{\circ} 24^{\prime} \mathrm{W}$ ], Jefferson County, Washington, USA, 22.vii.1978, by D.D. Wilder, labelled: "U.S.A.: WASHINGTON/ JeffersonCo., Olympic/ Nat. Pk. T26NR13W Sec./ 28. Sweeping coastal/ forest. 22-VII-1978/ D.D. Wilder, collector"; "D. Dee Wilder/ Collection [yellow label]"; "HOLOTYPE/ Schistostoma chloeae/ Brooks \& Cumming [red label]" (CAS). PARATYPES:

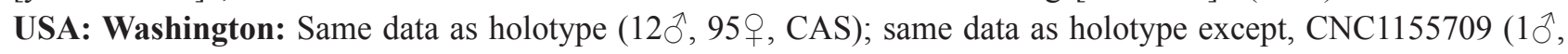
CAS).

Other material examined. USA: Oregon: Crook County: Prineville [ $\left.c a 4^{\circ} 18^{\prime} \mathrm{N} 120^{\circ} 49^{\prime} \mathrm{W}\right]$, 31.vii.1962, F.C. Harmston \& R.A. McHugh (1 $\hat{\partial}$, USNM). Washington: Grays Harbor County: Olympic NF, Willaby Campground 


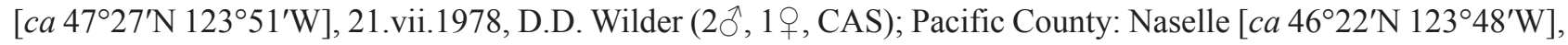
2.vii.1925, A.L. Melander (1 $\delta^{\top}$, USNM).

Diagnosis. This species can be distinguished from other members of the $S$. atratum species group by its dark body, legs and wing veins, distinctively shaped left surstylus (Fig. 112), extremely long subequal pair of apical setae on the medial hypandrial prolongation, and narrow phallus, as indicated in couplets 32-34 of the key.

Description. Male (Figs 88, 112): Body length 2.4-2.6 mm, wing length 2.7-3.1 mm. Head: Ocellar tubercle with 3 pairs of black proclinate setae, anterior and posterior pair subequal in length, middle pair short or absent, posterior pair inserted at posterior margin. Occiput dark grey pruinose, mostly clothed with black setae, almost bare in upper part, except for postoculars. Gena and parafacial narrow along lower eye margin. Antenna dark brown; postpedicel elongate subtriangular with apical 1/2 narrow and digitiform; stylus about $1.5 \mathrm{X}$ length of postpedicel. Palpus brown to dark brown, elongate ovate, slightly longer than length of labrum, pubescent with microtrichia and bearing scattered black setulae. Proboscis greyish-brown to dark brown, moderately long, approximately $2 / 3$ as long as head height, directed forward. Thorax: Mesonotum greyish-brown to blackish-brown. Proepisternum with thin patch of setae. Mesonotal setae black, relatively long with dorsocentrals arranged in single row per side or irregularly biserial. Notopleuron with 2-3 strong setae. Scutellum with 3 pairs of setae, middle pair stronger. Mesopleuron grey to blackish-brown. Halter darkish-brown. Legs: Entirely blackish-brown, with black setae. Foreleg: Coxa with several setae on anterior surface. Femur subequal in length to tibia, posterior surface with series of long posteriorly projecting posterodorsal and posteroventral setae (longer than femur width) and shorter setae along middle, anterior surface with short setae and series of slightly longer anteroventral setae in basal third. Tibia slender, with short setae. Tarsus subequal in length to tibia, with short setae, tarsomere 1 slightly longer than combined length of tarsomeres 2-4, tarsomeres 2-4 decreasing in length apically, tarsomere 5 subequal in length to tarsomere 2. Midleg: Coxa with several setae on anterior surface. Femur subequal in length to tibia, with series of longer posteroventral setae (subequal to slightly longer than femur width) and shorter setae on posterior and anterior surface. Tibia slender, with short setae (subequal to tibia width), with slightly longer anterodorsal/posterodorsal pair of setae in basal part, with 1 stout preapical ventral seta. Tarsus slightly longer than tibia, with short setae, tarsomere 1 slightly shorter than combined length of tarsomeres 2-5, tarsomeres 2-4 decreasing in length apically, tarsomere 5 subequal in length to tarsomere 3. Hindleg: Coxa with 3-4 setae on outer surface, a few setae near apex of anterior surface and 1 seta on posterior surface. Femur subequal in length to tibia, with series of longer dorsal and anteroventral setae (subequal to slightly longer than femur width), anterior surface with shorter setae on upper half, posterior surface with short fine setae. Tibia slender, with series of longer dorsal setae (slightly longer than tibia width), otherwise with short setae. Tarsus subequal in length to tibia, with short setae (ventral setae shorter), tarsomere 1 subequal to combined length of tarsomeres $2-5$, tarsomeres $2-4$ decreasing in length apically, tarsomere 5 subequal in length to tarsomere 2. Wing (Fig. 88): With brown tinge, veins dark brown. $R_{2+3}$ and $R_{4+5}$ more or less evenly diverging to apex with cell $r_{2+3}$ subtriangular, weakly compressed in middle part. $\mathrm{R}_{4+5}$ straight in basal portion with gradual posterior curve to apex with cell $\mathrm{r}_{4+5}$ subtriangular and evenly narrowed in basal part. $\mathrm{R}_{4+5}$ and $\mathrm{M}_{1}$ subparallel beyond cell dm. $\mathrm{M}_{2}$ and $\mathrm{M}_{4}$ subparallel beyond cell $\mathrm{dm}$. Costal section $\mathrm{M}_{1}-\mathrm{M}_{2}$ slightly longer than $\mathrm{M}_{2}-\mathrm{M}_{4}$. Cell dm moderately-sized, extended to around middle of wing, distal section of vein $\mathrm{M}_{1}$ (beyond base of $\mathrm{M}_{2}$ ) longer than preceding section (between $\mathrm{r}-\mathrm{m}$ and base of $\mathrm{M}_{2}$ ). Crossvein dm-m broadly curved and convergent with $\mathrm{M}_{1}$ distally. Abdomen: Black, with black setae on tergites and sternites. Tergites 1-6 clothed with long, dense setae laterally, setae short and sparse dorsomedially. Sternites 2-5 with some long and short setae medially, sternites 3-5 with long setae along lateral margins (progressively stronger posteriorly). Sternite 6 with short setae. Segment 7 with setae on sternite, tergite bare. Sternite 8 quadrate, setose. Hypopygium (Fig. 112): Small, about 1/4 length of abdomen. Left epandrial lamella (Fig. 112) subquadrate basally, with single-lobed surstylus projecting distally, with patch of setae at base of surstylus and marginal seta below surstylus. Left surstylus beak-like, curved and projecting ventrally, with basal 3/4 broad and straight, apex strongly narrowed. Right epandrial lamella subrectangular, longer than high, with single-lobed surstylus projecting distally, with setae on dorsal margin and on surstylus. Right surstylus broad, short and setose, with broadly rounded medially projected apex. Hypandrium with irregular series of 5-6 setae on each side of basal part (setae longer on right side). Medial hypandrial prolongation digitiform, curved to right side; apex bearing pair of extremely long thick setae of similar length and over $2 \mathrm{X}$ longer than prolongation. Left hypandrial lobe broad, posterior margin broadly rounded. Right hypandrial lobe broad, posterior margin broadly rounded, with hump-like ventral projection. Postgonite with left and right dorsal postgonite lobes not substantially developed. Left ventral postgonite lobe broad and subquadrate, with pair of circular pores near mid basal part. Right ventral postgonite lobe 
large, broadly subrectangular, with fang-like process ventrobasally, with pair of circular pores near mid basal part. Postgonite apodeme V-shaped in ventral view with robust rod-like left and right branch. Phallus with apical portion long and narrow. Ejaculatory apodeme small, with short posterior extension. Left and right cercus with hump-like base bearing several setae and narrow short digitiform apex bearing several setae.

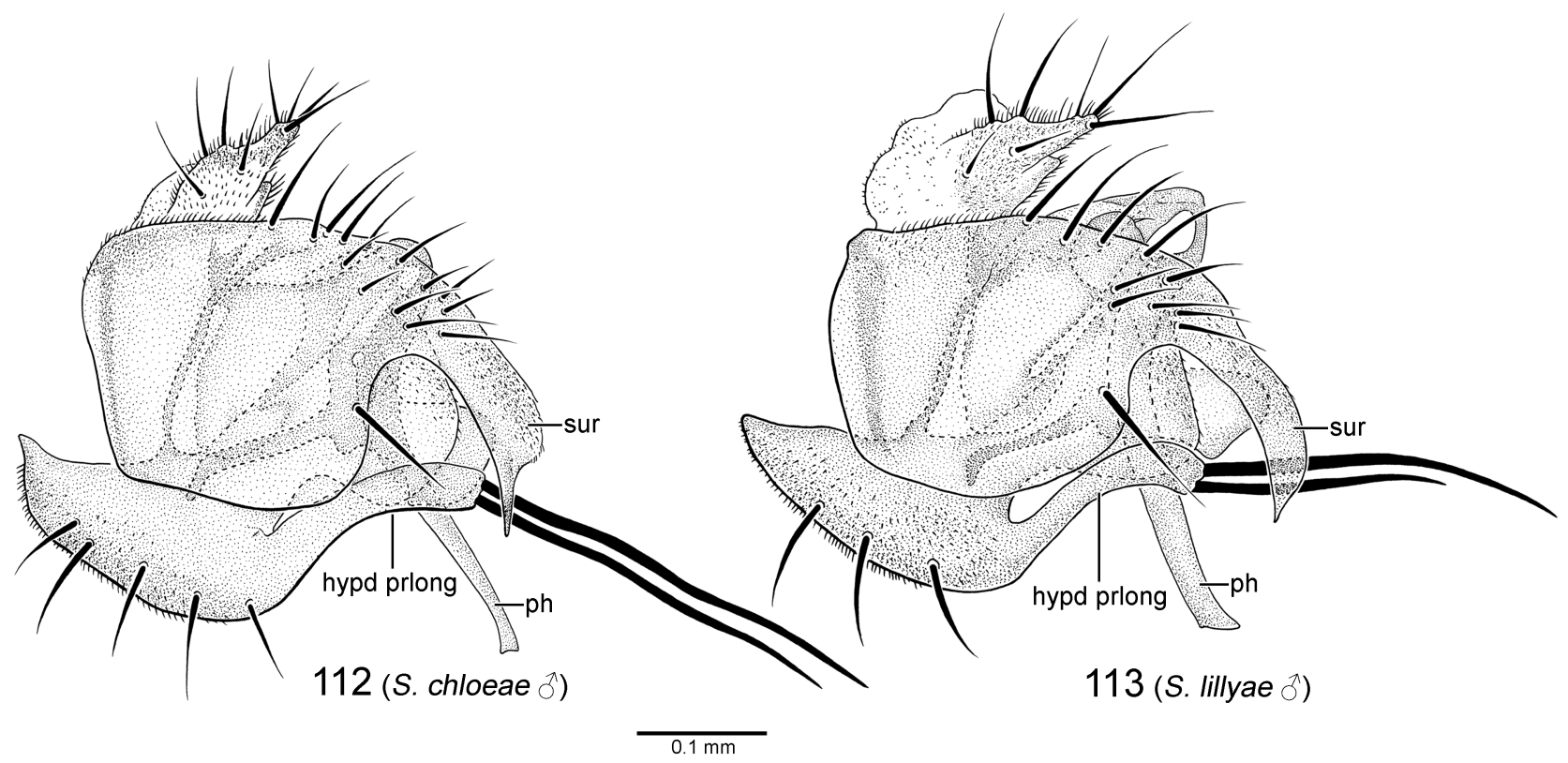

FIGURES 112-113. Hypopygia of Nearctic Schistostoma, left lateral view. 112. S. chloeae sp. nov. 113. S. lillyae sp. nov. Figure 112 based on specimen CNC1155709 (Olympic National Park, Washington). Figure 113 based on specimen CNC1155652 (Naselle, Washington). Abbreviations: hypd prlong—hypandrial prolongation; ph—phallus; sur—surstylus.

Female: Body length 1.9-2.3 mm, wing length 2.6-3.2 mm. Similar to male except as follows: Thorax: Halter brown to pale. Legs: With shorter setae. Wing: Anal lobe smaller. Abdomen: Tergites and sternites with short setae. With 6 exposed abdominal segments, segment 6 concolorous with anterior abdominal segments, often shiny, often partially retracted into segment 5 , segment 7 also often partially exposed. Terminalia (similar to Figs 95, 96, 102): Segment 6 with tergite and sternite subrectangular, wider than long, with setae along posterior and lateral margins (sternite with additional setae anteriorly) and with narrow band-like posterior sclerite extension on each side. Segment 7 with tergite subrectangular (slightly wider than long), sternite subquadrate, each with setae along posterior margin and narrow band-like posterior sclerite extension on each side. Tergite 8 narrowly divided (desclerotized) medially, narrowly articulated with sternite 8 anterolaterally. Sternite 9 sclerotized, about $2 X$ longer than wide, shallowly concave below. Spermatheca ovoid. Syntergite $9+10$ with hemitergites subquadrate, each with 4-5 acanthophorite setae. Sternite 10 subtriangular, undivided, with several setae, apically setulose. Cercus conicalsubtriangular, pointed apically, with long setae apically, ventrally and laterally.

Distribution and seasonal occurrence. Schistostoma chloeae sp. nov. is known from Washington and Oregon (Fig. 115). Adults have been collected in July.

Etymology. This species is named after the first author's youngest, Chloé Brooks, and is closely related to $S$. lillyae sp. nov., its putative sister species.

\section{Schistostoma lillyae sp. nov.}

(Figs 113, 114)

urn:lsid:zoobank.org:act: 99955271-220F-4B9E-BC2B-0DC7AFA261F3

Type material. HOLOTYPE, ô collected from Strychnine Creek, $15 \mathrm{mi}$ ENE Potlatch [ca $\left.46^{\circ} 56^{\prime} \mathrm{N} 116^{\circ} 38^{\prime} \mathrm{W}\right]$, Latah County, Idaho, USA, 22.vi.1979, by R.S. Zack, labelled: "IDAHO: Strychnine/ Creek, 15 mi. ENE/ Potlatch, Latah Co./ 2900ft., 22 Jun 79/ R.S. Zack"; "HOLOTYPE/ Schistostoma lillyae/ Brooks \& Cumming [red label]" (WSU). 
Other material examined. USA: California: Del Norte County: Smith River [ $c a 41^{\circ} 49^{\prime} \mathrm{N} 124^{\circ} 06^{\prime} \mathrm{W}$ ],

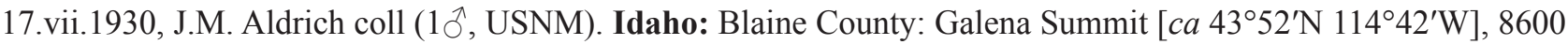
ft, 15.vii.1961, dry hillside, J.G. Chillcott (1ð̄, CNC); Custer County: Imogene Pass, 10 mi. SW Obsidian [ca $43^{\circ} 52^{\prime} \mathrm{N} 114^{\circ} 42^{\prime} \mathrm{W}$ ], 9.viii.1966, M.A. Brusven (2犬․ WFBM); Idaho County: Lolo Pass on Hwy 12 [ca 46 $36^{\circ} \mathrm{N}$ $114^{\circ} 34^{\prime} \mathrm{W}$ ], 26.vi.1987, J.B. Johnson (1 ${ }^{\AA}$, WFBM). Washington: Pacific County: Naselle [ $c a 46^{\circ} 22^{\prime} \mathrm{N} 123^{\circ} 48^{\prime} \mathrm{W}$ ], 2.vii.1925, A.L. Melander, CNC1155652 (1ð̄, USNM).

Diagnosis. This species can be distinguished from other members of the S. atratum species group by its dark body, legs and wing veins, the distinctively shaped left surstylus (Fig. 113), and long unequal pair of apical setae on the medial hypandrial prolongation, as indicated in couplets 32-34 of the key.

Description. Male (Fig. 113): Wing length 2.5-2.9 mm. Head: Ocellar tubercle with 3 pairs of black proclinate setae, anterior and posterior pair subequal in length, middle pair short or absent, posterior pair inserted at posterior margin. Occiput dark greyish pruinose, mostly clothed with black setae, almost bare in upper part, except for postoculars. Gena and parafacial narrow along lower eye margin. Antenna dark brown; postpedicel elongate conical with apical 1/2 narrow and digitiform; stylus about 1.5X length of postpedicel. Palpus dark brown, elongate ovate, slightly longer than length of labrum, pubescent with microtrichia and bearing scattered black setulae. Proboscis dark brown, moderately long, approximately $2 / 3$ as long as head height, directed forward. Thorax: Mesonotum blackish-brown. Proepisternum with thin patch of setae. Mesonotal setae black, relatively long with dorsocentrals arranged in single row per side or irregularly biserial. Notopleuron with 2 strong setae. Scutellum with 4 pairs of setae, inner middle pair stronger. Mesopleuron blackish-brown. Halter brown. Legs: Entirely blackish-brown, with black setae. Foreleg: Coxa with several setae on anterior surface. Femur slightly shorter than tibia, posterior surface with series of long posteriorly projecting posterodorsal and posteroventral setae (longer than femur width) and shorter setae along middle, anterior surface with short setae and series of slightly longer anteroventral setae in basal third. Tibia slender, with short setae. Tarsus subequal in length to tibia, with short setae, tarsomere 1 slightly longer than combined length of tarsomeres 2-4, tarsomeres 2-4 decreasing in length apically, tarsomere 5 subequal in length to tarsomere 2. Midleg: Coxa with several setae on anterior surface. Femur subequal in length to tibia, with series of longer posteroventral setae (subequal to slightly longer than femur width) and shorter setae on posterior and anterior surface. Tibia slender, with short setae (shorter than tibia width), with slightly longer anterodorsal/ posterodorsal pair of setae in basal part, with 1 stout preapical ventral seta. Tarsus slightly longer than tibia, with short setae, tarsomere 1 slightly shorter than combined length of tarsomeres $2-5$, tarsomeres $2-4$ decreasing in length apically, tarsomere 5 subequal in length to tarsomere 3. Hindleg: Coxa with 3-4 setae on outer surface, 2-3 setae near apex of anterior surface and 1 seta on posterior surface. Femur subequal in length to tibia, with series of longer dorsal and anteroventral setae (subequal to slightly longer than femur width), anterior surface with shorter setae on upper half, posterior surface with short fine setae. Tibia slender, with series of longer dorsal setae (subequal to tibia width), otherwise with short setae. Tarsus subequal in length to tibia, with short setae, tarsomere 1 subequal to combined length of tarsomeres 2-5, tarsomeres 2-4 decreasing in length apically, tarsomere 5 subequal in length to tarsomere 3. Wing: With slight grey-brown tinge, veins dark brown. Pterostigma well-developed. Anal lobe with proximal margin convex. $\mathrm{R}_{2+3}$ and $\mathrm{R}_{4+5}$ evenly diverging to apex with cell $\mathrm{r}_{2+3}$ subtriangular. $\mathrm{R}_{4+5}$ straight in basal portion with gradual posterior curve to apex with cell $r_{4+5}$ subtriangular and evenly narrowed in basal part. $R_{4+5}$ and $M_{1}$ subparallel beyond cell dm. $M_{2}$ and $M_{4}$ subparallel beyond cell $\mathrm{dm}$. Costal section $M_{1}-M_{2}$ slightly longer than $\mathrm{M}_{2}-\mathrm{M}_{4}$. Cell dm moderately-sized, extended to around middle of wing, distal section of vein $\mathrm{M}_{1}$ (beyond base of $\mathrm{M}_{2}$ ) slightly longer than preceding section (between $\mathrm{r}-\mathrm{m}$ and base of $\mathrm{M}_{2}$ ). Crossvein $\mathrm{dm}-\mathrm{m}$ broadly curved and convergent with $\mathrm{M}_{1}$ distally. Abdomen: Brownish-black, with black setae on tergites and sternites. Tergites 1-6 clothed with long, dense setae laterally, setae short and sparse dorsomedially. Sternites $2-5$ with some long and short setae medially, sternites 3-5 with long setae along lateral margins (progressively stronger posteriorly). Sternite 6 with short setae. Segment 7 with setae on sternite, tergite bare. Sternite 8 subrectangular, setose. Hypopygium (Fig. 113): Small, about $1 / 4$ length of abdomen. Left epandrial lamella (Fig. 113) subquadrate basally, with single-lobed surstylus projecting distally, with patch of setae at base of surstylus and marginal seta below surstylus. Left surstylus beak-like, curved and projecting ventrally, broad along most of length with pointed tip. Right epandrial lamella subrectangular, longer than high, with single-lobed surstylus projecting distally, with setae on dorsal margin and on surstylus. Right surstylus broad, short and setose, with broadly rounded medially projected apex. Hypandrium with irregular series of 3-4 setae on each side of basal part (setae longer on right side). Medial hypandrial prolongation digitiform, curved to right side; apex bearing pair of long thick setae with upper seta longer than lower seta and 
longer than prolongation. Left hypandrial lobe broad, posterior margin straight, broadly rounded ventrally. Right hypandrial lobe broad, posterior margin broadly rounded, with hump-like ventral projection. Postgonite with left and right dorsal postgonite lobes not substantially developed. Left ventral postgonite lobe broad and subquadrate, with pair of circular pores near mid basal part. Right ventral postgonite lobe relatively narrow, subrectangular, with fanglike process ventrobasally, with pair of circular pores near mid basal part. Postgonite apodeme V-shaped in ventral view with robust rod-like left and right branch. Phallus with apical portion long and relatively narrow. Ejaculatory apodeme small, with short posterior extension. Left and right cercus with hump-like base bearing several setae and narrow short digitiform apex bearing several setae.

Female: Unknown.

Distribution and seasonal occurrence. Schistostoma lillyae sp. nov. is known from northwestern USA, including Idaho, southern Washington and northern California (Fig. 114). Adults have been collected from late June to early August.

Etymology. This species is named after the first author's oldest, Lilly Brooks, and is closely related to $S$. chloeae sp. nov., its putative sister species.
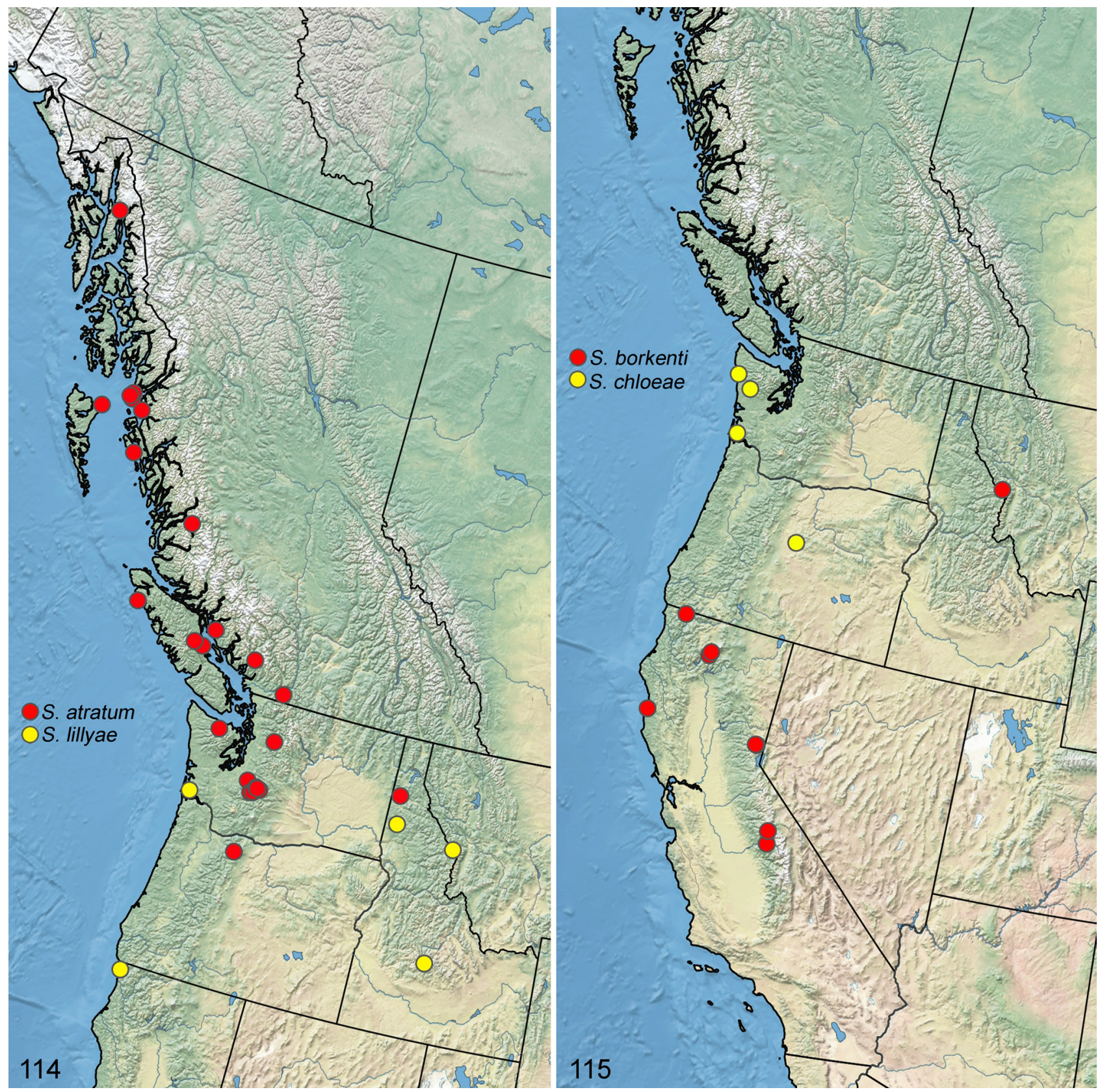

FIGURES 114-115. Known geographical distributions of Nearctic Schistostoma. 114. S. atratum (Coquillett) comb. nov. and S. lillyae sp. nov. 115. S. borkenti sp. nov. and S. chloeae sp. nov. 
Diagnosis. Setae of body and legs predominantly black, body and legs dark brown to dull grey or blueish grey (Figs 5, 6, 116, 117); male compound eye without distinct demarcation line between dorsal and ventral ommatidia (Figs 118, 119); female head with gena and parafacial distinctly projected along lower eye margin (Figs 120, 121); antenna with stylus longer than postpedicel (Figs 119, 121); thorax with mesonotal setae widely spaced and conspicuous; acrostichals biserial, dorsocentrals arranged in a single row per side; scutellum with 2 setae per side; male fore tibia with series of 3-5 erect posterodorsal setae on basal half; male midleg unmodified, trochanter without medial spine-like setal pair; hind tibia of both sexes enlarged apically (Figs 116, 117); wing (Figs 89, 90) with cell $r_{2+3}$ compressed in middle and flared apically, cell $r_{4+5}$ compressed in basal part, cell dm moderately-sized; male pregenitalic abdominal sternites modified and adorned with specialized setae, partially enclosing posterior end of hypopygium (Figs 122-124, 126-131); hypopygium (Figs 132-152) large, epandrium with group of specialized setae adjacent to cercus, surstylus multilobate with dorsal, middle (upper and lower) and ventral lobes, hypandrium with bulbous projecting base and 1 seta per side, medial hypandrial prolongation with apical pair of divergent setae, postgonite with elongate dorsal lobes projecting below cerci, left ventral postgonite lobe longer and larger than right lobe, cercus with long digitiform apex; female terminalia (Fig. 125) retracted into segment 7 (i.e., with 7 exposed abdominal segments), segment 7 concolorous with anterior abdominal segments, syntergite $9+10$ with acanthophorite setae, cercus broad and short and rounded apically (Figs 97, 98).

Remarks. This species group includes $S$. caroleae sp. nov., S. evisceratum comb. nov., S. fitzgeraldi $\mathbf{s p .}$ nov., S. isommatum comb. nov., S. powelli sp. nov., S. shamshevi sp. nov., S. sinclairi sp. nov., S. susanae sp. nov. and S. tacomae comb. nov. There is an undescribed Palaearctic species from Japan in the USNM and $S$. negrobovi Shamshev from the Russian Far East (Shamshev 2021), which are also part of this species group.

\section{Schistostoma caroleae sp. nov.}

(Figs 11, 126, 253)

urn:lsid:zoobank.org:act: EB3D47A1-9B11-4576-A1FE-BE67CD4ACC66

Type material. HOLOTYPE, $\widehat{\jmath}$ collected from the margin of the Cascade River, Skagit County, Washington, USA, 9.vi.2018, by S.E. Brooks, labelled: “USA: WA: Skagit Co.,/ Cascade River margin,/ 48²7'54"N 121¹3'1"W,/ 1186 ft, 9.vi.2018, S.E./ Brooks, CNC1099623”; "HOLOTYPE/ Schistostoma caroleae/ Brooks \& Cumming [red label]" (CNC).

Diagnosis. This species is differentiated from other members of the $S$. isommatum species group by the large spatulate setae on male abdominal sternite 5 (Fig. 126), as indicated in couplet 38 of the key.

Description. Male (Fig. 126): Body length $2.4 \mathrm{~mm}$, wing length $2.5 \mathrm{~mm}$. Head: Ocellar tubercle with 2 pairs of black proclinate setae, anterior pair longer than posterior pair. Occiput dark grey pruinose, mostly clothed with black setae, almost bare in upper part, except for postoculars. Gena and parafacial slightly projected along lower eye margin. Antenna dark brown; postpedicel conical, evenly tapered to apex; stylus about 1.5X length of postpedicel. Palpus grey, elongate ovate, slightly longer than length of labrum, pubescent with microtrichia and bearing scattered black setulae. Proboscis dark brown, slightly less than 1/2 as long as head height, directed forward. Thorax: Mesonotum brownish-grey. Proepisternum with 1 seta. Mesonotal setae black, relatively long with dorsocentrals arranged in single row per side. Notopleuron with 2 strong setae. Scutellum with 2 pairs of setae. Mesopleuron dark grey. Halter pale. Legs: Blackish-brown, with black setae. Foreleg: Coxa with several setae on anterior surface. Femur subequal in length to tibia, posterior surface with series of longer posterodorsal and posteroventral setae (shorter than femur width) and short rather sparse setae along middle, anterior surface with series of short anteroventral setae in basal third, otherwise with short sparse setae. Tibia slender, with series of 4-5 long erect posterodorsal setae (2X longer than tibia width) along basal half, otherwise with short setae. Tarsus subequal in length to tibia, with short setae, tarsomere 1 subequal to combined length of tarsomeres 2-4, with 2 stout basiventral setae, tarsomeres 2-4 decreasing in length apically, tarsomere 5 subequal in length to tarsomere 2. Midleg: Coxa setose on anterior surface, with pair of shorter setae on posterior surface. Femur subequal in length to tibia, posterior and anterior surfaces with short setae, with a few longer setae anterobasally. Tibia slender, with short setae, with 1 long stout 
preapical ventral seta (about $2 \mathrm{X}$ tibia width). Tarsus slightly shorter than tibia, with short setae, tarsomere 1 subequal to combined length of tarsomeres 2-4, with 3 stout erect basiventral setae and a few smaller ventral setae, apex slightly enlarged, tarsomeres 2-4 decreasing in length apically, tarsomere 5 subequal in length to tarsomere 2 . Hindleg: Coxa with 3 setae on outer surface and several shorter setae on anterior surface. Femur subequal in length to tibia, with series of longer dorsal and anteroventral setae (at most subequal to femur width), anterior surface with short setae, posterior surface with short fine setae. Tibia enlarged apically, with series of longer posterodorsal and anterodorsal setae (subequal to basal tibia width on basal 2/3 then short), otherwise with short setae (denser apically), ventral surface with short setae basally giving rise to dense setulae apically, apical margin with stout anteroventral seta and long posterior seta (adjacent to apical comb-like row of setulae). Tarsus slightly shorter than tibia, with short setae, tarsomere 1 subequal to combined length of tarsomeres $2-4$, slightly broadened, with dense setulae ventrally, tarsomeres 2 and 3 subequal in length, tarsomere 4 shorter, tarsomere 5 slightly longer than tarsomere 2. Wing: With brownish tinge, veins dark brown. Pterostigma well-developed. Anal lobe with proximal margin obscured from view. $R_{2+3}$ and $R_{4+5}$ parallel in middle part and diverging near apex with cell $r_{2+3}$ compressed in middle part and flared at apex. $\mathrm{R}_{4+5}$ sinuous with pronounced posterior curve to apex with cell $\mathrm{r}_{4+5}$ compressed in basal part. $R_{4+5}$ and $M_{1}$ diverging beyond cell dm. $M_{2}$ and $M_{4}$ subparallel beyond cell dm. Costal section $M_{1}-M_{2}$ slightly longer than $\mathrm{M}_{2}-\mathrm{M}_{4}$. Cell dm moderately-sized, extended to around middle of wing, distal section of vein $\mathrm{M}_{1}$ (beyond base of $\mathrm{M}_{2}$ ) longer than preceding section (between r-m and base of $\mathrm{M}_{2}$ ). Crossvein dm-m broadly curved and convergent with $\mathrm{M}_{1}$ distally. Abdomen (Fig. 126): Greyish-brown with blue-green tinge, with black setae on tergites and sternites. Tergites 1-5 clothed with long, dense setae laterally, setae short and sparse dorsomedially. Tergite 6 with setae along posterior margin, otherwise bare. Sternite 2 with relatively short setae. Sternites 3 and 4 with some longer setae medially and along lateral margins (lateral setae progressively stronger posteriorly). Sternite 5 modified, polished and shiny, with large spatulate setae on posterior margin, outer 2 spatulate setae about $2 \mathrm{X}$ longer than inner setae, with 1 long and strong laterally projecting seta on posterolateral margin. Sternite 6 not visible on unique undissected holotype. Segment 7 robust, bare. Sternite 8 large and subrectangular, setose, distal margin apparently with longer setae (several setae missing on holotype). Hypopygium (Fig. 126): Large, about 1/3 length of abdomen, posterior end partially enclosed by modified pregenitalic sternites. Some hypopygial structures not visible on unique undissected holotype, as noted below. Left epandrial lamella largely hidden from view, with row of thick apically branched setae adjacent to base of cercus. Left surstylar lobes not visible. Right epandrial lamella (Fig. 126) rounded basally, with surstylar lobes projecting distally and mostly hidden by sternite 5. Right ventral lobe of surstylus short, broadly rounded. Hypandrium with base bulbous and strongly produced anteriorly, with single large seta on each side of basal part (right seta broken off on unique holotype). Medial hypandrial prolongation long, straight, projected to right side, with pair of strong divergent apical setae, each seta projecting at right angle to prolongation. Postgonite mostly not visible; left and right dorsal postgonite lobes digitiform and nearly as long as long as cerci. Phallus and ejaculatory apodeme not visible. Left and right cercus with hump-like base and narrow elongate strap-like apex bearing several setae.

Female: Unknown.

Distribution and seasonal occurrence. Schistostoma caroleae sp. nov. is known from Skagit County, Washington (Fig. 253). The unique holotype was collected from the shores of the Cascade River (Fig. 11) in early June.

Etymology. This species is named after the first author's wife, Carole Chenard.

Remarks. This species was collected together with S. evisceratum and S. susanae sp. nov. along the Cascade River (Fig. 11) in Washington by the authors in June, 2018.

Schistostoma evisceratum (Melander) comb. nov.

(Figs 5, 6, 11, 12, 89, 90, 97, 98, 103, 116-125, 132-139, 153)

Microphorus evisceratus Melander, 1940b: 65.

Microphorus ravus Melander, 1940b: 67 syn. nov.

Schistostoma ravum (Melander, 1940b) comb. nov.

Type material examined. Microphor evisceratus: HOLOTYPE, ${ }^{\wedge}$ collected from Kendrick [ $\left.c a 46^{\circ} 36^{\prime} \mathrm{N} 116^{\circ} 38^{\prime} \mathrm{W}\right]$, Latah County, Idaho, USA, 7.vi.1917 (USNM), labelled: "KendrickIda/ 7.vi.17”; "ALMelander/Collection/ 1961"; 
"Microphorus/ evisceratus/ Mel."; "HOLOTYPE/ Microphorus evisceratus/ Melander [red label]" (USNM).

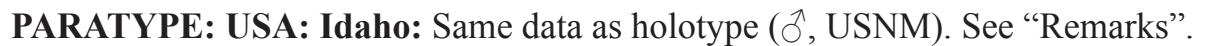
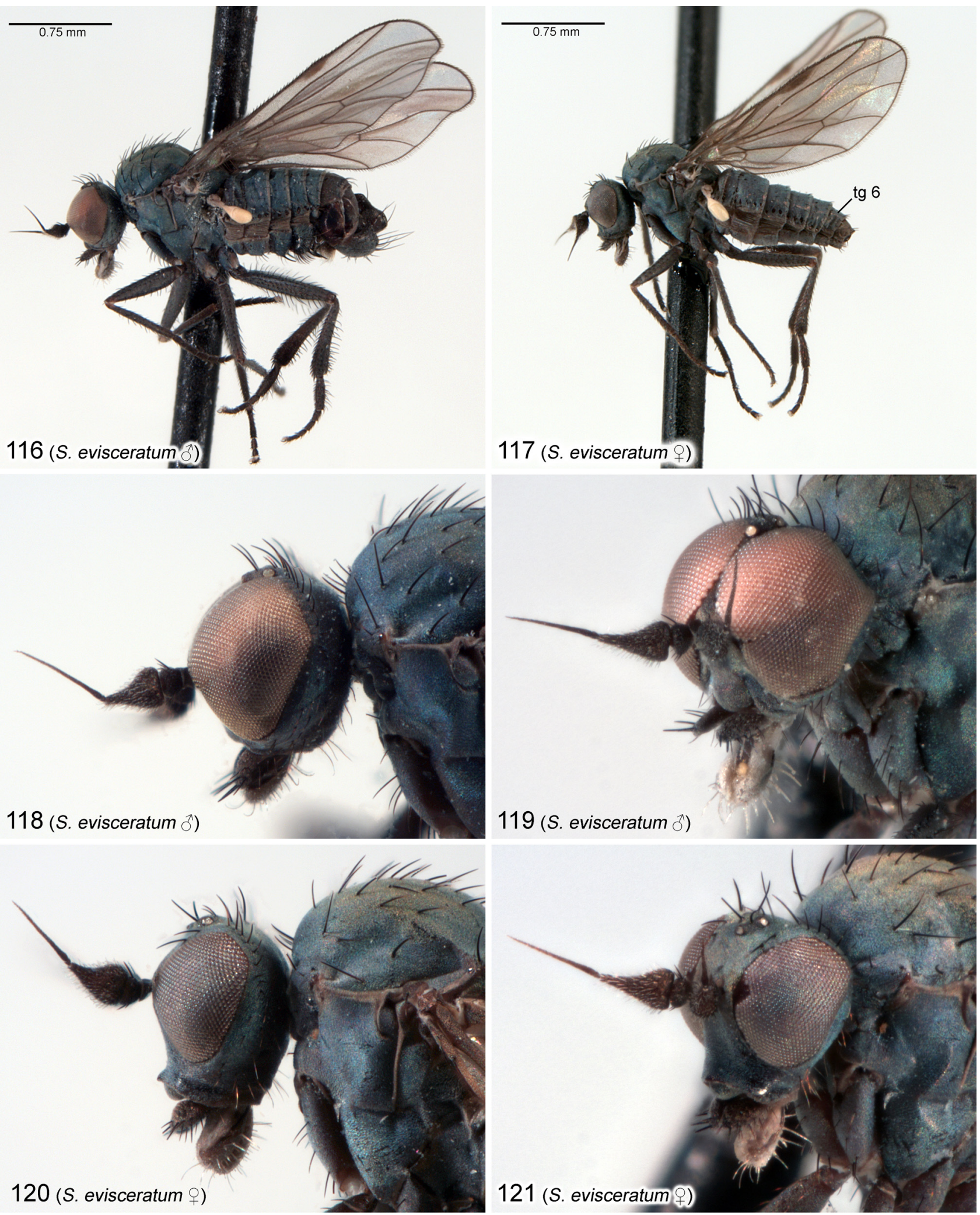

FIGURES 116-121. Habitus and head of Schistostoma evisceratum (Melander) comb. nov. 116. Male habitus. 117. Female habitus. 118. Male head and anterior portion of thorax, lateral view. 119. Male head and anterior portion of thorax, oblique view. 120. Female head and anterior portion of thorax, lateral view. 121. Female head and anterior portion of thorax, oblique view. Specimens from: La Wis Wis Campground, Washington (Figs 116, 119); Nisqually River, Washington (Figs 117, 120, 121); Nooksack River, Washington (Fig. 118). Abbreviation: tg-tergite. 

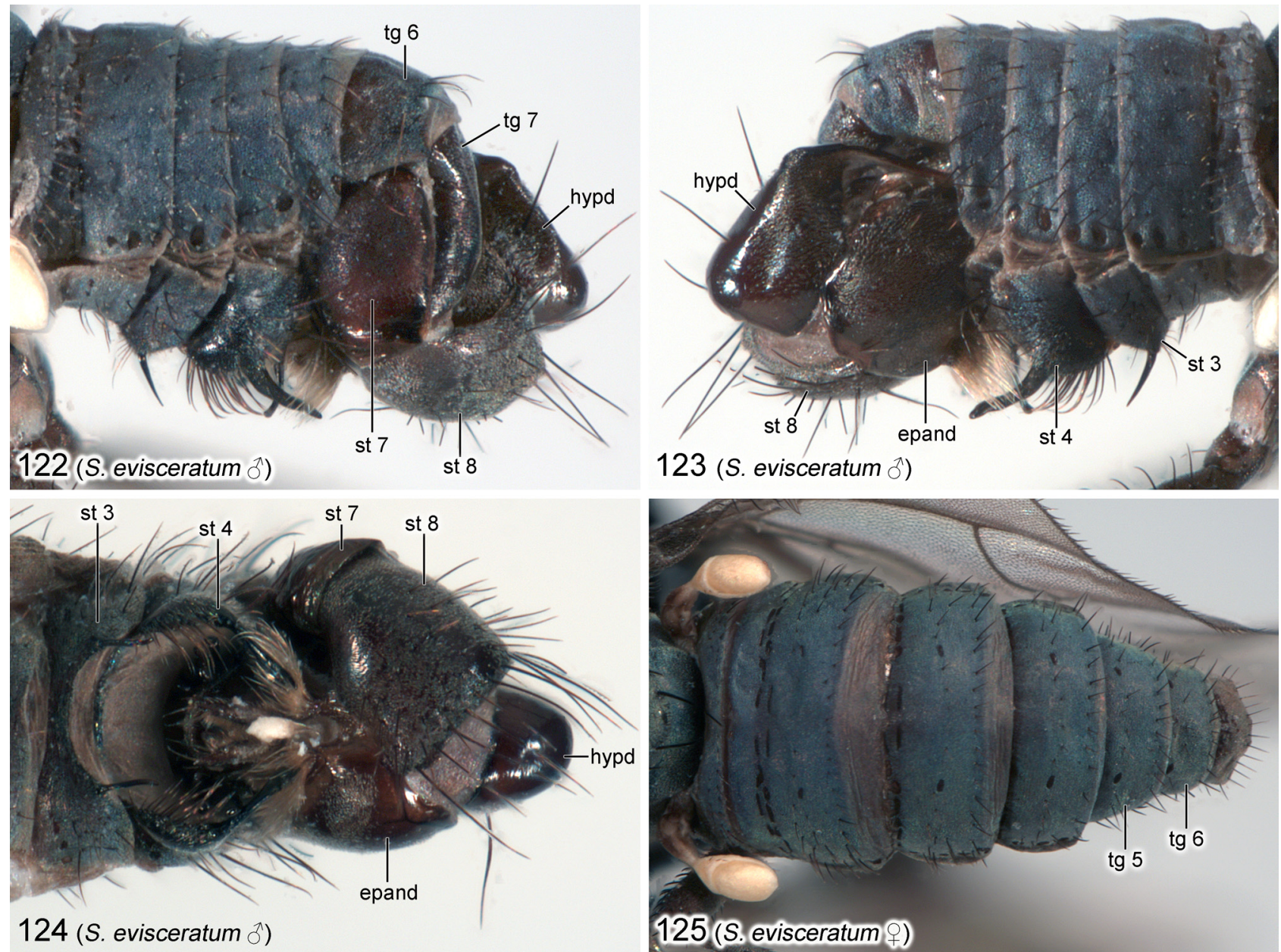

124 (S. evisceratum $\left.{ }^{\lambda}\right)$

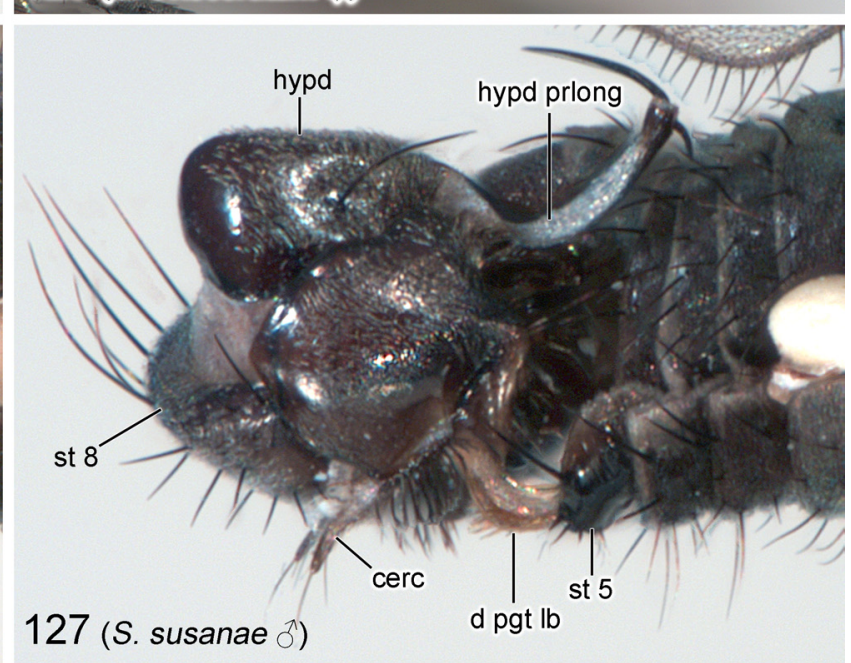

126 (S. caroleae $\left.{ }^{\jmath}\right)$ cerc

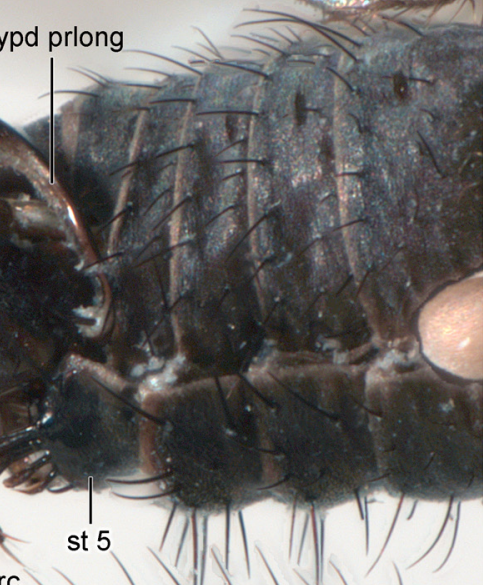
Narc

127 (S. susanae $\left.{ }^{\lambda}\right)$

FIGURES 122-127. Abdomens of Nearctic Schistostoma. 122. Male of S. evisceratum (Melander) comb. nov., left lateral view. 123. Male of $S$. evisceratum (Melander) comb. nov., right lateral view. 124. Male S. evisceratum (Melander) comb. nov., ventral view. 125. Female $S$. evisceratum (Melander) comb. nov., dorsal view. 126. Male holotype of S. caroleae sp. nov., right lateral view. 127. Male $S$. susanae sp. nov., right lateral view. Specimens from: La Wis Wis Campground, Washington (Figs 122 , 123); Cowichan Lake, British Columbia (Fig. 124); Cascade River, Washington (Figs 125, 126); Middle Fork Nooksack River, Washington (Fig. 127). Abbreviations: cerc — cercus; d pgt lb — dorsal postgonite lobe; epand —epandrium; hypd—hypandrium; hypd prlong—hypandrial prolongation; st—sternite; tg—-tergite. 

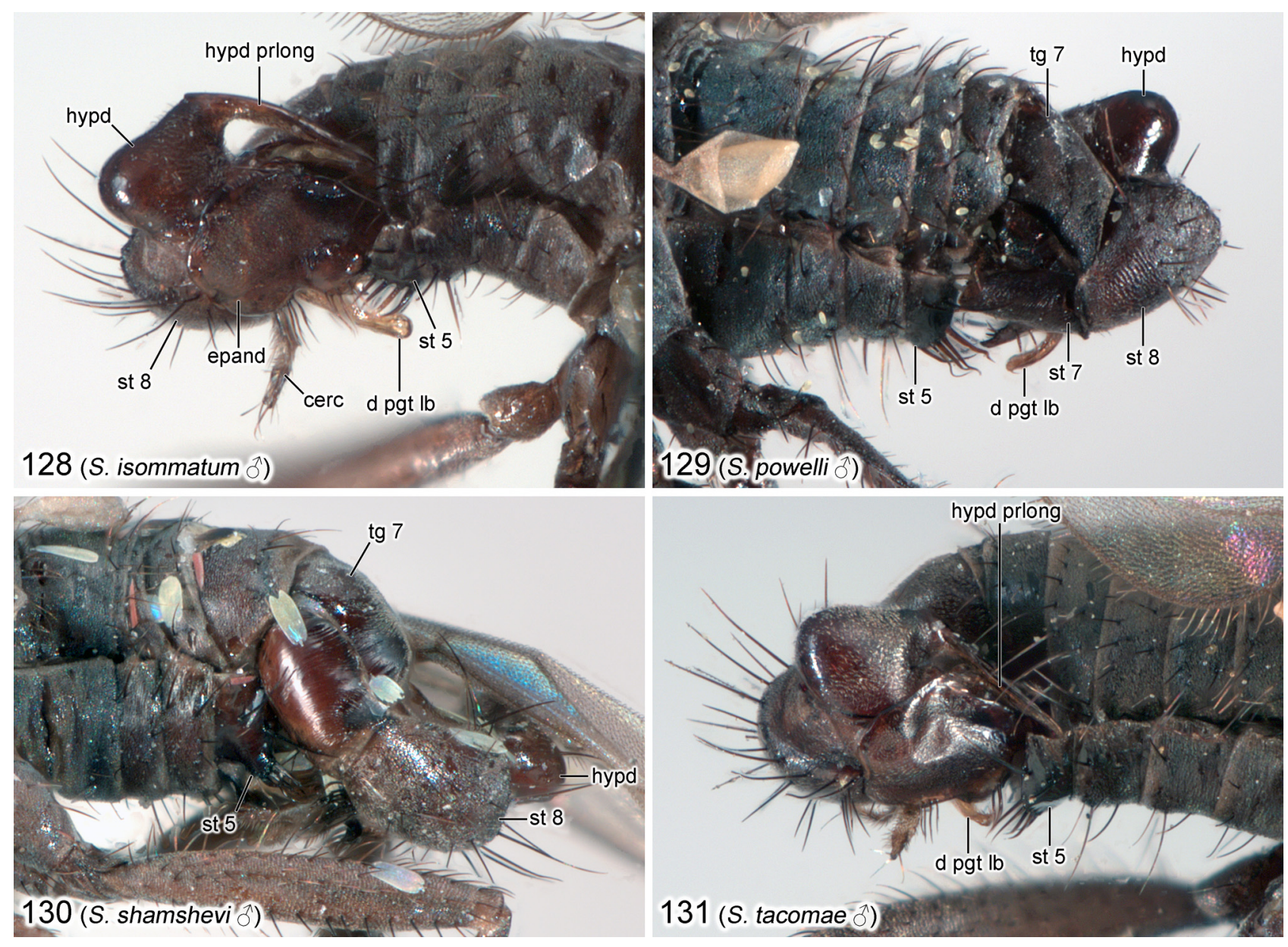

FIGURES 128-131. Male abdomens of Nearctic Schistostoma. 128. S. isommatum (Melander) comb. nov., right lateral view. 129. S. powelli sp. nov., left lateral view. 130. S. shamshevi sp. nov., holotype, left lateral view. 131. S. tacomae (Melander) comb. nov., right lateral view. Specimens from: Mt Revelstoke, British Columbia (Fig. 128); Weldon, California (Fig. 129); Slims River delta, Yukon (Fig. 130); Paradise Park, Washington (Fig. 131). Abbreviations: cerc — cercus; d pgt lb — dorsal postgonite lobe; epand — epandrium; hypd—hypandrium; hypd prlong—hypandrial prolongation; st—sternite; tg—-tergite.

Microphor ravus: HOLOTYPE, $q$ collected from Los Angeles County $\left[\mathrm{ca} 34^{\circ} 05^{\prime} \mathrm{N} 118^{\circ} 12^{\prime} \mathrm{W}\right]$, California, USA, in March, by D.W. Coquillett, labelled: "LosAngeles/ Co., CAL."; "Mar."; "Collection/ Coquillett"; "PARATYPE/ Microphorus/ ravidus/ Coq [red label]"; "ALMelander/Collection/ 1961"; "HOLOTYPE/ Microphorus/ ravus Melander, 1940 [red label]" (USNM). See "Remarks". PARATYPES: California: Humboldt County: Blue Lake [ca $40^{\circ} 52^{\prime} \mathrm{N} 124^{\circ} 00^{\prime} \mathrm{W}$ ], 20-27.vi., J.C. Bradley, Cornell U. Lot. 434 Sub. 48 (3ㅇ, USNM). Washington: Skagit County: Mt Vernon [ $\left.\mathrm{ca} 48^{\circ} 25^{\prime} \mathrm{N} 122^{\circ} 20^{\prime} \mathrm{W}\right]$, 3.vii.1924, A.L. Melander (1 9 , USNM).

Other material examined. CANADA: Alberta: Banff [ca $\left.51^{\circ} 10^{\prime} \mathrm{N} 115^{\circ} 34^{\prime} \mathrm{W}\right], 4455 \mathrm{ft}, 26 . v i .1960$, W.W.

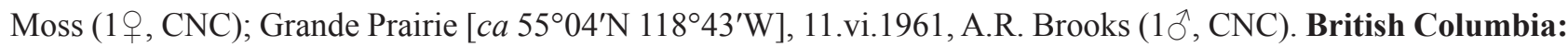

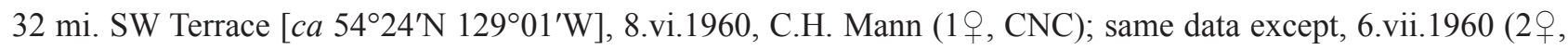
CNC); same data except, 11.vi.1960, in cut over area, low shrubs, J.G. Chillcott (1․, CNC); same data except, 9.vii.1960, cutover swampland (1, CNC); same data except, $100 \mathrm{ft}, 13 . v i i .1960$, B. Hemming (1ð̄, CNC); same data except, 5.vii.1960, in clearing near river (1, CNC); Exchamsiks River $58 \mathrm{~km} \mathrm{SW}$ of Terrace, $54^{\circ} 20.00^{\prime} \mathrm{N}$ $129^{\circ} 17.81^{\prime} \mathrm{W}, 18 . v i i i .2008$, S.E. Brooks $\left(1 \hat{\prime}, 2\right.$,, CNC); same data except, 18.viii.2008, J.M. Cumming (1 , $^{\circ}$ CNC); same data except, 15-17.viii.2008, YPT, J.M. Cumming \& S.E. Brooks (19, CNC); same data except, 15-17.viii.2008, MT, S.E. Brooks \& J.M. Cumming (2へ̂, 6우, CNC); same data except, 17-18.viii.2008, MT, S.E. Brooks \& J.M. Cumming (1⿵人, 2q, CNC); Highway 97, Salmon Valley Campground, 14.7 mi. N Prince George

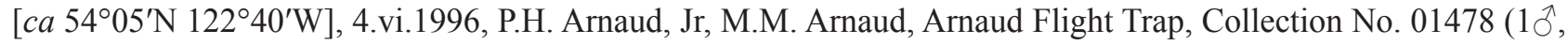
USNM); Kinbasket Reservoir, Canoe Reach nr Valemount [ca 52 $2^{\circ} 46^{\prime} \mathrm{N} 119^{\circ} 10^{\prime} \mathrm{W}$ ], 743-753m, 12.vi-17.vii.2010, N. Shaw, H. Schindler, V. Prigmore, V. Smith (37 ${ }^{\wedge}, 43$ \% , RBCM); Kitimat [ca $\left.54^{\circ} 03^{\prime} \mathrm{N} 128^{\circ} 36^{\prime} \mathrm{W}\right]$, 2.vi.1960, 


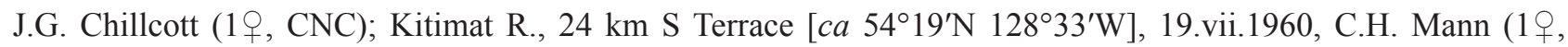
CNC); Vancouver Is., Cowichan Lake Res. Stn, $48^{\circ} 49.60^{\prime} \mathrm{N} 124^{\circ} 8.20^{\prime} \mathrm{W}, 10-11 . v i i i .2008$, YPT along lakeshore, sandy beach, J.M. Cumming \& S.E. Brooks (10^, 7q, CNC); same data except, CNC1155621, CNC1155623

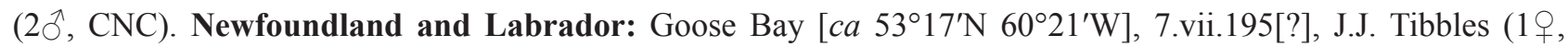
CNC). Northwest Territories: Wrigley [ $\left.c a 63^{\circ} 13^{\prime} \mathrm{N} 123^{\circ} 27^{\prime} \mathrm{W}\right]$, 14.vi.1969, G.E. Shewell (1ㅇ, CNC) Ontario: Thunder Bay Dist., mouth of Pic River, N side, $48^{\circ} 36^{\prime} \mathrm{N} 86^{\circ} 18^{\prime} \mathrm{W}$, dunes/Equisetum, yellow pans, 19-22.vii.2001, M. \& B. Buck, (1 $\hat{\jmath}$, UGIC); same data except, dunes/Arctostaphylos (1ㅇ, UGIC). USA: Alaska: Valdez-Cordova Census Area: Chitina [ca $61^{\circ} 30^{\prime} \mathrm{N} 144^{\circ} 26^{\prime} \mathrm{W}$ ], 18.vi.1953, W.C.F. (19, WSU); Valdez [ca $61^{\circ} 08^{\prime} \mathrm{N} 146^{\circ} 20^{\prime} \mathrm{W}$ ], 5.vii.1948, AlaskaIns Project, R.I. Sailer (1+, USNM). California: Alpine County: Arnot Creek nr Clark Fork

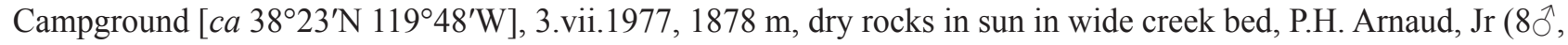

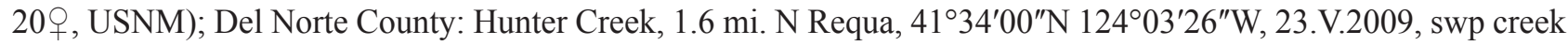
margin \& veg., S.E. Brooks (2ㅇ, CNC); Jedediah Smith Redwoods SP, Howland Hill Rd at Mill Creek [ca 41 ${ }^{\circ} 46^{\prime} \mathrm{N}$ $124^{\circ} 05^{\prime}$ W], 16.v.1978, D.D. Wilder (48 $0^{\top}, 57$, CAS); Jedediah Smith Redwoods SP, Smith River at end Walker

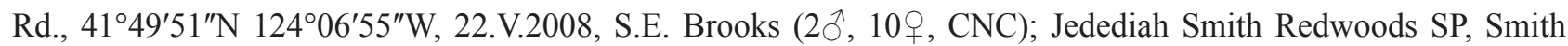

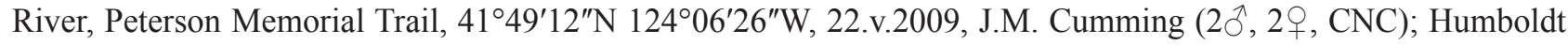

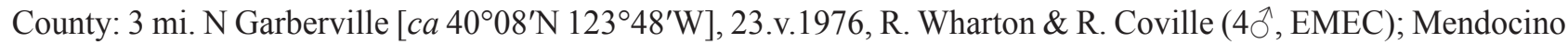

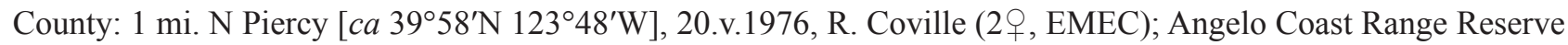

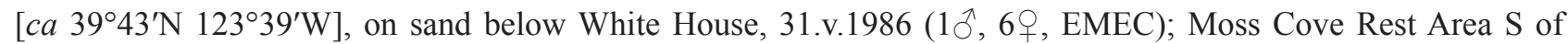

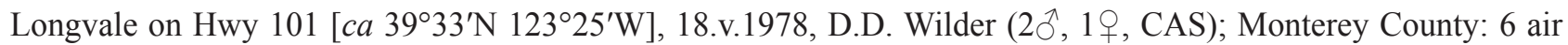
mi. SW Greenfield, Arroyo Seco River [ca $\left.36^{\circ} 16^{\prime} \mathrm{N} 121^{\circ} 19^{\prime} \mathrm{W}\right], 400 \mathrm{ft}, 9 / 10 . v .1975$, flight trap, E. Rogers $\left(1 \delta^{\top}\right.$,

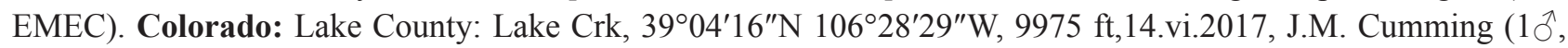

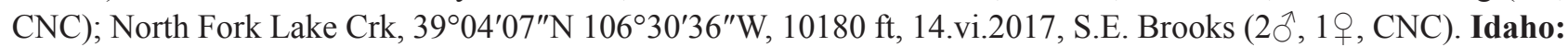

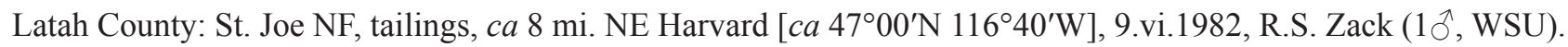
Indiana: Tippecanoe County: Lafayette $\left[\mathrm{ca} 40^{\circ} 24^{\prime} \mathrm{N} 86^{\circ} 54^{\prime} \mathrm{W}\right.$ ], 20/27.v.1917, on sand by stream abundant, J.M. Aldrich Coll (5 $0^{\wedge}, 5$,, USNM). Oregon: Hood River County: $18 \mathrm{mi}$. S. Hood River [ca $45^{\circ} 42^{\prime} \mathrm{N} 121^{\circ} 31^{\prime} \mathrm{W}$ ],

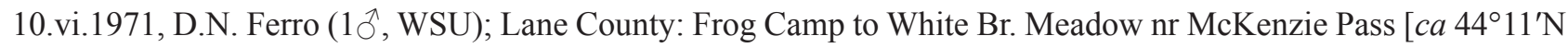
$121^{\circ} 53^{\prime} \mathrm{W}$ ], 4700-5675 ft, 6.viii.1935, H.A. Scullen (1, CUIC). Washington: Jefferson County: Olympic NP,

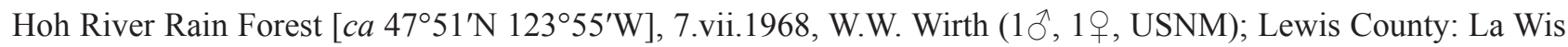
Wis Campground, $46^{\circ} 40^{\prime} 30^{\prime \prime} \mathrm{N} 121^{\circ} 35^{\prime} 17^{\prime \prime} \mathrm{W}, 1240 \mathrm{ft}, 14 . v i .2018$, S.E. Brooks (5 $\jmath^{\wedge}, 17$,, CNC); same data except,

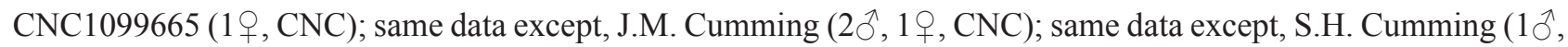

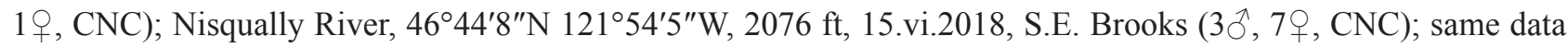
except, J.M. Cumming $\left(1 \jmath^{\top}, 4+\right.$, CNC); Mason County: $17.5 \mathrm{~km}$ NW Lilliwaup, Staircase, Olympic NP, E side of

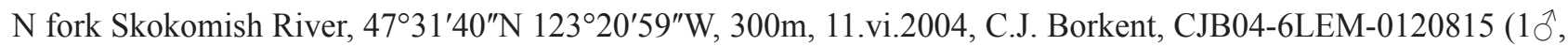
LEMQ); Skagit County: Cascade River margin, $48^{\circ} 27^{\prime} 54^{\prime \prime} \mathrm{N} 121^{\circ} 13^{\prime} 1^{\prime \prime} \mathrm{W}, 1186 \mathrm{ft}$, 9.vi.2018, S.E. Brooks (13 ${ }^{\prime}$, 34ㅇ, CNC); same data except, 17.vi.2018 (2犬̂, 6우, CNC); same data except, J.M. Cumming (2ㅇ, CNC); same

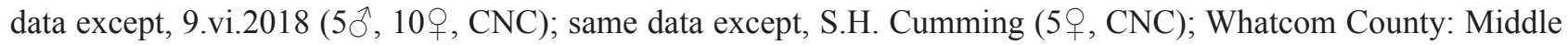
Fork Nooksack River, $48^{\circ} 47^{\prime} 5^{\prime \prime} \mathrm{N} 122^{\circ} 6^{\prime} 49^{\prime \prime} \mathrm{W}, 535 \mathrm{ft}$, 11.vi.2018, at bridge, S.E. Brooks (8วิ, 18ㅇ, CNC); same

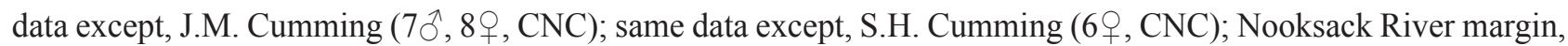

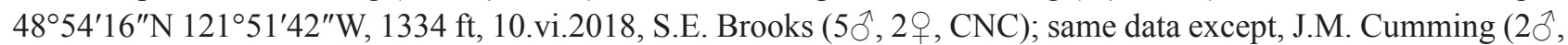
1 ,, $\mathrm{CNC}$ ); Yakima County: 8 mi. SW Tieton R.S., Bear Creek [ca $\left.46^{\circ} 32^{\prime} \mathrm{N} 121^{\circ} 15^{\prime} \mathrm{W}\right]$, nr Rimrock Lake, $3000 \mathrm{ft}$, 7-9.vi.1983, Malaise, W.J. Turner (1今ึ, WJTC).

Diagnosis. As indicated in couplet 36 of the key, this distinctive and widespread species is easily distinguished from other members of the $S$. isommatum species group by its highly modified male pregenitalic abdominal sternites (Figs 122-124), cluster of pale brush-like epandrial setae beside cerci (Fig. 136), and blueish-grey body colour of both sexes (Figs 116, 117).

Redescription. Male (Figs 89, 116-119, 122-124, 132-139): Body length 2.1-2.6 mm, wing length 2.0-2.3 $\mathrm{mm}$. Head (Figs 118, 119): Ocellar tubercle with 2 pairs of black proclinate setae, anterior pair distinctly longer than posterior pair. Occiput blueish-grey pruinose, mostly clothed with black or brown setae, almost bare in upper part, except for postoculars. Gena and parafacial slightly projected along lower eye margin. Antenna dark brown; postpedicel conical, evenly tapered to apex; stylus about $1.5 \mathrm{X}$ length of postpedicel. Palpus grey to dark brown, elongate ovate, slightly longer than length of labrum, pubescent with microtrichia and bearing scattered black setulae. Proboscis brown, slightly less than $1 / 2$ as long as head height, directed forward. Thorax (Figs 116, 118, 119): 


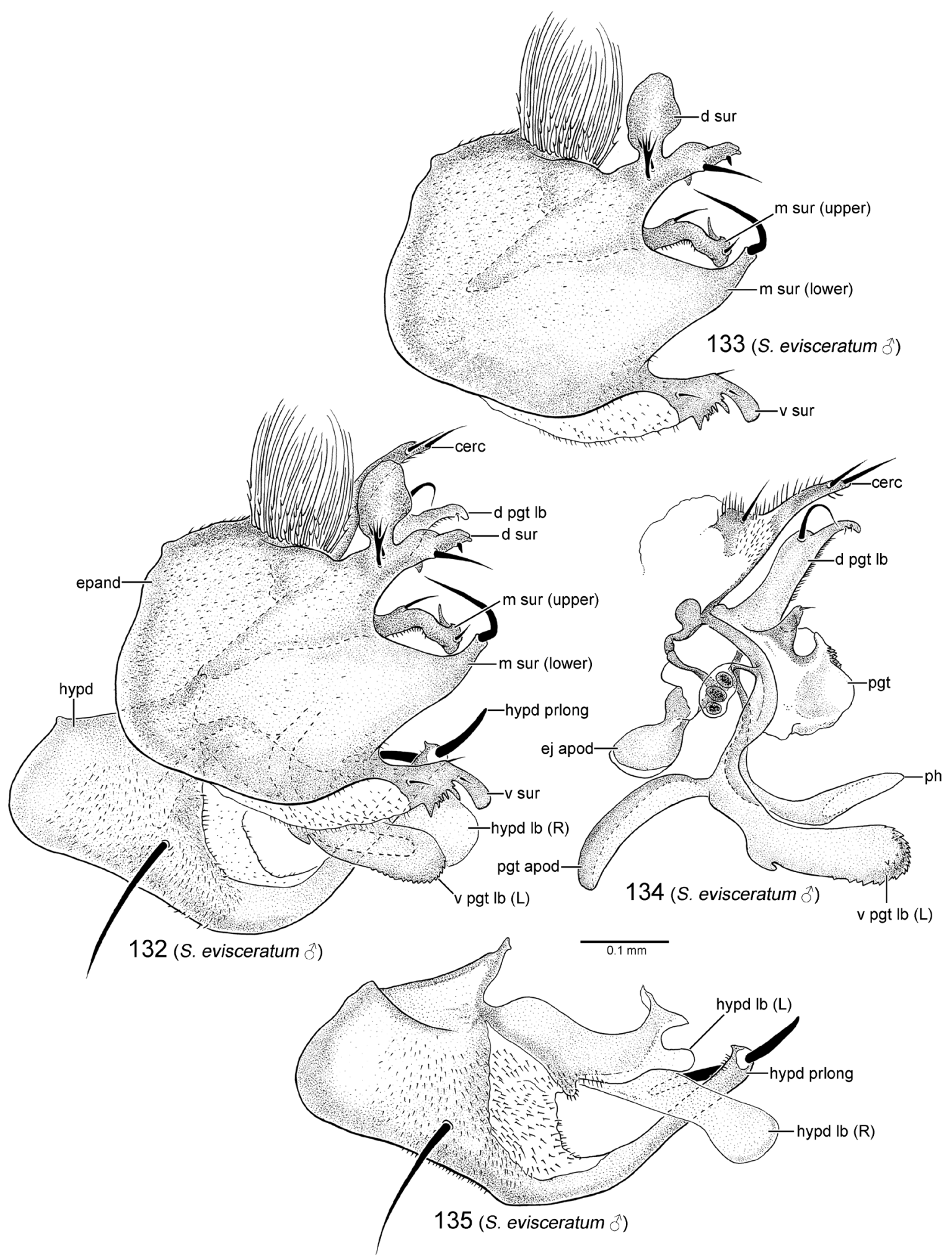

FIGURES 132-135. Hypopygium of Schistostoma evisceratum (Melander) comb. nov., left lateral view 132. Hypopygium. 133. Epandrium. 134. Phallus, postgonite and cercus. 135. Hypandrium. Figures 132 and 133 based on specimen CNC1155623 (Cowichan Lake Res. Stn, British Columbia). Figures 134 and 135 based on specimen CNC1155621 (Cowichan Lake Res. Stn, British Columbia). Abbreviations: cerc-cercus; d pgt lb-dorsal postgonite lobe; d sur-dorsal lobe of surstylus; ej apod - ejaculatory apodeme; epand - epandrium; hypd — hypandrium; hypd lb-hypandrial lobe; hypd prlong-hypandrial prolongation; (L)—left; m sur—middle lobe of surstylus; pgt—postgonite; pgt apod—postgonite apodeme; ph—phallus; (R)— right; v pgt lb—ventral postgonite lobe; v sur—ventral lobe of surstylus. 


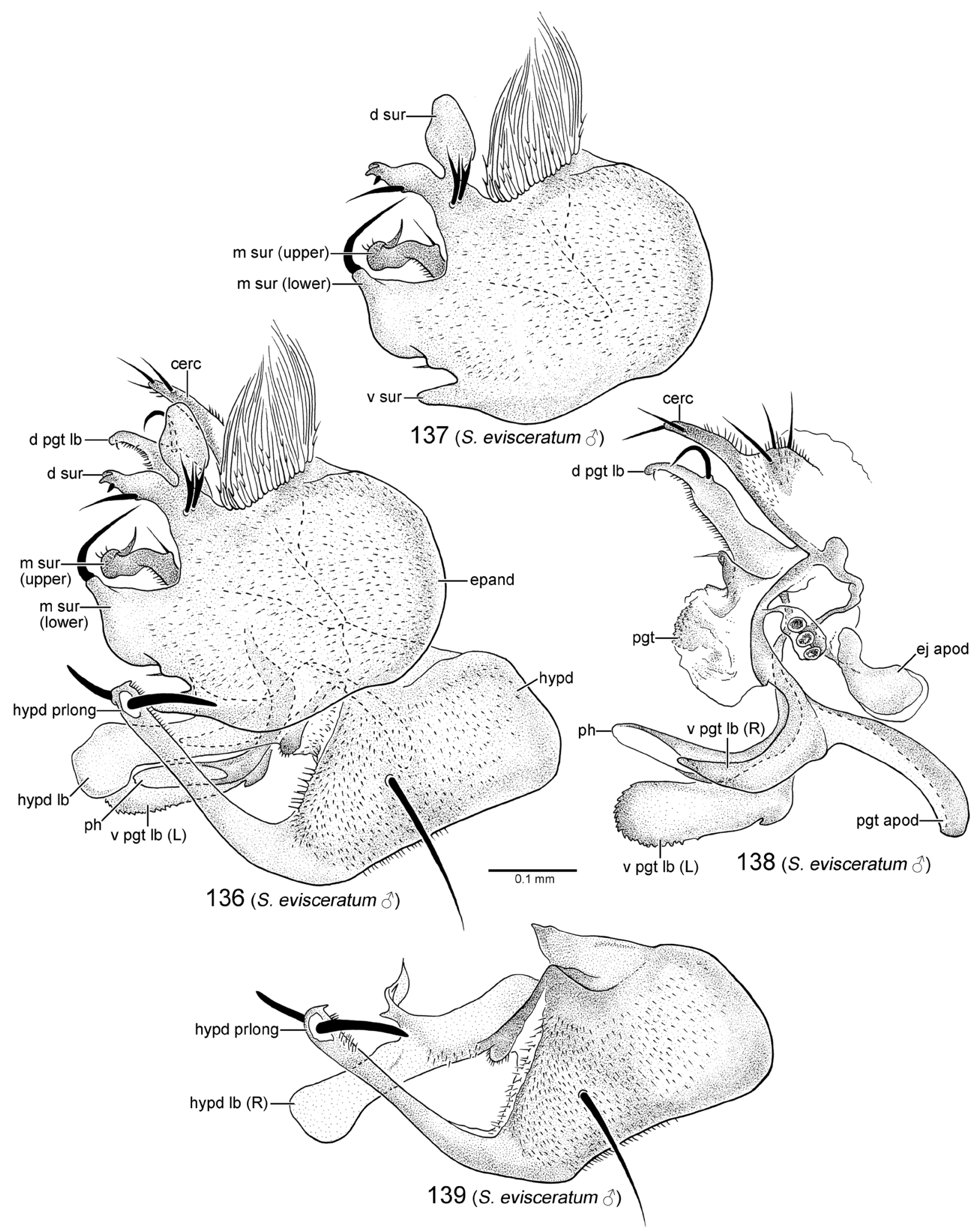

FIGURES 136-139. Hypopygium of Schistostoma evisceratum (Melander) comb. nov., right lateral view 136. Hypopygium. 137. Epandrium. 138. Phallus, postgonite and cercus. 139. Hypandrium. Figures 136 and 137 based on specimen CNC1155623 (Cowichan Lake Res. Stn, British Columbia). Figures 138 and 139 based on specimen CNC1155621 (Cowichan Lake Res. Stn, British Columbia). Abbreviations: cerc-cercus; d pgt lb-dorsal postgonite lobe; d sur-dorsal lobe of surstylus; ej apod - ejaculatory apodeme; epand - epandrium; hypd—hypandrium; hypd lb-hypandrial lobe; hypd prlong—hypandrial prolongation; (L) — left; $\mathrm{m}$ sur — middle lobe of surstylus; pgt—postgonite; pgt apod — postgonite apodeme; ph—phallus; (R) — right; v pgt lb—ventral postgonite lobe; v sur—ventral lobe of surstylus. 
Mesonotum blueish-grey with brownish-gold tints dorsally. Proepisternum with 1-2 setae. Mesonotal setae black, relatively long with dorsocentrals arranged in single row per side. Notopleuron with 2 strong setae. Scutellum with 2 pairs of setae, inner pair stronger. Mesopleuron blueish-grey. Halter pale. Legs (Fig. 116): Blackish-brown with faint blueish reflections, with black setae. Foreleg: Coxa with several setae on anterior surface. Femur subequal in length to tibia, posterior surface with series of slightly longer posterodorsal and posteroventral setae (shorter than femur width) and shorter setae along middle, anterior surface with series of short anteroventral setae in basal third, otherwise with short sparse setae. Tibia slender, with series of 3-4 long erect posterodorsal setae (slightly longer than tibia width) along basal half, otherwise with short setae. Tarsus subequal in length to tibia, with short setae, tarsomere 1 subequal to combined length of tarsomeres 2-4, with small basiventral seta and adjacent setulae, tarsomeres 2-4 decreasing in length apically, tarsomere 5 subequal in length to tarsomere 2. Midleg: Coxa setose on anterior surface, with 1-3 shorter setae on posterior surface. Femur subequal in length to tibia, posterior and anterior surfaces with short setae. Tibia slender, with short setae, with 1 erect slightly thicker anterodorsal seta near basal 1/4, with 1 long stout preapical ventral seta (about $2 \mathrm{X}$ tibia width). Tarsus slightly shorter than tibia, with short setae, tarsomere 1 subequal to combined length of tarsomeres 2-4, with 2-3 stout erect basiventral setae, apex enlarged, tarsomeres 2-4 decreasing in length apically, tarsomere 5 subequal in length to tarsomere 3. Hindleg: Coxa with 3 setae on outer surface and a few setae near apex of anterior surface. Femur subequal in length to tibia, with series of longer anteroventral setae on distal half (subequal to femur width) and relatively shorter series of dorsal setae, anterior surface with short setae, posterior surface with short fine setae. Tibia (Fig. 116) enlarged apically, with series of longer dorsal setae (subequal to basal tibia width) and series of shorter erect anterodorsal setae, otherwise with short setae (denser apically), ventral surface with short setae basally giving rise to dense setulae apically, apical margin with stout anteroventral seta and long stout posterior seta (adjacent to apical comb-like row of setulae). Tarsus slightly shorter than tibia, tarsomere 1 slightly longer than combined length of tarsomeres 2-4, slightly broadened, with relatively long fine dorsal setae (subequal to slightly longer than tarsomere width), with dense setulae ventrally, tarsomeres 2-5 with short setae, tarsomeres 2-4 decreasing in length apically, tarsomere 5 subequal in length to tarsomere 2. Wing (Fig. 89): With slight greyish tinge, veins dark brown. Pterostigma welldeveloped. Anal lobe with proximal margin straight. $\mathrm{R}_{2+3}$ and $\mathrm{R}_{4+5}$ parallel in middle part and diverging near apex with cell $r_{2+3}$ compressed in middle part and flared at apex. $R_{4+5}$ sinuous with pronounced posterior curve to apex with cell $\mathrm{r}_{4+5}$ compressed in basal part. $\mathrm{R}_{4+5}$ and $\mathrm{M}_{1}$ diverging beyond cell $\mathrm{dm} . \mathrm{M}_{2}$ and $\mathrm{M}_{4}$ subparallel beyond cell $\mathrm{dm}$. Costal section $\mathrm{M}_{1}-\mathrm{M}_{2}$ subequal to $\mathrm{M}_{2}-\mathrm{M}_{4}$. Cell dm moderately-sized, extended to around middle of wing, distal section of vein $M_{1}$ (beyond base of $M_{2}$ ) longer than preceding section (between $r-m$ and base of $M_{2}$ ). Crossvein dm-m broadly curved and convergent with $\mathrm{M}_{1}$ distally. Abdomen (Figs 122-124, 132-139): Blueish-grey, with black setae on tergites and sternites. Tergites $1-5$ clothed with long, dense setae laterally, setae tiny and sparse dorsomedially. Tergite 6 with setae along posterior margin, otherwise bare. Sternite 2 with short setae. Sternites 3-5 modified and adorned with specialized setae. Sternites 3 and 4 laterally with long setae. Sternite 3 with thick blunttipped seta on each side of posteromedial emargination. Sternite 4 with large medial membranous cavity enclosed by projecting lateral margin of sternite adorned with ventral setal fringe and large spatulate seta. Sternite 5 (mostly hidden by sternite 4 ) with 3 large highly modified setae per side on posterior margin, outer 2 setae spatulate. Sternite 6 angled dorsally, bare, hidden by sternite 5 . Segment 7 robust, bare. Sternite 8 large and subtriangular, widening distally, setose, distal margin with fringe of longer setae. Hypopygium (Figs 132-139): Large, about 1/2 length of abdomen, posterior end partially enclosed by modified pregenitalic sternites. Left epandrial lamella (Figs 132, 133) rounded basally, with surstylar lobes projecting distally, with dense brush-like row of fine pale setae adjacent to base of cercus. Left dorsal lobe of surstylus with lateral pair of branch-tipped setae near base of ovoid dorsal projection, distal portion bearing strong midventral seta and bifid apex with short preapical spine-like seta ventrally, medial surface with broadly rounded projection. Left upper middle lobe of surstylus digitiform, ventrally bent near middle, with basal and preapical setae and leaf-like medially directed apical process. Left lower middle lobe of surstylus subtriangular, tapered to narrow upturned apex bearing large hook-like seta. Left ventral lobe of surstylus serrate ventrally with downturned thumb-like tip, with 3 short setae, membranous basiventrally. Right epandrial lamella (Figs 136, 137) largely similar to left side. Right dorsal lobe of surstylus similar to left side. Right upper middle lobe of surstylus similar to left side. Right lower middle lobe of surstylus similar to left side, but with ventral margin rounded. Right ventral lobe of surstylus short, simple, thumb-like. Hypandrium (Figs 135, 139) with base bulbous and strongly produced anteriorly, with single large seta on each side of basal part. Medial hypandrial prolongation long, straight, projected to right side, with pair of strong divergent apical setae, each seta projecting at right angle 
to prolongation, setae of similar length. Left hypandrial lobe small and short with rounded apex, covered by ventral lobe of surstylus. Right hypandrial lobe broad and elongate with apex expanded and rounded. Left dorsal postgonite lobe as long as cercus, evenly broad in basal $2 / 3$ with curved dorsal seta, apex narrow, digitiform and curved down. Left ventral postgonite lobe broad and long with apex expanded and serrate, with small ventral process near base. Right dorsal postgonite lobe similar to left side. Right ventral postgonite lobe short narrow and pointed apically, covered by hypandrial lobe. Postgonite apodeme narrowly heart-shaped in ventral view, unbranched. Phallus (Figs $134,138)$ slender, broadly C-shaped and projecting posteriorly. Ejaculatory apodeme ovoid. Left and right cercus (Figs 132, 134, 136, 138) with hump-like base and narrow elongate strap-like apex bearing several setae.

Female (described for the first time, Figs 90, 97, 98, 103, 117, 120, 121, 125): Body length 1.8-2.6 mm, wing length 1.8-2.3 mm. Similar to male except as follows: Head (Figs 120, 121): Gena and parafacial distinctly projected along lower eye margin. Thorax (Figs 117, 120, 121). Legs (Fig. 117): With shorter setae. Midleg: Tarsomere 1 without enlarged apex. Wing (Fig. 90): Anal lobe slightly smaller. $\mathrm{R}_{4+5}$ with posterior curve slightly weaker. Abdomen (Figs 117, 125): Tergites and sternites with short setae. With 7 exposed abdominal segments, segment 7 concolorous with anterior abdominal segments. Terminalia (Figs 97, 98, 103): Segment 6 with tergite and sternite subrectangular (wider than long), with setae on posterior half. Segment 7 with tergite subrectangular (slightly wider than long), sternite subquadrate, with setae on posterior third, with band-like posterior sclerite extension on each side (tergite extensions broad, sternite extensions narrow). Tergite 8 narrowly divided (desclerotized) medially, with pair of setae laterally, narrowly fused to sternite 8 anterolaterally. Sternite 9 desclerotized and inconspicuous. Spermatheca (Fig. 103) elongate-ovoid. Syntergite 9+10 with hemitergites subquadrate, each with 4 acanthophorite setae. Sternite 10 with anterior margin narrowly sclerotized and divided (desclerotized) medially, mainly membranous posteriorly, with setulae and short setae. Cercus short, wider than long, membranous ventrally, rounded apically, with prominent subapical seta and additional short setae ventrally.

Distribution and seasonal occurrence. Schistostoma evisceratum is a widespread transcontinental species, known from Alaska, Northwest Territories and Labrador in the north to southern California, Colorado and Indiana in the south (Fig. 153). Adults have been collected from March to mid-August, generally along rivers and lakeshores (Figs 11, 12).

Remarks. Melander (1940b) mentions a second paratype of M. evisceratus (presumably a male) from Upper St. Regis River, Montana, July 28, 1918, but the whereabouts of this specimen are unknown. We have added new type labels to the holotype and paratype specimens of $M$. evisceratus examined. We have also added new type labels to the holotype and paratype specimens of M. ravus. The female holotype of M. ravus Melander 1940b: 67 is also a paralectotype of M. ravidus Coquillett 1895: 409; see "Remarks" under Schistostoma ravidum (Coquillett) below, and we have added a $M$. ravidus paralectotype label to that specimen.

Flower visitation records for this species are listed in Table 1.

This species was collected together with $S$. caroleae sp. nov. and S. susanae sp. nov. along the Cascade River (Fig. 11), and also with $S$. susanae sp. nov. along the the Cowlitz River at La Wis Wis Campground and along the Middle Fork of the Nooksack River in Washington by the authors in June, 2018.

\section{Schistostoma fitzgeraldi sp. nov.}

(Figs 151, 152, 253)

urn:lsid:zoobank.org:act: B8B9104C-A07B-4950-8528-AD678FE7EF38

Type material. HOLOTYPE, $\widehat{\partial}$ collected from Hunter Creek, $1.6 \mathrm{mi}$. N Requa, Del Norte County, California, 23.v.2009, by S.E. Brooks, labelled: "USA: CA: Del Norte County/ Hunter Crk., 1.6 mi. N Requa/ N41 $34^{\circ} 00^{\prime \prime}$ W12403'26"/ 23.V.2009, swp creek margin/ \& veg., S.E. Brooks"; "HOLOTYPE/ Schistostoma fitzgeraldi/ Brooks \& Cumming [red label]" (CNC). PARATYPES: USA: California: Same data as holotype (16 $\jmath^{\circ}, 3$, CNC); same data as holotype except, J.M. Cumming $(25 \hat{\jmath}, 3 \uparrow, \mathrm{CNC})$.

Other material examined. USA: Oregon: Clackamas County: Bruin Run Creek, Camp Creek Campground

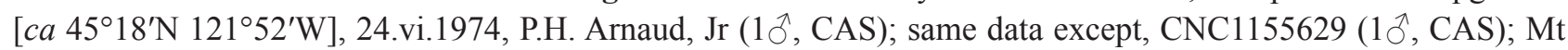
Hood NF, Tollgate Campground T3S R7E Sec. 11 [ca $45^{\circ} 19^{\prime} \mathrm{N} 121^{\circ} 54^{\prime} \mathrm{W}$ ], 22.vi.1977, D.D. Wilder (1 ${ }^{\lambda}$, CAS). Washington: Yakima County: $10 \mathrm{mi}$. E Chinook Pass, $3400 \mathrm{ft}$, on American River [ $c a 46^{\circ} 56^{\prime} \mathrm{N} 121^{\circ} 20^{\prime} \mathrm{W}$ ], 12.vii.1977, sweeping, W.J. Turner $(1 \delta$, 1 \%, WJTC). 
Diagnosis. This species is very close to $S$. susanae sp. nov. and $S$. sinclairi sp. nov., and is distinguished from other members of the $S$. isommatum species group by the short marginal setae on male abdominal sternite 5 , long curved medial hypandrial prolongation, broad spiculate dorsal postgonite lobe, and shape of the dorsal lobe of the surstylus (Figs 151, 152), as indicated in the key (couplets 37, 42, 43).

Description. Male (Figs 151, 152): Body length 1.7-2.0 mm, wing length 1.9-2.1 mm. Head: Ocellar tubercle with 2 pairs of black proclinate setae, anterior pair distinctly longer than posterior pair. Occiput dark grey pruinose, mostly clothed with black or brown setae, almost bare in upper part, except for postoculars. Gena and parafacial moderately projected along lower eye margin. Antenna dark brown; postpedicel conical, evenly tapered to apex; stylus about 2.0X length of postpedicel. Palpus brownish-grey, elongate ovate, slightly longer than length of labrum, pubescent with microtrichia and bearing scattered black setulae. Proboscis brown, slightly less than $1 / 2$ as long as head height, directed forward. Thorax: Mesonotum brownish-grey. Proepisternum with 1-2 setae. Mesonotal setae black, relatively long with dorsocentrals arranged in single row per side. Notopleuron with 2 strong setae. Scutellum with 2 pairs of setae, inner pair stronger. Mesopleuron grey. Halter pale. Legs: Blackish-brown, with black setae. Foreleg: Coxa with several setae on anterior surface. Femur subequal in length to tibia, posterior surface with series of posteroventral setae increasing in length distally (at most slightly longer than femur width) and shorter setae on upper half, anterior surface with series of short anteroventral setae in basal third, otherwise with short sparse setae. Tibia slender, with series of 3-5 long erect posterodorsal setae (longer than tibia width) along basal half, otherwise with short setae. Tarsus subequal in length to tibia, with short setae, tarsomere 1 subequal to combined length of tarsomeres 2-4, with small basiventral seta and adjacent setulae, tarsomeres 2-4 decreasing in length apically, tarsomere 5 subequal in length to tarsomere 2. Midleg: Coxa setose on anterior surface, with 1-3 setae on posterior surface. Femur subequal in length to tibia, posterior and anterior surfaces with short setae. Tibia slender, with short setae, with 1 long stout preapical ventral seta (about $2 \mathrm{X}$ tibia width). Tarsus slightly shorter than tibia, with short setae, tarsomere 1 subequal to combined length of tarsomeres $2-4$, with several short ventral setae, apex usually weakly enlarged (sometimes indistinctly), tarsomeres 2-4 decreasing in length apically, tarsomere 5 subequal in length to tarsomere 2. Hindleg: Coxa with 3 setae on outer surface and a few setae near apex of anterior surface. Femur subequal in length to tibia, with series of longer anteroventral setae (at most slightly longer than femur width) and relatively shorter series of dorsal setae, anterior surface with short setae, posterior surface with short fine setae. Tibia enlarged apically, with short setae. Tarsus slightly shorter than tibia, with short setae, tarsomere 1 subequal to combined length of tarsomeres $2-4$, with setulae ventrally, tarsomeres $2-4$ decreasing in length apically, tarsomere 5 subequal in length to tarsomere 3. Wing: With slight grey-brown tinge, veins dark brown. Pterostigma well-developed. Anal lobe with proximal margin straight. $\mathrm{R}_{2+3}$ and $\mathrm{R}_{4+5}$ parallel in middle part and diverging near apex with cell $\mathrm{r}_{2+3}$ compressed in middle part and flared at apex. $\mathrm{R}_{4+5}$ sinuous with pronounced posterior curve to apex with cell $r_{4+5}$ compressed in basal part. $R_{4+5}$ and $M_{1}$ diverging beyond cell $\mathrm{dm} . \mathrm{M}_{2}$ and $\mathrm{M}_{4}$ subparallel beyond cell $\mathrm{dm}$. Costal section $\mathrm{M}_{1}-\mathrm{M}_{2}$ subequal to $\mathrm{M}_{2}-\mathrm{M}_{4}$. Cell $\mathrm{dm}$ moderately-sized, extended to around middle of wing, distal section of vein $M_{1}$ (beyond base of $M_{2}$ ) longer than preceding section (between r-m and base of $\mathrm{M}_{2}$ ). Crossvein dm-m broadly curved and convergent with $M_{1}$ distally. Abdomen (Figs 151, 152): Dark browngrey, with black setae on tergites and sternites. Tergites 1-5 clothed with long, dense setae laterally, setae short and sparse dorsomedially. Tergite 6 with setae along posterior margin, otherwise bare. Sternites $2-4$ with some long and short setae medially, sternites 3 and 4 with longer setae along lateral margins (progressively stronger posteriorly). Sternite 5 modified, polished and shiny, shallowly emarginate posteromedially, with tiny medial protrusion and short spine-like marginal setae on each side of emargination, with 2 long strong laterally projecting setae near outer margin. Sternite 6 angled dorsally, bare. Segment 7 robust, bare. Sternite 8 large and subrectangular, setose, distal margin with longer setae. Hypopygium (Figs 151, 152): Large, nearly 1/2 length of abdomen, posterior end partially enclosed by pregenitalic sternites. Left epandrial lamella (Fig. 151) rounded basally, with surstylar lobes projecting distally, with row of apically branched setae adjacent to base of cercus. Left dorsal lobe of surstylus broad, convex dorsally with ventral bend near middle, with strong lateral seta at base and weaker seta closer to apex; apex with short dentiform apicodorsal process, without notch, ventral margin irregular with strong seta. Left upper middle lobe of surstylus digitiform, with close-set pair of setae near middle, apex with strong claw-like seta projecting medially. Left lower middle lobe of surstylus broad and flap-like, rounded apically with long apical seta. Left ventral lobe of surstylus serrate ventrally with pointed downturned tip, with 3 short setae, membranous basiventrally. Right epandrial lamella (Fig. 152) largely similar to left side. Right dorsal lobe of surstylus similar to left side. Right upper middle lobe of surstylus similar to left side. Right lower middle lobe of surstylus similar to left side, but ventral 
margin with short setae and basal projection. Right ventral lobe of surstylus dorsoventrally flattened, with rounded apex. Hypandrium with base bulbous and strongly produced anteriorly, with single large seta on each side of basal part. Medial hypandrial prolongation long, curved to right side, with pair of strong divergent apical setae, each seta projecting at right angle to prolongation, right seta longer. Left hypandrial lobe short, covered by ventral lobe of surstylus. Right hypandrial lobe broad and elongate, apex with narrow down-curved dorsal flap-like projection. Left dorsal postgonite lobe longer than cercus, broad, with dorsal fringe of spicules near base. Left ventral postgonite lobe broad and long with apex rounded and serrate, with small ventral process near base. Right dorsal postgonite lobe similar to left side. Right ventral postgonite lobe short narrow and pointed apically, covered by hypandrial lobe. Postgonite apodeme narrowly heart-shaped in ventral view, unbranched. Phallus slender, broadly C-shaped and projecting posteriorly. Ejaculatory apodeme subrectangular. Left and right cercus with hump-like base and narrow elongate digitiform apex bearing long apical seta.

Female: Body length 2.0-2.1 mm, wing length 2.1-2.2 mm. Similar to male except as follows: Head: Gena and parafacial distinctly projected along lower eye margin. Legs: With shorter setae. Midleg: Tarsomere 1 without enlarged apex. Wing: Anal lobe slightly smaller. $\mathrm{R}_{4+5}$ with posterior curve slightly weaker. Abdomen: Tergites and sternites with short setae. With 7 exposed abdominal segments, segment 7 concolorous with anterior abdominal segments. Terminalia (similar to Figs 97, 98): Segment 6 with tergite and sternite subrectangular (wider than long), with setae on posterior half (setae denser on sternite). Segment 7 with tergite and sternite subquadrate with setae on posterior half (setae denser on sternite), with band-like posterior sclerite extension on each side (tergite extensions broad, sternite extensions narrow). Tergite 8 narrowly divided (desclerotized) medially, with 4-5 setae laterally, narrowly fused to sternite 8 anterolaterally. Sternite 9 desclerotized and inconspicuous. Spermatheca ovoid. Syntergite 9+10 with hemitergites subquadrate, each with 4-6 acanthophorite setae. Sternite 10 with anterior margin narrowly sclerotized and divided (desclerotized) medially, mainly membranous posteriorly with setulae and short setae. Cercus short, about as long as wide, membranous ventrally, rounded apically, with several setae ventrally.

Distribution and seasonal occurrence. Schistostoma fitzgeraldi sp. nov. is known from northwestern USA, including Washington, Oregon and northern California (Fig. 253). Adults have been collected from late May to mid-July.

Etymology. This species is named in honour of fellow dipterist, Dr. Scott J. Fitzgerald, who helped us collect various empidoid specimens in Oregon and also provided us with excellent information about collecting localities in Colorado.

Schistostoma isommatum (Melander) comb. nov.

(Figs 128, 140, 141, 155)

Microphorus isommatus Melander, 1928: 92.

Type material examined. HOLOTYPE, ô collected from London Hill Mine, Bear Lake [ca $54^{\circ} 29^{\prime} \mathrm{N} 122^{\circ} 40^{\prime} \mathrm{W}$ ], British Columbia, Canada, 29.vii.1903, by R.P. Currie, labelled: "LondonHill/ Mine"; "BearLake/ 29.7.03 BC"; "Altitude/ 70 00ft"; "RPCurrie/ Collector"; "TYPE/ Microphorus/ isommatus/ Mel. [red label]"; "Microphorus/ isommatus/ Mel. [handwritten]" (USNM). See "Remarks". PARATYPES: CANADA: Bristish Columbia: Same data as holotype (2犬, 4, USNM); same data as holotype except, 21.vii.1903 (4へ̂, USNM); same data except, J.W. Cockle $(1 \hat{\jmath}, 4$ ㅇ, USNM).

Other material examined. CANADA: British Columbia: Mt Cheam, $49^{\circ} 10^{\prime} 28.32^{\prime \prime} \mathrm{N} 121^{\circ} 40^{\prime} 52.80^{\prime \prime} \mathrm{W}, 1500$ m, meadow below summit, 8.viii.2001, Gillespie, Goulet \& Klassen, DRG-26-2001 (10̄, CNC); Mt Revelstoke [ca $51^{\circ} 02^{\prime} \mathrm{N} 118^{\circ} 08^{\prime} \mathrm{W}$ ], $6000 \mathrm{ft}$, 25.vii.1952, G.J. Spencer (10ð, 4, CNC); same data except, 22.vii.1952 (1우, CNC); Mt Revelstoke NP [ $\left.c a 51^{\circ} 02^{\prime} \mathrm{N} 118^{\circ} 08^{\prime} \mathrm{W}\right]$, Mt Harry, $6200 \mathrm{ft}$, 21.viii.1952, G.J. Spencer (19, CNC); Top of

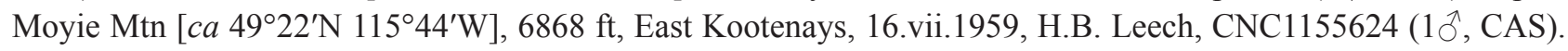
USA: Washington: Clallam County: Olympic NP, Mt Angeles [ca 47 $59^{\prime} \mathrm{N} 123^{\circ} 27^{\prime} \mathrm{W}$ ], $1600 \mathrm{~m}$, unnamed creek, 23.vii.1978, D.D. Wilder (2 ${ }^{\wedge}$, CAS); Olympic NP, Obstruction Peak [ca $\left.47^{\circ} 55^{\prime} \mathrm{N} 123^{\circ} 22^{\prime} \mathrm{W}\right]$, 23.vii.1978, D.D. Wilder (9 ${ }^{\jmath}, 3$,, CAS); Pierce County: Mt Rainier NP, Indian Henry's [ca $\left.46^{\circ} 45^{\prime} \mathrm{N} 121^{\circ} 48^{\prime} \mathrm{W}\right]$, 6.viii.1922, A.L.

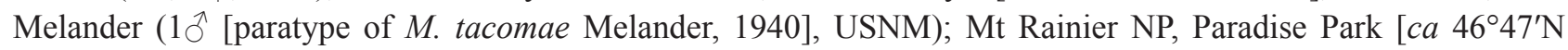
$121^{\circ} 44^{\prime} \mathrm{W}$ ], viii.1917, A.L. Melander (3 $\delta^{\wedge}$ [including 1 paratype of M. tacomae Melander, 1940], USNM; $1 \delta^{\lambda}$ 
[paratype of M. tacomae Melander, 1940], CUIC); Whatcom County: 23 mi. E Glacier, Austin Pass [ca $48^{\circ} 51^{\prime} \mathrm{N}$

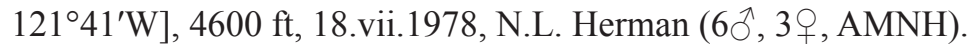

Diagnosis. This species is distinguished from other members of the $S$. isommatum species group by the large and mainly straight spine-like marginal setae on male abdominal sternite 5 (Fig. 128), long straight medial hypandrial prolongation, apically broad and rounded dorsal postgonite lobe, and distinctive morphology of the surstylar lobes (Figs 140, 141), as indicated in the key (couplet 41).
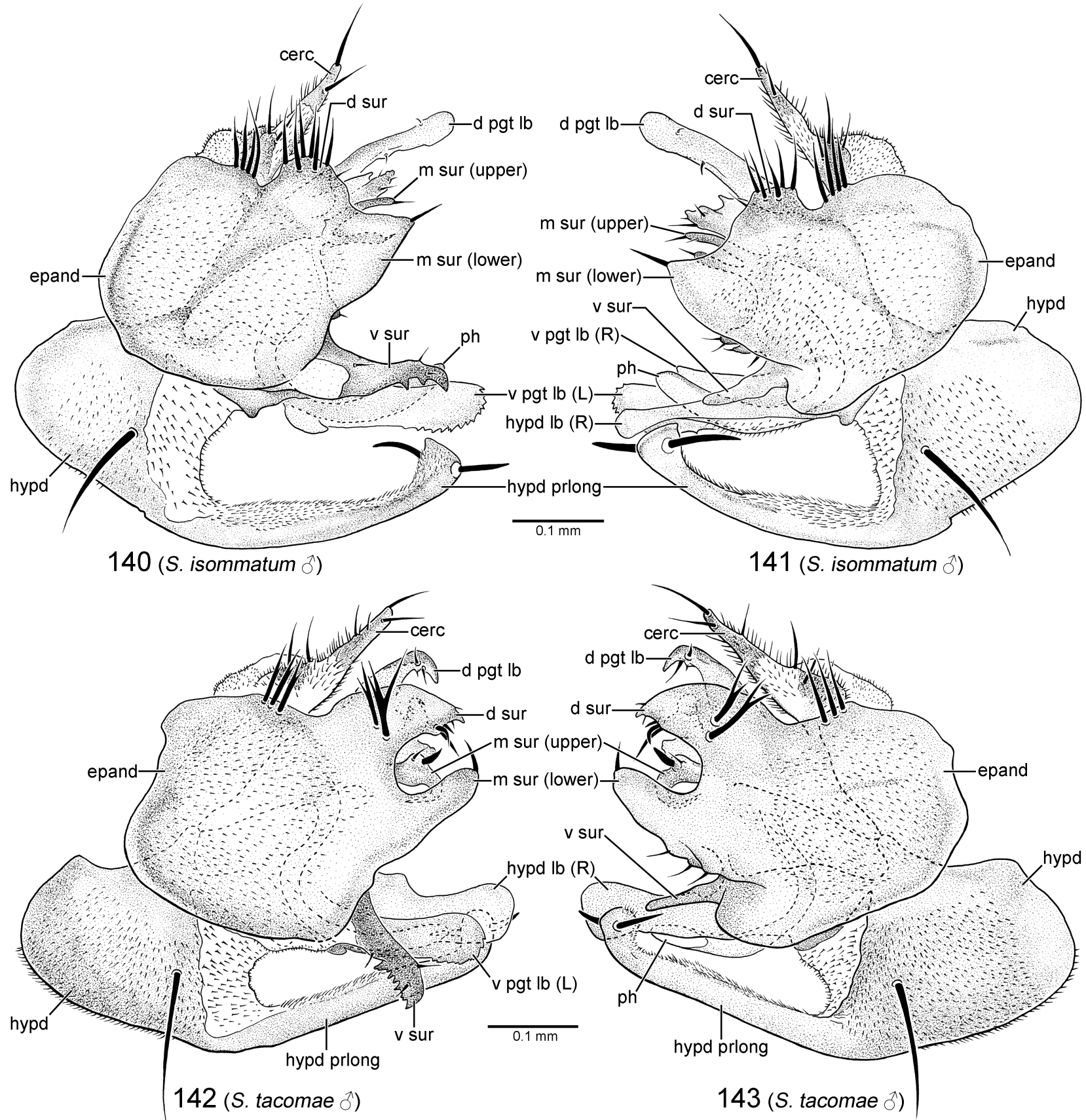

FIGURES 140-143. Hypopygia of Nearctic Schistostoma. 140. S. isommatum (Melander) comb. nov., left lateral view. 141. S. isommatum (Melander) comb. nov., right lateral view. 142. S. tacomae (Melander) comb. nov., left lateral view. 143. $S$. tacomae (Melander) comb. nov., right lateral view. Figures 140 and 141 based on specimen CNC1155624 (Moyie Mtn, British Columbia). Figures 142 and 143 based on specimen CNC1155628 (Alta Vista, Washington). Abbreviations: cerc_ cercus; d pgt lb — dorsal postgonite lobe; d sur — dorsal lobe of surstylus; epand — epandrium; hypd — hypandrium; hypd lb — hypandrial lobe; hypd prlong — hypandrial prolongation; (L) — left; m sur — middle lobe of surstylus; ph — phallus; (R) — right; v pgt lb — ventral postgonite lobe; v sur — ventral lobe of surstylus. 
Redescription. Male (Figs 128, 140, 141): Body length 1.7-2.0 mm, wing length 1.7-2.0 mm. Head: Ocellar tubercle with 2 pairs of black proclinate setae, anterior pair distinctly longer than posterior pair. Occiput dark grey pruinose, mostly clothed with black or brown setae, almost bare in upper part, except for postoculars. Gena and parafacial moderately projected along lower eye margin. Antenna dark brown; postpedicel conical, evenly tapered to apex; stylus about 2.0X length of postpedicel. Palpus dark brown, elongate ovate, slightly longer than length of labrum, pubescent with microtrichia and bearing scattered black setulae. Proboscis brown, slightly less than $1 / 2$ as long as head height, directed forward. Thorax: Mesonotum brownish-grey. Proepisternum with 1-2 setae. Mesonotal setae black, relatively long with dorsocentrals arranged in single row per side. Notopleuron with 2 strong setae. Scutellum with 2 pairs of setae, inner pair stronger. Mesopleuron grey. Halter pale. Legs: Blackish-brown, with black setae. Foreleg: Coxa with several setae on anterior surface. Femur subequal in length to tibia, posterior surface with series of longer posterodorsal and posteroventral setae (shorter than femur width) and shorter setae along middle, anterior surface with series of short anteroventral setae, otherwise with short sparse setae. Tibia slender, with series of 3-6 long erect posterodorsal setae (longer than tibia width), otherwise with shorter setae. Tarsus subequal in length to tibia, with short setae, tarsomere 1 subequal to combined length of tarsomeres 2-4, tarsomeres 2-4 decreasing in length apically, tarsomere 5 subequal in length to tarsomere 2. Midleg: Coxa setose on anterior surface, with 1-3 setae on posterior surface. Femur subequal in length to tibia, posterior and anterior surfaces with short setae. Tibia slender, with short setae, with 1 stout preapical ventral seta (subequal to tibia width). Tarsus slightly shorter than tibia, with short setae, tarsomere 1 subequal to combined length of tarsomeres $2-4$, with 2-5 stout erect basiventral setae, apex sometimes slightly enlarged, tarsomeres 2-4 decreasing in length apically, tarsomere 5 subequal in length to tarsomere 2. Hindleg: Coxa with 3 setae on outer surface and a few setae near apex of anterior surface. Femur subequal in length to tibia, with series of longer dorsal and anteroventral setae (at most subequal to femur width), anterior surface with short setae, posterior surface with short fine setae. Tibia enlarged apically, with short setae. Tarsus slightly shorter than tibia, with short setae, tarsomere 1 subequal to combined length of tarsomeres 2-4, with setulae ventrally, tarsomeres 2-4 decreasing in length apically, tarsomere 5 subequal in length to tarsomere 2. Wing: With slight grey-brown tinge, veins dark brown. Pterostigma somewhat faint. Anal lobe with proximal margin straight. $\mathrm{R}_{2+3}$ and $\mathrm{R}_{4+5}$ parallel in middle part and diverging near apex with cell $\mathrm{r}_{2+3}$ compressed in middle part and flared at apex. $\mathrm{R}_{4+5}$ sinuous with pronounced posterior curve to apex with cell $\mathrm{r}_{4+5}$ compressed in basal part. $\mathrm{R}_{4+5}$ and $\mathrm{M}_{1}$ diverging beyond cell dm. $\mathrm{M}_{2}$ and $\mathrm{M}_{4}$ subparallel beyond cell $\mathrm{dm}$. Costal section $M_{1}-M_{2}$ subequal to $M_{2}-M_{4}$. Cell dm moderately-sized, extended to around middle of wing, distal section of vein $M_{1}$ (beyond base of $\mathrm{M}_{2}$ ) longer than preceding section (between r-m and base of $\mathrm{M}_{2}$ ). Crossvein dm-m broadly curved and convergent with $\mathrm{M}_{1}$ distally. Abdomen (Figs 128, 140, 141): Dark brown-grey, with black setae on tergites and sternites. Tergites 1-5 clothed with long, dense setae laterally, setae short and sparse dorsomedially. Tergite 6 with setae along posterior margin, otherwise bare. Sternites 2-4 with short setae medially, sternites 3 and 4 with longer setae along lateral margins (progressively stronger posteriorly); sternite 4 with strong mediolateral seta on each side. Sternite 5 modified, polished and shiny, deeply emarginate postermedially, with digitiform microtrichose medial protrusion and 5 large sharply pointed spine-like setae on each side of emargination, with 2 long strong laterally projecting setae near outer margin. Sternite 6 angled dorsally, bare. Segment 7 robust, bare. Sternite 8 large and subrectangular, setose, distal margin with longer setae. Hypopygium (Figs 128, 140, 141): Large, about 1/2 length of abdomen, posterior end partially enclosed by modified pregenitalic sternites. Left epandrial lamella (Fig. 140) rounded basally, with surstylar lobes projecting distally, with row of strong setae adjacent to base of cercus. Left dorsal lobe of surstylus hump-like with several strong dorsal setae, medial surface with broad flap-like process. Left upper middle lobe of surstylus comprised of 2 long digitiform projections each bearing an apical seta. Left lower middle lobe of surstylus subtriangular with apical seta. Left ventral lobe of surstylus with 2 dentiform projections ventrally and pointed downturned tip, with 3 short setae, membranous basiventrally. Right epandrial lamella (Fig. 141) largely similar to left side. Right dorsal lobe of surstylus similar to left side. Right upper middle lobe of surstylus similar to left side. Right lower middle lobe of surstylus similar to left side. Right ventral lobe of surstylus dorsoventrally flattened, with rounded apex. Hypandrium with base bulbous and strongly produced anteriorly, with single large seta on each side of basal part. Medial hypandrial prolongation long, straight, projected to right side, with pair of strong divergent apical setae, each seta projecting at right angle to prolongation, setae of similar length. Left hypandrial lobe short, covered by ventral lobe of surstylus. Right hypandrial lobe elongate and narrow with apex slightly expanded and rounded. Left dorsal postgonite lobe longer than cercus, broadly rounded apically. Left ventral postgonite lobe broad and long with apex rounded and serrate, with small ventral process near base. Right 
dorsal postgonite lobe similar to left side. Right ventral postgonite lobe narrow and pointed apically, nearly as long as phallus. Postgonite apodeme narrowly heart-shaped in ventral view, unbranched. Phallus slender, broadly Cshaped and projecting posteriorly. Ejaculatory apodeme subrectangular. Left and right cercus with hump-like base and narrow elongate digitiform apex bearing long apical seta.

Female: Body length 1.7-2.1 mm, wing length 1.8-2.0 mm. Similar to male except as follows: Head: Gena and parafacial distinctly projected along lower eye margin. Legs: With shorter setae. Wing: Anal lobe slightly smaller. $\mathrm{R}_{4+5}$ with posterior curve slightly weaker. Abdomen: Tergites and sternites with short setae. With 7 exposed abdominal segments, segment 7 concolorous with anterior abdominal segments, shiny. Terminalia (similar to Figs 97, 98): Segment 6 with tergite and sternite subrectangular (wider than long), tergite with setae on posterior, lateral and anterior margins, sternite evenly setose. Segment 7 with tergite and sternite subrectangular (slightly wider than long) tergite with setae on posterior and lateral margins, sternite with setae on posterior third, with band-like posterior sclerite extension on each side (tergite extensions broad, sternite extensions narrow). Tergite 8 narrowly divided (desclerotized) medially, with pair of setae laterally, narrowly fused to sternite 8 anterolaterally. Sternite 9 desclerotized and inconspicuous. Spermatheca ovoid. Syntergite $9+10$ with hemitergites subquadrate, each with 5 acanthophorite setae. Sternite 10 membranous with setulae and short setae. Cercus short, about as long as wide, membranous ventrally, rounded apically, with subapical seta and several additional setae ventrally.

Distribution and seasonal occurrence. Schistostoma isommatum is known from British Columbia and Washington (Fig. 155). Adults have been collected from mid-July to late August.

Remarks. According to the label data, the holotype was collected by R.P. Currie on 29.vii.1903, not by J.W. Cockle on 21.vii.1903, as originally indicated by Melander (1928). Although Melander (1940b) mentions only the holotype (USNM) and one paratype (Melander collection) in his listing of type material, he clearly states that the type series consists of "several specimens" in the original description (Melander 1928).

\section{Schistostoma powelli sp. nov.}

(Figs 129, 144-146, 154)

urn:lsid:zoobank.org:act: 594BC4B4-B7DE-4A52-B1C2-ACC5CCB7EC20

Type material. HOLOTYPE, ô collected 1 mile south of Temecula [ $c a 33^{\circ} 28^{\prime} \mathrm{N} 117^{\circ} 08^{\prime} \mathrm{W}$ ], Riverside County, California, USA, 11.iv.1965, by J. Powell, labelled: "Calif: Riv. Co./ Temecula, 1/ mi. S. IV-11-65"; "J. Powell/ collector"; "UC Berkeley/ EMEC/ 1189155"; "HOLOTYPE/ Schistostoma powelli/ Brooks \& Cumming [red label]" (EMEC). PARATYPE: USA: California: Same data as holotype except, 1189154 (1+, EMEC).

Other material examined. USA: California: Kern County, Weldon, 16 mi. S [ $c a 35^{\circ} 29^{\prime} \mathrm{N} 118^{\circ} 12^{\prime} \mathrm{W}$ ], 26.vi.1964, ex Salix, P. Rude (1ð, EMEC).

Diagnosis. This species is distinguished from other members of the $S$. isommatum species group by the large wavy spine-like marginal setae on male abdominal sternite 5 (Fig. 129), and short curved medial hypandrial prolongation with large horn-like apical setae (Figs 144-146), as indicated in the key (couplet 40).

Description. Male (Figs 129, 144-146): Body length $2.1 \mathrm{~mm}$, wing length $1.9 \mathrm{~mm}$. Head: Ocellar tubercle with 2 pairs of black proclinate setae, anterior pair distinctly longer than posterior pair. Occiput grey to dark grey pruinose, mostly clothed with black or brown setae, almost bare in upper part, except for postoculars. Gena and parafacial moderately projected along lower eye margin. Antenna dark brown; postpedicel conical, evenly tapered to apex; stylus about $1.75 \mathrm{X}$ length of postpedicel. Palpus dark brown, elongate ovate, slightly longer than length of labrum, pubescent with microtrichia and bearing scattered black setulae. Proboscis dark brown, slightly less than 1/2 as long as head height, directed forward. Thorax: Mesonotum greyish-black. Proepisternum with 1 seta. Mesonotal setae black, relatively long with dorsocentrals arranged in single row per side. Notopleuron with 2-3 strong setae. Scutellum with 2 pairs of setae, inner pair stronger. Mesopleuron grey. Halter pale. Legs: Blackish-brown, with black setae. Foreleg: Coxa with several setae on anterior surface. Femur subequal in length to tibia, posterior surface with series of longer posterodorsal and posteroventral setae (shorter than femur width) and shorter setae along middle, anterior surface with series of short anteroventral setae, otherwise with short sparse setae. Tibia slender, usually with series of 3-4 slightly longer and erect posterodorsal setae along basal half, otherwise with shorter setae. Tarsus subequal in length to tibia, with short setae, tarsomere 1 subequal to combined length of tarsomeres $2-4$, with 1 short basiventral seta and adjacent setulae, tarsomeres $2-4$ decreasing in length apically, tarsomere 5 subequal 
in length to tarsomere 3. Midleg: Coxa setose on anterior surface, with 2-3 setae on posterior surface. Femur subequal in length to tibia, posterior and anterior surfaces with short setae. Tibia slender, with short setae, with 1 stout preapical ventral seta (slightly longer than tibia width). Tarsus subequal in length to tibia, with short setae, tarsomere 1 subequal to combined length of tarsomeres 2-4, with 2-3 stout erect basiventral setae, apex slightly enlarged, tarsomeres 2-4 decreasing in length apically, tarsomere 5 subequal in length to tarsomere 3 . Hindleg: Coxa with 3 setae on outer surface and a few setae near apex of anterior surface. Femur subequal in length to tibia, with series of longer dorsal and anteroventral setae (at most subequal to femur width), anterior surface with short setae, posterior surface with short fine setae. Tibia enlarged apically, with series of longer dorsal setae (subequal to basal tibia width), otherwise with short setae. Tarsus slightly shorter than tibia, with short setae, tarsomere 1 subequal to combined length of tarsomeres $2-4$, with setulae ventrally, tarsomeres $2-4$ decreasing in length apically, tarsomere 5 subequal in length to tarsomere 3. Wing: With slight grey-brown tinge, veins dark brown. Pterostigma well-developed. Anal lobe with proximal margin concave. $\mathrm{R}_{2+3}$ and $\mathrm{R}_{4+5}$ parallel in middle part and diverging near apex with cell $\mathrm{r}_{2+3}$ compressed in middle part and flared at apex. $\mathrm{R}_{4+5}$ sinuous with pronounced posterior curve to apex with cell $r_{4+5}$ compressed in basal part. $R_{4+5}$ and $M_{1}$ diverging beyond cell $\mathrm{dm} . \mathrm{M}_{2}$ and $\mathrm{M}_{4}$ subparallel beyond cell dm. Costal section $\mathrm{M}_{1}-\mathrm{M}_{2}$ subequal to $\mathrm{M}_{2}-\mathrm{M}_{4}$. Cell dm moderately-sized, extended to around middle of wing, distal section of vein $M_{1}$ (beyond base of $M_{2}$ ) longer than preceding section (between $r-m$ and base of $M_{2}$ ). Crossvein $\mathrm{dm}-\mathrm{m}$ broadly curved and convergent with $\mathrm{M}_{1}$ distally. Abdomen (Figs 129, 144-146): Dark grey, with black setae on tergites and sternites. Tergites 1-5 clothed with long, dense setae laterally, setae short and sparse dorsomedially. Tergite 6 with setae along posterior margin, otherwise bare. Sternites 2-4 with some long and short setae medially, sternites 3 and 4 with longer setae along lateral margins (progressively stronger posteriorly). Sternite 5 modified, polished and shiny, weakly emarginate posteromedially, with patch of short microtrichia medially and 5 large sharply pointed wavy marginal spine-like setae on each side of emargination, with 2 long strong laterally projecting setae near outer margin. Sternite 6 angled dorsally, bare. Segment 7 robust, bare. Sternite 8 large and subrectangular, setose, distal margin apparently with longer setae (several broken off in known males). Hypopygium (Figs 129, 144-146): Large, nearly $1 / 2$ length of abdomen; posterior end partially enclosed by modified pregenitalic sternites. Left epandrial lamella (Fig. 144) rounded basally, with surstylar lobes projecting distally, with row of strong setae adjacent to base of cercus. Left dorsal lobe of surstylus broad basally, with pair 2-3 setae laterally and group of 3 stout preapical ventral setae; apex narrow. Left upper middle lobe of surstylus slender and curved medially, with long curved medially directed apical seta; basal part with 2 setae each borne on short tubercle. Left lower middle lobe of surstylus thumb-like with apical seta. Left ventral lobe of surstylus with short serrate process ventrally and pointed downturned tip, with 3 short setae, membranous basiventrally. Right epandrial lamella (Fig. 145) largely similar to left side. Right dorsal lobe of surstylus similar to left side. Right upper middle lobe of surstylus similar to left side. Right lower middle lobe of surstylus similar to left side but constricted at base, with several short setae below. Right ventral lobe of surstylus short, with broadly rounded apex. Hypandrium with base bulbous and strongly produced anteriorly, with single large seta on each side of basal part. Medial hypandrial prolongation (Fig. 146) short, broad and weakly curved to the right, with large horn-like apical setae of similar size. Left hypandrial lobe short, covered by ventral lobe of surstylus. Right hypandrial lobe elongate and very broad with apex expanded. Left dorsal postgonite lobe longer than cercus, slender and broadly curved. Left ventral postgonite lobe broad and long with apex rounded and serrate, with small ventral process near base. Right dorsal postgonite lobe similar to left side. Right ventral postgonite lobe broad with squared-off apex, as long as phallus. Postgonite apodeme narrowly heart-shaped in ventral view, unbranched, projecting anteriorly. Phallus slender, broadly C-shaped and projecting posteriorly. Ejaculatory apodeme subrectangular. Left and right cercus with hump-like base and narrow elongate digitiform apex bearing long apical seta.

Female: Wing length $2.0 \mathrm{~mm}$. Similar to male except as follows: Head: Gena and parafacial distinctly projected along lower eye margin. Legs: With shorter setae. Wing: Anal lobe slightly smaller. $R_{4+5}$ with posterior curve slightly weaker. Abdomen: Tergites and sternites with short setae. With 7 exposed abdominal segments, segment 7 concolorous with anterior abdominal segments. Terminalia (similar to Figs 97, 98): Segment 6 with tergite and sternite subrectangular (wider than long), with setae on posterior third. Segment 7 with tergite subrectangular (wider than long), sternite subquadrate, tergite with setae on posterior margin, sternite setose on posterior third, with band-like posterior sclerite extension on each side (tergite extensions broad, sternite extensions narrow). Tergite 8 narrowly divided (desclerotized) medially, with pair of setae laterally, narrowly fused to sternite 8 anterolaterally. Sternite 9 desclerotized and inconspicuous. Spermatheca spherical. Syntergite $9+10$ with hemitergites subquadrate, 
each with 4-5 acanthophorite setae. Sternite 10 with anterior margin narrowly sclerotized and divided (desclerotized) medially, mainly membranous posteriorly with setulae and short setae. Cercus short, wider than long, membranous ventrally, rounded apically, with prominent subapical seta and shorter setae ventrally.

Distribution and seasonal occurrence. Schistostoma powelli sp. nov. is known from Kern and Riverside Counties in California (Fig. 154). Adults have been collected from mid-April to late June.

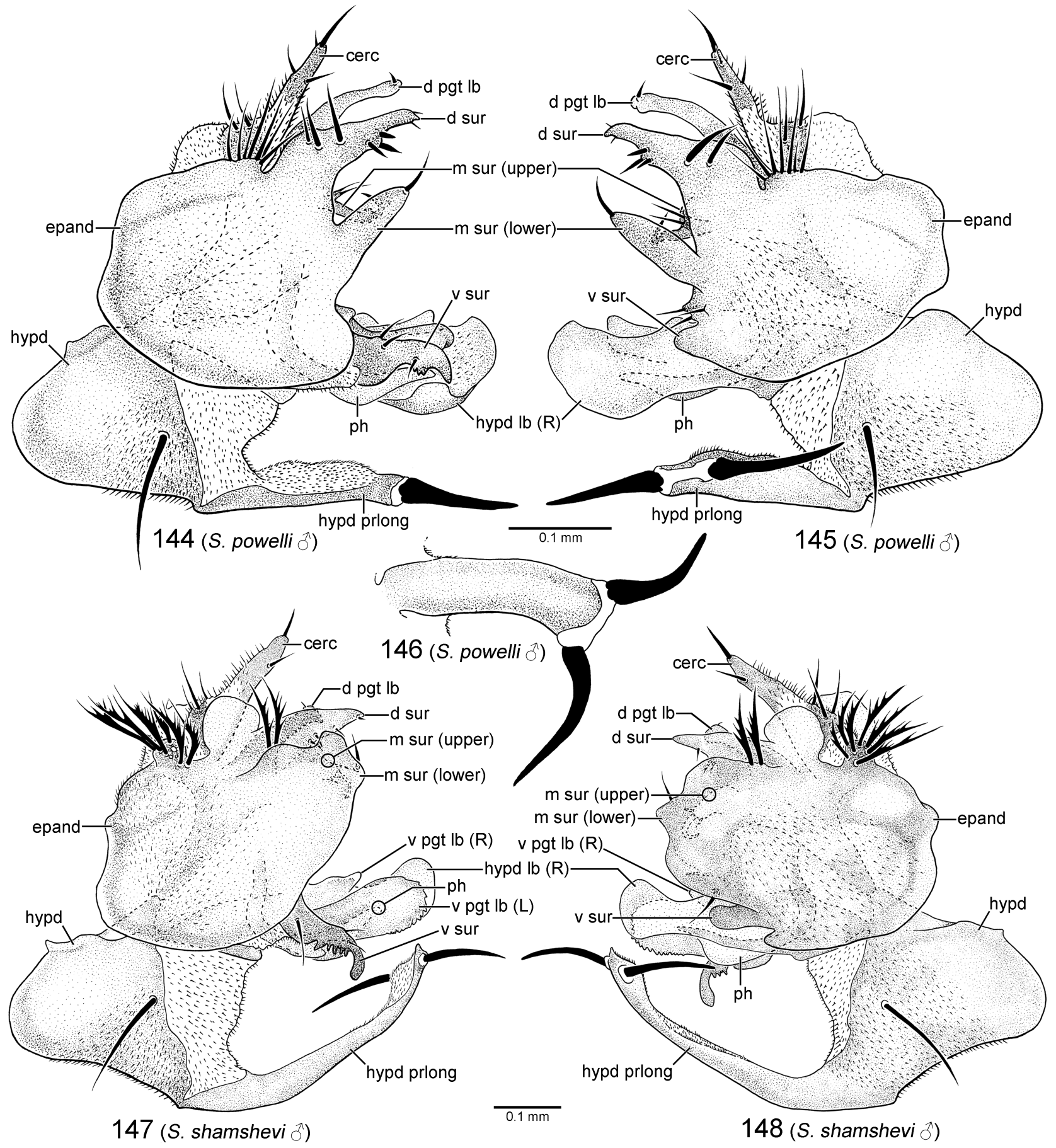

FIGURES 144-148. Hypopygia of Nearctic Schistostoma. 144. S. powelli sp. nov., left lateral view of holotype. 145. S. powelli sp. nov., right lateral view of holotype. 146. Medial hypandrial prolongation of S. powelli sp. nov., ventral view of holotype. 147. S. shamshevi sp. nov., left lateral view. 148. S. shamshevi sp. nov., right lateral view. Figures 144-146 based on holotype (near Temecula, California). Figures 147 and 148 based on specimen CNC1155650 (Muncho Lake Provincial Park, British Columbia). Abbreviations: cerc — cercus; d pgt lb — dorsal postgonite lobe; d sur — dorsal lobe of surstylus; epand — epandrium; hypd — hypandrium; hypd lb — hypandrial lobe; hypd prlong — hypandrial prolongation; (L) —left; m sur-middle lobe of surstylus; ph—phallus; (R)—right; v pgt lb—ventral postgonite lobe; v sur—ventral lobe of surstylus. 
Etymology. This species is named in honour of fellow entomologist, Dr. Jerry A. Powell, who collected many of the specimens examined in this study, including the type series of this new species, and who also recorded numerous flower visits by various western species of Microphorinae.

Remarks. Flower visitation records for this species are listed in Table 1.

\section{Schistostoma shamshevi sp. nov.}

(Figs 130, 147, 148, 155)

urn:Isid:zoobank.org:act: D77DC312-60FF-43CF-8673-0E404A78B875

Type material. HOLOTYPE, $\widehat{\jmath}$ collected from Alaska Hwy km 1706, west side Slims River delta, Yukon, Canada, 8.vi.1979, by Royal Ontario Museum Field Party, labelled: "Y.T.: Alaska Hwy. km/ 1706, w. side Slims R./ delta. $60^{\circ} 59^{\prime} \mathrm{Nx} / 138^{\circ} 34^{\prime} \mathrm{W}$, on plants/ along rd. 8.vi.1979./ \#791007a. ROM Fld. Pty."; "HOLOTYPE/ Schistostoma shamshevi/ Brooks \& Cumming [red label]" (ROM).

Other material examined. CANADA: British Columbia: Muncho Lake Provincial Park, Muncho Lake,

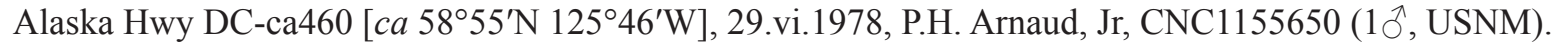

Diagnosis. This species is distinguished from other members of the $S$. isommatum species group by the deeply cleft male abdominal sternite 5 with blunt-tipped marginal setae (Fig. 130), cluster of antler-like epandrial setae beside cerci, long straight medial hypandrial prolongation, and distinctive morphology of the surstylar lobes (Figs $147,148)$, as indicated in the key (couplet 39).

Description. Male (Figs 130, 147, 148): Body length $2.3 \mathrm{~mm}$, wing length $2.2 \mathrm{~mm}$. Head: Ocellar tubercle with 2 pairs of black proclinate setae, anterior pair distinctly longer than posterior pair. Occiput dark grey pruinose, mostly clothed with black or brown setae, almost bare in upper part, except for postoculars. Gena and parafacial moderately projected along lower eye margin. Antenna dark brown; postpedicel conical, evenly tapered to apex; stylus slightly greater than length of postpedicel. Palpus dark brown, elongate ovate, slightly longer than length of labrum, pubescent with microtrichia and bearing scattered black setulae. Proboscis brown, slightly less than $1 / 2$ as long as head height, directed forward. Thorax: Mesonotum greyish-black. Proepisternum with 1 seta. Mesonotal setae black, relatively long with dorsocentrals arranged in single row per side. Notopleuron with 2 strong setae. Scutellum with 2 pairs of setae, inner pair stronger. Mesopleuron grey to greyish-black. Halter pale. Legs: Blackishbrown, with black setae. Foreleg: Coxa with several setae on anterior surface. Femur subequal in length to tibia, posterior surface with series of longer posterodorsal and posteroventral setae (shorter than femur width) and short rather sparse setae along middle, anterior surface with series of short anteroventral setae, otherwise with short sparse setae. Tibia slender, with series of 3-5 long erect posterodorsal setae ( $2 \mathrm{X}$ longer than tibia width) along basal half, otherwise with short setae. Tarsus subequal in length to tibia, with short setae, tarsomere 1 subequal to combined length of tarsomeres 2-4, with a few basiventral setae, tarsomeres $2-4$ decreasing in length apically, tarsomere 5 subequal in length to tarsomere 2. Midleg: Coxa setose on anterior surface, with pair of setae on posterior surface present or absent. Femur subequal in length to tibia, posterior and anterior surfaces with short setae, with a few longer setae anterobasally and preapically. Tibia slender, with short setae, with 1 long stout preapical ventral seta (slightly longer than tibia width). Tarsus slightly shorter than tibia, with short setae, tarsomere 1 subequal to combined length of tarsomeres $2-4$, with 2-3 stout erect basiventral setae and a few smaller ventral setae, apex slightly enlarged, tarsomeres 2-4 decreasing in length apically, tarsomere 5 subequal in length to tarsomere 2 . Hindleg: Coxa with 3 setae on outer surface and several setae on anterior surface. Femur subequal in length to tibia, with series of longer dorsal and anteroventral setae (subequal to femur width), anterior surface with short setae, posterior surface with series of short setae along basal 1/3, otherwise with short fine setae. Tibia enlarged apically, with series of longer posterodorsal, anterodorsal and ventral setae (at most slightly longer than basal tibia width on basal 2/3 then shorter), otherwise with short setae (denser apically). Tarsus slightly shorter than tibia, tarsomere 1 subequal to combined length of tarsomeres $2-4$, slightly broadened, with relatively long dorsal setae (subequal to slightly longer than tarsomere width) and dense setulae ventrally, tarsomeres $2-5$ with shorter setae, tarsomeres 2 and 3 subequal in length, tarsomere 4 shorter, tarsomere 5 slightly longer than tarsomere 2 . Wing: With slight grey-brown tinge, veins dark brown. Pterostigma well-developed. Anal lobe with proximal margin straight. $\mathrm{R}_{2+3}$ and $\mathrm{R}_{4+5}$ parallel in middle part and diverging near apex with cell $\mathrm{r}_{2+3}$ compressed in middle part and flared at apex. $\mathrm{R}_{4+5}$ sinuous with pronounced posterior curve to apex with cell $\mathrm{r}_{4+5}$ compressed in basal part. $\mathrm{R}_{4+5}$ and $\mathrm{M}_{1}$ 
diverging beyond cell dm. $M_{2}$ and $M_{4}$ subparallel beyond cell dm. Costal section $M_{1}-M_{2}$ subequal to $M_{2}-M_{4}$. Cell $\mathrm{dm}$ moderately-sized, extended to around middle of wing, distal section of vein $\mathrm{M}_{1}$ (beyond base of $\mathrm{M}_{2}$ ) longer than preceding section (between $\mathrm{r}-\mathrm{m}$ and base of $\mathrm{M}_{2}$ ). Crossvein $\mathrm{dm}-\mathrm{m}$ broadly curved and convergent with $\mathrm{M}_{1}$ distally. Abdomen (Figs 130, 147, 148): Dark brown-grey, with black setae. Tergites 1-5 clothed with long, dense setae laterally, setae short and sparse dorsomedially. Tergite 6 with setae along posterior margin, otherwise bare. Sternite 2 with short setae; sternites 3 and 4 with some long and short setae medially and long setae along lateral margins (progressively stronger posteriorly). Sternite 5 modified, polished and shiny, deeply and narrowly cleft posteromedially, with 3 blunt-tipped digitiform setae on each side of cleft, with 2 long strong laterally projecting setae near outer margin. Sternite 6 angled dorsally, bare. Segment 7 robust, bare. Sternite 8 large and subrectangular, setose, distal margin with longer setae. Hypopygium (Figs 147, 148): Large, about 1/2 length of abdomen; posterior end partially enclosed by modified pregenitalic sternites. Left epandrial lamella (Fig. 147) rounded basally, with surstylar lobes projecting distally, with dense cluster of thick, antler-like epandrial setae borne on pronounced knoblike tubercle adjacent to base of cercus. Left dorsal lobe of surstylus with bare subcircular dorsal projection basally, with pair of thick, antler-like setae near base (at margin with upper middle lobe of surstylus), distal portion of lobe tapered to acute point. Left upper middle lobe of surstylus conical and short, with long blade-like medially directed apical seta; with pair of small setae near base, entirely covered by lower middle lobe of surstylus. Left lower middle lobe of surstylus very broad, with relatively short apical seta. Left ventral lobe of surstylus serrate ventrally with downturned thumb-like tip, with 3 short setae, membranous basiventrally. Right epandrial lamella (Fig. 148) largely similar to left side. Right dorsal lobe of surstylus similar to left side. Right upper middle lobe of surstylus similar to left side. Right lower middle lobe of surstylus broader than left side. Right ventral lobe of surstylus flap-like, with rounded apex. Hypandrium with base bulbous and strongly produced anteriorly, with single large seta on each side of basal part. Medial hypandrial prolongation long, straight, projected to right side, with pair of strong divergent apical setae, each seta projecting at right angle to prolongation, setae of similar size. Left hypandrial lobe short, covered by ventral lobe of surstylus. Right hypandrial lobe broad and elongate with apex expanded and rounded. Left dorsal postgonite lobe slender and subequal in length to cercus. Left ventral postgonite lobe broad and long with apex rounded and serrate, with small ventral process near base. Right dorsal postgonite lobe similar to left side. Right ventral postgonite lobe pointed apically, nearly as long as phallus. Postgonite apodeme narrowly heart-shaped in ventral view, unbranched. Phallus slender, broadly C-shaped and projecting posteriorly. Ejaculatory apodeme subrectangular. Left and right cercus with hump-like base and narrow elongate digitiform apex bearing apical seta.

Female: Unknown.

Distribution and seasonal occurrence. Schistostoma shamshevi sp. nov. is known from Yukon and northern British Columbia (Fig. 155). Adults have been collected in June.

Etymology. This species is named in honour of fellow empidoid worker, Dr. Igor V. Shamshev, who has contributed significantly to the systematic study of Microphorinae and other Empidoidea.

\section{Schistostoma sinclairi sp. nov.}

(Figs 149, 150, 156)

urn:lsid:zoobank.org:act: D10FF245-690F-474E-A51E-F9940270A7FD

Type material. HOLOTYPE, ô collected from Angelo Coast Range Reserve [ca $39^{\circ} 43^{\prime} \mathrm{N} 123^{\circ} 39^{\prime} \mathrm{W}$ ], Mendocino County, California, 31.v.1986, labelled: "USA: California:/ Mendocino County:/ Angelo Coast Range"; "Reserve, on sand below/ White House/ 31.v.1986"; "UC Berkeley/ EMEC/ 1188695"; "HOLOTYPE/ Schistostoma sinclairi/ Brooks \& Cumming [red label]" (EMEC). PARATYPES: USA: California: Same data as holotype except, EMEC 1188558, EMEC 1188559, EMEC 1188560, EMEC 1188561, EMEC 1188692, EMEC 1188693 (6ð, EMEC); same data as holotype except, EMEC 1188691, CNC1155630 (10, EMEC).

Diagnosis. This species is very close to $S$. fitzgeraldi sp. nov. and $S$. susanae sp. nov., and is distinguished from other members of the $S$. isommatum species group by the short marginal setae on male abdominal sternite 5, long curved medial hypandrial prolongation, broad spiculate dorsal postgonite lobe, and shape of the dorsal lobe of the surstylus (Figs 149, 150), as indicated in the key (couplets 37, 42, 43).

Description. Male (Figs 149, 150): Body length 1.6-1.8 mm, wing length 1.7-1.9 mm. Head: Ocellar tubercle with 2 pairs of black proclinate setae, anterior pair distinctly longer than posterior pair. Occiput dark grey pruinose, mostly clothed with black or brown setae, almost bare in upper part, except for postoculars. Gena and parafacial 
moderately projected along lower eye margin. Antenna dark brown; postpedicel conical, evenly tapered to apex; stylus about $1.75 \mathrm{X}$ length of postpedicel. Palpus dark brown, elongate ovate, slightly longer than length of labrum, pubescent with microtrichia and bearing scattered black setulae. Proboscis brown, slightly less than $1 / 2$ as long as head height, directed forward. Thorax: Mesonotum brownish-grey. Proepisternum with 1-2 setae. Mesonotal setae black, relatively long with dorsocentrals arranged in single row per side. Notopleuron with 2 strong setae. Scutellum with 2 pairs of setae, inner pair stronger. Mesopleuron grey. Halter pale. Legs: Blackish-brown, with black setae. Foreleg: Coxa with several setae on anterior surface. Femur subequal in length to tibia, posterior surface with series of longer posterodorsal and posteroventral setae (shorter than femur width) and shorter setae along middle, anterior surface with series of short anteroventral setae, otherwise with short sparse setae. Tibia slender, with series of 2-4 long erect posterodorsal setae (longer than tibia width) along basal half, otherwise with short setae. Tarsus subequal in length to tibia, with short setae, tarsomere 1 subequal to combined length of tarsomeres 2-4, with small basiventral seta and adjacent setulae, tarsomeres 2-4 decreasing in length apically, tarsomere 5 subequal in length to tarsomere 2. Midleg: Coxa setose on anterior surface, with 1 seta on posterior surface. Femur subequal in length to tibia, posterior and anterior surfaces with short setae. Tibia slender, with short setae, with 1 long stout preapical ventral seta (slightly longer than tibia width). Tarsus slightly shorter than tibia, with short setae, tarsomere 1 subequal to combined length of tarsomeres 2-4, with 2-3 stout erect basiventral setae, apex slightly enlarged, tarsomeres 2-4 decreasing in length apically, tarsomere 5 subequal in length to tarsomere 3 . Hindleg: Coxa with 3 setae on outer surface and a few setae near apex of anterior surface. Femur subequal in length to tibia, with series of longer anteroventral setae (subequal to femur width), and relatively shorter series of dorsal setae, anterior surface with short setae, posterior surface with short fine setae. Tibia enlarged apically, with short setae. Tarsus slightly shorter than tibia, with short setae, tarsomere 1 subequal to combined length of tarsomeres $2-4$, with setulae ventrally, tarsomeres 2-4 decreasing in length apically, tarsomere 5 subequal in length to tarsomere 3. Wing: With slight brownish tinge, veins dark brown. Pterostigma somewhat faint. Anal lobe with proximal margin straight. $\mathrm{R}_{2+3}$ and $\mathrm{R}_{4+5}$ parallel in middle part and diverging near apex with cell $\mathrm{r}_{2+3}$ compressed in middle part and flared at apex. $\mathrm{R}_{4+5}$ sinuous with pronounced posterior curve to apex with cell $\mathrm{r}_{4+5}$ compressed in basal part. $R_{4+5}$ and $M_{1}$ diverging beyond cell dm. $M_{2}$ and $M_{4}$ subparallel beyond cell dm. Costal section $M_{1}-M_{2}$ subequal to $\mathrm{M}_{2}-\mathrm{M}_{4}$. Cell dm moderately-sized, extended to around middle of wing, distal section of vein $\mathrm{M}_{1}$ (beyond base of $\mathrm{M}_{2}$ ) longer than preceding section (between $\mathrm{r}-\mathrm{m}$ and base of $\mathrm{M}_{2}$ ). Crossvein $\mathrm{dm}-\mathrm{m}$ broadly curved and convergent with $\mathrm{M}_{1}$ distally. Abdomen (Figs 149, 150): Dark brown-grey, with black setae. Tergites 1-5 clothed with long, dense setae laterally, setae short and sparse dorsomedially. Tergite 6 with setae along posterior margin, otherwise bare. Sternites 2-4 with some long and short setae medially, sternites 3 and 4 with longer setae along lateral margins (progressively stronger posteriorly). Sternite 5 modified, polished and shiny, shallowly emarginate posteromedially, with tiny medial protrusion and short spine-like marginal setae on each side or emargination, with 2 long strong laterally projecting setae near outer margin. Sternite 6 angled dorsally, bare. Segment 7 robust, bare. Sternite 8 large and subrectangular, setose, distal margin with longer setae. Hypopygium (Figs 149, 150): Large, nearly 1/2 length of abdomen; posterior end partially enclosed by modified pregenitalic sternites. Left epandrial lamella (Fig. 149) rounded basally, with surstylar lobes projecting distally, with row of thick apically branched setae adjacent to base of cercus. Left dorsal lobe of surstylus with concave dorsal margin, with lateral seta near base and lateral preapical seta, apex notched. Left upper middle lobe of surstylus digitiform, with close-set pair of setae on tubercle near middle; apex with strong claw-like seta projecting medially. Left lower middle lobe of surstylus broad and flap-like, rounded apically with long apical seta. Left ventral lobe of surstylus serrate ventrally, with short pointed downturned tip, with 3 short setae, membranous basiventrally. Right epandrial lamella (Fig. 150) largely similar to left side. Right dorsal lobe of surstylus similar to left side. Right upper middle lobe of surstylus similar to left side. Right lower middle lobe of surstylus subtriangular, ventral margin with 2-3 setae and medial basal projection. Right ventral lobe of surstylus dorsoventrally flattened, with rounded apex. Hypandrium with base bulbous and strongly produced anteriorly, with single large seta on each side of basal part. Medial hypandrial prolongation long, curved to right side, with pair of strong divergent apical setae, each seta projecting at right angle to prolongation, setae similar in length. Left hypandrial lobe short, covered by ventral lobe of surstylus. Right hypandrial lobe broad and elongate, apex with narrow dorsal flap-like projection. Left dorsal postgonite lobe longer than cercus, broad and bent forward at right angle, with dorsal fringe of spicules near base. Left ventral postgonite lobe broad and long with apex rounded and serrate, with small ventral process near base. Right dorsal postgonite lobe similar to left side. Right ventral postgonite lobe short narrow and pointed apically, covered by hypandrial lobe. Postgonite apodeme 
narrowly heart-shaped in ventral view, unbranched. Phallus slender, broadly C-shaped and projecting posteriorly. Ejaculatory apodeme subrectangular. Left and right cercus with hump-like base and narrow elongate digitiform apex bearing long apical seta.

Female: Unknown.

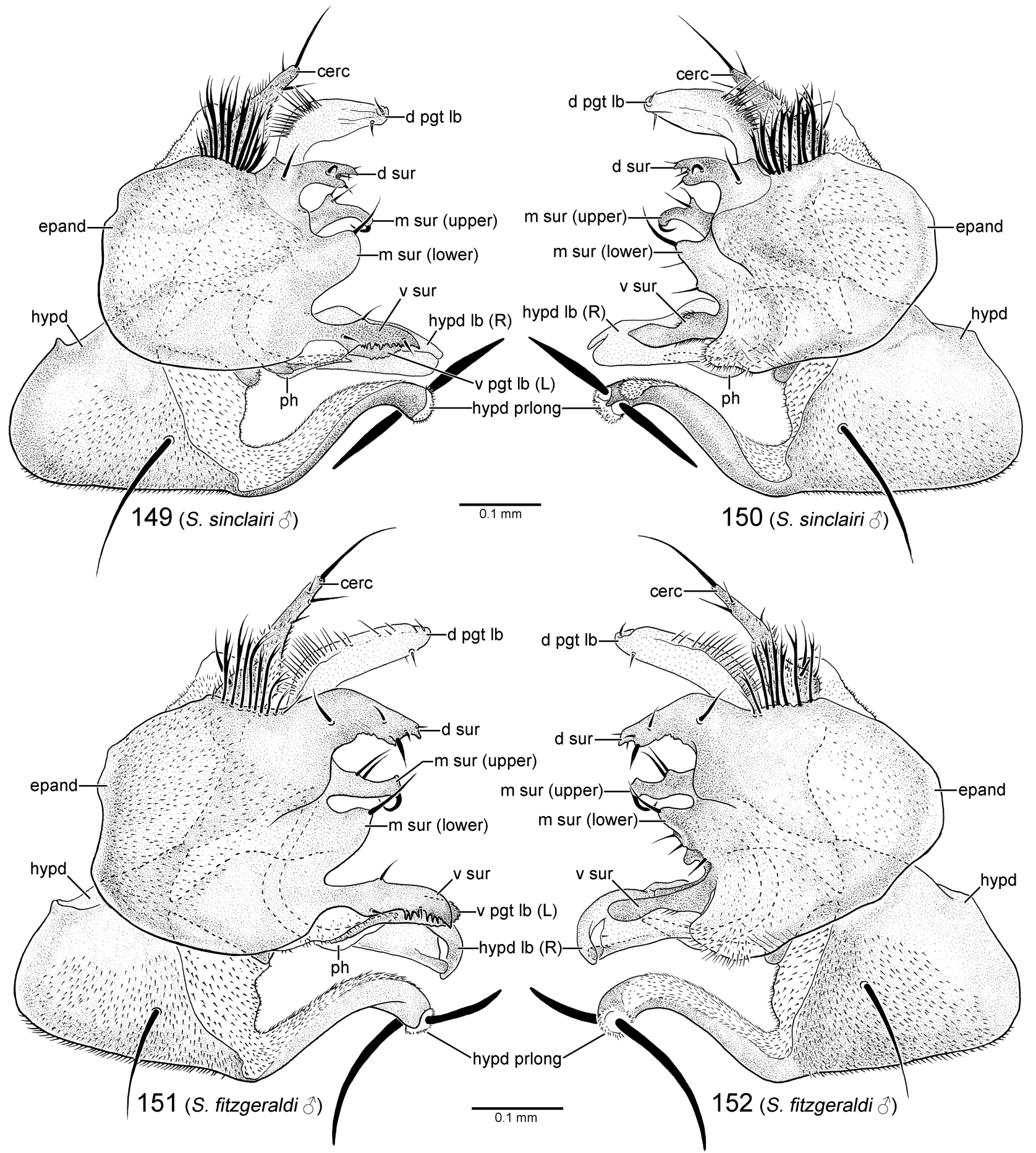

FIGURES 149-152. Hypopygia of Nearctic Schistostoma. 149. S. sinclairi sp. nov., left lateral view. 150. S. sinclairi $\mathbf{s p .}$ nov., right lateral view. 151. S. fitzgeraldi sp. nov., left lateral view. 152. S. fitzgeraldi sp. nov., right lateral view. Figures 149 and 150 based on specimen CNC1155630 (Angelo Coast Range Reserve, California). Figures 151 and 152 based on specimen CNC1155629 (Camp Creek Campground, Oregon). Abbreviations: cerc — cercus; d pgt lb — dorsal postgonite lobe; d sur-dorsal lobe of surstylus; epand - epandrium; hypd — hypandrium; hypd lb — hypandrial lobe; hypd prlong — hypandrial prolongation; (L) — left; m sur — middle lobe of surstylus; ph—phallus; (R) — right; v pgt lb—ventral postgonite lobe; v sur-ventral lobe of surstylus. 
Distribution and seasonal occurrence. Schistostoma sinclairi sp. nov. is known from Mendocino County, California (Fig. 156). Adults were collected at the end of May.

Etymology. This species is named in honour of our colleague and empidoid specialist, Dr. Bradley J. Sinclair, who collected numerous specimens of Microphorinae used in this study.

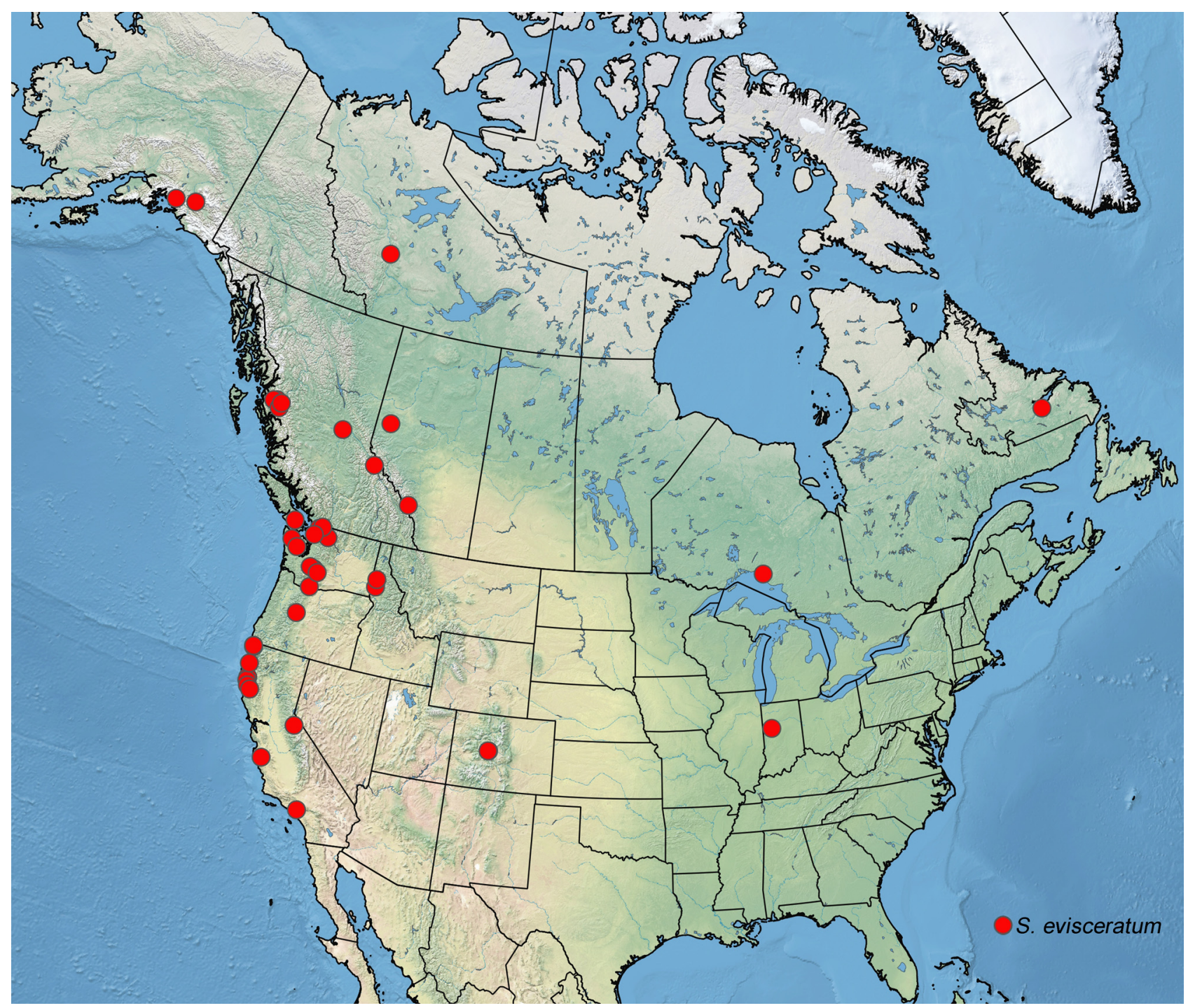

FIGURE 153. Known geographical distribution of Schistostoma evisceratum (Melander) comb. nov.

\section{Schistostoma susanae sp. nov.}

(Figs 11, 127, 154)

urn:lsid:zoobank.org:act: 56C90638-7B50-4FE7-9F99-8FBA7FB48637

Type material. HOLOTYPE, ô collected from Middle Fork of Nooksack River, Whatcom County, Washington, USA, 11.vi.2018, by J.M. Cumming, labelled: "USA: WA: Whatcom Co.,/ Middle Fork Nooksack R., 48 47'5"N $122^{\circ} 6^{\prime} 49^{\prime \prime} \mathrm{W}, / 535 \mathrm{ft}, 11 . v i .2018$, at bridge,/ J.M. Cumming, CNC1106878”; "HOLOTYPE/ Schistostoma susanae/ Brooks \& Cumming [red label]" (CNC). PARATYPES: USA: Washington: Same data as holotype, except, CNC1106867, CNC1106874, CNC1106879 (3 $\left.\hat{O}^{\wedge}, \mathrm{CNC}\right)$; same data as holotype except, S.E. Brooks, CNC1099708, CNC1099709, CNC1099711, CNC1099718, CNC1099719, CNC1099723, CNC1099726, CNC1099727, CNC1099731, CNC1099733, CNC1099742, CNC1099744, CNC1099745, CNC1099746, CNC1099747 (12ð, 3 q, CNC); same data as holotype except, S.H. Cumming, CNC1106884 (1 + , CNC). 


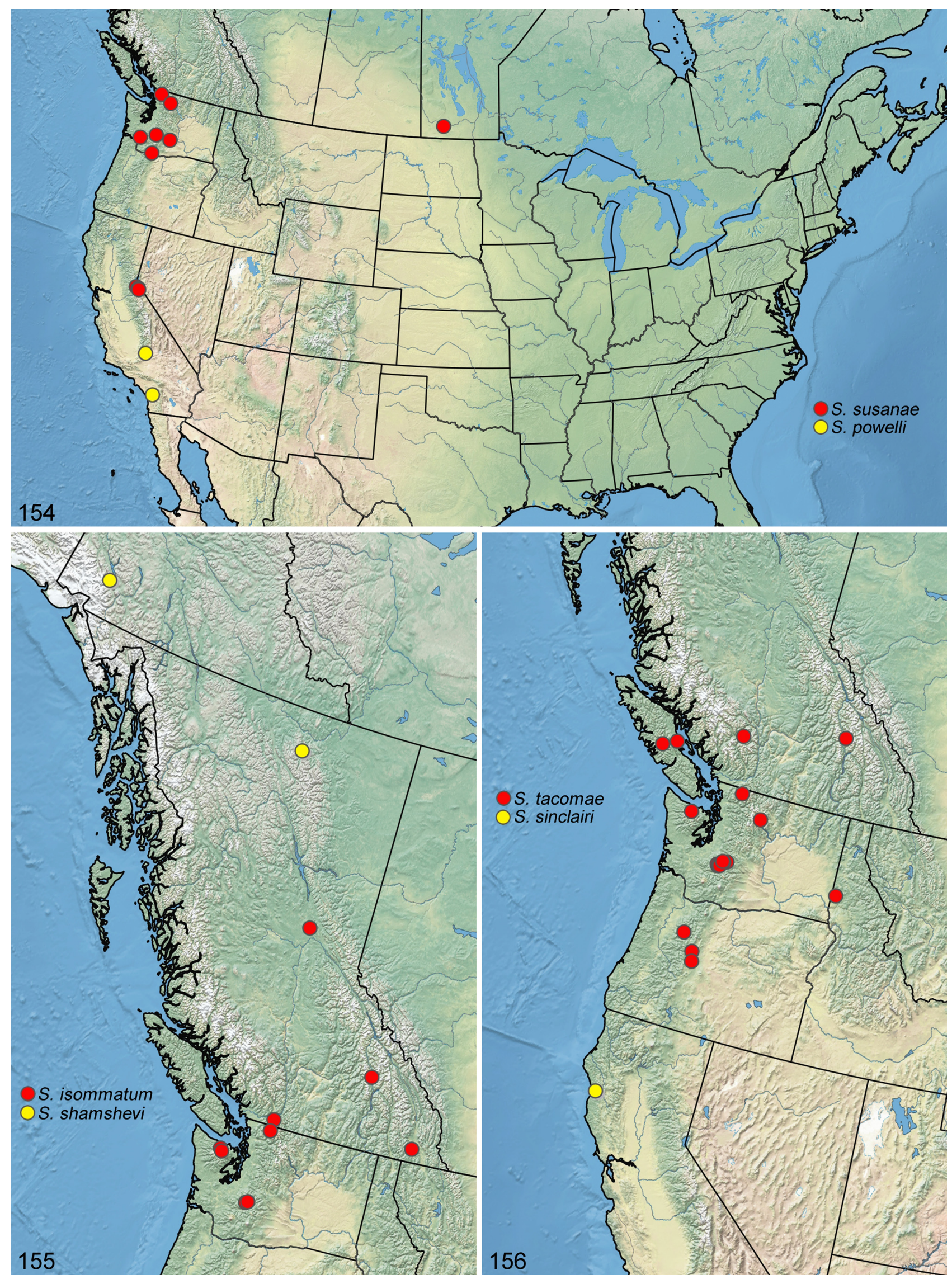

FIGURES 154-156. Known geographical distributions of Nearctic Schistostoma. 154. S. susanae sp. nov. and S. powelli sp. nov. 155. S. isommatum (Melander) comb. nov. and S. shamshevi sp. nov. 156. S. tacomae (Melander) comb. nov. and $S$. sinclairi sp. nov. 
Other material examined. CANADA: Manitoba: Treesbank [ $c$ a $\left.49^{\circ} 38^{\prime} \mathrm{N} 99^{\circ} 36^{\prime} \mathrm{W}\right]$, 30.v.1915, Collection

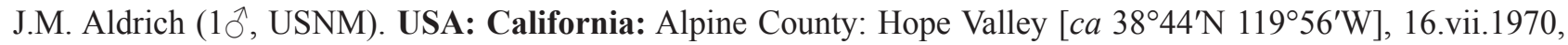

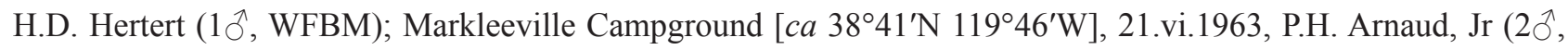

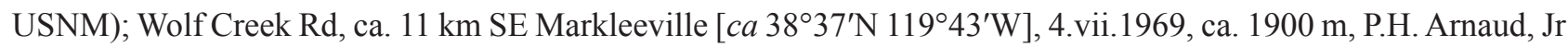

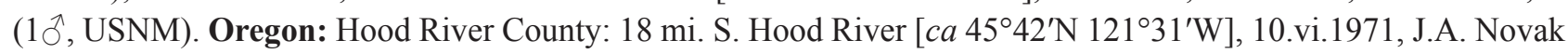
(1 $\left.\jmath^{\lambda}, \mathrm{WSU}\right)$; same data except, D.N. Ferro (6ㅇ, WSU). Washington: Cowlitz County: S Fork Toutle River [ca

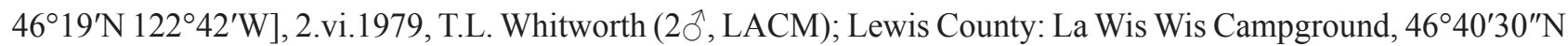

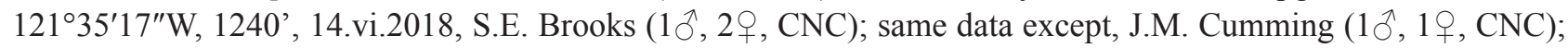
Skagit County: Cascade River margin, 48 $27^{\prime} 54^{\prime \prime} \mathrm{N} 121^{\circ} 13^{\prime} 1^{\prime \prime} \mathrm{W}, 1186^{\prime}, 9 . v i .2018$, S.E. Brooks $\left(2{ }^{\prime}, 3\right.$, 3 , CNC); same data except, J.M. Cumming (1§ิ, 4ㅇ, CNC); same data except, 17.vi.2018 (2q, CNC); Yakima County: No.

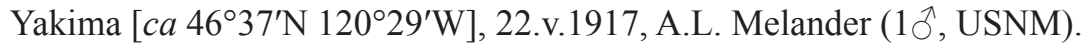

Diagnosis. This species is very close to $S$. fitzgeraldi sp. nov. and $S$. sinclairi $\mathbf{s p . ~ n o v . , ~ a n d ~ i s ~ d i s t i n g u i s h e d ~ f r o m ~}$ other members of the $S$. isommatum species group by the short marginal setae on male abdominal sternite 5, long curved medial hypandrial prolongation (Fig. 127), broad spiculate dorsal postgonite lobe, and shape of the dorsal lobe of the surstylus, as indicated in the key (couplets 37, 42, 43).

Description. Male (Fig. 127): Body length 1.7-1.9 mm, wing length 1.9-2.0 mm. Head: Ocellar tubercle with 2 pairs of black proclinate setae, anterior pair distinctly longer than posterior pair. Occiput dark grey pruinose, mostly clothed with black or brown setae, almost bare in upper part, except for postoculars. Gena and parafacial moderately projected along lower eye margin. Antenna dark brown; postpedicel conical, evenly tapered to apex; stylus about 2.0X length of postpedicel. Palpus brownish-grey, elongate ovate, slightly longer than length of labrum, pubescent with microtrichia and bearing scattered black setulae. Proboscis brown, slightly less than $1 / 2$ as long as head height, directed forward. Thorax: Mesonotum brownish-grey. Proepisternum with 1-2 setae. Mesonotal setae black, relatively long with dorsocentrals arranged in single row per side. Notopleuron with 2 strong setae. Scutellum with 2 pairs of setae, inner pair stronger. Mesopleuron grey. Halter pale. Legs: Blackish-brown, with black setae. Foreleg: Coxa with several setae on anterior surface. Femur subequal in length to tibia, posterior surface with series of posteroventral setae increasing in length distally (at most slightly longer than femur width) and shorter setae on upper half, anterior surface with series of short anteroventral setae in basal third, otherwise with short sparse setae. Tibia slender, with series of 2-4 long erect posterodorsal setae (longer than tibia width) along basal half, otherwise with short setae. Tarsus subequal in length to tibia, with short setae, tarsomere 1 subequal to combined length of tarsomeres 2-4, with small basiventral seta and adjacent setulae, tarsomeres 2-4 decreasing in length apically, tarsomere 5 subequal in length to tarsomere 2. Midleg: Coxa setose on anterior surface, usually with 1 seta on posterior surface. Femur subequal in length to tibia, posterior and anterior surfaces with short setae. Tibia slender, with short setae, with 1 long stout preapical ventral seta (about $2 \mathrm{X}$ tibia width). Tarsus slightly shorter than tibia, with short setae, tarsomere 1 subequal to combined length of tarsomeres 2-4, with pair of stout erect basiventral setae and some shorter ventral setae, apex slightly enlarged, tarsomeres 2-4 decreasing in length apically, tarsomere 5 subequal in length to tarsomere 2. Hindleg: Coxa with 3 setae on outer surface and a few setae near apex of anterior surface. Femur subequal in length to tibia, with series of longer anteroventral setae (at most slightly longer than femur width), and relatively shorter series of dorsal setae, anterior surface with short setae, posterior surface with short fine setae. Tibia enlarged apically, with short setae. Tarsus slightly shorter than tibia, with short setae, tarsomere 1 subequal to combined length of tarsomeres 2-4, with setulae ventrally, tarsomeres 2-4 decreasing in length apically, tarsomere 5 subequal in length to tarsomere 3. Wing: With slight grey-brown tinge, veins dark brown. Pterostigma well-developed. Anal lobe with proximal margin weakly concave. $\mathrm{R}_{2+3}$ and $\mathrm{R}_{4+5}$ parallel in middle part and diverging near apex with cell $r_{2+3}$ compressed in middle part and flared at apex. $R_{4+5}$ sinuous with pronounced posterior curve to apex with cell $\mathrm{r}_{4+5}$ compressed in basal part. $\mathrm{R}_{4+5}$ and $\mathrm{M}_{1}$ diverging beyond cell $\mathrm{dm}$. $M_{2}$ and $M_{4}$ subparallel beyond cell $\mathrm{dm}$. Costal section $M_{1}-M_{2}$ subequal to or slightly longer than $M_{2}-M_{4}$. Cell $\mathrm{dm}$ moderately-sized, extended to around middle of wing, distal section of vein $\mathrm{M}_{1}$ (beyond base of $\mathrm{M}_{2}$ ) longer than preceding section (between $\mathrm{r}-\mathrm{m}$ and base of $\mathrm{M}_{2}$ ). Crossvein $\mathrm{dm}-\mathrm{m}$ broadly curved and convergent with $\mathrm{M}_{1}$ distally. Abdomen (Fig. 127): Dark brown-grey, with black setae on tergites and sternites. Tergites 1-5 clothed with long, dense setae laterally, setae short and sparse dorsomedially. Tergite 6 with setae along posterior margin, otherwise bare. Sternites 2-4 with some long and short setae medially, sternites 3 and 4 with longer setae along lateral margins (progressively stronger posteriorly). Sternite 5 modified, polished and shiny, shallowly emarginate posteromedially, with tiny medial protrusion and short spine-like marginal setae on each side or emargination, with 
2 long strong laterally projecting setae near outer margin. Sternite 6 angled dorsally, bare. Segment 7 robust, bare. Sternite 8 large and subrectangular, setose, distal margin with longer setae. Hypopygium (Fig. 127): Large, nearly $1 / 2$ length of abdomen; posterior end partially enclosed by modified pregenitalic sternites. Left epandrial lamella rounded basally, with surstylar lobes projecting distally, with row of thick apically branched setae adjacent to base of cercus. Left dorsal lobe of surstylus broad, convex dorsally with ventral bend near middle, with strong lateral seta at base (sometimes branched apically) and weaker seta near middle, with crest-like lateral process; apex with short dentiform apicodorsal process, without notch, ventral margin irregular with strong seta. Left upper middle lobe of surstylus digitiform, with close-set pair of setae near middle, apex with strong claw-like seta projecting medially. Left lower middle lobe of surstylus broad and flap-like, rounded apically with long apical seta. Left ventral lobe of surstylus serrate ventrally with short pointed downturned tip, with 3 short setae, membranous basiventrally. Right epandrial lamella largely similar to left side. Right dorsal lobe of surstylus similar to left side. Right upper middle lobe of surstylus similar to left side. Right lower middle lobe of surstylus similar to left side, but ventral margin with short setae and basal projection. Right ventral lobe of surstylus dorsoventrally flattened, with rounded apex. Hypandrium with base bulbous and strongly produced anteriorly, with single large seta on each side of basal part. Medial hypandrial prolongation long, curved to right side, with pair of strong divergent apical setae, each seta projecting at right angle to prolongation, right seta longer. Left hypandrial lobe short, covered by ventral lobe of surstylus. Right hypandrial lobe broad and elongate, apex with narrow down-curved dorsal flap-like projection. Left dorsal postgonite lobe longer than cercus, broad, with dorsal fringe of spicules near base. Left ventral postgonite lobe broad and long with apex rounded and serrate, with small ventral process near base. Right dorsal postgonite lobe similar to left side. Right ventral postgonite lobe short narrow and pointed apically, covered by hypandrial lobe. Postgonite apodeme narrowly heart-shaped in ventral view, unbranched. Phallus slender, broadly C-shaped and projecting posteriorly. Ejaculatory apodeme subrectangular. Left and right cercus with hump-like base and narrow elongate digitiform apex bearing long apical seta.

Female: Body length 1.9-2.0 mm, wing length 1.8-2.0 mm. Similar to male except as follows: Head: Gena and parafacial distinctly projected along lower eye margin. Legs: With shorter setae. Midleg: Tarsomere 1 without enlarged apex. Wing: Anal lobe slightly smaller. $\mathrm{R}_{4+5}$ with posterior curve slightly weaker. Abdomen: Tergites and sternites with short setae. With 7 exposed abdominal segments, segment 7 concolorous with anterior abdominal segments. Terminalia (similar to Figs 97, 98): Segment 6 with tergite and sternite subrectangular (wider than long), tergite with setae on lateral and posterior margins, sternite setose on posterior half. Segment 7 with tergite subrectangular (wider than long), sternite subquadrate, tergite with setae on posterior and lateral margins, sternite setose on posterior half, with band-like posterior sclerite extension on each side (tergite extensions broad, sternite extensions narrow). Tergite 8 narrowly divided (desclerotized) medially, with pair of setae laterally, narrowly fused to sternite 8 anterolaterally. Sternite 9 desclerotized and inconspicuous. Spermatheca spherical. Syntergite $9+10$ with hemitergites subrectangular, each with 3 acanthophorite setae. Sternite 10 with anterior margin narrowly sclerotized and divided (desclerotized) medially, mainly membranous posteriorly with setulae and short setae. Cercus short, wider than long, membranous ventrally, rounded apically, with several setae ventrally.

Distribution and seasonal occurrence. Schistostoma susanae sp. nov. is a western North America species known from localities in Manitoba, Washington (e.g., Fig. 11), Oregon and central California (Fig. 154). Adults have been collected from late May to mid-July.

Etymology. This species is named after the second author's wife, Susan Cumming, who collected a number of Microphorinae specimens used in this study, including a paratype of this new species.

Remarks. This species was collected together with S. caroleae sp. nov. and S. evisceratum along the Cascade River (Fig. 11), and also with S. evisceratum along the Cowlitz River at La Wis Wis Campground and along the Middle Fork of the Nooksack River in Washington by the authors in June, 2018.

\section{Schistostoma tacomae (Melander) comb. nov.}

(Figs 131, 142, 143, 156)

Microphorus tacomae Melander, 1940b: 69.

Type material examined. HOLOTYPE, ô collected from Indian Henry Park [ $c a 46^{\circ} 45^{\prime} \mathrm{N} 121^{\circ} 48^{\prime} \mathrm{W}$ ], Mount Rainier, Pierce County, Washington, USA, 2.viii.1922, by A.L. Melander, labelled: "Mt Rainier/ Ind. Henry/ 2 
Aug 1922/ ALMelander"; "ALMelander/Collection/ 1961"; "Microphorus/ tacomae/ Mel."; "HOLOTYPE/ Microphorus/ tacomae Melander, 1940 [red label]" (USNM). See "Remarks". PARATYPES: USA: Washington:

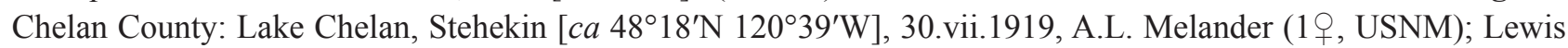

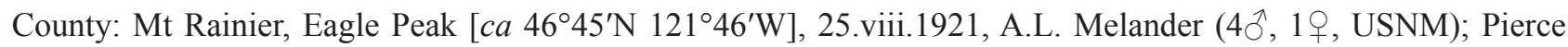

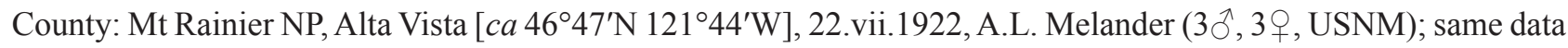

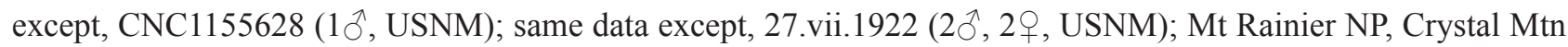
[ca $46^{\circ} 55^{\prime} \mathrm{N} 121^{\circ} 29^{\prime} \mathrm{W}$ ], 3.viii.1922, A.L. Melander (2, USNM); Mt Rainier NP, Indian Henry Park [ca $46^{\circ} 45^{\prime} \mathrm{N}$ $\left.121^{\circ} 48^{\prime} \mathrm{W}\right]$, 2.viii.1922, by A.L. Melander (1 $0^{\top}, 1$, , USNM); Mt Rainier NP, Mazama Ridge [ca $46^{\circ} 47^{\prime} \mathrm{N} 121^{\circ} 43^{\prime} \mathrm{W}$ ], 23.vii.1922, A.L. Melander (2 ${ }^{\top}$, USNM); Mt Rainier NP, Paradise Park [ca $46^{\circ} 47^{\prime} \mathrm{N} 121^{\circ} 44^{\prime} \mathrm{W}$ ], viii.1917, A.L.

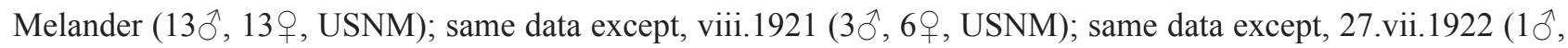
USNM); Mt Rainier NP, Sluiskin [ca 46 $46^{\circ} \mathrm{N} 121^{\circ} 43^{\prime} \mathrm{W}$ ], 28.vii.1922, A.L. Melander (1 9 , USNM); Mt Rainier NP, Squaw Lake [ $\mathrm{ca} 46^{\circ} 47^{\prime} \mathrm{N} 121^{\circ} 50^{\prime} \mathrm{W}$ ], 4.viii.1922, A.L. Melander (1 $0^{\wedge}, 1$, , USNM); Mt Rainier NP, Summerland [ca $46^{\circ} 53^{\prime} \mathrm{N} 121^{\circ} 36^{\prime} \mathrm{W}$ ], 24.vii.1924, A.L. Melander (2 $0^{\wedge}, 1$, , USNM); Mt Rainier NP, Van Trump [ca 46 $47^{\circ} \mathrm{N}$ $\left.121^{\circ} 46^{\prime} \mathrm{W}\right], 21 . v i i .1922$, A.L. Melander (60, 1 \%, USNM).

Other material examined. CANADA: British Columbia: Duffy Lake, Blowdown Creek, base Gott Peak [ $c a$ $\left.50^{\circ} 23^{\prime} \mathrm{N} 122^{\circ} 21^{\prime} \mathrm{W}\right]$, 20.vii.1988, C.S. Guppy (1 ${ }^{\hat{}}$, RBCM); Revelstoke, Mount Revelstoke NP, summit and trail to Miller Lake, $2175 \mathrm{~m}, 51.095818^{\circ} \mathrm{N} 118.056309^{\circ} \mathrm{W}$, 6.viii.2012, (CC12-30), R. Bennett, C. \& D. Copely (10,

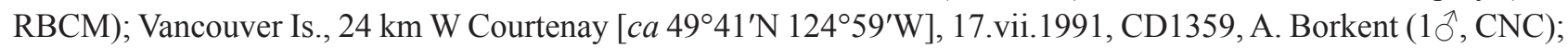

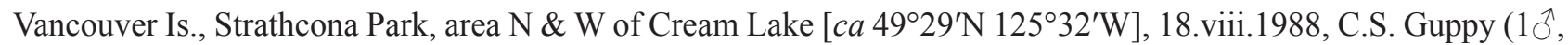

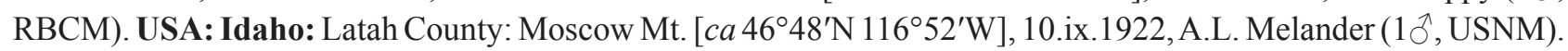
Oregon: Deschutes Co., E side McKenzie Pass near summit [ca $44^{\circ} 15^{\prime} \mathrm{N} 121^{\circ} 47^{\prime} \mathrm{W}$ ], ca. $1585 \mathrm{~m}$, 25.vii.1974, P.H.

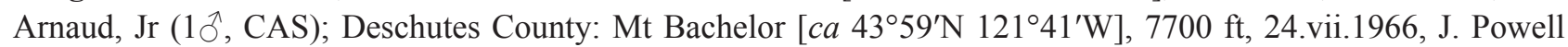

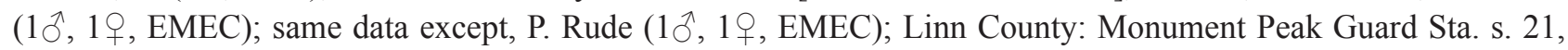

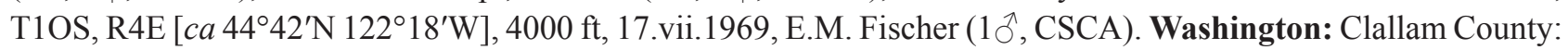
Olympic NP, meadow below Sunrise Ridge, Mt Angeles [ca 47 $58^{\prime} \mathrm{N} 123^{\circ} 29^{\prime} \mathrm{W}$ ], $1550 \mathrm{~m}$, 22.vii.1978, D.D. Wilder (1へ, CAS); same data except, 24.vii.1978 (8ภ, CAS); Lewis County: Mt Rainier NP, along Sunbeam Creek above Louise Lake [ $c a 46^{\circ} 46^{\prime} \mathrm{N} 121^{\circ} 43^{\prime} \mathrm{W}$ ], 1520m, 4.viii.1977, D.D. Wilder (1 ${ }^{\lambda}$, CAS); Pierce County: Mt Rainier [ca $46^{\circ} 47^{\prime} \mathrm{N} 121^{\circ} 44^{\prime} \mathrm{W}$ ], $5500 \mathrm{ft}$, 1.vii.1934, O. Bryant (1+, CAS); same data except, 5000-6000 ft, 4.vii.1934 (4万人, 2ᄋ, CAS); Mt Rainier NP, Edith Creek at Paradise Park [ca 46 $47^{\prime} \mathrm{N} 121^{\circ} 44^{\prime} \mathrm{W}$ ], $1650 \mathrm{~m}$, 2.viii.1977, D.D. Wilder

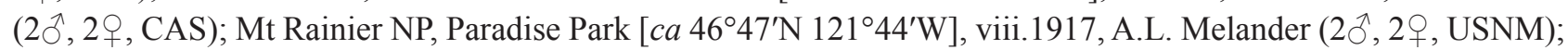
same data except, viii.1921 (2 ${ }^{\prime}$, USNM); Mt Rainier NP, Paradise Valley [ca 46 $47^{\prime} \mathrm{N} 121^{\circ} 43^{\prime} \mathrm{W}$ ], 12.viii.1928,

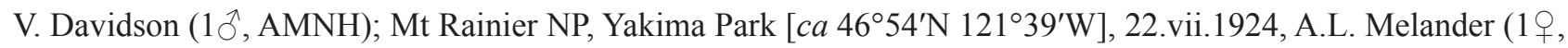
USNM); same data except, along creek draining E end Yakima Park, 1830 m, 3.viii.1977, D.D. Wilder (4ð, CAS);

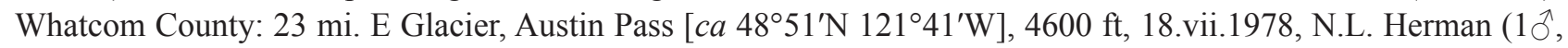
AMNH).

Diagnosis. This species is distinguished from other members of the $S$. isommatum species group by the large and mainly straight spine-like marginal setae on male abdominal sternite 5 (Fig. 131), long straight medial hypandrial prolongation, apically hooked dorsal postgonite lobe, and the distinctive structure of the surstylar lobes (Figs 142, 143), as indicated in the key (couplet 41).

Redescription. Male (Figs 131, 142, 143): Body length 2.0-2.3 mm, wing length 2.2-2.3 mm. Head: Ocellar tubercle with 2 pairs of black proclinate setae, anterior pair distinctly longer than posterior pair. Occiput dark grey pruinose, mostly clothed with black or brown setae, almost bare in upper part, except for postoculars. Gena and parafacial moderately projected along lower eye margin. Antenna dark brown; postpedicel conical, evenly tapered to apex; stylus about 2.0X length of postpedicel. Palpus dark brown, elongate ovate, slightly longer than length of labrum, pubescent with microtrichia and bearing scattered black setulae. Proboscis brown, slightly less than $1 / 2$ as long as head height, directed forward. Thorax: Mesonotum brownish-grey. Proepisternum with 1-2 setae. Mesonotal setae black, relatively long with dorsocentrals arranged in single row per side. Notopleuron with 2 strong setae. Scutellum with 2 pairs of setae, inner pair stronger. Mesopleuron grey to dark grey. Halter pale. Legs: Blackish-brown, with black setae. Foreleg: Coxa with several setae on anterior surface. Femur subequal in length to tibia, posterior surface with series of longer posterodorsal and posteroventral setae (shorter than femur width) and shorter setae along middle, anterior surface with series of short anteroventral setae, otherwise with short sparse setae. Tibia slender, usually with series of 3-4 slightly longer and erect posterodorsal setae along basal half, otherwise 
with shorter setae. Tarsus subequal in length to tibia, with short setae, tarsomere 1 subequal to combined length of tarsomeres 2-4, with 1 or a few short basiventral setae and adjacent setulae, tarsomeres $2-4$ decreasing in length apically, tarsomere 5 subequal in length to tarsomere 3. Midleg: Coxa setose on anterior surface, with 2-3 setae on posterior surface. Femur subequal in length to tibia, posterior and anterior surfaces with short setae. Tibia slender, with short setae, with 1 stout preapical ventral seta (subequal to tibia width). Tarsus slightly shorter than tibia, with short setae, tarsomere 1 subequal to combined length of tarsomeres 2-4, with 2-5 stout erect basiventral setae, apex slightly enlarged, tarsomeres 2-4 decreasing in length apically, tarsomere 5 subequal in length to tarsomere 2. Hindleg: Coxa with 3 setae on outer surface and a few setae near apex of anterior surface. Femur subequal in length to tibia, with series of longer dorsal and anteroventral setae (at most subequal to femur width), anterior surface with short setae, posterior surface with short fine setae. Tibia enlarged apically, with short setae. Tarsus slightly shorter than tibia, with short setae, tarsomere 1 subequal to combined length of tarsomeres 2-4, with setulae ventrally, tarsomeres 2-4 decreasing in length apically, tarsomere 5 subequal in length to tarsomere 2. Wing: With slight grey-brown tinge, veins dark brown. Pterostigma well-developed. Anal lobe with proximal margin straight. $\mathrm{R}_{2+3}$ and $\mathrm{R}_{4+5}$ parallel in middle part and diverging near apex with cell $\mathrm{r}_{2+3}$ compressed in middle part and flared at apex. $\mathrm{R}_{4+5}$ sinuous with pronounced posterior curve to apex with cell $\mathrm{r}_{4+5}$ compressed in basal part. $\mathrm{R}_{4+5}$ and $\mathrm{M}_{1}$ diverging beyond cell $\mathrm{dm} . \mathrm{M}_{2}$ and $\mathrm{M}_{4}$ subparallel beyond cell $\mathrm{dm}$. Costal section $\mathrm{M}_{1}-\mathrm{M}_{2}$ subequal to $\mathrm{M}_{2}-\mathrm{M}_{4}$. Cell $\mathrm{dm}$ moderately-sized, extended to around middle of wing, distal section of vein $\mathrm{M}_{1}$ (beyond base of $\mathrm{M}_{2}$ ) longer than preceding section (between $\mathrm{r}-\mathrm{m}$ and base of $\mathrm{M}_{2}$ ). Crossvein dm-m broadly curved and convergent with $\mathrm{M}_{1}$ distally. Abdomen (Figs 131, 142, 143): Dark brown-grey, with black setae on tergites and sternites. Tergites 1-5 clothed with long, dense setae laterally, setae short and sparse dorsomedially. Tergite 6 with setae along posterior margin, otherwise bare. Sternite 2 with short setae. Sternites 3 and 4 with some long and short setae medially and long setae along lateral margins (progressively stronger posteriorly). Sternite 5 modified, polished and shiny, weakly emarginate postermedially, with dense patch of short microtrichia medially and 5 large sharply pointed marginal spine-like setae on each side of emargination, with 2 long strong laterally projecting setae near outer margin. Sternite 6 angled dorsally, bare. Segment 7 robust, bare. Sternite 8 large and subrectangular, setose, distal margin with longer setae. Hypopygium (Figs 131, 142, 143): Large, nearly 1/2 length of abdomen; posterior end partially covered by modified pregenitalic sternites. Left epandrial lamella (Fig. 142) rounded basally, with surstylar lobes projecting distally, with row of strong setae adjacent to base of cercus. Left dorsal lobe of surstylus broad with rounded dorsal margin, with pair of branch-tipped setae laterally near base; apex with acute spur-like tip and several preapical ventral setae. Left upper middle lobe of surstylus slender and curved medially, with long anteriorly directed apical seta; basal part with dorsal tubercle bearing blade-like setae and small unmodified seta. Left lower middle lobe of surstylus thumb-like with apical seta. Left ventral lobe of surstylus serrate ventrally with short pointed downturned tip, with 3 short setae, membranous basiventrally. Right epandrial lamella (Fig. 143) largely similar to left side. Right dorsal lobe of surstylus similar to left side. Right upper middle lobe of surstylus similar to left side. Right lower middle lobe of surstylus similar to left side, but ventral margin with several short setae. Right ventral lobe of surstylus dorsoventrally flattened, with rounded apex. Hypandrium with base bulbous and strongly produced anteriorly, with single large seta on each side of basal part. Medial hypandrial prolongation long, straight, projected to right side, with pair of strong divergent apical setae, each seta projecting at right angle to prolongation, left seta slightly longer. Left hypandrial lobe short, covered by ventral lobe of surstylus. Right hypandrial lobe elongate and broad with apex slightly expanded. Left dorsal postgonite lobe subequal in length to cercus, with ventrally projecting pointed hook-like tip. Left ventral postgonite lobe broad and long with apex rounded and serrate, with small ventral process near base. Right dorsal postgonite lobe similar to left side. Right ventral postgonite lobe narrow and pointed apically, nearly as long as phallus. Postgonite apodeme narrowly heart-shaped in ventral view, unbranched. Phallus slender, broadly C-shaped and projecting posteriorly. Ejaculatory apodeme subrectangular. Left and right cercus with hump-like base and narrow elongate digitiform apex bearing long apical seta.

Female: Body length 2.1-2.3 mm, wing length 2.1-2.4 mm. Similar to male except as follows: Head: Gena and parafacial distinctly projected along lower eye margin. Legs: With shorter setae. Midleg: Tarsomere 1 without enlarged apex. Wing: Anal lobe slightly smaller. $\mathrm{R}_{4+5}$ with posterior curve slightly weaker. Abdomen: Tergites and sternites with short setae. With 7 exposed abdominal segments, segment 7 concolorous with anterior abdominal segments, shiny. Terminalia (similar to Figs 97, 98): Segment 6 with tergite and sternite subrectangular (wider than long), with setae on posterior half (setae denser on sternite). Segment 7 with tergite and sternite subrectangular (wider than long), tergite with setae on posterior and lateral margins, sternite setose on posterior half, with band-like 
posterior sclerite extension on each side (tergite extensions broad, sternite extensions narrow). Tergite 8 narrowly divided (desclerotized) medially, with pair of setae laterally, narrowly fused to sternite 8 anterolaterally. Sternite 9 desclerotized and inconspicuous. Spermatheca ovoid. Syntergite 9+10 with hemitergites subrectangular, each with 3-4 acanthophorite setae. Sternite 10 membranous with setulae and short setae. Cercus short, slightly wider than long, membranous ventrally, rounded apically, with subapical seta and several setae ventrally.

Distribution and seasonal occurrence. Schistostoma tacomae is a northwestern North America species known from British Columbia, Washington, Oregon and Idaho (Fig. 156). Adults have been collected from early June to early September.

Remarks. Melander (1940b) mentions the "Type" from Indian Henry Park collected on August 2, 1922; however, there are also two paratypes from the same collecting event. The presumed holotype does not bear an original type label. We have added a holotype label to this specimen. The paratype series of S. tacomae includes one male of $S$. atratum and three males of $S$. isommatum, all from Mount Rainier (Paradise Park and Indian Henry's). These specimens are listed in the "Other material examined" sections of S. atratum and S. isommatum above.

\section{Schistostoma ravidum species group}

(Figs 7, 8, 13-15, 99, 100, 104, 157-176, 179-238)

Diagnosis. Setae of body and legs entirely black, or at least thoracic setae black with black, brown or pale setae on head legs and abdomen, body dark grey, grey or brown, legs dark brown to pale (Figs 157, 183, 192, 211, 222, 228); male compound eye with or without distinct demarcation line between dorsal and ventral ommatidia (Figs 160, 184, 193, 223); female head with gena and parafacial narrow (Figs 162, 163), or distinctly projected (Figs 199, 212, 228) along lower eye margin; antenna with stylus 1.5-3.5X longer than postpedicel (Figs 161, 162, 184, 193, 212, 223); thorax with mesonotal setae widely spaced and conspicuous; acrostichals biserial, dorsocentrals arranged in a single row per side; scutellum with 2 setae per side; male midleg modified (Figs 158, 159, 164, 167, 185, 200-203, $215,216,226)$, trochanter with spine-like setal pair on medial surface, femur usually with 2-6 long, sometimes modified posteroventral setae, tibia usually with swelling just beyond middle; wing (Figs 169-176) with cell $r_{2+3}$ usually compressed in middle part and flared at apex, cell $r_{4+5}$ evenly narrowed to compressed in basal part, cell $\mathrm{dm}$ moderately-sized to small; male pregenitalic abdominal sternites usually with specialized setae (Figs 166, 168, 186, 204, 205); hypopygium (Figs 166, 168, 179-182, 186-191, 194-198, 204-209, 214, 217-221, 227, 229-232) small and free, epandrium without specialized setae adjacent to cercus, surstylus single-lobed to multilobate, dorsal postgonite lobes not substantially developed, hypandrium with 1 seta per side, medial hypandrial prolongation with pair of apical or preapical setae; female terminalia (Fig. 165) retracted into segment 6 (i.e., with 6 exposed abdominal segments), segment 6 concolorous with anterior abdominal segments, syntergite $9+10$ with acanthophorite spines, cercus with curved pointed apex (Figs 99, 100).

Remarks. This species group includes $S$. armipes, $S$. arnaudi $\mathbf{s p . ~ n o v . , ~ S . ~ c i r r i p e s ~ c o m b . ~ n o v . , ~ S . ~ h e a t h e r a e ~} \mathbf{s p .}$ nov., S. longistylum sp. nov., S. michaeli sp. nov., S. oharai sp. nov., S. ravidum comb. nov., S. robustum comb. nov., S. rudei sp. nov., S. strigilifer comb. nov. and S. sycophantor. There is also an undescribed Palaearctic species in this group from Japan (CNC), which is similar to $S$. robustum (Melander).

There are four distinctive subgroups within the S. ravidum species group including: S. armipes + S. robustum (with long ventral setae on male fore femur and deeply bifurcate medial hypandrial prolongation); $S$. arnaudi sp.

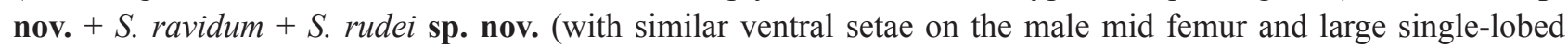
beak-like left surstylus); S. heatherae sp. nov. + S. oharai $\mathbf{s p . ~ n o v . ~}+$ S. sycophantor (with posterior fringe of setae on male fore tibia, flared phallus and elongated right and left dorsal surstylar lobes); and $S$. michaeli sp. nov. $+S$. strigilifer (with bulbous hypandrial base and broad medial hypandrial prolongation with laterally projecting setal pair on right margin). Schistostoma cirripes and S. longistylum sp. nov. do not show any obvious relationships to any of the other species of the $S$. ravidum group.

\section{Schistostoma armipes (Melander)}

(Figs 7, 8, 13-15, 99, 100, 104, 157-166, 169, 170, 179, 180, 234) 
Microphorus armipes Melander, 1928: 91.

Schistostoma armipes (Melander, 1928): Chvála (1987: 137).
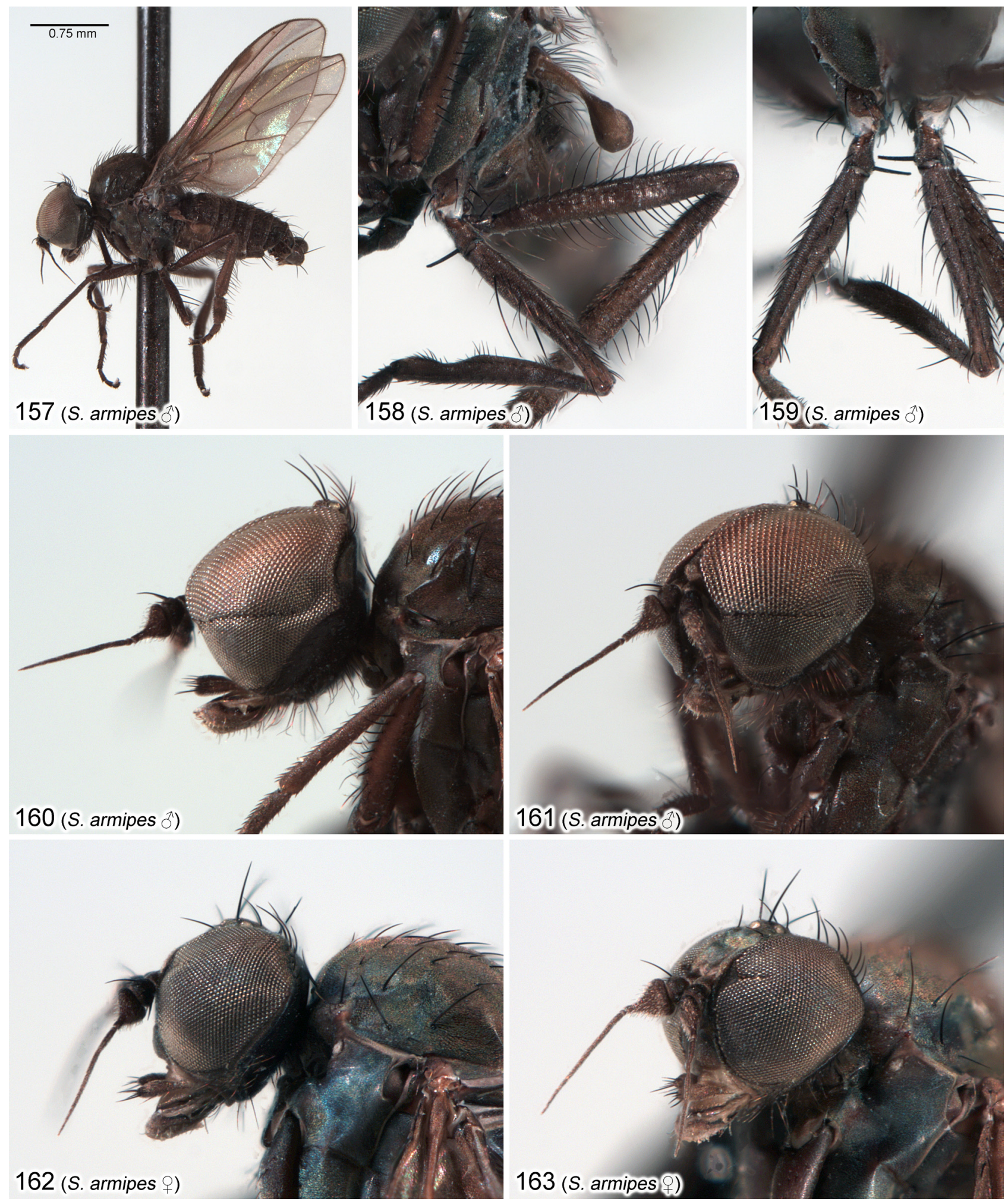

FIGURES 157-163. Habitus, head and legs of Schistostoma armipes (Melander). 157. Male habitus. 158. Male left midleg and hindleg, anterior view. 159. Male midlegs, anterodorsal view. 160. Male head and anterior portion of thorax, lateral view. 161. Male head and anterior portion of thorax, oblique view. 162. Female head and anterior portion of thorax, lateral view. 163. Female head and anterior portion of thorax, oblique view. Specimens from: Upper Parker Creek, Oregon (Figs 157, 158, 160-163); Rock Creek, Oregon (Fig. 159). 


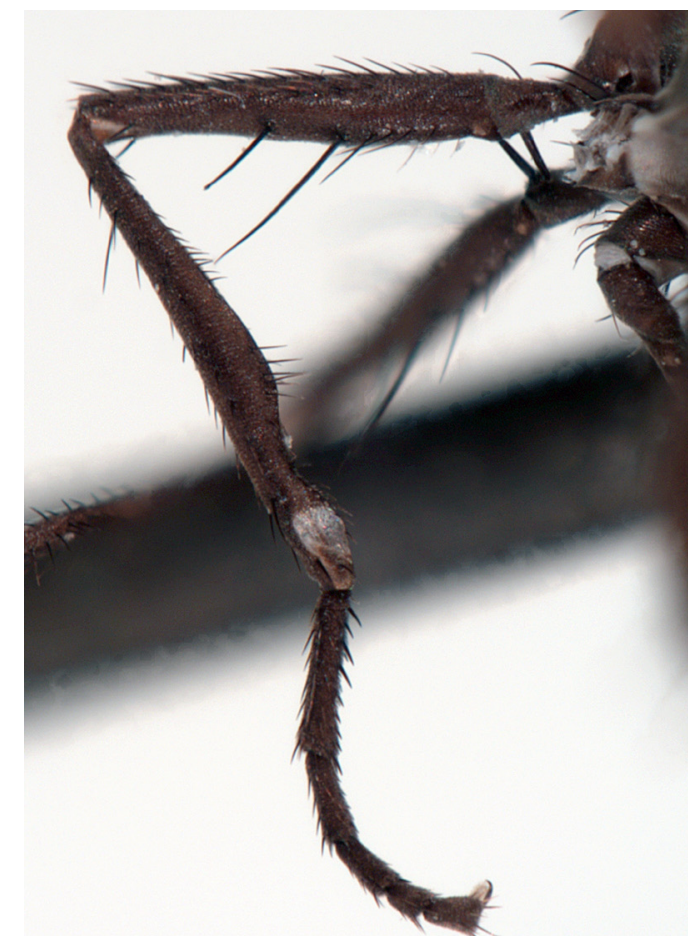

164 (S. armipes $\left.{ }^{\lambda}\right)$

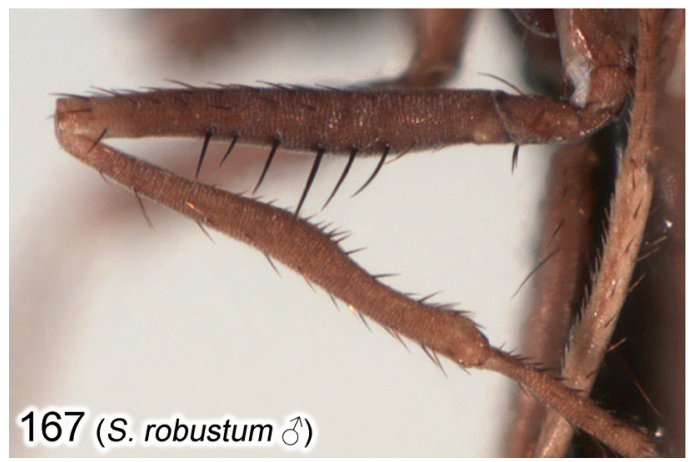

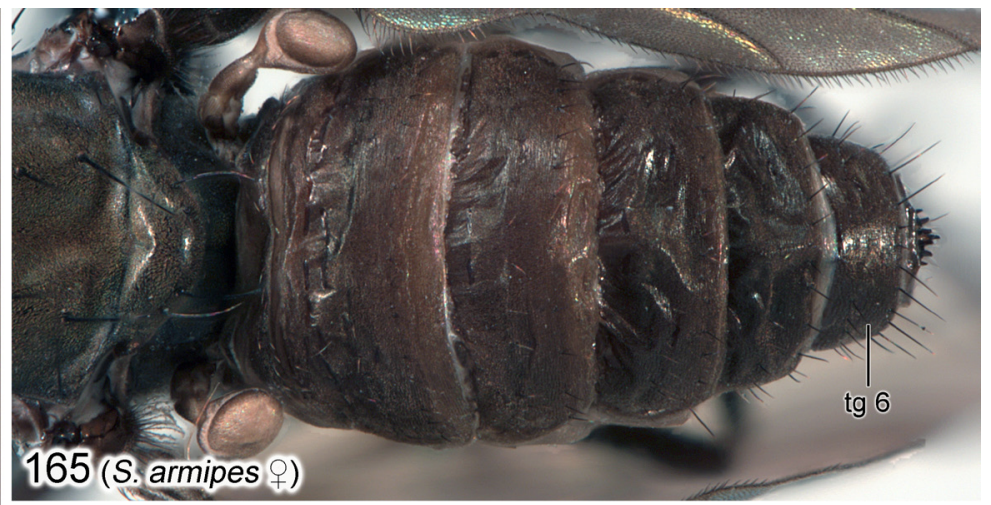
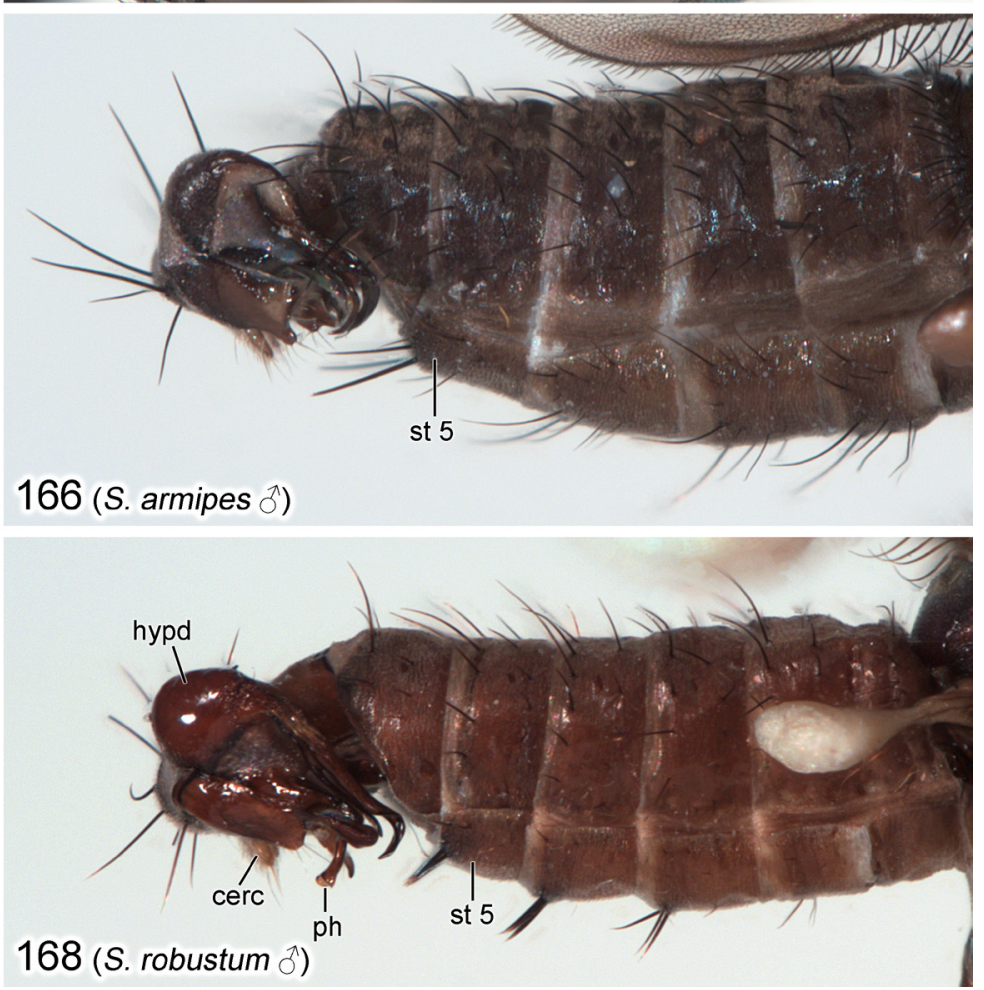

FIGURES 164-168. Legs and abdomens of Schistostoma armipes (Melander) and S. robustum (Melander) comb. nov. 164. Male midleg of $S$. armipes (Melander), posterior view. 165. Female abdomen of $S$. armipes (Melander), dorsal view. 166. Male abdomen and terminalia of $S$. armipes (Melander), right lateral view. 167. Male midleg of S. robustum (Melander) comb. nov., posterior view. 168. Male abdomen and terminalia of $S$. robustum (Melander) comb. nov., right lateral view. Specimens from: Rock Creek, Oregon (Fig. 164); Upper Parker Creek, Oregon (Figs 165, 166); Monongahela NF, West Virginia (Figs 167, 168). Abbreviations: cerc_-cercus; hypd—hypandrium; ph—phallus; st—sternite; tg—-tergite.

Type material examined. LECTOTYPE (here designated to fix the identity of the species), $\partial$ collected from Seattle

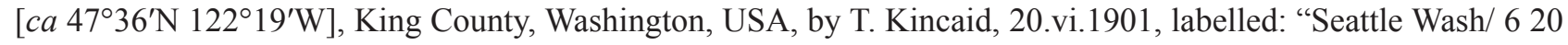
01"; "TYPE §ै/ Microphous/ armipes/ Mel. [red label]”; "ALMelander/ Collection/ 1961"; "Microphorus/ armipes/ Mel. [handwritten]"; "LECTOTYPE/ Microphorus/ armipes Melander/ des. Brooks \& Cumming 2022 [red label]" (USNM). PARALECTOTYPES: USA: Washington: Same locality and date as lectotype ( $3 \partial^{\lambda}$, USNM); same data as lectotype, except, 18.vi.1901 (1 ${ }^{\wedge}$, USNM); Jefferson County: Quilcene [ca $\left.47^{\circ} 49^{\prime} \mathrm{N} 122^{\circ} 52^{\prime} \mathrm{W}\right]$, 16.viii.1910, A.L. Melander (1 9 , USNM). See "Remarks".

Other material examined. CANADA: British Columbia: Abbotsford [ $\left.c a 49^{\circ} 03^{\prime} \mathrm{N} 122^{\circ} 18^{\prime}\right]$, 27.vi.1953,

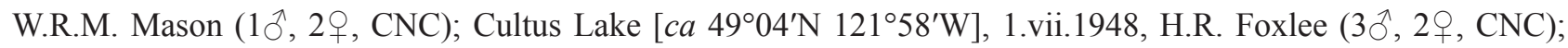

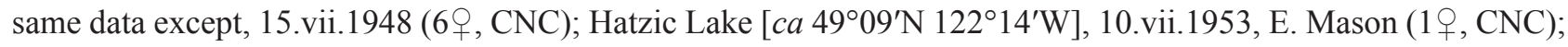

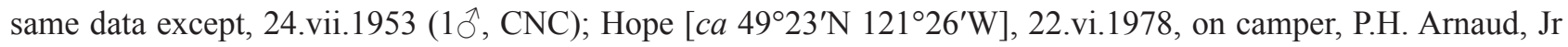

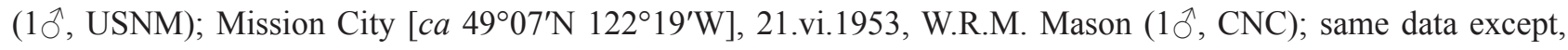

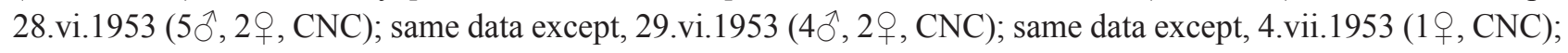


same data except, 28.vi.1953, G.J. Spencer ( $9{ }^{\lambda}, 3$,, CNC); same data except, 18.vii.1953 (1ㅇ, CNC); same data

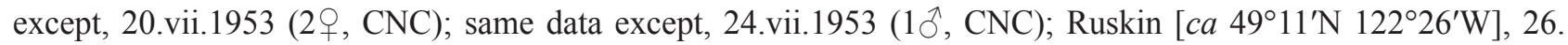

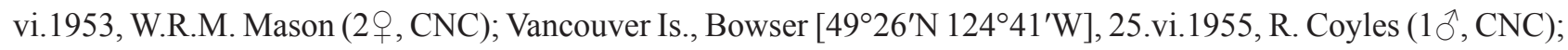
Vancouver Is., Lake Cowichan, $48^{\circ} 49^{\prime} \mathrm{N} 14^{\circ} 03^{\prime} \mathrm{W}$, 28.vi.1983, J.A. Downes, 1552/1/43- (1 $\widehat{O}^{\wedge}$, CNC); Vancouver Is., Qualicum [ $\left.\mathrm{ca} 49^{\circ} 20^{\prime} \mathrm{N} 124^{\circ} 26^{\prime} \mathrm{W}\right], 15$. vi.1955, G.E. Shewell (1 $\left.0^{\top}, \mathrm{CNC}\right)$. USA: California: Amador County:

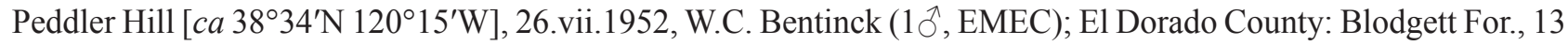

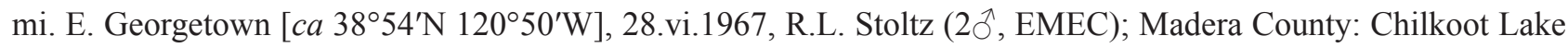
[ca 37 $24^{\prime} \mathrm{N} 119^{\circ} 28^{\prime} \mathrm{W}$ ], 23.vii.1946 (1 ${ }^{\top}$, CAS); Mariposa County: Summerdale Forest Camp, on Big Creek [ca

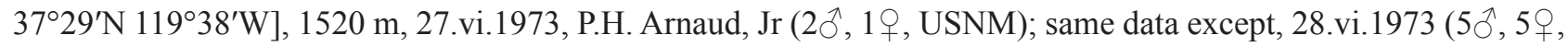

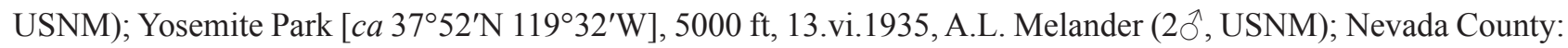
Lake Spaulding [ ca 39 $19^{\prime} \mathrm{N} 120^{\circ} 38^{\prime} \mathrm{W}$ ], $1535 \mathrm{~m}, 8-9$.vii.1994, flight trap among shaded Alnus near creek, $00152-$

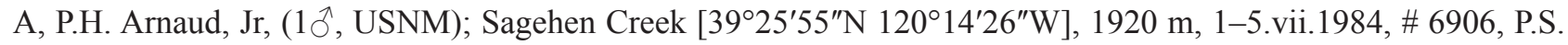

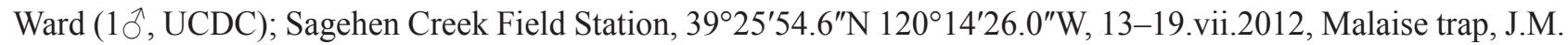
Cumming \& S.E. Brooks (2 $9, \mathrm{CNC})$; Sagehen Creek Field Station, Big Culvert along Sagehen Creek, 39²6'04.4'N $120^{\circ} 16^{\prime} 52.2^{\prime \prime} \mathrm{W}, 13-15 . v i i .2012$, yellow pan traps, J.M. Cumming \& S.E. Brooks (9수 4ㅇ, CNC); same data except,

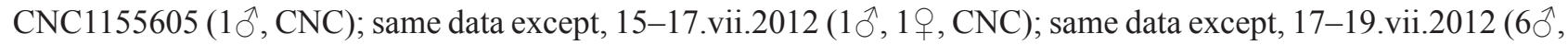
2, CNC); same data except, 11-17.vii.2012, Malaise trap, J.M. Cumming, S.E. Brooks, C. Borkent (19, CNC); Placer County: Blue Canyon, 39.2574 -120.7112, 1424m, 30.vi.2010, G.W. Forister (10̂, UCDC); Hwy 80, Exit 161, nr. Yuba Gap, 39.3230 -120.6016, 1716 m, 27.vi.2013, G.W. Forister (1 9 , UCDC); Sierra County: North Yuba River, Indian Valley Campground, 15.3 km NE Camptonville [39³0’ N $\left.120^{\circ} 58^{\prime} \mathrm{W}\right], 900 \mathrm{~m}$, 4.vii.1975, P.H. Arnaud,

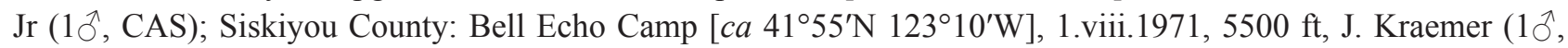
CAS); Trinity Alps, Caribou Mt. [ca 40 $\left.56^{\prime} \mathrm{N} 122^{\circ} 56^{\prime} \mathrm{W}\right], 6300-7000 \mathrm{ft}, 9 . v i i .1969$, J. Powell (1 ${ }^{\circ}$, EMEC); Trinity County: Mountain Meadow Ranch, head Coffee Creek [ $\left.c a 41^{\circ} 04^{\prime} \mathrm{N} 122^{\circ} 56^{\prime} \mathrm{W}\right], 5100 \mathrm{ft}, 8-10 . v i i .1969$, Ceanothus

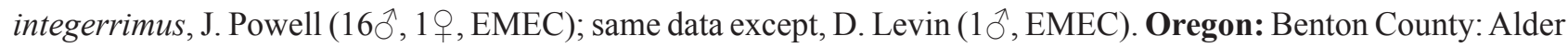

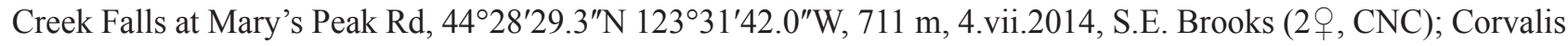

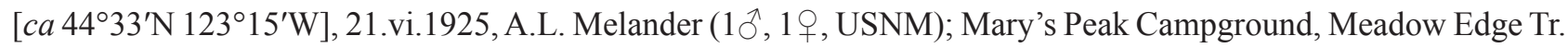

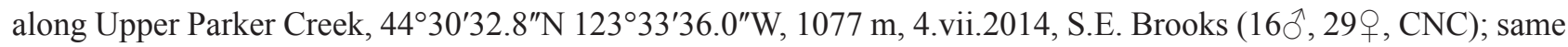

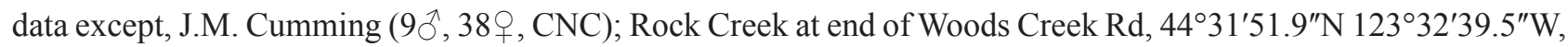

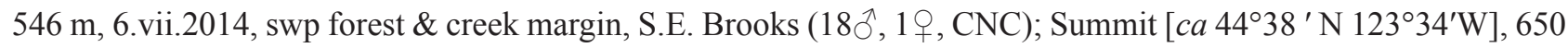

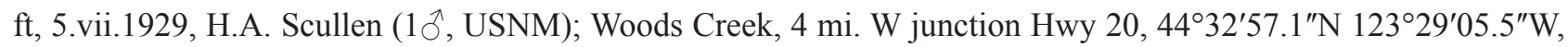
4-8.vii.2014, 235 m, yellow pan traps, J.M. Cumming \& S.E. Brooks (3ð̄, 11ㅇ, CNC); Clackamas County: Clear

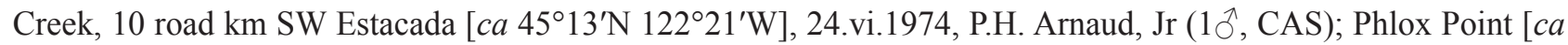
$45^{\circ} 19^{\prime} \mathrm{N} 121^{\circ} 42^{\prime} \mathrm{W}$ ], $5000 \mathrm{ft}$, 21.vii.1968, D. Klein (1 $\left.\widehat{\partial}^{\wedge}, \mathrm{CAS}\right)$; Hood River County: Homestead Inn, Mt Hood [ca $45^{\circ} 25^{\prime} \mathrm{N} 121^{\circ} 35^{\prime} \mathrm{W}$ ], 12.vii.1932, J.M. Aldrich coll (2 ${ }^{\gamma}$, USNM); same data except, 13.vii.1932 (1ㅇ, USNM); same

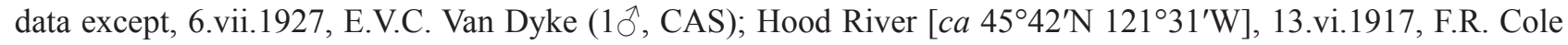

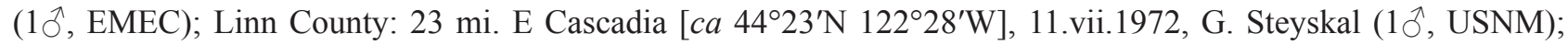

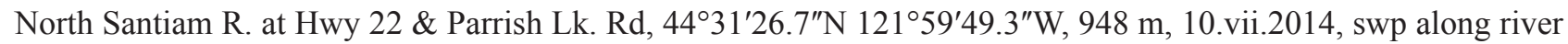
$\&$ in forest, S.E. Brooks (1 $\left.{ }^{\top}, \mathrm{CNC}\right)$; Trout Crk Campground, $44^{\circ} 23^{\prime} 47.9^{\prime \prime} \mathrm{N} 122^{\circ} 20^{\prime} 55.5^{\prime \prime} \mathrm{W}, 364 \mathrm{~m}$, 9.vii.2014, swp stony shore of S. Santiam R., J.M. Cumming (1 $\left.{ }^{\lambda}, \mathrm{CNC}\right)$; Marion County: Aurora [ $c a 45^{\circ} 13^{\prime} \mathrm{N} 122^{\circ} 45^{\prime} \mathrm{W}$ ],

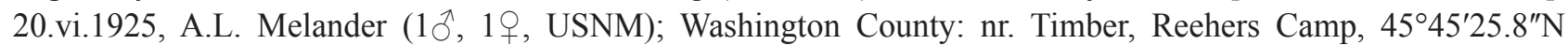

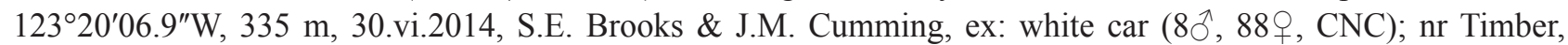

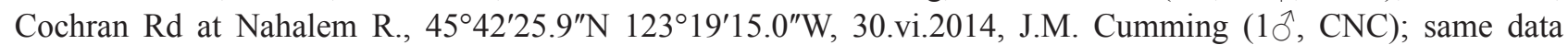

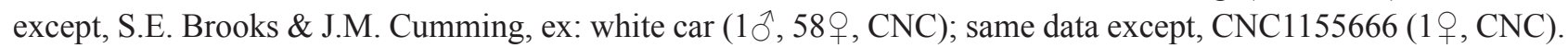

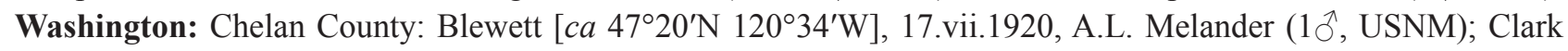
County: Vancouver [ $\mathrm{ca}^{4} 5^{\circ} 37^{\prime} \mathrm{N} 122^{\circ} 40^{\prime} \mathrm{W}$ ], 10.vii.1970 (19, WSU); same data except, 7.vii.1917, A.L. Melander

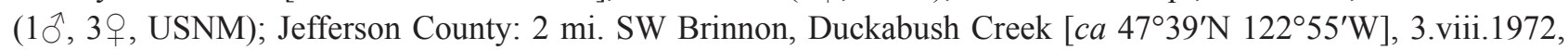
Malaise trap dry ice, W.J. Turner, W.B. Garnett (4ㅇ, WSU); King County: North Bend [ $c a 47^{\circ} 29^{\prime} \mathrm{N} 121^{\circ} 47^{\prime} \mathrm{W}$ ], 1.vii.1945, P.H. Arnaud, Jr (5 ${ }^{\lambda}$, USNM); Kittitas County: Ronald [ca $47^{\circ} 14^{\prime} \mathrm{N} 121^{\circ} 01^{\prime} \mathrm{W}$ ], 1.vii.1970, W.F. Barr

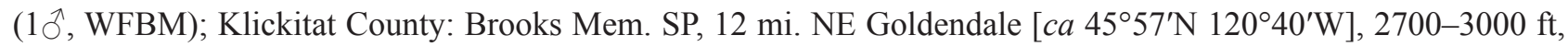

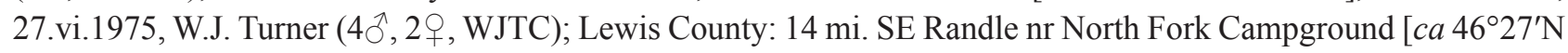
$\left.121^{\circ} 47^{\prime} \mathrm{W}\right], 29 . v i i .1972$, Malaise trap dry ice, W.J. Turner, W.B. Garnett (1ㅇ, WSU); Gifford Pinchot NF, Skate Creek Rd, mi. 14, $46^{\circ} 40.003^{\prime} \mathrm{N} 121^{\circ} 46.411^{\prime} \mathrm{W}, 660 \mathrm{~m}$, 7.vii.2013, roadside streams, B.J. Sinclair (4仓, 1, CNC); 


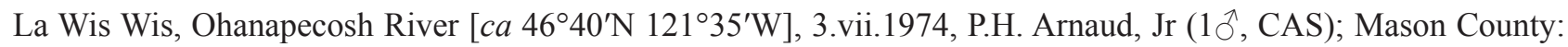
Lilliwaup [ $c a 7^{\circ} 27^{\prime} \mathrm{N} 12^{\circ} 06^{\prime} \mathrm{W}$ ], 23.vii.1917, A.L. Melander (29, USNM); Pacific County: Pluvius [ca 46 $32^{\prime} \mathrm{N}$ $123^{\circ} 24^{\prime} \mathrm{W}$ ], 16.vii.1922, A.L. Melander (1 9 , USNM); San Juan County: Friday Harbor [ca $48^{\circ} 32^{\prime} \mathrm{N} 123^{\circ} 01^{\prime} \mathrm{W}$ ], 6.vii.1928, M. Shackleford (1 $\left.\partial^{\top}, \mathrm{AMNH}\right)$; Mt Constitution [ $c a 48^{\circ} 40^{\prime} \mathrm{N} 122^{\circ} 49^{\prime} \mathrm{W}$ ], 31.vii.1908, A.L. Melander (1ㅇ, USNM); Skagit County: Mt Baker-Snoqualmie NF, $48^{\circ} 38.760^{\prime} \mathrm{N} 120^{\circ} 51.368^{\prime} \mathrm{W}, 935 \mathrm{~m}$, 19.vii.2012, roadcut seeps, B.J. Sinclair (1 ${ }^{\wedge}$, CNC); Rockport SP, 7 mi. E Concrete [ca $\left.48^{\circ} 29^{\prime} \mathrm{N} 121^{\circ} 36^{\prime} \mathrm{W}\right]$, 16-17.vi.1971, W.J. Turner (1 $1^{\wedge}$, WJTC); Snohomish County: Granite Falls [ $\left.c a 48^{\circ} 05^{\prime} \mathrm{N} 121^{\circ} 58^{\prime} \mathrm{W}\right]$, 25.vii.1925, A.L. Melander (1 9 , USNM); Yakima County: 8 mi. SW Tieton R.S., Bear Creek [ca 46 $\left.32^{\prime} \mathrm{N} 121^{\circ} 15^{\prime} \mathrm{W}\right]$, 16.vii.1972, Malaise trap dry ice, W.J. Turner, W.B. Garnett (2 $\hat{\jmath}$, WSU).

Diagnosis. Males of this species are distinguished from other members of the $S$. ravidum species group by the long posteroventral setae on the fore femur (about $2 \mathrm{X}$ femur width), antennal stylus 2.3-2.5X longer than postpedicel (Fig. 161), blackish body and legs (Figs 8, 157), mid femur with long ventral seta and shorter blunttipped posteroventral seta (Fig. 164), and additional features of the midleg, abdominal sternites (Fig. 166) and hypopygium (Figs 179, 180) indicated in the key (couplet 22). Females can be distinguished by their antennal stylus length (Fig. 163), narrow gena and parafacial (Figs 162, 163), normal cell dm (Fig. 170), and dark body and legs (Fig. 7). Schistostoma armipes is very similar to S. robustum, but is easily distinguished by its blackish coloration (versus brown in S. robustum), and the male characters listed above.

Redescription. Male (Figs 8, 157-161, 164, 166, 169, 179, 180): Body length 2.1-2.9 mm, wing length 2.1$2.4 \mathrm{~mm}$. Head (Figs 160, 161): Compound eye with demarcation line anteriorly between larger dorsal and smaller ventral ommatidia. Ocellar tubercle with 2 pairs of black proclinate setae, anterior pair slightly longer than posterior pair. Occiput dark grey pruinose, mostly clothed with black or dark brown setae, almost bare in upper part, except for postoculars. Gena and parafacial narrow along lower eye margin. Antenna dark brown; postpedicel elongate subtriangular with apical 1/2 narrow and digitiform; stylus about 2.0X length of postpedicel. Palpus dark brown, elongate ovate, slightly longer than length of labrum, pubescent with microtrichia and bearing scattered black setulae. Proboscis brown, slightly less than $1 / 2$ as long as head height, directed forward. Thorax (Figs 157, 160): Mesonotum brownish-black to black. Proepisternum with 1-2 setae. Mesonotal setae black, relatively long with dorsocentrals arranged in single row per side or irregularly biserial. Notopleuron with 2-3 strong setae. Scutellum with 2 pairs of setae, inner pair stronger. Mesopleuron brownish-black to black. Halter light brown to dark brown. Legs: Entirely dark brown, with black setae. Foreleg: Coxa with several setae on anterior surface. Femur subequal in length to tibia, posterior surface with short setae on upper half and series of about 8-10 long posteroventral setae (about $2 \mathrm{X}$ width of femur), anterior surface with series of fine anteroventral setae from base to midlength (distal setae longer). Tibia slender, with short setae mainly on dorsal surface. Tarsus subequal in length to tibia, with short setae, tarsomere 1 slightly shorter than combined length of tarsomeres $2-5$, tarsomeres $2-4$ decreasing in length apically, tarsomere 5 subequal in length to tarsomere 2. Midleg (Figs 158, 159, 164): Coxa with several setae on anterior surface. Trochanter with medial spine-like setal pair nearly straight, slightly longer than width of trochanter. Femur slightly shorter than tibia, posterior surface with short setae on upper half, 3-4 short ventral setae in basal part, 1 long ventral seta (half femur length) near middle and 1 shorter blunt-tipped posteroventral seta beyond middle, anterior surface with 1 long seta near base and 2-3 moderately long setae near middle, otherwise with short setae. Tibia modified, widened at middle and strongly compressed apically with white concavity on posterior surface, dorsal surface with short setae, 1 prominent anterodorsal seta near basal $1 / 4$, ventral surface with short erect setae on either side of middle. Tarsus slightly shorter than tibia, with short setae, tarsomere 1 as long as combined length of tarsomeres 2-3, with a few stout ventral setae, tarsomeres 2-4 decreasing in length apically, tarsomere 5 slightly longer than tarsomere 4. Hindleg (Figs 157, 158): Coxa with 2-3 setae on outer surface and several setae on anterior surface. Femur longer than tibia, with dorsal and ventral fringe of long setae (longer than femur width), anterior surface with short setae on upper half, posterior surface mainly bare. Tibia enlarged apically, with dorsal fringe of long setae (subequal to tibia width or longer), with ventral fringe of setae along basal $2 / 3$ giving rise to dense setulae apically, anterior and posterior surface setulose. Tarsus subequal in length to tibia, tarsomere 1 broad, as long as combined length of tarsomeres 2-5, with several long dorsal setae, tarsomeres 2-4 decreasing in length apically, with short setae dorsally, tarsomere 5 subequal in length to tarsomere 3. Wing (Fig. 169): With slight greybrown tinge, veins dark brown. Pterostigma well-developed. Anal lobe with proximal margin weakly convex. $\mathrm{R}_{2+3}$ and $\mathrm{R}_{4+5}$ parallel in middle part and diverging near apex with cell $\mathrm{r}_{2+3}$ compressed in middle part and flared at apex. $R_{4+5}$ sinuous with pronounced posterior curve to apex with cell $r_{4+5}$ slightly compressed in basal part. $R_{4+5}$ and $M_{1}$ 
diverging beyond cell dm. $M_{2}$ and $M_{4}$ weakly diverging beyond cell dm. Costal section $M_{1}-M_{2}$ subequal to $M_{2}-M_{4}$. Cell $\mathrm{dm}$ moderately-sized, extended to around middle of wing, distal section of vein $\mathrm{M}_{1}$ (beyond base of $\mathrm{M}_{2}$ ) longer than preceding section (between $\mathrm{r}-\mathrm{m}$ and base of $\mathrm{M}_{2}$ ). Crossvein $\mathrm{dm}-\mathrm{m}$ nearly straight and convergent with $\mathrm{M}_{1}$ distally. Abdomen (Fig. 166): Dark brown-grey to black, with black setae on tergites and sternites. Tergites 1-6 clothed with long, dense setae laterally, setae short and sparse dorsomedially. Sternites $2-4$ with 1 long mediolateral seta per side at posterior margin, other medial setae relatively short, lateral setae longer. Sternite 5 with pair of long spine-like mediolateral setae per side at posterior margin, other medial setae relatively short, lateral setae longer. Sternite 6 angled dorsally, with a few tiny setae. Segment 7 with a few tiny setae on sternite, otherwise bare. Sternite 8 subquadrate, setose. Hypopygium (Figs 179, 180): Small, about 1/4 length of abdomen. Left epandrial lamella (Fig. 179) subrectangular, longer than high, with surstylar lobes projecting distally. Left dorsal lobe of surstylus with several strong dorsal setae, with thin fin-like ventral process (apex broadly rounded in dorsal view). Left ventral lobe of surstylus broad with rounded downturned tip, with strong dorsobasal seta and pair of shorter setae mid-dorsally, membranous basiventrally. Right epandrial lamella (Fig. 180) subrectangular, longer than high, with surstylar lobes projecting distally. Right dorsal lobe of surstylus short, apical margin rounded with several setae. Right ventral lobe of surstylus short with truncate tip, with strong dorsolateral seta and pair of shorter setae dorsally. Hypandrium with single large seta on each side of basal part. Medial hypandrial prolongation long, deeply bifurcate; left branch (Fig. 179) broad, straight in basal third, distal part undulate with ventral bend followed by dorsal curve, with close-set pair of short parallel preapical setae; right branch (Fig. 180) narrow, apical part curved dorsally. Left hypandrial lobe short, with apical concavity surrounding base of ventral postgonite lobe. Right hypandrial lobe large and elongate, dorsally curved with apex expanded and rounded, surface finely spinose. Postgonite with dorsal postgonite lobes not substantially developed. Left ventral postgonite lobe long broad and spinose, apex bifid. Right ventral postgonite lobe short, tapered and pointed apically. Postgonite apodeme V-shaped in ventral view with short left and right branch. Phallus slender, L-shaped with distal portion nearly straight and projecting posteriorly, apex slightly expanded. Ejaculatory apodeme short. Left and right cercus with hump-like base bearing several setae and narrow stub-like apex bearing several setae.

Female (Figs 7, 99, 100, 104, 162, 163, 165, 170): Body length 2.0-2.7 mm, wing length 2.1-2.5 mm. Similar to male except as follows: Head (Figs 162, 163): Compound eye without demarcation line between dorsal and ventral ommatidia; ocellar tubercle with anterior pair of setae distinctly longer than posterior pair. Thorax (Figs 162, 163): Mesonotum blackish-brown. Legs: With shorter, unspecialized setae. Foreleg: Femur without long posteroventral setae, with only short anteroventral setulae. Midleg: Trochanter without spine-like setal pair; femur and tibia lacking specialized setae; tibia slender, unmodified. Hindleg: Femur with shorter dorsal and ventral fringe of setae; tibia not enlarged apically, with short dorsal setae; tarsomere 1 smaller, lacking distinct dorsal setae. Wing (Fig. 170): Anal lobe slightly smaller, proximal margin straight. $\mathrm{R}_{4+5}$ with posterior curve slightly weaker. Abdomen (Fig. 165): Tergites and sternites with short setae. With 6 exposed abdominal segments, segment 6 concolorous with anterior abdominal segments. Terminalia (Figs 99, 100, 104): Segment 6 with tergite and sternite subrectangular (wider than long), tergite with shallow anteromedial emargination, tergite and sternite with setae on posterior half, setae distinctly stronger on posterior margin (especially on tergite). Segment 7 with tergite longer than wide with pronounced anteromedial emargination (darkened along edge), anterior margin broadly rounded on either side of emargination, with small posterolateral seta, sternite shorter than tergite, subrectangular (slightly wider than long), with pair of small posterolateral setae, tergite and sternite with short band-like posterior sclerite extension on each side. Tergite 8 undivided, darkened along edge of anteromedial emargination, with small posterolateral seta, narrowly fused to sternite 8 anterolaterally. Sternite 9 desclerotized and inconspicuous. Spermatheca (Fig. 104) spherical. Syntergite $9+10$ with hemitergites subrectangular, each with 3 apically flattened and round-tipped (in dorsal view) acanthophorite spines. Sternite 10 with short setose lateral lobe below cercus (about half length of cercus), sternite produced posteromedially bearing setulae and about 3 adjacent short setae per side, anterolaterally with band-like extension to base of lateral lobe and cercus. Cercus with curved claw-like apex, with several small setae near midlength.

Distribution and seasonal occurrence. Schistostoma armipes is a northwestern North America species known from several localities in southern British Columbia, Washington, Oregon (e.g., Figs 13, 15), and northern and central (e.g., Fig. 14) California (Fig. 234). Adults have been collected from mid-June to mid-August.

Remarks. The whereabouts of several paralectotypes are unknown, but one male paralectotype is in the Oxford University Museum of Natural History (OUMNH), Oxford. Melander (1928) mentions types from Seattle, Quilcene and Olga in Washington. We have seen types from Seattle \& Quilcene (see above), but none from Olga. 


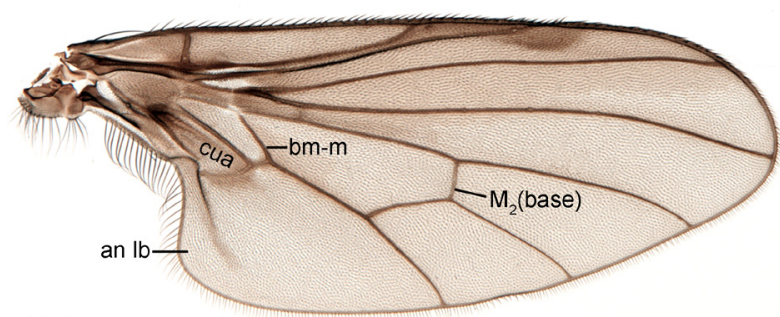

169 (S. armipes

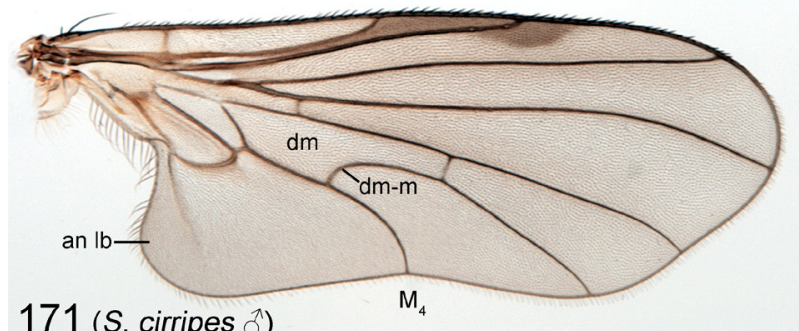

171 (S. cirripes $\left.\jmath^{\jmath}\right)$
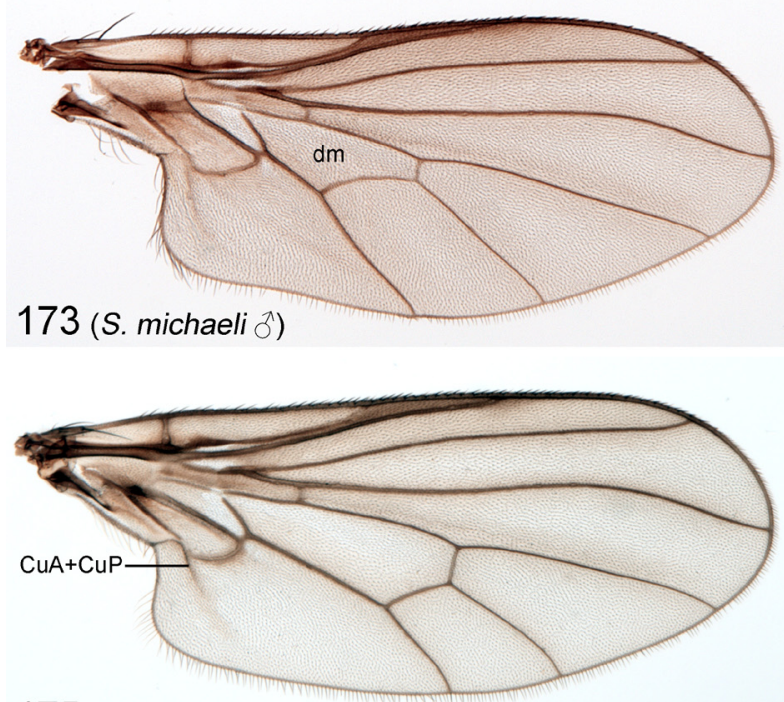

175 (S. strigilifer $\left.\partial^{\text {) }}\right)$

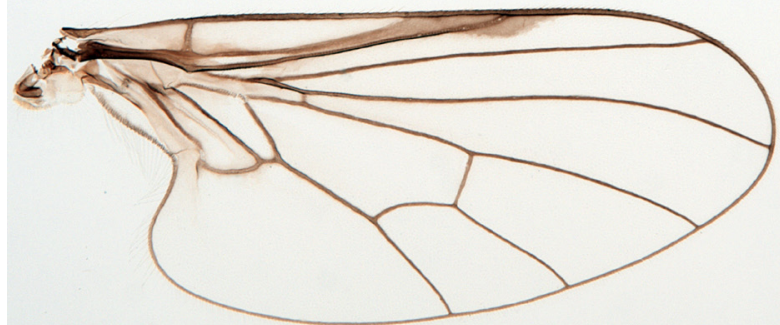

177 (S. runyoni 3)
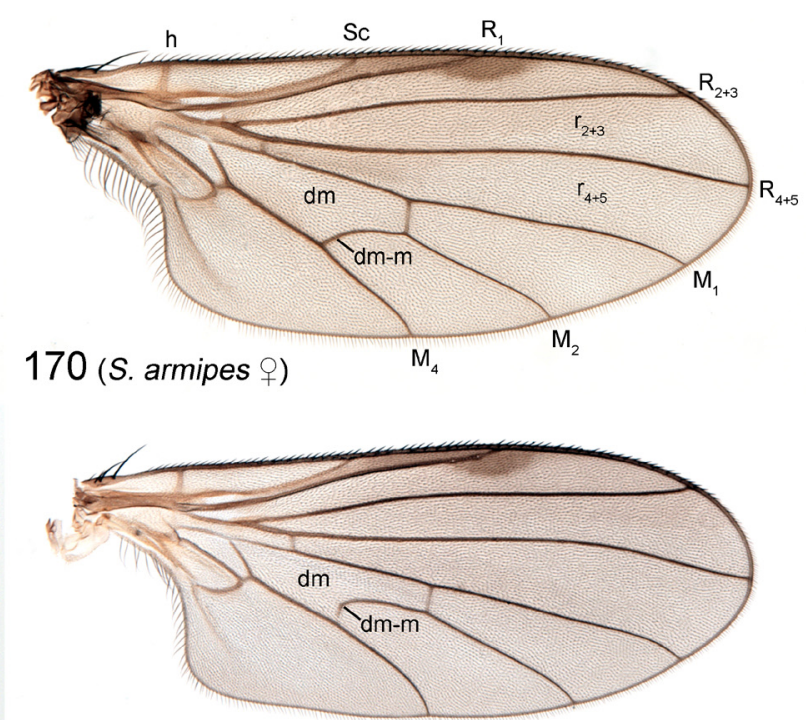

172 (S. cirripes $\bigcirc$ )
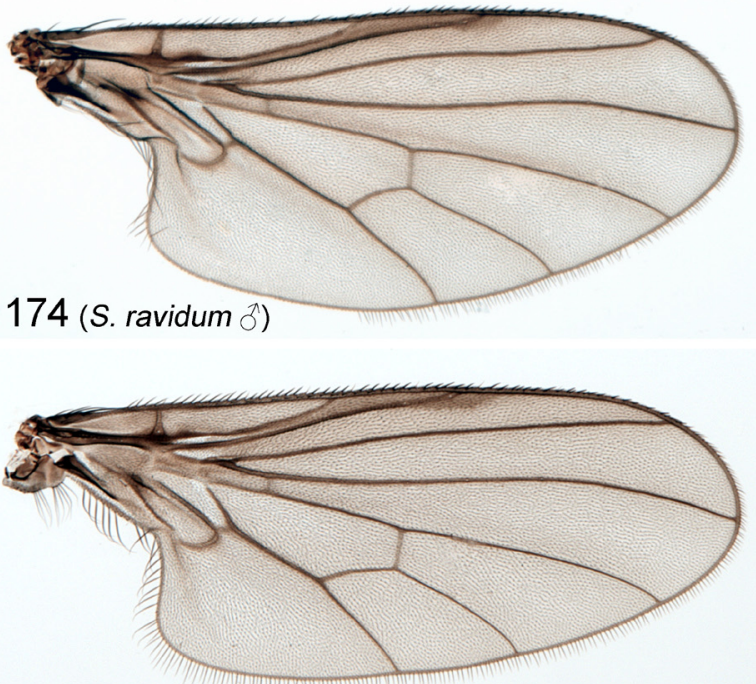

176 (S. sycophantor $\stackrel{\text { `) }}{ }$

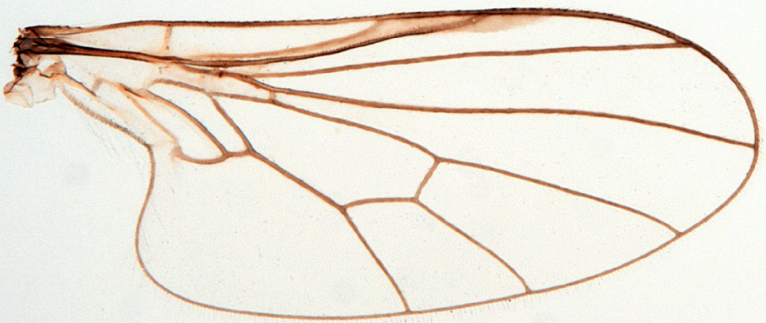

178 (S. yakimense ${ }^{\text {`) }}$

FIGURES 169-178. Wings of Nearctic Schistostoma. 169. S. armipes (Melander), male. 170. S. armipes (Melander), female. 171. S. cirripes (Melander) comb. nov., male. 172. S. cirripes (Melander) comb. nov., female. 173. S. michaeli sp. nov., male. 174. S. ravidum (Coquillett) comb. nov., male. 175. S. strigilifer (Melander) comb. nov., male. 176. S. sycophantor (Melander), male. 177. S. runyoni sp. nov., male. 178. S. yakimense (Melander), male. Specimens from: Upper Parker Creek, Oregon (Figs 169, 170); Trout Creek Campground, Oregon (Figs 171, 172); San Joaquin River Gorge, California (Fig. 173); N Fork San Gabriel River, California (Fig. 174); Largo Vista Rd, California (Fig. 175); Moscow Mtn, Idaho (Fig. 176); Williams Spring, Arizona (Fig. 177); Onefour, Alberta (Fig. 178). Abbreviations: an lb — anal lobe; bm-m — basal medial crossvein; cua — anterior cubital (=anal) cell; $\mathrm{CuA}+\mathrm{CuP}$ - anterior branch of cubital vein + posterior branch of cubital vein; dm-discal medial cell; dm$\mathrm{m}$-discal medial crossvein; $\mathrm{h}$ - humeral crossvein; $\mathrm{M}_{1}, \mathrm{M}_{2}, \mathrm{M}_{4}$ - medial veins; $\mathrm{R}_{1}, \mathrm{R}_{2+3}, \mathrm{R}_{4+5}$-radial veins; $\mathrm{r}_{2+3}, \mathrm{r}_{4+5}-$ radial cells; Sc — subcostal vein. 


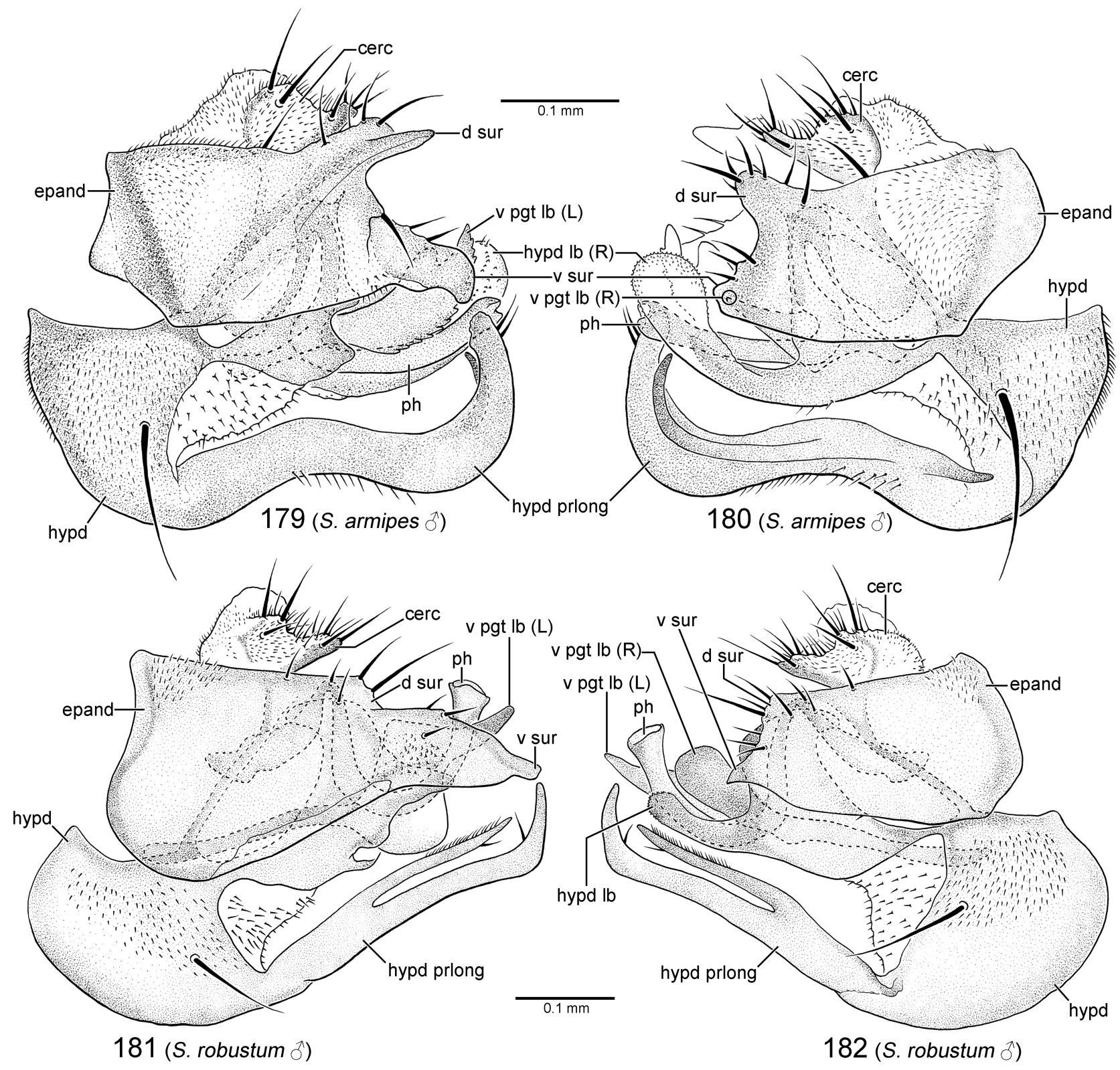

FIGURES 179-182. Hypopygia of Nearctic Schistostoma. 179. S. armipes (Melander), left lateral view. 180. S. armipes (Melander), right lateral view. 181. S. robustum (Melander) comb. nov., left lateral view. 182. S. robustum (Melander) comb. nov., right lateral view. Figures 179 and 180 based on specimen CNC1155605 (Sagehen Creek, California). Figures 181 and 182 based on specimen CNC1155608 (Bethesta, Maryland). Abbreviations: cerc — cercus; d sur-dorsal lobe of surstylus; epandepandrium; hypd — hypandrium; hypd lb — hypandrial lobe; hypd prlong—hypandrial prolongation; (L) —left; ph—phallus; (R) — right; v pgt lb—ventral postgonite lobe; v sur — ventral lobe of surstylus.

Pollen grains have been found in the gut of a dissected female of $S$. armipes and females have also been observed feeding on thimbleberry pollen (Fig. 7). Flower visitation records for this species are listed in Table 1.

This species was collected together with $S$. borkenti sp. nov. and S. sycophantor along Sagehen Creek (Fig. 14) in California, and also with S. cirripes at Trout Creek Campground along the Santiam River (Fig. 15) in Oregon by the authors in July, 2012 and 2014 respectively. 
Schistostoma arnaudi sp. nov.

(Figs 202, 208, 209, 234)

urn:lsid:zoobank.org:act: 3BDC44BD-C980-4D3D-8C87-0669AA880B8A

Type material. HOLOTYPE, ô collected from McWilliams Campground [ $c a 36^{\circ} 18^{\prime} \mathrm{N} 115^{\circ} 40^{\prime} \mathrm{W}$ ], Clark County, Nevada, USA, 14.v.1971, by P.H Arnaud, Jr \& M.M. Arnaud, labelled: "USA: NEVADA: ClarkCo/ unty, Mount Charles-/ ton, LeeCanyon, Mc-/ Williams Camground[sic]”; "14-V-1971/ Paul H. Arnaud, Jr./ Madeline M. Arnaud/ On camper/truck."; "COLLECTION OF/ PAUL H. ARNAUD, JR."; "HOLOTYPE/ Schistostoma arnaudi/ Brooks \& Cumming [red label]" (USNM). PARATYPES: USA: Nevada: Same data as holotype (4^, 16, USNM); same data as holotype except, CNC1155647 (10, USNM).

Other material examined. USA: Nevada: Clark County: Spring Mts, Kyle Canyon Campground [ $\mathrm{ca} 36^{\circ} 15^{\prime} \mathrm{N}$ $\left.115^{\circ} 36^{\prime} \mathrm{W}\right], 7000 \mathrm{ft}, 15 . v i .1971$, P.H. \& M. Arnaud (3 ${ }^{\wedge}$, USNM). Utah: Washington County: Leeds Canyon [ca $\left.37^{\circ} 14^{\prime} \mathrm{N} 113^{\circ} 21^{\prime} \mathrm{W}\right], 19-20$. iii.1987, MT, M. Youssef (10̂, LACM).

Diagnosis. Males of this species are distinguished from other members of the $S$. ravidum species group by the spine-like setae on male sternite 5 (similar to Fig. 205), series of 3 thick curved spine-like posteroventral setae on the mid femur (Fig. 202), straight setae on the mid tibial callus (Fig. 202), and the distinctive shape of the left surstylus (Fig. 208), as indicated in the key (couplets 15 and 17). Schistostoma arnaudi sp. nov. is very similar to $S$. ravidum and $S$. rudei $\mathbf{s p . ~ n o v . ~ F e m a l e s ~ o f ~ t h i s ~ s u b g r o u p ~ c a n ~ b e ~ r e c o g n i z e d ~ t o ~ s u b g r o u p ~ l e v e l , ~ b u t ~ t h e ~ s p e c i e s ~ a r e ~ n o t ~}$ readily discernible, as indicated in the key (couplet 30 ).

Description. Male (Figs 202, 208, 209): Body length 1.9-2.4 mm, wing length 2.0-2.3 mm. Head: Compound eye without demarcation line between larger dorsal and smaller ventral ommatidia. Ocellar tubercle with 2 pairs of black proclinate setae, anterior pair distinctly longer than posterior pair. Occiput dark grey pruinose, mostly clothed with black or brown setae, almost bare in upper part, except for postoculars. Gena and parafacial narrow along lower eye margin. Antenna dark brown; postpedicel conical, evenly tapered to apex; stylus about $1.5 \mathrm{X}$ length of postpedicel. Palpus dark brown, elongate ovate, slightly longer than length of labrum, pubescent with microtrichia and bearing scattered black setulae. Proboscis dark brown, slightly less than $1 / 2$ as long as head height, directed forward. Thorax: Mesonotum brownish-black. Proepisternum with 1-2 setae. Mesonotal setae black, relatively long with dorsocentrals arranged in single row per side. Notopleuron with 2 strong setae. Scutellum with 2 pairs of setae, inner pair stronger. Mesopleuron brownish-black. Halter brown. Legs: Entirely dark brown, with black setae. Foreleg: Coxa with several setae on anterior surface. Femur subequal in length to tibia, posterior surface with posterodorsal and posteroventral series of setae (slightly shorter than femur width) projecting laterally, 1 posteroventral preapical seta. Tibia slender, with short setae. Tarsus subequal in length to tibia, with short setae, tarsomere 1 subequal to combined length of tarsomeres 2-4, tarsomeres 2-4 decreasing in length apically, tarsomere 5 subequal in length to tarsomere 3. Midleg (Fig. 202): Coxa with several setae on anterior surface. Trochanter with medial spine-like setal pair weakly curved, longer than width of trochanter. Femur slightly shorter than tibia, posterior surface with short setae on upper half, ventral surface with 3-4 small posteroventral setae in basal part, distal half with distinctively modified series of 3 thick, curved, spine-like posteroventral setae (proximal seta larger and longer), 1 posteroventral preapical seta, anterior surface with slightly longer setae than posterior surface. Tibia modified, dorsal surface mainly with short setae, with longer anterodorsal seta near basal $1 / 4$, ventral surface with dense short straight setae along middle part and callus at $2 / 3$ also densely covered with short straight setae, with preapical ventral callus bearing short setae. Tarsus slightly longer than tibia, with short setae, tarsomere 1 as long as combined length of tarsomeres 2-4, base with weak dorsal bend, tarsomeres 2-4 decreasing in length apically, tarsomere 5 about as long as tarsomere 3. Hindleg: Coxa with 3 setae on outer surface and a few setae on anterior surface. Femur subequal in length to tibia, with dorsal and shorter anteroventral series of setae (shorter than femur width), anterior surface with short setae on upper part, posterior surface with sparse fine setae. Tibia slightly enlarged apically, with series of dorsal setae (subequal to tibia width), otherwise with short setae. Tarsus subequal in length to tibia, with short setae, tarsomere 1 as long as combined length of tarsomeres 2-4, tarsomeres $2-4$ decreasing in length apically, tarsomere 5 subequal in length to tarsomere 3. Wing: With slight grey-brown tinge, veins dark brown. Pterostigma small, weakly developed. Anal lobe with proximal margin weakly convex. $\mathrm{R}_{2+3}$ and $\mathrm{R}_{4+5}$ parallel in middle part and diverging near apex with cell $\mathrm{r}_{2+3}$ compressed in middle part and flared at apex. $\mathrm{R}_{4+5}$ sinuous with pronounced posterior curve to apex with cell $r_{4+5}$ slightly compressed in basal part. $R_{4+5}$ and $M_{1}$ diverging beyond cell dm. $M_{2}$ and $\mathrm{M}_{4}$ slightly diverging beyond cell $\mathrm{dm}$. Costal section $\mathrm{M}_{1}-\mathrm{M}_{2}$ subequal to $\mathrm{M}_{2}-\mathrm{M}_{4}$. Cell $\mathrm{dm}$ moderately-sized, 
extended to around middle of wing, distal section of vein $\mathrm{M}_{1}$ (beyond base of $\mathrm{M}_{2}$ ) longer than preceding section (between $\mathrm{r}-\mathrm{m}$ and base of $\mathrm{M}_{2}$ ). Crossvein dm-m broadly curved and convergent with $\mathrm{M}_{1}$ distally. Abdomen: Dark brown, with black setae on tergites and sternites, finer setae brown. Tergites 1-6 clothed with long, dense setae laterally, setae short and sparse dorsomedially. Sternites 2 and 3 with short setae. Sternite 4 with close-set row of unmodified or spine-like mediolateral setae on each side, with additional short setae and long posterolateral seta. Sternite 5 with close-set row of 3 long thick spine-like mediolateral setae on each side, additionally with sparse short setae and long lateral and posterolateral setae. Sternite 6 angled dorsally, with posterior margin slightly protruding medially, with close-set row of 3 spine-like mediolateral setae on each side, otherwise with a few lateral setae. Segment 7 with a few tiny setae on sternite, otherwise bare. Sternite 8 subrectangular, setose, distal margin with setae longer and stronger. Hypopygium (Figs 208, 209): Small, about 1/4 length of abdomen. Left epandrial lamella (Fig. 208) larger and bulkier than right epandrial lamella, ovoid basally, longer than high, with group of setae middorsally, with single-lobed surstylus projecting distally. Left surstylus, beak-like, broad basally, tapered to pointed apex with acute ventrally projected tip, with lateral seta at base and a few setae on dorsal margin. Right epandrial lamella (Fig. 209) smaller than left epandrial lamella, ovoid, longer than high, with group of setae mid-dorsally, with single-lobed surstylus projecting distally, posterior epandrial margin below surstylus broadly curved, not projecting. Right surstylus short, hook-like in lateral view with apex projected lateroventrally, with 2 short setae laterally near base. Hypandrium with single large seta on each side of basal part. Medial hypandrial prolongation long and straight, with shallow basal concavity on left side, apex shallowly bifurcate and curved left, with pair of apical setae (left seta longer). Left hypandrial lobe with apical margin broadly rounded. Right hypandrial lobe elongate, curved dorsally and spinose. Postgonite with dorsal postgonite lobes not substantially developed. Left ventral postgonite lobe broad basally with slender apical extension. Right ventral postgonite lobe tubular, with short acute conical tip. Postgonite apodeme narrowly Y-shaped in ventral view. Phallus slender, L-shaped, distal portion straight with apex curved to right. Ejaculatory apodeme short. Left and right cercus with hump-like base bearing several setae and short stubby apex bearing long setae.

Female: Body length 1.7-1.8 mm, wing length 2.0-2.1 mm. Similar to male except as follows: Head: Gena and parafacial strongly projected along lower eye margin. Thorax: Mesonotum and mesopleuron greyish-black. Halter pale. Legs: With shorter, unspecialized setae. Midleg: Trochanter without spine-like setal pair; femur and tibia lacking specialized setae; tibia slender, unmodified; tarsomere 1 without basal bend. Hindleg: Femur and tibia with shorter setae. Wing: Pterostigma absent. Anal lobe slightly smaller, proximal margin straight. Abdomen: Tergites and sternites with short setae. With 6 exposed abdominal segments, segment 6 concolorous with anterior abdominal segments, shiny. Terminalia (similar to Figs 99, 100, 104): Segment 6 with tergite and sternite subrectangular (wider than long), tergite with shallow anteromedial emargination, tergite and sternite setose on posterior half with setae distinctly stronger on posterior margin (especially on tergite). Segment 7 with tergite slightly wider than long with pronounced anteromedial emargination, anterior margin broadly rounded on either side of emargination, with small posterolateral seta, sternite subrectangular with short setae on posterior margin, tergite and sternite with short band-like posterior sclerite extension on each side. Tergite 8 undivided, darkened along edge of anteromedial emargination, with small posterolateral seta, narrowly fused to sternite 8 anterolaterally. Sternite 9 desclerotized and inconspicuous. Spermatheca spherical. Syntergite $9+10$ with hemitergites subrectangular, each with 3 acanthophorite spines. Sternite 10 with short setose lateral lobe below cercus (about half length of cercus), sternite produced posteromedially bearing setulae and about 3 adjacent short setae per side, anterolaterally with band-like extension to base of lateral lobe and cercus. Cercus with curved claw-like apex, with several small setae near midlength.

Distribution and seasonal occurrence. Schistostoma arnaudi sp. nov. is a southwestern USA species known from Nevada and Utah (Fig. 234). Adults have been collected from mid-March to mid-June.

Etymology. This species is named in honour of fellow dipterist, Dr. Paul H. Arnaud, Jr, who collected the type series with his wife Madeline from Clark County, Nevada.

Remarks. Pollen grains have been found in the gut of a dissected female of this species.

\section{Schistostoma cirripes (Melander) comb. nov.}

(Figs 15, 171, 172, 183-191, 233)

Microphorus cirripes Melander, 1940b: 64. 
Type material examined. HOLOTYPE: ${ }^{\wedge}$ collected from Eagle Creek [ $\left.c a 45^{\circ} 20^{\prime} \mathrm{N} 122^{\circ} 21^{\prime} \mathrm{W}\right]$, Clackamas County, Oregon, 24.vi.1935, by A.L. Melander, labelled: "EagleCrkOREG/ 24 June 1935/ A.L. Melander"; "Microphorus/ cirripes/ PTYPE Mel. [pink label]"; "ALMelander/ Collection/ 1961" (USNM). See "Remarks". PARATYPES: CANADA: British Columbia: Vancouver Is., Goldstream [ $\left.c a 48^{\circ} 28^{\prime} \mathrm{N} 123^{\circ} 32^{\prime} \mathrm{W}\right]$, 12.vii.1924, A.L. Melander ( 1 ㅇ, USNM). USA: California: Humboldt County: Dyerville [ca $40^{\circ} 21^{\prime} \mathrm{N} 123^{\circ} 55^{\prime} \mathrm{W}$ ], 20.vi.1935, A.L. Melander

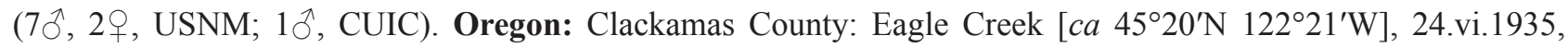

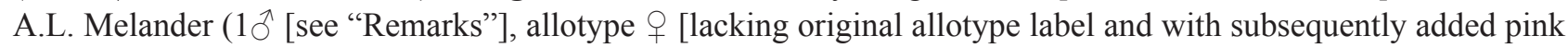

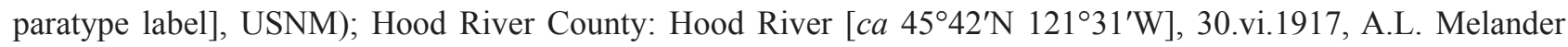
(2へ, USNM); same data except, 1.viii.1917, L. Childs (4へ, USNM). Washington: Chelan County: Lake Chelan, Stehekin [ $c a 48^{\circ} 18^{\prime} \mathrm{N} 120^{\circ} 39^{\prime} \mathrm{W}$ ], 30.vii.1919, A.L. Melander (1ㅅ, 2ㅇ, USNM); Jefferson County: Quilcene [ca

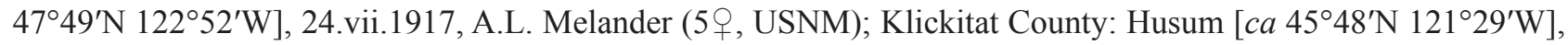

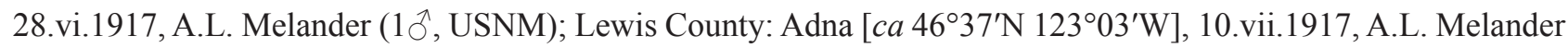

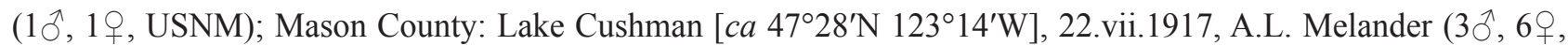

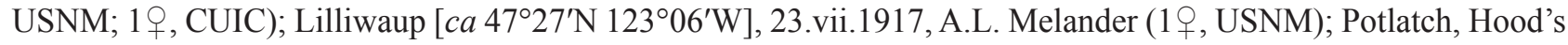
Canal [ $47^{\circ} 22^{\prime} \mathrm{N} 123^{\circ} 08^{\prime} \mathrm{W}$ ], 28.vii.1917, A.L. Melander (2수, 7우, USNM); Snohomish County: Granite Falls [ca $\left.48^{\circ} 05^{\prime} \mathrm{N} 121^{\circ} 58^{\prime} \mathrm{W}\right]$, 5.viii.1917, A.L. Melander (1ㅇ, USNM).

Other material examined. CANADA: British Columbia: Vancouver Is., Little Qualicum Provincial Park, [49 $18.56^{\prime} \mathrm{N} 124^{\circ} 33.08^{\prime} \mathrm{W}$ ], 7 mi. W Coombs, 7.vii.1990, swept over rocky shore of Little Qualicum River, J.M.

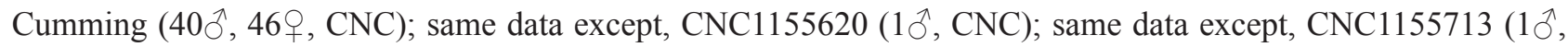
CNC); same data except, Little Qualicum River, $10 \mathrm{~km} \mathrm{~W} \mathrm{Coombs,} \mathrm{ex} \mathrm{rocky} \mathrm{shore,} \mathrm{11.viii.2008} \mathrm{(2ᄋ,} \mathrm{CNC).} \mathrm{USA:}$ California: Mariposa County: Summerdale Forest Camp, on Big Creek [ca 37²9'N 119³8'W], 1520 m, 27.vi.1973,

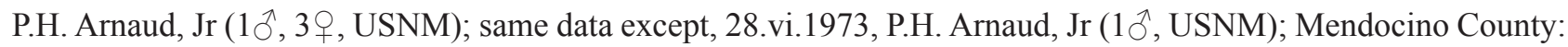

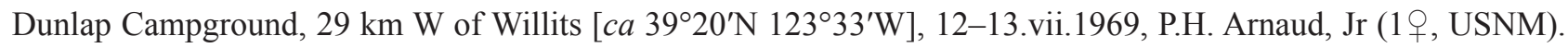

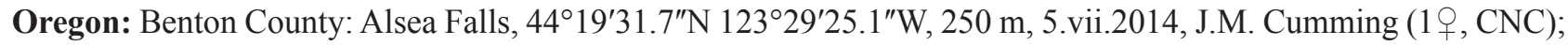

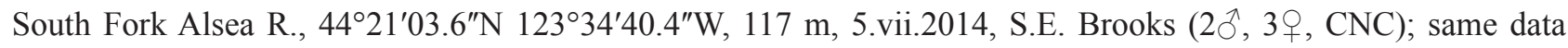

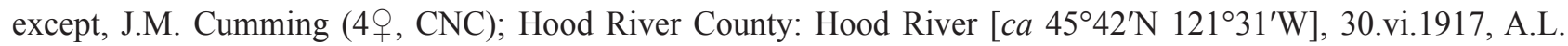

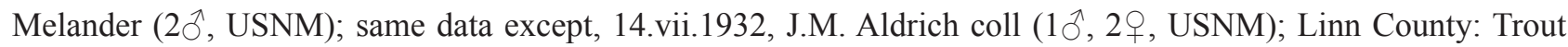
Crk Campground, $44^{\circ} 23^{\prime} 47.9^{\prime \prime} \mathrm{N} 122^{\circ} 20^{\prime} 55.5^{\prime \prime} \mathrm{W}, 364$ m, 9.vii.2014, swp stony shore of S. Santiam R., S.E. Brooks

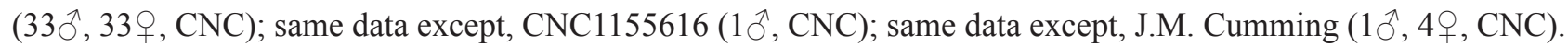
Washington: Clallam County: Sappho, Tumbling Rapids Recreation Area along Soleduck River ca. $48^{\circ} 04^{\prime} \mathrm{N}$

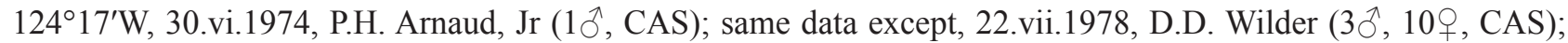

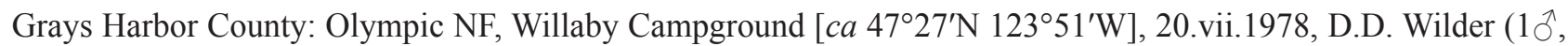
2ㅇ, CAS); same data except, 21.vii.1978 (1へ̂, 1우 CAS); Jefferson County: 2 mi. SW Brinnon, Duckabush Creek

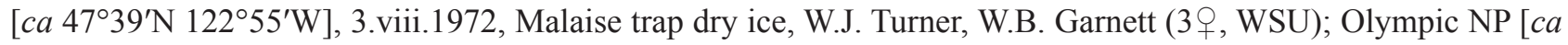
$47^{\circ} 42^{\prime} \mathrm{N} 124^{\circ} 24^{\prime} \mathrm{W}$ ], T26NR13W Sec. 28, sweeping coastal forest, 22.vii.1978, D.D. Wilder (5 $0^{\wedge}$, CAS); Lewis

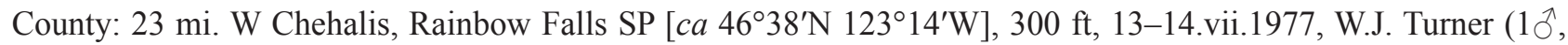
WJTC); Skagit County: Marblemount, Cascade River Rd, Mt Baker-Snoqualmie NF, $48^{\circ} 32.176^{\prime} \mathrm{N} 121^{\circ} 17.795^{\prime} \mathrm{W}$, 410 m, 18-19.vii.2012, roadside seep, B.J. Sinclair (1人̂, CNC).

Diagnosis. As indicated in the key (couplets 12 and 23), males and females of this species can be easily distinguished from other members of the S. ravidum species group (and other Schistostoma) by their distinctively shaped wing cell dm (Figs 171, 172). Males (Figs 183-186) are further characterized by their densely fringed fore femur, modified posterior wing margin, sternite 5 chaetotaxy, and spine-like dorsal surstylar seta (Figs 187, 188).

Redescription. Male (Figs 171, 183-191): Body length 2.4-3.1 mm, wing length 2.6-3.0 mm. Head (Fig. 184): Compound eye without demarcation line between larger dorsal and smaller ventral ommatidia. Ocellar tubercle with 2 pairs of black proclinate setae, anterior pair distinctly longer than posterior pair. Occiput grey pruinose, mostly clothed with black to light brown setae, almost bare in upper part, except for postoculars. Gena and parafacial narrow along lower eye margin. Antenna brown; postpedicel conical, evenly tapered to apex; stylus about 2.0X length of postpedicel. Palpus dark brown, elongate ovate, slightly longer than length of labrum, pubescent with microtrichia and bearing scattered black setulae. Proboscis brown, approximately $1 / 2$ as long as head height, directed forward. Thorax (Fig. 183): Mesonotum brownish-grey. Proepisternum with 1-2 setae. Mesonotal setae black, relatively long with dorsocentrals arranged in single row per side. Notopleuron with 2-3 strong setae. Scutellum with 2 pairs 
of setae, inner pair stronger. Mesopleuron grey to brownish-grey. Halter pale. Legs: Dark brown, knees of foreleg and midleg pale, with black setae except as noted. Foreleg: Coxa with pale setae on anterior surface, apex with dense fringe of long brownish setae. Femur slightly shorter than tibia, swollen basally, posterior side with dense fringe of up-curled long fine setae (Fig. 184), with 1 posteroventral preapical seta and a few short setae near apex. Tibia slender, with short setae along dorsal and posterior surface. Tarsus slightly shorter than tibia, tarsomere 1 slightly shorter than combined length of tarsomeres 2-5, setose dorsally, tarsomeres 2-4 decreasing in length apically, tarsomere 5 subequal in length to tarsomere 3. Midleg (Fig. 185): Coxa with several pale setae on anterior surface. Trochanter with medial spine-like setal pair thick and strongly curved, slightly longer than width of trochanter. Femur shorter than tibia, swollen in basal 2/3, apical 1/3 narrow, posterior surface with short setae on upper half, ventral surface with a few short setae in basal part, distal half with series of 3 long strong setae (proximal and distal setae sinuous, proximal seta half as long as femur), anterior surface with several long setae on basal half (setae about $2 \mathrm{X}$ femur width or slightly longer) and short setae on distal part. Tibia modified, basal half slender with long anterodorsal seta and series of short curved ventral setae and several additional short setae; distal half with posteroventral callus near midlength bearing series of long setae and patch of short setae, with second smaller preapical ventral callus bearing short setae and glabrous posterior surface, apex of tibia dorsoventrally flattened. Tarsus subequal in length to tibia, tarsomere 1 as long as combined length of tarsomeres $2-4$, dorsoventrally flattened at base, with prominent lateral setae (slightly longer than width of tarsomere) and shorter ventral setae, tarsomeres 2-4 decreasing in length apically, tarsomere 5 slightly shorter than tarsomere 3. Hindleg: Coxa with 3 pale brown setae on outer surface several pale setae on anterior surface. Femur subequal in length to tibia, with dorsal and ventral fringe of long setae (long as or slightly longer than femur width), anterior surface with short setae on upper half, posterior surface with sparse fine setae. Tibia enlarged apically, with dorsal fringe of long setae, with ventral fringe of shorter setae along basal $2 / 3$, anterior surface with short setae, apical $1 / 3$ of posterior surface with dense pale setulae. Tarsus subequal in length to tibia, tarsomere 1 large, longer than combined length of tarsomeres $2-5$, with prominent dorsal setae and series of short spine-like ventral setae, tarsomeres $2-4$ short, decreasing in length apically, with short setae dorsally, tarsomere 5 subequal in length to tarsomere 3. Wing (Fig. 171): With slight grey-brown tinge, veins dark brown. Pterostigma well-developed. Anal lobe large with proximal margin convex. Posterior wing margin expanded on either side of vein $\mathrm{M}_{4} \cdot \mathrm{R}_{2+3}$ and $\mathrm{R}_{4+5}$ parallel in middle part and diverging near apex with cell $\mathrm{r}_{2+3}$ compressed in middle part and flared at apex. $\mathrm{R}_{4+5}$ sinuous with pronounced posterior curve to apex with cell $\mathrm{r}_{4+5}$ evenly narrowed in basal part. $R_{4+5}$ and $M_{1}$ diverging beyond cell $\mathrm{dm} . \mathrm{M}_{2}$ and $\mathrm{M}_{4}$ diverging beyond cell $\mathrm{dm}, \mathrm{M}_{4}$ strongly curved posteriorly to wing margin. Costal section $M_{1}-M_{2}$ shorter than $M_{2}-M_{4}$. Cell dm moderately-sized, extended to around middle of wing, distal section of vein $\mathrm{M}_{1}$ (beyond base of $\mathrm{M}_{2}$ ) longer than preceding section (between $\mathrm{r}-\mathrm{m}$ and base of $\mathrm{M}_{2}$ ). Crossvein dm-m strongly bent at base and running parallel with $\mathrm{M}_{1}$ distally (distal portion of cell dm narrow and straight). Abdomen (Fig. 186): Brown, with mainly fine pale setae basally to end of segment 4, setae on segment 5 and beyond mainly black. Tergites 1-6 clothed with long, dense setae laterally, setae short and sparse dorsomedially. Sternite 2 with setae slightly longer than on sternites 3 and 4. Sternite 5 with dense posterolateral patch of long setae on each side, otherwise bare. Sternite 6 angled dorsally, with several short pale setae. Segment 7 with a few tiny setae on sternite, otherwise bare. Sternite 8 subrectangular, setose, distal margin with setae very long. Hypopygium (Figs 187-191): Small, about 1/4 length of abdomen. Left epandrial lamella (Figs 187, 189) ovoid basally, longer than high, with surstylar lobes projecting distally. Left dorsal lobe of surstylus with short broad tubercle bearing long thick spine-like modified seta, with several long setae surrounding base of tubercle. Left ventral lobe of surstylus long and broad, apex tapered to rounded ventrally projected tip, with 1 strong lateral seta, membranous basally. Right epandrial lamella (Fig. 188) rounded basally, with surstylar lobes projecting distally. Right dorsal lobe of surstylus similar to left side. Right ventral lobe of surstylus long and hook-like, with apical portion strongly curving to right, with pair of lateral setae in basal third. Hypandrium with single large seta on each side of basal part. Medial hypandrial prolongation long slender and straight, with pair of subparallel apical setae. Left hypandrial lobe usually short and broadly rounded (Fig. 187), rarely elongate and spinose (Fig. 189). Right hypandrial lobe elongate, curved dorsally and tapered apically, spinose. Postgonite with dorsal postgonite lobes not substantially developed. Left ventral postgonite lobe long and broad, apex expanded with margin weakly serrate. Right ventral postgonite lobe long and broad with rounded apical margin. Postgonite apodeme V-shaped in ventral view with short left and right branch. Phallus thick, with C-shaped basal curve, apical portion elongate and curved dorsally with flared tip. Ejaculatory apodeme short. Left and right cercus with hump-like base bearing several setae and narrow digitiform apex bearing several setae. 
Female (Fig. 172): Body length 2.1-2.8 mm, wing length 2.4-2.7 mm. Similar to male except as follows: Head: Gena and parafacial distinctly projected along lower eye margin. Legs: With shorter, unspecialized setae. Foreleg: Coxa with apical fringe of brownish setae present but weaker; femur not swollen basally; femur, tibia and tarsus lacking specialized setae. Midleg: Trochanter without spine-like setal pair; femur, tibia and tarsus unmodified and lacking specialized setae. Hindleg: Femur with short setae; tibia weakly broadened apically, with short setae; tarsomere 1 smaller, lacking distinct dorsal and ventral setae. Wing (Fig. 172): Anal lobe smaller, proximal margin straight. $\mathrm{R}_{4+5}$ with posterior curve weaker. $\mathrm{M}_{4}$ weakly curved posteriorly to wing margin. Posterior wing margin evenly curved. Abdomen: Tergites and sternites with short setae. With 6 exposed abdominal segments, segment 6 concolorous with anterior abdominal segments. Terminalia (similar to Figs 99, 100, 104): Segment 6 with tergite and sternite subrectangular (wider than long), tergite with shallow narrow anteromedial emargination, tergite and sternite setose on posterior half. Segment 7 with tergite slightly wider than long with pronounced anteromedial emargination, anterior margin broadly rounded on either side of emargination, with small posterolateral seta, sternite subquadrate with short setae on posterior margin, tergite and sternite with short band-like posterior sclerite extension on each side. Tergite 8 undivided, darkened along edge of anteromedial emargination, with small posterolateral seta, narrowly fused to sternite 8 anterolaterally. Sternite 9 desclerotized and inconspicuous. Spermatheca spherical. Syntergite $9+10$ with hemitergites subrectangular, each with 3 acanthophorite spines. Sternite 10 with short setose lateral lobe below cercus (about half length of cercus), sternite produced posteromedially (weakly sclerotized) bearing dense setulae intermixed with setae, anterolaterally with band-like extension to base of lateral lobe and cercus. Cercus with curved claw-like apex, with several small setae near midlength.
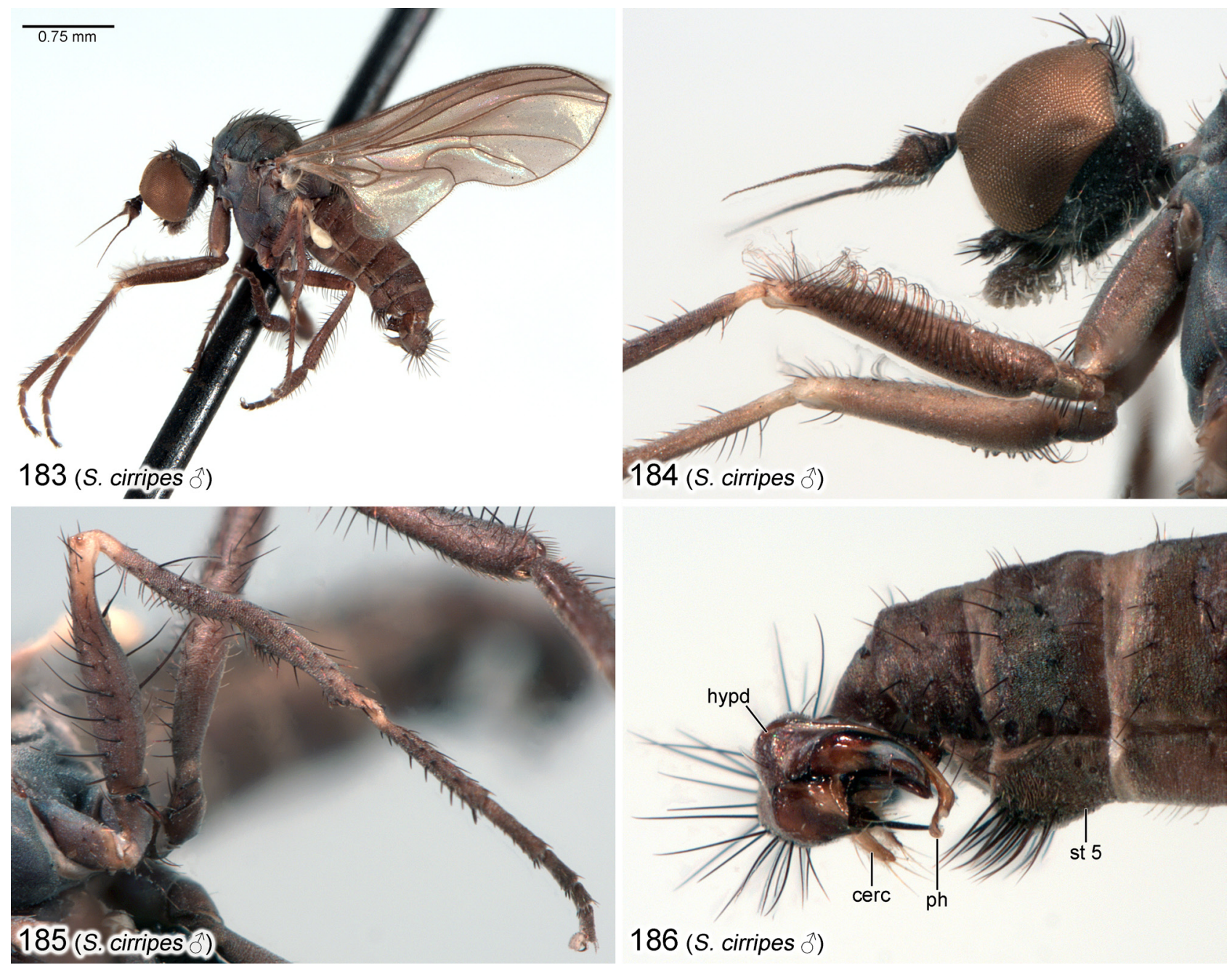

FIGURES 183-186. Habitus, head, legs and abdomen of male Schistostoma cirripes (Melander) comb. nov. 183. Habitus. 184. Head and forelegs, lateral view. 185. Midleg, anterior view. 186. Abdomen and terminalia, right lateral view. Specimens from: Little Qualicum Provincial Park, British Columbia (Figs 183-186). Abbreviations: cerc—cercus; hypd—hypandrium; ph-phallus; st-sternite. 


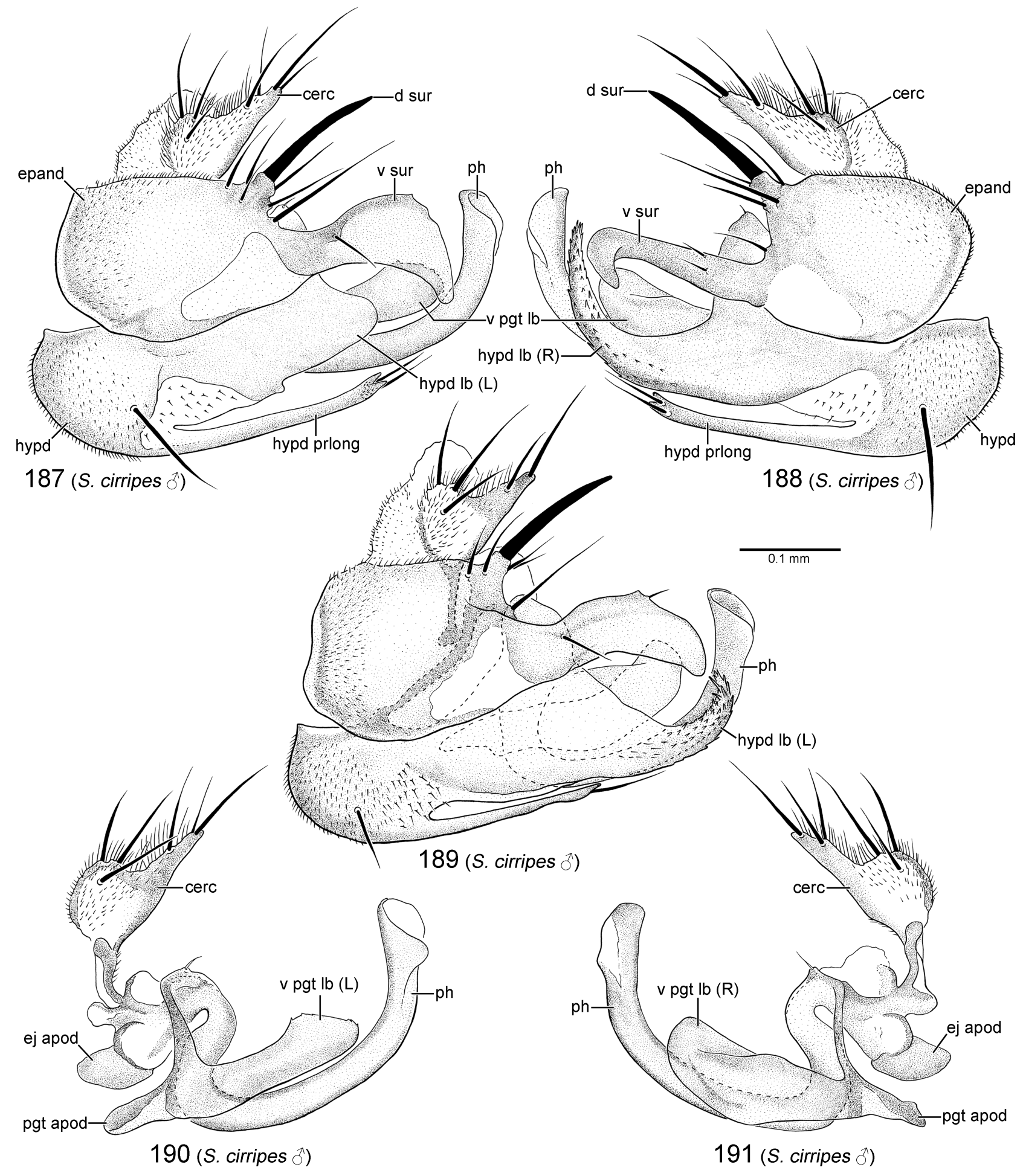

FIGURES 187-191. Hypopygium of Schistostoma cirripes (Melander) comb. nov. 187. Hypopygium, left lateral view. 188. Hypopygium, right lateral view. 189. Hypopygium of aberrant male, left lateral view. 190. Phallus, postgonite and cercus, left lateral view. 191. Phallus, postgonite and cercus, right lateral view. Figures 187 and 188 based on specimen CNC1155620 (Little Qualicum Provincial Park, British Columbia). Figure 189 based on specimen CNC1155616 (Trout Crk Campground, Oregon). Figures 190 and 191 based on specimen CNC1155713 (Little Qualicum Provincial Park, British Columbia). Abbreviations: cerc — cercus; ej apod — ejaculatory apodeme; d sur — dorsal lobe of surstylus; epand —epandrium; hypd—hypandrium; hypd lb—hypandrial lobe; hypd prlong — hypandrial prolongation; (L)—left; pgt apod—postgonite apodeme; ph—phallus; (R) — right; v pgt lb—ventral postgonite lobe; v sur — ventral lobe of surstylus. 
Distribution and seasonal occurrence. Schistostoma cirripes is a northwestern North America species known from several localities in southern British Columbia, Washington, Oregon (e.g., Fig. 15), and northern and central California (Fig. 233). Adults have been collected from mid-June to mid-August.

Remarks. The holotype specimen is one of two conspecific males collected by Melander from Eagle Creek on June $24^{\text {th }}, 1935$ along with the female allotype. Unfortunately neither male has an original type label and both have pink paratype labels that were added subsequently.

This species was collected together with S. armipes at Trout Creek Campground along the Santiam River (Fig. 15) in Oregon by the authors in July, 2014.

\section{Schistostoma heatherae sp. nov.}

(Figs 231-233)

urn:Isid:zoobank.org:act: 5C147F35-A537-478B-84FF-A4382EB9109D

Type material. HOLOTYPE, ô collected from Milk River, Alberta, Canada, 5.vi.1955, by J.R. Vockeroth, labelled: "Milk R., Alta./ 4908' 11048'/ 5.VI.1955/ J.R. Vockeroth"; "IDEMA/ illustration"; "HOLOTYPE/ Schistostoma heatherae/ Brooks \& Cumming [red label]" (CNC). PARATYPE: CANADA: Alberta: Same data as holotype $(10, \mathrm{CNC})$.

Other material examined. CANADA: Alberta: Hailstone Butte, 50.2024 $-114.4498^{\circ}, 2073 \mathrm{~m}$, alpine

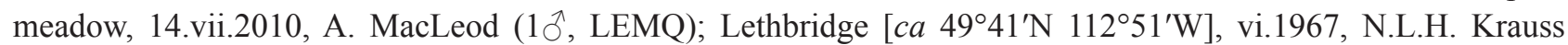

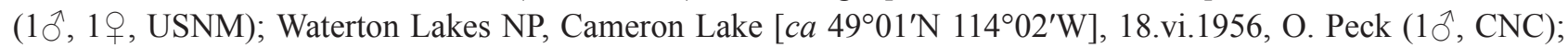
Waterton Lakes NP, Coppermine Creek, 49.1104 $-113.9579^{\circ}, 1634$ m, higher alpine, 12.vii.2010, A. MacLeod

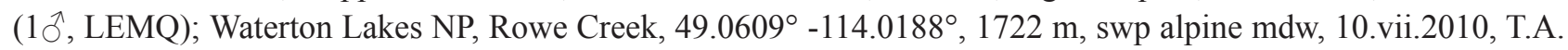
Wheeler (1 $\hat{O}^{\hat{\prime}}$, LEMQ). Manitoba: Ninette [ca $49^{\circ} 24^{\prime} \mathrm{N} 99^{\circ} 37^{\prime} \mathrm{W}$ ], 14.v.1958, swept from Symphoricarpos sp., R.B.

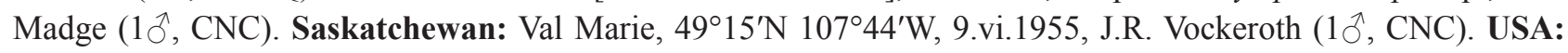

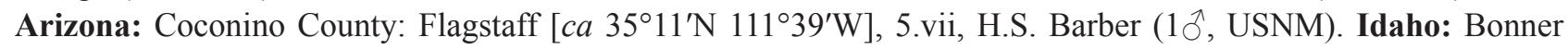
County: Priest River Exp. For. [ca 48 $21^{\prime} \mathrm{N} 116^{\circ} 47^{\prime} \mathrm{W}$ ], 3.vi.1963, M.M. Furniss (10, WFBM); Franklin County: $21 \mathrm{mi}$. NE Preston [ $\left.\mathrm{ca} 42^{\circ} 19^{\prime} \mathrm{N} 111^{\circ} 38^{\prime} \mathrm{W}\right], 15 . v i .1968$, W.F. Barr (1 ${ }^{\AA}$, WFBM). North Dakota: Billings County:

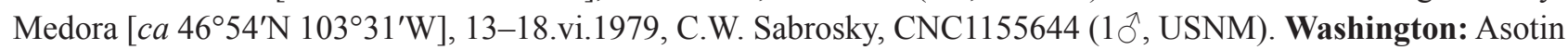
County: 17 mi. S Anatone, nr Grande Ronde R. [ca 46 $02^{\prime} \mathrm{N} 117^{\circ} 15^{\prime} \mathrm{W}$ ], $1950 \mathrm{ft}$, 15.vi.1977, ex. fls Lonicera, W.J. Turner $(1 \hat{\jmath}$, WJTC).

Diagnosis. Males of this species are distinguished from other members of the $S$. ravidum species group by the series of long fine posterior setae on the fore tibia (similar to Fig. 225), dark body and legs, abdominal sternite 5 with subequal pair of short stout spine-like setae, narrow dorsal surstylar lobes (Figs 231, 232), and strongly flared phallus tip, as indicated in the key (couplets 18 and 20). Females are characterized by their dark body and legs, normal wing cell dm (similar to Fig. 176), antennal stylus length (less than $2 \mathrm{X}$ postpedicel length), and projecting gena and parafacial (similar to Fig. 228). Schistostoma heatherae sp. nov. is very similar to S. sycophantor, but can be distinguished by its slightly shorter antennal stylus, chaetotaxy of male abdominal sternite 5 , narrow surstylar lobes and other hypopygial features provided in couplet 20 of the key.

Description. Male (Figs 231, 232): Body length 2.2-2.3 mm, wing length 2.2-2.3 mm. Head: Compound eye with demarcation line anteriorly between larger dorsal and smaller ventral ommatidia. Ocellar tubercle with 2 pairs of black proclinate setae, anterior pair slightly longer than posterior pair. Occiput dark grey pruinose, mostly clothed with black or brown setae, almost bare in upper part, except for postoculars. Gena and parafacial narrow along lower eye margin. Antenna dark brown; postpedicel conical, evenly tapered to apex; stylus about 1.5X length of postpedicel. Palpus dark brown, elongate ovate, slightly longer than length of labrum, pubescent with microtrichia and bearing scattered black setulae. Proboscis brown, slightly less than $1 / 2$ as long as head height, directed forward. Thorax: Mesonotum brownish-grey to greyish-black. Proepisternum with 1-2 setae. Mesonotal setae black, relatively long with dorsocentrals arranged in single row per side. Notopleuron with 2-3 strong setae. Scutellum with 2 pairs of setae, inner pair stronger. Mesopleuron grey. Halter light brown to pale. Legs: Entirely dark brown to blackish, with black setae. Foreleg: Coxa with several setae on anterior surface. Femur subequal in length to tibia, with short setae, dorsal setae longer, 1 prominent posteroventral preapical seta. Tibia slender, with series of fine erect setae along posterior surface (setae about $3 \mathrm{X}$ tibia width in anterior view), otherwise with short setae. Tarsus subequal in length 
to tibia, with short setae, tarsomere 1 subequal to combined length of tarsomeres $2-4$, tarsomeres $2-4$ decreasing in length apically, tarsomere 5 subequal in length to tarsomere 3. Midleg: Coxa with several setae on anterior surface. Trochanter with medial spine-like setal pair curved, nearly $2 \mathrm{X}$ longer than width of trochanter. Femur subequal in length to tibia, posterior surface with short setae on upper part, ventral surface with series of about 5-7 prominent posteroventral setae (subequal to femur width), 1 posteroventral preapical seta, anterior surface with series of anterodorsal setae (shorter towards apex) and 1 long seta near basal 1/3, otherwise with short setae. Tibia slender, weakly enlarged near middle, with short setae, with series of small close-set ventral setae, apex glabrous on posterior surface. Tarsus slightly longer than tibia, with short setae, tarsomere 1 as long as combined length of tarsomeres 2-3, with somewhat thicker setae ventrally, tarsomeres 2-4 decreasing in length apically, tarsomere 5 about as long as tarsomere 3. Hindleg: Coxa with 3 setae on outer surface and a few setae on anterior surface. Femur subequal in length to tibia, with dorsal and anteroventral series of setae (subequal to femur width), anterior surface with short setae on upper part, posterior surface with sparse fine setae. Tibia slightly enlarged apically, with series of dorsal setae (slightly shorter than tibia width), otherwise with short setae. Tarsus subequal in length to tibia, with short setae, tarsomere 1 slightly swollen basally, subequal to combined length of tarsomeres 2-4, tarsomeres 2-4 decreasing in length apically, tarsomere 5 subequal in length to tarsomere 3. Wing: With slight grey-brown tinge, veins dark brown. Pterostigma small, somewhat faint. Anal lobe with proximal margin weakly convex. $\mathrm{R}_{2+3}$ and $\mathrm{R}_{4+5}$ parallel in middle part and weakly diverging near apex with cell $r_{2+3}$ compressed in middle part and slightly flared at apex. $\mathrm{R}_{4+5}$ straight in basal part with gradual posterior curve to apex with cell $\mathrm{r}_{4+5}$ weakly compressed in basal part. $R_{4+5}$ and $M_{1}$ diverging beyond cell dm. $M_{2}$ and $M_{4}$ diverging beyond cell dm. Costal section $M_{1}-M_{2}$ subequal to $\mathrm{M}_{2}-\mathrm{M}_{4}$. Cell dm moderately-sized, extended to around middle of wing, distal section of vein $\mathrm{M}_{1}$ (beyond base of $\mathrm{M}_{2}$ ) longer than preceding section (between $\mathrm{r}-\mathrm{m}$ and base of $\mathrm{M}_{2}$ ). Crossvein dm- $\mathrm{m}$ broadly curved and convergent with $\mathrm{M}_{1}$ distally. Abdomen: Dark greyish-black, with black setae on tergites and sternites. Tergites 1-6 clothed with long, dense setae laterally, setae short and sparse dorsomedially. Sternites 2-4 with intermixed long and short setae. Sternite 5 with subequal pair of short stout spine-like setae on each side of posterior margin, other setae smaller. Sternite 6 angled dorsally, with several short spine-like setae. Segment 7 with a few short setae on sternite, tergite bare or with a few tiny setae. Sternite 8 subquadrate, distal margin with setae stronger and longer. Hypopygium (Figs 231, 232): About 1/3 length of abdomen. Left epandrial lamella (Fig. 231) rounded basally, longer than high, with dorsal seta near base of cercus, with surstylar lobes projecting distally. Left dorsal lobe of surstylus long, slightly expanded apically with rounded margin, separated from ventral lobe of surstylus by deep cleft, with dorsal and ventral seta near base and several setae on medial surface. Left ventral lobe of surstylus longer than dorsal lobe, narrow, apex flattened and curved laterally (appearing pointed in lateral view), with dorsolateral seta and 2 smaller dorsal setae before mid-length. Right epandrial lamella (Fig. 232) rounded basally, longer than high, with dorsal seta near base of cercus, with surstylar lobes projecting distally. Right dorsal lobe of surstylus long, base with hump-like projection that mostly hides cercus, slightly expanded apically with rounded margin, with dorsal seta near middle and several setae on medial surface. Right ventral lobe of surstylus comprised of inner and outer lobe; inner lobe longer than dorsal lobe, narrow, apex flattened (appearing pointed in lateral view); outer lobe as long as inner lobe, very broad, apical margin rounded and serrate, with seta on dorsal margin. Hypandrium with single large seta on each side of basal part. Medial hypandrial prolongation long, apical half curved dorsally and to right, with pair of small apical setae. Left hypandrial lobe subequal in length to dorsal lobe of surstylus, broad with truncate and weakly serrate apical margin, weakly sclerotized. Right hypandrial lobe narrow with weakly sclerotized apex. Postgonite with dorsal postgonite lobes not substantially developed. Left ventral postgonite lobe short with pointed apex. Right ventral postgonite lobe short with irregularly rounded margin. Postgonite apodeme short U-shaped in ventral view. Phallus thick, apical half curved dorsally and strongly flared with large phallotrema. Ejaculatory apodeme relatively long. Left and right cercus with hump-like base bearing several setae and narrow stub-like apex bearing several setae.

Female: Body length $1.9 \mathrm{~mm}$, wing length $2.2 \mathrm{~mm}$. Similar to male except as follows: Head: Compound eye without demarcation line between dorsal and ventral ommatidia; ocellar tubercle with anterior pair of setae distinctly longer than posterior pair. Gena and parafacial distinctly projected along lower eye margin. Thorax: Mesonotum and mesopleuron dark grey. Legs: With shorter, unspecialized setae. Foreleg: Tibia without series of fine erect setae along posterior surface. Midleg: Trochanter without spine-like setal pair; femur lacking posteroventral setae and long seta near basal 1/3; tibia slender, unmodified. Hindleg: femur and tibia with short setae, tibia and tarsomere 1 not enlarged. Wing: Anal lobe slightly smaller, proximal margin straight. Abdomen: Tergites and sternites 
with short setae. With 6 exposed abdominal segments, segment 6 concolorous with anterior abdominal segments. Terminalia (single known female specimen not dissected): Syntergite 9+10 with hemitergites subrectangular each with 3 acanthophorite spines. Cercus with curved claw-like apex.

Distribution and seasonal occurrence. Schistostoma heatherae sp. nov. is a mid-western North America species known from southern Alberta, southern Saskatchewan and southern Manitoba in the north, through eastern Washington, Idaho, and North Dakota, to central Arizona in the south (Fig. 233). Adults have been collected from mid-May to mid-July.

Etymology. This species is named after the second author's daughter, Heather Cumming, who has supported her father's entomological endeavours in many ways.

Remarks. The single presumed female specimen of this species has the right wing, hind leg and abdomen partially encased together in glue. In order to reduce the possibility of damage, dissection of the terminalia of this specimen was not attempted. Flower visitation records for this species are listed in Table 1.

\section{Schistostoma longistylum sp. nov.}

(Figs 192-196, 235)

urn:lsid:zoobank.org:act: 46756028-F0AE-4167-8264-5FB9C76C05A1

Type material. HOLOTYPE, ô collected from San Joaquin River Gorge, Fresno County, California, USA, 12.vi.2012, by K. Will, labelled: "U.S.A.: Fresno Co., San Joaquin/ River Gorge, 375'21"N/ 119³3'3"W, 316 m, Malaise trap,/ 12.v.2012, K. Will,/ [CAL2012.v.12.10], CNC304485"; "HOLOTYPE/ Schistostoma longistylum/ Brooks \& Cumming [red label]" (CNC). PARATYPES: USA: California: Same data as holotype except, CNC304350-CNC304406, CNC304408-CNC304419, CNC304421-CNC304442, CNC304444, CNC304446CNC304448, CNC304451-CNC304472, CNC304475, CNC304478-CNC304479, CNC304481-CNC304482, CNC304484, CNC304486-CNC304491, CNC304512 (99ð̊, 37ㅇ, CNC).

Other material examined. USA: California: Contra Costa County: Concord, Mangini Ranch, $37^{\circ} 55^{\prime} 05^{\prime \prime} \mathrm{N}$

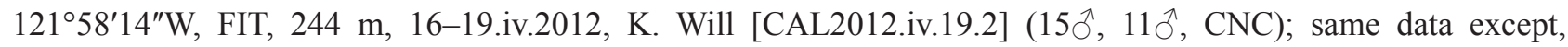

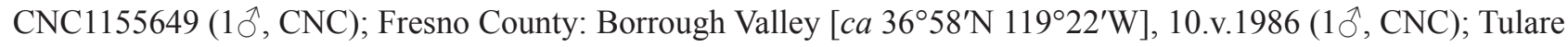
County: Three Rivers [ca 36 $26^{\prime} \mathrm{N} 118^{\circ} 54^{\prime} \mathrm{W}$ ], 8.vi.1985, D.J. Burdick (1ㅇ, CNC); Ash Mtn, Kaweah River, Power Station No. 3 [ $c a 36^{\circ} 26^{\prime} \mathrm{N} 118^{\circ} 54^{\prime} \mathrm{W}$ ], 2.vi.1993, M. Hannel (10’, CNC).

Diagnosis. As indicated in the key (couplets 21 and 25), males and females of this species can be easily distinguished from other members of the S. ravidum species group by their elongate antennal stylus (Fig. 193), distinctive male terminalia (Figs 194-196), and straight subtriangular female cerci.

Description. Male (Figs 192-196): Body length 1.9-2.6 mm, wing length 2.2-2.4 mm. Head (Fig. 193): Compound eye with weak demarcation line anteriorly between larger dorsal and smaller ventral ommatidia. Ocellar tubercle with 2 pairs of black proclinate setae, anterior pair slightly longer than posterior pair. Occiput dark grey pruinose, mostly clothed with black (postoculars) or pale setae, almost bare in upper part, except for postoculars. Gena and parafacial narrow along lower eye margin. Antenna brown; postpedicel conical, evenly tapered to apex; stylus about 3.5X length of postpedicel. Palpus dark brown, elongate ovate, slightly longer than length of labrum, pubescent with microtrichia and bearing scattered black setulae. Proboscis brown, slightly less than $1 / 2$ as long as head height, directed forward. Thorax (Figs 192, 193): Mesonotum brownish-grey. Proepisternum with 1-2 setae. Mesonotal setae black, with acrostichals and anterior dorsocentrals short, 2 posterior dorsocentrals and other setae relatively long with dorsocentrals arranged in single row per side. Notopleuron with 2 strong setae. Scutellum with 2 pairs of setae, inner pair stronger. Mesopleuron brownish-grey. Halter pale. Legs (Fig. 192, 193): Pale brown to yellowish, with black and pale setae (pale setae noted). Foreleg: Coxa with pale setae on anterior surface (Fig. 193). Femur subequal in length to tibia, with series of pale posteroventral setae (shorter than femur width), 1 posteroventral preapical seta, otherwise with short setae. Tibia slender, with short setae. Tarsus longer than tibia, with short setae, tarsomere 1 subequal to combined length of tarsomeres 2-5, tarsomeres 2-4 decreasing in length apically, tarsomere 5 subequal in length to tarsomere 3. Midleg: Coxa with several pale setae on anterior surface. Trochanter with medial spine-like setal pair pale, weakly curved, slightly longer than width of trochanter, setae narrow. Femur slightly longer than tibia, posterior surface with short setae on upper half, ventral surface with a few small posteroventral setae in basal part, with 2 strong spine-like posteroventral setae near midlength (proximal 
seta slightly longer), 1 posteroventral preapical seta, anterior surface with 1 long anterodorsal and 1 long pale anteroventral seta at $1 / 3$, with surrounding setae moderately long, distal setae short. Tibia slender, weakly enlarged near middle, dorsal surface with short setae, ventral surface with somewhat close-set series of short setae. Tarsus about $1.5 \mathrm{X}$ longer than tibia, with short setae, tarsomere 1 as long as combined length of tarsomeres $2-5$, tarsomeres 2-4 decreasing in length apically, tarsomere 5 slightly longer than tarsomere 4. Hindleg: Coxa with 3 pale setae on outer surface and pale setae on anterior surface. Femur subequal in length to tibia, with dorsal series of long pale setae (slightly longer than femur width), anterior surface with short setae on upper part, ventral surface with short pale setae, posterior surface with sparse fine setae. Tibia slightly enlarged apically, with series of dorsal setae (subequal to tibia width), otherwise with short setae. Tarsus subequal in length to tibia, with short setae, tarsomere 1 slightly swollen basally, as long as combined length of tarsomeres $2-4$, tarsomeres $2-4$ decreasing in length apically, tarsomere 5 slightly longer than tarsomere 4 . Wing: With slight grey-brown tinge, veins dark brown. Pterostigma somewhat faint. Anal lobe with proximal margin weakly convex. $\mathrm{R}_{2+3}$ and $\mathrm{R}_{4+5}$ parallel in middle part and diverging near apex with cell $r_{2+3}$ compressed in middle part and flared at apex. $R_{4+5}$ sinuous with pronounced posterior curve to apex with cell $r_{4+5}$ compressed in basal part. $R_{4+5}$ and $M_{1}$ diverging beyond cell dm. $M_{2}$ and $M_{4}$ weakly diverging beyond cell $\mathrm{dm}$. Costal section $\mathrm{M}_{1}-\mathrm{M}_{2}$ subequal to $\mathrm{M}_{2}-\mathrm{M}_{4}$. Cell $\mathrm{dm}$ moderately-sized, extended to around middle of wing, distal section of vein $M_{1}$ (beyond base of $M_{2}$ ) longer than preceding section (between $r-m$ and base of $M_{2}$ ). Crossvein dm-m nearly straight and convergent with $M_{1}$ distally. Abdomen (Fig. 194): Brown, with intermixed pale and dark setae on tergites and pale setae on sternites. Tergites 1-6 clothed with long, dense setae laterally, setae short and sparse dorsomedially. Sternites 2-5 with mainly short sparse setae. Sternite 6 angled dorsally, with short sparse setae. Segment 7 with a few tiny setae on sternite, otherwise bare. Sternite 8 subrectangular, widening distally, setose. Hypopygium (Figs 195, 196): Small, about 1/3 length of abdomen. Left epandrial lamella (Fig. 195) subrectangular basally, longer than high, with surstylar lobes projecting distally. Left dorsal lobe of surstylus short and acute, with several setae basally and preapically. Left ventral lobe of surstylus large, long and acute, with 1 long seta and 2 small setae dorsobasally. Right epandrial lamella (Fig. 196) subrectangular basally, with surstylar lobes projecting distally. Right dorsal lobe of surstylus short and acute, with several setae basally. Right middle lobe of surstylus short and acute, subequal in length to dorsal lobe, with ventral seta basally. Right ventral lobe of surstylus long, large, long and acute (but shorter than left dorsal lobe), with 1 long seta and 2 smaller setae dorsobasally. Hypandrium with single large seta on each side of basal part. Medial hypandrial prolongation long, slender and straight, with pair of small apical setae. Left hypandrial lobe short with apical margin broadly rounded. Right hypandrial lobe acute, apex extending about as far as tip of medial hypandrial prolongation. Postgonite with dorsal postgonite lobes not substantially developed. Left ventral postgonite lobe long and slender with narrow apex projecting dorsally. Right ventral postgonite lobe short, fin-like. Postgonite apodeme heart-shaped in ventral view, unbranched. Phallus fairly thick with C-shaped basal curve, apical portion elongate and slightly expanded, spinose on left side, deeply cleft on right side, with bifurcate tip. Ejaculatory apodeme short. Left and right cercus with hump-like base bearing several setae and short stubby apex bearing long setae.

Female: Body length $1.8-2.7 \mathrm{~mm}$, wing length $2.2-2.4 \mathrm{~mm}$. Similar to male except as follows: Head: Compound eye without weak demarcation line between dorsal and ventral ommatidia; ocellar tubercle with anterior pair of setae distinctly longer than posterior pair; antenna with stylus about 3.0X length of postpedicel. Legs: With shorter, unspecialized setae. Foreleg: Femur without series of pale posteroventral setae. Midleg: Trochanter without spine-like setal pair; femur and tibia lacking specialized setae. Hindleg: Femur without dorsal series of long pale setae; tibia and tarsomere 1 not enlarged. Wing: Anal lobe slightly smaller, proximal margin straight. Abdomen: Tergites and sternites with short setae. With 6 or 7 exposed abdominal segments (segment 7 often partially exposed), segments 6 and 7 concolorous with anterior abdominal segments. Terminalia: Segment 6 with tergite and sternite subrectangular (wider than long), setose on posterior half. Segment 7 with tergite subrectangular (wider than long) with broad anteromedial emargination, posterior margin with relatively strong setae, sternite subquadrate with short setae on posterior third, tergite and sternite with short band-like posterior sclerite extension on each side. Tergite 8 divided (desclerotized) medially, with posterolateral seta, narrowly fused to sternite 8 anterolaterally. Sternite 9 desclerotized and inconspicuous. Spermatheca spherical. Syntergite $9+10$ with hemitergites subtriangular, each with 2 relatively long slender acanthophorite spines and 1 strong lateral seta. Sternite 10 with setose lateral lobe below cercus (nearly as long as cercus), sternite broadly subtriangular, densely setulose and with about 4 setae per side. Cercus subtriangular with long ventrally-directed apical seta, 1 short dorsal seta, several short ventral setae intermixed with setulae. 
Distribution and seasonal occurrence. Schistostoma longistylum sp. nov. is known from central California (Fig. 235). Adults were collected from mid-April to mid-June.

Etymology. The species name refers to the long antennal stylus in both males and females.
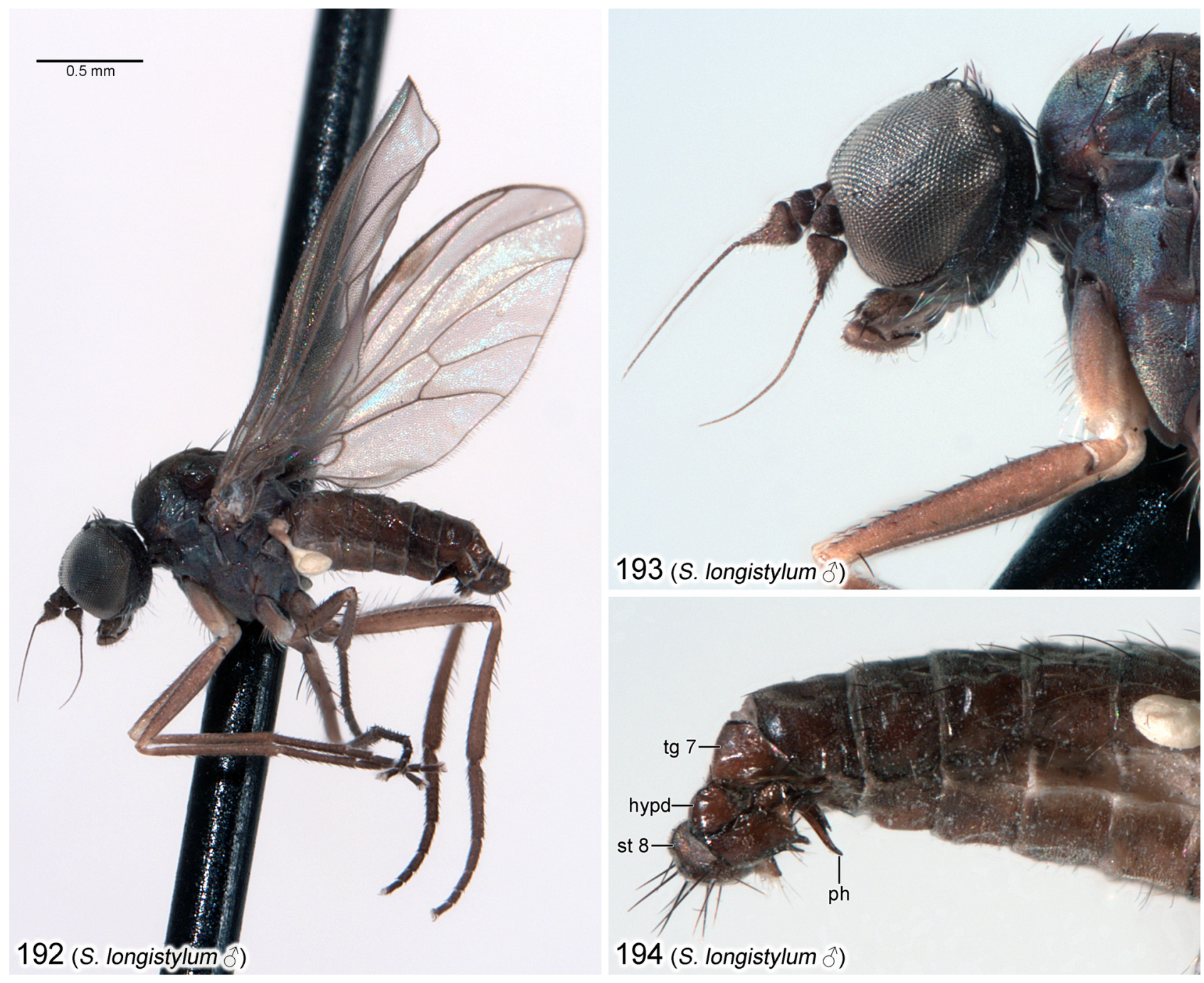

FIGURES 192-194. Habitus, head and abdomen of male Schistostoma longistylum sp. nov. 192. Habitus of holotype. 193. Head and anterior portion of thorax of holotype, lateral view. 194. Abdomen and terminalia, right lateral view. Specimens from: San Joaquin River Gorge, California (Figs 192-194). Abbreviations: hypd—hypandrium; ph—phallus; st—sternite; tg—tergite.

\section{Schistostoma michaeli sp. nov.}

(Figs 173, 216-218, 233)

urn:lsid:zoobank.org:act: B3C2E8F2-479B-4DA1-A809-0D876BF1F0C6

Type material. HOLOTYPE, ổ collected from Cal Lodge [ca 39 $19^{\prime} \mathrm{N} 120^{\circ} 21^{\prime} \mathrm{W}$ ], Norden Nevada County, California, USA, 21.vi.1987, by, P.H. Arnaud, Jr, labelled: "USA: California: Nevada/ Co., Norden, Cal Lodge/, 2130 m. 21 June 1987/ P.H. Arnaud, Jr."; "HOLOTYPE/ Schistostoma michaeli/ Brooks \& Cumming [red label]" (USNM).

Other material examined. USA: California: Tuolumne County: along Clark Fork River, T6N R19E Sec14 [ca $\left.38^{\circ} 24^{\prime} \mathrm{N} 119^{\circ} 47^{\prime} \mathrm{W}\right]$, 11.vii.1977, D. Wilder (1つ̄, CAS). Nevada: Washoe County: Lake Tahoe, Incline Village

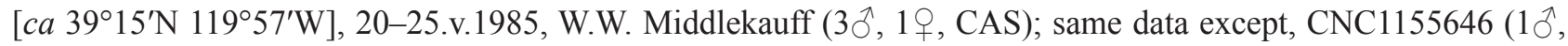
CAS).

Diagnosis. Males and females of this rarely collected species are distinguished from other members of the S. ravidum species group (and other Schistostoma) by their small wing cell dm (Fig. 173), as indicated in the key (couplets 14 and 28). Schistostoma michaeli sp. nov. is closely related to S. strigilifer and males of both species are 
characterized by their enlarged bulbous hypandrium (Figs 214, 217-220), broad medial hypandrial process (Fig. 221), and notched hind tarsomere 1 (Fig. 213), as indicated in the key (couplet 13). Males of S. michaeli sp. nov. are further characterized by their deformed mid tibia (Fig. 216), compared to that of S. strigilifer (Fig. 215).

Description. Male (Figs 173, 216-218): Body length 2.5-2.6 mm, wing length 2.4-2.6 mm. Head: Compound eye with demarcation line anteriorly between larger dorsal and smaller ventral ommatidia. Ocellar tubercle with 2 pairs of black proclinate setae, anterior pair distinctly longer than posterior pair. Occiput dark grey pruinose, mostly clothed with black or pale brown setae, almost bare in upper part, except for postoculars. Gena and parafacial narrow along lower eye margin. Antenna dark brown to black; postpedicel conical, evenly tapered to apex; stylus about $1.5 \mathrm{X}$ length of postpedicel. Palpus dark brown to black, elongate ovate, slightly longer than length of labrum, pubescent with microtrichia and bearing scattered black setulae. Proboscis dark brown, moderately long, approximately $2 / 3$ as long as head height, directed forward. Thorax: Mesonotum greyish-brown. Proepisternum with 1-2 setae. Mesonotal setae black, relatively long with dorsocentrals arranged in single row per side. Notopleuron with 2 strong setae. Scutellum with 2 pairs of setae, inner pair stronger. Mesopleuron grey. Halter pale. Legs: Dark brown to pale brown, with black and pale setae (pale setae noted). Foreleg: Coxa with pale setae on anterior surface. Femur slightly shorter than tibia, 1 posteroventral preapical seta, otherwise with short setae. Tibia slender, with short setae. Tarsus subequal in length to tibia, with short setae, tarsomere 1 subequal to combined length of tarsomeres 2-4, tarsomeres 2-4 decreasing in length apically, tarsomere 5 slightly shorter than tarsomere 3. Midleg (Fig. 216): Coxa with several pale setae on anterior surface. Trochanter with medial spine-like setal pair nearly straight with curved tip, about $2 \mathrm{X}$ width of trochanter. Femur slightly shorter than tibia, swollen basally, slightly curved posteriorly, with short setae dorsally and on anterior surface, ventral surface with series of 3 spine-like posteroventral setae basally (proximal seta pale and about $2 \mathrm{X}$ longer than femur width, other setae shorter) and another series of 3 smaller hooked posteroventral setae near midlength, 1 long curved posteroventral preapical seta and 1 smaller anteroventral preapical seta. Tibia modified, enlarged and strongly bowed near middle, dorsal surface mainly with short setae, with longer anterodorsal and posterodorsal seta near basal $1 / 4$, anterior surface with series of short erect setae near middle, ventral surface with small cluster of short erect setae near base, distal 2/3 with posteroventral and anteroventral series of short erect setae, apex glabrous on posterior surface. Tarsus longer than tibia, with short setae (ventral setae shorter and somewhat thicker), tarsomere 1 as long as combined length of tarsomeres 2-3, notched basally with basiventral cluster of short setae, tarsomeres 2-4 decreasing in length apically, tarsomere 5 slightly shorter than tarsomere 3. Hindleg: Coxa with 2 pale setae on outer surface and pale setae on anterior surface. Femur subequal in length to tibia, with dorsal series of long fine pale setae on basal half (setae subequal to femur width), with a few short pale setae ventrally near base, anterior and dorsal surface with short setae, posterior surface with fine erect intermixed pale and dark setae. Tibia slightly enlarged apically, with series of dorsal setae (subequal to tibia width), otherwise with short setae, posterior surface with cluster of erect hair-like setulae on apical 1/3. Tarsus shorter than tibia, with short setae, tarsomere 1 moderately notched near base on posterior surface, subequal to combined length of tarsomeres 2-3, tarsomeres 2-4 decreasing in length apically, tarsomere 5 slightly shorter than tarsomere 3. Wing (Fig. 173): With brown tinge, veins dark brown. Pterostigma indistinct. Anal lobe with proximal margin weakly convex. Posterior wing margin projected slightly near middle. $R_{2+3}$ and $R_{4+5}$ parallel in middle part and diverging near apex with cell $r_{2+3}$ compressed in middle part and flared at apex. $\mathrm{R}_{4+5}$ sinuous with pronounced posterior curve to apex with cell $r_{4+5}$ slightly compressed in basal part. $R_{4+5}$ and $M_{1}$ diverging beyond cell $\mathrm{dm} . \mathrm{M}_{2}$ and $\mathrm{M}_{4}$ subparallel beyond cell $\mathrm{dm}$. Costal section $\mathrm{M}_{1}-\mathrm{M}_{2}$ longer than $\mathrm{M}_{2}-\mathrm{M}_{4}$. Cell dm small and short, ending slightly before middle of wing, distal section of vein $M_{1}$ (beyond base of $M_{2}$ ) $3 X$ longer than preceding section (between $\mathrm{r}-\mathrm{m}$ and base of $\mathrm{M}_{2}$ ). Crossvein dm-m broadly curved and convergent with $\mathrm{M}_{1}$ distally. Cell cua somewhat enlarged. Abdomen: Brown, with predominantly pale setae and some intermixed black setae (black setae more numerous distally). Tergites 1-6 clothed with long, dense setae laterally, setae short and sparse dorsomedially. Sternites 2-6 with close-set pair of mediolateral setae on each side at posterior margin (anterior seta long on sternite 2, setae stronger and darker on sternites 4 and 5), with strong posterolateral seta on sternites 3-5. Sternites 4 and 5 with posterior margin projecting. Segment 7 with sternite bulging near middle, with a few minute setae on bulging area of sternite, otherwise bare. Sternite 8 large and ovoid, about $2 \mathrm{X}$ longer than wide, posterior half bulbous, setose on distal third. Hypopygium (Figs 217, 218): Small, about 1/4 length of abdomen. Left epandrial lamella (Fig. 217) longer than high, with surstylar lobes projecting distally. Left dorsal lobe of surstylus shorter than cercus, broad with truncate apex, with setae on dorsal margin and apically. Left ventral lobe of surstylus long, broad basally, tapering to pointed apex, with strong lateral seta at base and pair of preapical setae on dorsal margin. Right epandrial 
lamella (Fig. 218) subrectangular, longer than high, with surstylar lobes projecting distally. Right dorsal lobe of surstylus shorter than cercus, broad with rounded apex, with several setae on lateral surface. Right middle lobe of surstylus broad with rounded apex, slightly shorter than dorsal lobe, with ventral projected seta on medial surface. Right ventral lobe of surstylus narrow and elongate, curved right, with pair of setae basally. Hypandrium with base enlarged, bulbous and strongly produced anteriorly (slightly less so than S. strigilifer), with single large seta on each side of basal part. Medial hypandrial prolongation long and broad, widening apically, with distal pair of setae closeset and projecting laterally from right margin (similar to Fig. 221). Left hypandrial lobe short with rounded apex, covered by ventral lobe of surstylus. Right hypandrial lobe elongate, tapered apically and curved to right, surface spinose. Postgonite with dorsal postgonite lobes not substantially developed. Left ventral postgonite lobe long and broad with rounded apical margin. Right ventral postgonite lobe short with acute apex. Postgonite apodeme weakly developed, short and shallowly U-shaped in ventral view. Phallus slender, curved dorsally and to right, subequal in length to right hypandrial lobe. Ejaculatory apodeme short. Left and right cercus with hump-like base bearing several setae and elongate narrow digitifom apex bearing long apical seta.

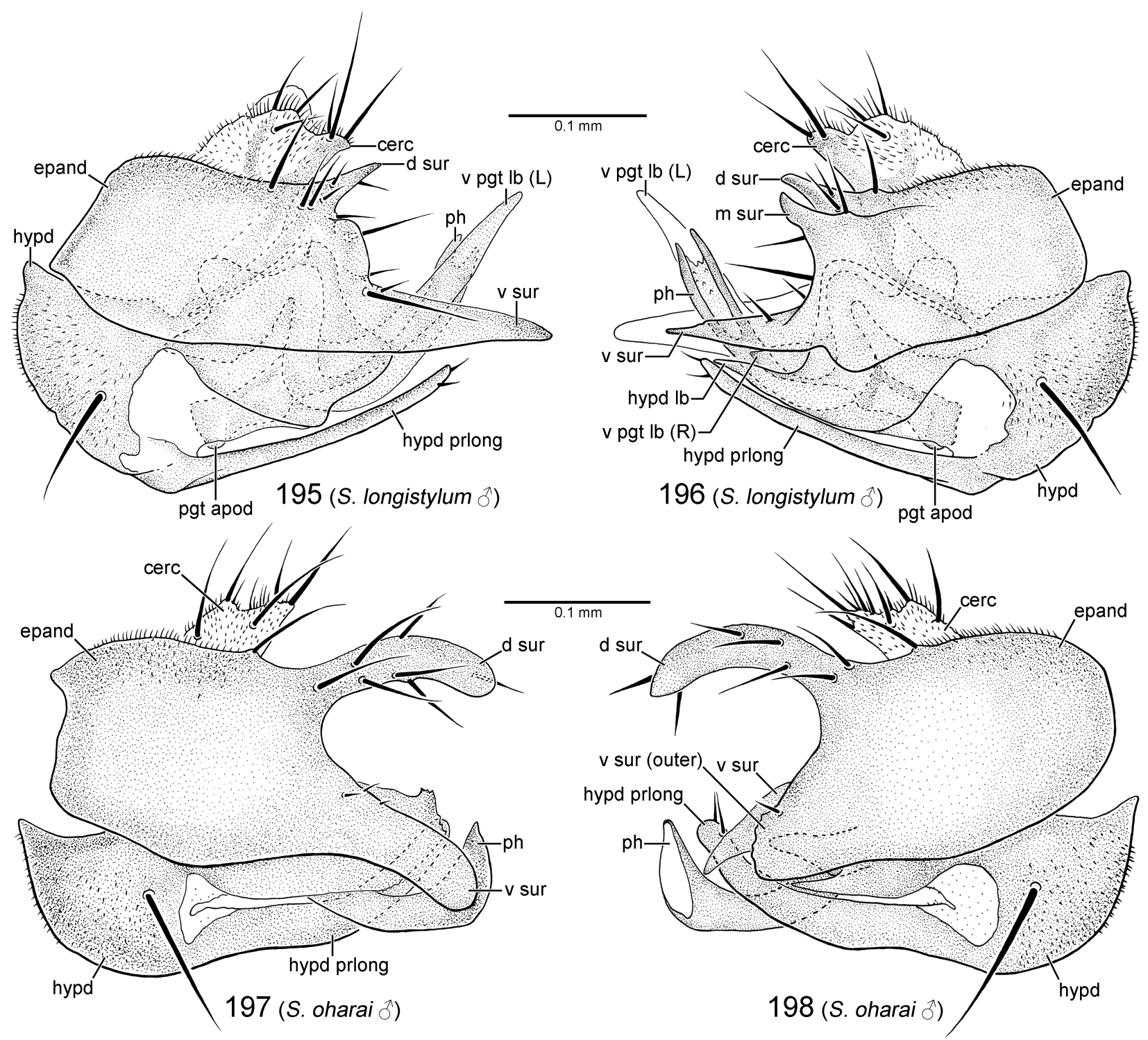

FIGURES 195-198. Hypopygia of Nearctic Schistostoma. 195. S. longistylum sp. nov., left lateral view. 196. S. longistylum sp. nov., right lateral view. 197. S. oharai sp. nov., left lateral view. 198. S. oharai sp. nov., right lateral view. Figures 195 and 196 based on specimen CNC1155649 (Mangini Ranch, California). Figures 197 and 198 based on specimen CNC1155714 (Bear Canyon Bridge, Arizona). Abbreviations: cerc - cercus; d sur-dorsal lobe of surstylus; epand-epandrium; hypdhypandrium; hypd lb — hypandrial lobe; hypd prlong — hypandrial prolongation; (L) — left; m sur — middle lobe of surstylus; pgt apod—postgonite apodeme; ph—phallus; (R)—right; v pgt lb—ventral postgonite lobe; v sur—ventral lobe of surstylus. 
Female: Wing length $2.0 \mathrm{~mm}$. Similar to male except as follows: Head: Compound eye without demarcation line between dorsal and ventral ommatidia. Gena and parafacial distinctly projected along lower eye margin. Legs: With shorter, unspecialized setae. Midleg: Trochanter without spine-like setal pair; femur and tibia unmodified and lacking specialized setae. Hindleg: Femur with dorsal series of pale setae shorter; tibia not enlarged apically; tarsomere 1 without notch. Wing: Pterostigma absent. Anal lobe slightly smaller, proximal margin straight. Posterior wing margin evenly curved. Cell cua not enlarged. Abdomen: Tergites and sternites with short setae. With 6 exposed abdominal segments, segment 6 concolorous with anterior abdominal segments. Terminalia (similar to Figs 99, 100, 104): Segment 6 with tergite and sternite subrectangular (wider than long), tergite and sternite setose on posterior half with setae distinctly stronger on posterior margin (especially on tergite). Segment 7 with tergite slightly wider than long with pronounced anteromedial emargination, anterior margin broadly rounded on either side of emargination, with small posterolateral seta, sternite subrectangular with short setae on posterior margin, tergite and sternite apparently with short band-like posterior sclerite extension on each side. Tergite 8 undivided, darkened along edge of anteromedial emargination, with small posterolateral seta, narrowly fused to sternite 8 anterolaterally. Sternite 9 desclerotized and inconspicuous. Spermatheca spherical. Syntergite 9+10 with hemitergites subrectangular, each with 3 acanthophorite spines. Sternite 10 with short setose lateral lobe below cercus (about half length of cercus), sternite produced posteromedially bearing setulae and 3 adjacent short setae per side, anterolaterally with bandlike extension to base of lateral lobe and cercus. Cercus with curved claw-like apex, with several small setae near midlength.

Distribution and seasonal occurrence. Schistostoma michaeli sp. nov. is known from eastern California and western Nevada (Fig. 233). Adults were collected from late May to mid-July.

Etymology. This species is named after the second author's son, Michael Cumming.

Remarks. Pollen grains have been found in the gut of a dissected male and female of this species.

\section{Schistostoma oharai sp. nov.}

(Figs 197, 198, 237)

urn:Isid:zoobank.org:act: 9DBD710B-60B7-4989-B787-EF27F815A030

Type material. HOLOTYPE, ô collected from Bear Canyon Bridge [ $c a 31^{\circ} 20^{\prime} \mathrm{N} 110^{\circ} 37^{\prime} \mathrm{W}$ ], Santa Cruz County, Arizona, USA, 29.vii.1965, by H.B. Leech, labelled: "ARIZ: Santa Cruz/ Co., Bear Canyon/ Bridge, LochielBisbee/ road, alt. 5300 ft./ 29.VII.1965"; "Collector/ Hugh B. Leech"; "Microphorus/ spp./ Det. D.D. Wilder"; "HOLOTYPE/ Schistostoma oharai/ Brooks \& Cumming [red label]" (CAS). PARATYPES: USA: Arizona:

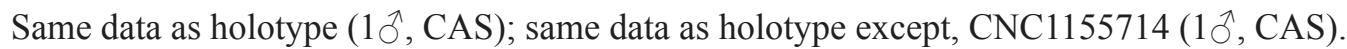

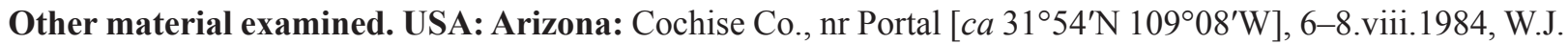
Hanson (2, LACM).

Diagnosis. Males of this rare species are distinguished from other members of the $S$. ravidum species group by the series of fine posterior setae on the fore tibia (similar to Fig. 225, although shorter), light-coloured, mainly grey body, and symmetrical curved dorsal surstylar lobes (Figs 197, 198), as indicated in the key (couplet 19). Females are characterized by their light grey body, normal wing cell dm (similar to Fig. 176), antennal stylus length (less than $2 \mathrm{X}$ postpedicel length), and projecting gena and parafacial (similar to Fig. 228).

Description. Male (Figs 197, 198): Body length 2.1-2.2 mm, wing length 2.2-2.3 mm. Head: Compound eye with demarcation line anteriorly between larger dorsal and smaller ventral ommatidia. Ocellar tubercle with 2 pairs of black proclinate setae, anterior pair distinctly longer than posterior pair. Occiput grey pruinose, mostly clothed with black (postoculars) or pale brown setae, almost bare in upper part, except for postoculars. Gena and parafacial narrow along lower eye margin. Antenna dark brown; postpedicel conical, evenly tapered to apex; stylus about $1.5 \mathrm{X}$ length of postpedicel. Palpus dark brown, elongate ovate, slightly longer than length of labrum, pubescent with microtrichia and bearing scattered black setulae. Proboscis brown, slightly less than $1 / 2$ as long as head height, directed forward. Thorax: Mesonotum light brownish-grey. Proepisternum with 1 seta. Mesonotal setae black, relatively long with dorsocentrals arranged in single row per side. Notopleuron with 2 strong setae. Scutellum with 2 pairs of setae, inner pair stronger. Mesopleuron light grey. Halter pale. Legs: Mainly pale brown, base of coxae darker (concolorous with thorax), joints yellowish, with mainly brown setae, except as noted. Foreleg: Coxa infuscated basally, with several pale setae on anterior surface. Femur subequal in length to tibia, with short dorsal 
setae, 1 prominent posteroventral preapical seta. Tibia slender, with series of fine erect pale setae along posterior surface (setae about 1.5X tibia width in anterior view), otherwise with short setae. Tarsus slightly shorter than tibia, with short setae, tarsomere 1 slightly shorter than combined length of tarsomeres $2-5$, tarsomeres 2-4 decreasing in length apically, tarsomere 5 subequal in length to tarsomere 3. Midleg: Coxa with several pale setae on anterior surface. Trochanter with medial spine-like setal pair curved, longer than width of trochanter, setae slender. Femur subequal in length to tibia, posterior surface with short setae on upper part, ventral surface with series of 4-5 prominent posteroventral setae (longer than femur width), 1 posteroventral preapical seta, anterior surface with 1 long seta near basal 1/3, otherwise with short setae. Tibia slender, weakly enlarged near middle, with short setae, with series of small close-set ventral setae near middle, apex glabrous on posterior surface. Tarsus longer than tibia, with short setae, tarsomere 1 as long as combined length of tarsomeres 2-4, tarsomeres 2-4 decreasing in length apically, tarsomere 5 about as long as tarsomere 3. Hindleg: Coxa with 3 pale setae on outer surface and a few setae on anterior surface. Femur subequal in length to tibia, with longer dorsal series of setae (slightly longer than femur width) and relatively shorter anteroventral series of setae, anterior surface with short setae on upper part, posterior surface with sparse fine setae. Tibia slightly enlarged apically, with series of dorsal setae (subequal to tibia width), otherwise with short setae. Tarsus subequal in length to tibia, with short setae, tarsomere 1 slightly swollen basally, subequal to combined length of tarsomeres 2-4, tarsomeres 2-4 decreasing in length apically, tarsomere 5 subequal in length to tarsomere 3. Wing: With slight grey tinge, veins pale brown. Pterostigma faint. Anal lobe with proximal margin weakly convex. $\mathrm{R}_{2+3}$ and $\mathrm{R}_{4+5}$ parallel in middle part and weakly diverging near apex with cell $\mathrm{r}_{2+3}$ compressed in middle part and slightly flared at apex. $\mathrm{R}_{4+5}$ sinuous with posterior curve to apex with cell $\mathrm{r}_{4+5}$ slightly compressed in basal part. $R_{4+5}$ and $M_{1}$ diverging beyond cell $\mathrm{dm} . \mathrm{M}_{2}$ and $\mathrm{M}_{4}$ diverging beyond cell $\mathrm{dm}$. Costal section $\mathrm{M}_{1}-\mathrm{M}_{2}$ subequal to $\mathrm{M}_{2}-\mathrm{M}_{4}$. Cell dm moderately-sized, extended to around middle of wing, distal section of vein $\mathrm{M}_{1}$ (beyond base of $\mathrm{M}_{2}$ ) longer than preceding section (between $\mathrm{r}-\mathrm{m}$ and base of $\mathrm{M}_{2}$ ). Crossvein dm-m broadly curved and convergent with $\mathrm{M}_{1}$ distally. Abdomen: Greyish-brown, with mainly pale brown setae, stronger setae on posterior end dark brown. Tergites 1-6 clothed with long, dense setae laterally, setae short and sparse dorsomedially. Sternites 2-4 with short setae. Sternite 5 with long spine-like seta on each side at posterior margin, with long posterolateral seta. Sternite 6 angled dorsally, with several short setae. Segment 7 with pair of relatively long setae on sternite, otherwise bare. Sternite 8 subrectangular, distal margin with setae stronger and longer. Hypopygium (Figs 197, 198): Small, about 1/4 length of abdomen. Left epandrial lamella (Fig. 197) rounded basally, longer than high, with dorsal seta near base of cercus, with surstylar lobes projecting distally. Left dorsal lobe of surstylus long, digitiform, curved ventrally, apex flattened with rounded margin, with long lateral and medial setae. Left ventral lobe of surstylus long, as long as dorsal lobe, curved ventrally with rounded apical margin, with a few short setae dorsally at base. Right epandrial lamella (Fig. 198) rounded basally, longer than high, with dorsal seta near base of cercus, with surstylar lobes projecting distally. Right dorsal lobe of surstylus long, digitiform, curved ventrally, apex flattened with rounded margin, with long lateral and medial setae. Right ventral lobe of surstylus comprised of inner and outer lobe; inner lobe slightly shorter than dorsal lobe, appearing pointed in lateral view (tongue-like in dorsal view); outer lobe shorter than inner lobe, apical margin broadly rounded and serrate, with seta on dorsal margin. Hypandrium with single large seta on each side of basal part. Medial hypandrial prolongation long, apical half curved dorsally, with pair of small apical setae. Left hypandrial lobe subequal in length to dorsal medial hypandrial prolongation, broad with truncate and weakly serrate apical margin. Right hypandrial lobe narrowly pointed and weakly sclerotized. Postgonite with dorsal postgonite lobes not substantially developed. Left ventral postgonite lobe indiscernible. Right ventral postgonite lobe conical with pointed apex. Postgonite apodeme short Y-shaped in ventral view. Phallus thick, curved dorsally, apex flared. Ejaculatory apodeme relatively long. Left and right cercus with weak hump-like base bearing several setae and narrow stub-like apex bearing several setae.

Female: Body length $1.7 \mathrm{~mm}$, wing length 2.2-2.3 mm. Similar to male except as follows: Head: Compound eye without demarcation line between dorsal and ventral ommatidia. Gena and parafacial distinctly projected along lower eye margin. Thorax: Mesonotum light grey. Legs: With shorter, unspecialized setae. Foreleg: Tibia without series of fine erect setae along posterior surface. Midleg: Trochanter without spine-like setal pair; femur lacking posteroventral setae and long seta near basal 1/3; tibia slender, unmodified. Hindleg: Femur and tibia with short setae, tibia and tarsomere 1 not swollen. Wing: Anal lobe slightly smaller, proximal margin straight. Abdomen: Tergites and sternites with short setae. With 6 exposed abdominal segments, segment 6 concolorous with anterior abdominal segments. Terminalia (similar to Figs 99, 100, 104): Segment 6 with tergite and sternite subrectangular (wider than long), tergite with shallow anteromedial emargination, tergite and sternite setose on posterior half with setae slightly stronger on posterior margin. Segment 7 with tergite about as wide as long with pronounced anteromedial 
emargination, anterior margin broadly rounded on either side of emargination, with small posterolateral seta, sternite subquadrate with short setae on posterior margin, tergite and sternite with short band-like posterior sclerite extension on each side. Tergite 8 undivided, darkened along edge of anteromedial emargination, with small posterolateral seta, narrowly fused to sternite 8 anterolaterally. Sternite 9 desclerotized and inconspicuous. Spermatheca spherical. Syntergite 9+10 with hemitergites subrectangular, each with 3 acanthophorite spines. Sternite 10 with short setose lateral lobe below cercus (about half length of cercus), sternite produced posteromedially bearing setulae and 2-3 adjacent short setae per side, anterolaterally with band-like extension to base of lateral lobe and cercus. Cercus with curved claw-like apex, with several small setae near midlength.

Distribution and seasonal occurrence. Schistostoma oharai sp. nov. is known from southern Arizona (Fig. 237). Adults were collected from late July to early August.

Etymology. This species is named in honour of our colleague and dipterist, Dr. James E. O'Hara, who has collected many valuable empidoid specimens from Arizona and New Mexico.

\section{Schistostoma ravidum (Coquillett) comb. nov.}

(Figs 174, 199-201, 204, 206, 207, 236)

Microphorus ravidus Coquillett, 1895: 409.

Holoclera ravida (Coquillett, 1895): Melander, 1902: 333.

Microphorus ravidus: Coquillett, 1903: 263.

Type material examined. LECTOTYPE (here designated to fix the identity of the species), $\partial$ collected from Los Angeles County [ $\left.\mathrm{ca} 34^{\circ} 05^{\prime} \mathrm{N} 118^{\circ} 12^{\prime} \mathrm{W}\right]$, California, USA, in March, by D.W. Coquillett, labelled: "LosAngeles/ Co., CAL."; "Mar."; "Collection/ Coquillett"; "Type/ No 3188/ U.S.N.M [red label]”; "Microphorus/ ravidus/ Type. Coq. [handwritten]"; "LECTOTYPE/ Microphorus/ ravidus Coquillett / des. Brooks \& Cumming 2022 [red label]" (USNM). PARALECTOTYPES: USA: California: Same data as lectotype $(4 \hat{\jmath}, 8 \uparrow, 1$ mostly missing specimen

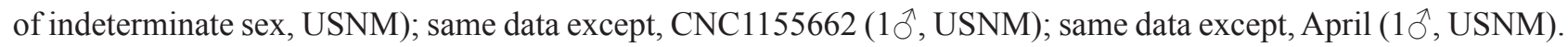
See "Remarks".

Other material examined. USA: California: Los Angeles County: N Fork San Gabriel River along Hwy 39, 3.3 mi. S Coldbrook Stn [ca $34^{\circ} 15^{\prime} \mathrm{N} 117^{\circ} 50^{\prime} \mathrm{W}$ ], 2.v.1978, D.D. Wilder (29 ${ }^{\lambda}, 40$,, CAS); Tie Canyon [ca $34^{\circ} 23^{\prime} \mathrm{N}$

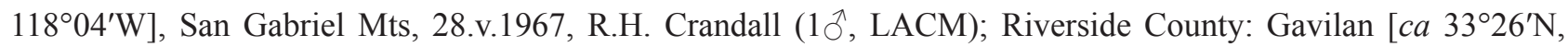

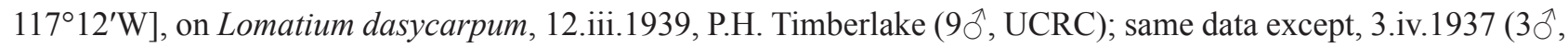

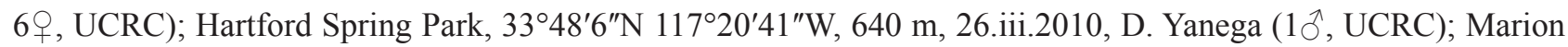

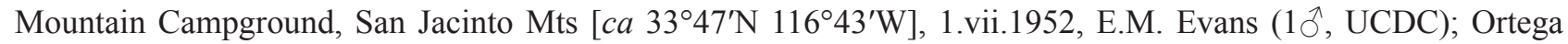
Highway [ $c a 33^{\circ} 36^{\prime} \mathrm{N} 117^{\circ} 25^{\prime} \mathrm{W}$ ], 28.iii.1935, A.L. Melander (1 ${ }^{\prime}$, USNM); Riverside [ca $33^{\circ} 58^{\prime} \mathrm{N} 117^{\circ} 22^{\prime} \mathrm{W}$ ], on Nemophila menziesii, 19.iii.1937, P.H. Timberlake (1へ̂, 1ㅇ, UCRC); same data except, 26.iii.1937 (2q, UCRC);

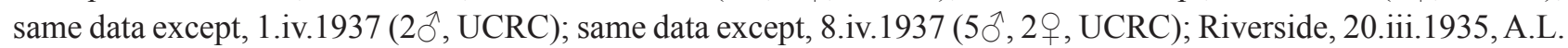

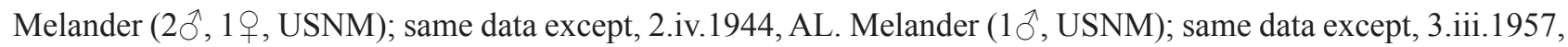

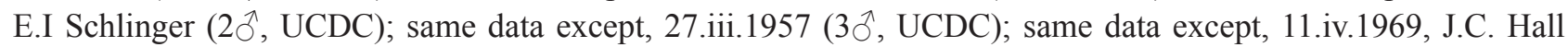

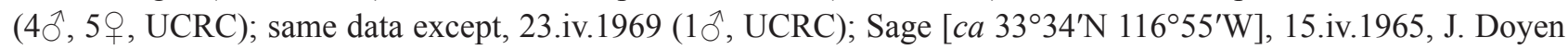

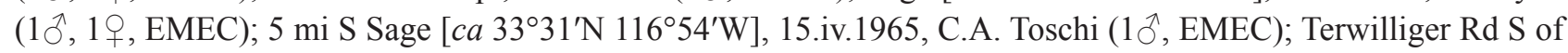

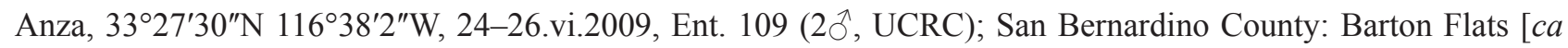

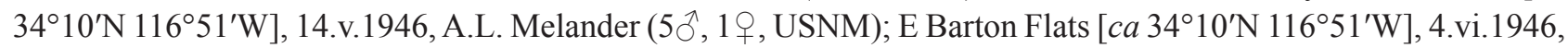
J.L. Sperry (1 $0^{\wedge}$, USNM); Camp Angelus (Angelus Oaks) [ca $\left.34^{\circ} 08^{\prime} \mathrm{N} 116^{\circ} 59^{\prime} \mathrm{W}\right]$, 26.v.1947, A.L. Melander (1 $0^{\wedge}$, USNM); Phelan [ $c a 34^{\circ} 25^{\prime} \mathrm{N} 117^{\circ} 34^{\prime} \mathrm{W}$ ], Sheep Creek Canyon, 21.iv.1949, A.L. Melander (1 ${ }^{\jmath}$, USNM); 2 mi. S Rock Camp, L. Arrowhead [ca $34^{\circ} 17^{\prime} \mathrm{N} 117^{\circ} 12^{\prime} \mathrm{W}$ ], 13.v.1961, P.E. Paige (20, UCDC); S Fork Santa Ana River [ca $34^{\circ} 10^{\prime} \mathrm{N} 116^{\circ} 49^{\prime} \mathrm{W}$ ], 17.vi.1945, A.L. Melander (10, USNM); same data except, 18.vi.1945, A.L. Melander (2ᄋ, USNM); same data except, 19.vi.1945, A.L. Melander (19, USNM); same data except, white Ceanothus, A.L.

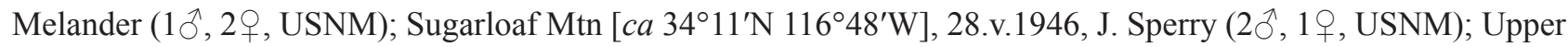
Santa Ana River [ $c a 34^{\circ} 10^{\prime} \mathrm{N} 116^{\circ} 49^{\prime}$ W], 16.vi.1955, A.L. Melander (5 9 , USNM); same data except, 6.vi.1956,

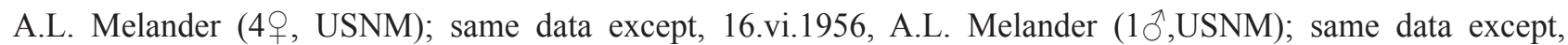

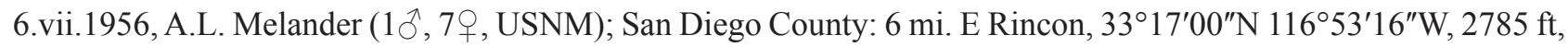
20.iv.2003, S.D. Gaimari, E.M. Fisher (6 ${ }^{\wedge}, 4$, , CSCA); Alpine [ca 32 $50^{\prime} \mathrm{N} 116^{\circ} 45^{\prime} \mathrm{W}$ ], 8.iv.1915, A.L. Melander 


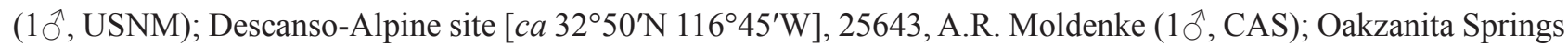

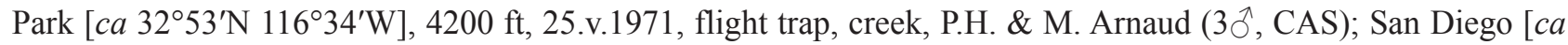

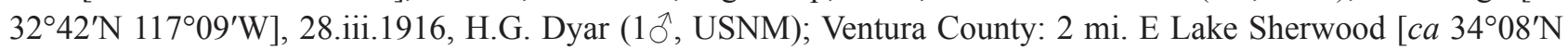

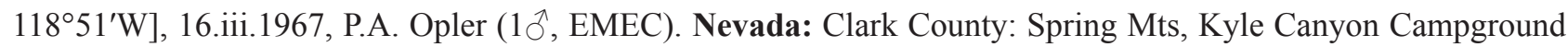
[ca $\left.36^{\circ} 15^{\prime} \mathrm{N} 115^{\circ} 36^{\prime} \mathrm{W}\right], 7000 \mathrm{ft}, 15 . v i .1971$, P.H. \& M. Arnaud (10, USNM).
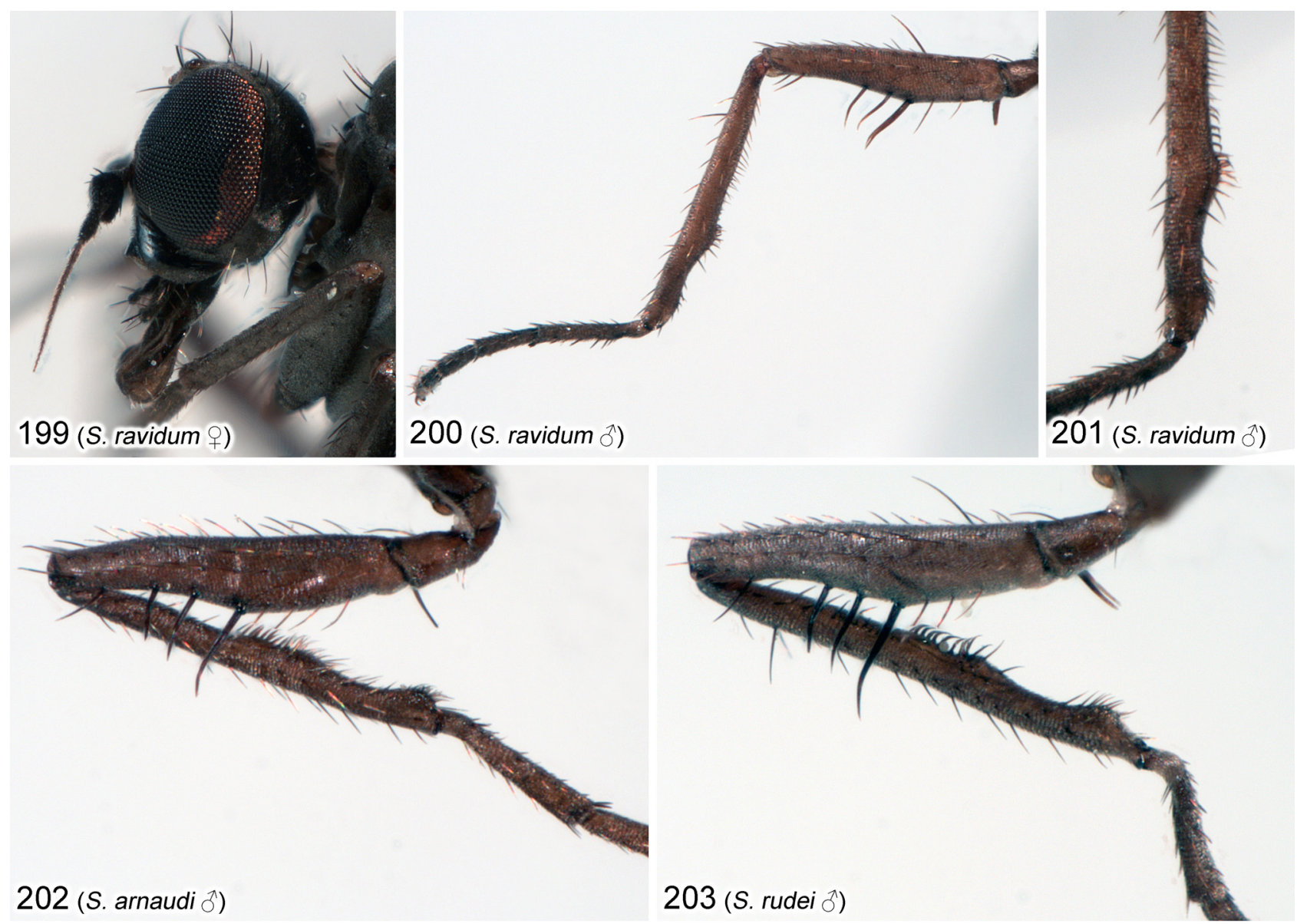

$202($ S. arnaudi ふ)

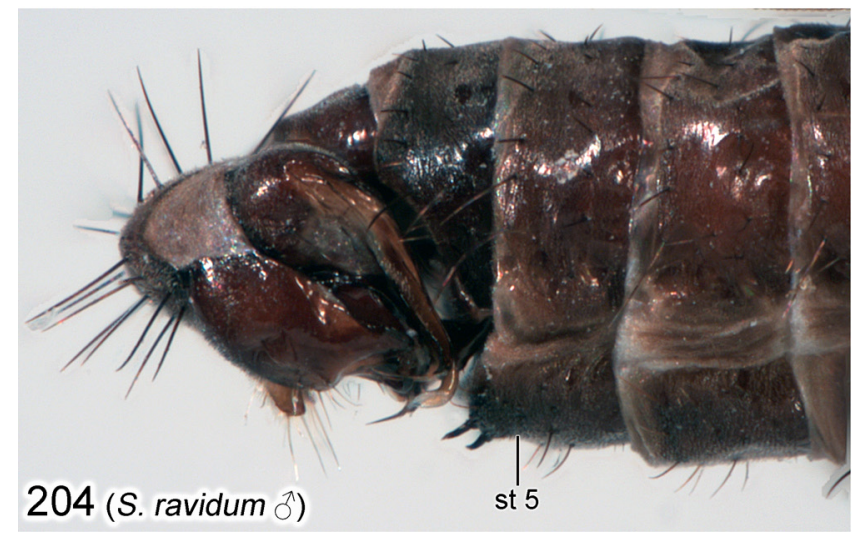

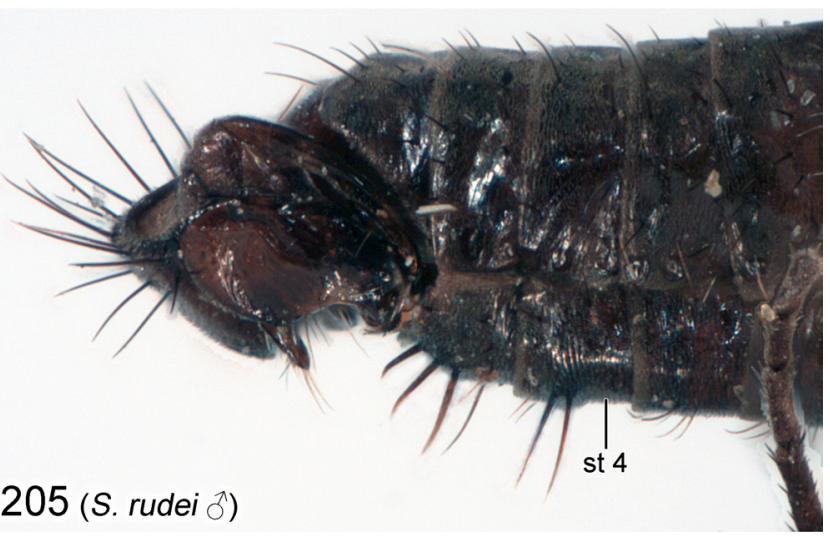

FIGURES 199-205. Schistostoma ravidum (Coquillett) comb. nov., S. arnaudi sp. nov. and S. rudei sp. nov. 199. Head of female $S$. ravidum (Coquillett) comb. nov., lateral view. 200. Male midleg of $S$. ravidum (Coquillett) comb. nov., posterior view. 201. Apex of male mid tibia and first tarsomere of $S$. ravidum (Coquillett) comb. nov., posterior view. 202. Male midleg of $S$. arnaudi sp. nov., posterior view. 203. Male midleg of $S$. rudei sp. nov., posterior view. 204. Male abdomen and terminalia of $S$. ravidum (Coquillett) comb. nov., right lateral view. 205. Male abdomen and terminalia of $S$. rudei sp. nov., right lateral view. Specimens from: 6 mi. E Rincon, California (Figs 199-201); Mount Charleston, Nevada (Fig. 202); Miracle Springs, California (Fig. 203); Hartford Spring Park, California (Fig. 204); Johnsondale, California (Fig. 205). Abbreviation: st—sternite. 
Diagnosis. Males of this species are distinguished from other members of the $S$. ravidum species group by the pair of short stout fang-like setae on male sternite 5 (Fig. 204), series of 3 thick curved spine-like posteroventral setae on the mid femur (Fig. 200), hooked setae on the mid tibial callus (Fig. 201), and the distinctive shape of the left surstylus (Fig. 206), as indicated in the key (couplets 15 and 16). Schistostoma ravidum is very similar to $S$. arnaudi sp. nov. and $S$. rudei sp. nov. Females of this subgroup can be recognized to subgroup level, but are not readily discernible, as indicated in the key (couplet 30 ).

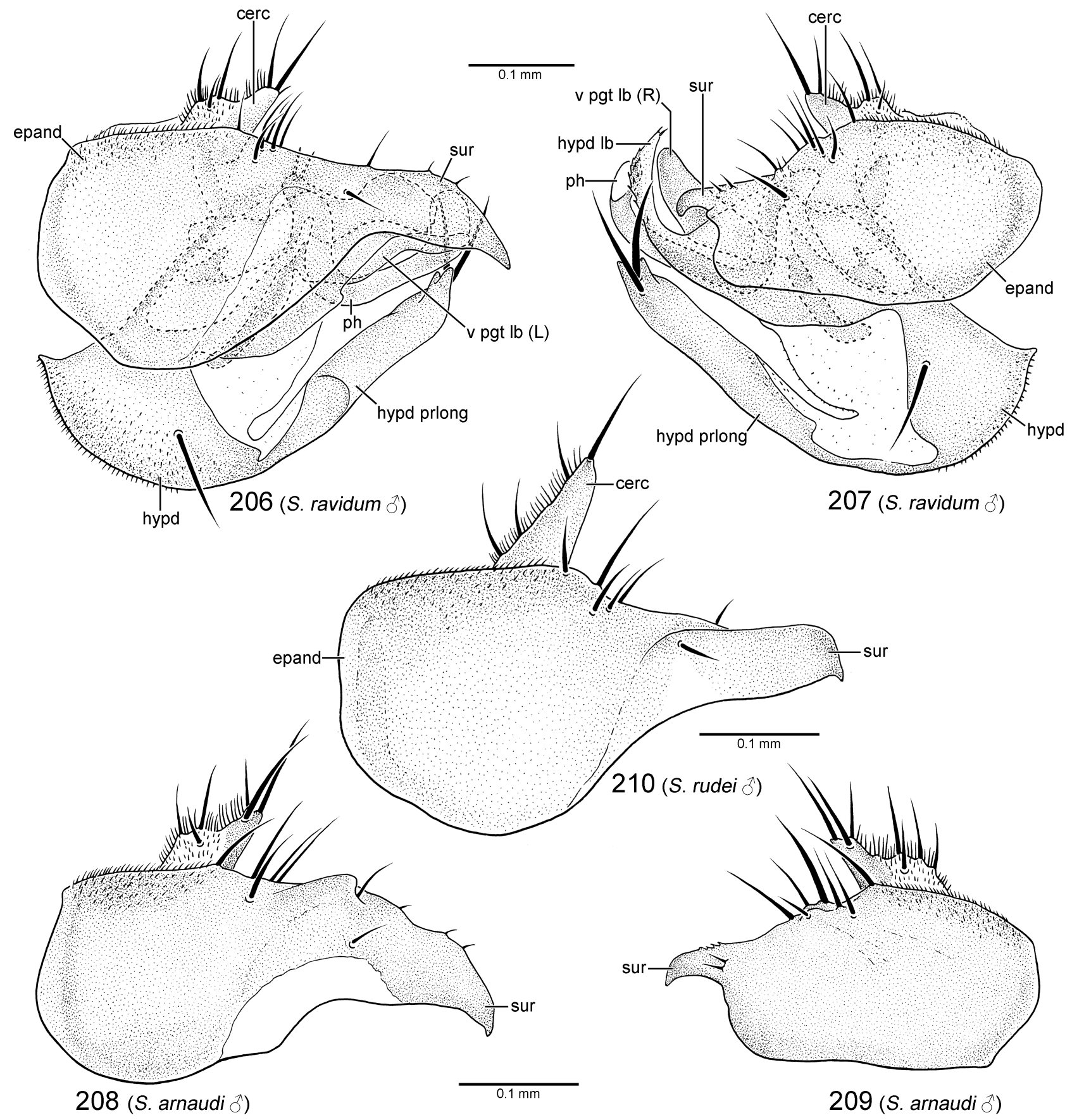

FIGURES 206-210. Hypopygia of Nearctic Schistostoma. 206. S. ravidum (Coquillett) comb. nov., left lateral view. 207. S. ravidum (Coquillett) comb. nov., right lateral view. 208. Epandrium and cercus of S. arnaudi sp. nov., left lateral view. 209. Epandrium and cercus of $S$. arnaudi sp. nov., right lateral view. 210. Epandrium and cercus of $S$. rudei sp. nov., left lateral view. Figures 206 and 207 based on paralectotype specimen CNC1155662 (Los Angeles County, California). Figures 208 and 209 based on specimen CNC1155647 (McWilliams Campground, Nevada). Figure 210 based on specimen CNC1155665 (3 mi. W Wofford Heights, California). Abbreviations: cerc — cercus; epand — epandrium; hypd—hypandrium; hypd lb-hypandrial lobe; hypd prlong — hypandrial prolongation; ph—phallus; (R) — right; sur — surstylus; v pgt lb—ventral postgonite lobe. 
Redescription. Male (Figs 174, 200, 201, 204, 206, 207): Body length 2.0-2.8 mm, wing length 2.0-2.3 mm. Head: Compound eye without demarcation line between larger dorsal and smaller ventral ommatidia. Ocellar tubercle with 2 pairs of black proclinate setae, anterior pair distinctly longer than posterior pair. Occiput dark grey pruinose, mostly clothed with black or brown setae, almost bare in upper part, except for postoculars. Gena and parafacial narrow along lower eye margin. Antenna dark brown; postpedicel conical, evenly tapered to apex; stylus about $1.5 \mathrm{X}$ length of postpedicel. Palpus dark brown, elongate ovate, slightly longer than length of labrum, pubescent with microtrichia and bearing scattered black setulae. Proboscis dark brown, approximately $1 / 2$ as long as head height, directed forward. Thorax: Mesonotum brownish-black. Proepisternum with 1-2 setae. Mesonotal setae black, relatively long with dorsocentrals arranged in single row per side. Notopleuron with 2 strong setae. Scutellum with 2 pairs of setae, inner pair stronger. Mesopleuron brownish-black. Halter brown to light brown. Legs: Entirely dark brown, with black setae. Foreleg: Coxa with several setae on anterior surface. Femur subequal in length to tibia, posterior surface with posterodorsal and posteroventral series of short setae projecting laterally, 1 posteroventral preapical seta. Tibia slender, with short setae. Tarsus subequal in length to tibia, with short setae, tarsomere 1 subequal to combined length of tarsomeres $2-4$, tarsomeres 2-4 decreasing in length apically, tarsomere 5 subequal in length to tarsomere 3. Midleg (Figs 200,201): Coxa with several setae on anterior surface. Trochanter with medial spine-like setal pair weakly curved, longer than width of trochanter. Femur shorter than tibia, posterior surface with short setae on upper half, ventral surface with 3 small posteroventral setae in basal part, distal half with distinctively modified series of 3 thick, curved, spine-like posteroventral setae (proximal seta larger and longer), 1 posteroventral preapical seta, anterior surface with 1 long seta near base, otherwise with short setae. Tibia modified, dorsal surface mainly with short setae, with longer anterodorsal and posterodorsal seta near basal $1 / 4$, ventral surface with short erect setae along basal half, with hooked setae along middle part and callus at $2 / 3$ also densely covered with hooked setae, with preapical ventral callus bearing short setae. Tarsus subequal in length to tibia, with short setae, tarsomere 1 as long as combined length of tarsomeres $2-3$, base with strong dorsal bend, tarsomeres 2-4 decreasing in length apically, tarsomere 5 about as long as tarsomere 3. Hindleg: Coxa with 3 setae on outer surface and a few setae on anterior surface. Femur subequal in length to tibia, with dorsal and anteroventral series of setae (subequal to femur width), anterior surface with short setae on upper part, with 1 strong posteroventral seta near midlength, posterior surface with sparse fine setae. Tibia slightly enlarged apically, with series of dorsal setae (subequal to tibia width), otherwise with short setae. Tarsus subequal in length to tibia, with short setae, tarsomere 1 as long as combined length of tarsomeres 2-4, tarsomeres $2-4$ decreasing in length apically, tarsomere 5 subequal in length to tarsomere 3. Wing (Fig. 174): With slight grey-brown tinge, veins dark brown. Pterostigma small, weakly developed. Anal lobe with proximal margin weakly convex. $\mathrm{R}_{2+3}$ and $\mathrm{R}_{4+5}$ parallel in middle part and diverging near apex with cell $\mathrm{r}_{2+3}$ compressed in middle part and flared at apex. $\mathrm{R}_{4+5}$ sinuous with posterior curve to apex with cell $r_{4+5}$ slightly compressed in basal part. $R_{4+5}$ and $M_{1}$ diverging beyond cell dm. $M_{2}$ and $M_{4}$ diverging beyond cell dm. Costal section $\mathrm{M}_{1}-\mathrm{M}_{2}$ subequal to $\mathrm{M}_{2}-\mathrm{M}_{4}$. Cell dm moderately-sized, extended to around middle of wing, distal section of vein $M_{1}$ (beyond base of $M_{2}$ ) longer than preceding section (between $r-m$ and base of $M_{2}$ ). Crossvein dm-m broadly curved and convergent with $M_{1}$ distally. Abdomen (Fig. 204): Dark brown, with black setae on tergites and sternites. Tergites 1-6 clothed with long, dense setae laterally, setae short and sparse dorsomedially. Sternites 2-4 with short setae medially and longer setae laterally. Sternite 5 with close-set pair of short, stout fanglike mediolateral setae on posterior margin of each side, otherwise with sparse short setae and long posterolateral seta. Sternite 6 angled dorsally, with posterior margin protruding medially, with pair of relatively strong setae on each side, posterior setae with bent tip. Segment 7 with a few tiny setae on sternite, otherwise bare. Sternite 8 subrectangular, setose, distal margin with setae stronger and longer. Hypopygium (Figs 206, 207): Small, about 1/4 length of abdomen. Left epandrial lamella (Fig. 206) larger and bulkier than right epandrial lamella, ovoid basally, longer than high, with group of setae mid-dorsally, with single-lobed surstylus projecting distally. Left surstylus beak-like, narrowed basally, widening slightly beyond base with acute ventrally projected tip, with lateral seta at base and a few setae on dorsal margin. Right epandrial lamella (Fig. 207) smaller than left epandrial lamella ovoid, longer than high, with group of setae mid-dorsally, with single-lobed surstylus projecting distally, posterior epandrial margin below surstylus rounded and projecting. Right surstylus short, hook-like in lateral view with apex projected lateroventrally, with 2 short setae dorsolaterally near base. Hypandrium with single large seta on each side of basal part. Medial hypandrial prolongation long and straight, with shallow basal concavity on left side, apex shallowly bifurcate and curved left, with pair of large flat apical setae of similar length. Left hypandrial lobe with apical margin broadly rounded. Right hypandrial lobe elongate, curved dorsally and spinose. Postgonite with dorsal postgonite 
lobes not substantially developed. Left ventral postgonite lobe broad basally with slender apical extension. Right ventral postgonite lobe conical, tapered apically. Postgonite apodeme narrowly Y-shaped in ventral view. Phallus slender, L-shaped, distal portion straight with apex upturned and slightly expanded. Ejaculatory apodeme short. Left and right cercus with hump-like base bearing several setae and short stubby apex bearing long setae.

Female (Fig. 199): Body length 1.9-2.3 mm, wing length 2.0-2.3 mm. Similar to male except as follows: Head (Fig. 199): Gena and parafacial strongly projected along lower eye margin. Thorax: Mesonotum and mesopleuron greyish-black. Legs: With shorter, unspecialized setae. Midleg: Trochanter without spine-like setal pair; femur and tibia lacking specialized setae; tibia slender, unmodified; tarsomere 1 without basal bend. Hindleg: Femur and tibia with shorter setae. Wing: Pterostigma absent. Anal lobe slightly smaller, proximal margin straight. Abdomen: Tergites and sternites with short setae. With 6 exposed abdominal segments, segment 6 concolorous with anterior abdominal segments. Terminalia (similar to Figs 99, 100, 104): Segment 6 with tergite and sternite subrectangular (wider than long), tergite with shallow anteromedial emargination, tergite and sternite setose on posterior half with setae distinctly stronger on posterior margin (especially on tergite). Segment 7 with tergite slightly wider than long with pronounced anteromedial emargination, anterior margin broadly rounded on either side of emargination, with small posterolateral seta, sternite subrectangular with short setae on posterior margin, tergite and sternite with short band-like posterior sclerite extension on each side. Tergite 8 undivided, darkened along edge of anteromedial emargination, with small posterolateral seta, narrowly fused to sternite 8 anterolaterally. Sternite 9 desclerotized and inconspicuous. Spermatheca spherical. Syntergite 9+10 with hemitergites subrectangular, each with 3 acanthophorite spines. Sternite 10 with short setose lateral lobe below cercus (about half length of cercus), sternite produced posteromedially bearing setulae and 2 adjacent short setae per side, anterolaterally with band-like extension to base of lateral lobe and cercus. Cercus with curved claw-like apex, with several small setae near midlength.

Distribution and seasonal occurrence. Schistostoma ravidum is known from southern California and southern Nevada (Fig. 236). Adults were collected from early March to late June.

Remarks. Coquillett (1895) mentions an additional seven specimens in the type series. The whereabouts of most of these paralectotypes are unknown, but one male paralectotype is in the Oxford University Museum of Natural History (OUMNH), Oxford. One of the female paralectotypes of M. ravidus Coquillett is the holotype of M. ravus Melander, subsequently described by Melander (1940b: 67). Microphorus ravus Melander is newly transferred to Schistostoma and synonymized with S. evisceratum (Melander) above.

Pollen grains have been found in the gut of a dissected male and female of S. ravidum. Flower visitation records for this species are listed in Table 1.

Schistostoma robustum (Melander) comb. nov.

(Figs 167, 168, 181, 182, 233)

Microphorus robustus Melander, 1928: 91.

Type material. HOLOTYPE, $0^{\wedge}$ collected from Swarthmore $\left[\mathrm{ca} 39^{\circ} 54^{\prime} \mathrm{N} 75^{\circ} 21^{\prime} \mathrm{W}\right]$, Delaware County, Pennsylvania, USA, 1.vi.1901, by E.T. Cresson, Jr (ANSP). PARATYPES: USA: Pennsylvania: Same data as holotype (3 $\widehat{\jmath}$, USNM). See "Remarks".

Other material examined. USA: Florida: Walton County: DeFuniak Springs [ca $\left.30^{\circ} 43^{\prime} \mathrm{N} 86^{\circ} 06^{\prime} \mathrm{W}\right]$, 7-

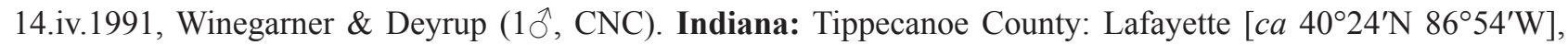
10.v.1916, Collection J.M. Aldrich (1 ${ }^{\wedge}$, USNM). Louisiana: DeSoto Parish: Logansport [ca $31^{\circ} 58^{\prime} \mathrm{N} 93^{\circ} 59^{\prime} \mathrm{W}$ ], 24.iii.1908, on Crataegus sp., E.S. Tucker (19, USNM). Maryland: Montgomery County: Bethesta [ca 3859'N $77^{\circ} 05^{\prime} \mathrm{W}$ ], 18.v.1968, G. Steyskal (1ㅇ, USNM); same data except, 5.v.1969 (10, USNM); same data except,

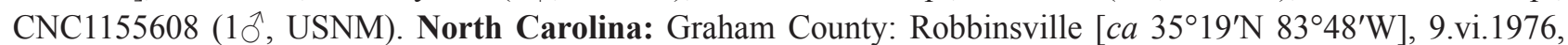

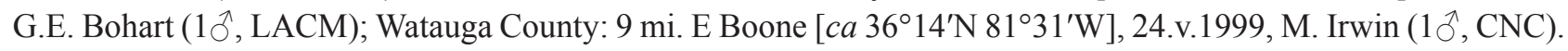
Tennessee: Blount County: Lackey Creek at Middle Settlement Road, $35^{\circ} 47.4^{\prime} \mathrm{N} 84^{\circ} 02.6^{\prime} \mathrm{W}$, vi.2008, J.K. Moulton

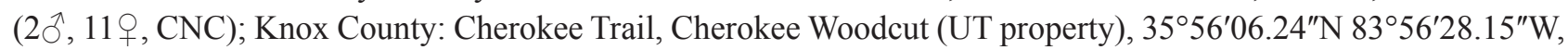
293 m, 15.iv-30.v.2003, J.K. Moulton (3今ึ, 5ㅇ, CNC). Virginia: Augusta County: George Washington NF,

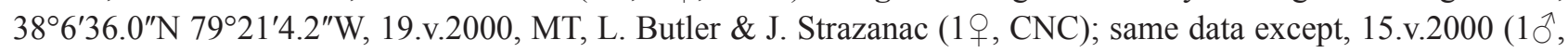

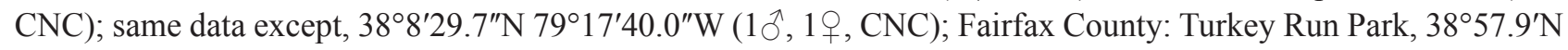




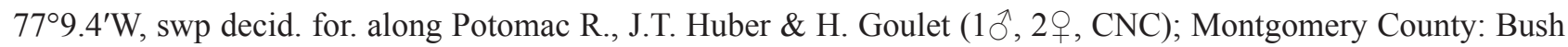

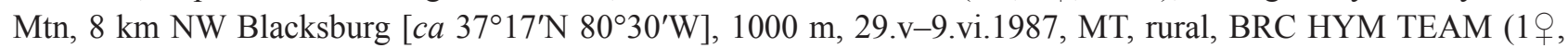
CNC). West Virginia: Pocahontas County: Monongahela NF, $38^{\circ} 20^{\prime} 34.1^{\prime \prime} \mathrm{N} 79^{\circ} 46^{\prime} 40.9^{\prime \prime} \mathrm{W}, 29 . v .2000$, MT, L. Butler \& J. Strazanac $(3 \hat{\partial}, 1$,, CNC).

Diagnosis. Males of this species are distinguished from other members of the $S$. ravidum species group by the long posteroventral setae on the fore femur (about $2 \mathrm{X}$ femur width), antennal stylus 2.3-2.5X longer than postpedicel (similar to Fig. 161), brown body and legs (Figs 167, 168), mid femur with 4-6 long ventral setae (Fig. 167), and additional features of the midleg, abdominal sternites (Fig. 168) and hypopygium (Figs 181, 182) indicated in the key (couplet 22). Females can be distinguished by their antennal stylus length (similar to Fig. 163), narrow gena and parafacial (similar to Figs 162, 163), normal cell dm (similar to Fig. 170), and brown body and legs. Schistostoma robustum is very similar to $S$. armipes, but is easily distinguished by its brown coloration (versus blackish in $S$. armipes), and the male characters listed above.

Redescription. Male (Figs 167, 168, 181, 182): Body length 2.2-2.8 mm, wing length 2.1-2.7 mm. Head: Compound eye with demarcation line anteriorly between larger dorsal and smaller ventral ommatidia. Ocellar tubercle with 2 pairs of black proclinate setae, anterior pair slightly longer than posterior pair, rarely middle pair present. Occiput dark grey pruinose, mostly clothed with black or dark brown setae, almost bare in upper part, except for postoculars. Gena and parafacial narrow along lower eye margin. Antenna brown to dark brown; postpedicel elongate subtriangular with apical 1/3 narrow and digitiform; stylus about 2.0X length of postpedicel. Palpus dark brown, elongate ovate, slightly longer than length of labrum, pubescent with microtrichia and bearing scattered black setulae. Proboscis brown, slightly less than $1 / 2$ as long as head height, directed forward. Thorax: Mesonotum brown to darkish-brown. Proepisternum with 1-2 setae. Mesonotal setae black, relatively long with dorsocentrals arranged in single row per side. Notopleuron with 2 strong setae. Scutellum with 2 pairs of setae, inner pair stronger. Mesopleuron brown to darkish-brown. Halter pale. Legs: Entirely pale brown, with black setae. Foreleg: Coxa with several short setae on anterior surface. Femur subequal in length to tibia, posterior surface with short setae on upper half and series of about 6-8 long posteroventral setae (distal setae over $2 \mathrm{X}$ width of femur), anterior surface with series of long anteroventral setae from base to midlength (distal setae longer). Tibia slender, slightly compressed laterally, with short setae mainly on dorsal surface. Tarsus subequal in length to tibia, with short setae, tarsomere 1 slightly shorter than combined length of tarsomeres 2-5, tarsomeres 2-4 decreasing in length apically, tarsomere 5 subequal in length to tarsomere 2. Midleg (Fig. 167): Coxa with several setae on anterior surface. Trochanter with medial spine-like setal pair weakly curved, slightly longer than width of trochanter. Femur slightly shorter than tibia, posterior surface with short setae on upper half, 3-4 short ventral setae in basal part followed by series of 4-6 long strong ventral setae (as long or slightly longer than femur width), anterior surface with 1 long seta near base, otherwise with short setae. Tibia modified, widened at middle, apex glabrous on posterior surface, dorsal surface with short setae, ventral surface with short erect setae near midlength. Tarsus slightly shorter than tibia, with short setae, tarsomere 1 as long as combined length of tarsomeres 2-4, with a few stout ventral setae, tarsomeres 2-4 decreasing in length apically, tarsomere 5 about as long as tarsomere 3. Hindleg: Coxa with 2-3 setae on outer surface and several setae on anterior surface. Femur longer than tibia, with dorsal and ventral fringe of long setae (dorsal setae as long as femur width, ventral setae shorter), anterior surface with short setae on upper part, posterior surface with sparse fine setae. Tibia enlarged apically, with dorsal fringe of long setae (subequal to tibia width or shorter), anterior and posterior surface setulose. Tarsus subequal in length to tibia, tarsomere 1 broad, as long as combined length of tarsomeres 2-5, with slightly longer setae dorsally, tarsomeres 2-4 decreasing in length apically, with shorter setae dorsally, tarsomere 5 subequal in length to tarsomere 3. Wing: With slight grey-brown tinge, veins brown. Pterostigma well-developed. Anal lobe with proximal margin weakly convex. $\mathrm{R}_{2+3}$ and $\mathrm{R}_{4+5}$ parallel in middle part and diverging near apex with cell $r_{2+3}$ compressed in middle part and flared at apex. $\mathrm{R}_{4+5}$ sinuous with pronounced posterior curve to apex with cell $r_{4+5}$ slightly compressed in basal part. $R_{4+5}$ and $M_{1}$ diverging beyond cell dm. $M_{2}$ and $M_{4}$ weakly diverging beyond cell $\mathrm{dm}$. Costal section $M_{1}-M_{2}$ subequal to $M_{2}-M_{4}$. Cell dm moderatelysized, extended to around middle of wing, distal section of vein $M_{1}$ (beyond base of $M_{2}$ ) longer than preceding section (between $\mathrm{r}-\mathrm{m}$ and base of $\mathrm{M}_{2}$ ). Crossvein dm- $\mathrm{m}$ broadly curved and convergent with $\mathrm{M}_{1}$ distally. Abdomen (Fig. 168): Dark brown, with black setae on tergites and sternites. Tergites 1-6 clothed with long, dense setae laterally, setae short and sparse dorsomedially. Sternite 2 with 1 long mediolateral seta per side at posterior margin, other setae relatively short. Sternite 3 with close-set pair of long mediolateral seta per side at posterior margin, other medial setae relatively short, lateral setae longer. Sternites 4 and 5 with close-set pair of long thick spine-like 
mediolateral setae at posterior margin, setae pairs more widely separated on sternite 5 , other medial setae if present relatively short, lateral setae longer. Sternite 6 angled dorsally, with a few tiny setae. Segment 7 with a few minute setae on sternite, otherwise bare. Sternite 8 subrectangular, setose. Hypopygium (Figs 181, 182): Small, about 1/4 length of abdomen. Left epandrial lamella (Fig. 181) larger than right epandrial lamella, subtriangular, longer than high, with surstylar lobes projecting distally. Left dorsal lobe of surstylus not substantially developed with a few strong apical setae and a few small lateral setae. Left ventral lobe of surstylus large, broad in basal half, apical half tapered, with a few short setae near middle, membranous basiventrally. Right epandrial lamella (Fig. 182) smaller than left epandrial lamella, subrectangular, longer than high, with surstylar lobes weakly projecting distally. Right dorsal lobe of surstylus similar to left side. Right ventral lobe of surstylus short with acute apex. Hypandrium with single large seta on each side of basal part. Medial hypandrial prolongation long, deeply bifurcate; upper branch narrow and straight, with fine hairs dorsally and ventral preapical seta; lower branch broader, straight in basal 2/3, apical third strongly upturned with preapical dorsal seta. Left hypandrial lobe short, tapered to rounded apex. Right hypandrial lobe moderately long with rounded apex, surface finely spinose. Postgonite with dorsal postgonite lobes not substantially developed. Left ventral postgonite lobe with broadly rounded ventral margin, apex narrow and pointed. Right ventral postgonite lobe large and broad, apex greatly expanded and rounded, tapered and pointed apically. Postgonite apodeme narrowly V-shaped in ventral view with long rod-like left and right branch. Phallus slender, C-shaped, apex flared. Ejaculatory apodeme short. Left and right cercus with hump-like base bearing several setae and narrow stub-like apex bearing several setae.

Female (described for the first time): Body length 2.0-2.4 mm, wing length 2.2-2.5 mm. Similar to male except as follows: Head: Compound eye without demarcation line between dorsal and ventral ommatidia; ocellar tubercle with anterior pair of setae distinctly longer than posterior pair. Legs: With shorter, unspecialized setae. Foreleg: Femur lacking long posteroventral setae, with only short anteroventral setulae. Midleg: Trochanter without spine-like setal pair; femur and tibia lacking specialized setae; tibia slender, unmodified. Hindleg: Femur with shorter dorsal and ventral fringe of setae; tibia not enlarged apically, with short setae; tarsomere 1 smaller, lacking distinct dorsal setae. Wing: Anal lobe slightly smaller, proximal margin straight. $\mathrm{R}_{4+5}$ with posterior curve slightly weaker. Abdomen: Tergites and sternites with short setae. With 6 exposed abdominal segments, segment 6 concolorous with anterior abdominal segments. Terminalia (similar to Figs 99, 100, 104): Segment 6 with tergite and sternite subrectangular (wider than long), tergite with shallow anteromedial emargination, tergite and sternite setose on posterior half with setae distinctly stronger on posterior margin (especially on tergite). Segment 7 with tergite longer than wide with pronounced anteromedial emargination, anterior margin broadly rounded on either side of emargination, with small posterolateral seta, sternite shorter than tergite, subquadrate, with pair of small posterolateral setae, tergite and sternite with short band-like posterior sclerite extension on each side. Tergite 8 undivided, darkened along edge of anteromedial emargination, with small posterolateral seta, narrowly fused to sternite 8 anterolaterally. Sternite 9 desclerotized and inconspicuous. Spermatheca spherical. Syntergite 9+10 with hemitergites subrectangular, each with 3 acanthophorite spines. Sternite 10 with short setose lateral lobe below cercus (about half length of cercus), sternite produced posteromedially bearing setulae and about 2 adjacent short setae per side, anterolaterally with band-like extension to base of lateral lobe and cercus. Cercus with curved claw-like apex, with several small setae near midlength.

Distribution and seasonal occurrence. Schistostoma robustum is known from eastern USA, from Indiana, Maryland and Pennsylvania in the north, through West Virginia, Virginia, Tennessee and North Carolina, to western Louisiana and northwestern Florida in the south (Fig. 233). Adults have been collected from late March to early June.

Remarks. Melander (1928) only mentions the "type" specimen in his original description (i.e., the specimen that is deposited in the ANSP and not examined by us); however, later Melander (1940b) indicates that there are additional males in the type series. Three of these male paratypes, which were examined by us, are deposited in the USNM and bear red paratype labels.

Pollen grains have been found in the gut of a dissected female of S. robustum. Flower visitation records for this species are listed in Table 1. 
Schistostoma rudei sp. nov.

(Figs 203, 205, 210, 235)

urn:lsid:zoobank.org:act: C15078FC-87F9-49BB-943C-EB1240DC08AE

Type material. HOLOTYPE, ô collected $3 \mathrm{mi}$. W Wofford Heights [ $\left.\mathrm{ca} 35^{\circ} 43^{\prime} \mathrm{N} 118^{\circ} 30^{\prime} \mathrm{W}\right]$, Kern County, California, USA, 29.iv.1964, by C.A. Toschi, labelled: "3 mi. W. Wofford/ Hts., KernCo.,/ Calif: IV-29-64"; "C.A. Toschi/ collector"; "HOLOTYPE/ Schistostoma rudei/ Brooks \& Cumming [red label]" (EMEC). PARATYPES: USA: California: Same data as holotype (1q, EMEC); same data as holotype except, 2.v.1964, P. Rude (1 $\hat{\gamma}^{\text {, }}$ EMEC); same data except, 28.iv.1964, ex Coreopsis bigelovii (2ð, 1으, EMEC); same data except, 29.iv.1964, ex Plagiobothrys (1§, 1 ㅇ, EMEC); same data except, ex Plagiobothrys nothofulvus, J. Powell (2 + , EMEC); same data

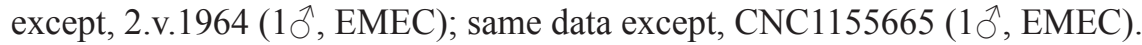

Other material examined. USA: California: Kern County: Glennville [ $c a 3^{\circ} 43^{\prime} \mathrm{N} 118^{\circ} 42^{\prime} \mathrm{W}$ ], 26.iv.1950, E.I. Schlinger (2犬̂, 1 \& , UCDC); same data except, 24.iv.1949, Ceanothus, E.G. Linsley, J.W. MacSwain, R.F. Smith

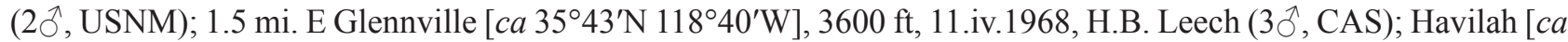

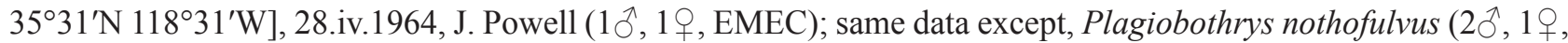
EMEC); Miracle Springs [ $c a 5^{\circ} 34^{\prime} \mathrm{N} 118^{\circ} 32^{\prime} \mathrm{W}$ ], 29.iv.1964, ex Lomatium, J. Powell (7ô, 10오. EMEC); Tulare County: Fairview [ $c a 35^{\circ} 55^{\prime} \mathrm{N} 118^{\circ} 29^{\prime} \mathrm{W}$ ], 27.iv.1964, ex Salix, P. Rude (1 $\widehat{O}^{\wedge}$, EMEC); Johnsondale, 2 mi. E [ca $\left.35^{\circ} 58^{\prime} \mathrm{N} 118^{\circ} 30^{\prime} \mathrm{W}\right]$, 2.v.1964, P. Rude (19, EMEC); same data except, 27.iv.1964, C.A. Toschi (1 9 , EMEC); same

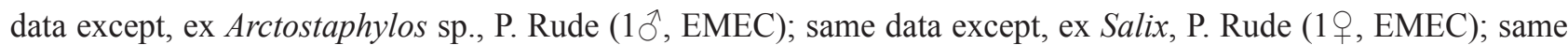

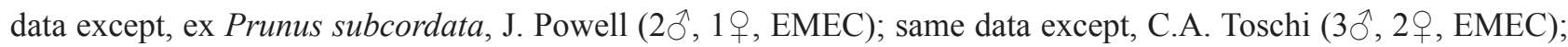
same data except, ex Ceanothus sp. (1今̄, EMEC).

Diagnosis. Males of this species are distinguished from other members of the S. ravidum species group by the spine-like setae on male sternite 5 (Fig. 205), series of 3 thick curved spine-like posteroventral setae on the mid femur (Fig. 203), hooked setae on the mid tibial callus (Fig. 203), and the distinctive shape of the left surstylus (Fig. 210), as indicated in the key (couplets 15 and 17). Schistostoma rudei sp. nov. is very similar to S. arnaudi sp. nov. and $S$. ravidum. Females of this subgroup can be recognized to subgroup level, but are not readily discernible, as indicated in the key (couplet 30).

Description. Male (Figs 203, 205, 210): Body length 2.0-2.4 mm, wing length 2.0-2.2 mm. Head: Compound eye without demarcation line between larger dorsal and smaller ventral ommatidia. Ocellar tubercle with 2 pairs of black proclinate setae, anterior pair distinctly longer than posterior pair. Occiput dark grey pruinose, mostly clothed with black or brown setae, almost bare in upper part, except for postoculars. Gena and parafacial slightly projected along lower eye margin. Antenna dark brown to black; postpedicel conical, evenly tapered to apex; stylus about 1.5X length of postpedicel. Palpus black, elongate ovate, slightly longer than length of labrum, pubescent with microtrichia and bearing scattered black setulae. Proboscis dark brown, moderately long, nearly $2 / 3$ as long as head height, directed forward. Thorax: Mesonotum brownish-black. Proepisternum with 1-2 setae. Mesonotal setae black relatively long with dorsocentrals arranged in single row per side. Notopleuron with 2 strong setae. Scutellum with 2 pairs of setae, inner pair stronger. Mesopleuron brownish-black. Halter brown to light brown. Legs: Entirely dark brown, with black setae. Foreleg: Coxa with several setae on anterior surface. Femur subequal in length to tibia, posterior surface with posterodorsal and posteroventral series of setae (slightly shorter than femur width) projecting laterally, 1 posteroventral preapical seta. Tibia slender, with short setae. Tarsus subequal in length to tibia, with short setae, tarsomere 1 subequal to combined length of tarsomeres $2-4$, tarsomeres $2-4$ decreasing in length apically, tarsomere 5 subequal in length to tarsomere 3. Midleg (Fig. 203): Coxa with several setae on anterior surface. Trochanter with medial spine-like setal pair weakly curved, longer than width of trochanter. Femur shorter than tibia, posterior surface with short setae on upper half, ventral surface with 2 small posteroventral setae in basal part, distal half with distinctively modified series of 3 thick, curved, spine-like posteroventral setae (proximal seta larger and longer), 1 posteroventral preapical seta, anterior surface with 1 long seta near base, otherwise with short setae. Tibia modified, dorsal surface mainly with short setae, with longer anterodorsal and posterodorsal seta near basal $1 / 4$, ventral surface with hooked setae along middle part and callus at $2 / 3$ also densely covered with hooked setae, with preapical ventral callus bearing short setae. Tarsus subequal in length to tibia, with short setae, tarsomere 1 as long as combined length of tarsomeres $2-3$, base with strong dorsal bend, tarsomeres $2-4$ decreasing in length apically, tarsomere 5 about as long as tarsomere 3. Hindleg: Coxa with 3 setae on outer surface and a few setae on anterior surface. Femur subequal in length to tibia, with dorsal and anteroventral series of setae (subequal to femur 
width), anterior surface with short setae on upper part, often with 1 strong posteroventral seta near midlength, posterior surface with sparse fine setae. Tibia slightly enlarged apically, with series of dorsal setae (subequal to tibia width), otherwise with short setae. Tarsus subequal in length to tibia, with short setae, tarsomere 1 as long as combined length of tarsomeres 2-4, tarsomeres 2-4 decreasing in length apically, tarsomere 5 subequal in length to tarsomere 3. Wing: With slight grey-brown tinge, veins dark brown. Pterostigma small, weakly developed. Anal lobe with proximal margin weakly convex. $\mathrm{R}_{2+3}$ and $\mathrm{R}_{4+5}$ parallel in middle part and diverging near apex with cell $\mathrm{r}_{2+3}$ compressed in middle part and flared at apex. $\mathrm{R}_{4+5}$ sinuous with pronounced posterior curve to apex with cell $r_{4+5}$ slightly compressed in basal part. $R_{4+5}$ and $M_{1}$ diverging beyond cell dm. $\mathrm{M}_{2}$ and $\mathrm{M}_{4}$ slightly diverging beyond cell dm. Costal section $M_{1}-M_{2}$ subequal to $M_{2}-M_{4}$. Cell dm moderately-sized, extended to around middle of wing, distal section of vein $M_{1}$ (beyond base of $M_{2}$ ) longer than preceding section (between r-m and base of $M_{2}$ ). Crossvein dm-m broadly curved and convergent with $M_{1}$ distally. Abdomen (Fig. 205): Dark brown, with black setae on tergites and sternites, finer setae brown. Tergites 1-6 clothed with long, dense setae laterally, setae short and sparse dorsomedially. Sternites 2 and 3 with short setae medially and longer setae laterally. Sternite 4 with close-set row of unmodified or spine-like mediolateral setae on each side, with additional short setae and long posterolateral seta. Sternite 5 with close-set row of 3 long thick spine-like mediolateral setae on each side, otherwise with sparse short setae and long lateral and posterolateral setae. Sternite 6 angled dorsally, with short setae. Segment 7 with a few tiny setae on sternite, otherwise bare. Sternite 8 subrectangular, setose, distal margin with setae longer and stronger. Hypopygium (Fig. 210): Small, about 1/4 length of abdomen. Left epandrial lamella (Fig. 210) larger and bulkier than right epandrial lamella, ovoid basally, longer than high, with group of setae mid-dorsally, with single-lobed surstylus projecting distally. Left surstylus beak-like, straight and evenly broad, apex truncate with small pointed apicoventral process. Right epandrial lamella smaller than left epandrial lamella, ovoid, longer than high, with group of setae mid-dorsally, with single-lobed surstylus projecting distally, posterior epandrial margin below surstylus rounded and projecting. Right surstylus short, hook-like in lateral view with apex projected lateroventrally, with 2 short setae laterally near base. Hypandrium with single large seta on each side of basal part. Medial hypandrial prolongation long and straight, with shallow basal concavity on left side, apex shallowly bifurcate and curved left, with pair of long curved apical setae of similar length. Left hypandrial lobe with apical margin broadly rounded. Right hypandrial lobe elongate, curved dorsally and spinose. Postgonite with dorsal postgonite lobes not substantially developed. Left ventral postgonite lobe broad basally with slender apical extension. Right ventral postgonite lobe conical, tapered apically. Postgonite apodeme narrowly Y-shaped in ventral view. Phallus slender, L-shaped, distal portion straight with apex curved to right. Ejaculatory apodeme short. Left and right cercus evenly tapered to apex, with dorsal setae and long apical seta.

Female: Body length 1.9-2.5 mm, wing length $2.0-2.3 \mathrm{~mm}$. Similar to male except as follows: Head: Gena and parafacial strongly projected along lower eye margin. Thorax: Mesonotum and mesopleuron greyish-black. Halter light brown to pale. Legs: With shorter, unspecialized setae. Midleg: Trochanter without spine-like setal pair; femur and tibia lacking specialized setae; tibia slender, unmodified; tarsomere 1 without basal bend. Hindleg: Femur and tibia with shorter setae. Wing: Pterostigma absent. Anal lobe slightly smaller, proximal margin straight. $\mathrm{R}_{4+5}$ with posterior curve slightly weaker. Abdomen: Tergites and sternites with short setae. With 6 exposed abdominal segments, segment 6 concolorous with anterior abdominal segments. Terminalia (similar to Figs 99, 100, 104): Segment 6 with tergite and sternite subrectangular (wider than long), tergite with shallow anteromedial emargination, tergite and sternite setose on posterior half with setae distinctly stronger on posterior margin (especially on tergite). Segment 7 with tergite slightly longer than wide with pronounced anteromedial emargination, anterior margin broadly rounded on either side of emargination, with small posterolateral seta, sternite subquadrate with short setae on posterior margin, tergite and sternite with short band-like posterior sclerite extension on each side. Tergite 8 undivided, darkened along edge of anteromedial emargination, with small posterolateral seta, narrowly fused to sternite 8 anterolaterally. Sternite 9 desclerotized and inconspicuous. Spermatheca spherical. Syntergite $9+10$ with hemitergites subrectangular, each with 3 acanthophorite spines. Sternite 10 with short setose lateral lobe below cercus (about half length of cercus), sternite produced posteromedially bearing setulae and about 2 adjacent short setae per side, anterolaterally with band-like extension to base of lateral lobe and cercus. Cercus with curved clawlike apex, with several small setae near midlength.

Distribution and seasonal occurrence. Schistostoma rudei sp. nov. is known from Tulare and Kern Counties in California (Fig. 235). Adults were collected from mid-April to early May.

Etymology. This species is named after fellow entomologist, Paul A. Rude, who collected many of the specimens 
examined in this study, including several paratypes of this new species, and who also recorded numerous flower visits by various western species of Microphorinae.

Remarks. Pollen grains have been found in the gut of a dissected female of this species. Flower visitation records for this species are listed in Table 1.

\section{Schistostoma strigilifer (Melander) comb. nov.}

(Figs 175, 211-215, 219-221, 237)

Microphorus strigilifer Melander, 1940b: 68.

Type material examined. LECTOTYPE (here designated to fix the identity of the species), $\widehat{\partial}$ collected from Valley of the Falls [ $\mathrm{ca} 34^{\circ} 05^{\prime} \mathrm{N} 116^{\circ} 55^{\prime} \mathrm{W}$ ], San Bernardino County, California, USA, 25.v.1935, on Phacelia davidsonii, by P.H. Timberlake, labelled: "Valley of the Falls/ Cal May 25, 35"; "on Phacelia/ davidsonii”"; "Timberlake/ Coll.”; "ALMelander/Collection/ 1961"; "Microphorus/ strigilifer/ Mel.”; "LECTOTYPE/ Microphorus/ strigilifer Melander/ des. Brooks \& Cumming 2022 [red label]" (USNM). PARALECTOTYPES: USA: California: San Bernardino County: Same data as lectotype (3 $\hat{\partial}, 2$, , USNM); same data except, CNC1155645 (1 $\hat{\jmath}$, USNM); Forest Home [ca $\left.34^{\circ} 05^{\prime} \mathrm{N} 116^{\circ} 55^{\prime} \mathrm{W}\right]$, 25.v.1935, A.L. Melander (10, USNM). See "Remarks".

Other material examined. USA: California: Contra Costa County: Mt Diablo [ca 37 $53^{\prime} \mathrm{N} 121^{\circ} 54^{\prime} \mathrm{W}$ ], 21.iv.1953, P.D. Hurd (2`, EMEC); Fresno County: 12 mi. W Coalinga [ca $\left.36^{\circ} 06^{\prime} \mathrm{N} 120^{\circ} 31^{\prime} \mathrm{W}\right]$, 8.iv.1951, E.G. Linsley ( $3{ }^{\circ}$, USNM); Kern County: $1.5 \mathrm{mi}$. E Glennville [ca $35^{\circ} 43^{\prime} \mathrm{N} 118^{\circ} 40^{\prime} \mathrm{W}$ ], $3600 \mathrm{ft}, 11 . i v .1968$, H.B.

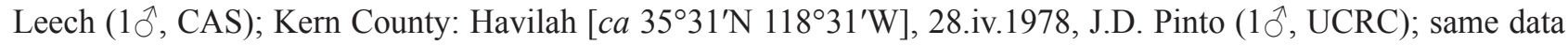

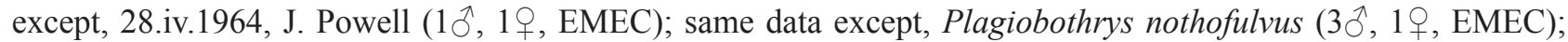

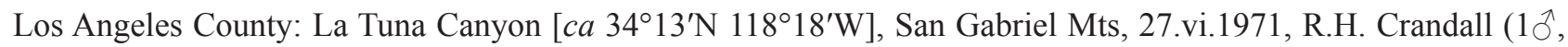
LACM); Largo Vista Rd, N of Mile High, $34.42^{\circ} \mathrm{N} 117.77^{\circ} \mathrm{W}, 1518 \mathrm{~m}, \mathrm{MT}, 23-27 . v .2003$, J. Skevington (12 ${ }^{\AA}, 2$, CNC); Tie Canyon [ $\mathrm{ca} 34^{\circ} 23^{\prime} \mathrm{N} 118^{\circ} 04^{\prime} \mathrm{W}$ ], San Gabriel Mts, 6.vi.1965, R.H. Crandall (1 ${ }^{\lambda}$, LACM); Mariposa

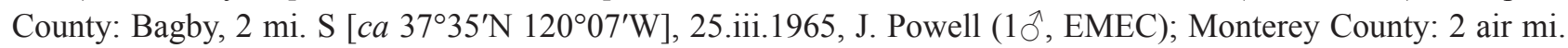
S Arroyo Seco Guard Station [ca 36 $12^{\prime} \mathrm{N} 121^{\circ} 29^{\prime} \mathrm{W}$ ], $2500 \mathrm{ft}$, 3.v.1975, R. Wharton, on Ceanothus $\left(1 \mathrm{o}^{\wedge}, 1\right.$, EMEC); same data except, Indians Rd, on Ceanothus/ Achillea milefolium, J. Powell (10 $\widehat{0}, 8 \uparrow$, EMEC); same

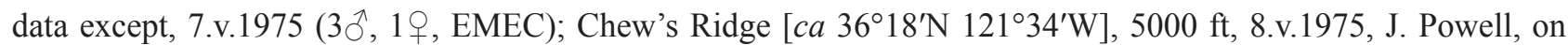
Nemophila (1 $\mathrm{O}^{\top}, 1$,, EMEC); 0.5 air mi. N Escondito Campground [ca $36^{\circ} 08^{\prime} \mathrm{N} 121^{\circ} 29^{\prime} \mathrm{W}$ ], Santa Lucia Mts, 2800 ft, 9.v.1975, E. Rogers (2犬̂, EMEC); Paloma Creek, 3 air mi. NE Arroyo Seco Guard Station [ca 36 ${ }^{\circ} 16^{\prime} \mathrm{N}$ $121^{\circ} 27^{\prime} \mathrm{W}$ ], 5.v.1975, on Gilla capitata (1 9 , EMEC); Placer County: Dutch Flat [ca $\left.39^{\circ} 12^{\prime} \mathrm{N} 120^{\circ} 50^{\prime} \mathrm{W}\right]$, 20.v.1952,

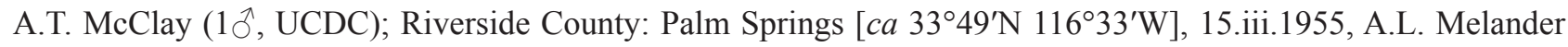
(1ㅅ, USNM); San Benito County: 2 mi. S jct. Cienega and Lime Kiln Roads [ca 36 $41^{\prime} \mathrm{N} 121^{\circ} 21^{\prime} \mathrm{W}$ ], 4.iv.1970, D.C. Rentz, on dried leaves on ground, in bright sunlight in oak woodland ( $3{ }^{\lambda}$, CAS); San Bernardino County: E Barton Flats [ca $34^{\circ} 10^{\prime} \mathrm{N} 116^{\circ} 51^{\prime} \mathrm{W}$ ], 4.vi.1946, J.L. Sperry (10, 1ㅇ, USNM); San Bernardino Mts, Rd 2N93+38, 1 mi. N Hwy 38, 2350 m, 24.vi.1997, pine scrub ravine, M.L. Buffington (10̂, UCRC); S Fork Santa Ana River

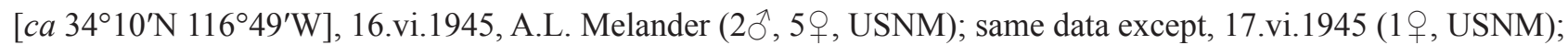

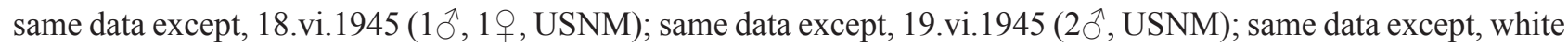

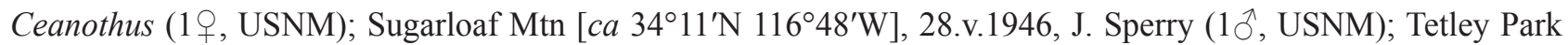
[Tetley's Mountain Camp], Crestline, San Bernardino Mountains, 34.246388, -117.309444, 1380 m, 15.v.1937, on Phacelia davidsonii, P.H. Timberlake (1 ${ }^{\wedge}$, UCRC); Upper Santa Ana River [ca 34 $\left.10^{\prime} \mathrm{N} 116^{\circ} 49^{\prime} \mathrm{W}\right]$, 16.vi.1955,

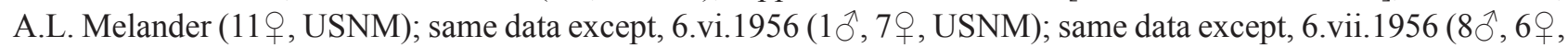
USNM); Valley of the Falls [ca $34^{\circ} 05^{\prime} \mathrm{N} 116^{\circ} 55^{\prime} \mathrm{W}$ ], 25.v.1935, on Phacelia davidsonii, P.H. Timberlake (2 ${ }^{\top}, 3$, UCRC); San Diego County: Oakzanita Springs Park [ca 32 $53^{\prime} \mathrm{N} 116^{\circ} 34^{\prime} \mathrm{W}$ ], 4200 ft, 25.v.1971, flight trap, creek,

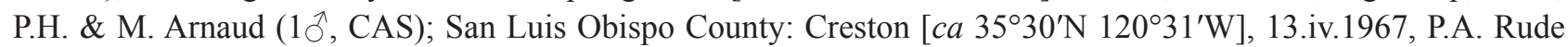

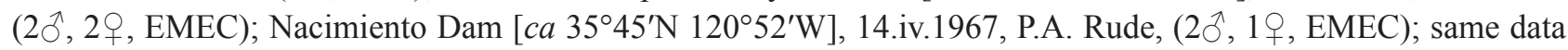

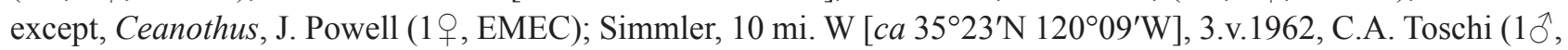
EMEC); Tremblor Range, 12 mi. E Simmler [ca $\left.35^{\circ} 19^{\prime} \mathrm{N} 119^{\circ} 47^{\prime} \mathrm{W}\right]$, J. Powell (1ㅇ, EMEC). USA: Nevada: Storey County: Cedar Hill Canyon, 1.6 km E Virginia City [ca $\left.39^{\circ} 19^{\prime} \mathrm{N} 119^{\circ} 38^{\prime} \mathrm{W}\right], 1859$ m, 27.v.1973, P.H. Arnaud, Jr $\left(10^{\lambda}, 9\right.$ ㅇ, USNM). 


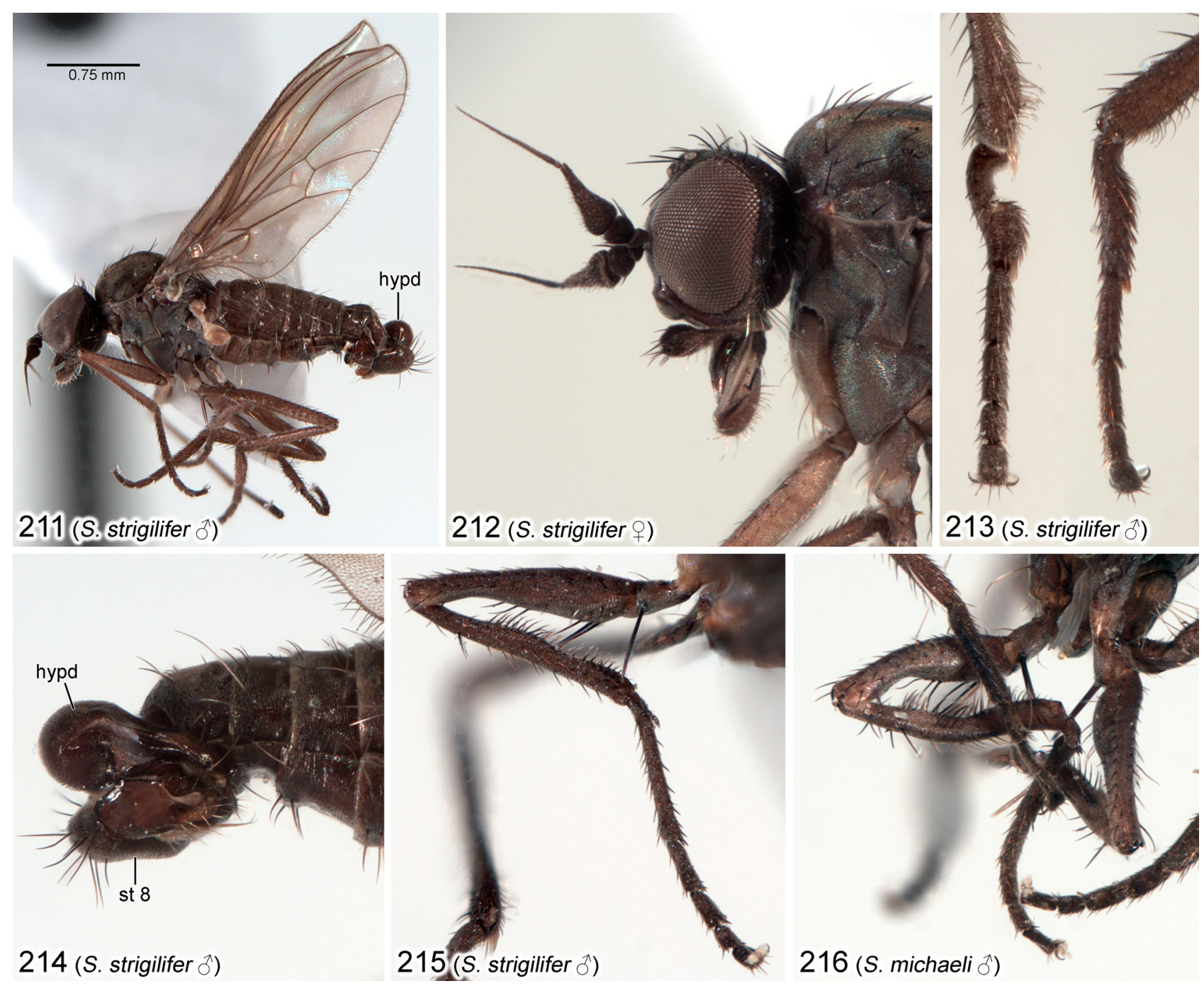

FIGURES 211-216. Schistostoma strigilifer (Melander) comb. nov. and S. michaeli sp. nov. 211. Male habitus of S. strigilifer (Melander) comb. nov. 212. Female of S. strigilifer (Melander) comb. nov., head and anterior portion of thorax, lateral view. 213. Male right hind tibia apex and tarsus of two specimens of $S$. strigilifer (Melander) comb. nov., dorsal view. 214. Male terminalia of S. strigilifer (Melander) comb. nov., right lateral view. 215. Male midleg of S. strigilifer (Melander) comb. nov., anterior view. 216. Male midlegs of $S$. michaeli sp. nov., anterior view. Specimens from: Largo Vista Rd, California (Figs 211213 right tarsus, 214); Valley of the Falls, California (213 left tarsus); Indians Rd, California (Fig. 215); Lake Tahoe, California (Fig. 216). Abbreviations: hypd—hypandrium; st—sternite.

Diagnosis. As indicated in the key (couplets 13 and 14), males of this species are distinguished from other members of the S. ravidum species group by their enlarged bulbous hypandrium (Figs 214, 219-220), broad medial hypandrial process (Fig. 221), notched hind tarsomere 1 (Fig. 213), and normal-sized wing cell dm (Fig. 175), compared to the small cell dm of the closely related S. michaeli sp. nov. (Fig. 173). Females can be distinguished by the posterior patch of fine erect setulae on the hind tibia and other leg characters provided in the key (couplet 29 ) in combination with a short antennal stylus, projected gena and parafacial, and normal-sized wing cell $\mathrm{dm}$ (as in Fig. 175).

Redescription. Male (Figs 175, 211, 213-215, 219-221): Body length 2.3-3.1 mm, wing length 2.3-2.6 mm. Head: Compound eye with demarcation line anteriorly between larger dorsal and smaller ventral ommatidia. Ocellar tubercle with 2 pairs of black proclinate setae, anterior pair distinctly longer than posterior pair. Occiput dark grey pruinose, mostly clothed with black or pale brown setae, almost bare in upper part, except for postoculars. Gena and parafacial narrow to strongly projected along lower eye margin. Antenna dark brown to black; postpedicel conical, evenly tapered to apex; stylus about $1.5 \mathrm{X}$ length of postpedicel. Palpus dark brown to black, elongate ovate, slightly longer than length of labrum, pubescent with microtrichia and bearing scattered black setulae. Proboscis 
dark brown, moderately long, approximately $2 / 3$ as long as head height, directed forward. Thorax (Fig. 211): Mesonotum greyish-brown to greyish-black. Proepisternum with 1-2 setae. Mesonotal setae black, relatively long with dorsocentrals arranged in single row per side. Notopleuron with 2 strong setae. Scutellum with 2 pairs of setae, inner pair stronger. Mesopleuron grey to greyish-brown. Halter pale. Legs: Dark brown to pale brown, with black and pale setae (pale setae noted). Foreleg: Coxa with pale setae on anterior surface. Femur slightly shorter than tibia, with posterodorsal series of short setae, 1 posteroventral preapical seta, basally with posteroventral and anteroventral series of short pale setae. Tibia slender, with short setae. Tarsus subequal in length to tibia, with short setae, tarsomere 1 slightly shorter than combined length of tarsomeres $2-5$, tarsomeres $2-4$ decreasing in length apically, tarsomere 5 subequal in length to tarsomere 3. Midleg (Fig. 215): Coxa with several pale setae on anterior surface. Trochanter with medial spine-like setal pair nearly straight, about $2 \mathrm{X}$ width of trochanter. Femur subequal in length to tibia, swollen in basal part, posterior surface with short setae on upper half, ventral surface with series of 3 spine-like posteroventral setae basally (rarely up to 8 ) and another series of 3 smaller posteroventral setae near middle, 1 prominent posteroventral preapical seta and 1 smaller anteroventral preapical seta, anterior surface with 1 longer seta near base, otherwise with short setae. Tibia modified, slightly enlarged near middle and apically, dorsal surface mainly with short setae, with longer anterodorsal and posterodorsal seta near basal $1 / 4$, ventral surface with short erect setae along distal 2/3, apex with patch of short spine-like (rarely thick) setae on anterior surface, glabrous on posterior surface. Tarsus longer than tibia, with short setae (ventral setae somewhat shorter and thicker), tarsomere 1 subequal to combined length of tarsomeres 2-4, with or without bend or notch basally, with basiventral cluster of short setae, tarsomeres 2-4 decreasing in length apically, tarsomere 5 slightly shorter than tarsomere 3. Hindleg: Coxa with 2-3 pale setae on outer surface and pale setae on anterior surface. Femur subequal in length to tibia, basal 1/3-1/2 with series of long fine pale setae dorsally and posteroventrally (setae longer than femur width), otherwise with short setae (sparse and fine on posterior surface). Tibia enlarged apically, with series of dorsal setae (subequal to tibia width), otherwise with short setae, posterior surface with cluster of erect hair-like setulae on apical 1/3 (Fig. 213), apex often with enlarged rounded posteroventral opening at articulation point with tarsomere 1. Tarsus (Fig. 213) shorter than tibia, with short setae, tarsomere 1 moderately to strongly notched near base on posterior surface with distal half slightly to greatly enlarged, subequal to combined length of tarsomeres $2-3$, tarsomeres 2-4 decreasing in length apically, tarsomere 5 subequal in length to tarsomere 3. Wing (Fig. 175): With slight grey-brown tinge, veins dark brown. Pterostigma indistinct. Anal lobe with proximal margin weakly convex. $\mathrm{R}_{2+3}$ and $\mathrm{R}_{4+5}$ parallel in middle part and diverging near apex with cell $\mathrm{r}_{2+3}$ compressed in middle part and flared at apex. $\mathrm{R}_{4+5}$ sinuous with pronounced posterior curve to apex with cell $\mathrm{r}_{4+5}$ slightly compressed in basal part. $\mathrm{R}_{4+5}$ and $M_{1}$ diverging beyond cell dm. $M_{2}$ and $M_{4}$ weakly diverging beyond cell dm. Costal section $M_{1}-M_{2}$ longer than $M_{2}-$ $\mathrm{M}_{4}$. Cell dm moderately-sized, extended to around middle of wing, distal section of vein $\mathrm{M}_{1}$ (beyond base of $\mathrm{M}_{2}$ ) longer than preceding section (between $\mathrm{r}-\mathrm{m}$ and base of $\mathrm{M}_{2}$ ). Crossvein $\mathrm{dm}-\mathrm{m}$ nearly straight and convergent with $\mathrm{M}_{1}$ distally. Abdomen (Fig. 214): Brown, with predominantly pale setae and some intermixed black setae (black setae more numerous distally on tergites and sternites. Tergites 1-6 clothed with long, dense setae laterally, setae short and sparse dorsomedially. Sternites 2-6 with pair of close-set mediolateral setae per side at posterior margin (setae stronger and darker on sternites 4 and 5), with strong posterolateral seta on sternite 5 . Sternite 5 with posterior margin projecting. Segment 7 with sternite bulging near middle, with a few minute setae on bulging area of sternite, otherwise bare. Sternite 8 large and ovoid, about $2 \mathrm{X}$ longer than wide, posterior half bulbous, setose on distal third. Hypopygium (Figs 214, 219-221): About 1/3 length of abdomen. Left epandrial lamella (Fig. 219) subrectangular, longer than high, with surstylar lobes projecting distally. Left dorsal lobe of surstylus subequal in length to cercus, broad with truncate apex, with setae on dorsal margin and apically. Left ventral lobe of surstylus long, broad basally, tapering to pointed apex, with strong lateral seta at base and pair of preapical setae on dorsal margin (lobe flexed down in illustrated specimen). Left ventral lobe of surstylus broad basally with strong lateral seta; apical portion with pair of setae on posterior margin and tapered ventral projection with notched tip. Right epandrial lamella (Fig. 220) subrectangular, longer than high, with surstylar lobes projecting distally. Right dorsal lobe of surstylus longer than cercus, broad with rounded apex, with several setae on lateral surface. Right middle lobe of surstylus broad with rounded apex, shorter than dorsal lobe, with ventral projected seta on medial surface. Right ventral lobe of surstylus narrow and elongate, curved right, with pair of setae basally. Hypandrium with base enlarged, bulbous and strongly produced anteriorly, with single large seta on each side of basal part. Medial hypandrial prolongation (Fig. 221) long and broad, widening apically, with distal pair of setae close-set and projecting laterally from right margin. Left hypandrial lobe short with rounded apex, covered by ventral lobe of surstylus. Right hypandrial lobe elongate, 
tapered apically and curved to right, surface spinose. Postgonite with dorsal postgonite lobes not substantially developed. Left ventral postgonite lobe long and broad with rounded apical margin. Right ventral postgonite lobe short with acute apex. Postgonite apodeme weakly developed, short and shallowly U-shaped in ventral view. Phallus slender, curved dorsally and to right, subequal in length to right hypandrial lobe. Ejaculatory apodeme short. Left and right cercus with hump-like base bearing several setae and narrow digitiform apex bearing long apical seta.

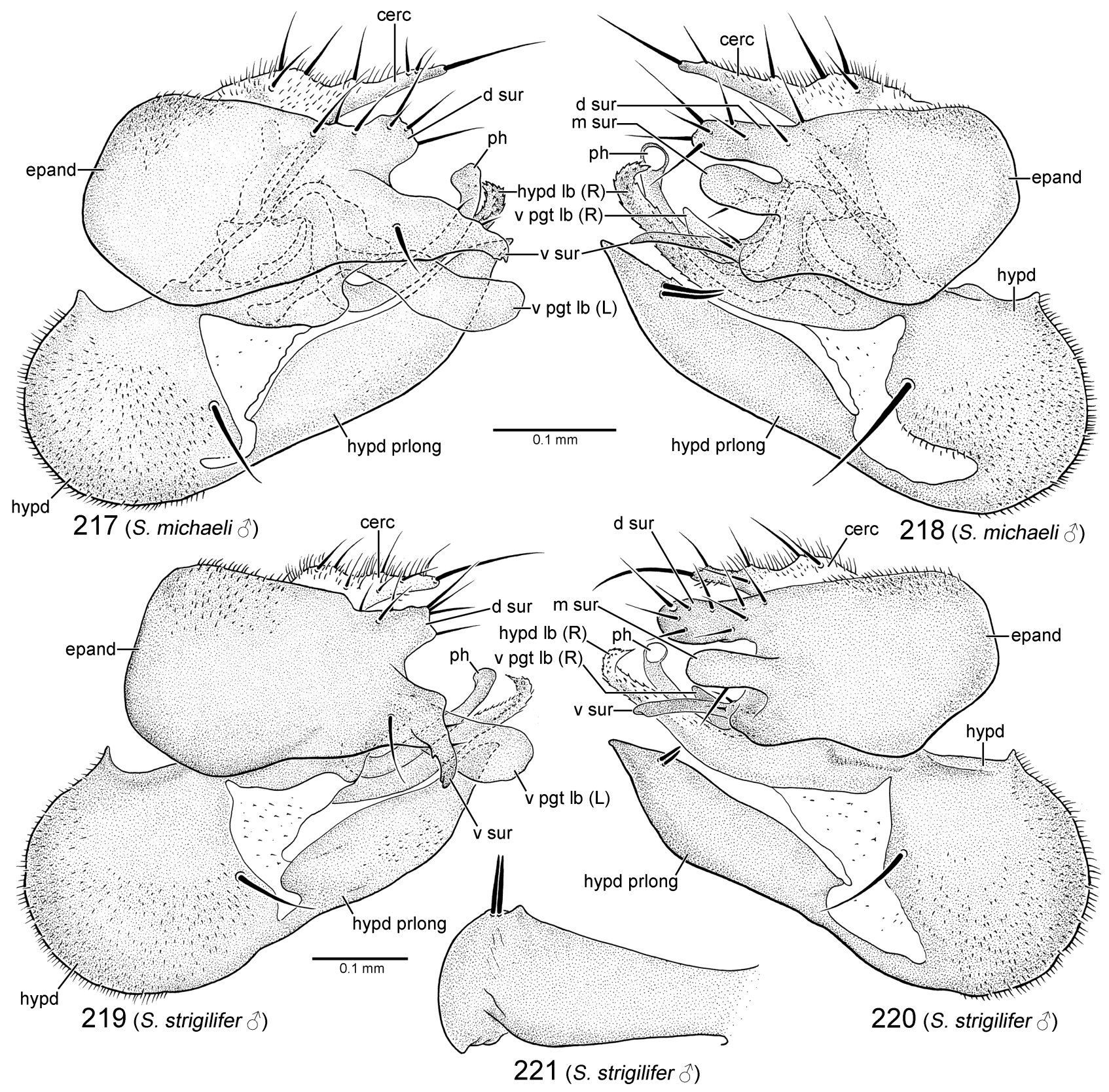

FIGURES 217-221. Hypopygia of Nearctic Schistostoma. 217. S. michaeli sp. nov., left lateral view. 218. S. michaeli sp. nov., right lateral view. 219. S. strigilifer (Melander) comb. nov., left lateral view. 220. S. strigilifer (Melander) comb. nov., right lateral view. 221. Hypandrial prolongation of S. strigilifer (Melander) comb. nov., ventral view. Figures 217 and 218 based on specimen CNC1155646 (Incline Village, Nevada). Figures 219-221 based on specimen CNC1155645 (Valley of the Falls, California). Abbreviations: cerc — cercus; d sur — dorsal lobe of surstylus; epand —epandrium; hypd—hypandrium; hypd lb— hypandrial lobe; hypd prlong — hypandrial prolongation; (L)—left; m sur — middle lobe of surstylus; ph—phallus; (R) — right; v pgt lb—ventral postgonite lobe; v sur — ventral lobe of surstylus.

Female (Fig. 212): Body length 1.9-2.6 mm, wing length 2.1-2.4 mm. Similar to male except as follows: Head (Fig. 212): Compound eye without demarcation line between dorsal and ventral ommatidia. Gena and parafacial distinctly projected along lower eye margin. Thorax (Fig. 212). Legs: With shorter, unspecialized setae. Midleg: 
Trochanter without spine-like setal pair; femur, tibia and tarsomere 1 unmodified and lacking specialized setae. Hindleg: Femur with dorsal series of pale setae shorter, posteroventral series not developed; tibia not enlarged apically; tarsomere 1 without notch, not enlarged. Wing: Pterostigma absent. Anal lobe slightly smaller, proximal margin straight. Abdomen: Tergites and sternites with short setae. With 6 exposed abdominal segments, segment 6 concolorous with anterior abdominal segments. Terminalia (similar to Figs 99, 100, 104): Segment 6 with tergite and sternite subrectangular (wider than long), tergite and sternite setose on posterior half with setae distinctly stronger on posterior margin (especially on tergite). Segment 7 with tergite subrectangular (wider than long) with moderately developed anteromedial emargination, with small posterolateral seta, sternite subrectangular (wider than long) with setae on posterior margin, tergite and sternite with short band-like posterior sclerite extension on each side. Tergite 8 undivided, darkened along edge of anteromedial emargination, with small posterolateral seta, narrowly fused to sternite 8 anterolaterally. Sternite 9 desclerotized and inconspicuous. Spermatheca spherical. Syntergite $9+10$ with hemitergites subrectangular, each with 3 acanthophorite spines. Sternite 10 with short setose lateral lobe below cercus (about half length of cercus), sternite produced posteromedially bearing setulae and 3 adjacent short setae per side, anterolaterally with band-like extension to base of lateral lobe and cercus. Cercus with curved claw-like apex, with several small setae near midlength.

Distribution and seasonal occurrence. Schistostoma strigilifer is known from Storey County in western Nevada and from numerous localities in California, from Contra Costa and Placer Counties in the north to San Diego County in the south (Fig. 237). Adults have been collected from mid-March to late June.

Remarks. Melander (1940b) mentions five males in the type series; however, six males are deposited in the USNM, including four from Valley of the Falls collected by Timberlake, and one from Forest Home collected by Melander, all taken on 25.v.1935. None of these males bear original type labels, and we consider all six specimens to be part of the type series.

Both males and females of $S$. strigilifer show variation in development of the gena and parafacial along the lower eye margin, ranging from strongly projected (e.g., in the type series) to less projected (e.g., in the specimens from Largo Vista Rd). Males also show variation in the development of the notch on tarsomere 1 of the hindleg (Fig. 213), which seems to be positively correlated with the projection of the gena and parafacial (i.e., stronger notch correlated with stronger projection of gena and parafacial). Further variation is seen in the male from Cedar Hill Canyon, Nevada, which has additional ventral spines on the mid femur and stout spine-like setae anteriorly near the apex of the mid tibia. All this variation suggests that the current concept S. strigilifer may comprise a complex of species, which will require further study to elucidate.

Pollen grains have been found in the gut of a dissected female of S. strigilifer. Flower visitation records for this species are listed in Table 1.

\section{Schistostoma sycophantor (Melander)}

(Figs 14, 176, 222-230, 238)

Holoclera sycophantor Melander, 1902: 334.

Anthalia sycophantor (Melander, 1902): Coquillett (1903: 263).

Microphorus sycophantor (Melander, 1902): Melander (1928: 92).

Schistostoma sycophantor (Melander, 1902): Chvála (1987: 137).

Type material examined. LECTOTYPE (here designated to fix the identity of the species), of collected from Moscow [ca 46 $46^{\circ} \mathrm{N} 116^{\circ} 52^{\prime} \mathrm{W}$ ], Latah County, Idaho, USA, by J.M Aldrich, labelled: "Moscow/ Idaho"; W.M. Wheeler/ Collection"; "TYPE/ No./ A.M.N.H. [red label]"; “Am. Mus. Nat. Hist./ Dept. Invert. Zool./ No. 986"; "LECTOTYPE/ Holoclera/ sycophantor Melander/ des. Brooks \& Cumming 2022 [red label]" (USNM). PARALECTOTYPES: USA: Idaho: Latah County: Same data as lectotype (2 $\hat{\partial}, \mathrm{AMNH} ; 4 \hat{\jmath}$, USNM); same data as lectotype except, 20.vi.1901 (1ð, USNM). See "Remarks".

Other material examined. CANADA: Alberta: Burmis [ca 49 $\left.33^{\prime} \mathrm{N} 114^{\circ} 17^{\prime} \mathrm{W}\right]$, 15.vi.1962, K.C. Hermann

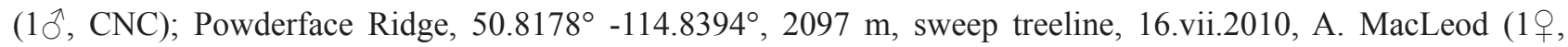

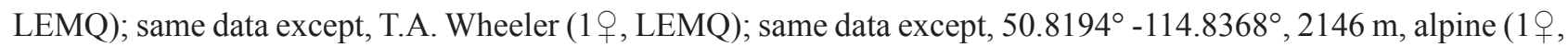
LEMQ); Powderface Trail, 50.9198 $-114.9213^{\circ}, 1759 \mathrm{~m}$, sweep meadow, 15.vii.2010, T.A. Wheeler (1 , LEMQ);

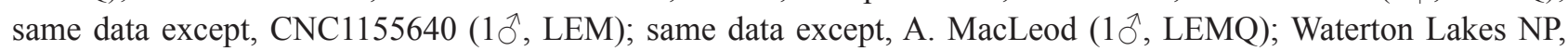


$49^{\circ} 6^{\prime} 13.02^{\prime \prime} \mathrm{N} 113^{\circ} 57^{\prime 2} 2.34^{\prime \prime} \mathrm{W}, 1425 \mathrm{~m}$, meadow, 5.vii.2005, Goulet \& Boudreault (1今, CNC); Waterton Lakes NP,

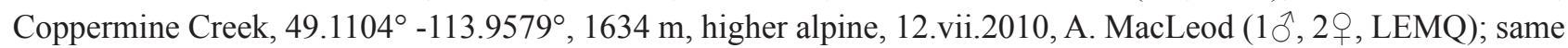
data except, T.A. Wheeler (2犬̂, $5 \hat{\jmath}$, LEMQ); same data except, $49.1066^{\circ}-113.9600^{\circ}, 1509 \mathrm{~m}$, sweep alpine, 12.vii.2010, A. MacLeod (3, LEMQ); Waterton Lakes NP, Red Rock Parkway, 49.0996 $-113.9061^{\circ}, 1390 \mathrm{~m}$, 8.vii.2010, sweep meadow, A. MacLeod (1ㅇ, LEMQ); same data except, T.A. Wheeler (2ㅇ, LEMQ); Waterton Lakes NP, Rowe Creek, 49.0609 -114.0188, 1722m, swp alpine, 10.vii.2010, A. MacLeod (3 $0^{\top}, 4 \odot$, LEMQ); same data except, swp alpine mdw, T.A. Wheeler (4 $\partial^{\lambda}, 3$, LEMQ); Waterton Lakes NP, Ruby Ridge, (higher), $49.0706^{\circ}$ $-114.0081,1800 \mathrm{~m}$, alpine swp, 8.vii.2010, A. MacLeod (2今, 19, LEMQ); same data except, $49.0683^{\circ}-114.0082$,

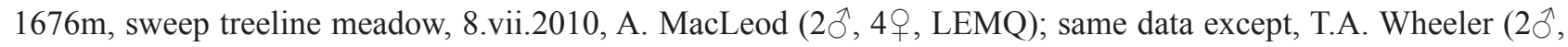
5+, LEMQ). British Columbia: Hedley [ca 49 $21^{\prime} \mathrm{N} 120^{\circ} 04^{\prime} \mathrm{W}$ ], Nickel Plate, 5000', 13.vii.1953, J.R. McGillis

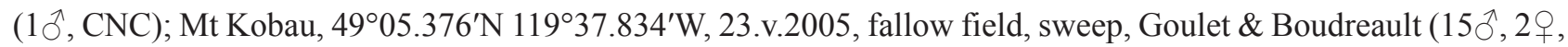
CNC); Osoyoos, Mt Kobau [ca 4905’N 119³7’W], 990 m, 31.v.1991, D. Blades, C. Maier, SOCAP-OT1C2 (3 ${ }^{\prime}$, RBCM); same data except, 29.v-3.vi.1991, SOCAP-MA1 (1 ${ }^{\Uparrow}$, RBCM); same data except, 31.v-3.vi.1991, SOCAP-

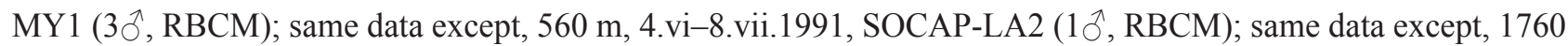

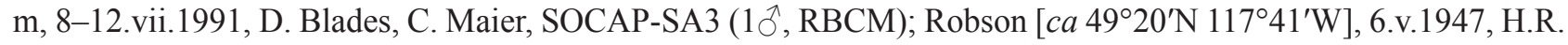

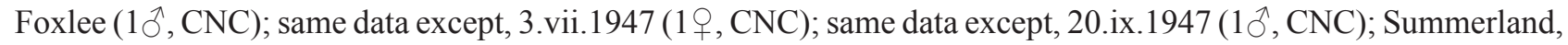
$49^{\circ} 33.839^{\prime} \mathrm{N} 119^{\circ} 39.034^{\prime} \mathrm{W}, 22 . v .2005$, fallow field, Goulet \& Boudreault (1へ̂, CNC); White Lake, Oliver [ca $\left.49^{\circ} 10^{\prime} \mathrm{N} 119^{\circ} 33^{\prime} \mathrm{W}\right], 28 . v .1959$, R.E. Leech (20, CNC). Manitoba: Aweme, Criddle homestead, 49 $42^{\prime} 34^{\prime \prime} \mathrm{N}$ 99 $34^{\prime} 58^{\prime \prime} \mathrm{W}$, 24.vii.2007, mixed grass prairie, sweep, H. Goulet (4خ, CNC). Saskatchewan: W of Estevan, Hwy $39,49^{\circ} 10.279^{\prime} \mathrm{N} 103^{\circ} 03.370^{\prime} \mathrm{W}$, 3.vi.2007, $585 \mathrm{~m}$, alfalfa + grass, Goulet, Boudreault, Fernandez ( $\left.1 \mathrm{O}^{\top}, \mathrm{CNC}\right)$. USA: California: Alpine County: West Fork Carson River, Snowshoe Springs Campground [ca $38^{\circ} 46^{\prime} \mathrm{N} 119^{\circ} 53^{\prime} \mathrm{W}$ ], 6600 ft, 19.vi.1971, P.H. \& M. Arnaud (2`, USNM); El Dorado County: South Lake Tahoe [ $\left.c a 38^{\circ} 56^{\prime} \mathrm{N} 119^{\circ} 58^{\prime} \mathrm{W}\right]$,

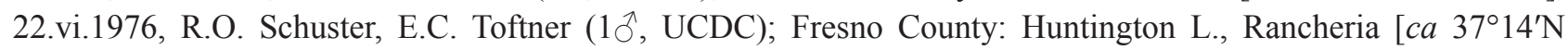

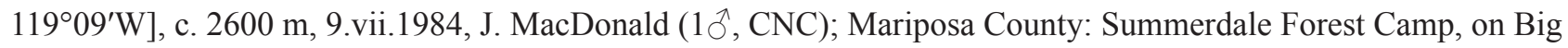

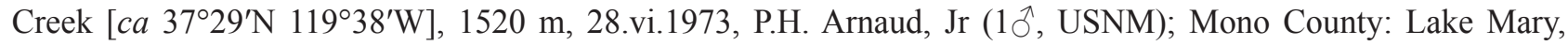

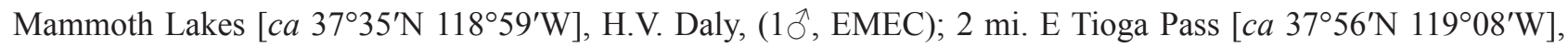
23.vii.1982, N.J. Smith $\left(2{ }^{\wedge}, 2\right.$,, UCDC); Tioga Pass-Hall Area site [ca $\left.37^{\circ} 56^{\prime} \mathrm{N} 119^{\circ} 08^{\prime} \mathrm{W}\right]$, on Horkelia fusca,

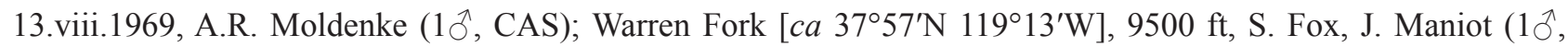

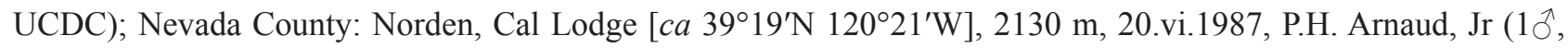

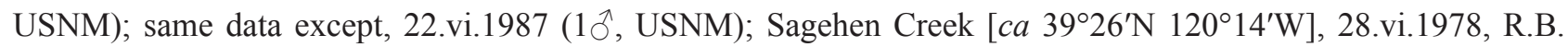

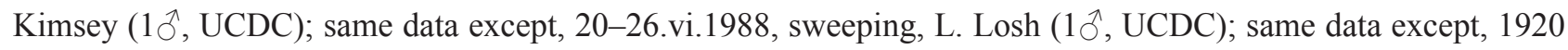

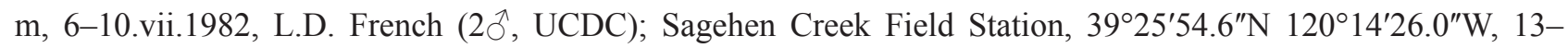
19.vii.2012, Malaise, J.M. Cumming \& S.E. Brooks (2, CNC); Sagehen Creek Field Station, Big Culvert along

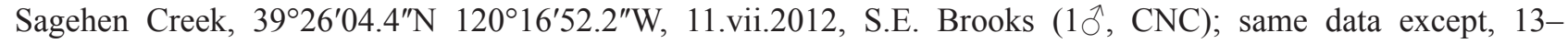
15.vii.2012, YPT, J.M. Cumming \& S.E. Brooks (1§ึ, 5우 CNC); same data except, 15-17.vii.2012 (1 , CNC); same data except, 17-19.vii.2012 (19, CNC); same data except, 11-17.vii.2012, Malaise, J.M. Cumming, S.E.

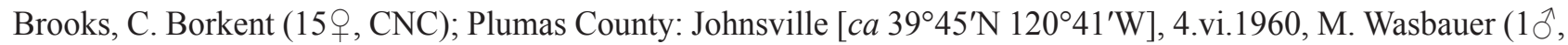
CSCA); Siskiyou County: Ash Creek Ranger Station, 9 mi. E McCloud [ $c a 41^{\circ} 15^{\prime} \mathrm{N} 121^{\circ} 57^{\prime} \mathrm{W}$ ], $3500 \mathrm{ft}$, 7-9.vi.1974,

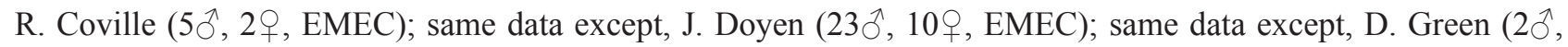

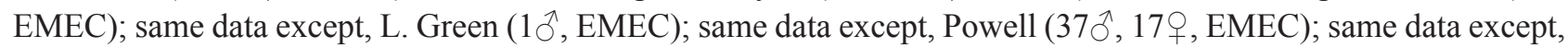

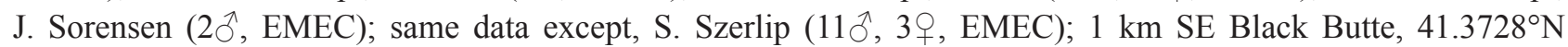
$122.324^{\circ} \mathrm{W}, 1353 \mathrm{~m}$, sweep open pine forest, 6.vi.2009, J. Mlynarek (2 $0^{\top}, 4 \%$, LEMQ); Jct. Forest Service Rds

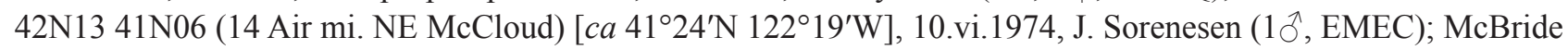
Springs [ $c a 41^{\circ} 21^{\prime} \mathrm{N} 122^{\circ} 17^{\prime} \mathrm{W}$ ], $5200 \mathrm{ft}, 10-14 . v i .1974$, J. Doyen (8ว’, EMEC); Mt Shasta City [ca $41^{\circ} 18^{\prime} \mathrm{N}$ $122^{\circ} 18^{\prime} \mathrm{W}$ ], 2.vii.1958, Eriogonum nudum, J. Powell (1 $\widehat{O}^{\top}$, EMEC); Mt Shasta, Panther Meadows [ca $41^{\circ} 21^{\prime} \mathrm{N}$ $122^{\circ} 12^{\prime} \mathrm{W}$ ], $7400 \mathrm{ft}$, 9.viii.1967, P.H. Arnaud, Jr (10, USNM); same data except, 7500 ft, 8.vii.1968, B.V. Peterson

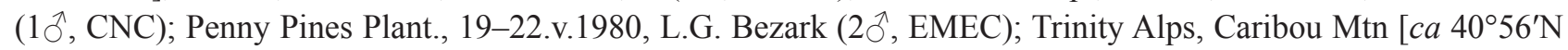
$122^{\circ} 56^{\prime} \mathrm{W}$ ], 6300-7000 ft, 9.vii.1969, J. Powell (2 ${ }^{`}$, EMEC); Trinity County: Deer Creek [ca 40 $51^{\prime} \mathrm{N} 122^{\circ} 53^{\prime} \mathrm{W}$ ],

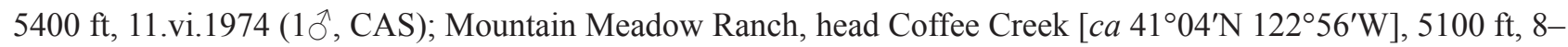
10.vii.1969, Ceanothus integerrimus, J. Powell (11 $\hat{0}, 5$ ㅇ, EMEC); Tuolumne County: Columns of the Giants [ca $\left.38^{\circ} 20^{\prime} \mathrm{N} 119^{\circ} 48^{\prime} \mathrm{W}\right]$, Hwy 108, 1830 m, 2.vii.1977, at flower of Ceanothus cordulatus Kell. (Snow Bush), P.H.

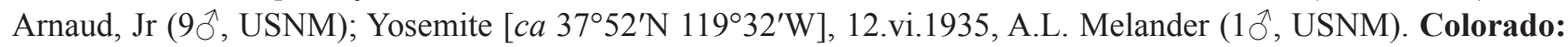




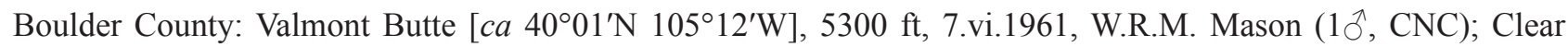

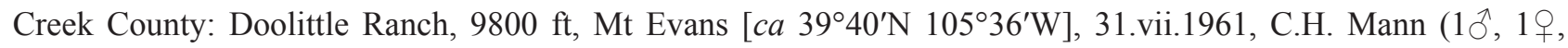

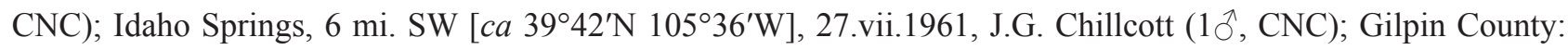
Kelly-Dahl, south of Nederland [ $c a 3^{\circ} 55^{\prime} \mathrm{N} 105^{\circ} 29^{\prime} \mathrm{W}$ ], $2615 \mathrm{~m}$, 4.viii.1973, sweeping herbage, P.H. Arnaud, Jr

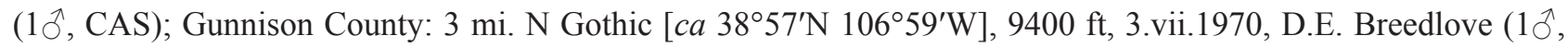
CAS); Rocky Mountain Biological Laboratory, Gothic [ca 38 $\left.57^{\prime} \mathrm{N} 106^{\circ} 59^{\prime} \mathrm{W}\right]$, 27.vi.1988, Malaise, G. Eickwort $\left(2 \hat{\jmath}, 1\right.$ ㅇ, CUIC); Whiterock Rd, 38.8574 $-107.0551^{\circ}, 2952 \mathrm{~m}$, sweep alpine meadow, A. MacLeod $(115 \hat{\jmath}, 12$, LEMQ); same data except, T.A. Wheeler (550^, 11 + , LEMQ); Hinsdale County: West Fork Cebolla Creek, $37^{\circ} 57^{\prime} 37^{\prime \prime} \mathrm{N} 107^{\circ} 10^{\prime} 42^{\prime \prime} \mathrm{W}, 10454 \mathrm{ft}, 16 . v i .2017$, S.H. Cumming (1 $\left.{ }^{\wedge}, \mathrm{CNC}\right)$; Jefferson County: Golden [ca 39 $45^{\prime} \mathrm{N}$ $105^{\circ} 14^{\prime} \mathrm{W}$ ], 17.vi.1940, A.L. Melander (1 $\widehat{\partial}^{\wedge}$, USNM). Idaho: Boundary County: Moyie Springs [ca $48^{\circ} 43^{\prime} \mathrm{N}$

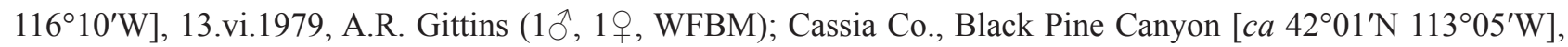
$5400 \mathrm{ft}, 4-12 . v i .1974$, Malaise (2へ, CAS; $10 \AA$, 7 , LACM); same data except, 4.vi.1974, G.E. Bohart (1 + , CAS);

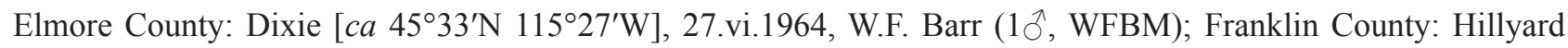

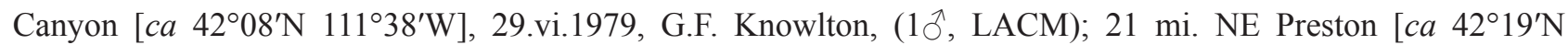

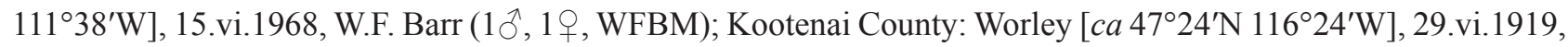

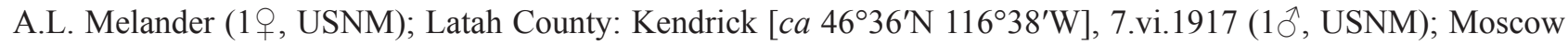
[ca 46 $\left.48^{\prime} \mathrm{N} 116^{\circ} 52^{\prime} \mathrm{W}\right]\left(10^{\top}, 3\right.$ \% , USNM); same data except, 20.vi.1901 (2ㅇ, USNM); same data except, 3.vii.1912,

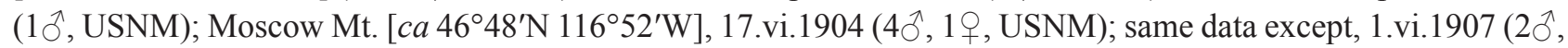
USNM); same data except, 13.vii.1907 (1ㅇ, USNM); same data except, 2.vii.1911 (10ิ, 2ᄋ, EMEC); same data except, 2.vii.1911 (10§, USNM); same data except, 6.vii.1912 (4ㅇ, USNM); same data except, 4.vii.1915, A.L. Melander (2ᄋ, USNM); same data except, 4.vii.1916 (1 $\circ$, USNM); same data except, 24.vi.1919 (3ð, 1, USNM);

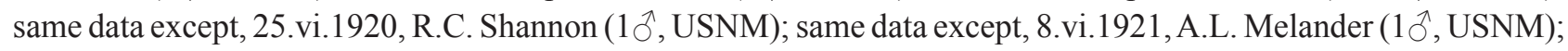

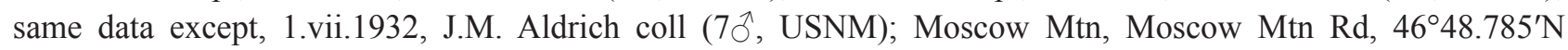
$116^{\circ} 53.871^{\prime} \mathrm{W}, 1250 \mathrm{~m}, 16 . v i .2014$, ex. ridge trail, B.J. Sinclair (17ð̊, 6ㅇ, CNC); Moscow Mts, West Twin Peak, ca.

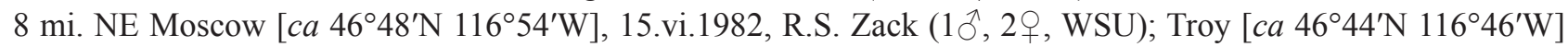

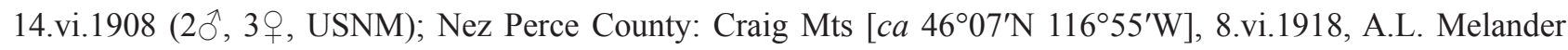
(10 $0^{\lambda}, 4$, USNM; 1 , CUIC); Lake Waha [ca $\left.46^{\circ} 12^{\prime} \mathrm{N} 116^{\circ} 50^{\prime} \mathrm{W}\right]$, 9.vi.1918, A.L. Melander (7 ${ }^{\lambda}, 1+$, USNM);

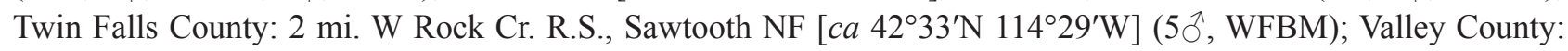
NFD 22, $33.6 \mathrm{~km}$ E Cascade, $44.6333^{\circ}-115.7241^{\circ}$, 19.vi.2009, G.W. Forister (10ㅅ, 5ㅇ, UCDC). Montana: Lewis \& Clark County: Lewis \& Clark NF nr Cyanide Mountain, $47.4109^{\circ}-112.7116^{\circ}, 1601 \mathrm{~m}$, sweep alpine, 7.vii.2010,

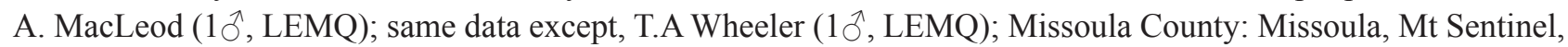

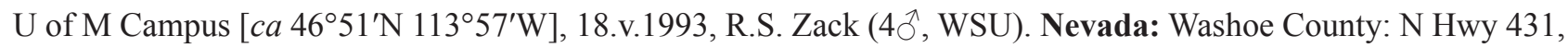
NF-051, 2806 m, 39.30812 $-119.9234^{\circ}$, 2.vii.2012, G.W. Forister (1 ${ }^{\circ}, 1$, $q$, UCDC). Oregon: Clackamas County: Mt Hood [ $c a 4^{\circ} 18^{\prime} \mathrm{N} 121^{\circ} 49^{\prime} \mathrm{W}$ ], 25.vi.1935, $5000 \mathrm{ft}$, A.L. Melander (7ð’, USNM); Hood River County: Hood

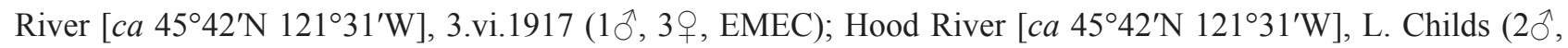
USNM); same data except, 6.vi.1917, L. Childs (10, USNM); Linn County: 23 mi. E Cascadia [ca $44^{\circ} 23^{\prime} \mathrm{N}$

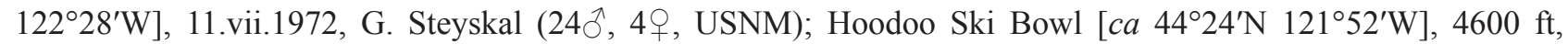

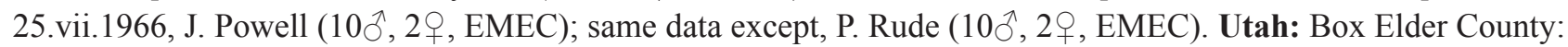
Willard Peak Rd, Perry Reservoir [ca $41^{\circ} 25^{\prime} \mathrm{N} 111^{\circ} 57^{\prime} \mathrm{W}$ ], 14.vii.1983, W.J. Hanson (10َ, LACM); Cache County:

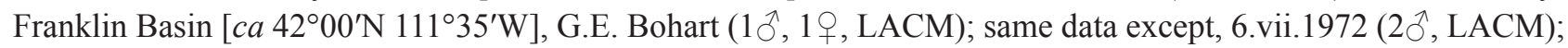

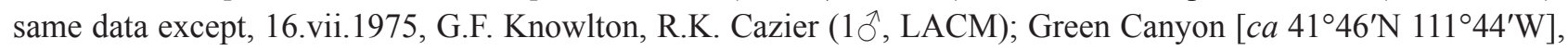
28-31.v.1985, W.J. Hanson (2m, 19, LACM); same data except, 1-7.vi.1985 (10, LACM); same data except, 1519.vi.1985 (2ᄋ, LACM); Logan Canyon [ca 41 ${ }^{\circ} 56^{\prime} \mathrm{N} 111^{\circ} 29^{\prime}$ W], 21.vi.1976, G.F. Knowlton (1 ${ }^{\lambda}$, LACM); same data except, sum., 27.vi-3.vii.1980, Malaise trap (10, 2ᄋ, LACM); same data except, 16-23.vii.1982, W.J. Hanson

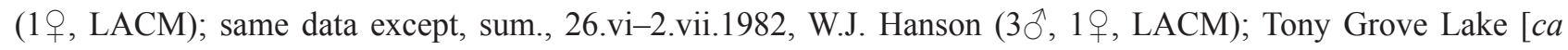
$\left.41^{\circ} 53^{\prime} \mathrm{N} 111^{\circ} 38^{\prime} \mathrm{W}\right]$, 2.vii.1983, G.F. Knowlton (19, LACM); same data except, 12-19.vii.1983, Malaise trap, W.J. Hanson (1 9 , LACM); same data except, $21 \mathrm{~km}$ WSW Garden City, 2460 m, 28.vii.1993, R.M. Bohart (2へ̂, UCDC);

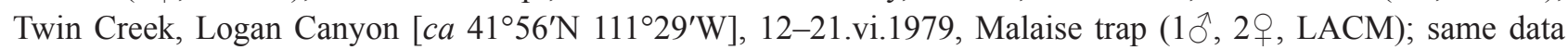
except, 1-6.vii.1979 (1 $0^{\top}, 2$,, LACM); Wellsville Mts, trail E Stewart Pass [ $\left.c a 41^{\circ} 40^{\prime} \mathrm{N} 112^{\circ} 01^{\prime} \mathrm{W}\right], 7200-8200 \mathrm{ft}$,

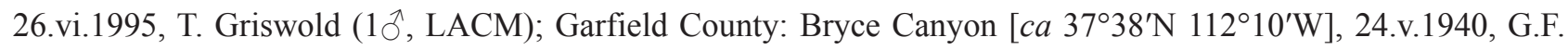

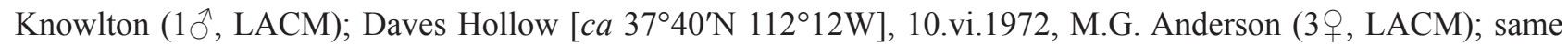

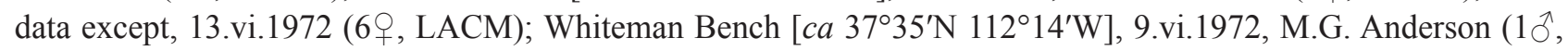


LACM); Rich County: Logan Canyon summit [ $c a 4^{\circ} 56^{\prime} \mathrm{N} 111^{\circ} 28^{\prime} \mathrm{W}$ ], Malaise trap, 11-21.vii.1980 (1 9 , LACM); same data except, 21-23.vii.1980 (1 , LACM); same data except, 26.vi-2.vii.1982, Malaise trap (4ðิ, 19, LACM); same data except, 2-8.vii.1982 (3 $\widehat{\jmath}, 4$, , LACM); same data except, 8-16.vii.1982 (2ㅇ, LACM); same data except,

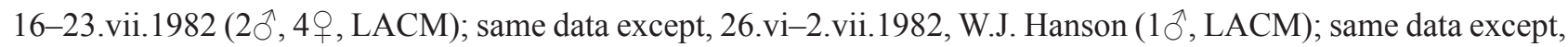

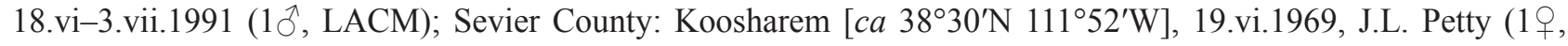

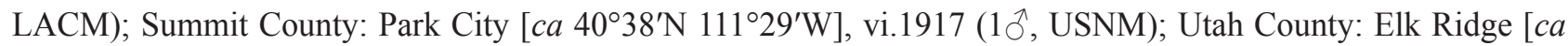

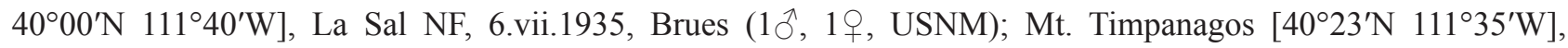

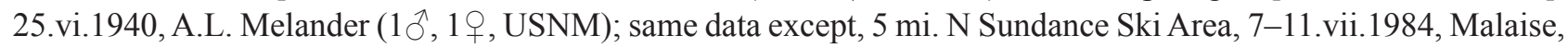
C.R. Nelson (5 ${ }^{\wedge}$, BYU); Wasatch County: Daniel's Pass [ca 40 $\left.18^{\prime} \mathrm{N} 111^{\circ} 15^{\prime} \mathrm{W}\right]$, 12.viii.1975, G.E. Bohart (1우, LACM); 15 mi. N Wallsburg [ca 40 $23^{\prime} \mathrm{N} 111^{\circ} 25^{\prime} \mathrm{W}$ ], 30.vi.1970, J.L. Petty (1ㅇ, LACM); Weber County: Monte Cristo [ $\mathrm{ca} 41^{\circ} 20^{\prime} \mathrm{N} 111^{\circ} 36^{\prime} \mathrm{W}$ ], 19.vi.1972, G.F. Knowlton (1 ${ }^{\circ}$, LACM). Washington: Adams County: Paha Coulee $\mathrm{nr}$ Lind [ $c a 4^{\circ} 58^{\prime} \mathrm{N} 118^{\circ} 34^{\prime} \mathrm{W}$ ], $1550 \mathrm{ft}, 16 . v .1991$, S.D. Gaimari (3 ${ }^{\lambda}, 1$ ㅇ, WSU); Asotin County: 4 mi. S Anatone, Fields Spring SP [ca $\left.46^{\circ} 05^{\prime} \mathrm{N} 117^{\circ} 10^{\prime} \mathrm{W}\right]$, 30.vi.1975, on Physocarpus capitatus, J. Powell (1 $\widehat{O}^{\wedge}$, EMEC); 4 mi. S Anatone, nr Fields Spring SP, 3600 ft, 10.vi.1980, sweep, W.J. Turner (10ิ, 19, WJTC); 5 mi. S Anatone, Fields

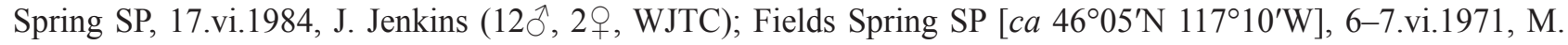

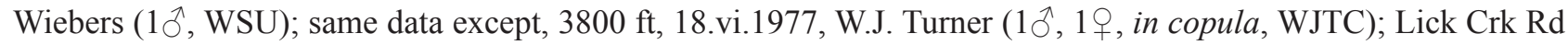
ca. 12 mi. SW Asotin [ $c a 46^{\circ} 15^{\prime} \mathrm{N} 117^{\circ} 18^{\prime} \mathrm{W}$ ], 24.v.1987, R.S. \& V.L. Zack (2 ${ }^{\prime}$, WSU); Benton County: Hanford Site, ALE, radio telescope, $46^{\circ} 23.549^{\prime} \mathrm{N} 119^{\circ} 35.125^{\prime} \mathrm{W}$, 23.v.1995, R.S. Zack (2犬̂', WSU); same data except,

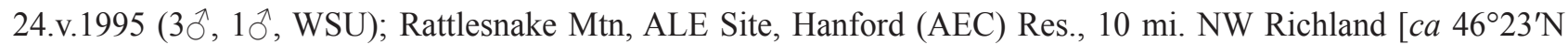
$\left.119^{\circ} 34^{\prime} \mathrm{W}\right], 3000 \mathrm{ft}, 10 . v i .1976$, N.E. Woodley (4⿳⺈, USNM); Chelan County: 5 mi. SSW Wenatchee, Squillchuck

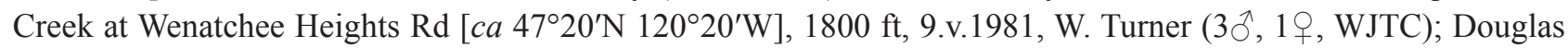
County: Rt 2, 17.4 mi. W Coulee City [ $c a 7^{\circ} 32^{\prime} \mathrm{N} 11^{\circ} 28^{\prime} \mathrm{W}$ ], 4.v.1989, R.S. Zack (10, WSU); Klickitat County:

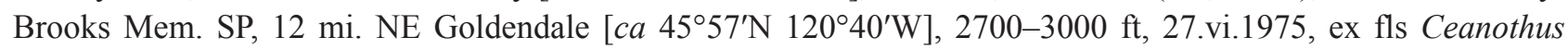

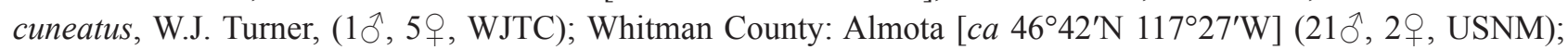

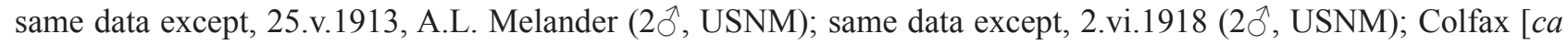

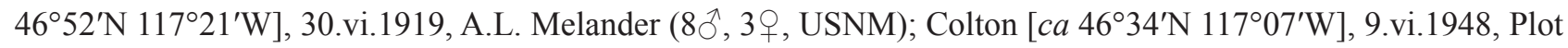

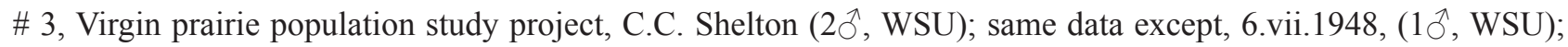
same data except, 25.vi.1960, W.W. Cone, Festuca/Symphor. (1 ${ }^{\wedge}$, WSU); 3 mi. SW Colton [ca $46^{\circ} 32^{\prime} \mathrm{N} 117^{\circ} 11^{\prime} \mathrm{W}$ ],

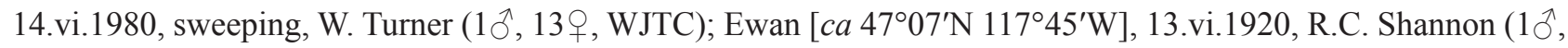

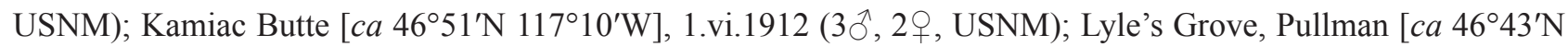

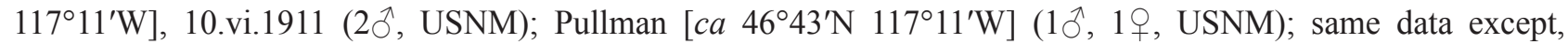

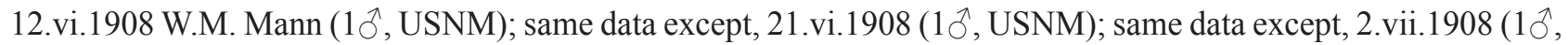

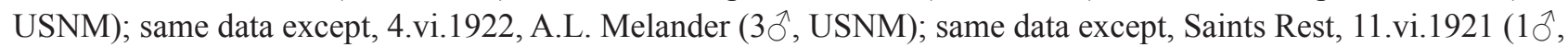
1, USNM); Steptoe Butte [ca $47^{\circ} 02^{\prime} \mathrm{N} 117^{\circ} 18^{\prime} \mathrm{W}$ ], ca. 4 mi. NE Steptoe, 11.vi.1989, R.S. Zack (10 ${ }^{\jmath}, 4 \uparrow$, WSU);

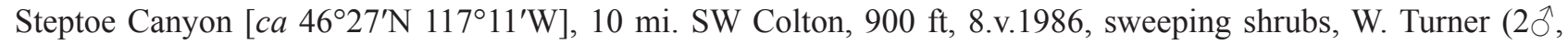

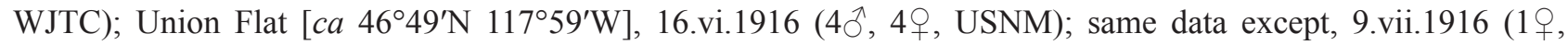

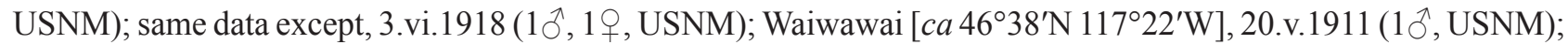

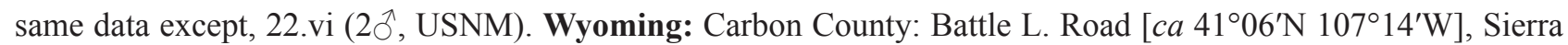
Madre Range, 8000 ft, 18.vii.1961, B.H. Poole (3 ${ }^{\wedge}, 1$ ㅇ, CNC); Teton County: Teton Pass [ca $43^{\circ} 29^{\prime} \mathrm{N} 110^{\circ} 57^{\prime} \mathrm{W}$ ], E side, 74-8400 ft, 16.vii.1961, J.G. Chillcott (2犬, 19, CNC).

Diagnosis. Males of this species are distinguished from other members of the $S$. ravidum species group by the series of long fine posterior setae on the fore tibia (Fig. 225), dark body and legs (Fig. 222), abdominal sternite 5 with short inner seta and longer thicker outer seta, apically expanded dorsal surstylar lobes (Figs 227, 229, 230), and flared phallus tip, as indicated in the key (couplets 18 and 20). Females are characterized by their dark body and legs, normal wing cell dm (similar to Fig. 176), antennal stylus length (2X postpedicel length), and projecting gena and parafacial (Fig. 228). Schistostoma sycophantor is very similar to $S$. heatherae sp. nov., but can be distinguished by its slightly longer antennal stylus, chaetotaxy of male abdominal sternite 5 , apically expanded surstylar lobes and other hypopygial features provided in couplet 20 of the key.

Redescription. Male (Figs 176, 222-227, 229, 230): Body length 2.0-2.5 mm, wing length 2.1-2.2 mm. Head (Figs 223, 224): Compound eye with demarcation line anteriorly between larger dorsal and smaller ventral ommatidia. Ocellar tubercle with 2 pairs of black proclinate setae, anterior pair distinctly longer than posterior pair. Occiput dark grey pruinose, mostly clothed with black or brown setae, almost bare in upper part, except for postoculars. 

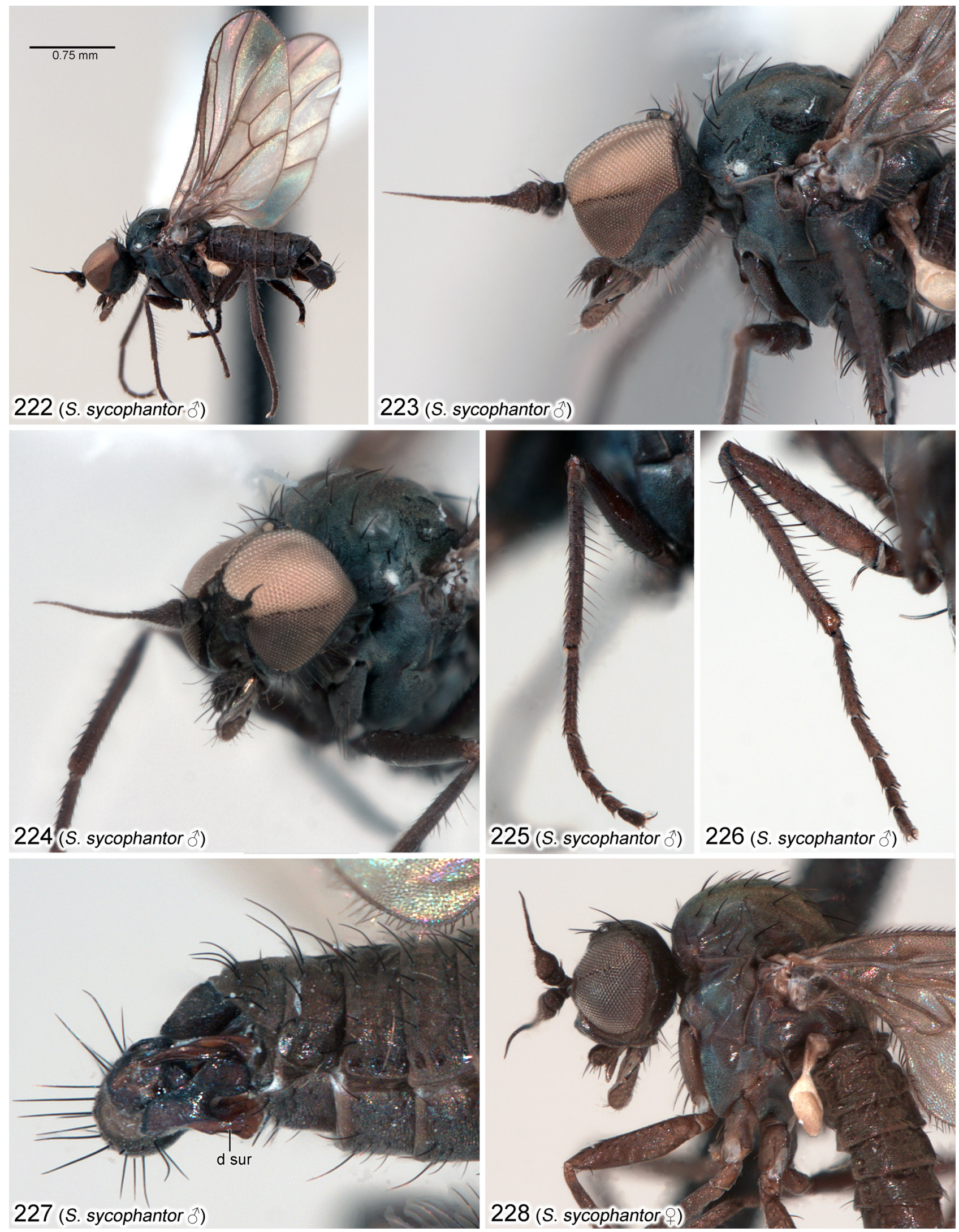

FIGURES 222-228. Habitus, head, male legs and male abdomen of Schistostoma sycophantor (Melander). 222. Male habitus. 223. Male head and thorax, lateral view. 224. Male head and thorax, oblique view. 225. Male left foreleg, posterodorsal view. 226. Male left midleg, posterior view. 227. Male abdomen and terminalia, right lateral view. 228. Female head and thorax, lateral view. Specimens from: Mt Kobau, British Columbia (Figs 222-225); Whiterock Rd, Colorado (Fig. 226); Moscow Mtn, Idaho (Fig. 227); Sagehen Creek, California (Fig. 228). Abbreviation: d sur-dorsal lobe of surstylus. 


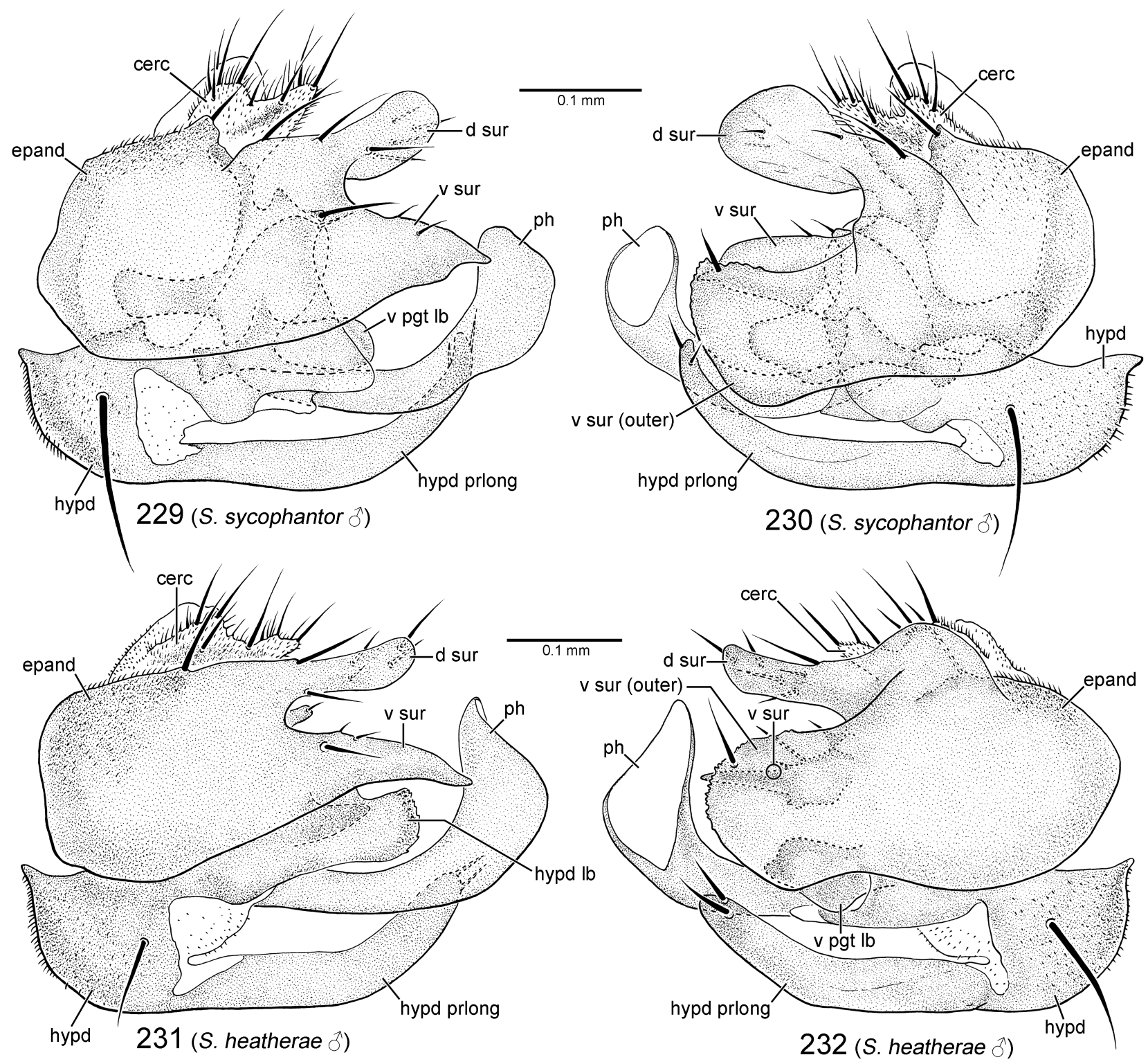

FIGURES 229-232. Hypopygia of Nearctic Schistostoma. 229. S. sycophantor (Melander), left lateral view. 230. S. sycophantor (Melander), right lateral view. 231. S. heatherae sp. nov., left lateral view. 232. S. heatherae sp. nov., right lateral view. Figures 229 and 230 based on specimen CNC1155640 (Powderface Trail, Alberta). Figures 231 and 232 based on specimen CNC1155644 (Medora, North Dakota). Abbreviations: cerc — cercus; d sur — dorsal lobe of surstylus; epand — epandrium; hypd — hypandrium; hypd lb — hypandrial lobe; hypd prlong — hypandrial prolongation; ph—phallus; v pgt lb_-ventral postgonite lobe; v surventral lobe of surstylus.

Gena and parafacial narrow along lower eye margin. Antenna dark brown to black; postpedicel conical, evenly tapered to apex; stylus about 2.0X length of postpedicel. Palpus black, elongate ovate, slightly longer than length of labrum, pubescent with microtrichia and bearing scattered black setulae. Proboscis dark brown, approximately $1 / 2$ as long as head height, directed forward. Thorax (Figs 222-224): Mesonotum brownish-grey to greyish-black. Proepisternum with 1-2 setae. Mesonotal setae black, relatively long with dorsocentrals arranged in single row per side. Notopleuron with 2-3 strong setae. Scutellum with 2 pairs of setae, inner pair stronger. Mesopleuron greyishblack. Halter light brown to pale. Legs: Entirely dark brown to blackish, with black setae. Foreleg: Coxa with several setae on anterior surface. Femur subequal in length to tibia, with short setae, dorsal setae longer, 1 prominent posteroventral preapical seta. Tibia slender, with somewhat irregular series of fine erect setae along posterior surface (setae about $3 \mathrm{X}$ tibia width in anterior view), otherwise with short setae. Tarsus subequal in length to tibia, with short setae, tarsomere 1 subequal to combined length of tarsomeres 2-4, tarsomeres 2-4 decreasing in length apically, 
tarsomere 5 subequal in length to tarsomere 3. Midleg (Figs 225, 226): Coxa with several setae on anterior surface. Trochanter with medial spine-like setal pair curved, about $2 X$ longer than width of trochanter, setae slender. Femur slightly shorter than tibia, posterior surface with short setae on upper part, ventral surface with series of about 6 prominent posteroventral setae (middle setae longer than femur width), 1 posteroventral preapical seta, anterior surface with 1 long seta near basal 1/3, otherwise with short setae. Tibia slender, weakly enlarged near middle, with short setae, with series of small close-set ventral setae, apex glabrous on posterior surface. Tarsus subequal in length to tibia, with short setae, tarsomere 1 as long as combined length of tarsomeres $2-3$, with slightly stronger setae ventrally, tarsomeres 2-4 decreasing in length apically, tarsomere 5 about as long as tarsomere 3 . Hindleg: Coxa with 3 setae on outer surface and a few setae on anterior surface. Femur subequal in length to tibia, with dorsal and anteroventral series of setae (slightly longer than femur width), anterior surface with short setae on upper part, posterior surface with sparse fine setae. Tibia slightly enlarged apically, with series of dorsal setae (subequal to tibia width), otherwise with short setae. Tarsus slightly longer than tibia, with short setae, tarsomere 1 slightly swollen basally, subequal to combined length of tarsomeres 2-4, tarsomeres 2-4 decreasing in length apically, tarsomere 5 subequal in length to tarsomere 3. Wing (Fig. 176): With grey-brown tinge, veins dark brown. Pterostigma small. Anal lobe with proximal margin weakly convex. $\mathrm{R}_{2+3}$ and $\mathrm{R}_{4+5}$ parallel in middle part and diverging near apex with cell $\mathrm{r}_{2+3}$ compressed in middle part and flared at apex. $\mathrm{R}_{4+5}$ sinuous with posterior curve to apex with cell $\mathrm{r}_{4+5}$ slightly compressed in basal part. $R_{4+5}$ and $M_{1}$ diverging beyond cell dm. $M_{2}$ and $M_{4}$ diverging beyond cell $\mathrm{dm}$. Costal section $\mathrm{M}_{1}-\mathrm{M}_{2}$ longer than $\mathrm{M}_{2}-\mathrm{M}_{4}$. Cell dm moderately-sized, extended to around middle of wing, distal section of vein $M_{1}$ (beyond base of $M_{2}$ ) longer than preceding section (between $r-m$ and base of $M_{2}$ ). Crossvein dm-m broadly curved and convergent with $\mathrm{M}_{1}$ distally. Abdomen (Fig. 227): Dark brownish-black, with black setae on tergites and sternites. Tergites 1-6 clothed with long, dense setae laterally, setae short and sparse dorsomedially. Sternites 2-4 with 1 long mediolateral seta per side at posterior margin, other medial setae relatively short, lateral setae longer. Sternite 5 with short inner seta, longer thicker outer seta and long posterolateral seta on each side of posterior margin, other setae smaller. Sternite 6 angled dorsally, with several short spine-like setae. Segment 7 with a few short setae on sternite, otherwise bare. Sternite 8 subquadrate, distal margin with setae stronger and longer. Hypopygium (Figs 229, 230): About 1/3 length of abdomen. Left epandrial lamella (Fig. 229) rounded basally, longer than high, with seta on short squared-off tubercle on dorsal margin near base of cercus, with surstylar lobes projecting distally. Left dorsal lobe of surstylus long, apical half expanded ovoid and flap-like, separated from ventral lobe of surstylus by shallow cleft, with 2 dorsal setae on basal part, with lateral seta near middle and several setae on medial surface. Left ventral lobe of surstylus longer than dorsal lobe, apex curved laterally, appearing pointed in lateral view, with dorsolateral seta basally and 2 smaller dorsal setae near mid-length. Right epandrial lamella (Fig. 230) rounded basally, longer than high, with seta on short squared-off tubercle on dorsal margin near base of cercus, with surstylar lobes projecting distally. Right dorsal lobe of surstylus long, with 2 dorsal setae on basal part (distal seta small), apical half greatly expanded ovoid and flap-like (larger than left dorsal lobe), with lateral seta near middle and several setae on medial surface. Right ventral lobe of surstylus comprised of inner and outer lobe; inner lobe longer than dorsal lobe, broad with apex appearing pointed in lateral view; outer lobe as long as inner lobe, very broad, apical margin rounded and serrate, with seta on dorsal margin. Hypandrium with single large seta on each side of basal part. Medial hypandrial prolongation long, apical half curved dorsally and to right, with pair of small apical setae. Left hypandrial lobe short, tapered to rounded apex, weakly sclerotized and lying close to ventral postgonite lobe. Right hypandrial lobe not substantially developed. Postgonite with dorsal postgonite lobes not substantially developed. Left ventral postgonite lobe short with rounded apical margin. Right ventral postgonite lobe short with irregularly rounded apical margin. Postgonite apodeme short T-shaped in ventral view. Phallus thick, apical half curved dorsally and flared with moderately-sized phallotrema. Ejaculatory apodeme relatively long. Left and right cercus with hump-like base bearing several setae and narrow stub-like apex bearing several setae.

Female (Fig. 228): Body length 2.0-2.5 mm, wing length 2.0-2.2 mm. Similar to male except as follows: Head (Fig. 228): Compound eye without demarcation line between dorsal and ventral ommatidia. Gena and parafacial distinctly projected along lower eye margin. Thorax (Fig. 228). Legs: With shorter, unspecialized setae. Foreleg: Tibia without series of fine erect setae along posterior surface. Midleg: Trochanter without spine-like setal pair; femur lacking posteroventral setae and long seta near basal 1/3; tibia slender, unmodified. Hindleg: femur and tibia with short setae, tibia and tarsomere 1 not enlarged. Wing: Anal lobe slightly smaller, proximal margin straight. Abdomen: Tergites and sternites with short setae. With 6 exposed abdominal segments, segment 6 concolorous with anterior abdominal segments. Terminalia (similar to Figs 99, 100, 104): Segment 6 with tergite and sternite 

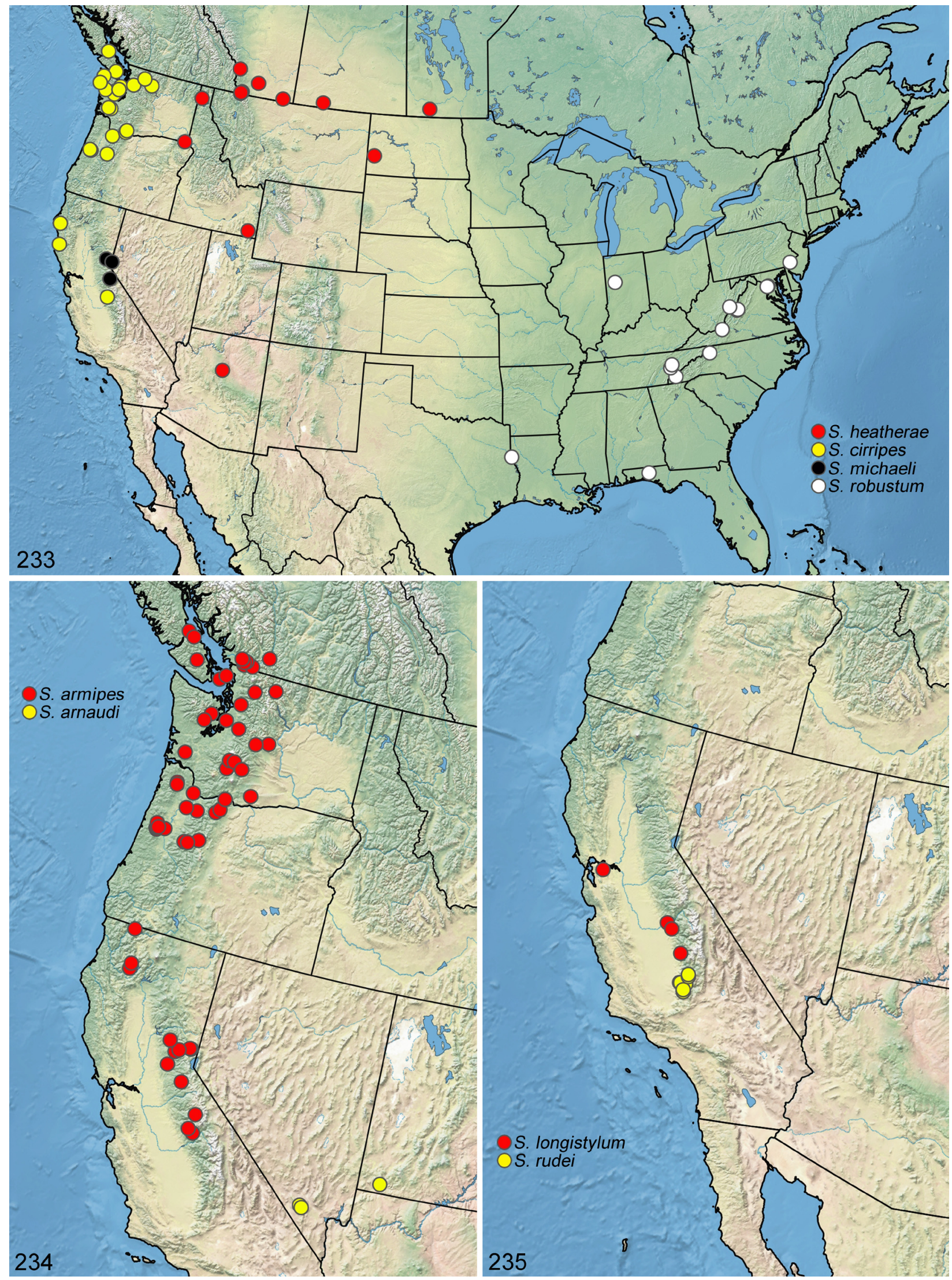

FIGURES 233-235. Known geographical distributions of Nearctic Schistostoma. 233. S. heatherae sp. nov., S. cirripes (Melander) comb. nov., S. michaeli sp. nov. and S. robustum (Melander) comb. nov. 234. S. armipes (Melander) and $S$. arnaudi sp. nov. 235. S. longistylum sp. nov. and $S$. rudei sp. nov. 

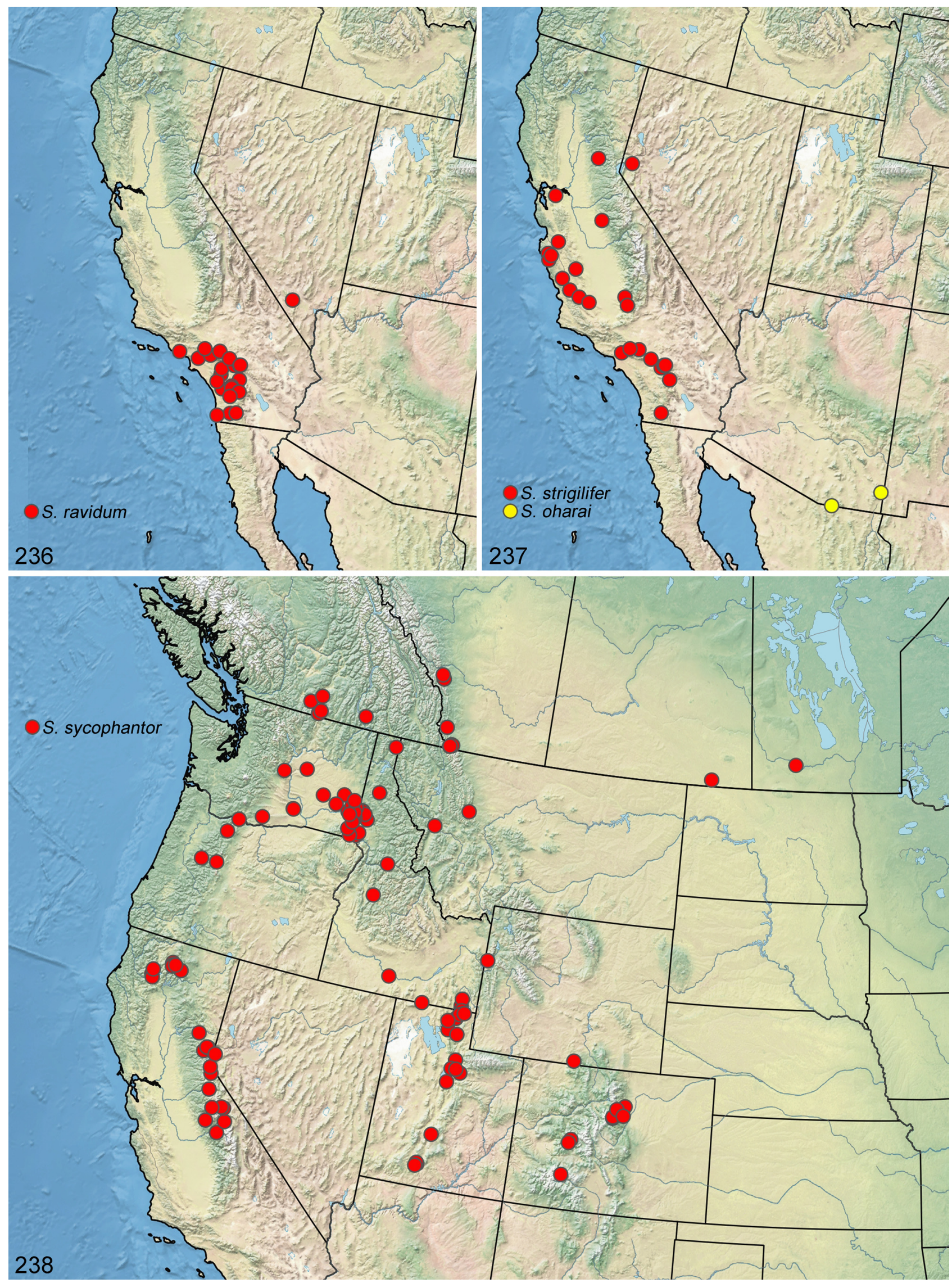

FIGURES 236-238. Known geographical distributions of Nearctic Schistostoma. 236. S. ravidum (Coquillett) comb. nov. 237. S. strigilifer (Melander) comb. nov. and S. oharai sp. nov. 238. S. sycophantor (Melander). 
subrectangular (wider than long), tergite and sternite setose on posterior half with setae distinctly stronger on posterior margin (especially on tergite). Segment 7 with tergite subrectangular (wider than long) with moderately developed anteromedial emargination, with small posterolateral seta, sternite subrectangular (wider than long) with setae on posterior margin, tergite and sternite with short band-like posterior sclerite extension on each side. Tergite 8 undivided, darkened along edge of anteromedial emargination, with small posterolateral seta, narrowly fused to sternite 8 anterolaterally. Sternite 9 desclerotized and inconspicuous. Spermatheca spherical. Syntergite $9+10$ with hemitergites subrectangular, each with 3 acanthophorite spines. Sternite 10 with short setose lateral lobe below cercus (about half length of cercus), sternite produced posteromedially bearing setulae and about 2 adjacent short setae per side, anterolaterally with band-like extension to base of lateral lobe and cercus. Cercus with curved clawlike apex, with several small setae near midlength.

Distribution and seasonal occurrence. Schistostoma sycophantor is a widespread western North American species, known from numerous localities in southern British Columbia, Alberta, Saskatchewan and Manitoba in the north, through Washington, Oregon, Idaho, Montana and Wyoming, to central California (e.g., Fig. 14), Nevada, Utah and Colorado in the south (Fig. 238). Adults have been collected from early May to mid-September.

Remarks. In the original description, Melander (1902) mentions the type series comprises eight males from Idaho collected by J.M. Aldrich, and later Melander (1940b) indicates the type locality to be Moscow. Among the material from the USNM is a female from Moscow bearing a red "COTYPE label which is not part of the type series. Similarly, among the material from the AMNH, there is a badly damaged male from "Craig's Mt Idaho" bearing a red "TYPE/ No./ A.M.N.H." label, which is also not part of the type series.

Pollen grains have been found in the gut of a dissected female of S. sycophantor. Flower visitation records for this species are listed in Table 1 .

This species was collected together with $S$. armipes and $S$. borkenti sp. nov. along Sagehen Creek (Fig. 14) in California by the authors in July, 2012.

\section{Schistostoma yakimense species group}

(Figs 16, 101, 177, 178, 239-253)

Diagnosis. Setae of body and legs predominantly bright white (Figs 239, 242-244), body and legs silvery-grey; male compound eye without distinct demarcation line between dorsal and ventral ommatidia; male and female head with gena and parafacial moderately projected along lower eye margin (Fig. 243); antenna with stylus subequal to length of postpedicel; thorax with mesonotal setae widely spaced and conspicuous; acrostichals biserial, dorsocentrals arranged in a single row per side (rarely irregularly biserial in some males); scutellum with 1 seta per side; male midleg unmodified, trochanter without pair of close-set spine-like setae; wing (Figs 177, 178) with cell $\mathrm{r}_{2+3}$ compressed in middle part and flared at apex, cell $\mathrm{r}_{4+5}$ compressed in basal part, cell $\mathrm{dm}$ moderately-sized; male pregenitalic abdominal sternites unmodified; hypopygium (Figs 240, 241, 244-251) long and free, epandrium without specialized setae adjacent to cercus, dorsal lobe of surstylus elongate and straight, projecting alongside similarly elongated dorsal postgonite lobe, hypandrium with 1 seta per side, medial hypandrial prolongation with small pair of apical setae, dorsal postgonite comprised of elongate unpaired medial lobe; female terminalia retracted into segment 6 (i.e., with 6 exposed abdominal segments), segment 6 (Fig. 242) dark and sharply contrasting with silvery-grey anterior abdominal segments, syntergite $9+10$ with acanthophorite spines, cercus with curved claw-like apex (Fig. 101).

Remarks. This species group includes $S$. pecki sp. nov., S. runyoni sp. nov. and S. yakimense from western North America (Fig. 252, 253). There is also a single female belonging to this species group in the CNC from Kuujjuaq (Fort Chimo) in northern Quebec (collected by J.F. McAlpine on July 2, 1954) which likely represents an additional Nearctic species.

Schistostoma pecki sp. nov.

(Figs 239-241, 252)

urn:lsid:zoobank.org:act: F8E4949A-352D-4336-B0B5-7B55726532F4

Type material. HOLOTYPE, ô collected along kilometers $1-70$ of the Dempster Highway $\left[\mathrm{ca} 64^{\circ} 14^{\prime} \mathrm{N} 138^{\circ} 31^{\prime} \mathrm{W}\right]$, 
Yukon, Canada, 11.vi.1984, by S. \& J. Peck, labelled: "CANADA: YT: Dempster Hwy/ km 1-70, 11.vi.1984, morning/ car netting, spruce-willow/ forest, S. \& J. Peck"; "HOLOTYPE/ Schistostoma pecki/ Brooks \& Cumming [red label]" (CNC).

Diagnosis. This rare species is distinguished from other members of the S. yakimense species group by its broad dorsal postgonite lobe, apically bulbous right ventral postgonite lobe, and ridged male abdominal sternite 6 (Figs 240,241 ), as indicated in the key (couplet 6).

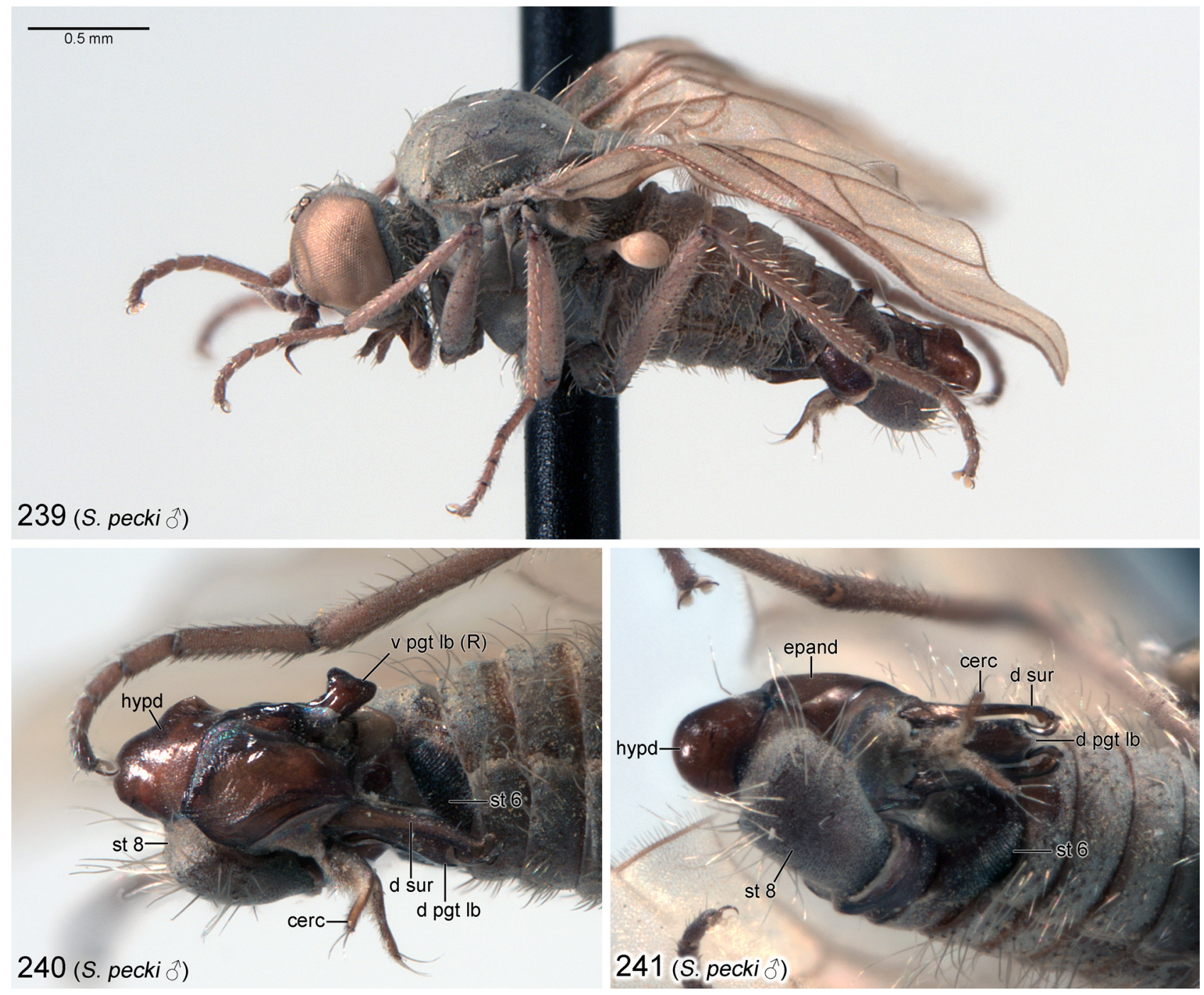

FIGURES 239-241. Male holotype of Schistostoma pecki sp. nov., habitus and male terminalia. 239. Habitus. 240. Male abdomen and terminalia, right lateral view. 241. Male abdomen and terminalia, ventral view of abdomen showing dorsal aspect of hypopygium. Specimen from: Dempster Highway, Yukon (Figs 239-241). Abbreviations: cerc—cercus; d pgt lb — dorsal postgonite lobe; d sur — dorsal lobe of surstylus; epand — epandrium; hypd—hypandrium; (R)—right; st—sternite; v pgt lb— ventral postgonite lobe.

Description. Male (Figs 239-241): Body length $3.0 \mathrm{~mm}$. Head: Ocellar tubercle with 2 pairs of bright white proclinate setae, anterior pair slightly shorter than posterior pair. Occiput silvery-grey pruinose, mostly clothed with bright white setae, almost bare in upper part, except for postoculars. Gena and parafacial moderately projected along lower eye margin. Antenna dark brown; postpedicel conical, evenly tapered to apex; stylus about equal to length of postpedicel. Palpus brown, elongate ovate, subequal to length of labrum, pubescent with microtrichia and bearing scattered bright white setulae. Proboscis brown, slightly less than $1 / 2$ as long as head height, directed forward. Thorax (Fig. 239): Mesonotum silvery-grey. Proepisternum with 1 seta. Mesonotal setae bright white, relatively long with dorsocentrals arranged in single row per side. Notopleuron with 2 strong setae. Scutellum with 1 pair of setae. Mesopleuron silvery-grey. Halter pale. Legs (Fig. 239): Pale grey, with bright white setae, except as noted. 
Foreleg: Coxa with several setae on anterior surface. Femur subequal in length to tibia, somewhat sparsely setose, with series of longer posteroventral setae (slightly shorter than femur width). Tibia slender, with short setae. Tarsus slightly shorter than tibia, with short setae, tarsomere 1 subequal to combined length of tarsomeres $2-4$, with pair of slightly longer basiventral setae (slightly shorter than tarsomere width), tarsomeres 2-4 decreasing in length apically, tarsomere 5 subequal in length to tarsomere 3. Midleg: Coxa with several setae on anterior surface. Femur subequal in length to tibia, posterior and anterior surfaces setose (at most subequal to femur width). Tibia slender, with short setae. Tarsus subequal in length to tibia, with short setae, tarsomeres 1-4 with dark ventral setae near apex, tarsomere 1 slightly longer than combined length of tarsomeres $2-4$, with pair of slightly longer basiventral setae (subequal to tarsomere width), tarsomeres 2-4 decreasing in length apically, tarsomere 5 subequal in length to tarsomere 2. Hindleg: Coxa with several setae on outer surface and a few shorter setae near apex of anterior surface. Femur subequal in length to tibia, with close-set series of dorsal and ventral setae (at most subequal to femur width), otherwise with short setae (finer on posterior surface). Tibia slender, with dorsal setae subequal to slightly longer than tibia width, basal half with anteroventral setae longer (subequal to tibia width). Tarsus subequal in length to tibia, with short setae, tarsomeres 1-4 with a few dark ventral setae near apex, tarsomere 1 as long as combined length of tarsomeres $2-4$, with a few slightly longer basiventral setae, posterior surface densely setulose, tarsomeres 2-4 decreasing in length apically, tarsomere 5 subequal in length to tarsomere 3 . Wing: Coated with opaque debris on unique holotype, veins brown. Pterostigma small. Anal lobe large with proximal margin convex. $R_{2+3}$ and $R_{4+5}$ parallel in middle part and diverging near apex with cell $r_{2+3}$ compressed in middle part and flared at apex. $R_{4+5}$ sinuous with posterior curve to apex with cell $\mathrm{r}_{4+5}$ compressed in basal part. $\mathrm{R}_{4+5}$ and $\mathrm{M}_{1}$ diverging beyond cell dm. $\mathrm{M}_{2}$ and $\mathrm{M}_{4}$ slightly diverging beyond cell $\mathrm{dm}$. Costal section $\mathrm{M}_{1}-\mathrm{M}_{2}$ subequal to $\mathrm{M}_{2}-\mathrm{M}_{4}$. Cell $\mathrm{dm}$ somewhat broad, extended to around middle of wing, distal section of vein $\mathrm{M}_{1}$ (beyond base of $\mathrm{M}_{2}$ ) longer than preceding section (between $\mathrm{r}-\mathrm{m}$ and base of $\mathrm{M}_{2}$ ). Crossvein dm-m broadly curved and convergent with $\mathrm{M}_{1}$ distally. Abdomen (Figs 240, 241): Silvery-grey, with bright white setae on tergites and sternites. Tergites 1-5 clothed with long, dense setae laterally, setae short and sparse dorsomedially. Tergite 6 mainly bare. Sternites $2-5$ with short setae medially and longer setae laterally. Sternite 6 angled dorsally, dark and heavily sclerotized with fine longitudinal ridges, bare. Segment 7 bare. Sternite 8 subrectangular, setose. Hypopygium (Figs 240, 241): Large and long, about 1/2 length of abdomen. Left epandrial lamella longer than high, with surstylar lobes projecting distally, largely hidden from view on unique undissected holotype. Left dorsal lobe of surstylus similar to right side. Left ventral lobe of surstylus not visible. Right epandrial lamella (Fig. 240), longer than high, with surstylar lobes projecting distally. Right dorsal lobe of surstylus elongate and slender, with dorsomedial flange near base, apical half with several short setae, with short pointed ventrally projected tip. Right ventral lobe of surstylus short and broadly rounded with a few short setae. Hypandrium with single large seta on each side of basal part. Medial hypandrial prolongation long, slender and straight, with pair of divergent apical setae. Left hypandrial lobe not visible. Right hypandrial lobe short. Unpaired medial dorsal postgonite lobe elongate and broad (Fig. 241), running adjacent to and parallel with dorsal lobes of surstylus, apex bluntly bifid, with short hook-like process on each side. Left ventral postgonite lobe not visible. Right ventral postgonite lobe (Fig. 240) projecting ventrally with bulbous apex. Phallus and ejaculatory apodeme not visible. Left and right cercus with small hump-like base and narrow elongate digitiform apex bearing 3 long apical setae.

Female: Unknown.

Distribution and seasonal occurrence. Schistostoma pecki sp. nov. is known from along the Dempster Highway in Yukon (Fig. 252). The unique holotype was collected in mid-June.

Etymology. This species is named in honour of colleague Dr. Stewart B. Peck, who collected the unique holotype along with his wife Dr. Jarmila Kukalová-Peck, using a car net while driving along the Dempster Highway (Peck \& Cook 1992).

\section{Schistostoma runyoni sp. nov.}

(Figs 16, 177, 249-251, 253)

urn:lsid:zoobank.org:act: 8B01126C-3C37-4222-BC03-AC15200E8D5C

Type material. HOLOTYPE, $\widehat{\jmath}$ collected from Carson Slough, Ash Meadows NWR, Nye County, Nevada, USA, 24.iv.2014, by J.B. Runyon, labelled: "NEVADA: Nye Co./ Ash Meadows NWR/ Carson Slough/ N36 ${ }^{\circ} 25.51^{\prime}$ W116²1.90'/ 24APR2014, JB Runyon"; "HOLOTYPE/ Schistostoma runyoni/ Brooks \& Cumming [red label]" 
(CNC). PARATYPES: USA: Nevada: Same data as holotype $(3 \stackrel{\jmath}{\jmath}, 6 \circ, \mathrm{CNC})$; same data except, CNC1155637 $\left(1 \jmath^{\lambda}, \mathrm{CNC}\right)$.

Other material examined. USA: Arizona: Pima County: Organ Pipe Cactus National Monument, Quitobaquito Res. [ $\mathrm{ca} 31^{\circ} 56^{\prime} \mathrm{N} 113^{\circ} 01^{\prime} \mathrm{W}$ ], 22.iv.1979, K.N. Barber (1q, UGIC); Organ Pipe Cactus National

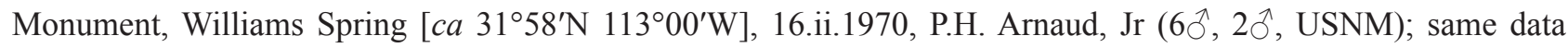

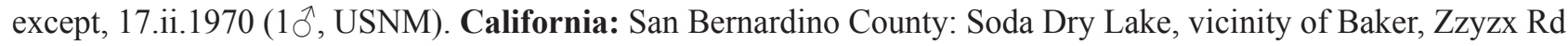

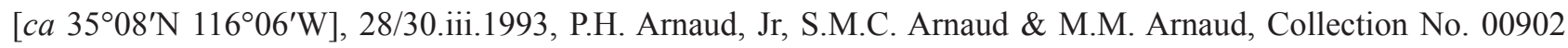

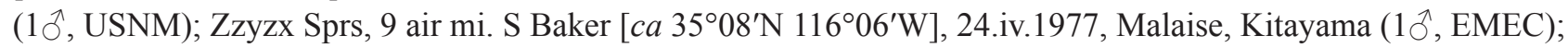
same data except, 25.iv.1977, Ulrich (3ð, EMEC). Nevada: Nye County: Ash Meadows NWR, Crystal Spring,

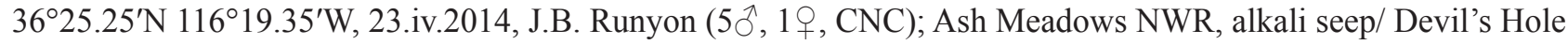
$\mathrm{Rd}, 36^{\circ} 24.754 \mathrm{~N} 116^{\circ} 17.704^{\prime} \mathrm{W}, 24 . i v .2014$, J.B. Runyon (3ㅇ, CNC).

Diagnosis. This species is distinguished from other members of the $S$. yakimense species group by its slender dorsal postgonite lobe, apically rounded right ventral postgonite lobe, spinose left dorsal postgonite lobe, and shape of the left ventral lobe of the surstylus (Figs 249-251), as indicated in the key (couplets 6 and 7).

Description. Male (Figs 177, 249-251): Body length 2.2-2.8 mm, wing length 2.0-2.7 mm. Head: Ocellar tubercle with 2 pairs of bright white proclinate setae, anterior pair subequal in length to posterior pair. Occiput silverygrey pruinose, mostly clothed with bright white setae, almost bare in upper part, except for postoculars. Gena and parafacial moderately projected along lower eye margin. Antenna dark brown to black; postpedicel conical, evenly tapered to apex; stylus about equal to length of postpedicel. Palpus dark brown to black, elongate ovate, subequal to length of labrum, pubescent with microtrichia and bearing scattered bright white setulae. Proboscis dark brown, about $1 / 2$ as long as head height, directed forward. Thorax: Mesonotum silvery-grey with faint vitta between acrostichals and dorsocentrals. Proepisternum with 1-3 setae. Mesonotal setae bright white, relatively long with dorsocentrals arranged in single row per side. Notopleuron with 2 strong setae. Scutellum with 1 pair of setae. Mesopleuron silvery-grey. Halter pale. Legs: Entirely silvery-grey, with bright white setae, except as noted. Foreleg: Coxa with several setae on anterior surface. Femur subequal in length to tibia, with posteroventral setae and basal anteroventral setae somewhat longer (subequal to femur width), otherwise with short setae. Tibia slender, with short setae. Tarsus slightly shorter than tibia, with short setae, tarsomere 1 subequal to combined length of tarsomeres $2-4$, with pair of slightly longer basiventral setae (subequal to tarsomere width), tarsomeres 2-4 decreasing in length apically, tarsomere 5 subequal in length to tarsomere 3. Midleg: Coxa with several setae on anterior surface. Femur subequal in length to tibia, with posteroventral setae and basal anteroventral setae somewhat longer (subequal to femur width), otherwise with short setae. Tibia slender, with short setae. Tarsus subequal in length to tibia, with short setae, tarsomeres 1-4 with dark ventral setae near apex, tarsomere 1 slightly longer than combined length of tarsomeres 2-4, with pair of slightly longer basiventral setae (subequal to tarsomere width), tarsomeres 2-4 decreasing in length apically, tarsomere 5 subequal in length to tarsomere 3. Hindleg: Coxa with 2-4 setae on outer surface and 2-3 setae on apical margin of anterior surface. Femur subequal in length to tibia, with series of longer dorsal and anteroventral setae (subequal to slightly longer than femur width), anteroventral setae stronger, otherwise with short setae (finer on posterior surface). Tibia slender, with dorsal setae subequal to slightly longer than tibia width, basal half to $2 / 3$ with anteroventral setae longer (subequal to tibia width). Tarsus slightly longer than tibia, with short setae, tarsomeres 1-4 with a few dark ventral setae near apex, tarsomere 1 as long as combined length of tarsomeres 2-4, with a few slightly longer basiventral setae, posterior surface densely setulose, tarsomeres $2-4$ decreasing in length apically, tarsomere 5 subequal in length to tarsomere 3. Wing (Fig. 177): Hyaline, veins dark brown. Pterostigma small. Anal lobe large with proximal margin convex. $\mathrm{R}_{2+3}$ and $\mathrm{R}_{4+5}$ parallel in middle part and diverging near apex with cell $r_{2+3}$ compressed in middle part and flared at apex. $R_{4+5}$ sinuous with pronounced posterior curve to apex with cell $r_{4+5}$ slightly compressed in basal part. $R_{4+5}$ and $M_{1}$ diverging beyond cell $\mathrm{dm} . \mathrm{M}_{2}$ and $\mathrm{M}_{4}$ diverging beyond cell $\mathrm{dm}$. Costal section $\mathrm{M}_{1}-\mathrm{M}_{2}$ longer than $\mathrm{M}_{2}-\mathrm{M}_{4}$. Cell dm somewhat broad, extended to around middle of wing, distal section of vein $M_{1}$ (beyond base of $M_{2}$ ) longer than preceding section (between $r-m$ and base of $M_{2}$ ). Crossvein dm-m broadly curved and convergent with $\mathrm{M}_{1}$ distally. Abdomen: Silvery-grey, with bright white setae on tergites and sternites. Tergites 1-5 clothed with long, dense setae laterally, setae short and sparse dorsomedially. Tergite 6 mainly bare. Sternites $2-5$ with short setae medially and longer setae laterally. Sternite 6 angled dorsally, with a few tiny setae. Segment 7 bare. Sternite 8 subrectangular, setose. Hypopygium (Figs 249-251): Long, about 1/2 length of abdomen. Left epandrial lamella (Fig. 249) longer than high, with surstylar lobes projecting distally. Left dorsal lobe of surstylus elongate and slender, with medial dentiform projection near base, apical half with several 
short setae. Left ventral lobe of surstylus ventrally curved with apex broadly rounded, with short dorsal and lateral setae, membranous basoventrally. Right epandrial lamella, longer than high, with surstylar lobes projecting distally. Right dorsal lobe of surstylus similar to left side. Right ventral lobe of surstylus short and broadly rounded with a few short setae. Hypandrium with single large seta on each side of basal part. Medial hypandrial prolongation long, slender and straight, with pair of divergent relatively thick apical setae, right seta longer. Left hypandrial lobe with apex bearing long dense spines, largely covered by ventral lobe of surstylus. Right hypandrial lobe long and narrow. Unpaired medial dorsal postgonite lobe elongate and slender, running adjacent to and parallel with dorsal lobes of surstylus, apex tripartite with pointed medial process and blunt-tipped lateral processes. Left ventral postgonite lobe bearing several spine-like apical projections (Fig. 250). Right ventral postgonite lobe long and relatively broad, curved medially, apex rounded (Fig. 251). Postgonite apodeme heart-shaped in ventral view, unbranched. Phallus slender, weakly undulate basally, nearly as long as medial hypandrial prolongation. Ejaculatory apodeme spatulate. Left and right cercus with hump-like base and narrow elongate digitiform apex bearing long apical seta.

Female: Body length 2.0-2.3 mm, wing length $2.2-2.3 \mathrm{~mm}$. Similar to male except as follows: Legs: Setae of femora and hind tibia somewhat shorter and weaker. Abdomen (similar to Fig. 242): Tergites and sternites with short setae. With 6 exposed abdominal segments, segment 6 dark, shiny and sharply contrasting with silvery-grey anterior abdominal segments. Terminalia (similar to Fig. 101): Segment 6 with tergite and sternite subrectangular (wider than long), setose (tergite bare centrally), tergite with shallow anteromedial emargination. Segment 7 with tergite longer than wide, U-shaped with deep anteromedial emargination (darkened along edge and medially beyond emargination), anterior margin broadly rounded on either side of emargination, sternite about half length of tergite, U-shaped with deep posteromedial emargination, tergite and sternite with small posterolateral seta and band-like posterior sclerite extension on each side. Tergite 8 undivided, darkened along edge of anteromedial emargination, with small posterolateral seta, narrowly fused to sternite 8 anterolaterally. Sternite 9 partially sclerotized. Spermatheca elongate-ovoid with tapered base. Syntergite $9+10$ with hemitergites subrectangular, each with 3 apically flattened and round-tipped (in dorsal view) acanthophorite spines. Sternite 10 with short setose lateral lobe below cercus (about half length of cercus), V-shaped in ventral view with setulae posteromedially and 3-4 setae per side. Cercus with curved claw-like apex, with dorsal and ventral seta near midlength.

Distribution and seasonal occurrence. Schistostoma runyoni sp. nov. is a southwestern USA species known from southern California, Nevada and Arizona (Fig. 253). Adults have been collected from mid-February to late April, in relatively dry open habitats (Fig. 16).

Etymology. The species name honours our fellow empidoid worker, Dr. Justin B. Runyon, who collected the type series from Nye County, Nevada.

\section{Schistostoma yakimense (Melander)}

(Figs 101, 178, 242-248, 252)

Microphorus (Schistostoma) yakimensis Melander, 1928: 94.

Schistostoma yakimensis (Melander): Melander (1965: 453).

Schistostoma yakimense (Melander): Yang et al. (2007: 319).

Type material examined. HOLOTYPE, ô collected from, Yakima [ca $46^{\circ} 36^{\prime} \mathrm{N} 120^{\circ} 28^{\prime} \mathrm{W}$ ], Yakima County, Washington, USA, iv.1915, labelled: "Yakima/ Wash"; "TYPE Schistostoma/ yakimensis/ Mel. [red label]"; “ALMelander/Collection/ 1961" (USNM).

Other material examined. CANADA: Alberta: Milk River, $49^{\circ} 08^{\prime} \mathrm{N} 110^{\circ} 48^{\prime} \mathrm{W}$, 5.vi.1955, J.R. Vockeroth

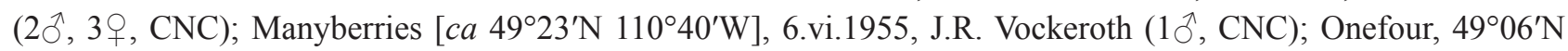
$110^{\circ} 28^{\prime} \mathrm{W}, 7 . v i .1955$, J.R. Vockeroth $\left(2 \hat{O}^{\wedge}, 4\right.$,, $\left.\mathrm{CNC}\right)$; same data except, 5.vi.1955, A.R. Brooks, CNC1155707

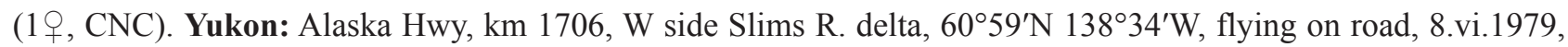
\#791007c, ROM Field Party (1§, ROM). USA: California: San Bernardino County: Zzyzx Desert Study Area

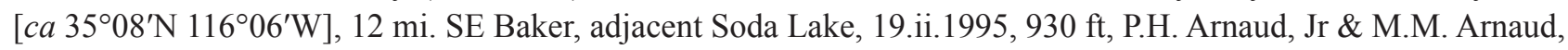
Arnaud flight trap, Collection \# 01267 (3 9 , USNM); same data except, CNC1155632 (1 $\overbrace{}^{\Uparrow}$, USNM). Idaho: Butte County: 12 mi. N Howe [ca $43^{\circ} 55^{\prime} \mathrm{N} 113^{\circ} 07^{\prime} \mathrm{W}$ ], 21.v.1978, W.F. Barr (12 $\bigcirc^{\top}, 5 \circ$, WFBM). Oregon: Lake County:

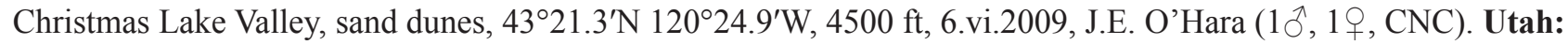
San Juan County: Recapture Creek [ca $37^{\circ} 18^{\prime} \mathrm{N} 109^{\circ} 27^{\prime} \mathrm{W}$ ], 7 mi. E Bluff, 19.iv.2003, $4500 \mathrm{ft}$, J. Runyon \& R. Hurley (1へ, MTEC). 
Diagnosis. This species is distinguished from other members of the $S$. yakimense species group by its slender dorsal postgonite lobe (Fig. 245), apically truncate right ventral postgonite lobe with apicodorsal spur, pointed left dorsal postgonite lobe, and shape of the left ventral lobe of the surstylus (Figs 249-251), as indicated in the key (couplets 6 and 7).
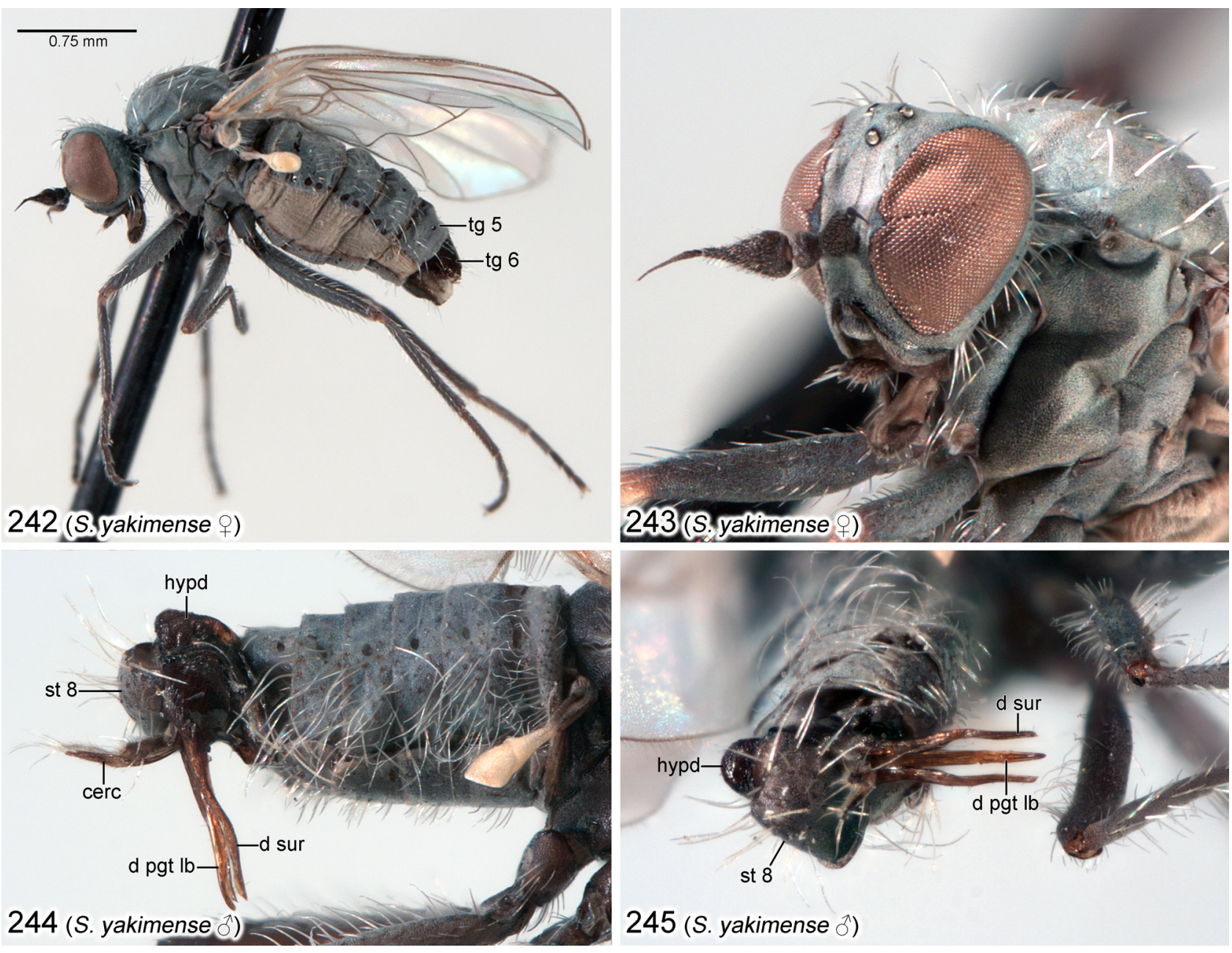

245 (S. yakimense $\left.{ }^{3}\right)$

FIGURES 242-245. Female habitus, female head and male terminalia of Schistostoma yakimense (Melander) 242. Female habitus. 243. Female head and anterior portion of thorax, oblique view. 244. Male abdomen and terminalia, right lateral view. 245. Male abdomen and terminalia, posteroventral view showing dorsal aspect of hypopygium. Specimens from: Christmas Lake Valley, Oregon (Figs 242, 243); Milk River, Alberta (Figs 244, 245). Abbreviations: cerc_-cercus; d pgt lb—dorsal postgonite lobe; d sur-dorsal lobe of surstylus; hypd—hypandrium; st—sternite; tg — tergite.

Redescription. Male (Figs 178, 244-248): Body length 2.4-2.8 mm, wing length 2.4-2.7 mm. Head: Ocellar tubercle with 2 pairs of bright white proclinate setae, anterior pair subequal in length to posterior pair. Occiput silvery-grey pruinose, mostly clothed with bright white setae, almost bare in upper part, except for postoculars. Gena and parafacial moderately projected along lower eye margin. Antenna dark brown to black; postpedicel conical, evenly tapered to apex; stylus about equal to length of postpedicel. Palpus dark brown to black, elongate ovate, subequal to length of labrum, pubescent with microtrichia and bearing scattered bright white setulae. Proboscis dark brown, about 1/2 as long as head height, directed forward. Thorax: Mesonotum silvery-grey with faint vitta between acrostichals and dorsocentrals. Proepisternum with 1-3 setae. Mesonotal setae bright white, relatively long with dorsocentrals arranged in single row per side. Notopleuron with 2-3 strong setae. Scutellum with 1 pair of setae. Mesopleuron silvery-grey. Halter pale. Legs: Entirely silvery-grey, with bright white setae, except as noted. Foreleg: Coxa with several setae on anterior surface. Femur subequal in length to tibia, with setae at most subequal to femur width, anterior surface with short setae, posterior surface sparsely setose. Tibia slender, with short setae. Tarsus subequal in length to tibia, with short setae, tarsomere 1 subequal to combined length of tarsomeres $2-4$, with pair of slightly longer basiventral setae (subequal to tarsomere width), tarsomeres 2-4 decreasing in length apically, 
tarsomere 5 subequal in length to tarsomere 3. Midleg: Coxa with several setae on anterior surface. Femur subequal in length to tibia, with series of longer posteroventral setae (at most slightly longer than femur width), otherwise with shorter setae. Tibia slender, with short setae. Tarsus slightly longer than tibia, with short setae, tarsomeres 1-4 with dark ventral setae near apex, tarsomere 1 subequal to combined length of tarsomeres $2-4$, with pair of slightly longer basiventral setae (subequal to tarsomere width), tarsomeres 2-4 decreasing in length apically, tarsomere 5 subequal in length to tarsomere 3. Hindleg: Coxa with 2-5 setae on outer surface and several shorter setae near apex of anterior surface. Femur subequal in length to tibia, with series of longer dorsal and anteroventral setae (at most slightly longer than femur width), anterior surface with shorter setae, posterior surface fine sparse setae. Tibia slender, with dorsal setae subequal to slightly longer than tibia width. Tarsus subequal in length to tibia, with short setae, tarsomeres 1-4 with a few dark ventral setae near apex, tarsomere 1 as long as combined length of tarsomeres $2-4$, with a few slightly longer basiventral setae, posterior surface densely setulose, tarsomeres $2-4$ decreasing in length apically, tarsomere 5 subequal in length to tarsomere 3. Wing (Fig. 178): Hyaline, veins brown. Pterostigma small. Anal lobe large with proximal margin convex. $\mathrm{R}_{2+3}$ and $\mathrm{R}_{4+5}$ subparallel in middle part and diverging near apex with cell $\mathrm{r}_{2+3}$ compressed in middle part and flared at apex. $\mathrm{R}_{4+5}$ sinuous with posterior curve to apex with cell $r_{4+5}$ compressed in basal part. $R_{4+5}$ and $M_{1}$ diverging beyond cell $\mathrm{dm} . \mathrm{M}_{2}$ and $\mathrm{M}_{4}$ diverging beyond cell $\mathrm{dm}$. Costal section $\mathrm{M}_{1}-\mathrm{M}_{2}$ longer than $\mathrm{M}_{2}-\mathrm{M}_{4}$. Cell dm somewhat broad, extended to around middle of wing, distal section of vein $\mathrm{M}_{1}$ (beyond base of $\mathrm{M}_{2}$ ) longer than preceding section (between $\mathrm{r}-\mathrm{m}$ and base of $\mathrm{M}_{2}$ ). Crossvein dm-m broadly curved and convergent with $M_{1}$ distally. Abdomen (Figs 244, 245): Silvery-grey, with bright white setae on tergites and sternites. Tergites 1-5 clothed with long, dense setae laterally, setae short and sparse dorsomedially. Tergite 6 mainly bare. Sternites 2-5 with short setae medially and longer setae laterally. Sternite 6 angled dorsally, with a few tiny setae. Segment 7 bare. Sternite 8 subrectangular, setose. Hypopygium (Figs 246-248): long, over 1/2 length of abdomen. Left epandrial lamella (Fig. 246) longer than high, with surstylar lobes projecting distally. Left dorsal lobe of surstylus elongate and slender, with medial dentiform projection near base, apical half with several short setae. Left ventral lobe of surstylus broad basally with apex narrowed, with short dorsal and lateral setae, membranous basoventrally. Right epandrial lamella (Fig. 247) longer than high, with surstylar lobes projecting distally. Right dorsal lobe of surstylus similar to left side. Right ventral lobe of surstylus short and acute with a few short setae. Hypandrium with single large seta on each side of basal part. Medial hypandrial prolongation long, slender and straight, with pair of divergent apical setae, right seta slightly longer. Left hypandrial lobe with upcurved apex bearing short spines, largely covered by ventral lobe of surstylus. Right hypandrial lobe long narrow and pointed. Unpaired medial dorsal postgonite lobe elongate and slender, running adjacent to and parallel with dorsal lobes of surstylus, apex tripartite with pointed medial process and blunt-tipped lateral processes. Left ventral postgonite lobe long, apex curved to left and tapered to pointed tip. Right ventral postgonite lobe long and relatively broad, curved medially, apex with acute upturned tip. Postgonite apodeme heart-shaped in ventral view, unbranched. Phallus slender, weakly undulate basally, nearly as long as medial hypandrial prolongation. Ejaculatory apodeme spatulate. Left and right cercus with hump-like base and narrow elongate digitiform apex bearing long apical seta.

Female (described for the first time, Figs 101, 242, 243): Body length 2.1-2.8 mm, wing length 2.6-2.7 mm. Similar to male except as follows: Thorax (Figs 242, 243). Legs (Fig. 242): Setae of femora and hind tibia somewhat shorter and weaker. Abdomen (Fig. 242): Tergites and sternites with short setae. With 6 exposed abdominal segments, segment 6 dark, shiny and sharply contrasting with silvery-grey anterior abdominal segments. Terminalia (Fig. 101): Segment 6 with tergite and sternite subrectangular (wider than long), tergite with shallow anteromedial emargination, with setae laterally and on posterior margin, sternite with setae mainly on posterior third. Segment 7 with tergite longer than wide, U-shaped with deep anteromedial emargination (darkened along edge and medially beyond emargination), anterior margin broadly rounded on either side of emargination, sternite about half length of tergite, U-shaped with deep posteromedial emargination, tergite and sternite with small posterolateral seta and band-like posterior sclerite extension on each side. Tergite 8 undivided, darkened along edge of anteromedial emargination, with small posterolateral seta, narrowly fused to sternite 8 anterolaterally. Sternite 9 partially sclerotized. Spermatheca elongate-ovoid with tapered base. Syntergite $9+10$ with hemitergites subrectangular, each with 3 apically flattened and round-tipped (in dorsal view) acanthophorite spines. Sternite 10 with short setose lateral lobe below cercus (about half length of cercus), V-shaped medially with setulae and 4 setae per side, anterolaterally with band-like extension to base of lateral lobe and cercus. Cercus with curved claw-like apex, with dorsal and ventral seta near midlength.

Distribution and seasonal occurrence. Schistostoma yakimense is a widespread western North American 
species, known from Yukon in the north, through Alberta, Washington, Oregon and Idaho, to California and southern Utah in the south (Fig. 252). Adults have been collected from mid-February to early June, apparently in relatively dry open habitats.

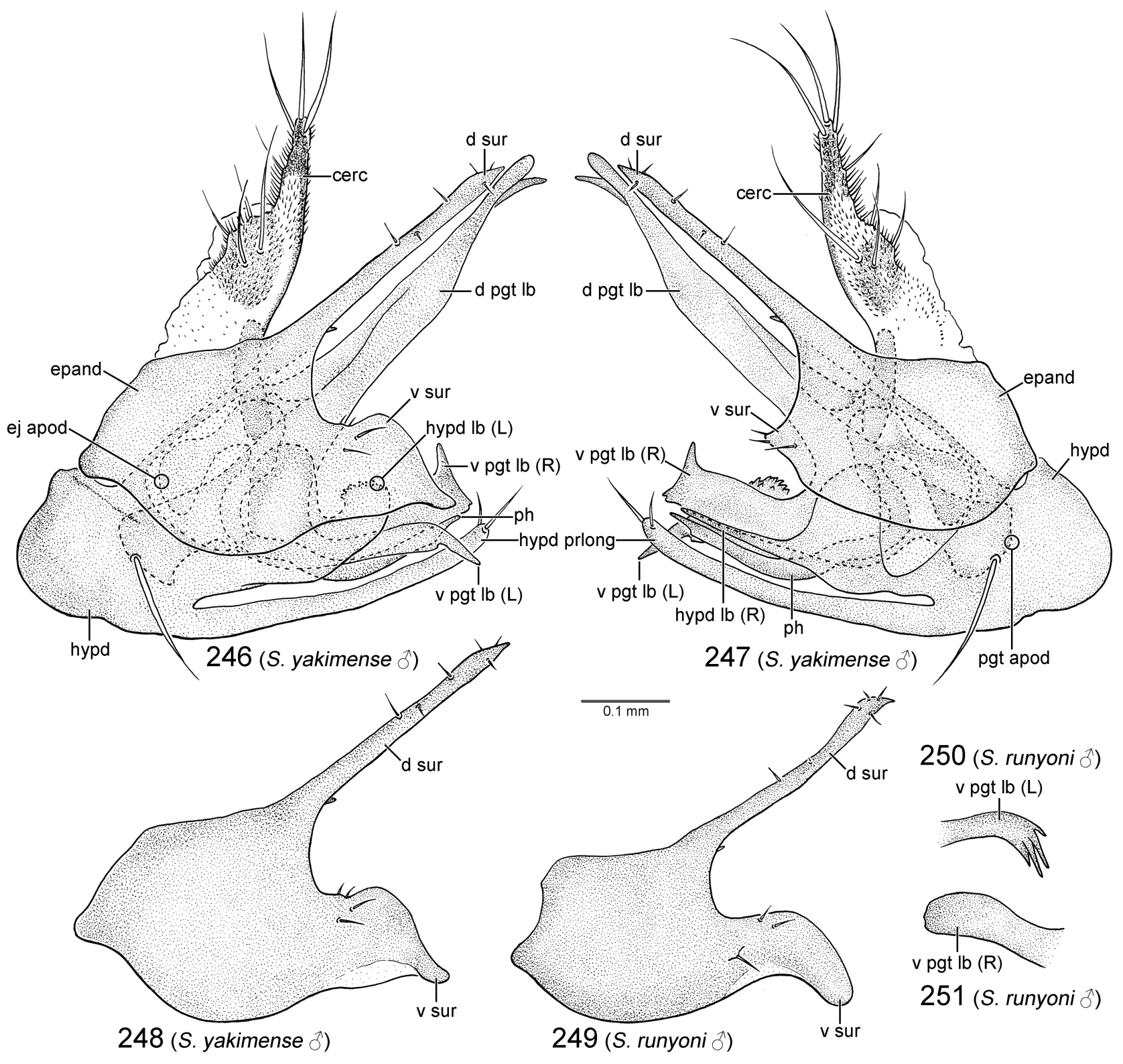

FIGURES 246-251. Hypopygia of Nearctic Schistostoma. 246. S. yakimense (Melander), left lateral view. 247. S. yakimense (Melander), right lateral view. 248. Epandrium of S. yakimense (Melander), left lateral view. 249. Epandrium of S. runyoni sp. nov., left lateral view. 250. Left postgonite lobe of $S$. runyoni sp. nov., left lateral view. 251. Right postgonite lobe of $S$. runyoni sp. nov., right lateral view. Figures 246-248 based on specimen CNC1155632 (Soda Lake, California). Figures 249-251 based on specimen CNC1155637 (Carson Slough, Nevada). Abbreviations: cerc — cercus; d pgt lb — dorsal postgonite lobe; d surdorsal lobe of surstylus; ej apod — ejaculatory apodeme; epand — epandrium; hypd—hypandrium; hypd lb—hypandrial lobe; hypd prlong — hypandrial prolongation; (L)—left; pgt apod—-postgonite apodeme; ph—phallus; (R) —right; v pgt lb — ventral postgonite lobe; v sur — ventral lobe of surstylus.

\section{Discussion}

The phylogenetic relationships within the subfamily Microphorinae require analysis at the generic and species group level on a worldwide basis. The monophyly of the subfamily needs to be validated and the monophyly of the included genera, including fossil taxa, still needs to be determined. Microphor is a Northern Hemisphere 
genus that might be monophyletic based on the presence in males of a phallic process and a hook-shaped right ventral postgonite lobe, although the phallic process is very short in some species. Globally Schistostoma could be paraphyletic in relation to Microphor, so the relationships of the Nearctic species groups of Schistostoma to the Palaearctic, Oriental and Afrotropical species in the genus require additional study. We have only examined a few of these extralimital species of Schistostoma, so presently we are unable to carry out a worldwide phylogenetic analysis of the Microphorinae as we did for the subfamily Parathalassiinae (Cumming \& Brooks 2019). The medial hypandrial prolongation in males of Schistostoma is the only unique feature that currently supports the monophyly of this broadly defined genus. However, the greater number of exposed female abdominal segments in Schistostoma (six or seven), versus five in most Dolichopodidae sensu lato, except Amphithalassius Ulrich and Plesiothalassius Ulrich (Sinclair \& Cumming 2006, p. 40), may be additional evidence supporting the monophyly of Schistostoma.
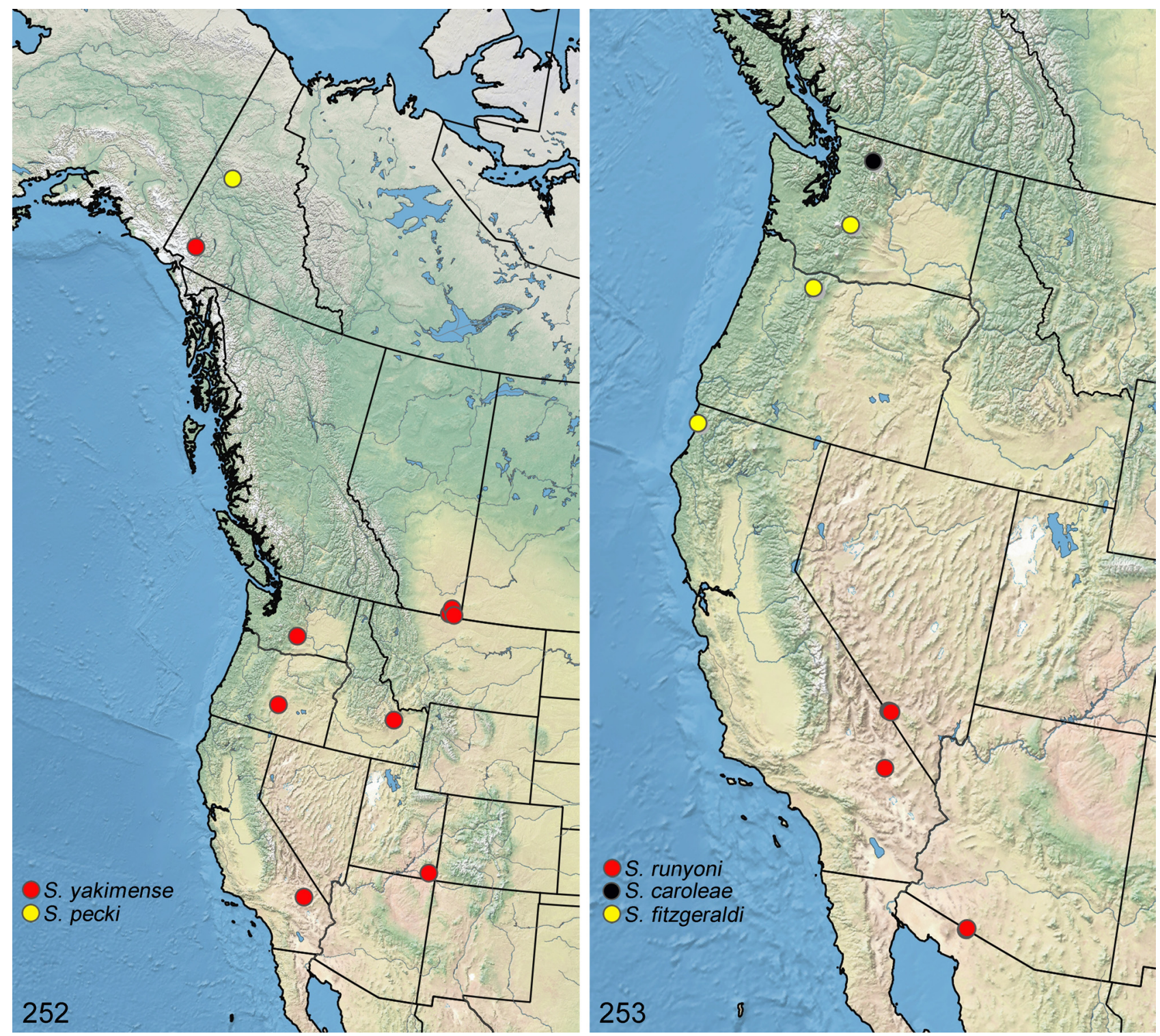

FIGURES 252-253. Known geographical distributions of Nearctic Schistostoma. 252. S. yakimense (Melander) and S. pecki sp. nov. 253. S. runyoni sp. nov., S. caroleae sp. nov. and $S$. fitzgeraldi sp. nov.

Continued discovery of new extralimital taxa will probably also uncover additional distinctive Microphorinae species groups, as has recently been revealed for Schistostoma from mid-Cretaceous Burmese amber (Brooks et al. 2019). Possible relationships of Nearctic species groups with some of the Old World fauna are apparent. The M. obscurus species group appears related to M. anomalus, M. crassipes Macquart, M. gissaricus Shamshev, $M$. intermedius Collin, M. pilimanus Strobl, M. rostellatus Loew and M. sinensis Saigusa \& Yang, whereas the M. discalis species group seems closer to M. holosericeus and M. strobli Chvála. Within Schistostoma the S. yakimense 
species group appears closely related to Chvála's (1987) Old World $S$. eremita species group and part of his $S$. truncatum species group (especially those species with distinctively elongated dorsal surstyli and postgonite lobes) and all these species together (along with the S. albopilosum species group) may be related to the S. ravidum species group, based on similarities in the female terminalia. The $S$. ravidum and $S$. isommatum species groups are also known from the Palaearctic Region based on discovery of Japanese specimens of both groups in the CNC, and the recent description of S. negrobovi from the Russian Far East (Shamshev 2021), which belongs in the S. isommatum species group. In contrast, the Nearctic $S$. atratum species group is currently not known from other faunal realms.

Future revisionary work on Microphorinae should focus on the relationships among the various species groups discussed here on a worldwide basis. Phylogenetic analyses should be conducted on both morphological and molecular data. The latter in particular will require additional collection of freshly preserved specimens as much of the material currently available is too old to be readily sequenced.

\section{Acknowledgements}

Thanks to Stephanie Boucher (LEMQ), Brian Brown and Giar-Ann Kung (LACM), Claudia Copley (RBCM), Doug Currie (ROM), Steve Gaimari and Chris Borkent (CSCA), David Grimaldi (AMNH), Charles Griswold (CAS), Michael Ivie and Justin Runyon (MTEC), Lynn Kimsey and Steven Heydon (UCDC), Luc Leblanc (WFBM), James Liebherr (CUIC), Steve Marshall (UGIC), Karen Needham (UBCZ), Peter Oboyski and Paul Rude (EMEC), Bill Turner (WJTC), Norm Woodley, Allen Norrbom and Gary Ouellette (USNM), Doug Yanega (UCRC) and Richard Zack (WSU), for the loan of specimens in their care. We are grateful to Steve Gaimari (CSCA) for arranging collecting permits for us with the California Department of Parks and Recreation and the California Department of Fish and Wildlife. We would also like to acknowledge Susan Cumming, the second author's wife, for accompanying us in the field and collecting many of the specimens used in this study. Thanks to Steve Marshall (UGIC) for allowing us to publish his excellent photos of M. obscurus Coquillett (Figs 1 and 2) and S. evisceratum (Melander) (Figs 5 and 6). Thanks to Juergen Peters (Borgholzhausen, Germany) for his impressive photo of a female Microphor feeding on a male Neurigona trapped in a spider's web (Fig. 3). Gerrit Öhm (Göttingen, Germany) kindly gave us permission to publish his fantastic photo of Microphor females feeding on a crab spider's caterpillar prey (Fig. 4), which was brought to our attention by Martin Hauser (CSCA). Thanks also to Robb Bennett (RBCM) and Chris Schmidt (CNC) for their respective identifications of the crab spider and noctuid caterpillar in Fig. 4. Justin Runyon (U.S. Forest Service, Bozeman, Montana, USA) and Igor Shamshev (St. Petersburg, Russia) provided helpful comments on the manuscript.

\section{References}

Becker, T. (1902) Aegyptische Dipteren gesammelt und beschrieben. Mitteilungen aus dem Zoologischen Museum zu Berlin, II, 2, 1-66, 1 pl.

Beling, T. (1882) Beitrag zur metamorphose zweiflügeliger Insecten aus den familien Tababidae, Leptidae, Asilidae, Empidae, Dolichopidae und Syrphidae. Archiv für Naturgeschichte, 48 (1), 187-240.

Brooks, S.E. \& Cumming, J.M. (2017) Revision of the Nearctic Parathalassius Mik (Diptera: Dolichopodidae: Parathalassiinae), with a review of the world fauna. Zootaxa, 4314 (1), 1-64. https://doi.org/10.11646/zootaxa.4314.1.1

Brooks, S.E. \& Cumming, J.M. (2018) New species of Chimerothalassius Shamshev \& Grootaert (Diptera: Dolichopodidae: Parathalassiinae) from the West Indies and Costa Rica. Zootaxa, 4387 (3), 511-523. https://doi.org/10.11646/zootaxa.4387.3.6

Brooks, S.E. \& Ulrich, H. (2012) Microphorella similis sp. nov. from Switzerland, a close relative of the type species, $M$. praecox (Loew) (Diptera: Dolichopodidae: Parathalassiinae). Zootaxa, 3489 (1), 45-57. https://doi.org/10.11646/zootaxa.3489.1.3

Brooks, S.E., Cumming, J.M. \& Grimaldi, D.A. (2019) Remarkable new fossil species of Schistostoma Becker (Diptera: Dolichopodidae: Microphorinae) from mid-Cretaceous Burmese amber. Zootaxa, 4624 (1), 121-131. https://doi.org/10.11646/zootaxa.4624.1.8

Chvála, M. (1983) The Empidoidea (Diptera) of Fennoscandia and Denmark. II. General Part. The families Hybotidae, Atelestidae and Microphoridae. Fauna Entomologica Scandinavica, 12, 1-279.

Chvála, M. (1986) Revision of Palearctic Microphoridae (Diptera) 1. Microphor Macq. Acta Entomologica Bohemoslovaca, 
$83,432-454$.

Chvála, M. (1987) Revision of Palearctic Microphoridae (Diptera) 2. Schistostoma Beck. Acta Entomologica Bohemoslovaca, 84, 133-155.

Chvála, M. (1991) A new species of the Holarctic genus Schistostoma Becker (Diptera: Microphoridae) from South Africa, and first record of the family from South America. Annals of the Natal Museum, 32, 19-26.

Collin, J.E. (1961) Empididae. In British Flies. Vol. 6. University Press, Cambridge, 782 pp.

Coquillett, D.W. (1895) Revision of the North American Empidae-A family of two-winged insects. Proceedings of the United States National Museum, 18 (1896), 387-440. https://doi.org/10.5479/si.00963801.18-1073.387

Coquillett, D.W. (1900) Papers from the Harriman Alaska Expedition. IX. Entomological results (3): Diptera. Proceedings of the Washington Academy of Sciences, 2, 389-464.

Coquillett, D.W. (1903) The genera of the dipterous family Empididae, with notes and new species. Proceedings of the Entomological Society of Washington, 5, 245-272.

Cumming, J.M. \& Brooks, S.E. (2019) Phylogenetic analysis and preliminary classification of the Parathalassiinae (Diptera: Empidoidea: Dolichopodidae sensu lato). Zootaxa, 4648 (1), 111-129. https://doi.org/10.11646/zootaxa.4648.1.5

Cumming, J.M. \& Wood, D.M. (2017) [Chapter] 3. Adult morphology and terminology. In: Kirk-Spriggs, A.H. \& Sinclair, B.J. (Eds.), Manual of Afrotropical Diptera. Vol. 1. Introductory chapters and keys to Diptera families. Suricata 4. South African National Biodiversity Institute, Pretoria, pp. 89-133.

Downes, J.A. \& Smith, S.M. (1969) New or little known feeding habits in Empididae (Diptera). The Canadian Entomologist, 101 (4), 404-408. https://doi.org/10.4039/Ent101404-4

Gatt, P. (2014) Order Diptera, family Dolichopodidae. A new species of the subfamily Microphorinae. In: van Harten, A. (Ed.), Arthropod fauna of the UAE. Vol. 5. Department of President's Affairs, Abu Dhabi, pp. 718-724.

Grichanov, I.Y. \& Brooks, S.E. (2017) [Chapter] 56. Dolichopodidae (long-legged dance flies). In: Kirk-Spriggs, A.H. \& Sinclair, B.J. (Eds.), Manual of Afrotropical Diptera. Vol. 2. Nematocerous Diptera and lower Brachycera. Suricata 5. South African National Biodiversity Institute, Pretoria, pp. 1265-1320.

Kröber, O. (1912) Die Thereviden der indo-australischen region (Dipt.). Entomologische Mitteilungen, 1, $242-256$.

Lundbeck, W. (1910) Diptera Danica. Genera and species of flies hitherto found in Denmark. Part III. Empididae. G. E. C. Gad, Copenhagen, 324 pp.

Macquart, J. (1827) Insectes diptères du nord de la France. Platypézines, dolichopodes, empides, hybotides. Impr. de Leleux, Lille, 159 pp. https://doi.org/10.5962/bhl.title.148911

Macquart, J. (1834) Histoire naturelle des Insectes. Diptères. Tome premier. In: Roret, N.E. (Ed.), (Collection des suites à Buffon), Paris, 1, pp. 1-578, 12 pls. https://doi.org/10.5962/bhl.title. 14274

Meigen, J.W. (1804) s.n. In: Klassifikazion und Beschreibung der europäischen zweiflügeligen Insekten. (Diptera Linn.). Erster Band. Abt. I \& II. s.n., Braunschweig, pp. i-xxviii + 1-152, pls. 1-8 \& pp. i-vi + 153-314, pls. 9-15.

Melander, A.L. (1902) A monograph of the North American Empididae. Part 1. Transactions of the American Entomological Society, 28, 195-367.

Melander, A.L. (1928) Diptera, Fam. Empididae. In: Wytsman, P. (Ed.), Genera Insectorum, 185 (1927), pp. 1-434.

Melander, A.L. (1940a) The dipterous genus Microphorus. I. Phylogeny (Diptera, Empididae). Pan-Pacific Entomologist, 16 (1), 5-11.

Melander, A.L. (1940b) The dipterous genus Microphorus. II. Taxonomy (Diptera, Empididae). Pan-Pacific Entomologist, 16 (2), 59-69.

Melander, A.L. (1965) Family Empididae (Empidae, Hybotidae). In: Stone, A., Sabrosky, C.W., Wirth, W.W., Foote, R.H. \& Coulson, J.R. (Eds.), A Catalog of the Diptera of America north of Mexico. United States Department of Agriculture, Agriculture Handbook No. 276. United States Department of Agriculture, Washington, D.C., pp. 446-481.

Nentwig, W. (1985) Obligate kleptoparasitic behaviour of female flies at spider webs (Diptera: Empidoidea: Microphoridae). Zoologischer Anzeiger, 215, 348-354.

Peck, S.B. \& Cook, J. (1992) Use of "car-nets" to sample flying micro-coleoptera. The Canadian Entomologist, 124 (5), $745-$ 749. https://doi.org/10.4039/Ent124745-5

Procter, W. (1938) Biological Survey of the Mount Desert Region. Part VI. The Insect Fauna. The Wistar Institute of Anatomy and Biology, Philadelphia, Pennsylvania, $496 \mathrm{pp}$.

Rondani, C. (1856) Dipterologiae Italicae prodromus. Vol. 1. Genera Italica ordinis Dipterorum ordinatim disposita et distincta et in familias et stirpes aggregata. A. Storschi, Parmae [Parma], $228+[2] \mathrm{pp}$. https://doi.org/10.5962/bhl.title.8160

Saigusa, T. \& Yang, D. (2003) Empididae (Diptera) from Funiu Mountains, Henan, China (I). Studia dipterologica, 9 (2), 519-543. [2002]

Shamshev, I.V. (1991) A new species of the genus Schistostoma (Diptera, Empidoidea, Microphoridae) from Mongolia. 
Zoologichesky Zhurnal, 10, 149-151. [in Russian, English translation: Entomological Review, 1992, 71 (1), 170-172]

Shamshev, I.V. (1992) A new species of the genus Microphor Macquart (Diptera, Empidoidea, Microphoridae) from Tadjikistan. Byulleten' Moskovskogo Obshchestva Ispytatelei Prirody. Otdel Biologicheskii, 97 (4), 48-52. [in Russian with English summary]

Shamshev, I.V. (1993) A review of species of the genus Schistostoma Becker (Diptera, Microphoridae) of the Ukraine, Transcaucasia, and Central Asia. Entomologicheskoe obozrenie, 72 (3), 684-697. [in Russian, English translation: Entomological Review, 1994, 73 (4), 73-87]

Shamshev, I.V. (1995) A review of species of the genus Microphor Macquart (Diptera, Microphoridae) of the fauna of Russia and neighboring countries. Entomologicheskoe obozrenie, 74 (1), 209-213. [in Russian, English translation: Entomological Review, 1996, 75 (4), 44-48]

Shamshev, I.V. (2020) First record of an extant species of the genus Schistostoma Becker (Diptera: Dolichopodidae: Microphorinae) from the Oriental Region. Russian Entomology Journal, 29 (3), 303-306. https://doi.org/10.15298/rusentj.29.3.11

Shamshev, I.V. (2021) Schistostoma negrobovi, a new species of the subfamily Microphorinae (Diptera: Dolichopodidae) from the Russian Far East. Proceedings of the Russian Entomological Society, 92, 77-81.

Shamshev, I.V. \& Sinclair, B.J. (2006) The genus Schistostoma Becker from southern Africa, with an evaluation of its generic status (Diptera: Dolichopodidae s.l.: Microphorinae). African Invertebrates, 47, 335-346.

Shorthouse, D.P. (2010) SimpleMappr, an online tool to produce publication-quality point maps. [Retrieved from https://www. simplemappr.net (accessed 14 January 2020)

Sinclair, B.J. \& Cumming, J.M. (2006) The morphology, higher-level phylogeny and classification of the Empidoidea (Diptera). Zootaxa, $1180(1), 1-172$. https://doi.org/10.11646/zootaxa.1180.1.1

White, A. (1916) The Diptera-Brachycera of Tasmania. Part III. Families Asilidae, Bombyliidae, Empidae, Dolichopodidae, \& Phoridae. Papers \& Proceedings of the Royal Society of Tasmania, 1916, 148-266. https://doi.org/10.5962/bhl.part.28993

Zetterstedt, J.W. (1842) Diptera scandinaviae disposa et descripta. ex Officina Lundbergiana, sumtibus auctoris, Lundae [Lund], 1, 1-140.

Yang, D., Zhang, K., Yao, G. \& Zhang, J. (2007) World Catalog of Empididae (Insecta: Diptera). China Agricultural University Press, Beijing, 599 pp.

(C) Copyright belonging to the Crown in Right of Canada, that is, to the Government of Canada. 